VERÖFFENTLICHUNGEN DES

BRANDENBURGISCHEN LANDESHAUPTARCHIVS

Dietmar Bleyl

\title{
Die Schweizer Kolonisten im Golmer Bruch bei Potsdam
}

Das Schicksal einer reformierten Gemein(d)e 

Die Schweizer Kolonisten

im Golmer Bruch bei Potsdam

- 


\section{VERÖFFENTLICHUNGEN DES}

BRANDENBURGISCHEN LANDESHAUPTARCHIVS

Begründet von Friedrich Beck

Herausgegeben von Mario Glauert

BAND 76 
Dietmar Bleyl

\section{Die Schweizer Kolonisten im Golmer Bruch bei Potsdam}

Das Schicksal einer reformierten Gemein(d)e 
Dieses Buch ist eine Open-Access-Publikation.

\section{(9) $(\mathbb{Q} \Theta \Theta$}

Dieses Werk ist lizenziert unter einer Creative Commons Namensnennung Nicht kommerziell - Keine Bearbeitungen 4.0 International Lizenz.

https://creativecommons.org/licenses/by-nc-nd/4.0/deed.de

Bibliografische Information der Deutschen Nationalbibliothek:

Die Deutsche Nationalbibliothek verzeichnet diese Publikation in der Deutschen Nationalbibliografie; detaillierte bibliografische Daten sind im Internet über http://dnb.d-nb.de abrufbar.

Dieses Werk einschließlich aller seiner Teile ist urheberrechtlich geschützt. Jede Verwertung außerhalb der engen Grenzen des Urheberrechtes ist unzulässig und strafbar.

() 2021 BWV | BERLINER WISSENSCHAFTS-VERLAG GmbH, Behaimstraße 25, 10585 Berlin, E-Mail: bwv@bwv-verlag.de, Internet: http://www.bwv-verlag.de

Umschlagabbildung: Kopie aus dem im Staatsarchiv Bern befindlichen "Teutschlandbuch"; der vollständige Text ist in Anhang 23, S. 252 nachlesbar.

Druck: Memminger MedienCentrum, Memmingen

Gedruckt auf holzfreiem, chlor- und säurefreiem, alterungsbeständigem Papier.

Printed in Germany.

ISBN Print 978-3-8305-5092-1

ISBN E-Book 978-3-8305-4311-4

https://doi.org/10.35998/9783830543114 


\section{Danksagung}

Die vorgelegte Arbeit ist nicht im luftleeren Raum entstanden. Als Initialzündung dafür kann wohl der Umzug meiner Familie im Jahre 2000 nach Nattwerder angesehen werden. Die Geschichte dieses Ortes war mir bis dahin völlig unbekannt, es war darüber aber auch außer in der Jubiläumsschrift von Heese aus dem Jahre 1985 nicht viel in Erfahrung zu bringen. Hier erwachte Neugier bei mir, die sich noch ein wenig gedulden musste. Das 325-jährige Jubiläum der Ansiedlung Schweizer Kolonisten im Golmer Bruch 2010 stellte die erste Gelegenheit dar, sich mit der Historie von Nattwerder auseinanderzusetzen und eine Jubiläumsschrift zu verfassen. Die vorliegende Arbeit vertieft diese damaligen Bemühungen dadurch, dass die Geschichte des Ortes, die unmittelbar mit der Geschichte der hier angesiedelten Schweizer Kolonisten verbunden ist, systematisch in wirtschaftlicher Hinsicht bis ins 19. Jahrhundert (Separation) und konfessionell gesehen bis zum Ende des Zweiten Weltkrieges aufgearbeitet wird.

Durch Recherchen in zehn Archiven kam eine überraschende Menge an bislang ungesichtetem Material zusammen. Daraus ergab sich ein vollständigeres und vor allem ein in wesentlichen Punkten von den seit Böge (1924) tradierten Darstellungen über die im Golmer Bruch angesiedelten Schweizer Kolonisten abweichendes Bild. Dies veranlasste mich, 2017 bei Prof. Dr. Klaus Neitmann anzufragen, ob ich bei ihm über diese kleine nach Brandenburg eingewanderte und bislang wenig beachtete Kolonistengruppe promovieren könne. Er stimmte zu.

Während des rund dreijährigen Entstehungsprozesses der Arbeit habe ich als Nichthistoriker von ihm eine Vielzahl von Hilfestellungen erfahren, und dafür bedanke ich mich. Das betrifft vor allem die konkrete Formulierung des Themas, Hinweise auf Archivquellen, die Vorbereitungen und methodischen Konzeptionen bis zur konkreten Umsetzung.

Ich bedanke mich darüber hinaus bei Dr. Lutz Partenheimer, Prof. Dr. Klaus Neitmann und Prof. Dr. Frank Göse dafür, dass ich an deren Vorlesungen bzw. Seminaren teilnehmen durfte und auch die von der Universität Potsdam mir auferlegten Masterseminararbeiten schreiben konnte.

Mein Dank gilt auch Frau Kerstin Bühring und Herrn Dr. Gebhard Falk, die mir bei der Transkription von schwierigen Textstellen hilfreich zur Seite standen. Und schließlich möchte ich mich bei allen denen bedanken, die mir Mut gemacht, mich beraten, mir geholfen und Verständnis für das Vorhaben gezeigt haben. Stellvertretend für diesen Personenkreis nenne ich meine Lebenspartnerin Gudrun Wätzel, Frau Gudrun Engelbrecht und meinen Bruder, Herrn Dr. Hans-Jürgen Bleyl, welche die Arbeit minutiös korrigiert haben. Der Familie möchte ich für ihre Geduld und ihr Zurückstehen in den letzten Jahren danken. Bei speziell die Schweiz betreffenden Fragen erhielt ich Auskunft von den Herren Ulrich Zwahlen und Heinrich Christoph Affolter.

Nattwerder im November 2020

Dr. sc. med. vet. Dietmar Bleyl 



\section{Zum Geleit: \\ die Geschichte eines außergewöhnlichen brandenburgischen Ortes}

Die nachfolgende Darstellung ist die für den Druck noch leicht überarbeitete Fassung einer im Sommersemester 2020 von der Philosophischen Fakultät der Universität Potsdam angenommenen Dissertation - die durch ihren Verfasser aus dem üblichen Rahmen dieser akademischen Qualifikationsschrift herausfällt. Denn sie ist nicht von einem jungen Nachwuchshistoriker zur Beförderung seiner anlaufenden Karriere geschrieben worden, sondern von einem „Ruheständler“, der seine Berufslaufbahn weit jenseits der Geschichtswissenschaften verbracht hat. Dietmar Bleyl war von Hause aus Veterinärmediziner und wurde als solcher an der Humboldt-Universität zu Berlin promoviert. Nach der friedlichen Revolution in der DDR und der Wiedererstehung des Landes Brandenburg übernahm er die Stellung als dessen Landesbeauftragter für den Datenschutz - und in dieser Funktion lernte der Unterzeichnende als damaliger Direktor des Brandenburgischen Landeshauptarchivs ihn kennen, als die Benutzung des personenbezogenen Archivgutes unter den neuen gesetzlichen Vorschriften eingehender zu erörtern und zu regeln war. Nach Beendigung seiner Berufstätigkeit entschloss Dietmar Bleyl sich zur Aufnahme eines Geschichtsstudiums an der Universität Potsdam, mit der Absicht, es innerhalb der Philosophischen Fakultät mit der Promovierung zum Doktor der Philosophie zu vollenden. Das für die Dissertation ausgewählte landesgeschichtliche Thema führte ihn wieder mit dem auch an der Universität Potsdam als außerplanmäßigen Professor tätigen Direktor des Landeshauptarchivs zusammen, der die in diesem Fall ein wenig ungewöhnliche Rolle des Doktor,vaters“ übernahm und sie mit intensiven gemeinsamen Gesprächen zur fachlichen Begleitung der werdenden Doktorschrift gerne ausfüllte.

Dietmar Bleyl trat an seinen Betreuer mit einem ausgereiften Plan heran, der nicht dem Zufall zuzuschreiben war: Er wollte die Geschichte der Schweizer Kolonisten in dem im westlichen Potsdamer Umland gelegenen Golmer Bruch untersuchen. Denn in der dort liegenden, ihnen ihre Existenz verdankenden Gemeinde Nattwerder hatte er sich mittlerweile niedergelassen und sich mit großem Einsatz um die Erforschung und Vermittlung ihrer Vergangenheit bemüht. Unter seiner Herausgeberschaft erschien im Jahr 2010 anlässlich eines Jubiläums der Schweizer Kolonisation der Band „Nattwerder 1685-2010. 325 Jahre Besiedlung des Golmer Bruches“ im Auftrag des Vereins „Schweizer Kolonistendorf Nattwerder e. V. Der 1992 gegründete, aus Dorfbewohnern wie aus auswärtigen Interessenten bestehende Verein war nicht nur für die Erarbeitung und Veröffentlichung dieser Festschrift und für die Durchführung einer Festveranstaltung verantwortlich, sondern er hat sich überhaupt des geschichtlichen und kulturellen Erbes des kleinen Ortes angenommen und bemüht sich mit seinen Aktivitäten um dessen Bewahrung und Erhaltung für künftige Generationen. Er hat sich in enger Zusammenarbeit mit der Evangelischen Kirchengemeinde Alt-Töplitz um die schrittweise Restaurierung der denkmalgeschützten Dorfkirche und die Sanierung des umliegenden 
Friedhofsensembles einschließlich der dortigen Grabsteine gekümmert, bietet Führungen, Vorträge und Lesungen an, zeigt Ausstellungen, organisiert Sommerkonzerte in der Kirche und sorgt zugleich dafür, dass sie in dieser Jahreszeit zur Einkehr und Stille geöffnet bleibt.

Das Dissertationsthema war, wie diese Hinweise zeigen, aus dem ehrenamtlichen Einsatz Dietmar Bleyls für den eigenen Wohnort bzw. Lebensmittelpunkt erwachsen; es war gespeist aus der Überzeugung, dass gerade ein Zuzügler nach Nattwerder, der nicht zu den Nachfahren der einstigen Schweizer Kolonisten gehört, es auf sich nehmen sollte, deren Schicksale durch ihre eingehende Erforschung und Darstellung den Heutigen bewusst zu machen und den gegenwärtigen und künftigen Dorfbewohnern zu verdeutlichen, unter welchen Umständen ihre Gemeinde geschaffen worden ist und in welchem Gestaltwandel sie durch die Zeiten gegangen ist. Der Verfasser hat sich für seinen Gegenstand jedenfalls nicht vorrangig allein aus wissenschaftsinternen Gründen entschieden, etwa weil es gewünscht war, eine nach Prüfung der Forschungslage entdeckte „Forschungslücke“ zu füllen, sondern seine Wahl ist seinem Engagement für seine eigene „Lebenswelt“ entsprungen und verdankt ihr ihren Antrieb. Für ortsgeschichtliche Darstellungen wie die hier vorliegende ist eine solche Gegebenheit nicht ungewöhnlich. Wer die folgenden Seiten liest, wird bald spüren, dass ihr Autor nicht distanziert und teilnahmslos einen weitentfernten vergangenen Vorgang zur Vermehrung des geschichtswissenschaftlichen Wissens behandelt, sondern dass seine untergründige Zuneigung den Schweizer Kolonisten und ihren wechselvollen Geschicken im Laufe von eineinhalb Jahrhunderten gilt. Es dürfte nur wenig übertrieben sein, wenn man bemerkt, dass er mit ihnen, mit den schweren Herausforderungen, denen sie sich gegenübergestellt sahen, mit den Widerständen, die sie in der Einrichtung ihrer neuen Heimat zu überwinden hatten, „mitleidet", dass er sie voller Mitgefühl begleitet in ihren Anstrengungen um ihre Selbstbehauptung in kirchlichen wie in weltlichen Angelegenheiten, in ihrem reformierten Bekenntnis wie in ihrer bäuerlichen Wirtschaft, in ihrem Ringen mit der ihnen nicht immer freundlich gesonnenen Obrigkeit.

Dietmar Bleyls eigentliches Anliegen ist die umfassende Darstellung einer Epoche der Schweizer Kolonie im Golmer Bruch, denn er will die Entwicklung „seiner" Siedlungsgemeinschaft in sozioökonomischer wie in konfessioneller Hinsicht über 150 Jahre, von der Anlage der Siedlung bis zum grundlegenden, von altpreußischer Kirchenunion und agrarischer Separation gekennzeichneten Strukturwandel beschreiben: „Die vorliegende Arbeit stellt sich die Aufgabe, das Schicksal der reformierten, Schweizer Gemeinde im Bruch bei Potsdam' von ihrer Entstehung 1685 bis zu ihrem Aufgehen in der lutherischen Gemeinde Alt Töplitz 1835 hinsichtlich ihrer Vorgeschichte, ihrer eigenen Geschichte und ihrer Beziehungen zu anderen Schweizer Kolonisten zu untersuchen und zu würdigen." Es geht ihm nicht darum, ein systematisches Thema der Frühneuzeitforschung wie etwa die Konfessionsoder Agrargeschichte mit einem neuen lokalen Beispiel aufzugreifen und zur Weiterführung allgemeiner Thesenbildungen zu benutzen, wie es einem akademischen Historiker innerhalb seiner Zunft vorschweben mag. Stattdessen legt er Wert darauf, allen Gemeindeangehörigen wie überhaupt allen Interessenten an der brandenburgischen Orts-, Regional- und Landesgeschichte die sich mit den Generationen wandelnden Lebensumstände einer besonderen, 
außergewöhnlichen Siedlungsgemeinschaft in der frühneuzeitlichen Mark Brandenburg zu vermitteln - und zwar auf wissenschaftlicher Grundlage und nach wissenschaftlicher Methode. Es ist hinzuzufügen, dass unter seiner spürbaren Sympathie für die Schweizer und deren Lage die Überzeugungskraft der wissenschaftlichen Argumentation nicht gelitten hat.

$\mathrm{Zu}$ den eingangs hervorzuhebenden Stärken des Werkes gehört unzweifelhaft die gegenüber der älteren Forschung merklich verbreiterte archivalische Quellengrundlage. Der Autor hat sowohl eine größere Anzahl von Archiven als auch eine Vielzahl von Archivbeständen im Hinblick auf sein Thema zielgerichtet ausgewertet, dabei etliche zuvor unbekannte Funde gemacht und sich dadurch in die Lage versetzt, an zahlreichen Stellen seine Vorgänger zu korrigieren und über sie hinaus zu kommen, was umso mehr anzuerkennen ist, als gerade eine frühneuzeitliche Lokalgeschichte sich kaum vorrangig auf einen kommunalen Bestand, der in der Kommune selbst durch ihre Tätigkeit entstanden ist, stützen kann, sondern die Bestände ihrer staatlichen Mit- und Gegenspieler, der der landesherrlichen Behörden zu sichten hat. Zwar entstammt das aus Lager-, Kirchen-, Rechnungsbüchern und Sachakten bestehende, vom Verfasser erst erschlossene und ausgiebig herangezogene Pfarrarchiv Alt Töplitz der Schweizer Kirchengemeinde und ermöglicht Einblicke in deren demographische Entwicklung, aber vor allem profitiert die Studie davon, dass die Überlieferungen der verschiedenen Verwaltungsebenen des brandenburgisch-preußischen Staates von der Zentral- bis zur Lokalbehörde umfassend und erfolgreich gesichtet worden sind, wie auch die Berücksichtigung der Briefbücher des Berner Rates die Entstehungsgeschichte dicht zu rekonstruieren erlaubt hat.

Den Leser erwartet wie schon angedeutet eine brandenburgische Ortsgeschichte - aber eine außergewöhnliche. Dieses Buch handelt von den Schweizer Kolonistenfamilien im Golmer Bruch und von der Entwicklung ihrer Gemeinschaft in besitzrechtlicher, wirtschaftlicher und konfessioneller Hinsicht von der Ansiedlung 1685 bis in die ersten Jahrzehnte des 19. Jahrhunderts. Die Gemeinde verdankte ihre Entstehung den Bestrebungen des Großen Kurfürsten Friedrich Wilhelm von Brandenburg zur „Repeuplierung“, zur Wiederbesiedlung seines Landes nach den Verwüstungen des 30-jährigen Krieges, und sie war durch ihre Nähe zur neuen landesherrlichen Residenz Potsdam ausgezeichnet. Die Schweizer Kolonie hob sich von ihrer Umgebung dadurch ab, dass ihre Höfe bzw. Hofinhaber durch den Ansiedlungsvertrag von 1685 vom Kurfürsten in Absetzung von den Rechtsverhältnissen der altansässigen Bevölkerung besonders privilegiert waren. Der von ihm mit ihnen vereinbarte Ansiedlungsvertrag erwies sich als „Prototyp aller weiteren Ansiedlungen von Schweizern und anderen Kolonisten im 17. und 18. Jahrhundert in Brandenburg." Ihre Bewohnerschaft bekannte sich zum reformierten Glauben wie das hohenzollernsche Herrscherhaus, aber im Gegensatz zur sonstigen lutherischen Landbevölkerung; sie war die erste und zugleich einzige geschlossene Schweizer Einwanderergruppe nach Brandenburg und bildete die erste reformierte Gemeinde auf dem platten Land, die zeitweise für die Mark ein geistliches reformiertes Zentrum darstellte. Die Schweizer Kolonisten hoben sich sowohl durch ihre konfessionelle wie durch ihre besitzrechtliche Eigenart von den Einheimischen ab und unterlagen damit langfristig dem Druck der Assimilation. Beide angedeuteten Charakteristika verknüpfen die Geschich- 
te der Schweizer Gemeinde im Golmer Bruch mit großen Tendenzen der frühneuzeitlichen brandenburgisch-preußischen Geschichte und machen sie über die Lokalgeschichte hinaus für die allgemeine Geschichtswissenschaft anziehend. Daher sollen im Folgenden einige auf übergeordnete Vorgänge verweisende Ergebnisse dieser Studie noch ein wenig näher betrachtet werden.

Die in der Wublitzrinne liegenden Siedlungen, u.a. Leest, Grube und Golm, sind seit slawischer Zeit und in slawisch-deutscher Kontinuität nachgewiesen, während das trogförmige Golmer Bruch bis Ende des 17. Jahrhunderts siedlungsleer blieb, bedingt dadurch, dass der Anstieg der Havel und der folgende Rückstau der Wublitz regelmäßig zur Überschwemmung der Uferzonen und der Überflutung des Bruches führte. Im Rahmen der kurbrandenburgischen Absichten des 17. Jahrhunderts zur Kolonisation von Brüchen fiel der prüfende Blick des Kurfürsten Friedrich Wilhelm und seines Oberförsters Joachim Ernst v. Lüderitz 1678 erstmals auf den nahe der entstehenden neuen Residenzstadt Potsdam gelegenen Golmer Bruch, der nach seiner preiswerten Trockenlegung für Wiesenwuchs und Milchwirtschaft geeignet erschien, so dass in den folgenden Jahren ein holländischer Teichgräber das in der Grundstruktur bis heute bestehende Entwässerungssystem schuf und das Gebiet unter Investitionskosten von ca. 14.300 thlr. (bis 1687) für die vorgesehene Besiedlung und wirtschaftliche Nutzung erschlossen wurde. 1683 ließ der Kurfürst über seinen Beauftragten, den am Genfer See ansässigen Grafen Friedrich v. Dohna, der Stadt Bern seinen Wunsch vortragen, 10 oder 20 Familien, die in ländlicher Wirtschaft und Viehzucht erfahren seien, für die Ansiedlung an geeignetem brandenburgischen Ort mit erforderlicher Ausstattung und unter günstigen Pachtkonditionen zu werben. Eine vom Berner Magistrat eingesetzte Abordnung überprüfte den geplanten Siedlungsort und Wirtschaftsfläche und verhandelte mit dem Kurfürsten persönlich, so dass im November 1684 ein Vorvertrag über die Bedingungen der vereinbarten Siedlung abgeschlossen wurde. Der Berner Rat schrieb daraufhin 20 Kolonistenplätze in Brandenburg öffentlich aus, und es meldeten sich 14 Familien mit Gesinde, insgesamt 101 Personen, aus Ämtern des Berner Oberlandes, die im Mai/Juni 1685 in sechs Wochen auf dem Wasserwege (über Aare, Rhein, Zuider- und Nordsee, Elbe und Havel bis zur Wublitzmündung) - zur Vermeidung des beschwerlichen und umständlichen Landweges, den alle späteren Schweizer Kolonisten benutzten - zu ihrem havelländischen Zielort reisten, versehen mit der Zusicherung des Berner Rates, sie im Falle des Fehlschlages wieder in ihre Heimat zurückzuholen. Die weiteren Verhandlungen über die detaillierte Ausgestaltung des aus 21 Artikeln bestehenden Arrendevertrages mündeten im September 1685 in dessen Unterzeichnung. Die 14 Schweizer Kolonistenfamilien wurden als eine geschlossene Privilegiengemeinschaft behandelt; mit den ihnen zugestanden Rechten wie der Garantie ihrer persönlichen Freiheit, der Überlassung von Land und der für sie erbauten Höfe zu Erbpachtbedingungen nach Ablauf der Freijahre waren sie deutlich bessergestellt als die einheimischen Bauern und vergleichbar holländischen Kolonisten in der Uckermark und an der Elbe. Die Etablierung der Siedlung wurde vom Kurfürsten vorfinanziert, für noch zu rodendes Acker- und Wiesenland galten sechs Freijahre, für alle Lasten und Abgaben 30 Jahre mit der Option der Verlängerung. In konfessioneller Hinsicht gestand der Kurfürst den Siedlern 
$\mathrm{zu}$, dass sie einen reformierten Prediger aus ihrer Heimat mitbringen durften, an dessen Bezahlung ebenso wie an der des Schulmeisters er sich beteiligte. Der summus episcopus der märkischen Landeskirche verzichtete damit auf sein ius praesentandi zugunsten des Berner Rates, dem so die Möglichkeit zum Eingriff in die inneren Verhältnisse der Schweizer Gemeinde gegeben war. Die Anwerbung von reformierten Schweizer Kolonisten war vom Kurfürsten bereits seit 1660 verfolgt worden, allerdings für das Herzogtum Preußen und ohne Erfolg. Der Arrendevertrag von 1685 entwickelte Vorbildcharakter: Das ihm nur einige Wochen nachfolgende Potsdamer Edikt bot den geflüchteten französischen Hugenotten die ländliche Ansiedlung unter denselben Voraussetzungen wie den eingewanderten Schweizern an. Die nachfolgenden Verträge unter Friedrich III./I. für Schweizer Ansiedler im Ruppiner Land und in Ostpreußen und noch später orientierten sich an dem Vertrag von 1685, allerdings mit ungünstigeren Bedingungen für die Siedler, und führte zur Bildung größerer und personell stabilerer reformierter Gemeinden, denen nach ihrem zahlenmäßigen Zuwachs nach 1685 eigene Kirchenbehörden eingeräumt wurden.

Seit dem Sommer 1685 erfolgte der Aufbau der neuen Kolonie im Golmer Bruch: Die Häuser wurden errichtet, die Hofausstattung (Hofwehr) gegen sofortige Zahlung oder spätere Abzahlung (mit $5 \%$ Zinsen) ebenso wie das Saatgut für die erste Aussaat bereitgestellt; die eingesetzten Viehbestände zielten vorrangig auf Milchproduktion, die vorgesehenen Wiesenflächen waren zur Hälfte noch zu roden. Die Kolonisten mussten allerdings feststellen, dass sie auf einem beschränkten Wirtschaftsraum mitten in einem schwer zu entwässernden und für Viehzucht nicht sonderlich geeigneten Gebiet angesetzt waren. Dem „Jahrhunderthochwasser" des Jahres 1689 hielten die aus loser Brucherde aufgeworfenen Dämme nicht stand, das Bruch „soff ab“, die geleistete Aufbauarbeit war zunichte gemacht. Mit den technischen Möglichkeiten des 17. Jahrhunderts konnten, wie sich erwies, ausreichende wasserbauliche Voraussetzungen nicht geschaffen werden: Das Bruch lief im Überschwemmungsfall voll, und das Wasser verblieb dort, bis es durch Sonne und Wind verdampfte oder künstlich „ausgeschöpft“ wurde; erst 1929 gewährleisteten nach Fortschritten in der Elektro- und Maschinentechnik drei Dampfschöpfmaschinen effektiven Hochwasserschutz. Aber die im Herbst 1687 auf 17 Familien angewachsene Gemeinschaft gab nicht auf, nur ein einziger Kolonist machte mit seiner Familie 1688 von seinem Rückkehrrecht Gebrauch; zur Überwindung ihrer Krise wurden den Kolonisten in den Folgejahren benachbarte Wirtschaftsflächen bereitgestellt. Zunächst überließ die verwitwete Kurfürstin Dorothea sechs Schweizern wohl entsprechend deren Vorschlag mit einem Arrendevertrag vom Juni 1689 pensionsweise ihr Leibgedinge, das Vorwerk Golm. Am Ende des 18. Jahrhunderts lehnten die Schweizer das Angebot der preußischen Behörden zur erblichen Annahme ihrer Güter gegen Bezahlung des Bauholzes ab, da sie dann zur Zahlung der bisherigen Pachtsumme außerstande seien, und vermochten ihren Standpunkt mit ihrer Ausdauer weitgehend durchzusetzen. Die 1818 eingeleitete Separation führte 1839 nach schwierigen Verhandlungen mit insgesamt 42 Interessenten zur Entflechtung der auf der Golmer Feldmark gelegenen Grundstücke ortsansässiger wie fremder Wiesenbesitzer und zur Aufhebung der gemeinschaftlichen Hütungsberechtigungen. 
Kurz nach der Übernahme des Vorwerkes Golm gelang drei Schweizer Kolonisten eine zusätzliche Erwerbung: 1691 wurde ihnen vom Amt Lehnin zunächst übergangsweise, dann durch Arrende- und Pensionsvertrag das aus dem einstigen Lehniner Klosterdorf Töplitz hervorgegangene Vorwerk Töplitz überlassen in der Absicht, der 1682 abgebrannten Anlage zum wirtschaftlichen Wiederaufstieg zu verhelfen. Die Vertragserneuerung von 1696 wandelte für die jetzt beteiligten sechs Familien die Zeit- in eine Erbpacht um. Die im Laufe des 18. Jahrhunderts erfolgende Erhöhung der jährlichen Pachtgelder nahmen die Schweizer nicht widerspruchslos hin, sondern nur unter bestimmten Bedingungen, deren fehlenden Erfüllung sie dann zur Abwehr einer weiteren Pachterhöhung nutzten - ein Beispiel für die Wirkung ihres Widerstandsgeistes gegenüber der (angeblich) absolutistischen Behörde. Die zahlreichen Streitigkeiten mit den Nachbargemeinden über Hütungs- und Nutzungsrechte, Grenzen und Holzberechtigungen bewogen die Schweizer erstmals 1802 dazu, die Separation vorzuschlagen, also die Zersplitterung der Feldmark zu beseitigen und geschlossene, von jedem gemäß alleiniger Verfügung zu nutzende Flächen herzustellen. Die vollzogene Separation schuf dann die Voraussetzung für einen außerordentlichen wirtschaftlichen Aufschwung der einstigen Erbpächter, wie er an den 1880/90 erbauten, für Brandenburg außergewöhnlich großen Höfen ablesbar ist. - Eine weitere benachbarte, wegen des begrenzten Platzes nur aus vier Höfen bestehende Schweizer Siedlung wurde wahrscheinlich nach dem Hochwasser von 1689 in Nattwerder errichtet. Der Arrendevertrag von 1685 wurde nach Verhandlungen der Inhaber mit der Amtskammer 1716 unter abgeänderten Bestimmungen erneuert, sie verloren ihren Erbpächterstatus, wurden aber im Unterschied zu den Golmer und Neu Töplitzer Schweizern von zusätzlichen Abgaben und von der militärischen Einquartierung befreit. 1764 beantragten die Kolonisten den Abschluss von Erbpachtverträgen, die zwar genehmigt, aber nicht vollzogen wurden, so dass nach späteren Auseinandersetzungen über das freie Bau- und Reparaturholz ein neuer, für sie günstiger Kontrakt erst 1841 genehmigt wurde; es schloss sich 1850/52 die Separation an.

Der gesamte hier skizzierte Siedlungsvorgang vollzog sich, wie zu seinem Verständnis hervorgehoben werden muss, in den Bahnen einer ständischen Gesellschaft, also im Rahmen einer sozialen Ordnung, die den (Rechts-)Stand einzelner Gruppen in Privilegien und Gewohnheiten beschrieb und die darin die unter ihnen bestehenden Unterschiede ausdrückte. Die Ansiedlung der Schweizer Kolonisten im Golmer Bruch folgte im Kern demselben Muster, nach dem die Ansiedlung der aus dem westlichen Altsiedelland kommenden deutschen bäuerlichen Zuwanderer in der entstehenden Mark Brandenburg des hohen Mittelalters abgelaufen war: Sie waren für die schwere Aufgabe des Landesausbaues angelockt worden mit dem Versprechen günstiger Rechte, mit der Aussicht auf freiere Rechtsstellung, erleichterte Dienste und verringerte Abgaben, verglichen mit ihrer Lage in ihrer bisherigen Heimat, und die bäuerliche Bevölkerung im Neusiedelland östlich von Elbe und Saale genoss lange Zeiten unter ihren Herren ein deutlich höheres Maß an Freiheiten als diejenigen in den west- und süddeutschen Territorien, bis diese durch die seit dem späteren 15. Jahrhundert aufkommende adlige Gutswirtschaft merklich eingeschränkt wurden. Die Schweizer Kolonisten im Golmer Bruch waren im späten 17. Jahrhundert mit den ihnen vom Landesherrn 
eingeräumten Rechten deutlich besser gestellt als die übrige, landesherrlichen oder adeligen Gutsherrschaften zugehörige Bauernschaft Brandenburgs, aber darin sahen die Zeitgenossen kein Problem, bestand die überkommene ständische Ordnung doch darin, dass die einzelnen Gruppen sich durch ihre unterschiedliche Privilegierungen in dem Ausmaß ihrer Eigenständigkeit und Selbständigkeit voneinander abhoben; ständische Ungleichheit verstand sich von selbst. Erst mit der Französischen Revolution kam der Ruf nach Gleichheit auf und begann sich schrittweise durch den Abbau der alten ständischen Privilegien durchzusetzen. Die vorausgesetzte ungleiche Stellung der einzelnen Stände oder ständischen Gruppen zog zudem für Neuansiedler wie die Schweizer im Golmer Bruch nach sich, dass sie nicht mit dem Ruf nach „Integration“ konfrontiert wurden, wie er heutzutage im Hinblick auf Migranten geradezu selbstverständlich erklingt. Die Schweizer beharrten darauf, dass ihnen ihr 1685 gewährtes Privilegienrecht und die darin verbriefte Eigenart unter Absetzung von ihrer Umwelt möglichst unverändert bewahrt blieb, und sie vermochten sich lange zu behaupten, auch wenn manche Eigentümlichkeiten sowohl im Ringen mit der staatlichen Obrigkeit als auch durch die Kontakte zur Umwelt sowie durch die Auflösung der Verbindungen zur schweizerischen Heimat im Laufe von Jahrzehnten abgeschliffen wurden. Zahlreiche Vorgänge zeigen, wie die Schweizer mit Ausdauer und Verbissenheit in ihren Verhandlungen mit den preußischen Behörden darum kämpften, in ihrer Rechts- und Sozialverfassung bewahrt zu bleiben oder bessergestellt zu werden, und sie waren in ihren Bemühungen vielfach erfolgreich, so dass das verbreitete Klischee vom obrigkeitsgläubigen ostelbischen Bauern wieder einmal widerlegt wird. In sozial- und wirtschaftsgeschichtlicher Hinsicht beendeten erst die Separationen in der ersten Hälfte des 19. Jahrhunderts die Ordnung von 1685.

Nicht nur unter sozioökonomischen, sondern auch unter konfessionellen Gesichtspunkten setzten sich die Schweizer im Golmer Bruch von ihrer märkischen Nachbarschaft ab. Die Geschichte ihrer reformierten Kirchengemeinde beginnt eigentlich mit dem gemäß dem Versprechen des Kurfürsten Friedrich Wilhelm Ende der 1680er Jahre in Nattwerder errichteten, 1690 unter dem Namen „Friedensreichkirche“ eingeweihten Kirchenbau, den in Gestaltung und Ausstattung calvinistische Eigenarten (wie etwa der Abendmahlstisch als räumlicher und geistlicher Mitte in der Apsis) auszeichnen. Die Kirche mit ihrer soliden Bauweise, ihren schlichten Formen und geringem Bauzier, die den Vorrang des gesprochenen oder gesungenen Wortes nicht beeinträchtigen sollten, ist als „Musterbau“ einer Dorfkirche am Ende des 17. Jahrhunderts mit Vorbildwirkung für Kirchenbauten der Umgebung einzustufen. Auf dem die Kirche umgebenden Kirchhof wurden entsprechend der gefundenen Aufteilung die Angehörigen der einzelnen Kolonistenfamilien bestattet, die in den Inschriften der Grabmale wiederholt ihre schweizerische Herkunft betonten. Die Verbundenheit von Schweizer Kolonisten in der Mark Brandenburg mit ihrer Heimat kam übrigens auch dadurch zum Ausdruck, dass 1697 auf Anregung eines reformierten Schweizer Predigers mit Kollektengeldern aus der Schweiz ein reformiertes Kirchenbauprogramm für reformierte Gemeinden im Ruppiner Land zustande kam und in diesem Rahmen die Kapelle in Neu Töplitz und in mehreren anderen Kirchengemeinden Glocken erhielten, deren Widmungsinschriften an die dafür „,von denen loblichen reform[ierten] Cantons freygebig ubersandten Collektengelder" erinnerten. 
Die Stellung des Predigers der reformierten Gemeinde im Golmer Bruch beruhte zunächst auf dem Ansiedlungsvertrag von 1685, nach dem er ein jährliches Gehalt von 200 Taler und Garten-, Wiesen- und Ackerland zur eigenen Nutzung erhielt, so dass er nicht wie die lutherischen Pfarrer auf Stolgebühren angewiesen war. Das Präsentationsrecht stand dem Berner Magistrat zu, der dem Kurfürsten/König seine aus der Schweiz stammenden Kandidaten für die Besetzung der Pfarrstelle (verbindlich) empfahl. Nach reformierter Tradition wurde zum Abendmahl Brot und Wein gereicht, das Brot dabei gebrochen. Die ersten Prediger zeichneten sich dadurch aus, dass sie neben ihren seelsorgerischen Aufgaben ,als Verbindungsglieder zwischen der alten und neuen Heimat“ wirkten, dass sie in einer Art „Doppelunterstellung“ sowohl den Kontakt mit dem Berner Magistrat als auch zum Kurfürsten/König und seinen Beamten im (zeitweiligen) Kirchlichen Oberdirektorium und im Domänenamt pflegten. Sie berichteten dem Berner Magistrat von den Schwierigkeiten der Kolonisten in ihrer neuen märkischen Siedlung und baten zuweilen um Anweisungen für ihr Handeln. Auseinandersetzungen zwischen Bern und Zürich über die Aufteilung der in den evangelischen Schweizer Kantonen und Städten eingesammelte Gelder für im Ausland bestehende und aufzubauende reformierte Gemeinden gaben König Friedrich Wilhelm I. 1735 den Anlass dafür, fortan die Predigerstelle für das Golmer Bruch mit einheimischen Pfarrern zu besetzen, eine für die Kolonisten folgenreiche Maßnahme, da damit ihre institutionalisierte Verbindung zur alten Heimat abriss. Hervorgehobenen Rang dürfen die Prediger Albrecht Wyttenbach (1687-1705) und Sigismund Lupichius (1705-1717) beanspruchen. Dem ersten wurde 1691 das Visitationsrecht über die anderen Schweizer Prediger in den neuen Schweizer Kolonien des Ruppiner Landes übertragen, er wirkte später an der Schlichtung der Beschwerden dortiger Kolonisten mit und genoss offensichtlich die Anerkennung Friedrichs III./I. wegen des erfolgreichen Aufbaues seiner Golmer Gemeinde. Sein Nachfolger Lupichius trat, als 1713 die Pachtzinsen der Golmer Kolonisten drastisch erhöht werden sollten, für seine Schützlinge nachdrücklich gegenüber dem Amtskammerpräsidenten v. Görne ein und bat den Berner Magistrat um eine Interzession gegenüber König Friedrich Wilhelm I.; Bern verstand sich dazu, aber nicht ohne hinzuzufügen, dass die von den beschuldigten Kolonisten erwogene Rückkehr in die Schweiz keinesfalls in Betracht komme - und hatte damit seine einstigen Mitbürger im fernen Brandenburg abgeschrieben. Die Bestrebungen König Friedrich Wilhelms III. zum Zusammenschluß der Lutheraner und Reformierten führten 1817 zur Gründung der Union, die in der Folgezeit auf der lokalen Ebene durch die Vereinigung der lutherischen und reformierten Kirchengemeinden verwirklicht wurde. Zwar sicherte der heftige Widerspruch der Schweizer ihnen zunächst noch die erneute Einsetzung eines eigenen Predigers in Nattwerder, aber 1832 befahl der König den Zusammenschluss der (reformierten) Gemeinde in Nattwerder mit der (lutherischen) in Alt Töplitz, bestimmte die erstere zur Filialkirche der Mutterkirche Alt Töplitz. Trotzdem blieben reformierte Eigenarten, wie sie sich in der Abendmahlsfeier und in der Auswahl des Gesangbuches zeigten, noch lange in Gebrauch, bis 1949 der aus vier Erbpächtern bestehende Gemeindekirchenrat der Filialgemeinde Nattwerder endgültig auf den Anspruch einer selbständigen Kirchengemeinde verzichtete, da Nattwerder und Alt Töplitz sich mehr und mehr einander angepasst hätten und eine reformierte Tradition kaum noch bestehe. 
In methodischer Hinsicht verdient Dietmars Bleyls Werk Aufmerksamkeit, weil er die Erkenntnisse zu den inneren Verhältnissen der Schweizer Gemeinde im Golmer Bruch dadurch zu erweitern gesucht hat, dass er deren Kirchenbücher zu demographischen, sozial- und kirchengeschichtlichen Studien ausgewertet hat. Die Aussagekraft der frühneuzeitlichen Kirchenbücher für derartige Fragestellungen ist grundsätzlich seit langem von der Forschung erkannt, aber noch nicht allzu häufig in konkreten Untersuchungen erprobt worden. Die vorhandenen Kirchenbücher der Schweizer Gemeinde aus dem Zeitraum 1685 bis 1949 enthalten die üblichen Listen der Taufen und Hochzeiten (ab 1685/86), der Todesfälle ( $a b$ 1705) einschließlich der Todesursachen (ab 1728/86) und der Konfirmationen (ab 1726) und darüber hinaus noch vereinzelte zusätzliche Nachrichten zur Gemeinde. Der Verfasser hat aus den beiden ersten Kirchenbüchern vitalstatistische Daten für den Zeitraum von 1685 bis 1835 (327 Eheschließungen, 1039 Geborene und 650 Gestorbene) erfasst und im Stil einer Kirchenbuchverkartung das Material aufbereitet für seine wesentlichen Einzelaspekte: das Heiratsalter bei Erst- und Zweitehe, Kinderzahl pro Ehe, Zeitabstände zwischen Verwitwung und Wiederverheiratung, Säuglings-, Kinder- und altersspezifische Sterblichkeit, konfessionelle Mischehen, Auswahl der Paten; besonderes Interesse wird dem Heiratsverhalten im Hinblick auf Heiraten innerhalb der reformierten Schweizer Kolonisten und Öffnung zu lutherischen Ehepartnern gewidmet. Nur wenige Beobachtungen können hier aufgegriffen werden. Die Anzahl der Paten der Täuflinge liegt bei den gehobenen Schichten über lange Zeiträume deutlich über den obrigkeitlich vorgeschriebenen maximal fünf Paten, steigt bis auf 20 Paten, u. a. aus den Kreisen der Potsdamer Hof- und Militärgesellschaft, an, was auf die gute wirtschaftliche Lage der Familien deutet, während die unteren Schichten (Knechte, Büdner und Kossäten) durchschnittlich nur drei bis fünf Paten anzeigten. Das Bekenntnis eines Paten zur lutherischen Konfession wird im Kirchenbuch erstmals 1730 und dann bis 1770, bis zu einem Pfarrerwechsel, vermerkt, ein Zeichen dafür, dass die abweichende Konfession zunächst noch auffiel und schließlich wegen ihrer Häufigkeit nicht mehr der Erwähnung für Wert befunden wurde. Als der erste Täufling in Golm nach dem damaligen Landesherrn Friedrich Wilhelm benannt worden war, ordnete der bei der Taufe persönlich anwesende Kurfürst an, in dieser Familie solle der erste Sohn stets seinen Namen Friedrich Wilhelm erhalten, was sie bis auf den heutigen Tag befolgt hat. Schweizerisches Traditionsbewusstsein in der Namensauswahl war spätestens im frühen 19. Jahrhundert geschwunden.

Die Kirchenbucheintragungen beinhalten nur drei verstorbene Ledige, so dass die Ehe eindeutig als Lebensform angestrebt und den Alternativen einer Abhängigkeit als Dienstbote oder Nachordnung als Haushaltsmitbewohner vorgezogen wurde. Nach den Eintragungen zu 327 Eheschließungen lag das errechnete Durchschnittsalter der Männer bei 30, der Frauen bei 25 Jahren; die Ehe wurde also mit elterlicher Zustimmung erst dann eingegangen, wenn die Berufstätigkeit des Mannes und/oder die Mitgift der Frau die Ernährung der künftigen Familien gewährleisten konnten. Die (seltenen) Doppelhochzeiten unter Nachkommen zweier Familien erklären sich daraus, dass der von der Mitgift der eigenen verheirateten Tochter verursachte Kapitalabfluss durch den von der eingeheirateten Schwiegertochter verursachten Kapitalzufluss ausgeglichen wurde. Wiederverheiratungen nach dem Tode eines 
Ehepartners waren gängig - machten sogar jeden fünften Hochzeitseintrag aus -, weil der Witwer eine Ehefrau für Wirtschaft und Haushalt benötigte und die Witwe ihre Altersversorgung zu sichern hatte. Die Liste der Getrauten wurde 1686 vom ersten Prediger im Golmer Bruch überschrieben mit „Verzeichnus der Hochzeiten, Welche allhier im Schweitzerbruch zwüschen den Schweitzern gehalten worden" und deutet die Erwartung an, dass die Schweizer Kolonisten ausschließlich oder zumindest vorrangig untereinander heiraten würden - was offensichtlich über lange Zeiträume galt. Denn bei den 155 Hochzeiten, deren Eintragungen den Herkunftsort oder den künftigen Wohnort der Brautleute angeben, tauchen insgesamt 49 Orte auf, nahezu alle Orte mit Schweizer Kolonistensiedlungen, zumeist in der näheren Umgebung, aber auch aus dem Ruppiner Land oder gar aus Ostpreußen. Nach 1737 häuften sich die Einheiraten von Angehörigen der Potsdamer Garnison (Dragoner, Füsiliere, Grenadiere und Husaren) in die Schweizer Familien. Die durchschnittliche Zahl der geborenen Kinder liegt bei den auswertbaren 131 Familien bei 4,5; 5 bis 14 Kinder konnten sich die Erbpächter, die dörfliche Oberschicht, „leisten“, Familien mit 2-4 Kindern gehörten zur Handwerkerschaft, Ein-Kind-Familien - die ca. ein Fünftel der Gesamtfälle ausmachten - traten bei Dienstleuten, Kossäten und Hausmännern auf. Die Zahl der Geburten bzw. Taufen verdoppelte sich Anfang des 18. Jahrhunderts ein knappes Jahrzehnt lang im Verhältnis zum jährlichen Gesamtdurchschnitt, ein Zeichen für die gelungene Etablierung in der neuen Heimat, sank danach auf ein „Normalmaß“ ab und erreichte einen zweiten Höhepunkt nach den Befreiungskriegen. Die Gemeinde erhielt zudem Verstärkungen aus ihrer einstigen Schweizer Heimat durch vormals in der Schweiz angeworbene Soldaten, die ihren Lebensabend bei ihren Landsleuten in Neu Töplitz verbrachten, und durch eingewanderte Leineweber.

Dietmars Bleyls Studie über die Schweizer Kolonisten im Golmer Bruch bei Potsdam stellt ein gelungenes, ja herausragendes Beispiel einer frühneuzeitlichen (brandenburgischen) Ortsgeschichte dar, indem sie aus der mit Findersinn ermittelten archivalischen Überlieferung die besitzrechtlichen, wirtschaftlichen und konfessionellen Eigenarten der Bewohner und die Entwicklung ihrer Gemeinschaft zwischen Selbstbehauptung und Assimilation an die Umwelt in großer Vielfalt darstellt. Sie vermag dank der Vorliebe des Autors für deren „Mikrogeschichte" die vielfältigen Lebensumstände der Schweizer anziehend und anschaulich zu beschreiben. Der besondere Reiz seines Werkes liegt darin, dass immer wieder in verschiedenen sachlichen Zusammenhängen die Lage der Kolonisten „als Fremde im fremden Land“ erörtert, also das zwischen Abgrenzung und Assimilation schwankende, von Koexistenz zur Akkulturation übergehende Verhältnis der eingewanderten zur altansässigen Bevölkerung erhellt wird. Aus dem Nebeneinander der wenigen privilegierten anderskonfessionellen Schweizer Kolonisten und der vielen Alteingesessenen entwickelten sich in sozioökonomischer wie in konfessioneller Beziehung keine nennenswerten Konflikte, es blieb allerdings das Bewusstsein der Differenz bzw. der Andersartigkeit vor allem in der Anfangszeit, aber auch weit darüber hinaus erhalten. Die Kolonisten betonten ihre Abgrenzung, in ihrem Heiratsverhalten, in dessen Folge bis 1800 kein männlicher Fremder auf den Schweizerhöfen einheiratete, in ihrem Erbrecht, das die Schweizer Tradition mit der Gleichstellung der aus zwei aufeinander folgenden Ehen bewahrte, in ihrem konfessionellen Selbstbewusstsein, das 
(seltene) lutherische Ehepartner mit missbilligendem Unterton vermerkte oder sie zur Konversion bewog, das aber auch eigene Sitzplätze in der lutherischen Kirche zu Alt Töplitz oder eine lutherische Nottaufe einbezog. Wiederholt blickt der Verfasser über das Golmer Bruch hinaus und sucht den überregionalen Rang der dortigen Ansiedlung zu verdeutlichen, indem er etwa den Ansiedlungsbedingungen Vorbildwirkung zuschreibt. Auch wenn er nach seinem Anliegen eine Ortsgeschichte geschrieben hat, sind seine Ergebnisse doch dazu geeignet, dass die lokalen Gegebenheiten in übergeordnete Vorgänge und zentrale Themen der frühneuzeitlichen Geschichte Brandenburg-Preußens wie Kolonisation und Konfession eingeordnet und dafür systematisch ausgewertet werden.

Der Unterzeichnende möchte nicht versäumen, am Schluss seines zur Darstellung hinführenden Geleitwortes den geneigten Leser dazu aufzufordern, sich vor Ort in Nattwerder und im Golmer Bruch einen eigenen Eindruck von dieser außergewöhnlichen Gemeinde zu verschaffen, wofür sich ihm der Verein Schweizer Kolonistendorf Nattwerder e.V. und Dietmar Bleyl sicherlich gerne als Führer zur Verfügung stellen werden.

Potsdam, im Mai 2021

Prof. Dr. Klaus Neitmann

Direktor des Brandenburgischen Landeshauptarchivs a.D. 



\section{Inhaltsverzeichnis}

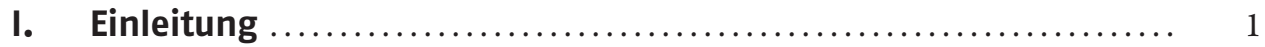

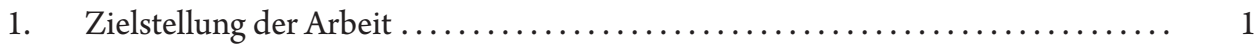

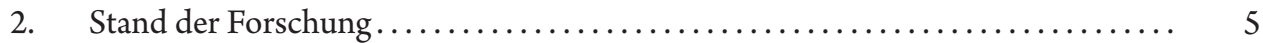

II. Die wirtschaftliche und konfessionelle Situation in Kurbrandenburg nach dem Dreißigjährigen Krieg............. 11

1. Die wirtschaftliche Situation in Kurbrandenburg................... 11

2. Die Konfessionelle Situation in Kurbrandenburg. .................... 14

III. Maßnahmen für die Urbarmachung des Golmer Bruchs um 1680 .. 19

1. Zur Topographie und Siedlungsgeschichte der Wublitzrinne.............. 19

2. Schaffung einer Infrastruktur für den Golmer Bruch.................. 21

3. Der Atlas der Herrschaft Potsdam ............................. 23

IV. Die Besiedlung des Golmer Bruchs mit Schweizer Kolonisten ...... 27

1. Die Schweiz als Auswandererland ............................. 28

2. Anfrage beim Schultheiß und Rat der Stadt Bern 1683

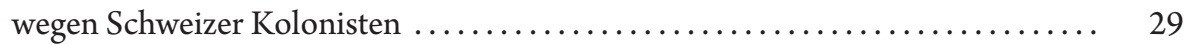

3. Erkundungen vor Ort durch eine Berner Abordnung .................. 34

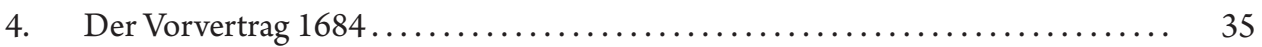

5. Schiffsreise von Bern nach Brandenburg in den Golmer Bruch ............. 36

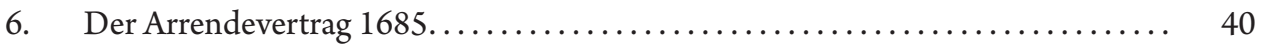

V. Die Siedlungen der Schweizer Kolonisten im Golmer Bruch vom Ende des 17. bis zum Ende des 19. Jahrhunderts .......... 47

1. Schwieriger Anfang im Golmer Bruch und auf dem Gallin -

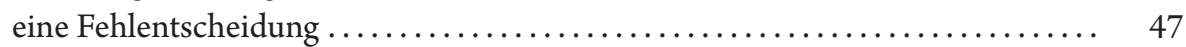

2. Die Ansiedlung der Schweizer Kolonisten in Golm................... 54

3. Die Ansiedlung der Schweizer Kolonisten in (Neu-)Töplitz............... 63

4. Die Ansiedlung der Schweizer Kolonisten auf dem Natte Werder............ 75

5. Die Regulierung des Golmer Bruchs . . . . . . . . . . . . . . . . . . . . . 84 


\section{Reformierte Schweizer Gemeinde im (Golmer) Bruch} bei Potsdam............................................ 87

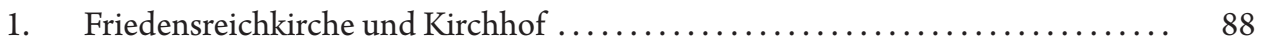

2. Das Wirken der reformierten Prediger für ihre Gemeinde................ 94

$2.1 \quad$ Elisaeus Malacrida ...................................... 100

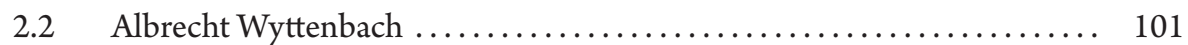

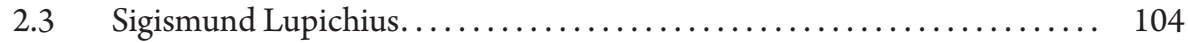

3. Zur Familie von Wykersloot ................................. 108

4. Kirchenvisitationen.................................... 110

5. Die Reformierte Schweizer Gemeinde als Filialgemeinde der unierten Gemeinde Alt Töplitz............................ 112

5.1 Das Aufgehen der reformierten Gemeinde Golmer Bruch in die Preußische Union.............................. 116

5.2 Umpfarrungen und Umwidmungen Anfang des 20. Jahrhunderts....... 121

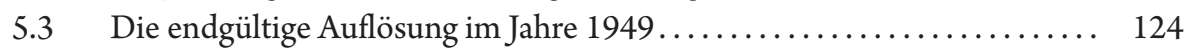

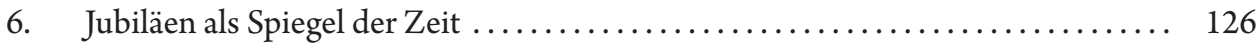

\section{Demographische, sozial- und kirchengeschichtliche Studien} über die Reformierte Schweizer Gemeinde im Bruch bei Potsdam .

1. Zur Methodik der Auswertung der Kirchenbücher von Nattwerder.......... 133

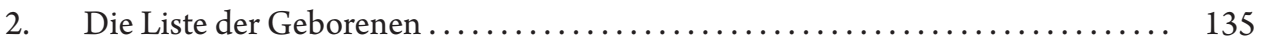

$2.1 \quad$ Die unehelichen Kinder................................. 136

2.2 Die Namen der getauften Kinder......................... 138

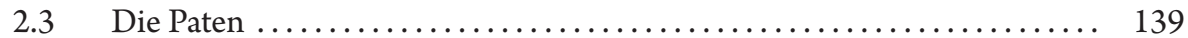

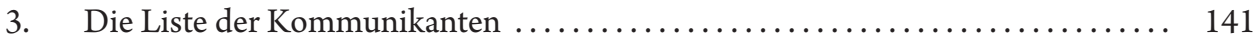

4. Die Liste der Getrauten ...................................... 142

$4.1 \quad$ Das Erstheiratsalter ..................................... 143

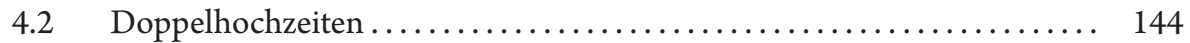

4.3 Wiederverheiratungen und Scheidungen $\ldots \ldots \ldots \ldots \ldots \ldots \ldots \ldots \ldots \ldots \ldots \ldots \ldots$

$4.4 \quad$ Woher kamen die Ehepartner?............................ 146

4.5 Anzahl der Kinder pro Familie und Geburtenregelung.............. 148

4.6 Die Militärs ........................................ 150

5. Die Liste der Verstorbenen .................................. 151

$5.1 \quad$ Die Todesursachen der Kinder und Jugendlichen $\ldots \ldots \ldots \ldots \ldots \ldots \ldots . \ldots \ldots$

5.2 Die Todesursachen der Erwachsenen......................... 155

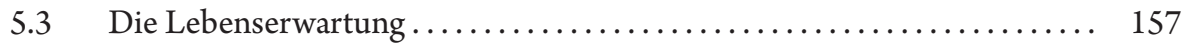

6. Zur Entwicklung der Schweizer Kolonistengemeinde $\ldots \ldots \ldots \ldots \ldots \ldots \ldots \ldots$ 
VIII. Als Fremde im fremden Land ............................ 161

1. Sprachliche Assimilation .................................... 161

2. Zum Verhältnis von einheimischen Märkern und den Schweizer Kolonisten im Golmer Bruch........................ 166

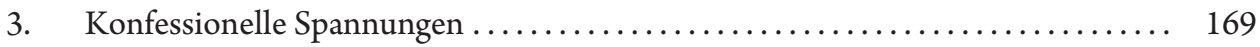

4. Beziehungen der reformierten Kolonistengemeinden untereinander......... 170

IX. Zusammenfassung ..................................... 173

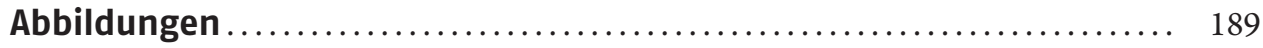

Abkürzungsverzeichnis .................................. 203

Quellen- und Literaturverzeichnis........................... 207

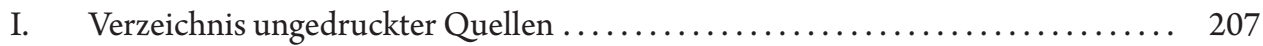

II. Quelleneditionen, Regestenübersicht und Bestandsverzeichnis ............ 208

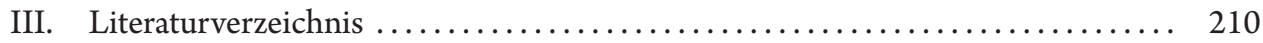

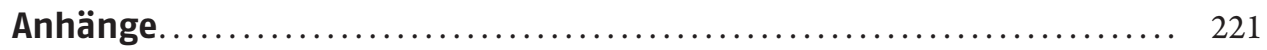

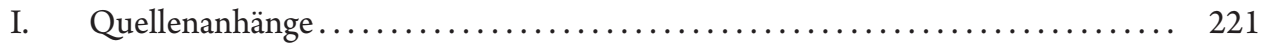

II. Liste der Prediger........................................ 253

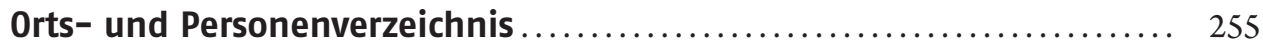





\section{Einleitung}

\section{Zielstellung der Arbeit}

Über die Situation nach dem Dreißigjährigen Krieg in der Mark Brandenburg ist viel geschrieben worden. Dem Mangel an Ressourcen und der Kriegsmüdigkeit ist es letztlich zuzuschreiben, dass die kriegführenden Parteien 1648 nach 30 Jahren Krieg zum Abschluss eines Kompromisses - des Westfälischen Friedens in Münster und in Osnabrück - bereit waren. Die Mark Brandenburg, Durchmarschgebiet zunächst von dänischen, später von kaiserlichwallensteinischen und von schwedischen Truppen, war unmittelbares Kriegsgebiet und war am Kriegsende - mit einer durchschnittlichen Entvölkerungsrate von $50 \%$ - ein „verheertes“ Land. Am stärksten war das platte Land betroffen - und hier vor allem die Prignitz, das Ruppiner Land und die Uckermark als Teil der sogenannten Verwüstungszone.

Wegen des Widerstands der Stände (Bewilligungsrecht für Steuern) ${ }^{1}$ ist die Mark Brandenburg, gemessen an der Kriegstechnik und Truppenstärke anderer deutscher Landesstaaten, zu Beginn des Dreißigjährigen Krieges in jeder Hinsicht schlecht gerüstet gewesen. ${ }^{2}$ Dadurch geriet Kurbrandenburg schnell und unversehens zwischen die Fronten der kriegführenden Parteien. Die notgedrungen betriebene wechselnde Bündnispolitik mit Schweden und dem Kaiser, von Kurfürst Georg Wilhelm begonnen und seinem Sohn Kurfürst Friedrich Wilhelm seit seinem Regierungsantritt 1640 fortgesetzt, brachte Kurbrandenburg zunehmend in die Rolle des Spielballs dieser Mächte. Zudem zog sich 1638 der Landesherr für lange Zeit außer Landes nach Preußen und Kleve zurück. Das trug ebenfalls dazu bei, dass die Mark Brandenburg von den durchziehenden Armeen nach Herzenslust geplündert, marodiert und gebrandschatzt wurde. ${ }^{3}$ Als Kurfürst Friedrich Wilhelm 1643 aus Königsberg nach Brandenburg zurückkam, fand er ein verwüstetes und entvölkertes Land vor. Diese Situation durfte sich aus brandenburgischer Sicht nicht wiederholen; selbst bei den Ständen hatte dies zu einem Umdenken in der Frage der Notwendigkeit einer schlagkräftigen Armee geführt.

Die Kriegsfolgenbewältigung stand nun für Kurfürst Friedrich Wilhelm an oberster Stelle seiner Staatspolitik. Besondere Bedeutung kam dabei der Wiederbesiedlung und Rekultivie-

1 Beck, Friedrich: Regesten und Urkunden kurmärkischer Stände (Rep. 23 A) des Brandenburgischen Landeshauptarchivs (2006), insbes. S. $18 \mathrm{ff}$.

2 Für den miserablen Zustand der brandenburgischen Lehnsarmee Anfang des 17. Jahrhunderts stellt das Ergebnis der anbefohlenen Musterung der Lehnspferde des Amtes Lehnin 1610 ein beredtes Beispiel dar. Die Schulzen von Gohlitz, Phöben, Derwitz, Schmergow, Netzen und Nahmitz hatten sie gar übel bestanden, und es wurde ihnen mit allen ernst der Verlust Ihres Lehns angedroht, wenn sie nicht Innerhalb Monatssfrist von dato an sich mit guten Pferden und dazu gehörigen Zeüge [aus] staffiren. [BLHA, Rep. 78 Kurmärkische Lehnskanzlei III Orte Nr. L 14 (nicht paginiert): Schr. Wichman von Rochow vom 8. März 1610 an den Kurfürsten].

3 Einige Ereignisse in Töplitz beschreibt der Amtmann von Lehnin, Wichman von Rochow, in seinem Schreiben vom 23. Juli 1626 an den Kurfürsten [GStA PK: I. HA, Rep. 21 Amt Lehnin Nr. 87/2 (Paket 7931, nicht paginiert, Mappe Töplitzesche Werder Göttin Leihest Amt Lehnin]. 


\section{Einleitung}

rung des Landes zu. Bereits vor Abschluss des Dreißigjährigen Krieges begannen 1647/16484 die Bemühungen um Repeuplierung mit der Anwerbung von Kolonisten aus den Generalstaaten. Diese erste systematische Maßnahme der Repeuplierungspolitik Kurfürst Friedrich Wilhelms entsprang den intensiven Beziehungen zu den Generalstaaten bzw. seiner Eheschließung mit Louise Henriette von Nassau-Oranien ein Jahr davor. Später verfolgte er diese Politik mittels europaweit gestreuter Werbungen, allerdings immer in Konkurrenz zu anderen, ebenfalls kriegsbedingt geschädigten Ländern. Für die Stärkung der Position im Reich einschließlich der angestrebten Souveränität Preußens galt es darüber hinaus, insbesondere den effektiven Ausbau der bestehenden landesherrlichen Verwaltungsstrukturen und den Aufbau eines stehenden Heeres zu bewältigen. Hierzu war ein wirtschaftlicher Aufschwung unbedingt erforderlich. Dieser konnte im agrarisch geprägten Kurbrandenburg nur mittels Repeuplierung verwüsteter Hofstellen sowie durch Urbarmachung und Besiedlung von bislang landwirtschaftlich nicht genutzten Flächen bzw. Regionen erreicht werden. Außerdem war es vordringlich notwendig, diplomatische Beziehungen, vor allem mit den protestantischen (reformierten) Ländern, aufzubauen.

Der Wiederaufbau- und Repeuplierungsprozess des Landes, unterbrochen durch den Schwedisch-Polnischen Krieg in den Jahren 1655-1660, dauerte mindestens ein halbes Jahrhundert an und erfuhr in der Nähe der neuen Residenz Potsdam verständlicherweise besondere Aufmerksamkeit. Unter diese speziellen Bemühungen fällt die Besiedlung des Golmer Bruchs.

Mit seiner Repeuplierungspolitik hatte Kurfürst Friedrich Wilhelm bis Anfang der 1680er Jahre nur mäßigen Erfolg. Beispielsweise lagen 1681 im Kreise Niederbarnim in 81 Dörfern von $3073 \frac{1}{2}$ steuerpflichtigen Hufen noch $1174 \frac{1}{2}$, also fast $40 \%$ wüst bzw. von 871 Bauernstellen waren nur 537, von $6791 \frac{1}{2}$ Kossätenstellen nur 367 besetzt. ${ }^{5}$ Die Situation änderte sich 1685 mit der Ansiedlung von Schweizern im Golmer Bruch nicht wesentlich. Aber der mit ihnen ausgehandelte Vertrag vom 16. September $1685^{6}$ wurde zum Prototyp aller weiteren Ansiedlungen von Schweizer und anderen Kolonisten im 17. und 18. Jahrhundert in Brandenburg. ${ }^{7}$ Sogar das „Edikt von Potsdam“ vom 29. Oktober 1685 nimmt in Pkt. 9 Bezug auf den Ansiedlungsvertrag der Schweizer Kolonisten im Golmer Bruch. ${ }^{8}$ Trotzdem ist festzustellen, dass die Rolle der Schweizer unter den Zuwanderern nach Brandenburg von der Migrationsforschung nur marginal wahrgenommen wurde. ${ }^{9}$ Im Grunde genommen wurde das

4 Neugebauer, Wolfgang (Hg.): Handbuch der Preußischen Geschichte, Berlin und New York ('2007), S. 176.

5 Philippson, Martin: Der Große Kurfürst Friedrich Wilhelm von Brandenburg III Teil: 1660 bis 1688, Berlin (1903), S. 112.

6 nach dem Julianischen Kalender; der Gregorianische Kalender wurde in Brandenburg am 1. Januar 1700 eingeführt.

7 Schmelz, Ulrich: Schweizer Kolonisten in der Kurmark Brandenburg im 17./18. Jahrhundert, in: Fremde in Brandenburg (Hg. Birgit Kletzin) Münster - Hamburg - London, ${ }^{2} 2003$ ) S. 48-69, bes. S. 54.

Mylius. Corpus Constitionum Marchicarum VI TH., Anhang S. $43 \mathrm{ff}$.

9 Fetscherin, Wilhelm: Die bernischen Colonien in Brandenburg am Ende des 17. Jahrhunderts, in: Berner Taschenbuch 17 (1868), S. 107-142; Beheim-Schwarzbach, Max:: Hohenzollernsche Colonisation, Beitrag zu der Geschichte des preußischen Staates und der Colonisation im östlichen Deutschland, Leipzig (1874), 
Thema seit Ende des 19. Jahrhunderts fast ausschließlich im Rahmen der Familienforschung abgehandelt. ${ }^{10}$

Die vorliegende Arbeit stellt sich die Aufgabe, das Schicksal der reformierten „Schweizer Gemeinde im Bruch bei Potsdam "11 von ihrer Entstehung 1685 bis zu ihrem Aufgehen in der lutherischen Gemeinde Alt Töplitz 1835 hinsichtlich ihrer Vorgeschichte, ihrer eigenen Geschichte und ihrer Beziehung zu anderen Schweizer Kolonisten zu untersuchen und zu würdigen. Die Recherchen hierfür seit 2009 haben sehr deutlich gezeigt, dass die Geschichte der Schweizer Kolonisten schon im 18./19. Jahrhundert bereits weitgehend in Vergessenheit geraten war und in naher Zukunft ganz vergessen sein könnte. Auch wenn beispielsweise in den Schweizer Kolonistendörfern außerhalb des Golmer Bruchs - in Linow, Storbeck und Vielitz bei Neuruppin - im Jahre 2016 das 325-jährige Jubiläum der Wiederbesiedlung dieser wüsten Feldmarken im Jahre 1691 durch Schweizer Kolonisten gefeiert wurde, ${ }^{12}$ wozu auch jeweils das ganze Dorf auf den Beinen war, hatte die Ausrichtung der Feste kaum noch einen inhaltlichen Bezug zum eigentlichen Anlass. Dies ist bedauerlich, aber in gewisser Hinsicht verständlich, wenn man bedenkt, dass in den genannten Ortschaften und anderen Schweizer Kolonistendörfern kaum noch direkte Nachkommen der ursprünglich angesiedelten Familien nachzuweisen sind.

Im Vergleich zu späteren Einwanderungswellen war die Reformierte Schweizer Gemeinde im Golmer Bruch zwar zahlenmäßig verhältnismäßig klein, aber sie gehörte in Kurbrandenburg zu den ersten reformierten Gemeinden auf dem platten Lande, die überdies ihren eigenen Prediger aus der Schweiz mitgebracht hatte. Kurfürst Friedrich Wilhelm hielt dies für notwendig. ${ }^{13}$ Aber es blieb nicht immer so. König Friedrich Wilhelm I. hob 1735 diesen Sonderstatus der Gemeinde auf und verfügte, dass die Stelle fortan mit einheimischen Theologen besetzt wurde. Anlass hierfür waren die Streitereien zwischen den Kantonen Bern und Zürich um die alternierende Besetzung der Pfarrpfründe bei den reformierten Schweizergemeinden im Raum Ruppin. ${ }^{14}$ In der Arbeit wird deswegen auch dargestellt, wie sich das Verhältnis der reformierten Kolonistengemeinde zum Haus Hohenzollern verändert hat.

Die innergemeindliche Situation spiegeln die Kirchenbücher in vielfältiger Hinsicht wider. Zu entscheiden war, welcher Zeitraum sinnvollerweise ausgewertet werden soll. Die ursprüngliche Absicht war, dafür nur das Kirchenbuch Vol. I (1685-1801) heranzuziehen. Dies hätte

S. $132 \mathrm{ff}$. und Tobler, Gustav: Die Reise der Berner Kolonisten nach Brandenburg, in: Alpenrose - Ein schweizerisches Sonntagsblatt, Bern, 19 (1889), S. 44-47.

10 Beek, Heinz van: Schweizer Kolonisten in Preußen, Mülheim (1990); Chronik der Familie Emanuel Dortschy, Frankfurt a.M. (2007), S. 77 ff.; Heese, Gerhard: Heese zu Golm bei Potsdam, Minden (1995) und Heese, Gerhard: Stammfolge des Geschlechtes, Minden (1982).

11 nach der Beschriftung des ersten Kirchenbuches (1685-1801) dieser Gemeinde.

12 In Nattwerder ist dies bereits 2010 geschehen.

13 StA Bern: A. V. 19 Teutschland Buch Preussen-Brandenburg fol. 69R.

14 daselbst: fol. 525, 530, 535, 539, 543, 547, 553, 595, 601, 607, 615, 623, 629, 657, 665, 669, 683, 685, 691, 695 und 697; Fetscherin, Wilhelm: Die bernischen Colonien in Brandenburg ..., 17 (1868) S. 107-142, bes. S. 135 . 


\section{Einleitung}

bedeutet, dass der gewählte Untersuchungszeitraum zufällig ohne einen historischen Bezug endet. Insofern ist das Kirchenbuch Vol. II. (1802-1835) auch zu diesen Untersuchungen herangezogen worden. $\mathrm{Ab}$ diesem Zeitpunkt wurde die Gemeinde vom Prediger in Alt Töplitz als Filialgemeinde geistlich betreut und verlor ihre Selbständigkeit. Dies ist im Zusammenhang mit der Schaffung der unierten Kirchen in Brandenburg geschehen. Da die „Unierung“ bei den reformierten Schweizer Kolonisten auf Widerstand stieß, wurde die Vereinigung dieser kleinen reformirten mit der lutherischen Parochie in Alt Töplitz zu einer evangelischen Gemeine per Königliche Order vom 8. Februar 1832 befohlen. ${ }^{15}$ Letztlich umgesetzt wurde dieser Befehl aber erst drei Jahre später. Es soll deshalb auch untersucht werden, wie die reformierte Gemeinde auf diese Kirchenreform von oben reagiert hat. Danach kann und soll nur auf singuläre Geschehnisse eingegangen werden, die den ursprünglichen Charakter dieser Gemeinde belegen und in einem eingeschränkten Umfang auf einen Fortbestand dieser reformierten Kirchengemeinde schließen lassen.

In der Sprache, der Kleidung und dem Glauben unterschieden sich die Schweizer Kolonisten von den Einheimischen. Sie waren zunächst „Fremde im fremden Land“. Wollten sie diese Situation ändern, mussten sie sich assimilieren. Dieser Prozess wird in der Arbeit in Kap. VIII belegt. Dazu wurden die Kirchenbücher und andere sonstige Schriftstücke herangezogen. Aber auch das persönliche Verhältnis zu den Einheimischen (Einheiraten, Wahl der Paten) änderte sich allmählich. Das zunächst strikt endogame Heiratsverhalten ${ }^{16}$ wurde allmählich aufgegeben.

Darüber hinaus stellt die Ansiedlung von Schweizer Kolonisten im Golmer Bruch eine weitere Besonderheit dar. Es ist eine mit großem logistischem Aufwand betriebene, staatlich organisierte Ansiedlung von Kolonisten aus verschiedenen, nahe Bern gelegenen Regionen (s. Abb. 3), die nicht einmal muttersprachlich eine Einheit bildeten. Die Auswahl der Familien oblag den Schweizer Ämtern anhand von vorzulegenden Reputationen. ${ }^{17}$ Insoweit handelt es sich zum einen um die erste und letztlich einzige, geschlossene Schweizer Einwanderergruppe nach Brandenburg, die zeitweise ein geistliches reformiertes Zentrum für die Region darstellte. Zum anderen handelt es sich nicht um eine historisch gewachsene (Kirchen)Gemeinde. Dagegen sind die Schweizer der späteren Einwanderungswellen auf wüste Höfe in mit Einheimischen besiedelten Dörfern im Raum Neuruppin (1690/91) und in Ostpreußen $(1710 / 11)^{18}$ verteilt worden. Bisher kaum in der Literatur beachtet ist die Einwanderung von Schweizern in den Jahren 1771 bis 1783 in die Altmark/Prignitz. ${ }^{19}$

Die Schweizer Kolonisten unterlagen schwersten Belastungen aufgrund der wirtschaftlichen und vor allem der wasserwirtschaftlichen Situation im Golmer Bruch. Schnell stellte sich

15 KA Alt Töplitz: Vereinigung Golmer Bruch mit Alttöplitz, ca. 1820 (nicht paginiert).

16 Endogamie ist das Heiraten innerhalb der eigenen sozialen Gruppe bzw. sozialen Schicht.

17 StA Bern: A. V. 19 Teutschland-Buch Preussen-Brandenburg fol. 23 u. 29.

18 Haagen, Bernhard: Burggraf Alexander zu Dohna und die Schweizerkirchen in Litauen - Zum zweihundertjährigen Gedächtnis der Entstehung der reformierten Gemeinden zu Judtschen und Gumbinnen 17131913, Berlin (1913).

19 GStA PK, II. HA Generaldirektion, Abt. 14 Materien Tit, 211 Generalia Nr. 16. 
heraus, dass nicht genügend geeignete Ackerflächen zum Anbau von Getreide vorhanden waren. Vor allem erwiesen sich die getroffenen Wasserschutzmaßnahmen (s. Kap. III.2.) als unzureichend, um eine Hochwassersituation zu verhindern. Wie die Einheimischen zu Recht befürchtet hatten, folgten den verhältnismäßig trockenen Jahren (ca. 1680-1683) ausgesprochen nasse Jahre. Die zuvor lediglich aufgeschütteten Dämme im Golmer Bruch wurden 1689 überflutet und hinweggespült. Die Häuser im Golmer Bruch waren nur per Kahn zu erreichen. ${ }^{20}$ Diese Situation ist in der Zeitspanne bis 1928 sporadisch immer wieder eingetreten. Erst dann konnten mittels elektrisch betriebener Pumpen die Wasserstände im Golmer Bruch beherrscht werden. Ein zuvor ab dem Jahre 1847 mit einer Dampfmaschine angetriebenes Schöpfwerk war ebenfalls erfolglos. ${ }^{21}$

Daraus ergab sich unumgänglich die Umsiedlung der Mehrheit der Schweizer Kolonisten auf die Vorwerke Golm und Neu Töplitz im Jahre 1691 und eine Zersplitterung der reformierten (Orts)Gemeinde. Dies bedeutete aber auch den Abschluss neuer Kontrakte, wobei die Domänen-Vorwerke nur gepachtet werden konnten. Ihr bisheriger Rechtsstatus - Erbpächter ging den betroffenen Kolonisten gegen ihren erbitterten Widerstand verloren. Sie fanden in den beiden Vorwerken auch unterschiedliche Bedingungen (gemischte/isolierte Ansiedlung, Boden, lebendes Inventar) vor. Deswegen soll in der Arbeit auch kurz auf die Geschichte dieser Vorwerke eingegangen und zu ihrer Bewirtschaftung Ausführungen gemacht werden. Die Aktenlage lässt dies nur an Hand von Einzeldokumenten zu. Das trifft vor allem auf Neu Töplitz zu - eine Gründung des Klosters Lehnin, seit 1542 Amtsvorwerk.

Von der reformierten Schweizer Gemeinde im Bruch bei Potsdam ist nicht viel übrig geblieben. Das Wenige davon trägt die Arbeit zusammen.

\section{Stand der Forschung}

Über den Stand der Forschung soll nachfolgend lediglich ein Überblick gegeben werden. In vielen historischen Abhandlungen findet die Ansiedlung Schweizer Kolonisten im Golmer Bruch im Jahre 1685 im Vergleich zur fast zeitgleichen Einwanderung der Hugenotten keine systematische Behandlung und Würdigung. Wenn es geschieht, wird lediglich die bis heute spektakuläre Anreise auf dem Wasserweg erwähnt. Ihr weiteres Schicksal wird in den älteren Übersichtsarbeiten nicht verfolgt. ${ }^{22}$ Ihre Ansiedlung hatte sich mit der Jahrhundertflut 1689 als Fehlentscheidung herausgestellt und die Schweizer Kolonisten in eine schwierige Situation gebracht. Für die glorifizierende Geschichtsforschung waren sie damit uninteressant, so dass sie bis in die 2. Hälfte des 19. Jahrhunderts in Vergessenheit gerieten.

20 StA Bern: A. V. 19 Teutschland-Buch Preussen Brandenburg, fol. 233; BLHA, Rep. 2 Kurmärkische Kriegsund Domänenkammer Nr. D 15382, fol. 3R.

21 Kaschube, Adolf: Das Golmer Luch (Bruch) und seine Entwässerungsanlagen, Ortszeitung der Gemeinde Golm, Juni 2010, S. 8-10.

22 Fetscherin, Wilhelm: Die bernischen Colonien in Brandenburg ..., 17 (1868), S. 107-142; BeheimSchwarzbach, Max: Hohenzollernsche Colonisation, Leipzig (1874), S. 143-147. und Tobler, Gustav: Die Reise der Berner Kolonisten ..., Bern, 19 (1889), S. 44-47. 


\section{Einleitung}

Der sehr rege Verein für die Geschichte Potsdams hat die Ansiedlung von Schweizern 1875 als erster wieder thematisiert (Engelcken ${ }^{23}$, Wagener ${ }^{24}$ und Bohse ${ }^{25}$ ). Etwa zeitgleich haben sich die Schweizer Historiker Fetscherin ${ }^{26}$, Tobler ${ }^{27}$ und Schneider ${ }^{28}$ mit diesen Auswanderern und ihren Schicksalen befasst. Dem Alt Töplitzer Lehrer Hermann Boege ${ }^{29}$ ist es zu verdanken, dass er Anfang des 20. Jahrhunderts in Wochenendbeilagen von Tageszeitungen darüber geschrieben und damit diese bis dahin wieder in Vergessenheit geratene Geschichte in Erinnerung gebracht hat. Aber seine Darstellungen sind dann lange Zeit tradiert worden. Die genealogischen Arbeiten von Wentscher sind als Teil der Sippenforschung im Dritten Reich anzusehen. ${ }^{30}$ Bemerkenswert ist vor allem die von Heese zur 300-jährigen Besiedlung des Golmer Bruchs verfasste Festschrift „300 Jahre Schweizer Kolonie am Golmischen Bruch bei Potsdam 1685-1985“31 - seit ihrem Erscheinen die am häufigsten zitierte Literaturstelle. Asche $^{32}$ meint, dass in ihr "die wichtigsten Akten zur Ansiedlung ediert“ sind. Dem ist nicht zuzustimmen. Ihre Bedeutung liegt vor allem darin, dass es eines der seltenen Beispiele ist, bei dem es vor der „Wende“ 1989/1990 gelungen ist, in einem inoffiziellen „Gemeinschaftsprojekt" von in der DDR und in der BRD lebenden Nachkommen der Schweizer Kolonisten eine Jubiläumsschrift mit unterschiedlichen, größtenteils genealogischen Beiträgen zu verfassen. Insofern zählt sie zu den kleinen Wundern aus der DDR-Zeit und richtete sich an eine breite Öffentlichkeit - erhebt aber nicht den Anspruch, eine wissenschaftliche Arbeit zu sein. Asche $^{33}$ beschreibt die Neubesiedlung wüster Stellen im Ruppiner Raum mit Schweizern, Franzosen und Pfälzern nach 1690/1691 und zieht Vergleiche mit der Ansiedlung Schweizer Kolonisten 1685 im Golmer Bruch bei Potsdam, obwohl es sich bei letzterer zunächst um eine Urbarmachung und Melioration eines bis dahin ungenutzten Gebietes handelt. Als

Engelcken: Der Grosse Kurfürst, in: Mitt. d. Vereins f. d. Geschichte Potsdams III Theil, 1867, S. 101-107, bes. S. 107.

Wagener, H.: Die Schweizer-Colonie, Mitt. d. Vereins f. d. Geschichte Potsdams, 1875 I. Theil, S. 211-227, bes. 221-222.

Bohse: Notizen aus Obligationen und Kaufbriefen in den ältesten Grundbüchern des Amtes Potsdam aus den Jahren 1678-1696, Mitt. d. Vereins f. d. Geschichte Potsdams, 1878, S. 41-68, bes. S. 57.

Fetscherin, Wilhelm: Die bernischen Colonien in Brandenburg ..., 17 (1868), S. 107-142.

Tobler, Gustav: Die Reise der Berner Kolonisten ..., Bern, 19 (1889), S. 44-47.

Schneider, Hermann: Die Schweizer Kolonie in der Mark. Beilage zum Programm des Königlichen Wilhelms-Gymnasium, Berlin (1906).

Boege, Hermann: Die Gründung der Schweizerkolonie, in: Potsdamer Tageszeitung Nr. 246 vom 18. Oktober 1924 und ders.: Die Wublitz und ihr Tal, in: Postamer Tageszeitung Nr. 54 vom 3. März 1928.

Wentscher, Erich: Die Schweizer Kolonien in der Mark Brandenburg, in: Archiv für Sippenforschung und alle verwandte Gebiete 7 (1930), S. 238-244, 291-194, 388-391 und 429-432; Ders: Schweizer in der Mark, in: Kleiner Bund (1932) Nr. 9; Ders. Woher stammen die ersten Schweizer Kolonisten in der Mark Brandenburg, in: Archiv für Sippenforschung und alle verwandte Gebiete 12 (1935), S. 60-61 und Ders: Familienbuch der Schweizer, hg. von der Schweizerischen Gesellschaft für Familienforschung und alle verwandte Gebiete 18 (1941), S. 166.

1 Heese, Henning (Hg.): 300 Jahre Schweizer Kolonie am Golmischen Bruch bei Potsdam 1685-1985, Sankt Augustin (1985).

2 Asche, Matthias: Neusiedler im verheerten Land - Kriegsfolgenbewältigung, Migrationssteuerung und Konfessionspolitik im Zeichen des Landeswiederaufbaus, Münster (2006), Anm. 822.

ders. S. $181-248$. 
Quelle hierfür nützte er die bereits oben erwähnte Festschrift Heeses. Als Ortschronist von Töplitz hat Vette ${ }^{34}$ die Wechselbeziehungen zwischen der Insel Töplitz und Nattwerder auf wirtschaftlichem, sozialem und kulturellem Gebiet in den Fokus genommen. Die von ihm erstellten einzelnen Kapitel ergeben diesbezüglich kein Gesamtbild. Zum 325-jährigen Jubiläum der Besiedlung des Golmer Bruchs im Jahre 2010 ist vom Verein Schweizer Kolonistendorf Nattwerder eine Jubiläumsschrift e. V. (SKDN) erstellt worden. ${ }^{35}$ Hier steht erstmals ausdrücklich die reformierte Kirchengemeinde im Mittelpunkt der Ausführungen. Schließlich ist 2013 zum 750-jährigen Jubiläum von Alt Töplitz eine Jubiläumsschrift erschienen, in der auch Neu Töplitz behandelt und das Schicksal der dort 1691 im Amtsvorwerk aus dem Golmer Bruch umgesiedelten Schweizer Kolonisten aufgegriffen und umrissen wird. ${ }^{36}$

Die Kirchenbücher der Schweizer Gemeinde im Golmer Bruch bei Potsdam werden in der Literatur zwar gern als besonders wertvolle Dokumente für die Kirchengeschichte und die genealogische Forschung erwähnt und abgebildet, aber darüber hinaus als historische Quelle nicht weiter gewürdigt. Die Entdeckung der Kirchenbücher als Informationsquellen steht für die historische Demographie überhaupt noch aus! ${ }^{37}$ Das trifft vor allem für die Auswertung ländlicher Kirchengemeinden in Berlin/Brandenburg zu. Bislang liegt lediglich eine Auswertung des Kirchenbuches von „Steglitz bei Berlin“ vor. ${ }^{38}$ Diese Situation ist deshalb verwunderlich, weil keine vergleichbaren Unterlagen aus dem 17./18. Jahrhundert für Studien der Sozial-, Bevölkerungs-, Wirtschafts- und Kirchengeschichte zur Verfügung stehen. Darauf hat bereits Süßmilch $1741^{39}$ und $1757^{40}$ hingewiesen. Die Arbeiten von Iida untersuchen mit Hilfe von Kirchenbüchern sowohl bäuerliche Wirtschaften innerhalb einer adligen Gutsherrschaft als auch innerhalb eines landesherrlichen Domänenamtes in den Dörfern Manker und Wustrau $^{41}$ sowie das Ruppinische Bauernleben in der zweiten Hälfte des 17. Jahrhunderts. ${ }^{42}$

Vette, Markus: Die Schweizer Gemeinde Nattwerder als wirtschaftliche, soziale und kulturelle Bereicherung für die Insel Töplitz, im Eigenverlag erschienen (2007).

Bleyl, Dietmar Walther Richard (Hg.): Nattwerder - 325 Jahre Besiedlung des Golmer Bruchs, Potsdam (2010).

ders.: Töplitz - 700-jährige Geschichte einer märkischen Kirchengemeinde, Potsdam (2013).

Imhof, Arthur: Einführung in die Historische Demographie, München (1977) S. 8 ff.

Zinke, Regine: Steglitz bei Berlin, Edition Hentrich (1996).

Süßmilch, Johann Peter: Die göttliche Ordnung, Berlin (1741), S. 284-286; Zur Person: lebte von 17071767, Studium der Theologie (1727-1732), zunächst als Hofmeister und Hauslehrer tätig, ab 1736 Feldprediger und später vom Brandenburger Domkapitel zum Prediger von Etzin und Knoblauch berufen, 1742 als Dompropst von Cölln (heute Berlin) und der Berliner Petrikirche im Rang eines Konsistorialrates tätig. Daneben war er Mitglied der königlich-preußischen Akademie. Er gilt als Begründer der modernen Statistik und Bevölkerungstheorie [Neue Deutsche Biographie, Bd. 25, S. 686.].

Süßmilch, Johann Peter: Gedanken von den epidemischen Krankheiten, Berlin (1757).

Iida, Takashi: Hof, Vermögen, Familie 1700-1820, Jb. f. d. Brandenburgische Geschichte Bd. 49 (1998), S. 143-182.

ders.: Ruppiner Bauernleben 1648-1806; in: Studien zur brandenburgischen und vergleichenden Landesgeschichte, Bd. 3 (2010), S. 130-180. 


\section{Einleitung}

Dass die Schweizer Kolonisten im Neuruppiner Raum, in der Uckermark, Ostpreußen und dem Golmer Bruch untereinander in Verbindung gestanden haben, ist grundsätzlich geklärt. ${ }^{43}$ Hierzu werden weitere Erkenntnisse hinzugefügt. Die Rolle der Prediger ist aber hierbei kaum beleuchtet worden. Bislang hieß es nur, sie hätten ihre Gemeindeglieder gegenüber den Behörden vertreten und die Verbindung zur alten Heimat gehalten. Ihre vermittelnde Rolle geht aber weit darüber hinaus. Besonders ist das persönliche Engagement der beiden Prediger Albrecht Wyttenbach (1687-1705) und Sigismund Lupichius (1705-1717) zu würdigen.

Für die Geschichtsforschung war die Besiedlung des Golmer Bruchs bislang im Wesentlichen nur bis zur Aufteilung der Kolonisten im Jahre 1691 auf verschiedene Standorte von Interesse. Auch auf die damit verbundene Änderung ihrer Rechtsstellung wird hingewiesen. Ihr weiteres Schicksal blieb bislang im Dunkeln. Allein schon aus den Übergabeprotokollen und Inventarlisten zeigt sich ihre unterschiedliche Wirtschaftssituation. Tradiert findet sich auch das Synonym „Schweizer“ und Melker. Das mag für andere Regionen durchaus zutreffen. In Neu Töplitz und Golm steht zunächst aber wegen der mageren Böden eindeutig die Bewirtschaftung der übernommenen Schafherden im Vordergrund. Mit dem Niedergang der Tuchindustrie auf dem Kontinent hat dies auch für die hiesigen Schweizer Konsequenzen. Eine Besonderheit stellt die bislang unbekannte Pferdezucht in Neu Töplitz dar, die sonst in der Gegend im 17./18. Jahrhundert nicht betrieben wurde. Allein daran sieht man schon, dass die Bedingungen für die Ansiedlung der Schweizer Kolonisten in Gallin, Golm, Nattwerder und Neu Töplitz sich unterschieden. Die Historie der Standorte spielt dabei eine Rolle, die im Falle von Neu Töplitz nur durch Urkunden bekannt ist. Darüber hinaus lag es nahe, in die Recherchen zu dieser Arbeit den Werdegang vom Klosterhof Töplitz (Gründung nach 1318), dem Amtsvorwerk Töplitz (seit 1542) und schließlich dem Pachtvorwerk Neu Töplitz (seit 1691) einzubeziehen.

Der Arbeit liegen Recherchen in folgenden inländischen Archiven zugrunde: Archiv der Evangelischen Kirche der Kirchenprovinz Sachsen (AKPS Magdeburg), Brandenburgisches Landeshauptarchiv (BLHA), Domstiftsarchiv Brandenburg (DStA Brandenburg), Evangelisches Landeskirchliches Archiv in Berlin (ELAB), Evangelisches Zentralarchiv (EZA), Geheimes Staatsarchiv Preußischer Kulturbesitz (GStA PK), Kirchenarchiv der Evangelischen Gemeinde Alt Töplitz (KA Alt Töplitz), Kreisarchiv Potsdam Mittelmark (KA PM), Stadtarchiv Potsdam (StadtA Potsdam). Deren vorhandene Archivalien wurden nach Informationen über die gesellschaftlichen, wirtschaftlichen, kulturellen und erbrechtlichen Belange der Schweizer Kolonisten im Golmer Bruch ausgewertet, wobei insbesondere die Bestände des Brandenburgisch Preußischen Hausarchivs, des Geheimen Rates, der Kurmärkischen Kriegs- und Domänenkammer, des Generaldirektoriums, der Regierung Potsdam, des Amtes Potsdam/Lehnin und der Kurmärkischen Stände sowie die Bestände der Konsistorien,

43 Stirnemann, Heinz: Woselbst sie wohl aufgenommen - 300 Jahre Schweizer Kolonie in der Mark Brandenburg am Beispiel der Gemeinde Storbeck, Frankfurt/a. M. (o.J.); Asche, Matthias: Neusiedler im verheerten Land, Münster (2006). 
der Superintendenturen ${ }^{44}$ und der Kirchengemeinde Alt Töplitz Berücksichtigung fanden. Wertvolle Hinweise über die Besiedlung des Golmer Bruchs enthielten die Registraturbücher der Kurmark. Darin befinden sich, nach diversen Sachgebieten geordnet, alle eingegangenen Vorgänge mit einem Betreff chronologisch aufgelistet und einem Hinweis versehen, in welchem Repertorium der Vorgang abgelegt ist. Bedauerlicherweise waren die zugehörigen Akten nicht alle aufzufinden. ${ }^{45}$ Es sei dahingestellt, ob hierfür kriegsbedingte Verluste oder die unsystematische Bündelung der Akten der Allgemeinen Verwaltung ursächlich in Frage kommen. Allein schon diese Recherchen haben das bisher gezeichnete Bild von der Besiedlung des Golmer Bruch wesentlich vervollständigt und abgerundet. Zusätzlich ist hierzu im Staatsarchiv Bern (StA Bern) der Schriftverkehr zwischen Brandenburg-Preussen und dem Kanton Bern Ende 17./Anfang 18. Jahrhundert gesichtet worden. Besonders das Teutschland Buch Preussen-Brandenburg ${ }^{46}$ ergänzt komplementär die Akten über auswärtige Beziehungen (Schweiz) im GStA Berlin-Dahlem (I. HA, Rep. 11) und enthält darüber hinaus die Berichte der nach Brandenburg abgeordneten, reformierten Prediger an ihre Oberen.

44 Nattwerder gehört von 1685-1832 zur Superintendentur Potsdam, seit der Unierung 1834 nach Neustadt Brandenburg und ab 1939 zur Superintendentur Lehnin, s. Veröffentlichungen des Staatsarchivs Potsdam, Bd. 11, Hg. Friedrich Beck; Historisches Ortslexikon für Brandenburg, Teil V Havelland, bearb. von Lieselotte Enders, Weimar (1972) S. 45/46. Inzwischen ist diese in den Kirchenkreis Brandenburg-Mittelmark eingegliedert geworden.

45 GStA PK, Registraturbuch Kurmark B.3. (1672-1688) und B.4. (1689-1698); So fand sich beispielsweise nicht: mensis Aprilis 1686: Elisabeth Kienerts, Churfl. Waschmägdchens geschenck Zur Hochzeit. 27. Apr: R. 9. Kastl. C. n: 5 (s. auch GStA PK, I. HA, Rep. Nr. 123 (Paket 7998, nicht paginiert), Schr. v. 28.08.1699). StA Bern: A. V. 19 Teutschland Buch Preussen-Brandenburg. 



\section{Die wirtschaftliche und konfessionelle Situation in Kurbrandenburg nach dem Dreißigjährigen Krieg}

\section{Die wirtschaftliche Situation in Kurbrandenburg}

Nach dem Dreißigjährigen Kriege wurde nicht nur die Stadt Potsdam durch den Kurfürsten Friedrich Wilhelm zu neuem Leben erweckt, indem er durch den Bau verschiedener Schlösser das Stadtbild ${ }^{47}$ und die nächste Umgebung Potsdams ${ }^{48}$ beträchtlich umgestalten ließ, sondern auch auf dem Lande zeigten sich wesentliche Veränderungen. Für diese Arbeit sind vor allem seine Repeuplierungsmaßnahmen auf dem platten Lande von Interesse. Ihm ging es dabei - im Gegensatz zu den lokalen Obrigkeiten, die ein Bauernlegen betrieben - um den Aufbau wüster Höfe und die Wiederherstellung eines beständigen Bauernstammes in den Domanialämtern. Langfristig erhoffte er sich, dadurch die Staatseinkünfte zu erhöhen und zu stabilisieren. Um dies zu erreichen, gewährte er siedlungswilligen Neubauern Freijahre, während derer sie keine Abgaben zu zahlen hatten, aber die ihnen vorgeschossenen Gelder zum Bau der Höfe sowie zum Kauf von landwirtschaftlichen Arbeitsgeräten, Vieh und Saatgut zurückzahlen sollten. Zudem betrieb er - mit unterschiedlichem finanziellem Erfolg - in großem Stil die einträgliche Erb- und Zeitverpachtung von Domanialämtern und Amtspertinenzen.

Vor diesem Hintergrund haben die Gebrüder Pierre und Hugues Lamy ${ }^{49} 1647$ dem Kurfürsten einen fast revolutionär anmutenden Vorschlag zur Besiedlung von „wüsten“ Stellen in Brandenburg Preußen unterbreitet. ${ }^{50}$ Nach ihrer Auffassung würde sich ein wesentlich größerer Erfolg einstellen, wenn die Neuansiedler ein eigenes kirchliches und bürgerliches Gemeinwesen bilden könnten und ihnen die Freiheit in ihrem wirtschaftlichen Handeln eingeräumt würde. Dahinter stand die Ansicht, dass das Gedeihen allen wirtschaftlichen Lebens von der Initiative der Beteiligten abhing.

Mit den Gebrüdern Lamy wurde dann am 22. Mai 1647 ein Vertrag abgeschlossen, in dem ihnen ein Prozent der erzielten Mehreinnahmen der Ämter zugesichert wurde. ${ }^{51}$ Die Einzelheiten sollten nach den ersten praktischen Erfolgen vereinbart werden. Diese Vorsichtsmaßregel erwies sich als sehr angebracht. Zwar wollten die Brüder Lamy die erforderlichen Aufwendungen für die Besiedlung wüster Ländereien in den kurfürstlichen Ämtern aus eigenen Mitteln leisten, dafür sollten aber zuerst Bedingungen geschaffen werden, die auf eine Veränderung der ganzen gesellschaftlichen Verhältnisse hinausgelaufen wären. Die Erbuntertänigkeit

47 Bau des Stadtschlosses Potsdam 1662-1668.

48 z. B. Bau der Schlösser Caputh 1662 und Bornim 1672.

49 vermutlich französische Hugenotten (Susanne Lachenich: Hugenotten in Europa und Nordamerika, Migration und Integration in der frühen Neuzeit, Frankfurt am Main (2010), S. 93.

50 Meinardus, Otto: Protokolle und Relationen des Brandenburgischen Geheimen Rathes aus der Zeit des Kurfürsten Friedrich Wilhelm, Dritter Bd., Leipzig, III. Bd., Leipzig (1835), Nr. 458, S. 691.

51 ders.: Nr. 469, S. 705. 


\section{Die wirtschaftliche und konfessionelle Situation in Kurbrandenburg}

der Bauern sollte abgeschafft werden, und zwar offenbar nicht nur auf den Domänen, denn es sollte eine allgemeine Freizügigkeit der Bevölkerung und Gleichberechtigung der Bewohner von Stadt und Land eintreten. Der Kurfürst hätte solche Veränderungen gegen den märkischen Adel gar nicht durchsetzen können, selbst wenn er das gewollt hätte.

Dies zeigt sich bei der Ansiedlung von Friesen in der Wische, einem feuchten Niederungsgebiet längs der Elbe von Werben bis Tangermünde. Der dafür am 9. Januar 1649 abgeschlossene Vertrag folgte dem Konzept der Gebrüder Lamy. ${ }^{52} \mathrm{Zu}$ anderen Bedingungen hätte man niederländische Siedler zu der Zeit wahrscheinlich kaum bekommen können. Der Versuch scheiterte am Widerstand des ansässigen Adels und der örtlichen Beamten, die solchen Vorhaben skeptisch gegenüberstanden. Sie argwöhnten, von den Fremden mancherlei Ärger wegen deren reformierten Konfession und wegen des Privilegs, Handel zu treiben, zu bekommen. Letzteres hatten die Gebrüder Lamy sich in Anlehnung an heimische Verhältnisse im Vertrag erwirkt, aber dies war unvereinbar mit der in Brandenburg üblichen Aufgabentrennung von Stadt und Land. Dennoch ist der Vertrag ein Zeichen dafür, dass das sozialpolitische Vorstellungsvermögen des Kurfürsten Friedrich Wilhelm sich nicht nur in den Bahnen der Gutswirtschaft und Erbuntertänigkeit bewegte, wie sie im Landtagsrezess von 1653 für die Mark Brandenburg als Norm festgelegt werden sollten. ${ }^{53}$

Auch die anderen Versuche mit niederländischen Siedlern blieben in ihrem Erfolg weit hinter den ursprünglichen Erwartungen zurück. 1651 wurde der größte Teil des Amtes Liebenwalde an eine Gruppe friesischer Bauern unter Leitung eines Kapitäns namens Strien verpachtet. ${ }^{54}$ Eine kurfürstliche Kommission erhielt aber 1655 von seiner Wirtschaftsweise einen so ungünstigen Eindruck, dass er und einige andere Pächter vor Ablauf der ursprünglich gesetzten Frist wieder entfernt wurden. Immerhin verblieb hier offenbar doch ein Teil der angesiedelten Bauern im Lande. Die Erfahrungen, die mit diesen anderssprachigen, anderskonfessionellen und anderskulturellen Siedlern gemacht wurden, flossen in den Erfahrungsschatz bei den späteren hohenzollernschen Kolonisationen ein.

Unterstützung bei diesen planmäßigen Neuansiedlungen bekam Kurfürst Friedrich Wilhelm durch seine Gemahlin, Kurfürstin Louise Henriette. ${ }^{55}$ Sie verfolgte energisch den Plan, aus ihrem Besitz in Oranienburg ein Mustergut zu machen. Dabei wollte sie keineswegs das Bauernlegen, wie es beim Adel üblich geworden war, unterstützen. Im Gegenteil; sie ordnete im Jahre 1665 ausdrücklich an, dass die Vorwerksäcker von Oranienburg nicht mehr durch Meiereigesinde und durch Hofdienste der Bauern bestellt werden dürften. Sie sei sich vielmehr schlüssig geworden, bei jedem Vorwerk eine bestimmte Anzahl Bauernhäuser auf ihre Kosten errichten zu lassen und Untertanen hier anzusiedeln.

52 Breysig, Kurt: Geschichte der brandenburgischen Finanzen in der Zeit von 1640 bis 1697, I. Bd., Leipzig (1895), S. 702-707.

53 Badstübner, Sibylle: Hugenotten in Berlin, Berlin (1988), S. 21.

54 Hierbei handelte es sich um eine „Ansiedlungs-Compagnie“. s. Opgenoorth, Ernst: Der Grosse Kurfürst von Brandenburg, Teil I, Göttingen, Frankfurt und Zürich (1971), S. 175.

55 Hüttl, Ludwich: Friedrich Wilhelm von Brandenburg - Eine politische Biographie, München (1981) S. 302. 
Ein weiteres besonderes Merkmal dieser Zeit ist die Rückführung vieler Dörfer oder Anteile derselben durch Aufkauf in landesherrlichen Besitz. In der Regel handelte es sich dabei um verschuldete Rittergüter. Fidicin ${ }^{56}$ führt dazu als Beispiele die Orte Sputendorf (1680), Brachwitz (1680), Buchholz (1680), Niebel (1681), Schlalach (1681) und Wittbrietzen (1681) an, die der Kurfürst erworben und zu den Ämtern Potsdam und Saarmund gelegt hat. Allerdings ist dies in einem viel umfangreicheren Maße geschehen, als dies Fidicin angibt. ${ }^{57}$ Allein in unmittelbarer Nähe von Potsdam kaufte der Kurfürst die Adelsgüter von Bornim $(1663)^{58}$, Bornstedt $(1660)^{59}$, Caputh $(1671)^{60}$, Geltow $(1660)^{61}$, Golm $(1662)^{62}$ und Grube $(1660)^{63}$ auf. Diese Dörfer wurden zur Herrschaft Potsdam zusammengeschlossen und durch ein Domänenamt verwaltet. Drewitz und Glienicke kamen später noch hinzu. Die Vorwerke Bornstedt und Grube dienten dem 1724 von König Friedrich Wilhelm I. gestifteten Potsdamer Großen Militärwaisenhaus als Versorgungsgüter. ${ }^{64}$

Vergleichsweise nur wenig lässt sich über die sonstigen Wirtschaftszweige in Kurbrandenburg in der 2. Hälfte des 17. Jahrhunderts sagen. Konkurse als Folge des Dreißigjährigen Krieges, wie sie vor allem in der Tuchindustrie nach dem Siebenjährigen Krieg beschrieben werden, hat es wohl nur in geringem Umfang gegeben. ${ }^{65}$ Neugebauer ${ }^{66}$ spricht an anderer Stelle von einer tendenziellen Verstärkung des [...] Gewerbes und dem weiterhin Bestehen eines starken agrarischen Elements in den Kleinstädten. Im Raum Berlin lassen sich die ersten Manufakturneugründungen (Zuckersiederei, Spiegelmanufaktur) nachweisen. Ansonsten verfügte die Mark Brandenburg über eine gewisse Eisenindustrie in Neustadt/Dosse, Peitz und Zehdenick. Die Grundlage hierfür ist das im Lande vorhandene Raseneisenerz. Für die Waffen- und Munitionsherstellung bedurfte es aber der Einfuhr von höherwertigen Eisenerzen vor allem aus Schweden. Die Belebung des Handwerks und der Wirtschaft durch die Hugenotten stand noch aus.

60 Historisches Ortslexikon für Brandenburg, Teil V Zauch-Belzig, bearb. von Peter P. Rohrlach, Weimar (1977), S 72.

61 Historisches Ortslexikon für Brandenburg Teil III Havelland, bearb. von Lieselotte Enders, Weimar (1972), S. 127; GStA PK, I. HA, Rep. 131 K 440 D Nr. 19.

62 daselbst, S. 136.

63 daselbst, S. 142, GStA PK, I. HA, Rep. 131 K 440 D Nr. 6.

64 275 Jahre Stiftung Großes Waisenhaus zu Potsdam, hg. Stiftung Großes Waisenhaus zu Potsdam (1999), S. 7.

65 Neugebauer, Wolfgang: Zentralprovinz im Absolutismus, Berlin (2001) S. $136 \mathrm{ff}$.

66 Neugebauer, Wolfgang: Brandenburg im absolutistischen Staat, in: Ingo Materna/Wolfgang Ribbe (Hg.): Brandenburgische Geschichte, Berlin (1995), S. 312 f.; Asche, Matthias: Neusiedler im verheerten Land, Münster (2006), S. 626. 


\section{Die wirtschaftliche und konfessionelle Situation in Kurbrandenburg}

Um den wirtschaftlichen Aufschwung seines Landes zu fördern, ließ Friedrich Wilhelm den Müllroser Kanal 1662-1664 errichten. ${ }^{67}$ Durch die so geschaffene Verbindung von Oder und Spree wurde dem schlesischen und südpolnischen Handel ein direkter Wasserweg zur Havel und Elbe erschlossen. Damit gelang es, trotz begrenzt verfügbarer Mittel und unter Ausnutzung geographischer Möglichkeiten eine nachhaltige merkantilistische Verkehrsförderung zu erzielen. Der Handel war nun nicht mehr an die natürlichen Wasserläufe gebunden und erwies sich dadurch dem Landhandel gegenüber überlegen - schneller, billiger, ganzjährig möglich. Ab 1886 wurde dieser Kanal zum Oder-Spree-Kanal erweitert.

\section{Die Konfessionelle Situation in Kurbrandenburg}

Die Konfessionalisierungsprozesse in Kurbrandenburg stellen eine Sonderentwicklung in den Territorien des Heiligen Römischen Reiches Deutscher Nation dar. Der Übertritt des Kurfürsten Johann Sigismund zum reformierten Glauben am 1. Weihnachtstag 1613 zog nicht den im Augsburger Religionsfrieden den Landesherren zugestandenen Bekenntniswechsel seiner Untertanen nach sich. Nur wenige Adelsfamilien folgten seinem Beispiel. Die sonstigen Untertanen blieben bei ihrer angestammten - lutherischen - Religion. Damit diese Situation bestehen blieb, ließen sich die Stände in den von ihnen erzwungenen Reversen immer wieder bestätigen, dass der Kurfürst und seine Nachfolger das Augsburger Bekenntnis (Confessio Augustana) in ihrer unveränderten Form und die Formula Concordiae garantierten. Praktisch verzichtete er damit förmlich auf das Ius reformandi. ${ }^{68}$ Seither gab es in der Mark Brandenburg ein Nebeneinander von lutherischer Mehrheits- und einer elitären reformierten Minderheitsreligion der Dynastie und des Hofes (s. auch Kap. VIII.3). Neben dem quantitativen Aspekt hat es zugleich in Brandenburg eine Distanzierung von der reformierten Glaubensrichtung gegeben, die sich im Berliner Tumult des Jahres 1615 am deutlichsten zeigt. Der Westfälische Frieden 1648 hat mit der Normaljahr-Regelung69 diese konfessionelle Situation noch zementiert.

Insoweit bestanden für die Hohenzollernschen Kurfürsten nur wenige Möglichkeiten, ihre Konfessionspolitik umzusetzen. Zu nennen ist die Aufnahme dynastischer Beziehungen zu anderen reformierten Herrscherhäusern wie z.B. durch die Heirat des späteren Kurfürsten

67 Opgenoorth, Ernst: Der Grosse Kurfürst von Brandenburg, Teil II 1660-1688, Göttingen, Frankfurt und Zürich (1978), S. 50/51.

68 Die Kernaussage des Augsburger Religionsfriedens ging nicht von einer religiösen, sondern von einer politischen Kompromissformel aus, der die katholische und evangelische Seite auf dem Augsburger Reichstag 1555 zustimmen konnten: Wer das Land regiert, sollte den Glauben in seinem Land bestimmen - cuius regio, eius religio - eine Formel, die der Greifswalder Kirchenrechtler Joachim Stephani (1544-1623) um 1604 für das ius reformandi einführte.

69 Im Westfälischen Frieden wurde der Augsburger Religionsfrieden bestätigt und ausdrücklich auf die Reformierte Religion als dritte gleichberechtigt anerkannte Konfession ausgedehnt. Als Grundregel des konfessionellen Besitzstandes wählte man ein „Normaljahr“, den 1. Januar 1624 (dies decretorius). Der an diesem Stichtag gegebene territoriale bzw. konfessionelle Zustand sollte in Zukunft wiederhergestellt bzw. beibehalten werden. Die reformierte Konfession war aber zu diesem Zeitpunkt nicht anerkannt. 
Georg Wilhelm mit Elisabeth Charlotte von der Pfalz 1616. ${ }^{70}$ Nach der verlorenen Schlacht am Weißen Berge bei Prag 1620 führte dies eher zu einem Autoritätsverlust der Evangelischen im Reich. Unter Kurfürst Friedrich Wilhelm gelang es, über die Berufung von Hofpredigern zumindest an den Haupt- und Nebenresidenzen ein lockeres Netz von kleinen deutsch-reformierten Personalgemeinden zu etablieren. Im Ergebnis dieser Bemühungen ${ }^{71}$ sind bis 1680 in der Mark Brandenburg insgesamt sechzehn ${ }^{72}$ und bis zum Ende der Regierungszeit Kurfürst Friedrich Wilhelms zwanzig deutsch-reformierte Gemeinden entstanden. ${ }^{73}$ Die hohe Zahl täuscht über den tatsächlichen Erfolg der hohenzollernschen Kirchenpolitik hinweg, denn die Zahl der Gemeindeglieder war und blieb lange - mit Ausnahme der Berliner Domgemeinde klein. Außerdem bestanden die Hofprediger-Gemeinden fast ausschließlich aus Hofbedienten und aus sogenannten unbeständigen „Communicanten“ aus den umliegenden Orten.

Damit bekam die Aufnahme von Einwanderern reformierten Glaubensbekenntnisses eine zentrale Bedeutung in der hohenzollernschen Kirchenpolitik, da auf diesem Weg größere und personell stabilere Gemeinden in der Mark Brandenburg entstehen konnten. In diesen Kontext gehört - chronologisch am Beginn der systematischen Repeuplierungsmaßnahmen - die Ansiedlung von niederländischen Kolonisten seit den späten 1640er Jahren, ${ }^{74}$ welche immerhin an einigen Orten in der Neumark und noch punktueller in der Mittel- und Altmark zu reformierten Gemeindegründungen geführt hat. Etwa 40 Jahre später folgten die angeworbenen Schweizer Kolonisten und vor allem die französischen, die salzburgischen und die pfälzischen Glaubensflüchtlinge. Dabei hatte der Kurfürst jedoch Rücksicht auf die

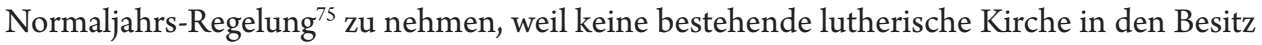
von Reformierten übergehen durfte.

Da aber selbst für die wenigen reformierten Gemeinden keine Finanzen für eigene Kirchenbauten vorhanden waren, stellten zunächst Simultaneen ${ }^{76}$ die gängige Form der religiösen Praxis dar. In der Regel stellten sich dabei mit der Zeit Spannungen zwischen den lutherischen und reformierten Ortsgemeinden wegen gegenseitiger Be- oder Verhinderungen der Glaubensausübung oder irgendwelcher Nichtigkeiten ein. Beredte Beispiele hierfür im dörf-

70 Hintze, Otto: Soziologie und Geschichte - Gesammelte Abhandlungen zur Soziologie, Politik und Theorie der Geschichte, Göttingen (1964), Bd. III, S. 299-300.

71 Unterstützung erhielt er hierbei u. a. durch Otto v. Schwerin (Oberpräsident des Geheimen Rates) und Kurfürstin Elisabeth-Charlotte, der auf seiner Herrschaft (Altlandsberg) bzw. die auf ihrem Witwenbesitz (Crossen) reformierte Kolonistengemeinden einrichteten (Martin Gabriel: Die reformierten Gemeinden in Mitteldeutschland), Geschichte und Verfassung einer Bekenntnisminderheit im 18. Jahrhundert und danach, Witten (1973), S. 35. Zum Wirken der Kurfürsten Louise Henriette hierzu in Oranienburg s. Kap. V.2.

72 Ribbe, Wolfgang: Brandenburg auf dem Wege zum polykonfessionellen Staatswesen, in: Gerd Heinrich (Hg.): Tausend Jahre Kirche in Berlin-Brandenburg, Berlin (1999), S. 267-292, bes. 281.

73 Thadden, Rudolf von: Die Hinwendung des Kurhauses zum reformierten Bekenntnis, in: Gerd Heinrich (Hg.): Tausend Jahre Kirche in Berlin-Brandenburg, Berlin (1999), S. 255-266.

74 wie bereits in der Einleitung erwähnt.

75 s. Anm. 69.

76 d.h., die Kirchen wurden von verschiedenen Konfessionen genutzt. 


\section{Die wirtschaftliche und konfessionelle Situation in Kurbrandenburg}

lichen Bereich sind Damsdorf ${ }^{77}$, Lehnin ${ }^{78}$ und Lindow ${ }^{79}$. Am häufigsten konnte bzw. wollte man sich nicht auf abgestimmte Gottesdienstzeiten für die lutherische und reformierte Ortsgemeinde einvernehmlich einigen. ${ }^{80}$ Oder dem wegen einer in Damsdorf vorzunehmenden Trauung angereisten Prediger Beauvais aus Lehnin ${ }^{81}$ wurde der Kirchenschlüssel verweigert, so dass daraufhin die Copulation in dem Hause eines benachbarten reformirten Bauers Zech [...] verrichtet wurde. ${ }^{82}$ In diesen Fällen wurde dann Klage gegen die andere (glaubensverwandte) Konfession beim Konsistorium geführt, und dieses verfügte hierüber - ggf. nach angeforderten Berichten. In den Städten kulminierte die Intoleranz in Form von gegenseitigen Verbalattacken, sogar von der Kanzel. Das betraf in erster Linie die zwischen der lutherischen und der reformierten Konfession bestehenden strittigen Glaubensfragen (vor allem im Verständnis des Abendmahls ${ }^{83}$ und der Prädestinationslehre) $)^{84}$, die fließend zu persönlichen Verunglimpfungen des glaubensverwandten lutherischen bzw. reformierten Predigers vor Ort übergingen. Kurfürst Friedrich Wilhelm war für die obrigkeitliche Ordnung im Land und in der Kirche als Summus episcopus ${ }^{85}$ verantwortlich und hatte deshalb für den konfessionellen Frieden im Lande zu sorgen. Insofern war er mehrfach veranlasst, beide Seiten aufzufordern, dass die theologischen Auseinandersetzungen geschehe ohne Bitterkeit, verketzerung, verdammung, oder anathematisiren, mit Sanfftmuth, und einem Gottesfürchtigen Theologo anständiger Christlichen Bescheidenheit, und beobachtung deßen, was sonsten bey tractirung der Controuersien beyden Theilen in denen Edictis anbefohlen, und allhier declariret, .. ${ }^{86} \mathrm{Im}$ Effekt kamen diese Aufforderungen zur Beendigung dieser von der Kanzel aus geführten Polemik der Minderheit - den Reformierten - zugute. Das bekannteste Beispiel stellt die Entlassung Paul Gerhardts dar, der nicht bereit war, das Toleranzedikt von 1664 zu unterschreiben.

GStA PK, I. HA, Rep. 243 Nr. 312 fol. 2R.

GStA PK, I. HA, Rep. 243 Nr. 307. Die Lehniner Kirche wurde sogar mit einer Trennmauer abgeteilt, die später dann einzustürzen drohte.

GStA PK, I. HA, Rep. 243 Nr. 424 fol. 90.

Die diesbezügliche Praxis bei den heute noch bestehenden 64 katholisch/evangelischen Simultankirchen in Deutschland zeigt, dass dies völlig reibungslos erfolgen kann (https//de.wikipedia.org/wiki/Simultankirche) Wilhelm Herrmann Beauvais war von 1761-1811 reformierter Prediger in Lehnin (Otto Fischer (bearb.): Evangelisches Pfarrerbuch für die Mark Brandenburg, Berlin (1941), Bd. 1, S. 108.

GStA PK, I. HA, Rep. 243 Nr. 312 fol. 2-2R.

Die lutherische Konfession sieht in dem beim Abendmahl gereichten Brot (für Leib) und Wein (für Blut) kraft der biblischen Einsetzungsworte die Gegenwart Christi realpräsent, wogegen die reformierte Konfession das Abendmahl als ein Erinnerungsmahl versteht; s. Schmidt, Heinrich Richard: Konfessionalisierung im 16. Jahrhundert, München (1992), S. 13.

Unter Prädestination wird die definitive göttliche Heils- (Lutheraner) oder doppelte Unheilsverfügung (Reformierte) über den Menschen und zwar ohne Rücksicht auf menschliches Handeln verstanden; s. Lexikon für Theologie und Kirche, Freiburg, Basel und Wien, 3. Aufl. 1993-2001, Bd. 8 Kolumne 467 und Heinrich Richard Schmidt: Konfessionalisierung im 16. Jahrhundert, München (1992), S. 13 ff.

die kirchenleitende Funktion eines Landesherrn (oberster Bischof).

Mylius. Corpus Constitionum Marchicarum I. Th. von geistlichen Sachen No. XXXIII Columne $389 \mathrm{ff}$. Ein Churfürstl. Rescript an den Magistrat hiesiger Residentzien, daß Prediger den Rekurs unterschreiben sollen; sambt dessen Copie sub A (13. April 1660) und I. Th. von geistlichen Sachen No. XXXVI Columne 395 ff.: Edict, daß die Reformirte und Lutherische Priester sich aller Anzüglichkeiten auff der Cantzel gegen einander enthalten sollen (6. Mai 1668). 
Strittig ist, ob die Einrichtung von Simultaneen nur der $\operatorname{Not}^{87}$ geschuldet oder möglicherweise darin auch ein Versuch des Kurfürsten Friedrich Wilhelm zu sehen ist, die orthodoxlutherische Ständeopposition aus Adel und Geistlichkeit sukzessiv zu schwächen und so dem eigenen reformierten Bekenntnis zu stärkerer Geltung zu verhelfen. Denn Lackner (1973) weist zu Recht darauf hin, dass wegen der Normaljahr-Regelung für ihn keine Möglichkeit bestand, das lutherische Bekenntnis zu unterdrücken, sondern es höchstens soweit wie möglich zurückzudrängen. ${ }^{88}$

Um die reformierten Gemeinden bevorzugt zu fördern, erhielten sie eigene Kirchenbehörden. Das war bis zur Kassierung des Edikts von Nantes 1685 nicht für nötig erachtet worden. Es änderte sich mit der Einwanderung von ca. 20000 Réfugiés in Kurbrandenburg in den nächsten acht Jahren. ${ }^{89}$ Ihnen wurde die Bildung einer Französischen Kolonie als eigenes Rechtsgebilde zugestanden, deren geistliches Leben einer Commission Ecclésiastique unterstellt wurde. Daraus ergab sich in der Folge das Bedürfnis, auch die bereits bestehenden deutsch-reformierten Gemeinden einem eigenen Kollegium zu unterstellen. Diese Funktion übernahm das 1713 durch die „Ordnung der reformierten Kirchen und das dazu bestellte Kirchen-Directorii“ "gegründete evangelisch-reformierte Kirchendirektorium ${ }^{90}$, das mit Ausnahme von Kleve, Mark und Ravensberg für alle preußischen Provinzen zuständig war. Das Kollegium wurde von einem adligen Präsidenten geleitet, dem die Geheimen Räte reformierter Konfession sowie jeweils zwei reformierte Theologen und zwei reformierte „Politicis“ beigeordnet wurden. An Aufgaben oblag diesem Kollegium vor allem die Einstellung und Führung der Geistlichkeit, ein Vorschlagsrecht für die durch den König direkt zu ernennenden Geistlichen und die Aufsicht über die reformierten Schulen. Noch im selben Jahr erließ das Kirchendirektorium in seinem Zuständigkeitsbereich eine Inspektions-, eine Presbyterial- und eine Klassikalordnung. ${ }^{91}$ Außerdem erging eine Gymnasial- und Schulordnung. Auch die 1696 von Kurfürst Friedrich III. zur Förderung reformierter Einrichtungen und Unterstützung von Glaubensflüchtlingen gegründete Stiftung Mons pietatis wurde dem Kirchendirektorium unterstellt. ${ }^{92}$ Das Kirchendirektorium war seinerseits zunächst dem Geheimen Rat, seit den 1730er Jahren dann dem Geistlichen Department unterstellt. Die Auflösung erfolgte 1811 zusammen mit den anderen höheren Kirchenbehörden des 18. Jahrhunderts im Zuge der Preußischen Reformen. An ihre Stelle traten die Kirchen- und Schulabteilungen der Provinzialregierungen und als zentrale Instanz für alle Religionssachen die Kultusabteilung des Ministeriums des Inneren bzw. ab 1817 das Ministerium für geistliche, Unterrichts- und Medizinalsachen („Kultusministerium“).

87 Mangel an Geld zum Kirchenbau.

88 Lackner, Martin: Die Kirchenpolitik des Großen Kurfürsten, Witten (1973), S. 250 ff.

89 Badstübner, Sybille: Hugenotten in Berlin, Berlin (1988), S. 17.

90 GStA PK, I. HA, Rep. 243 Nr. 436 fol. 1 ff.

91 Erster Präsident des Kirchendirektoriums wurde Marquard Ludwig Freiherr von Printzen (1675-1725), in: Allgemeine Deutsche Biographie, Leipzig (1888), Bd. 26, S. 596-600.

92 s. auch Kap. VI.2.3. 



\section{Maßnahmen für die Urbarmachung des Golmer Bruchs um 1680}

Wie in Kapitel V.1. gezeigt wird, ist die Urbarmachung des Golmer Bruchs zunächst einmal gescheitert. Dies ist im Wesentlichen den im 17. Jahrhundert noch sehr beschränkten Möglichkeiten zuzuschreiben, die für wasserwirtschaftliche Regulierungsmaßnahmen zur Verfügung standen. Die spezielle Situation beim Golmer Bruch wird aber nur verständlich, wenn die Topographie dieser Region dargestellt und erläutert wird. Vor diesem Hintergrund erhellt sich erst die Aussichtslosigkeit der Bemühungen, in dieser Zeit den Golmer Bruch urbar zu machen.

\section{Zur Topographie und Siedlungsgeschichte der Wublitzrinne}

In den heutigen westlichsten Ortsteilen von Potsdam ${ }^{93}$ nimmt die Landschaft bereits den typischen Charakter des Havellandes an (Abb. 1). Die geschlossenen Diluvialflächen lösen sich in kleine „Inseln“ auf. Die markanteste stellt der Reiherberg bei Golm dar. Von ihm aus ist der trogförmige Golmer Bruch mit seinen Dämmen, Wiesen und Gräben ganz zu überblicken und wäre - existierte nicht der landschaftszerstörende Müllberg ${ }^{94}$ - fast mit einer holländischen Polderlandschaft vergleichbar. Hinter Bäumen und einem Schilfgürtel liegen die in der Landschaft eingebettete Havel und Wublitz. ${ }^{95}$ Beide umfließen den Werder Töplitz. ${ }^{96}$ Während im Sommer grüne Wiesen vor allem mit Seggen das Bild im Golmer Bruch dominieren, wandeln sich diese im Winter zu einem weiten, im Sonnenschein aufglänzenden Eisspiegel.

Diese Niederungslandschaft hat sich während der letzten der drei norddeutschen Eiszeiten, der Weichseleiszeit, ausgebildet. Dabei sind zwei Phasen der Reliefgestaltung zu unterscheiden. In der ersten schufen die Schmelzwässer unter dem noch das Land bedeckenden Eis ein fächerförmiges System von Rinnen, die im Schwielowsee zusammengefasst bei Ferch in dem schönen Kegel des Beelitzer Sanders münden. Bis zu dieser Zeit floss das Wasser durch die später von Havel und Wublitz benutzten Rinnen entgegen den heutigen Abflussrichtungen nach Süden. Erst nach Rückzug des Eises aus der Potsdamer Gegend brachen die in den Urstromtälern vor dem Gletscher gesammelten Schmelzgewässer über das Nuthetal, die Niederung von Sanssouci und dem Golmer Bruch nach Westen durch. Dadurch wurde die diluviale Hochfläche weiter zerstückelt ${ }^{97}$ und die heutige Entwässerungsrichtung festgelegt. Und zwar folgt ihr die Havel mit den vielen Seen, während die Wublitz das alte Nord-Gefälle der

93 bedingt durch die Eingemeindung von Grube und Golm 1990/91 nach Potsdam.

94 Aufschüttung von Hausmüll von 1950-1989.

95 zu den Namen der beiden Flüsse s. Brandenburgisches Namenbuch, Teil 10: Die Gewässernamen Brandenburgs, bearb. v. Reinhard E. Fischer, Weimar (1996), S. 105 u. 311.

96 Daraus wurde nach der Errichtung des Sacrow-Paretzer-Kanals 1876 die Insel Töplitz; Grittner, Wolfgang: Vom Schiffgraben zum Kanal, in: Heimatkalender für den Landkreis Potsdam-Mittelmark 2002, S. 57-65.

97 Daneben sind Schmelzwasserablagerungen (z. B. der Reiherberg) dadurch entstanden, dass Spalten/Löcher im Eis mit Sand gefüllt wurden und nach dem Abtauen des Eises zusammengefallen sind; Scholz, Eberhard: 
Schmelzwasserrinnen beibehält. Letztere mündet dadurch scheinbar widersinnig frontal in die Havel am Rande des Großen Zernsees („Gegengefälle“), und zudem mit so geringem Gefälle, dass eine Strömung kaum festzustellen ist. Die Folge ist eine stockende Entwässerung ihres Wassereinzugsgebietes, die bei einem Anstieg der Havel fließend in einen zeitweiligen Rückstau wechselt bzw. sogar dazu führen kann, dass bei Hochwasser der Havel im Frühjahr und Herbst die Stromrichtung sich vorübergehend umzukehren vermag. Dies führt dann zwangsläufig zu einer Überschwemmung der Uferzonen und dem Überfluten des trogförmigen Golmer Bruchs - ein ehemaliger Gletschersee, der nicht mehr in Verbindung mit einem Fluss steht. ${ }^{98}$

Die Havel selbst unterliegt einem Rückstau durch die Elbe. Durch die Eindeichung der Elbe um 1200 ist dies weitgehend gebannt worden; die Anlage der Stauwerke bei Brandenburg und Havelberg hat dagegen den gegenteiligen Effekt bewirkt.

Wie korrespondieren diese topographischen Besonderheiten mit der Besiedlungsgeschichte? Ribbe $(1987)^{99}$ verdanken wir eine Siedlungsgeschichte des Havellandes und der angrenzenden Gebiete anhand der Bearbeitung von 770 Siedlungen, Wüstungen und sonstigen archäologischen Fundplätzen. Die in der Wublitzrinne liegenden Ortschaften (Paaren, Uetz, Marquardt, Leest, Grube, Golm) werden als kleine dichte Siedlungsballungen mit einer slawisch-deutschen Kontinuität beschrieben. Dabei liegt „die kleine Fundkonzentration von Golm jenseits eines weiten, fundleeren Gebietes am Niederungsrand des Golmer Luches“. 100 Im Gegensatz zu den genannten Ortschaften ist also eine Besiedlung dieses Gebietes bis 1685 unterblieben. Insofern kann man als sehr wahrscheinlich annehmen, dass die slawischen und später die deutschen Siedler in dieser Region aus eigener Erfahrung um die Schwierigkeiten einer Besiedlung des Golmer Bruchs wussten und sie deshalb unterließen. Nicht zuletzt geht dies auch aus der von Prediger Sigismund Lupichius im Jahre $1713^{101}$ zitierten Meinung der Einheimischen zum Vorhaben von Kurfürst Friedrich Wilhelm hervor: es hätten Ao 1685 bey ihrer ankunfft hiesige allte leüthe die Köpfe über dem gantzen wercke geschüttelt, und geprophezeyet, daß es keinen bestand haben würde, sondern bey Wiederkunfft der naßen Jahren und waßergrö$\beta e n$ alles wieder ruinirt werden, und in allten stande gerathen, wie dann auch, leider! geschehen: ...

Brandenburg zählt zu den wasserreichsten Gegenden in Deutschland. ${ }^{102}$ Insoweit wundert es nicht, dass nach dem Dreißigjährigen Krieg die bereits vor dem Krieg von Markgraf Johann

Bau- und Oberflächengestaltung des Reiherberges bei Golm westlich Potsdams; in: Zeitschrift für den Erdkundeunterricht 9 (1957) Heft 3, S. 129 ff.

98 Iwan, Walter: Das Golmer Luch, hg. vom Geogr. Institut der Universität Berlin, 1939, S. 1-2.

99 Ribbe, Wolfgang (Hg.): Havelland im Mittelalter, Berlin (1987), S. 124.

100 Einzelbefunde bei Herrmann, Joachim und Peter Donat: Corpus Archäologischer Quellen zur Frühgeschichte: Auf dem Gebiet der Deutschen Demokratischen Republik (7. bis 12. Jahrhundert, Berlin (1979) S. 257258 (Golm), S. 260-261 (Grube), S. 264-267 (Leest), S. 267-268 (Marquardt) und S. 278-279 (Uetz).

101 Prediger im Golmer Bruch von 1705-1717; BLHA, Rep. 2 Kurmärkische Kriegs- und Domänenkammer Nr. D 15382, fol. 3.

102 ca. 30000 km Fließgewässer. in: Stille Jagd auf stumme Tiere, hg. Ministerium für Landwirtschaft, Umwelt und Raumordnung (2001), S. 32 . 
von Küstrin und Kurfürst Joachim Friedrich in Ansätzen betriebenen Meliorationen und Kolonisationen von Brüchen wieder aufgenommen wurden. ${ }^{103}$ Dazu wurden erfahrene „Teichgräber" gebraucht, die aus Holland angeworben wurden. Die in der Nähe der neuen Residenz Potsdam vorkommenden Feuchtgebiete (Uetz, Golmer Bruch, Havelländischer Bruch) boten sich dafür geradezu als Experimentierfelder an. Die Informationen hierüber sind spärlich. Oberförster v. Lüderitz ${ }^{104}$ berichtete dem Kurfürsten Friedrich Wilhelm im Schreiben vom 15. Juli $1678^{105}$, dass er auftragsgemäß daß Golmische Bruch in augenschein genommen hat. Er habe die truckene Zeit genutzt, mit etlichen Leuthen auß dem Dorffe, denen daß Bruch bekannt ist, hinein gemachet, und solches in die lange und breite durchgangen. da ich dan befunden, daß es ein guther grundt, und schön graß darinnen wächset. ich dan auch einen schönen Werder gefunden, da kein waßer, es sey so groß als es woll [will], daraufkommen kann. Welcher Werder in der runde 600 schrit begriffen, stehen Eichen und Haseln darauf, lieget hart an der Havel, da die Wublitz in die Havel fallet. Nach seiner Einschätzung ließ sich das Golmer Bruch ohne sonderliche Kosten nutzbar machen. Und zwar müsse ein Hauptgraben in der Länge nach Grubo gezogen werden, der das Wasser in die Wubelitz abführe. Ein zweiter Graben müsse das Wasser in die Habel leiten. Zurzeit befinde sich zwar viel Strauchwerk, Rohr und Hüllen im Bruch, solches alles aber kann mit Feuer außgebrandt werden, und wan das alles weg wehre, ist es so trocken, daß man darinnen auch voriezo graß machen könne. Nach seiner unterthänigsten und unmaßgeblichen meinung [...] könne man [...] aufden Werder in solchen Bruch an der Habel, eine Milchbude legen. Wenn es nutzbar gemacht würde, könnten 100 milckende Kühe gehalten werden. Zu diesem Werder oder Milchbude, müsse lediglich ein Tam [Damm] gemacht werden. Die Situationsbeschreibung betrifft im Weiteren die verkehrsmäßige Anbindung von Bornim und Golm mit dem Golmer Bruch, worauf hier verzichtet werden soll. Es verwundert nicht, dass der Kurfürst bereits am 19. Juli $1678^{106}$ von Anklam aus anscheinend begeistert reagierte, und v. Lüderitz aufforderte, ferner sein bestes Zuthun und soweit es die Zeit und umbstände leiden mit seinem fleiß hirzu $\mathrm{Zu}$ continuiren. Als folgenschwer wird sich später herausstellen, dass v. Lüderitz die im Juli 1678 vorgefundene Situation vollkommen richtig beschrieb, die Situation übers Jahr aber außer Acht gelassen hatte.

\section{Schaffung einer Infrastruktur für den Golmer Bruch}

Es muss nicht besonders betont werden, dass die Infrastruktur des Golmer Bruchs ausschließlich mit damals zur Verfügung stehenden Mitteln - Handarbeit und Pferdegespannen - geschaffen worden ist. Soweit es die Grabenarbeiten betrifft, gibt darüber ein Schreiben des Oberjägermeisters v. Lüderitz an den Kurfürsten Friedrich Wilhelm detailliert Auskunft ${ }^{107}$

103 Asche, Matthias: Neusiedler im verheerten Land, Münster (2006), S. 626.

104 J.E. von Lüderitz (+29.5.1695) gehörte seit 1672 dem Hofstaat Kurfürst Friedrich Wilhelms an; er war von 1687 bis 1695 Oberjägermeister, davor als Oberforstmeister und in verwandten Positionen tätig. (Bahl, Peter: Der Hof des Großen Kurfürsten, Köln - Weimar - Wien (2001), S. 531.) In der Arbeit tritt er bei der Wahrnehmung verschiedener Funktionen in Erscheinung.

105 GStA PK: I. HA, Rep. 21 Nr. 123 (Paket 7997), fol. 151-153.

106 daselbst: fol. 150/150R.

107 daselbst: fol. 145/145R. 
(s. Anhang 1). Hierfür konnte der im Liebenbergschen Bruche ansässige holländische Teichgräber Friederich Witten als Spezialist für derartige Arbeiten gewonnen werden. Er hatte gemäß kurfürstlichem Befehl ein Entwässerungssystem zu schaffen, womit das Golmische Bruch, mit einem Graben, alß von der Havell ab biß in der Wubelitz in der länge undt dann von dem Gollmischen Acker an biß auff das Gemünde undt auch in der Wubelitz in die quer durchzogen werden soll, ... Mit den Arbeiten sollte sofort angefangen werden, alß das Bruch nur ausgebrandt sein wirdt, und continuiret werden, so lange das wetter und der frost es zulaßen wirdt. Als Entlohnung war vereinbart worden: Für solche arbeith, wenn solche wöchentlich richtig befunden, wirdt [...] Ihme [...] vor den Breiten graben, von jeder Niederländischen Ruhte 15 Fuß lang, Neün gr: an gelde undt von Zwantzig Ruthen, einen scheffel Rogken undt 1 tonne speise Bier zu entrichten. Von denen Zwo quer graben aber bekombt Er die Helffte,... Damit erhielt der Golmer Bruch ein Entwässerungssystem, das bis heute in der Grundstruktur unverändert geblieben ist.

Wie wichtig die Urbarmachung des Golmer Bruchs für Kurfürst Friedrich Wilhelm gewesen ist, kann man vor allem anhand der Baukosten von insgesamt 14300 thlr ermessen, die in den Jahren ab 1678 dafür investiert worden sind. Dabei ist aber auch festzuhalten, dass von der Gesamtsumme - wie Tabelle 1 zeigt - 2/3 schon vor der Entscheidung der Ansiedelung von Schweizer Kolonisten in den Golmer Bruch geflossen sind. Bis dahin war auch der Golmer Bruch zu einem guten Teil gerodet.

Tab. 1: Baukosten für die Erschließung des Golmer Bruchs in den Jahren 1678 bis $1687^{108}$

\begin{tabular}{lccc}
\hline Zeitraum & & Baukosten & d \\
\cline { 2 - 4 } & thlr & gr & 7 \\
\hline Von Ao: 1678 bis 1680 & 1182 & 2 & 6 \\
\hline Von Ao: 1680 bis 1681 & 2039 & 16 & - \\
\hline Von Ao: 1681 bis 1683 & 856 & 16 & 3 \\
\hline Von Ao: 1683 bis 1684 & 5085 & 7 & 5 \\
\hline Von Ao: 1684 bis 1686 & 3209 & 20 & - \\
\hline Von Ao: 1686 bis 1687 & 1955 & 6 & 9 \\
\hline Gesamtsumme & 14328 & 20 & \\
\hline
\end{tabular}

Diese tabellarische Zusammenstellung fand sich in den Akten über die Verhandlung eines Grundzinses für Äcker und Wiesen nach Ablauf der „Freijahre“ im Jahre 1692 (s. Kapitel IV.6.). Das Amt Potsdam hatte sie auß denen vorhandenen Amtsrechnungen extrahiret. ${ }^{109}$ Die zugrundeliegenden Rechnungsbücher konnten nicht aufgefunden werden, so dass die nähere Aufschlüsselung der Gesamtkosten auf die erbrachten Leistungen nicht mehr möglich ist. Da die Infrastruktur des Golmer Bruches 1683 so gut wie fertiggestellt war (s. Kapitel III.3.), dürfte es sich bei den in den folgenden Jahren ausgegebenen Summen um Kosten handeln, die in Ver- 
bindung mit der Ansiedlung der Schweizer Kolonisten 1685 ausgegeben wurden (Reise- und Zehrungskosten, Häuserbau u. dergl.). Hieran erkennt man, dass man zwischen einer Periode der Erschließung des Golmer Bruchs und einer Periode von dessen Besiedlung unterscheiden muss. In der Literatur wurden beide zusammengefasst und daher die Meinung vertreten, dass der Golmer Bruch für die Schweizer Kolonisten urbar gemacht worden wäre. ${ }^{10}$

\section{Der Atlas der Herrschaft Potsdam}

Eine besondere Form der Förderung ließ Kurfürst Friedrich Wilhelm dem Amt Potsdam angedeihen, indem er Ende 1679 Samuel de Suchodoletz ${ }^{111}$ den Auftrag zur topographischen Aufnahme der Herrschaft Potsdam erteilte. Das gilt umso mehr, da in Kurbrandenburg bis 1640 die Kartographie äußerst schwach entwickelt war. ${ }^{112}$ Danach erhielt sie eine unverkennbare Aufwertung. Der kurfürstliche Auftrag enthielt keine detaillierten Hinweise und Forderungen über Aufnahmeverfahren, Maßstab, Darstellungsprinzip und Grad der Erfassung des vorgegebenen Areals, so dass Suchodoletz die ihm gestellte Aufgabe nach eigenem Ermessen ausführen konnte. Die technischen Details sind bei Jänckel ${ }^{113}$ genau beschrieben. Erwähnt sei lediglich, dass Suchodoletz hierfür einen Urmesstisch verwandte. Im Ergebnis der Arbeit hat er 1683 eine Generalkarte „Ichnographia oder eigentlicher Grundris der Churfürstl. Herrschaft Potstamb“ $(4,10 \times 2,80 \mathrm{~m}$, Maßstab $1: 12554)$ vorgelegt, die später auf Grund ihrer Unhandlichkeit zerlegt und zu einem in Leder gebundenen Atlas (Querformat, $68 \times 48 \mathrm{~cm}$ ) mit 45 Blättern zusammengefasst worden ist. ${ }^{114}$

Blatt VI des Atlasses (betitelt in der Kartusche Eigentlicher Grund-Riß deß Churfl. Dorff Golm und dabey Gelegene Golmische Bruch, Aug. 1683) umfasst das Gebiet Golm und Grube und den südöstlichen Teil des Töplitzer Werders, die Havel (Großer Zernsee) und den nördlichen Teil der Insel Werder (s. Abb. 2). Damit verfügen wir über eine detailgetreue topographische Darstellung des Golmer Bruchs in toto aus dem Jahre 1683, also fünf Jahre nach Beginn seiner Urbarmachung bzw. zwei Jahre vor der Besiedlung mit Schweizer Kolonisten.

Ungewöhnlich für heutige Verhältnisse ist die Kartenausrichtung. Der heute übliche Nordpfeil fehlt. An Stelle dessen gibt in der rechten unteren Ecke ein Kompasssymbol die

110 Heese, Henning: Einleitende Bemerkungen zur Entstehung und Entwicklung der Schweizer Kolonie im Golmischen Bruch bei Potsdam, in: 300 Jahre Schweizer Kolonie am Golmischen Bruch bei Potsdam 16851985, Sankt Augustin (1985), S. 5-43, bes. S. 5; Asche, Matthias: Neusiedler im verheerten Land, Münster (2006), Anm. 822.

111 Samuel de Suchodoletz wurde wahrscheinlich 1642 geboren, stammt dem Namen nach aus polnischem Adel und wurde vermutlich mit den Antitrinitariern (sehen Gott nur in einer Person) aus seiner Heimat vertrieben. Seit 1672 stand er in brandenburgischen Kriegsdiensten. Im August 1679 legte er dem Kurfürsten Friedrich Wilhelm eine zu Landsberg bezeichnete Karte vor und bekam daraufhin den Auftrag zur Anfertigung des Atlas. Später war er im Herzogtum Preußen tätig.

112 Hanke, Max und Hermann Degner: Geschichte der amtlichen Kartographie Brandenburg-Preußens bis zum Ausgang der Friderrizianischen Zeit, in: Geogr. Abhandlungen, III. Reihe (1935) S. 50-56.

113 Jänckel, Ronald: Die kartographische und siedlungsgeographische Bedeutung des ältesten Atlas der Mark Brandenburg, Dissertation M.-L. Univ. Halle-Wittenberg, 1966 (Maschinenschrift).

114 GStA PK, XI. HA, AKS Atlas 221, Blatt VI Golm und Golmische Bruch 1683. 
Nordrichtung an und darunter den Maßstab. Diese Darstellung wählte Suchodoletz, um die dargestellte Gemarkung Golm voll zu erfassen. Darüber hinaus fällt außer der barocken Titelkartusche etwa in der Mitte der schwarze Adler mit Kurhut im Schnabel ins Auge, der in einem Fange den blauen Schild mit Zepter hält. Dies darf wohl als Huldigung an den Auftraggeber und Landesherrn angesehen werden.

Obwohl dem Atlas und den Einzelblättern ein Zeichenschlüssel fehlt, ist eine Auswertung der Karten ohne Schwierigkeiten möglich. Sehr hilfreich ist in dieser Karte, dass alle dargestellten flächenhaften Elemente und Einzelobjekte durch schriftliche Zusätze eine Erläuterung (namentliche Benennung und/oder Entstehungszeit) erfahren. Die Längen- bzw. Flächenmaße sind zeitgemäß in Holländischen Morgen bzw. Rheinländischen Quadratruthen angegeben. Die Teilflächen (Wälder, Wiesen, Wasser) werden durch Linien begrenzt und weiterhin durch besondere Kolorierung gekennzeichnet.

Da eine Detailauswertung des Atlas von Suchodoletz bis heute fehlt, soll sie im Folgenden für das Blatt VI vorgenommen werden. Welche Einzelheiten lassen sich über den Golmer Bruch der Karte entnehmen? Die Größe des eingedeichten Bruchs ist mit 421 Holländischen Morgen 185 Quadratruten à 5600 quadrat ausgewiesen. Der Wal (Damm) grenzt mit einem Vorland das Golmer Bruch gegenüber der Wubelitz (Wublitz) bzw. Havel ab. Er verläuft von Grubow (Grube) über Natte Werder (Nattwerder) bis zur Newen Brücke ${ }^{115}$, über die Wublitz (heute Einhaus) entlang dem Havel gemünde (Wublitzmündung) und dem Großen Zernsee bis zum Reyerberg (Reiherberg). Das letzte Teilstück ist der heutige Mühlendamm. Zwischen Grube und Nattwerder ist Anno 1681. gemacht vermerkt und kurz vor Nattwerder ein kleiner Bauer garten eingezeichnet. Die Strecke von Nattwerder bis zum Einhaus wird mit 1058 Reinl. Ruth. angegeben, und kurz vor dem Einhaus ist eine Milchstelle eingezeichnet, von der aus ein rot markierter Weg quer durch den Golmer Bruch bis Bornheimb (Bornim) geht. Durch den Bruch verläuft darüber hinaus Der Dam (Mitteldamm), der an drei Stellen mit Ausbuchtungen verbreitert ist. Davon ist die mittlere mit Espenhörste ${ }^{116}$ bezeichnet. Der Damm endet an der Golmischen Feldmarck; ein Weg führt über Bornim bis nach Potsdam weiter. Mit zwei graben in Längs- und Querrichtung besteht im nördlichen Teil des Golmer Bruchs ein Entwässerungssystem nach holländischem Muster, das bis auf die Eingriffe im Golmer Bruch durch die Müllaufschüttungen im 20. Jahrhundert heute noch unverändert erhalten ist. Eine Wind Mühle ist am Längsgraben auf der Höhe des heutigen Mühlendamms eingezeichnet. Es war als ein Wind getriebenes Schöpfwerk konzipiert, ${ }^{117}$ dass das Niederungswasser über den Damm förderte. ${ }^{118}$ Rechts vom Mitteldamm ist der Steinwerder eingezeichnet - eine leichte

115 Albrecht Bauernkönig bezeichnet sie als halbe Brücke und meint damit wahrscheinlich eine „Fußgängerbrücke" (StA Bern: A.V. 19 Teutschland-Buch Preussen-Brandenburg fol. 122.)

116 „Horst“ ist die Bezeichnung für eine Erhöhung im Gelände (Brandenburg-Berlinisches-Wörterbuch, Berlin, Bd. II (1985) Kolumne 720.

117 StA Bern: A.V. 19 Teutschland-Buch Preussen-Brandenburg fol. 79.

118 Nach dem auf der Karte verwendeten Mühlensymbol handelte es sich dabei um eine holländische Poldermühle. 
Erhöhung im ansonsten trogförmigen Golmer Bruch. Am Rande des Golmer Bruchs am Weg von Grube nach Golm ist eine Leim Caul (Lehmgrube) eingezeichnet.

Im Ergebnis der Auswertung der Atlaskarte VI drängen sich geradezu folgende Schlussfolgerungen auf: Die geschilderten Eintragungen belegen die starke anthropogene Veränderung des Golmer Bruchs schon vor der Besiedlung durch die Schweizer Kolonisten im Jahre 1685. Um dieses sumpfige Gebiet (Niedermoor) wirtschaftlich nutzen zu können, wurden Entwässerungsgräben gezogen, Dämme geschüttet und im Jahre 1681 der größte Teil des Bruchgebiets eingedeicht. Die Eintragung „Milchstelle“ deutet auf eine bereits bestehende landwirtschaftliche Nutzung des Golmer Bruchs mit Milchvieh hin. Zusätzlich wurde mit der errichteten Wublitzbrücke die wirtschaftliche Anbindung des Werders Töplitz an die Residenzstadt Potsdam geschaffen. 



\section{Die Besiedlung des Golmer Bruchs mit Schweizer Kolonisten}

Obwohl die Hohenzollernsche Repeuplierungspolitik - abgesehen von den Vorbehalten gegenüber den Katholiken und Juden - breit aufgestellt war, sind von den einzelnen Einwanderungen nur einige wenige im allgemeinen Bewusstsein heute noch präsent. Im Wesentlichen sind es die in den Städten angesiedelten Einwanderer, die sich mit ihren kulturellen, sozialen, wissenschaftlichen und technischen Leistungen bis heute einen bleibenden Namen gemacht haben, wohingegen von den im ländlichen Bereich angesiedelten Einwanderern nur in seltenen Ausnahmefällen überhaupt noch etwas erhalten ist und diese deswegen allmählich in Vergessenheit geraten sind. Dazu zählen auch die Schweizer Kolonisten, die zahlenmäßig mit geschätzten 6000-7 000 Personen ${ }^{119}$ durchaus ins Gewicht fallen, davon ist aber die Mehrheit (etwa 4200 Personen) 1710/1711 in Ostpreußen angesiedelt worden. Hierin ist nicht die Schweizer Garde einbegriffen (s. Kap. IV.1.). Unabhängig davon genossen die Schweizer Tierpfleger auf dem Lande offensichtlich einen guten Ruf, sonst könnte man sich nicht erklären, warum bis ins 19. Jahrhundert Melker als "Schweitzer" bezeichnet wurden.

Aber auch die Historiker haben dazu beigetragen, dass die Ansiedlung von Schweizern in Kurbrandenburg in Vergessenheit geraten ist. Sie ist ja nicht zuletzt auf Grund der intensiven diplomatischen Beziehungen von Kurbrandenburg mit den evangelischen (calvinistischen) Schweizer Kantonen zustande gekommen, die auf die Bildung einer "reformierten Allianz“ als Gegengewicht gegen die katholischen Länder im Heiligen Römischen Reich deutscher Nationen abzielte und letztendlich an den Bedenken der Schweizer Kantone scheiterte. ${ }^{120}$ Die historische Würdigung dieser Vorgänge steht noch aus. ${ }^{121}$

119 Beheim-Schwarzbach, Max: Hohenzollernsche Colonisation, Leipzig (1874), S. 143-147. Die Angaben in jüngeren Arbeiten basieren auf der Anzahl eingewanderter Familien, die bei den kinderreichen Schweizer Familien der Vergleichbarkeit wegen mindestens mit fünf multipliziert werden müssen (s. Abbs. 15).

120 GStA PK, I. HA, Geheimer Rat (Akten) Rep. 11 Nr. 10308 Auswärtige Beziehungen (Schweiz) - nicht paginiert; Im Schreiben vom 2. April 1686 der Evangelischen Städte (Kantone) an den Kurfürsten Friedrich Wilhelm und insbesondere aus dem beigefügten Anhang „Bedenchen“ wird um Verständnis wegen der gemischt konfessionellen Situation gebeten. Zum einen wird angeführt, dass sich durch einen Beitritt zu einer „Reformierten Allianz" die römisch-katholischen Kantone dadurch angegriffen fühlen könnten, mit denen sie sich aber im Pündtnuß befänden. Zum anderen befürchteten sie, dass der Kaiser und/oder Frankreich dies zum Anlass nehmen könnten in die Schweiz einzufallen. An die Ewigen Friedens-Verträge mit ihnen (Ertzhauß Österreich 1474 und Cron Franckhreich 1516 - zusätzlich defendsiv Pündtnuß 1663) fühlten sie sich gebunden. Im Übrigen seien beides Nachbarländer, und insbesondere liege Zürich - strategisch gesehen - ein Tag Fußmarsch von an der französischen Grenze entfernt.

121 GStA PK, I. HA, Geheimer Rat (Akten) Rep. 11 Auswärtige Beziehungen mit der Schweiz. 


\section{Die Schweiz als Auswandererland}

Das Phänomen der „Auswanderung der Bevölkerung in großem Umfang“ ist in der Schweiz seit dem 15. Jahrhundert anzutreffen. Dabei ist zu unterscheiden zwischen der Auswanderung (Übersiedler) und dem „Reislaufen“"122, der temporären Auswanderung für die Ableistung von Kriegsdiensten in fremden Staaten (s. Tab. 2). Ihre zeitlichen Verläufe und Ausmaße unterscheiden sich voneinander. Die Auswanderungen beginnen erst in nennenswerter Größe im 16. Jahrhundert und erreichen im 19. Jahrhundert extreme Werte. Es wird angenommen, dass zwischen 1820 und 1920 etwa 1/4 Million Schweizer in die USA emigriert sind. Auf die „Schweizer Garden“ soll im Rahmen dieser Arbeit nicht näher eingegangen werden. Zusätzlich zu den permanenten Auswanderungen und dem Reisläufertum gab es saisonale Auswanderungen („Schwabenzüge“ usw.).

Tab. 2: Auswanderung und Reislaufen aus der Schweiz im 15. bis 19. Jahrhundert ${ }^{123}$

\begin{tabular}{lccccc}
\hline Anzahl der Personen & \multicolumn{5}{c}{ Jahrhundert } \\
\cline { 2 - 6 } & $\mathbf{1 5 .}$ & $\mathbf{1 6 .}$ & $\mathbf{1 7 .}$ & $\mathbf{1 8 .}$ & $\mathbf{1 9 .}$ \\
\hline Reisläufer & 100000 & 300000 & 300000 & 350000 & \\
\hline Auswanderer (Übersiedler) & & 25000 & 50000 & 50000 & 500000 \\
\hline
\end{tabular}

Obwohl die Schweiz ein klassisches Auswanderungsland ist, steht die nationale Forschung darüber noch ganz am Anfang. Dies zeigen u. a. die Ausführungen von Feller (1953) über die Schweizer Kolonisten in Brandenburg. ${ }^{124}$ Selbst im 16-bändigen Historischen Lexikon der Schweiz (2016) ${ }^{125}$ wird unter dem Stichwort „Auswanderung“ nur die Ausreisewelle nach Ostpreußen aufgrund der Mangeljahre 1709-11 erwähnt.

Die Hauptursachen für die Auswanderung im 17. und 18. Jahrhundert waren vor allem die schlechten Lebensbedingungen der schweizerischen Landbevölkerung, die durch das Defizit bzw. die ungünstige Verteilung der landwirtschaftlichen Anbauflächen und nicht zuletzt durch die zunehmende Überbevölkerung hervorgerufen wurden. ${ }^{126}$ Die Dreifelderwirtschaft mit Flurzwang, Allmende und Weidewirtschaft ließ sich trotz intensiver Kulturtätigkeit und Güterteilung nicht mehr steigern. Bei den Auswanderern dieser Zeit handelte es sich meist um Personen aus ärmeren Schichten, größtenteils Heimarbeiter und Tagelöhner, vereinzelt

122 Gugger, Rudolf: Preußische Werbungen in der Eidgenossenschaft, in: Quellen und Forschungen zur brandenburgischen und preussischen Geschichte, Berlin, 12 (1997).

123 Berwein, Lothar: Ansiedlung von Schweizer Kolonisten im Rahmen der Repeuplierung Ostpreußens, Sonderschrift des Vereins für Familienforschung in Ost- und Westpreußen e. V. (2003), S. 31.

124 Feller, Richard: Die Geschichte Berns, Bern (1953), Bd. II. S. 149.

125 Historisches Lexikon der Schweiz (Hg.: Stiftung Historisches Lexikon der Schweiz, Basel (2016), Bd. I, S. 609.

126 Die Schweizer Kantone waren mit dem Getreidehandel im Dreißigjährigen Krieg zu Wohlstand gelangt; dies hatte ein explosives Bevölkerungswachstum zur Folge. 
auch Kleinbauern. ${ }^{127}$ Viele der Bauernsöhne, die aufgrund der Realteilung nur Stücke des elterlichen Hofes erben konnten, gingen ebenfalls außer Landes, um dort bessere Lebensbedingungen zu finden. Insofern war nach Rösli $(1940)^{128}$ die Abwanderung in der Schweiz und besonders im Kanton Bern zu einer wirtschaftlichen Notwendigkeit geworden. Weitere Ursachen von Emigrationswellen waren innerstaatliche Auseinandersetzungen, ${ }^{129}$ größere wirtschaftliche Katastrophen wie Missernten und Viehsterben ${ }^{130}$ und internationale militärische Konflikte.

Vor diesem Hintergrund und der wirtschaftlichen Situation in Kurbrandenburg erhellt sich die Anfrage von Kurfürst Friedrich Wilhelm 1683 beim Schultheiß und Rat der Stadt Bern (s. Kap. IV.2.).

\section{Anfrage beim Schultheiß und Rat der Stadt Bern 1683 wegen Schweizer Kolonisten}

In der Regel wird der Brief des Kurprinzen Friedrich vom 24. November $1683^{131}$ an den Schultheiß und Rat der Stadt Bern als der Beginn der Besiedlung des Golmer Bruchs angesehen. Wie die nachfolgenden Ausführungen zeigen sollen, stimmt diese Behauptung offensichtlich nicht. Ein so ungewöhnlicher Vorgang, dass ein Kurfürst wegen einer wirtschaftlichen Frage - die Überlassung von 10 bis 20 der Wirtschafft und Viehzucht erfahrener Familien -, sich an jemanden wendet, der nicht zum Heiligen Römischen Reich Deutscher Nationen und nicht zu „Seinesgleichen“ gehört, ist ohne eine vorangegangene Entwicklung nicht denkbar. Wie bereits im Kapitel II.2. gezeigt wird, spielt dabei das gemeinsame reformierte Glaubensbekenntnis eine wichtige Rolle. Aber in diesem Brief geht es nicht um Religion, sondern um die Repeuplierung des Landes mit ausländischen Kolonisten.

127 Durch die soziale Stellung dieser Personen und deren Anlass zur Auswanderung unterscheidet sich die schweizerische Emigration von der der Réfugiés (Hugenotten) und der Salzburger. Diese beiden Gruppen sind aus religiösen Gründen ausgewandert (Glaubensflüchtlinge). Aber auch ihre soziale Zusammensetzung war eine andere. Unter den Réfugiés waren zahlreiche Manufakturisten, Bankiers und Militärs; unter den Salzburgern meist Hofbesitzer.

128 Rösli, Joseph: Wanderungen der Berner, in: Der Schweizer Familienforscher, Bd. 7 (1940), S. 43-57, bes. S. 48.

129 Konflikte aller Form waren im Bund dieser unterschiedlichsten Territorien an der Tagesordnung. Konfessionell standen sich die reformierten und katholischen Landstände gegenüber, politisch-geographisch das Alpenland und das Mittelland, und wirtschaftlich gab es Auseinandersetzungen zwischen den Städten und dem Land. Vgl. de Capitani, Beharren und Umsturz (1648-1815), in: Geschichte der Schweiz- und der Schweizer. Bd. 2. Basel, Frankfurt 1983. S. 128.

130 Zwar betrafen diese Ereignisse ursächlich oft nur einzelne Täler, doch die Auswirkung war meist überregional. Die geschädigten Gebiete wurden verlassen, und die Ansiedlung in anderen Regionen führte dort zu einer Schmälerung des ohnehin schon ausgelasteten Lebensraumes, Vgl. de Capitani, Beharren und Umsturz ..., Bd. 2. Basel, Frankfurt (1983), S. 101.

131 StA Bern: A.V. 19 Teutschland-Buch Preussen-Brandenburg fol. 5 u. 6; der Brief ist vom Kurprinzen Friedrich sub nomine principis unterschrieben. 
Zur Umsetzung der Repeuplierungspläne erließ der Kurfürst Friedrich Wilhelm wiederholt Edikte und Patente, und seine Residenten hatten diese europaweit zu verbreiten. Damit begann er bereits unmittelbar nach dem Westfälischen Frieden. Im nachfolgend zitierten Beispiel vom 23. Oktober 1650 wird die Situation in Kurbrandenburg nach dem Dreißigjährigen Krieg skizziert. Um das Land wieder aufzubauen, wird denjenigen, die bereit sind, So sich unter Unsern Schutz zu begeben, in Unsern Aemtern niederlassen, und wüste Höfe und Güther anzunehmen und aufzubauen, das Angebot gemacht, von Sechs Jahre Contribution, Pächte, Dienste, und aller anderer Onerum befreit zu werden und zur Erbauung und Ausbesserung derer Häuser, Wohnungen, Scheunen, und Ställe zu solchen wüsten Bauer- und Coßäthen-Höfen die benannte 6. Jahr über frey Bau-Holtz hiemit gnädigst gewilligt werden. Danach sollen sie dasjenige an Pächten, Zinsen, Hufen-Schössen und Diensten tragen, was sich vor Alters von solchen Höfen zu thun gebühret, und sonsten im übrigen alles behöriger massen, als getreue Unterthanen gehorsamst willigst leisten. ${ }^{132}$ Diese wiederholten Werbungen - auch in Konkurrenz zu anderen verwüsteten deutschen Ländern - blieben trotz eingeräumter erheblicher Privilegien ${ }^{133}$ ohne großen Erfolg. Schon damals haftete Kurbrandenburg der Ruf an, eine Streusandbüchse zu sein.

Nach dem Frieden von Oliva (3. Mai 1660) wurde die Anwerbung neuer Siedler wieder forciert. Über die damit verfolgten Ziele und Projekte machen Orlich ${ }^{134}$, Opgenoorth ${ }^{135}$, Gloger $^{136}$ und Gugger ${ }^{137}$ unterschiedliche Angaben. Anscheinend wollte man den Fehler der zerstreuten Ansiedlung, den man bei der Ansiedlung der holländischen Kolonisten gemacht hatte, diesmal vermeiden (s. Kap. II.1.). Nach Orlich wurde 1661 Graf Friedrich v. Dohna ${ }^{138}$

132 Patent von derer Neu-anbauenden Freyheit, von Contribution Diensten vom 23.10.1650, in: Mylius, Corpus Constitionum Marchicarum VI. Th. I. Abth. Miscellaneis No. CXIII. fol. 1650/1651.

133 Siedlungswilligen wurde in der Regel drei bis max. sechs Jahre Abgabenfreiheit angeboten.

134 Orlich, Leopold von: Geschichte des Preußischen Staates, Berlin (1839), S. 440. [Ohne Angabe einer Quelle!] In Urkunden und Akten zur Geschichte Kurfürst Friedrich Wilhelm, Bd. 9 (1879), S. 473 Anm. 131 wird diese Beauftragung v. Dohnas fast gleichlautend erwähnt.

135 Opgenoorth, Ernst: Der Grosse Kurfürst, Teil II (1660-1688), Göttingen, Frankfurt und Zürich (1978), S. 54.

136 Gloger, Heinrich: Friedrich Wilhelm - Kurfürst von Brandenburg (Berlin), 1986, S. 316.

137 Gugger, Ernst: Preußische Werbungen in der Eidgenossenschaft. Ein nichtavouierter Dienstort auf dem schweizerischen Söldnermarkt im 18. Jhrhundert, Diss.; Berlin (1997), S. 39.

138 Der in Küstrin geborene Friedrich Burggraf und Graf zu Dohna (1621-1688) war durch seine Mutter, eine Gräfin von Solms-Braunfeld, sowohl mit der oranischen Familie als auch mit dem Kurfürsten Friedrich Wilhelm verwandt. Er war von 1636-1648 im Heer Friedrich Heinrichs von Oranien (zuletzt Generalleutnant) und als letzter Gouverneur [Statthalter] des Fürstentums Orange (1648-1660) tätig. Nachdem das Fürstentum Orange 1660 von Ludwig XIV. gewaltsam in Besitz genommen war, lebte er von 1662 an zu Coppet und Prangins am Genfer See und baute sich von hier aus eine neue Existenz auf. Ohne eigentliches Amt wurde er vom Kurfürsten von Brandenburg, von den Eidgenossen wie auch von den Generalstaaten mit politischen Aufgaben betraut. Zu seiner Person: A. Bachmann, S. 178.; Les mémoires du Burgrave et Comte Frédéric de Dohna (Hg.: Heinrich Borkowski), Königsberg i. Pr. (1898).; Vinzenz Czech: Brandenburg und seine kleinen Nachbarn, in: Jürgen Luh, Vinzenz Czech und Bert Becker: Preussen, Deutschland und Europa 17012001, Groningen (2003), S. 87 ff. Erfolgreich vermittelte er die Ansiedlung von schweizerischen Bauern in die Mark Brandenburg. Seine Bemühungen Anfang 1670, die Schweiz zum Anschluss an die europäische Defensivkoalition gegen Frankreich zu bringen, waren dagegen von keinem Erfolg gekrönt. Vgl. Allgemeine Deutsche Biographie, Leipzig (1877), S. 306-308; Christian Krollmann (Hg.) Altpreußische Biographie, Marburg/Lahn (1974), S. 143 und Lothar Graf zu Dohna: Die Dohnas und ihre Häuser, Bd. I, Göttingen 
beauftragt, sich wegen Werbung von Siedlern in die Schweiz zu begeben. In seiner Instruktion wird ihm aufgetragen, Sich zu bemühen, daß etwa drei oder vier Familien sich in Unsere Lande begeben, und die den Vortheil und Nutzen genißen sollen, welchen Wir denjenigen in der Taht widerfahren lassen, die in Unsere Landen zu wohnen, sich für beständig resolviret. ${ }^{139}$ Als Berner Bürger wandte Graf v. Dohna sich umgehend an die Stadt, wo das Projekt auf ein positives Echo stieß. Sein brandenburgischer Auftrag in der Schweiz bedeutete die erste Anknüpfung von offiziellen Beziehungen zwischen diesen beiden Staaten. Inzwischen machte sich aber in Kurbrandenburg Widerstand breit. In Anbetracht der als fort libertins verschrienen holländischen Kolonisten befürchtete man, dass auch die Schweizer als Freidenker ein schlechtes Beispiel für die Einheimischen abgeben würden. ${ }^{140}$ Wegen anderer, dringenderer Geschäfte wurden die veranschlagten Ausgaben zunächst gestrichen, das Projekt vom Kurfürsten 1664 vertagt: il faut remettre cette affaire à un autre tems. ${ }^{141}$ Das ist ein häufig bei Kurfürst Friedrich Wilhelm zu beobachtendes Verhalten: Wenn ein Projekt auf Anhieb keinen Erfolg hatte, wurde es für später auf Eis gelegt.

In diesem Zusammenhang ist eine Privatinitiative besonders erwähnenswert. Vermutlich erstmalig 1672 hat sich Jacob Burchard ${ }^{142}$ an den Kurfürsten Friedrich Wilhelm mit dem Vorschlag gewandt, Schweitzerische Leüte in Preußen anzusiedeln. ${ }^{143}$ Einem Vermerk in der gleichen Akte zufolge ist es dazu höchstwahrscheinlich nicht gekommen. Denn darin ist von einem von ihm 1675 begangenen Adulterium [Ehebruch] die Rede. Vermutlich nach Ableistung seiner Strafe in Küstrin macht er 1678 erneut - mit Bezug auf seinen früheren Vorstoß - dem Kurfürsten ein Angebot, Hundert Personenn, Mannes undt weibes Bildern au $\beta$ dem Schweitzer Landt nach Preußen zu führen. Sein Schreiben ist reichlich prahlerisch und ausschweifend abgefasst, und er fragt darin an, ... in welchen Ambt Ich am fueglichsten zue Ewr: Churf: Durchl: Nutzen undt auffwach $\beta$ eine wuesten ohrdts finde, mit diesen Leuthen zu Besetzenn, undt Uhrbahr zu machen gesonnenn, Wie auß der Beylage A zuersehen, Ich im Schweytzerlandt mit dehnen Leuthen aldahr Capituliret, anfängklichen alß Ein Dorff undt Nachfolgendts zu Einer Schweitzer Stadt gemachett werden kann ... Dementsprechend bezweifelt das dienstliche

(2013), S. 318-327 und Anm. 344. Für Kurfürst Friedrich Wilhelm war er darüber hinaus ein enger Vertrauter [GStA PK, I. HA, Rep. 131 K 126 C 21].

139 Diese Zitierung erfolgt ohne Angabe einer Quelle. Gestützt wird sie durch die 1. Eintragung im Register über einige Aktenstücke betr. Gewinnung von Schweizer-Kolonisten für Brandenburg und die Defension der Stadt Genf (GStA PK, VI. HA, Fürstliches Hausarchiv Dohna-Schlobitten Nr. 1157): Une Instruction du 14. d'Octobr. [1661] de S: A. Elect: te pour le Comte de Dohna, touchants le Transport de quelques Familles Suisses en Brandebourg, a à la quelle it ya joints les Propositions de la nouvelle Colonie des Cantons Suisses pour l'Irlande par le Colonel May en 1655.

140 Lothar Graf zu Dohna: Die Dohnas und ihre Häuser - Profil einer europäischen Adelsfamilie, Göttingen (2013), Anm. 350. Bei Breysig, Kurt (Geschichte der brandenburgischen Finanzen in der Zeit von 1640 bis 1697, I. Bd., Leipizig (1895), S. 248 ff.) findet sich eine lebhafte Beschreibung der Spannungen, die zwischen den Einheimischen und den Holländern bestanden.

141 „Die Angelegenheit soll auf andere Zeiten verschoben werden.“

142 Der Name ist verschieden geschrieben: Burchard, Borchardt usw.; er war mit einer Züricherin verheiratet.

143 GStA PK, I. HA, Rep. 11 (Akten) Nr. 10273 fol. 10-17. Dabei bezieht sich die Jahreszahl auf das Schreiben vom 29. Juni 1672. 


\section{Die Besiedlung des Golmer Bruchs mit Schweizer Kolonisten}

Votum vom 1. November 1678 Burchard's Glaubhaftigkeit und Kreditwürdigkeit. ${ }^{144}$ Wie die Sache ausgegangen ist, ließ sich nicht ermitteln.

Kurfürst Friedrich Wilhelm war also bereits - im Gegensatz zur gängigen Darstellung - mehrfach mit der Frage der Ansiedlung von Schweizern in Kurbrandenburg befasst bzw. konfrontiert, bevor Friedrich Graf und Burggraf v. Dohna ${ }^{145}$ am 24. November 1683 beauftragt wurde, ein gleichdatiertes Schreiben an den Magistrat der Stadt Bern ... zu übergeben. Ausdrücklich erging die Bitte an Dohna, auch durch Ewre freunde und Bekandten die sache Dergestalt zubefordern, daß Wir zu Unserer intention gelangen mögen. ${ }^{146}$ Allein die Abfassung dieses Schreibens an Graf v. Dohna macht sehr deutlich, wie sehr dem Kurfürst an dem Gelingen dieses Vorhabens gelegen war. Der Brief an den Schultheiß und Rat der Stadt der Bern enthielt die Bitte um Überlassung von Einwohnern auf dem Lande [10 oder 20 Familien]..., welche der Wirtsschafft und Viehzucht wohl erfahren seyn. ${ }^{147}$ Die Ansiedlungsbedingungen werden darin nur in allgemeiner Form dargelegt (s. Anhang 2). Zugesagt wurde diesen Familien, dass sie [in der Mark Brandenburg] wol aufgenommen, an bequeme örter gesetzet, mit wohnungen und behörigen besatz Versehen und gegen eine leidliche und erträgliche pacht wohl accomodiret werden. Der beabsichtigte Ansiedlungsort - auf dem Potsdamschen Werder - ist dem vorerwähnten Schreiben an Graf v. Dohna zu entnehmen.

Das Anliegen des Kurfürsten stieß beim Rat der Stadt Bern auf offene Ohren, und er signalisierte Graf v. Dohna bereits mit Schreiben vom 4. Januar 1684, bei den Ämtern und Orten nach Persohnen, die auf die Viehzucht sich am besten Verstehen, zu fragen, die an einer Umsiedlung nach Brandenburg interessiert und bereit seien. Für deren Entscheidung hielt er es aber für nothwendig und erforderlich, dass von Seiten des Kurfürsten weitere Ausführungen folgten, mit welchen Konditionen die Leuten rechnen könnten, die sein voriges Schreiben nicht austrücket. ${ }^{148}$ Der Kurfürst reagierte darauf mit dem Vorschlag, dass ein paar leüte vorher nach Brandenburg kommen sollten, damit Sie die gelegenheit des Landes erkundigen, den ohrt ihrer wohnungen, die Wir Ihnen anrichten laßen wollen, besichtigen, und dass angelegentlich dieser Ortsbesichtigung hiebeygefügte puncte [für einen abzuschließenden Ansiedlungsvertrag] erörtert und darüber eine gewiße abrede und Vergleich getroffen werden könne. ${ }^{149}$ Darin sind in 11 Ar-

144 GStA PK, I. HA, Rep. 11 (Akten) Nr. 10273 fol. 16.

145 zur Person s. Anm. 138.

Das Schreiben ist allerdings entgegen aller bisherigen Darstellungen vom Kurprinzen (Kurfürst Friedrich III./I.) unterzeichnet worden. In welcher Funktion er dies getan hat, ist nicht zu ermitteln gewesen. Der Kronprinz vertrat seinen Vater seit 1683 und besonders in dessen letzten Lebensjahren in Krankheitsfällen und in Abwesenheit (s. Anm. 131).

146 GStA PK, VI. HA, Fürstliches Hausarchiv Dohna-Schlobitten Nr. 1159, Aktenstück Nr. 46.

Dieser erneute Versuch zur Anwerbung Schweizer Kolonisten erfolgt zeitlich nach dem Sieg über die Türken am 12. September 1683 vor Wien und nun konnte das auf Eis gelegte Ziel erneut in Angriff genommen werden.

147 StA Bern: A. V. 19 Teutschland-Buch Preussen-Brandenburg, fol. 5/5R.

148 daselbst: fol. 9-10.

149 GStA PK, VI. HA, Fürstliches Hausarchiv Dohna-Schlobitten Nr. 1159, Aktenstück Nr. 48. 
tikeln Aspekte für die inhaltliche Gestaltung eines Ansiedlungsvertrags zusammengefasst. ${ }^{150}$ Die Berner Obrigkeit begrüßte den Vorschlag einer Vorortbesichtigung, da sie ihre Untertanen nicht gern einem ungewissen Schicksal weit weg von der Heimat aussetzen wollte. Aber da sie mit den brandenburgischen wirtschaftlichen und sozialen Verhältnissen offensichtlich gut vertraut war, verlangte sie Ergänzungen und Aufklärung zu verschiedenen Punkten. Das Hauptanliegen bestand darin, dass den families so hinziehen werden, als ein Freyen Volk, wann sie etwan nit die verhoffte Fortun antreffen sollten, jederweilen erlaubt sein, wider nach Hauß zukehren und sie keiner Leibeigenschaft unterwürffig sein söllind. ${ }^{151}$

Aus den vom Rat der Stadt Bern im Berner Oberland bzw. im Emmental angeschriebenen Ämtern Frutingen, Rottenberg, Saanen, Thun und Trachselwald trafen im Sommer 1684 Namenslisten mit insgesamt 51 übersiedlungswilligen Familien ein. Sie belegen, dass am Ende des 17. Jahrhunderts bei den ländlichen Bevölkerungsschichten im Kanton Bern eine hohe Bereitschaft zur Übersiedlung in ein anderes Land bestand (s. Kap. IV.2.), aber auch eine spürbare Unsicherheit, diesen Schritt zu wagen. Denn es sind, so schreibt am 21. August 1684 der Amtsmann Joh. Frid. Ryhiner aus Trachselwald, doch allerhand Obstacula ${ }^{152}$ vnd Hindernussen aufgetreten, weil in den Articklen auß [d] rükenlich stehet, das man Zuvor ein par männer hinunder schickten, das Land vnd ort, da sie hingesetz werden sollen, zu besichtigen, was er in seinen weiteren Ausführungen allerdings gut fand. ${ }^{153}$ Das Entgegenkommen des Kurfürsten Friedrich Wilhelm ist also teilweise nicht so recht verstanden worden und hat verschiedentlich Misstrauen geweckt. Zum anderen wird sich mehrfach entschuldigt, weil man die Leute, die derzeit auf der Alm seien, nicht habe erreichen können und deswegen ... den befelh [...] nit beßer zu exequieren [ausführen] gewüst, alß von Cantzlen verkündigen $z u$ laßen, ... ${ }^{154} \mathrm{Am}$ 2. September 1684 berichteten schließlich Schultheiß und Rat der Stadt Bern dem Kurfürsten, wie umfänglich sie Nachforschungen in seinem Sinne betrieben hätten. Um sein Anliegen ins werk zu bringen, hielten sie es für notwendig, dass zweyen Unserer underthanen sambt einem Meister Zimmer handwerck, under den geleit Unsers Burgers und Lieben getreüwen Stattartzets Albrecht Bauren Königs Verwilliget, an die ohrt sich Zu begeben, und der Landerey die Eüwer Churfürstlich Durchleücht [...] in augenschein zu nehmen und weitere Dinge zu klären. ${ }^{155} \mathrm{Als}$ möglicher Termin wurde der bevorstehende Winter genannt.

150 StA Bern: A. V. 19 Teutschland-Buch Preussen-Brandenburg, fol. 51-53.

151 daselbst: fol. 72 .

152 (lat.) Hindernisse.

153 StA Bern: A. V. 19 Teutschland-Buch Preussen-Brandenburg, fol. 37.

154 daselbst: fol. 29.

155 daselbst: fol. 45-49. 


\section{Erkundungen vor Ort durch eine Berner Abordnung}

In der Literatur findet diese Reise einer Abordnung unter der Leitung von Albrecht Bauernkönig ${ }^{156}$ mehrfach Erwähnung ${ }^{157}$, ohne dass sie näher beschrieben wird. Hierzu geben einzig und allein die Berichte an den Rat der Stadt Bern Auskunft. ${ }^{158}$

Die Berner Obrigkeit gab Bauernkönig eine sechs Punkte umfassende, „diplomatisch“ gehaltene Instruktion für seine Reise mit. ${ }^{159}$ Die Verantwortung für seine Begleiter wird ihm übertragen, mit deren Hilfe er den vorgeschlagenen Siedlungsort hinsichtlich Beschaffenheit deß Landes Vndt sonsten alle Umbstand wol in obacht nemmen soll. Insbesondere sind die aufgeführten detaillierten Verhaltensregeln interessant, die Bauernkönig verpflichteten, vor allem mit Bescheidenheit und Vorsicht die Interessen der künftigen Kolonistenfamilien zu vertreten. Dies bezog sich insbesondere auf die von Kurfürst Friedrich Wilhelm vorgeschlagenen Ansiedlungsbedingungen und die hierzu von Bauernkönig überbrachte Antwort der Berner Obrigkeit. Auch solle er nicht allzu große Hoffnung auf ein Gelingen des Projekts erwecken, damit ein eventueller Misserfolg später nicht den Kolonisten zugeschrieben werden könne. Im Übrigen sollte er sich nicht als Beauftragter der Berner Obrigkeit, sondern der Untertanen ausgeben; damit vermied seine vorgesetzte Stelle, im Vorfeld der Verhandlungen sich in irgendeiner Weise durch verbindliche Äußerungen zu prejudizieren.

Vom 29. September bis 27. November 1684 hielt sich Albrecht Bauernkönig mit seinen drei Begleitern ${ }^{160}$ in der Mark Brandenburg auf. In seinen zwei Berichten in Tagebuchform an die Berner Regierung ${ }^{161}$ schilderte er, dass er schon bald nach einer persönlichen Audienz beim

156 Der Name wird verschieden geschrieben: u.a. Baurenkönig, Bauwenkönig. Bauernkönig ist in Hamburg geboren. Er war Feldscher beim schweizerischen Regiment von Erlach in französischen Diensten. Danach war er ab 1652 zeitweise im Dienste des Herzogs von Braunschweig (StA Bern: A. V. Teutschland-Buch Preussen-Brandenburg, fol. 144.) und wurde später hochgeachteter Bürger und Stadtsyndikus von Bern. In dieser Funktion wurde er beauftragter „Kolonisator“ in Brandenburg und nach erfolgreichem Abschluss dieser Mission mit verschiedenen Aufgaben von Kurfürst Friedrich Wilhelm beauftragt. (z. B.: GStA PK, I. HA Geheimer Rat, Rep. 11 Auswärtige Angelegenheiten (Akten) Nr. 10273 fol. 23 und Nr. 10309).

157 Fetscherin, Wilhelm: Die bernischen Colonien in Brandenburg ..., 17 (1868), S. 107-142, bes. S. $112-$ 115; Henning Heese: Einleitende Bemerkungen zur Entstehung und Entwicklung der Schweizer Kolonie im Golmischen Bruch bei Potsdam, in: Henning Heese (Hg.): 300 Jahre Schweizer Kolonie bei Potsdam 1685-1985, Sankt Augustin (1985), S. 5-40, bes. 8-11. und ders.: Schweizer Kolonisten am Golmer Bruch bei Potsdam, in: Der Landkreis Potsdam- Heimatgeschichtliche und heimatkundliche Beiträge (1992), Heft 1, S. 54-62; Heinz van Beek: Schweingruber - Kolonisten aus der Schweiz in Preußen, Mühlheim an der Ruhr (1993), S. 12/13. und Marianne v. Klinski-Wetzel: Wildpark-West an der Havel, Potsdam (2007), S. $132 / 133$.

158 In ihnen werden auch viele zeitgeschichtliche Ereignisse beschrieben, z. B. Getreidepreise, daß große unglück Zu Alt Dreßden, das freüden feürge ob des Sieges über die Türken vor Wien. [StA Bern: A. V. 19 Teütschland-Buch Preussen, fol. 128/129.].

159 StA Bern: A. V. 19 Teutschland-Buch Preussen-Brandenburg, fol. 55-59.

160 Namentlich sind nur Davit Famckhufer und Peter Müller bekannt (StA Bern: A. V. 19 Teutschland-Buch Preussen-Brandenburg, fol. 84 bzw. 85.).

161 daselbst: fol. 75-81 (vom 11. Oktober 1684) und fol. 83-85 vom 9. Dezember 1684). 
Kurfürsten ${ }^{162}$ den neuen Siedlungsort und das Land im Golmischen Bruch mit dem Oberjägermeister und Potsdamer Amtmann von Lüderitz besichtigt habe. ${ }^{163}$ Dort seien bereits etliche Häuser gebaut worden. Das Land umfasse etwa 4.200 Morgen, in das mehr als 8.000 Reichstaler (vgl. Tab. 1) für die Entwässerung ausgegeben seien. Vor drei Jahren sei es noch Wildnis gewesen, nun sei es aber bereits zur Hälfte gerodet. Der Boden sei etwas morastig an vielen Orten. [...] Es ist auch hie und da etwas Landes darin, so dießmahlen wol fruchtbar zu dem Ackerbaw könnte genennet werden, ist aber noch pro portion deß Landes nit so gar viel, wiewohl man vermeint, waß Gersten, Habern und Bonen betriff, darinnen an allen orten, genugsam würde hervor wachsen, ... Das Entwässerungssystem mit einer Windmühle als Schöpfwerk, berichtete Bauernkönig, sei doch nur so obenhin gemacht, so dass seine Begleiter ihn darauf hingewiesen hätten, dass noch viel Arbeit nötig sei, bis alles vollendet sei.

Nach ihrem ersten Besuch des künftigen Koloniegebiets wurden die „Inspektoren“ zum Kurfürsten gerufen und gefragt, wie sie das Gesehene beurteilten. Der Zimmermeister bemängelte, dass die vier fertigen Häuser im Fall einer Feuergefahr zu nah aneinander stünden, nicht recht gesetzt und die Ställe zu niedrig ausgefallen seien. Er erklärte sich bereit, ein Haus nach seinen Vorstellungen zu errichten, das dann als Muster für weitere dienen könne. Die beiden anderen Schweizer hielten zwar das Land für fruchtbar, aber überwiegend nur als Weideland brauchbar, das zur Rodung noch viel Arbeit erfordere. Allerdings seien größere Wasserschäden in nassen Jahren nicht auszuschließen. Sollte es dazu kommen, erklärte sich der Kurfürst bereit, den Schaden zu ersetzen. Er ließ sich auch Ausweichstandorte für die Häuser nennen. Während ihres Aufenthaltes fanden Jagden, Feuerwerke und andere Festlichkeiten zu Ehre der Schweizer statt.

Im zweiten Bericht - bereits auf der Rückfahrt in Nürnberg geschrieben - informierte Bauernkönig über zwei Konferenzen mit Deputirten [Beamten], bei der endlich die conditionen (der Ansiedlung) zu einer volligen Richtigkeit [Abschluss] gebracht worden seien. Die Unterschrift des Vertrages habe er interim geleistet, vorbehaltlich der Ratification meiner Gnedigen Herren. Die Rückfahrt verzögerte sich; erst als der Schweizer Zimmermann das „Modellhaus“ fertig gestellt hatte, konnte Bauernkönig um Dimission anhalten und abreisen.

\section{Der Vorvertrag $\mathbf{1 6 8 4}$}

Nach der Rückkehr der Kundschafter gab Bauernkönig vor dem Schultheiß und dem Rat der Stadt Bern einen Bericht und übergab das Schreiben des Kurfürsten Friedrich Wilhelm vom 14. November 1684. ${ }^{164}$ Darin gab dieser nochmals seiner Zuversicht Ausdruck, daß diejenigen, denen Ihr anhero zu ziehen verstatten werdet, sich auf die von Uns offerirte Conditiones anher zu begeben und die Viehzucht und Melkerey anzulegen kein Bedenken, sondern vielmehr Begierde

162 Bei dieser Gelegenheit diente er als „Informationsquelle“ und wurde gefragt, ob man in Unserem Lande in guten frieden Lebte, und ob man sich nit vor dem König in Franckreich fürchtete, welcher wie die Rede gehet auch bei uns wie an anderen ohrten pretensiones formiren würde,...

163 In dieser Zeit war es durchaus üblich, dass Beamte mehrere Ämter innehatten. In diesem Fall wird er als Amtmann von Potsdam tätig geworden sein.

164 StA Bern: A. V. 19 Teutschland-Buch Preussen-Brandenburg, fol. 67-70. 
und Verlangen darzu haben werden. Er würde es auch begrüßen, wenn Albrecht Bauernkönig, der nunmehr bekannt sei, die Familien hierher begleiten werde. Er hielt es ferner für nötig, dass den Familien ein Prediger aus der Schweiz mitgegeben werde: Weil auch solche Familien hiesiger Landessprache noch nicht gewohnet, und daher die Prediger nicht Verstehen können. Der Schweizer Prediger sollte auch mit nothdürftigem Unterhalt versehen werden. Der Vertragsentwurf wurde ohne Einschränkung genehmigt.

Als Vertragspartner des Vertragsentwurfs vom 12. November 1684 traten einerseits Kurfürst Friedrich Wilhelm und andererseits die Löbliche Republik zu Bern auf. Er bestand aus 19 ungewöhnlich umfangreich ausgeführten Punkten und ist von brandenburgischer Seite von Joachim Ernst v. Lüderitz gezeichnet. Die Übersiedler erhielten im Vertrag ganz erhebliche weitere wirtschaftliche Vorteile und Garantien von Kurfürst Friedrich Wilhelm zugesagt: Übernahme der Kosten für die Anreise ${ }^{165}$ und den Häuserbau, bei Ankunft der Übersiedler Bereitstellung von Saatgut sowie Grundausstattung mit instrumenta rustica ${ }^{166}$ und Lebensmitteln, Errichtung eines eigenen Kruges, Bezahlung des aus der Schweiz kommenden Predigers und Anweisung von erforderlichem Holz.

Da die angebotenen Bedingungen für die Ansiedlung in Kurbrandenburg zumutbar erschienen, wurde der günstige Bericht von Albrecht Bauernkönig bekanntgegeben und erneut vom Rat der Stadt Bern 20 Kolonistenplätze in Brandenburg öffentlich ausgeschrieben. Zugleich nahm die Berner Obrigkeit mit der Vorderösterreichischen Regierung in Waldshut, dem Kurfürsten der Pfalz zu Heidelberg und anderen Landesherren längs des Rheines Verhandlungen auf, um den Auswanderern Schutz zu gewähren, ihnen die Zollgebühren zu erlassen und Rheinschiffer zur Verfügung zu stellen. ${ }^{167}$ Den Wasserweg wählte man, weil eine Landreise viel umständlicher und beschwerlicher gewesen wäre. Durch Rats-Manul wurde die Abreise der Brandenburger Kolonisten öffentlich bekanntgegeben (s. Anhang 3).

\section{Schiffsreise von Bern nach Brandenburg in den Golmer Bruch}

Der Schiffsreise von Bern bis in den Golmer Bruch haftet bis heute etwas Spektakuläres an. Nicht nur, dass diese „Luxusreise“ mit großem logistischem Aufwand Ende des 17. Jahrhunderts stattfand; vor allem hat es eine solche nie wieder gegeben. Alle späteren Schweizer Kolonisten mussten eine äußerst beschwerliche Anreise über Land als Einzelperson oder im Treck (ca. $1400 \mathrm{~km})$ zu Fuß auf sich nehmen. Über die erwähnten Vorbereitungen hinaus ist nichts Näheres bekannt, insbesondere was das Zustandekommen der Auswanderergruppe angeht. Dem Kurfürsten Friedrich Wilhelm wurde mit Schreiben vom 22. April 1685 mitgeteilt, dass die Reisewilligen mit Weib, kindern und Dienstleüthen [...] fertig stehen, [...] um under der Conduct $[\ldots]$ von Albrecht Baurenkönigs den Rhein hinunter gebracht $[\mathrm{zu}]$ werden. ${ }^{168}$ archiv Dohna-Schlobitten Nr. 1159, Aktenstück 51.

166 Grundausstattung eines Bauernhofes mit Werkzeugen und Gerätschaften, auch Hofwehr genannt.

167 StA Bern: A. V. 19 Teutschland-Buch Preussen-Brandenburg, fol. 91-92.

168 daselbst: fol. $87-89$, bes. 87 . 
Bei der Verabschiedung in der Nydeggkirche zu Bern hielt ein beauftragtes Ratsmitglied die entsprechende Mahnrede (s. Anhang 3) und versicherte den Kolonisten, sie könnten stets auf die treue Oberaufsicht der Berner Obrigkeit zählen. Sollte es ihnen gut gehen, so sollten sie ihre Heimat nicht vergessen; würden sie in ihren Hoffnungen enttäuscht, so wolle man sie wieder aufnehmen. Die Auswanderer sollten zusammenhalten und sich drunten so aufführen, dass es $z u$ der schweitzerischen Nation Lob und Ruhm gereichen thüye. ${ }^{169}$

Am 30. April 1685 ging es auf drei Schiffen ${ }^{170}$ von Bern aareabwärts. An Bord waren, wie die auftragsgemäß von Bauernkönig angefertigte Specification aller derer [mitreisenden] Familien ausweist, elf Berner Familien und ab Aarau weitere drei Familien mit acht Knechten, zwei Mägden und zwei angenommenen Kindern (insgesamt 101 Personen) ${ }^{171}$ :

1. Hanß Lederich von Riedt auf der Kilch heri Worb ${ }^{172}$ mit samt seinen Frawen und 5 Kindern als drei Meitli Catrin, Babi, Marie, und zwei Sohne als Jost, und Niclaus, Dazu gehört ein 15 Jahre alter Junge, Mattias Erisman, auf den Müliberg Kilch heri.

2. Nickeli Zech von Richingen auf der Kilch heri Worb samt seiner Frawen und fünf Kindern als Vier Söhne mit nahmen, Ulli, Pens, Hansi und Cristeli, daß meitli heist Elsebet, Hat auch einen Knecht, der heist Melcher Spring von Eckihorn auf der Kilch heri Kiltorf. seine Magt die er mit nimt heist Barbli Brenniman.

3. Nickeli Küntzi und sein Fraw von Münsingen, mit fünf Kindern als 3 Meitli und 2 Sohne, die Meitli heisßen Catrin, Babi, und Elsebet, die Söhne heisßen Vlli und Antoni. Hat noch 2 Starke Knecht, der einte heist Niclaus Wantzeried von Münsing. der ander heist Hanß Stücki ${ }^{173}$, ist auch von Münsing.

4. Christen Huetmacher und sein Fraw von Langernaw mit 2 Kindern als ein Meiteli Marie Magdalena und ein Sohn Samuel, hat einen gemeinder Hanß Wentzerider, ist von Stattern Künitz. Diese haben eine Magt Maria Reber von Signaw.

5. Bendicht Kiner und seine Fraw von Jaberg aus der Kilch heri Kilchtorf, hat 2; Sohn Zacharias die Tochter Madlene, und einen Knecht nahmens Christen Spring, von Eckihorn aus der Kilchheri Kiltorf.

6. Peter Schweingruber und sein Fraw in dem Wieler aus der Kilchheri Rükisberg, samt drei großen erwachsenen Söhnen, Peter, Niclaus und Jeronimus, unter welchen der Niclaus verheiratet ist, hat 2 Kinder, als 2 Söhne Christen und Hans. 17. Jahrhundert in deutschen gebieten, in: Der Bund (1985) Nr. 167 (20.07.), 172 (27.07.) und 179 (03.08.).

170 StA Bern: A. V. 19 Teutschland-Buch Preussen-Brandenburg, fol. 112.

171 daselbst: fol. 107-109; das Dokument soll hier nur in Form wiedergegeben werden.

172 Kilch heri = Kirchdorf

173 Er heiratete in die Familie Dortschy ein und wurde dadurch Erbpächter. 
7. Hanß Schnider und sein Fraw ${ }^{174}$ von Uetendorf aus der Kilch heri Tiracher, hat Sechs Kinder als 4 Söhne, Hanß, Christen, Maritz und Jacki, die 2 Meiteli heisßen Anni und Babi.

8. Crispinus Garmatter und sein Fraw von Tierracher samt 6 Kindern als 4 Sohne und 2 Tochter. Die Sohne heisßen Hanß, Crispinus, Davit und Manuel, Die Töchter heisßen, Babi, und Johanneli. ${ }^{175}$

9. Emanuel Turtschi und sein Fraw von Uetendorf aus der Kilch heri Tirracher samt 5 Kindern, als 3 Söhne und 2 Töchter, Christen, Emanuel und Heinrich, Elsebet und Marie, hat einen Knecht nahmens Benedicht Huntziger von Culm aus dem Ergew.

10. Hans Bilan und sein Fraw von Gurtzelen, hat 3 Kinder, als Hanß, Anni und Babeli.

11. Nickeli Hodler von Gurtzelen und sein Fraw und 2 Kinder als Anni und Hanß, hat einen Buben von 12 Jahren so, nit anders weis als daß er Hans Rudi heist, weilen er ein Fündeli ${ }^{176}$ ist, und ist zu Pelp gefunden worden. Den so hat er auch einen Knecht nahmens Abraham Zum Bach von Gurtzelen.

12. Beat Suter und sein Fraw von Kolligken aus dem Ergew, so den 2.te May Zue Arraw Zu mier gekommen; hat 3 Kinder als Babeli, Vlli, und Mareili, hat einen Knecht heist Jackeli Detwiler von dem Pötzberg.

13. Jagkeli Gerich und sein Fraw von Ammerswiel aus der Grafschaft Lentzburg, hat 4 Kinder, alle Töchter, als Frenele, Annele, Babi und Mareile, hat einen Knecht, heist Jagkeli Gerich, auch von Ammerswil, ist aber zu Neüburg unter Strasburg ausgerisßen.

14. Samuel Suter und sein Fraw, so auch Zu Arraw Zu mier gekommen, von Kölligken, hat Sieben Kinder, als Hanß, Samuel, Melcher, Rudi, Vrenne, Anneli und Marie. ${ }^{177}$

Die Herkunftsorte der einzelnen Familien sind Abbildung 3 zu entnehmen. Auf sie soll später näher in Verbindung mit den Eintragungen im Kirchenbuch der reformierten Gemeinde im Bruch bei Potsdam eingegangen werden (s. Kap. VII.). Außerdem waren an Bord zwei Patriziersöhne aus Bern (Gabriel Groß ${ }^{178}$ und Simon Bondeli ${ }^{179}$ ), ein Herr Bucher und ein Student Hürner sowie Elisaeus Malacrida, der erste Schweizerische Prediger im Golmer Bruch (16851687). ${ }^{180}$ Anhand der Berichterstattung in Tagebuchform, die Albrecht Bauernkönig von unterwegs dem Rat der Stadt Bern zukommen ließ, kann man diese „gefährliche" Wasserreise von

174 auf der Reise in Hamburg gestorben.

175 Sie fehlt im Kirchenbuch Nattwerder 1685-1801.

176 Findelkind.

177 Die Kolonistenliste im Kirchenbuch Nattwerder verzeichnet noch ein 8. Kind Ulli.

178 Gabriel Groß, Berner Patriziersohn, unternahm eine Bildungsreise an den brandenburgischen Hof. Ansonsten zur Person s. Tobler, Gustav: Die Reise der Berner Kolonisten ..., Bern, 19 (1889), S. 44-47, Anm. 1.

179 Simon Bondeli brachte es später am Hof des Kurfürsten Friedrich Wilhelm zum Kammerdiener und wurde mit mehreren diplomatischen Missionen in die Schweiz geschickt; Hensell, Gottfriede: Das protestantische Moment in der Außenpolitik des Großen Kurfürsten 1672-1688, Diss., Philosoph. Fak. Univ. Hamburg (1927), S. 49; Bahl, Peter: Der Hof des Großen Kurfürsten, Köln - Weimar - Wien (2001), S. 394.

180 Erster Prediger der reformierten Gemeinde im Bruch bei Potsdam. 
Bern über die Aare, den Rhein, über die Zuider- und Nordsee, die Elbe, die Havel bis in die Wublitzmündung gut nachvollziehen. Allerdings weisen die erhaltenen Briefe im Staatsarchiv Bern eine Lücke auf. Während der Fahrt von Köln nach Hamburg unternahm Bauernkönig mit den beiden Patriziersöhnen eine Landpartie als Teil ihrer Studienreise. Nach ca. sechs Wochen war die Reisegesellschaft am 18. Juni 1685 ... ohngefehr um 2 uhren Gott Lob und Danck frisch und gesund an ihr Bestimtes ort angelanget, ... ${ }^{181}$ Die genaue Anlegestelle ist heute nicht mehr auszumachen und deswegen ist darüber viel spekuliert worden. ${ }^{182}$ Sie dürfte im Mündungsbereich der Wublitz in die Havel gewesen sein, denn am heutigen Einhaus stand zu dieser Zeit eine halbe Brück, ${ }^{183}$ die kaum mit seetüchtigen Schiffen zu durchfahren gewesen sein wird.

Die Reise gestaltete sich zu einer abenteuerlichen Wasserfahrt mit so mancherlei Anekdoten. ${ }^{184}$ In der Berichterstattung an den Schultheis von Bern findet sich aber auch so manche Klage. So teilte Albrecht Bauernkönig in Verbindung mit der Teilnehmerliste mit, dass einige - obwohl sie es in die Hand gelobt hätten [... ausgeblieben seien. ${ }^{185}$ Manches wird nur angedeutet, weil unmüglich $\mathrm{Zu}$ beschreiben, waß ich aber vor müh und ungemach habe, bald mit diesen und ienen, sonderlich aber mit den proviant aufzutheilen, ihnen bei gelegenheit warme Suppen beizubringe, [...] die Zall abzurichten [Zoll entrichten], und frische Schifleüte zu bestellen, daß weis Gott ... ${ }^{186}$ Das Passieren der Stromschnellen bei Laufenburg muss ein enormer Kraftakt gewesen sein: Die beiden großen Schiffe mit dem Lauf ${ }^{187}$ mit großer gefahr hinunder gelassen. Das kleine Schiff wurde aus dem Wasser gehievt und ist $z u$ Lande biß wieder an den Rhein geschleifet und gefürt worden. Die Unkosten hierfür gibt Bauernkönig insgesamt mit 35 Talern an. ${ }^{188}$ In Hamburg starb Magdalena Schnyder aus Thierachern. Für die Reisegesellschaft muss es schockierend gewesen sein, dass der streng lutherische Rat der Stadt Hamburg der Reformierten ein ehrliches Begräbnis verweigerte. In Altona ${ }^{189}$ war man diesbezüglich toleranter. Die Elbe aufwärts hatten sie mehrfach Mühe, denn sie mussten gegen den Strom segeln und kamen wegen des fehlenden Windes nur mühsam voran. So kam es bei Havelberg an der Havelmündung zu folgendem komischem Zwischenfall. Es herrschte Windstille, und der Sohn des

181 nicht „im Frühjahr“, wie Asche schreibt; Asche, Matthias: Neusiedler im verheerten Land, Neumünster (2006), Anm. 822.

182 Heese, Henning: Einleitende Bemerkungen zur Entstehung und Entwicklung der Schweizer Kolonie im Golmischen Bruch bei Potsdam, in: Henning Heese: 300 Jahre Schweizer Kolonie am Golmischen Bruch bei Potsdam 1685-1985, St. Augustin (1985), S. 14; Beek-Schweingruber, Heinz van: Kolonisten aus der Schweiz in Preußen, Mühlheim an der Ruhr (Eigenverlag, 1993), S. 18.

183 StA Bern: A. V. 19 Teutschland-Buch Preussen-Brandenburg, fol. 122.

184 Fetscherin, Wilhelm: Die bernischen Colonien in Brandenburg ..., 17 (1868) S. 107-142, bes. S. 112-113; Tobler, Gustav: Die Reise der Berner Kolonisten ..., Bern, 19 (1889), S. 44-47; Alfred Hans Kuby: Die Schiffsreise der schweizerischen Kolonisten (1985), in: Heese, Henning (Hg.): 300 Jahre Schweizer Kolonie am Golmischen Bruch, Sankt Augustin (1986), S. 44-48; Heinz Stirnemann: Woselbst sie wohl aufgenommen, Frankfurt a. M. (o.J.), S. 17-18.

185 StA Bern: A. V 19 Teutschland-Buch Preussen-Brandenburg, fol. 99/100.

186 daselbst: fol. 106.

187 seit alters her volkstümliche Bezeichnung der Stromschnellen.

188 StA Bern: A. V. 19 Teutschland-Buch Preussen-Brandenburg, fol. 112.

189 damals nicht zu Hamburg gehörig. 
Schiffführers nutzte die Zeit, Gänsen nachzuschwimmen. Als wieder Wind aufkam, konnte er das Schiff nicht mehr erreichen. Er musste also ans Ufer schwimmen und an Land unbekleidet am Sonntag durch Havelberg dem Schiff nachlaufen, wo er allgemeines Aufsehen erregte. In den brandenburgischen Gewässern waren sie verwundert über die armseligen Dörfer und unansehnlichen Städte, die ihnen nicht einmal eine Unterkunft gewähren konnten, so dass sie etliche Male auffreiem Felde oder im Schiff übernachten mussten. Die Stimmung eines Fremden im fremden Land kam vielleicht auf.

Über die erste Audienz am 16. Juni $1685^{190}$ beim Kurfürsten konnte Bauernkönig dem Rat der Stadt Bern berichten: Er sei gantz gnediglich empfangen worden. Anlässlich der Ankunft der Schweizer habe der Kurfürst versprochen, über das Verabredete hinaus, [...] 4 fette Ochsen zu geben, damit sie nach ihrer ankunfft, $[\ldots]$ an warme Suppen., $[\ldots]$ wie sie gewohnt seint $[\ldots]$ sich erquicken ... Er habe weiter 36 Wispel $^{191}$ Mehl in 40 Vesser von Spandaw bringen lassen ... welches auch nach proportion ihren Haushaltungen unter ihnen aufgetheilet werden, und weilen Sie nit alsobalt konten Backen, ward dem $H[$ errn $]$ Amt schreiber [...] befohlen, ein guet theil Brodt Backen zue lassen, und bei ihrer ankunfft solches ihnen zu geben, [...], ferners so wollte er einer ieder Haushaltung eine Seite Speck, und 14 Scheffel Erbsen, so viel Grütz, noch über daß versprochene 2 Tonen Saltz auch noch etliche Tonnen Bier geben lassen, auch 2 Tonnen Butter und ein Schock Hüner und Gense, damit die so kranck oder übelmögend, ihnen ein Ey konten geben lassen, ... Welchem Einwanderer nach Brandenburg-Preußen ist ein solcher Empfang jemals wieder zuteil geworden!

\section{Der Arrendevertrag 1685}

Während sich die Schweizer Kolonisten in der neuen Heimat einrichteten, bemühte sich Bauernkönig, den Vertragsabschluss entsprechend seinen Instruktionen voranzutreiben. Der Oberjägermeister v. Lüderitz, der auch schon den Vorvertrag gezeichnet hatte, sah die Angelegenheit offensichtlich nicht als eilig an. Der Kurfürst bat Bauernkönig um Geduld. Schließlich konnte dieser von einem guten Stand der Dinge berichten. Ihm war der Vertragsentwurf zugeleitet und die Möglichkeit eingeräumt worden, dagegen Bedenken zu äußern. Fast alle seine Vorschläge fanden Zustimmung. Die vier bzw. sechs eingeräumten Freijahre an Pachtzins nahm er als gegeben hin, obwohl er sich noch mehr Freijahre für die Siedler gewünscht hatte. Er drängte aber darauf, dass klare und einfache Begriffe verwendet würden, da in Brandenburg solche wort gebraucht werden, die bei uns nit üblich, ... ${ }^{192}$

Am 16. September 1685 unterzeichnete Kurfürst Friedrich Wilhelm den Vertrag über die Ansiedlung von 14 Schweizerfamilien aus der Berner Region im Golmer Bruch bei Potsdam. ${ }^{193}$

190 Albrecht Bauernkönig war von Havelberg aus auf dem Lande vorausgefahren, um die Ankunft der Schweizer dem Kurfürsten zu melden. (StA Bern: A.V. 19 Teutschland-Buch Preussen-Brandenburg, fol. 121/122.).

191 Wispel (in Preußen 13,19hl.) = 24 Scheffel, 1 Scheffel = 16 Metzen.

192 StA Bern: A. V. 19 Teutschland-Buch Preussen-Brandenburg, fol. 139.

193 daselbst: fol. 213-225; in Deutschland existiert hiervon eine notariell beglaubigte Abschrift vom 14. August 1691, die im Zusammenhang mit der Vertragsbestätigung durch Friedrich III./Friedrich I. entstanden ist (BLHA: Rep. 7 Amt Potsdam Nr. 611/1, fol. 17-21R), und mehrere, nicht notariell bestätigte Abschriften (u. a. BLHA: Rep. 2 Kurmärkische Kriegs- und Domänenkammer. Nr. D 15409, fol. 152); H. Wagener: Die 
Er wurde dreifach - für das kurfürstliche Archiv, die Löbliche Republique zu Bern und denen Familien - ausgefertigt (s. Anhang 4). Schultheiß und Rat der Stadt Bern befassten sich erst am 5. Oktober 1687 mit dem Vertrag und akzeptierten ihn ohne Einschränkung. ${ }^{194}$

In 21 Artikeln wurden diesen 14 Familien - und drei auf dem Landweg später eingetroffenen Familien gleichermaßen ${ }^{195}$ - folgende Privilegien erteilt:

- Schadensausgleich bei zu befürchtenden Überschwemmungen, aber Instandhaltung und Anlage von Gräben durch die Kolonisten (Art. 1),

- Übernahme der Reisekosten durch den Kurfürsten (Art. 2),

- Bereitstellung eines erb- und eigentümlichen Hauses für jede Familie seitens des Kurfürsten (Art. 3),

- Bereitstellung von Rindvieh und Pferden gegen sofortige Bezahlung oder Verzinsung um $5 \%$ von deren geschätztem Wert (Art. 4 ),

- Einräumung von sechs Freijahren für noch zu rodendes bzw. von vier Freijahren bei mit Hüllen [Sträuchern] bewachsenem Land, dagegen Entrichtung eines Pachtzinses für nutzbares Land (Art. 5),

- Wegfall des Grundzinses bei Landkauf oder Entrichtung eines Grundzinses für den erhaltenen Acker nach den Freijahren gemäß dessen Bodengüte (Art. 6),

- Unterstellung der Schweizer Kolonie im Golmer Bruch unter das Amt Potsdam, Wahl eines Schulzen aus ihrer Mitte zur Beaufsichtigung der Wartungs- und Instandsetzungsarbeiten im Bruch sowie zur Schlichtung von Streitigkeiten in der Kolonie (Art. 7),

- Recht auf einen eigenen Prediger aus der Schweiz, Wahl eines Presbyteriums zur Einhaltung der Kirchenordnung, Bezahlung des Predigers und eines Schulmeisters durch den Kurfürsten und die Familien (Art. 8),

- Befreiung von allen „onera ${ }^{\text {“196 }}$ für 30 Jahre mit der Option von Verlängerungen (Art. 9),

- Errichtung eines Kruges auf Kosten des Kurfürsten und dessen Belieferung mit Bier und Brandwein aus dem Amte Potsdam (Art. 10),

- Bereitstellung des Saatgutes im ersten Jahr gegen Natural- oder Gelderstattung (Art. 11),

- Recht zur Rückkehr ins Vaterland und Ausschluss ihrer Leibeigenschaft (Art. 12),

- anfängliche Grundausstattung der Familien mit Roggen, Bier und Salz (Art. 13),

Schweizer-Colonie bei Alt Töplitz, in: Mitt. d. Vereins f.d. Geschichte Potsdam 1875 I. Theil, S. 211-227, bes. S. 213-216.

194 daselbst: fol. 228.

195 It. Kirchenbuch Golmer-Bruch (Vol. I, 1685-1801): Caspar Zobrist, Isaac Murhoffer und Niclaus Schweingruber.

196 völlige Befreiung von Abgaben und Lasten für eine bemessene Zeit. 
- Überlassung des vom Kurfürsten zusätzlich von der Stadt Werder gekauften Ackerlandes (Art. 14),

- auf Ansuchen kostenlose Bereitstellung von erforderlichem Bau- und Brennholz (Art. 15),

- Recht der Angelfischerei auf der Havel und aus den Gräben hinter ihren Grundstücken (Art. 16),

- Verbleib der Wirtschaft in der Hand der Familie beim Tode des Hauswirts (Art. 17),

- Gültigkeit des schriftlich verfassten letzten Willens (Art. 18),

- Übergabe der Wirtschaft beim Aussterben einer Familie an eine Nation ihrer Wahl (Art. 19),

- Regelung der Erbschaftsangelegenheiten im Falle des Einheiratens Einheimischer in einen Schweizer Hof (Art. 20) und

- jährliche Ausstattung des Schulzen mit einem neuen Rock oder Mantel (Art. 21). ${ }^{197}$

Dieser Ansiedlungsvertrag umfasste quasi alle gesellschaftlichen, wirtschaftlichen, kulturellen und erbrechtlichen Belange der Schweizer Kolonisten im Golmer Bruch. Er lässt aber bezüglich seiner Systematik zu wünschen übrig, was höchstwahrscheinlich darauf zurückzuführen ist, dass die Schweizer einige ihrer Forderungen erst bei den mehrmaligen Nachverhandlungen erreichen konnten. Grundsätzlich ist die Vertragsgestaltung unter Friedrich III./I. bei den späteren Einwanderungen von Schweizern im Ruppiner Land (1690/91), nach Ostpreußen (1710/11) und noch später beibehalten worden, allerdings in einer wesentlich eingeschränkteren Form. Beim Vertrag von 1685 handelte es sich um ein „Regierungsprojekt“, das außerdem sorgfältig und ohne Zeitdruck ausgehandelt worden war. Ohne diesen politischen Charakter wären die Ansiedlungsbedingungen für die Kolonistenfamilien vermutlich weniger günstig ausgefallen.

Die besondere Rechtsqualität, die sich für die Schweizer Kolonisten im Golmer Bruch aus ihrem Arrendevertrag als geschlossene Privilegiengemeinschaft ergab, bestand in der Garantie ihrer persönlichen Freiheit (Art. 12) ${ }^{198}$ sowie in der Überlassung von Land (Art. 5 und 6) und der für sie erbauten Höfe (Art. 3) zu Erbpachtbedingungen ${ }^{199}$ nach Ablauf der Freijahre (Art. 9). Damit waren sie den einheimischen Bauern gegenüber rechtlich deutlich besserge-

197 Nachweislich ist dem ersten Schulzen vom Golmer Bruch, Hans Bilang (s. Kap. IV.7.), auf seine Supplik in den Jahren 1689 und 1690 ein Rock verwilliget und der Amtskammer befohlen worden, die Verfügung zu thun, daß demselben ... ein Rock oder an deßen stat Zehn thr aus dem baren bestande des amts daselbst gereichet werde [GStA PK, I. HA, Rep. 21 Nr. 123 (Paket 7997) fol. 75 und 109.].

198 Die Aufhebung der Leibeigenschaft in Preußen erfolgte erst 1807 im Rahmen der Preußischen Reformen unter vom Stein und Hardenberg.

199 Die Erbpacht gewährt ein erblich und veräußerliches dingliches Nutzungsrecht bei Grundstücken oder (Bauern)Gütern. Der Erbpächter hat jährlich einen sog. Kanon und bei Besitzwechsel (auch innerhalb der Familie) ein Laudemium an den Grundherrn zu zahlen (Brockhaus Konservationslexikon, Leipzig (1902)). 
stellt. Die Verleihung des Erbpachtrechts war im 17. Jahrhundert in Kurbrandenburg nicht üblich, und es war bis dato nur ausnahmsweise den in der Uckermark und an der Elbe angesiedelten holländischen Kolonisten eingeräumt worden. ${ }^{200}$ Schon in den Vorverhandlungen zwischen dem Kurfürsten und der Stadt wurde dies den niederlassungswilligen Schweizer Familien im Vorvertrag vom 2. September $1684^{201}$ zugesichert. Ohne solche verlockenden Privilegien wäre es sicherlich auch nicht möglich gewesen, Schweizer Kolonisten ins Land $\mathrm{zu}$ holen, mit denen schweizerische Agrarmethoden importiert werden sollten. ${ }^{202}$ Hinzukommt, dass den künftigen Erbpächtern diese Privilegien gewährt wurden, ohne dass sie eine Kaution in Form von Barmitteln oder ihres beweglichen und unbeweglichen Vermögens zu stellen hatten. Lediglich in Artikel 12 wurde für den Fall einer gewünschten Rückkehr in die Schweiz ${ }^{203}$ die vorherige Abzahlung von Schulden bestimmt.

Die wirtschaftlichen Privilegien bestanden in den konkreten Ansiedlungsbedingungen. Dazu gehörte zunächst einmal die vollständige Vorfinanzierung der Etablierung

- durch Übernahme der Reise- und Zehrungskosten (Art. 2 und Art. 3) und

- der Grundausstattung der Haushalte mit Nahrungsmitteln (Roggen, Bier und Salz; Art. 13).

Hinzu kamen

- der preisgünstige Erwerb von Vieh und Hofinventar nach Ansuchen (Art. 4),

- die Freijahrsregelungen für noch zu rodendes Acker- und Wiesenland für 6 Jahre (Art. 5) bzw. für alle Lasten und Abgaben (... von allen oneribus, Sie haben Nahmen wie sie wollen,

200 Im Unterschied zum Arrendevertrag mit den Schweizer Kolonisten im Golmer Bruch stellten die verschiedenen, in den Jahren 1651/52 mit holländischen Kolonisten abgeschlossenen Arrendeverträge konkrete Ausformungen der von Otto von Grote (Hauptmann von Tangermünde, später Amtskammerrat) angestoßenen und von Kurfürst Friedrich Wilhelm vehement aufgegriffenen Reformabsichten dar, die überholte administrierte Domänenwirtschaft in Kurbrandenburg in eine zeitgemäße Pacht- und Geldwirtschaft umzuwandeln. Ämter, Vorwerke, Höfe und sogar Einzelstücke sollten verpachtet werden und dem Staat sichere Einnahmen einbringen. Auf dieser Finanzbasis sollte die Rückeinlösung verpfändeter Ämter (Reluisation) in Aussicht genommen, aber auch überflüssige Beamtenstellen eingespart werden. Diese Finanzreform scheiterte wegen Kapitalmangels im Lande, einer inkonsequenten Durchführung, einer geringen Autorität der Zentralverwaltung und des unterschätzten passiven Widerstands der unteren und mittleren Beamten. Erst die Denkschrift von Dodo von Knyphausen über die Reorganisation der Kammerverwaltung vom 13.02.1689 hat letztlich zur Annahme des Arrendesystem in Kurbrandenburg geführt [Breysig, Kurt: Geschichte der brandenburgischen Finanzen in der Zeit von 1640 bis 1697, Leipzig (1895), S. 246 ff., bes. S. 268, 285, 404ff.]. Der Arrendevertrag mit den Schweizer Kolonisten im Golmer Bruch war vielleicht in diesen Reformbestrebungen involviert.

201 StA Bern: A.V. 19. Teutschland-Buch Preussen-Brandenburg, fol. 52. (Art. 6): Sollen diese güter Ihnen Erbundt Eigenthümlich gegen eine gewißen Zinß undt eine so Leidentliche Recognition eingeräumet werden, daß sie damit Vergnüget und zu frieden seyn werden.

202 Als Nachkomme einer Schweizer Kolonistenfamilie gibt Dortschy die Auswanderungsgründe seiner Vorfahren mit verlockendem Angebot des Kurfürsten, Mangel an Ackerfläche und Weide in der Heimat sowie Familienzwist an [Dortschy, Jochen: Die Geschichte der Familie Dortschy, Frankfurt a. M. (2007), Anm. 54 (im Besitz des Autors)].

203 Die Schweizer Kolonisten hatten ein „freies Abzugsrecht“. 
auch so noch künfftige erdacht werden möchten ...) für 30 Jahre mit der Option einer Verlängerung (Art. 9),

- die kostenlose Zuweisung von Bau- und Brennholz aus der Lienewitzer Forst bei Caputh (Art. 15) $)^{204}$ und

- das Recht auf der Havel zu fischen (Art. 16).

Das ihnen überlassene Land sowie die ihnen auf Ansuchen gegebene Saat und das Vieh konnten sie sofort käufflich an sich bringen oder hierfür iärlich Zinsen zahlen. ${ }^{205}$ Derartige Privilegien sind in deutlich abgespeckter Form auch in den mit anderen Kolonisten oder einheimischen Bauern abgeschlossenen Arrendeverträgen zu finden, wogegen der Artikel 1 dieses Vertrages als eine Ausnahme anzusehen ist. Der Kurfürst versprach darin, allen Schaden, so durch Überschwemmung des Waßers an den Ländereyen zu befürchten, wieder [zu] erstatten. Im gleichen Atemzug (Art. 1 Satz 2) wurden die künftigen Kolonisten in die Pflicht genommen, daß ein ieder bey dem übergebenen Land auch allen Fleiß anwende, damit solches nicht allein verbeßert, sondern auch mit graben und wie es sonst die Nothdurff erforderst, conserviret, und aller Schaden nach Möglichkeit verhütet werde. Vage bleiben die Bestimmungen, was im Falle von Auftreten von Wirtschaftsschäden geschehen sollte. In dieser Beziehung wurde nur die Problematik der „gesundheitlichen Gewährleistung“ des gelieferten Viehs (Art. 4) geregelt - eine Rückgabe von (kranken) Tieren wurde ausgeschlossen; selbst die Problematik des Gemein Viehsterbens, die für Viehzüchter von existentieller Bedeutung sein kann, sollte erst im Falle des Auftretens einer Tierseuche geregelt werden. Völlig vergeblich sucht man im Arrendevertrag nach Regelungen bei Brand, Raub, Krieg, Sturmwind, Blitzschlag, Missernten, Hagelschlag und dergleichen.

Darüber hinaus regelte der Arrendevertrag eine Reihe von personellen Fragen. Nach Artikel 7 sollten die Kolonisten aus ihrer Mitte einen Schulzen wählen, dem neben den üblichen dorfpolizeilichen Aufgaben gleichberechtigt mit dem Amtmann von Potsdam die Inspektion darüber aufgetragen wurde, die Brücken, Graben und Dämme im Golmer Bruch in gutem Stande [zu] erhalten. ${ }^{206}$ In Artikel 8 wurde den Schweizer Kolonisten im Golmer Bruch ein reformierter Prediger aus ihrer Berner Heimat zugestanden. Damit begründete Kurfürst Friedrich Wilhelm eine Rechtspraxis, die auch für die 1690/1691 im Ruppiner Land angesiedelten Schweizer Kolonisten zum Muster wurde. Praktisch verzichtete damit der ansonsten auf die strikte Wahrung des landesherrlichen Kirchenregiments bedachte Kurfürst - ohne erkennbare Notwendigkeit oder äußeren Druck - auf das „Ius praesentandi“ zugunsten des Magistrats von Bern. ${ }^{207}$ Diese einmalige Position ermöglichte dem Rat der Stadt Bern Interzessionen in die inneren Angelegenheiten der Schweizer Gemeinde. Erst König Friedrich Wilhelm I. beseitigte schrittweise diese Praxis und setzte damit seine Vorstellungen von zentralisierter Verwaltung und persönlichem Kirchenregiment durch. Der Prediger erhielt aus dero Amt Pot-

204 Sie hatten damit kein Stamm- und Pflanzgehalt zu zahlen.

205 Für Rinder und Pferde (Art. 5) wurde er mit $5 \%$ festgelegt; beim Boden (Art. 6) ist nur von einem gewißen Zehend oder Grundzins die Rede.

$206 \mathrm{Ihm}$ wollte der Kurfürst iärlich einen neuen Rock oder Mantell geben (Art. 21).

207 Stellenbesetzungsrecht als Teil des landesherrlichen Patronats. 
stam Zwey Hundert thaler zum iärliche Salario und eine freie Wohnung in Potsdam, so lange die Pfarr Wohnung in dem Bruche nicht fertig war. Dem Prediger (Art. 8 Satz 3) wurde vergönnet Eltiste und ehrbahre Männer zu erwehlen, welche nebst ihm dahin sehen sollten, damit gute Kirchen Ordnung und Disciplin gehalten werde. ${ }^{208}$ Für Kurbrandenburg ungewöhnlich war die Bestellung eines Schulmeisters (Art. 8 Satz 4), an dessen jährlichen Bezahlung sich der Kurfürst mit 20 Thalern beteiligte. Das war kein ausreichendes Gehalt, so dass die 14 Schweizer Familien aufgefordert wurden, zur desto beßerer Unterhaltung des ... Schulmeisters hiernegst auch etwas beyzutragen. Auf diese Weise sollte ebenfalls das Gehalt des Predigers aufgestockt werden. Der vorgesehene Krug auf Kosten des Kurfürsten (Art. 10) ist nie zustande gekommen.

Die erbrechtlichen Bestimmungen wurden in den Artikeln 17 bis 20 geregelt. Im Einzelnen handelte es sich um die Handhabung der Weiterführung der Höfe beim Tode des Hauß Vater[s] (Art. 17), die Beachtung des testierten letzten Willens (Art. 18), die Übernahme der Höfe bei Aussterben der Familie (kein männlicher Nachkomme, Art. 19) und das Einheiraten Einheimischer in Schweizer Höfe (Art. 20). Letzteres wurde ausdrücklich gestattet, um die meistbietende Versteigerung ihrer Höfe durch frömde, so nicht ihrer nation angehören, zu verhindern. Trotzdem ist dies 1715 beim Vorwerk Gallin durch den Landrat Hans Wilhelm von Rochow auf Plessow geschehen.

Wenig beachtet wurde bislang, dass auf den Arrendevertrag für die Schweizer Kolonisten in einem anderen, sehr bekannten Ansiedlungsdokument der hohenzollernschen Repeuplierungspolitik direkt Bezug genommen wurde. Auf die Revokation des Edikts von Nantes aus dem Jahre 1598 durch König Ludwig XIV. erließ Kurfürst Friedrich Wilhelm am 29. Oktober 1685 das „Edikt von Potsdam ${ }^{\text {“209 }}$ und lud damit die in Frankreich verfolgten reformierten Glaubensgenossen ein, nach Kurbrandenburg zu kommen. Es richtete sich zwar vornehmlich an hochspezialisierte Handwerker, Gewerbetreibende und Manufakturisten („Professionalisten") sowie Offiziere und Adelige, enthielt aber in Artikel 9 auch ein Angebot zur Etablierung von Réfugiés auf dem Lande. Es sollte in der gleichen Form bestehen, wie es mit verschiedenen Familien, so sich aus der Schweiz in Unsere Lande begeben und darinnen niedergelassen, bis anhero gehalten worden. Offensichtlich sollten die ländlichen Réfugiés und die Schweizer Kolonisten gleich privilegiert werden. Das Edikt von Potsdamer unterschied sich aber in einem wesentlichen Punkt von anderen Ansiedlungsverträgen. Die dort gewährten Privilegien galten für alle Hugenotten, die wegen Glaubensverfolgung nach Kurbrandenburg kamen - auch wenn sie bereits vor Publikation des Ediktes ins Land gekommen waren (Art. 13, Satz 1). Man könnte sagen, dass die Ansiedlung der Schweizer Kolonisten 1685 im Golmer Bruch am Beginn einer neuen, für die hohenzollernsche Besiedlungspolitik geschichtlich bedeutsamen Epoche standen - sie gewissermaßen einläuteten.

208 Nach der apostolischen Gemeindeverfassung werden seit jeher in den reformierten Kirchen den Geistlichen angesehene Laien zur Wahrung der Kirchenzucht und zur Leitung der äußeren Gemeindeangelegenheiten beigegeben, sog. Presbyterium (griech., presbýteros).

209 Der genaue Titel lautet: Titel „Chur-Brandenburgisches Edict, Betreffend Diejenige Rechte, Privilegia und andere Wolthaten, welche Se. Churf. Durchl. zu Brandenburg denen Evangelisch-Reformirten Frantzösischer Nation, so sich in Ihren Landen niederlassen werden daselbst zu verstatten gnädigst entschlossen seyn". 


\section{Die Besiedlung des Golmer Bruchs mit Schweizer Kolonisten}

Kurioserweise hat der Ansiedlungsvertrag Anfang des 20. Jahrhunderts noch einmal eine Rolle gespielt. Der Rechtsstreit über die Fischereirechte des Erbkolonisten Mauerhoff wurde im Jahre 1927 auf der Grundlage des Artikels 16 des Ansiedlungsvertrages entschieden ${ }^{210}$. Der Antrag der Kietzer Fischereiinnung zu Potsdam auf Eintragung der Fischereirechte wurde mit der Begründung abgelehnt: Das einzige historische Zeugnis, daß wir über die Fischereiberechtigungen der zu Nattwerder angesiedelten Schweizer Erbkolonisten besitzen, ist der $\$ 16$ aus dem Vertrage von 1685. ${ }^{211}$ Damit folgte das Amtsgericht dem von dem Fischereihistoriker Friedrich Bestehorn eingeholten Gutachten, das auch in einem weiteren Punkt interessant ist. ${ }^{212}$ Er problematisierte die im $\$ 16$ enthaltene Formulierung, ... wie sie denn auch in den Gräben hinter ihren Häusern sich Fische halten und selbige vorzüglich geniessen mögen, und kam zu dem Schluss, dass damit nicht die Abzugsgräben des Golmer Bruchs in die Wublitz gemeint waren, sondern die zu dieser Zeit zwischen den Häusern und der Wublitz bestehenden künstlich angelegten Gräben, die zum Hältern von Fischen genutzt werden konnten. Darin habe die eigentliche Attraktivität der den Schweizer Kolonisten gewährten Fischereigerechtigkeiten gelegen, nicht in der Berechtigung auf der Wublitz zu angeln. ${ }^{213}$ Wo diese Bruchwehre gestanden haben, hat der Technische Regierungs-Inspektor Ehmer in einer Zeichnung vom 10. Mai 1924 zu rekonstruieren versucht. ${ }^{214}$

Davor hat es schon einmal im 19. Jahrhundert den Versuch gegeben, auf der Grundlage des längst ungültigen Arrendevertrages, mit Bezug auf dessen Artikel 1, Schadensersatzansprüche zu stellen. ${ }^{215}$ Die Überschwemmungen im Jahre 1868 veranlassten, Friedrich Mauerhoff (derzeitiger Erbpächter in Nattwerder), sich an die Regierung in Potsdam zu wenden: ... durch das hohe Wasser ist ein an der Wublitz belegenes Ackerstück von etwa einen Morgen groß dewastirt worden, so daß ich der Erndte verlustig gehe und gestatte ich mir daher, gestützt auf ... den Vertrag von 1685 ... bei Einer Königlichen hochlöblichen Regierung [...] die Bitte [...], mir eine Entschädigung gewähren zu möge[n]. Den erlittenen Schaden rechnete er detailliert in Summa mit 38 Talern vor. Auf dieses Gesuch antwortete die Regierung lapidar mit der Feststellung, dass für den angeblich erwachsenen Schaden diesseits keine Folge gegeben werden kann. Bemerkenswerter ist der im Konzept durchgestrichene Satz: Von der Urkunde, auf welche Sie Sich berufen, ist hier Nichts bekannt. ${ }^{216}$

210 Direkter männlicher Nachkomme des 1685 eingewanderten Isaac Murhoffer in 10. Generation.

211 BLHA, Rep. 31A Bezirksausschuss/Bezirksverwaltungsgericht Potsdam Nr. 3511, Blatt 12.

212 StA Potsdam: 1-12/46, S. 11.

213 In der Verhandlung am 21. Juni 1692 im Amt Bornstedt haben allerdings die Kolonisten zu Protokoll gegeben, die fischerey können sie nicht nutzen, weil die Graben iährlich bis auff dem grunde aus frühren [einfrieren] [BLHA, Rep. 2 Kurmärkische Kriegs- und. Domänenkammer Nr. D 15409, fol. 13].

214 BLHA, Rep. 31A Bezirksausschuss/Bezirksverwaltung Potsdam Nr. 3511 (Zeichnung vom 10. Mai 1924).

215 BLHA, Rep. 2A Regierung Potsdam III D Nr. 14999 (nicht paginiert), Schr. von F. Mauerhoff vom 15. Juni 1868 an die Regierung Potsdam.

216 daselbst: Schr. der Regierung Potsdam vom 29. Juni 1868. 


\section{Die Siedlungen der Schweizer Kolonisten im Golmer Bruch vom Ende des 17. bis zum Ende des 19. Jahrhunderts}

\section{Schwieriger Anfang im Golmer Bruch und auf dem Gallin - eine Fehlentscheidung}

Die Berichte Albrecht Bauernkönigs an den Rat der Stadt Bern dürften die bei der Ankunft der Schweizer Kolonisten im Golmer Bruch vorgefundene Situation authentisch schildern. Am 27. Juni 1685 schreibt er: Im Kontrast zum Vorjahr, wo erst 4 Häuser fertig waren, sind weitere 2 ganz aufgerichtet und fertig; ${ }^{217}$ bei zwei weiteren ist der Innenausbau noch nicht fertig, so dass sie noch nicht bewohnt werden können. $\mathrm{Zu}$ den übrigen Häusern liegt das Holz auf dem Platz und wiert taglich stark daran gearbeitet. Dieser Darstellung Bauernkönigs lässt sich allerdings der genaue Ansiedlungsort der Kolonisten im Golmer Bruch nicht entnehmen. Ausgehend von den natürlichen Gegebenheiten kamen dafür eigentlich nur zwei Stellen in Frage - die Espenhörste am Mitteldamm oder der etwa $3 \mathrm{~m}$ aus dem Golmer Bruch herausragende geologische Stock aus dem Diluvium ${ }^{218}$ direkt an der Wublitz -, der auf der Karte von Suchodoletz mit Natte Werder bezeichnet wird (s. Abb. 2). Bauernkönig berichtete am 11. Oktober 1685 nach Bern, dass Kurfürst Friedrich Wilhelm am 6. Oktober 1684 in den Golmer Bruch gekommen war, um sich selbst ein Bild von der dortigen Situation, der Windmühle und den erbauten Häusern zu machen. Er bemerkte einen Hügel und sagte: auf diesen kleinen Hügel [...] da will ich die Kirch und des Prediger Haus hinsetzen lassen. ${ }^{219}$ Diese Idee ist erst viel später zum Tragen gekommen (s. Kap. VI.1.), aber die Äußerung lässt die Schlussfolgerung zu, dass die ersten Häuser für die Schweizer Kolonisten nicht auf dem Natte Werder, sondern auf den Espenhörsten auf dem Mitteldamm (s. Abb. 2) erbaut worden sind. Erhärtet wird diese Meinung durch das Suplik der Schweizer Kolonisten im Jahre 1695 an Kurfürst Friedrich III. (s. Anhang 10)

Der Name bedeutet „niedrige, nasse Insel“ zum Unterschiede zu dem Gohlwerder, der jenseits der Wublitz liegt und dessen Name „hochgelegene Insel“ bedeutet.

Bauernkönig berichtete davor von seinem Besuch im Golmer Bruch am 19. Juni 1685, dass die Kolonistenfamilien sich selbst - theils durch daß Losß, theils freiwillig - auf die vorhande-

217 Die Grundrisse der Häuser kennen wir aus späteren Separationsakten (BLHA: Rep. 2A Kurmärkische Kriegs- und Domänenamt Nr. D 15007, fol. 54.). Es waren kombinierte Wohnstallhäuser.

218 eine Diluvialsandinsel, die ca. $3000 \mathrm{~m}^{2}$ groß ist [Iwan, Walter: Das Golmer Luch, BERLINER GEOGRAPHISCHE ARBEITEN, Heft 18, Stuttgart (1939), S. 32.]. Boege ist der Meinung, dass der Name Nattwerder nicht nur „nass“ impliziert, sondern in Beziehung zum jenseits der Wublitz liegenden Gohlwerder steht (s. Abb. 2). Nachweisbar bis ins 17. Jahrhundert wurde mit Nattwerder die „niedrige, nasse Insel“, dagegen mit Gohlwerder die „hochgelegene Insel“ bezeichnet. [Boege Hermann: Die Wublitz und ihr Tal. in Beilage der Postdamer Tageszeitung Nr. 54 vom 03.03.1928].

219 StA Bern: A. V. 19. Teutschland-Buch Preussen-Brandenburg fol. 79. 
nen Häuser aufgeteilt hätten. ${ }^{220}$ Sie seien vom Amt Potsdam inzwischen reichlich mit Lebensmitteln wie Salz, Fleisch, Brot usw. versorgt worden. Um sich nicht mit deren Verteilung aufhalten zu müssen, wurden von ihm und dem Amtsschreiber des Amtes Potsdam Hans Bilang von Gürtzelen zum Schulzen ${ }^{221}$ und Peter Schweingruber auf der Kilchheri Rüggisberg zum Krugwirt der Schweizer Kolonistengemeinde ernannt. Herr v. Lüderitz als Oberbefehlshaber habe später diese Entscheidung confirmirt. 222

In dem letzten Bericht vor seiner Abreise (am 29. September 1685) konnte Bauernkönig dem Rat der Stadt Bern melden, dass das letzte Haus aufgerichtet sei. Bei welchem dem Emanuel Turtschi von Tiracher ein großes unglück begegnet, in dem ihme ein Balcken auf daß Haupt gefallen und ihme ser übel zu gerichtet; es hat sich aber Gott Lob so weit mit ihme gebesßert, daß er ausßer der gefahr und guete Hofnung zu einer volkommenen Cur vorhanden, ... ${ }^{223}$

Die Kolonisten begannen sich im fremden Land einzurichten. Vordergründig mussten ihre Wirtschaften in Gang gebracht werden. Das Amt Potsdam stellte Vieh (insgesamt 23 Pferde, 19 Zugochsen, 71 Kühe, 47 Jungrinder, 31 Schweine und diverses Federvieh, ${ }^{224}$ aber auch Wagen, Pflüge, Äxte und drgl. zur Verfügung. Diese Hofwehr [Hofausstattung] wurde den einzelnen Kolonistenfamilien auf Verlangen entsprechend ihren Wünschen und Vorstellungen gemäß Artikel 4 des Arrendevertrages von 1685 (s. Anhang 4) gegen sofortige Zahlung oder spätere Abzahlung zu $5 \%$ Zinsen jährlich zur Verfügung gestellt, wie dies Tabelle 3 exemplarisch für die vier Schweizer Kolonisten von Nattwerder zeigt. Die Grundlage hierfür stellen die Berechnungstabellen („Inventar“) dar, die vor Abschluss des Anschlusskontraktes im Jahre 1716 vom Amt Potsdam über bereits erfolgte und noch ausstehende Abzahlungen aufgestellt wurden. ${ }^{225}$

Aus der Tabelle 3 geht eindeutig hervor, dass ihre Viehbestände mit 5-7 Kühen und entsprechender Nachzucht in erster Linie auf Milchproduktion ausgerichtet waren. Schweine und Geflügel wurden dagegen lediglich für den Eigenbedarf gehalten. Als Zugvieh standen je ein Pferd und ein Zugochse zur Verfügung. Das Fohlen wurde als über Jährig beschrieben. Dagegen fehlten Schafe gänzlich. In den Berechnungstabellen war auch die Herkunft der Tiere vermerkt, nämlich aus dem Vorwerck Gollm (obere Zeile in der Tab. 3) und aus der Meyerey Gollm (untere Zeile in der Tab. 3). Das außerdem in der Quelle angegebene Exterieur (fahle, rote bzw. schwarze Kuh) lässt den Schluss zu, dass die Tiere aus unterschiedlichen Gegenden stammten und ursprünglich möglicherweise mit züchterischen Absichten angeschafft waren. $^{226}$

220 Die Anzahl der Häuser wird nicht genannt.

221 StA Bern: A. V. 19. Teutschland-Buch Preussen-Brandenburg fol. 122.: wor Zu ich ihme gewis vor den Düchtigsten gefunden, ...

222 daselbst: fol. 122.

223 daselbst: fol. 140.

224 BLHA, Rep. 2 Kurmärkische Kriegs- und Domänenkammer Nr. D 15409, fol. 4/5.

225 BLHA, Rep. 7 Amt Potsdam Nr. 611/1, fol. 5a-9a.

226 Der Begriff Rasse im heutigen Sinne kam erst später auf. 
1. Schwieriger Anfang im Golmer Bruch und auf dem Gallin - eine Fehlentscheidung

Tab. 3: Die lebende Hofausstattung, die die Kolonisten von Nattwerder Zeidt dero hierseyens von der Königl. Herrschaft zur Verfügung gestellt bekommen hatten

\begin{tabular}{|c|c|c|c|c|c|c|c|c|c|c|c|}
\hline \multirow[t]{2}{*}{ Kolonist } & \multicolumn{5}{|c|}{ Rinder } & \multicolumn{2}{|c|}{ Pferde } & \multirow[t]{2}{*}{ Schweine } & \multicolumn{3}{|c|}{ Geflügel***** } \\
\hline & Kälb & irse & üh & hs & tier & hle & $1 \sigma^{*} * * * *$ & & Hühner & Enten & Gänse \\
\hline \multirow{2}{*}{$\begin{array}{l}\text { Hans } \\
\text { Stucky }\end{array}$} & & 2 & 5 & 1 & & & & & & & \\
\hline & & & 1 & 1 & 1 & & $1 / 0$ & 4 & $6 / 12$ & $12 / 12$ & $2 / 5$ \\
\hline \multirow{3}{*}{$\begin{array}{l}\text { Melchior } \\
\text { Suter* }\end{array}$} & & 2 & 6 & 2 & 1 & & $1 / 0$ & 4 & $6 / 12$ & $12 / 12$ & $2 / 5$ \\
\hline & & 4 & 4 & & & & & & & & \\
\hline & 1 & 3 & 2 & 1 & & & $\mathbf{0} / \mathbf{1}$ & 3 & $4 / 3$ & & \\
\hline \multirow{3}{*}{$\begin{array}{l}\text { Jacob } \\
\text { Jerig** }^{* *}\end{array}$} & 1 & 7 & 6 & 1 & & & $0 / 1$ & 3 & $4 / 3$ & & \\
\hline & & 3 & 4 & 1 & & & & & & & \\
\hline & & & 1 & & 1 & & $0 / 1$ & 2 & $4 / 3$ & & $4 / 1$ \\
\hline \multirow{4}{*}{$\begin{array}{l}\text { Hans } \\
\text { Wintzeridt }{ }^{* * *}\end{array}$} & & 3 & 5 & 1 & 1 & & $0 / 1$ & 2 & $4 / 3$ & & $4 / 1$ \\
\hline & & 2 & 5 & & & & & & & & \\
\hline & & 2 & 2 & 1 & 1 & 1 & & 2 & $3 / 2$ & & $2 / 1$ \\
\hline & & 4 & 7 & 1 & 1 & 1 & & 2 & $3 / 2$ & & $2 / 1$ \\
\hline \multicolumn{8}{|c|}{$\begin{array}{l}\text { * Sohn des eingewanderten Samuel Suter } \\
\text { ** Jacob Gerig }\end{array}$} & \multicolumn{4}{|c|}{$\begin{array}{l}* * * * \text { ○/ठ = Stute/Wallach } \\
* * * * * \text { junge/alte Tiere }\end{array}$} \\
\hline
\end{tabular}

Auch Hausgeräthe wurden ihnen gegen sofortige Zahlung oder spätere Abzahlung einschließlich $5 \%$ Zinsen zur Verfügung gestellt, wobei der Begriff „Hausgeräte“ im heutigen Sinne nicht mehr zutrifft und durch "Arbeitsgerätschaften“ ersetzt werden müsste. Tabelle 4 zeigt dies exemplarisch für die vier Schweizer Kolonisten von Nattwerder. Die Grundlage hierfür stellen wieder die bereits oben erwähnten Berechnungstabellen („Inventar“) aus dem Jahre 1716 dar, die vor Abschluss des Anschlusskontraktes aufgestellt wurden. ${ }^{227}$ Mit einem Ochsenjoch statteten sich alle Familien aus. Darüber hinaus ist auffällig, dass sich immer zwei Familien die wichtigsten Ackergeräte wie zum Beispiel Pflüge und Wagen teilten. Ist dies aus Sparsamkeitsgründen geschehen? Oder hielt man einen eigenen Pflug wegen der gering bemessenen Ackerflächen nicht für nötig? Den eigentlichen Hausrat besorgten sich die Schweizer Kolonisten selbst auf dem Markt in Potsdam und sorgten dabei mit ihren großen Degen an der Seite, ihren langen Bärten und ungewöhnlichen Hüten für Aufsehen. ${ }^{228}$

Und schließlich bekamen die Kolonisten auf Verlangen Saatgut für die erste Aussaat aus dem Magazine zu Spandow bzw. vom Amte Potsdam gegen Natural- oder Gelderstattung gemäß Art. 11 des Arrendevertrages geliefert (s. Anhang 4). Den Umfang und die Art des Saatgutes gibt Tabelle 5 wieder. Typisch für die Zeit ist, dass Weizen als Nahrungsmittel noch keine Rolle spielte, dagegen Erbsen eine große Bedeutung zukam. Die auffallend unterschiedlichen 
Tab. 4: Die Hausgeräte, die die Kolonisten von Nattwerder Zeidt dero hierseyens von der Königl. Herrschaft zur Verfügung gestellt bekommen hatten ${ }^{229}$

\begin{tabular}{|c|c|c|c|c|}
\hline \multirow[t]{2}{*}{ Hausgeräte } & \multicolumn{4}{|c|}{ Kolonist } \\
\hline & Hans Stucky & Melchior Suter & Jacob Jerig & Hans Wintzeridt \\
\hline $\mathrm{Siel}^{230}$ & 1 & 1 & 1 (alt) & \\
\hline Geschirr & & 1 & & \\
\hline $\begin{array}{l}\text { Drei(spänner)ge- } \\
\text { schirr }\end{array}$ & 1 & & 1 & \\
\hline Ochsenjoch & 1 & 1 & 1 & 1 \\
\hline Halskopffel ${ }^{231}$ & & & & 1 \\
\hline Zaum aus Hanf & & 1 & & \\
\hline Pflug & $1 / 2$ & $1 / 2$ & $1 / 2$ & $1 / 2$ \\
\hline Leine & & 1 & & \\
\hline Mistforke & & 1 & & \\
\hline Eimer & & 1 & $1^{*}$ & 1 \\
\hline Sense & & & 1 & $2^{* *}$ \\
\hline Milchtubbe $^{232}$ & 3 & & & \\
\hline Schlitten & 1 & & & \\
\hline
\end{tabular}

Tab. 5: Die Aussaat, die die Kolonisten von Nattwerder Zeidt dero hierseyens von der Königl. Herrschaft zur Verfügung gestellt bekommen hatten ${ }^{233}$

\begin{tabular}{lcccc}
\hline \multirow{2}{*}{ Aussaat } & \multicolumn{4}{c}{ Kolonist } \\
\cline { 2 - 5 } & Hans Stucky & Melchior Suter & Jacob Jerig & Hans Wintzeridt \\
\hline Roggen & 16 Schffl & 1 Wsp 6 Schffl & 16 Schffl & 4 Schffl \\
\hline Gerste & 3 Schffl & 4 Schffl & 3 Schffl & 1 Schffl \\
\hline Hafer & 3 Schffl & 2 Schffl & 2 Schffl & 3 Schffl \\
\hline Erbsen & $4 \mathrm{Mtz}$ & $4 \mathrm{Mtz}$ & \\
\hline
\end{tabular}

Mengen korrespondieren mit der jeweiligen Familiengröße. Familie Suter hatte acht Kinder, dagegen reiste Hans Wintzeridt als Einzelperson ein.

229 BLHA, Rep. 7 Amt Potsdam Nr. 611/1, fol. 5a-9a.

230 breiter Brustriemen beim Sielengeschirr.

231 „Halskoppel“, breiter Riemen um den Hals der Pferdes, der mit einer Kette mit der Deichselspitze verbunden ist und zum Aufhalten und Lenken des Wagens dient, Brandenburg-Berlinisches Wörterbuch, Bd. II, Neumünster (1985), Kolumne 489.

232 hölzerner Kübel; Brandenburg-Berlinisches Wörterbuch, Bd. IV, Berlin (2001), Kolumne 501.

233 BLHA, Rep. 7 Amt Potsdam Nr. 611/1, fol. 5a-9a. 
Der vom Kurfürsten bestellte Landmesser und der Amtsschreiber von Potsdam teilte den Golmer Bruch in einzelne Kaveln ${ }^{234}$ unter den Kolonisten auf, wie das in Abbildung 4 zu sehen ist. Daneben blieb ein Teil der Wiesen einer gemeinsamen Hütung vorbehalten. Das Gras wurde gemäht, um daraus Heu für den kommenden Winter zu machen. Aber etwa die Hälfte der ihnen zugedachten Wiesenflächen musste noch von Buschwerk, Weiden, Birken und Stubben befreit werden, eine besonders harte Arbeit bei den nassen Böden. Bauernkönig teilt dem Magistrat von Bern verwundert mit, waß vor arbeit die Leüte schon in denen Wiesen gethan und wie dieser große weite von denenselben ist zu Recht gemacht, wan nur müglich Ackerland zu Bekommen. ${ }^{235}$ Bei diesen Rodungsarbeiten stellten die Schweizer allerdings fest, dass das Bruchland für Ackerbau nicht geeignet war. Das gute Ackerland am Rande des Bruchs befand sich bereits im Besitz der einheimischen Bauern von Bornstedt, Golm und Leest. Deshalb durften sie sich nach dem Bericht Bauernkönigs vom 29. September 1685 unter dem Berg eine ziemliche Weite abstecken. ${ }^{236}$ Sie versprachen sich dort besonders gutes Land.

Im Oktober 1685 trafen weitere drei Schweizer Familien (insgesamt 22 Personen) ein: Isaac Murhoffer, Caspar Zobrist und Niclaus Schweingruber, der Sohn Peter Schweingrubers. Da alles Land bereits aufgeteilt war, wurden ihnen auf dem Gallin drei Häuser als Unterkunft gebaut. ${ }^{237}$ Mit ihnen war die Kolonie auf 17 Schweizer Familien angewachsen, die nun auf zwei Orte verteilt, auf dem Gallin und im Bruche, lebten. Albrecht Bauernkönig reiste Ende Oktober/Anfang November 1685 nach Bern zurück. ${ }^{238}$ Ein genaues Datum ist nicht bekannt.

Es hätte nun erwartet werden können, dass mit dieser Ausstattung und sonstigen getroffenen Maßnahmen alle Voraussetzungen für die vom Kurfürsten Friedrich Wilhelm geplante Schweizer Musterwirtschaft vorhanden waren. Die Kolonisten waren sich jedoch bald im Klaren darüber, dass sie schwere Arbeit zur Kultivierung des Golmer Bruchs zu leisten haben würden, und vor allem, dass ihre Arbeit in keinem rechten Verhältnis zum Erfolg stand. Im Vergleich zu den Randgemeinden des Golmer Bruchs (Bornstedt, Golm und Grube) hatten sie ein ungünstiges Los getroffen. Sie wurden mit über 100 Personen auf einem sehr beschränkten Wirtschaftsraum angesetzt, mitten in einem schwer zu entwässerndem Gebiet, das von der Havel häufig überschwemmt wurde. Die damaligen technischen Möglichkeiten zur Entwässerung waren unzureichend. Und so kam es, wie es die allte leüthe vorhergesagt hatten, im Jahre 1689 nach verhältnismäßig trockenen Jahren zu einem Jahrhunderthochwasser. Wie schwierig die Situation damals gewesen ist, beschrieb der zweite Prediger der reformierten Gemeinde Golmer Bruch, Sigismund Lupichius, in seinem Schreiben vom

234 streifenförmige Felder, Landlose.

235 StA Bern: A.V. 19. Teutschland-Buch Preussen-Brandenburg fol. 140.

236 daselbst.

237 Lange, Julius: Das Vorwerk Gallin, Zur Geschichte des Potsdamer Schlächtergewerks, in: Verein für die Geschichte Potsdams NF. 1. Theil (1875), S. 376-401, bes. S. 381-382; Klinski-Wetzel, Marianne von: Wildpark West an der Havel, Potsdam (Wildpark West), (2007), S. 145.

238 StA Bern: A.V. Teutschland-Buch Preussen-Brandenburg fol. 154. 
11. April 1713 an den Kammerpräsidenten v. Görne ${ }^{239}$ (s. Anhang 14). Die Dämme hatten den Wassermassen nicht standgehalten, und der Golmer Bruch war praktisch abgesoffen. Das war nicht verwunderlich, denn die Dämme waren ohne festen Grund nur mit loser Brucherde aufgeworfen und von den Wassermassen hinweggespült worden. Die unter Kapitel III.3. und IV.3. erwähnte Poldermühle war schon lange nicht mehr vom Amt unterhalten worden und im Golmer Bruch versunken. Kurfürstin Dorothea kam expresse von Potstam herausgefahren und konnte sich auch der Thränen nicht enthalten, als sie die für die Schweizer gebauten Häuser sah, die im Wasser standen und nicht anderß als mit Kahnen erreicht werden konnten. Damit war praktisch alles, was die Schweizer Kolonisten bis dahin zur Erhaltung der Dämme und des Golmer Bruchs getan hatten, mit einem Schlage - einschließlich ihrer dabei eingebrachten finanziellen Mittel - vernichtet.

In der Literatur ging man bislang davon aus, dass mit dem Tod von Kurfürst Friedrich Wilhelm am 6. Mai 1688 das Schicksal der Schweizer Kolonisten besiegelt worden sei. Unzweifelhaft hatte er sie ins Land geholt, und sie waren sich Zeit seines Lebens seiner Protektion sicher gewesen. Mit der verzögerten Konfirmierung des Arrendevertrages 1691 durch Kurfürst Friedrich III. deutete sich diesbezüglich eine Änderung an. Was aber bislang in der Literatur völlig außer Betracht gelassen wurde, ist ihre finanzielle Situation. Mit der ihnen gestellten taxierten Ausstattung (Hofwehr, Arbeitsgeräte, Aussaat) ${ }^{240}$ hatten sie praktisch ein Darlehen aufgenommen, und dies musste zurückgezahlt werden. Auf den ersten Blick erscheint die Schuldlast, wie in Tabelle 6 exemplarisch an Hand der vier Schweizer Kolonisten in Nattwerder gezeigt, nicht sonderlich groß; aber die Rückzahlung geschah anfangs mit mehreren kleinen Raten, kam ins Stocken und dauerte bis 1729. Hieran wird deutlich, in welche elende Situation die Schweizer Kolonisten im Golmer Bruch geraten waren.

Tab. 6: Die finanzielle Situation der 4 Schweizer Kolonisten in Nattwerder

\begin{tabular}{lrrrrl}
\hline \multirow{2}{*}{ Kolonist } & \multicolumn{3}{c}{ Höhe des Darlehns } & \multicolumn{2}{l}{ letzte Rate für die Rückzahlung des Darlehns } \\
\cline { 2 - 4 } & Rthl & Sgr & d & \\
\hline Hans Stucky & 93 & 15 & - & 20.05 .1716 \\
\hline Melchior Suter & 107 & 12 & 6 & 05.10 .1729 \\
\hline Jacob Jerig & 87 & 218 & - & 14.06 .1725 \\
\hline Hans Wintzeridt & 73 & 8 & 2 & 21.08 .1726 \\
\hline
\end{tabular}

239 zur Person: Hans Friedrich Christoph Görne (1670-1745) wurde 1703 zum Hof- und Legationsrat ernannt, war von 1708-19 Präsident der kurmärkischen Amtskammer und erhielt ab da im Generalfinanzdirektorium die „Direction in oeconomicis“. [DBE,2. überarbeitete Ausgabe (2006) Bd. 3, S. 89-893]. Im Schreiben von Prediger Lupichius an den Rat der Stadt Bern vom 28. Juni 1713 wird er als Lutheraner bezeichnet, was mit „kein Unterstützer“ gleichzusetzen ist [StA Bern: A. V. 19 fol. 395-401, bes. fol. 396.].

240 Daneben hatten sie auch untaxierte Gegenstände erhalten, zu denen nur jeweils bei den einzelnen Kolonisten bemerkt ist: Die übrigen nicht taxirte Stücke erstattet Er wie Er solche bekommen. 
Trotz aller dieser Schwierigkeiten verharrten die Schweizer zunächst weiter im Golmer Bruch, und nur ein einziger Schweizer Kolonist, Christian Hutmacher samt Weib und Kindern, ${ }^{241}$ machte von dem in Art. 12 des Arrendevertrages eingeräumten Recht - der Rückkehr in das Vaterland - Gebrauch. ${ }^{242}$ Hierzu war allerdings Voraussetzung, dass eingegangene Schulden zuvor beglichen sein mussten, was derselbe am 24. April 1688 aktenkundig getan hat: Christian Hutmacher, weile Er wieder nach der Schweitz zurück reyset, hat die 13 schl. Rogken, die Er empfangen, an den H: Schweitzer Prediger á 12 gr. mit $6 \frac{112}{2}$ thlr undt 8 gr. vor 1 schl. Gerste, so auf der andern seite stehet, bezahlet, so der $H$. Prediger an sich hat, undt wan Es begehret wirdt herau $\beta$ zugeben, erböthig ist. ${ }^{243}$ Er gab also seinen Anteil an den Prediger ab.

Im Zusammenhang mit der Unterbringung der später angekommenen drei Schweizer Kolonisten (Caspar Zobrist, Issak Murhofer und Peter Schweingruber) erwarb noch im Herbst 1685 der Kurfürst Friedrich Wilhelm auf dem Gallin von der Stadt Werder Land. Durch diesen Zukauf sollte der Mangel an Ackerland für die im Golmer Bruch angesiedelten Schweizer Kolonisten kompensiert werden. Der Golmer Bruch - ein Niedermoor - war mit seinen sauren Gräsern und Seggen nicht für Viehzucht sonderlich geeignet, geschweige denn zum Anbau von Getreide oder anderen Feldfrüchten als Nahrungsgrundlage für die Kolonisten. Das zur Verfügung gestellte Land auf dem Gallin ${ }^{244}$ wurde auf die 17 Schweizer Familien in einzelne Kaveln aufgeteilt. Für das Schicksal der Reformierten Gemeinde im Golmer Bruch spielen die Galliner Familien eine untergeordnete Rolle, die Lange (1875) bereits ausführlich beschrieb. ${ }^{245}$ Ergänzend soll deshalb nur zu dem dort Gesagten hinzugefügt werden, dass etwa um 1725 der Kontakt der Galliner Kolonisten zur Schweizer Kolonistengemeinde Golmer Bruch endgültig abbrach. Als Beleg hierfür können die Eintragungen im Kirchen-Buch der Schweizer Gemeinde im Bruch bei Potsdamb herangezogen werden: letzte Taufe am 1. Februar 1728 (Elisabeth Kiener), letzte Hochzeit 2. Mai 1719 (Hans Pfister/Maria Winkelmann) und letztes Begräbnis 13. März 1722 (Dorothea Pfister). Danach repräsentieren ausschließlich die in Golm (s. Kap. V.2.), Neu Töplitz (s. Kap. V.3.) und Nattwerder (s. Kap. V.4.) angesiedelten Kolonistenfamilien die Kirchengemeinde Golmer Bruch und sollen deshalb Gegenstand der weiteren Ausführungen sein.

241 Im Schreiben der sechs Schweizer Pächter des Vorwerks Golm an König Friedrich Wilhelm III. vom 18. Nov. 1790 [BLHA, Rep. 2 Kurmärkische Kriegs- und Domänenkammer Nr. D 15409 fol. 85R] ist von drei Familien die Rede, ohne dass Namen genannt werden.

242 KA Alt Töplitz: Kolonistenliste im Kirchenbuch Nattwerder (Vol. I, 1685-1801).

243 BLHA, Rep. 2 Kurmärkische Kriegs- und Domänenkammer Nr. D 15409, fol. 18/18R.

244 Damit ist das unbedeutende und sehr heruntergekommene Vorwerk Gallin gemeint, dass zum Amt Potsdam gehörte.

245 Lange, Julius: Das Vorwerk-Gallin; in: Mittheilungen des Vereins für die Geschichte Potsdams NF. 1. Theil (1875), S. 376-401, bes. 381-382; Klinski-Wetzel, Marianne von: Wildpark-West an der Havel, Potsdam (2007) übernimmt lediglich die dort gemachten Ausführungen. 


\section{Die Ansiedlung der Schweizer Kolonisten in Golm}

Das Jahr 1689 markierte einen Wendepunkt für das Schicksal der im Golmer Bruch angesiedelten Schweizer Kolonisten. Die näheren Umstände, die dazu geführt haben, dass die verwitwete Kurfürstin Dorothea Sophia ihr Leibgedinge, das Vorwerk Golm, pensionsweise den Schweizer Kolonisten zur Verfügung stellte, ließen sich nicht ermitteln. Die Initiative muss aber von den Schweizer Kolonisten ausgegangen sein, denn im Eingangsteil dieses Arrende Contracts vom 10. Juni 1689 wurde darauf abgehoben, dass sie bei der Kurfürstin vorstellig geworden seien, über ihre Not bezüglich des Erwerbs ausreichender Nahrung für die Ihrigen geklagt hätten und dahero demüthigst gebeten, Ihnen anderweit Äcker zuzulegen. [...] Wie sie dann auch zugleich in Vorschlag gebracht, daß ihnen das Vorwergk Gollm und was darzu gehörig, pensionsweise eingethan und übergeben werden möchte. ${ }^{246}$ Wegen der angeführten Motive und in erwegung Ihrer vielen Kinder willigte die Kurfürstin auf dieses Ansuchen ein. Einerseits wurde dieser Vertrag von der Kurfürstin eigenhändig und andererseits vom Prediger Albrecht Wyttenbach ${ }^{247}$, dem Schulzen Hans Bilang und dem Schulmeister Niclaus Hodler unterschrieben. Abgeschlossen wurde er mit allen 17 Kolonistenfamilien im Schweitzerbruche und auffen Gallien und galt von unten gesatzten dato an, so lange, al $\beta$ Sie sich alß Gehorsamme und getreüe Unterthanen verhalten werden. Ob sie damit Zeitpächter wurden, war bis zur Separation zwischen der Obrigkeit und den Schweizer Kolonisten umstritten. Die Kriegs- und Domänenkammer stufte sie als solche ein, wogegen sich die Kolonisten mit Hinweis auf den Arrendevertrag von 1685, so gut sie konnten, wehrten. ${ }^{248}$ Denn dies bedeutete eine deutliche Verschlechterung ihres Rechtsstatus, insbesondere drohte ihnen als Erbpächter keine Kündigung, falls sie ihre Pension nicht vertragsmäßig bezahlten. Aber es wurde mit diesem Ansiedlungsvertrag erreicht, dass sie zu den bisherigen Ländereien im Golmer Bruch und auf dem Gallin ein ganzes kurfürstliches Vorwerk zusätzlich zugeschlagen bekamen. ${ }^{249}$

Den Kolonistenfamilien stand das Vorwerk bis auf die drei Weinberge mit seinen Gebäuden und deren Inventar, Gärten, Äckern, Triften, Hütungen und landwirtschaftlichen Nutztieren uneingeschränkt zur Verfügung, wie es bißhero genutzet wurde. Das bedeutete, dass ihnen generell auch die bestehenden Verpflichtungen des Vorwerks übertragen wurden,

- die Gebäude in gutem Dach und Fach zu erhalten (\$3),

- die Nutzung der Triften und Hütungen auf dem Golmer Feld mit der Schäferei in Bornim und Bornstedt zu teilen $(\$ 5)$,

246 BLHA, Rep. 2 Kurmärkische Kriegs- und Domänenkammer Nr. D 15409, fol. $22-26$.

247 Die Schreibweise des Namens ist gelegentlich Wittenbach oder Weitenbach. Er selbst hat sich immer Wyttenbach geschrieben.

248 Nach dem Geheimen Kriegs- und Domänenrat Meinhart bestand nicht die Absicht, die Schweizer Kolonisten auf eine abänderliche Zeitpacht zu setzen, und der Kündigung zu unterwerfen, daher erhielten sie die ausdrückliche Versicherung, daß die Arrende so lange bestehen sollte, als sie als getreue Unterthanen sich verhalten und mit der Zahlung der Pacht continuiren würden. [BLHA, Rep. 2 Kurmärkische Kriegs- und Domänenkammer Nr. D 15409, fol. 47].

249 Insgesamt waren es 101 1/2 Morgen Acker, 228 1/4 Morgen Wiesen und 233 1/4 Morgen gemeinschaftliche Hütung. Dem Prediger standen für seine Bedürfnisse auf dem Gallin 3 Morgen Acker und 15 Morgen an Wiesen zur Verfügung. 
- dem Weinmeister Land für etwas Leinen, Hirse und Rüben zuzuteilen (\$ 6),

- dem Dorfhirten seinen Lohn zu entrichten (\$ 7$)$,

- das benöthigte Stroh zum Anheften des Weinholzes dem Weinmeister zu verabfolgen $(\$ 8)$,

- dem Pfarrer eine Dreißigste Mandel von allem Korn abzugeben (\$ 9) und

- den 8 Kossäten in Golm Land und 2 Scheffel Aussaat für ihre Nothdurfft zur Verfügung zu stellen $(\$ 10)$,

und darüber hinaus, dass sie sich mit den Einheimischen über die gemeinsamen Weiderechte [Allmende] zu einigen hatten.

Die bestellten Sommer- und Winterfelder wurden ihnen übergeben, mit der Option, im Fall der Vertragskündigung sie im gleichen Zustand zu hinterlassen. Die Weinberge, so bey Golm belegen, hatte sich die Kurfürstin für ihre eigenen Zwecke vorbehalten; sie verpflichtete darüber hinaus die Kolonisten, so lange Sie das Vorwergk in der Arrende haben werden, Jährlich 100. Fuhder guten Mist [...] zu den Senckgruben bey den Weinbergen zu liefern und anzufahren (\$ 4). Dem Vorwerk wurde damit praktisch viel organischer Dünger entzogen, was gravierende Auswirkungen auf die Erträge in den folgenden Jahrzehnten hatte.

Dem Arrendevertrag wurde eine vom Amt Potsdam vorgenommene Taxierung des Vorwerks - und zwar der Aussaat, des Viehbestandes und der Hausgeräte (u. a. Pflüge und Wagen) - angefügt, die sich für einen Einzelpächter auf insgesamt 222 thlr. 8 gr. und 2 d belief. ${ }^{250}$ Erstaunlicherweise hat die Kurfürstin diesen Pensionsbetrag heruntergesetzt und die jährliche Pacht für jede Familie auf nur 5 Rthl. - insgesamt 85 Rthl. - festgelegt. ${ }^{251}$ Sie war sich wohl im Klaren, dass diese 17 Familien bei einer derartig hohen Vorwerkspacht nicht hätten subsistieren können. Die Zahlung der Pacht sollte zur Hälfte auff nechstkommende Weynachten 1689 und die andere Helffte auf Trinitatis 1690 sowie in allen folgenden Jahren geschehen. Dafür wurden sie allerdings in „Gemeinschaftshaftung“ genommen: Die Pensionarii [versprachen] allesämblich, ein Jeder vor sich und die seinigen, wie solches obbeschriebener maßen verabredet, treülich zu stehen und zu bezahlen, Wie Sie dann alle Ihre Vermögen, so Sie alhier im Lande oder noch in der Schweitz haben, zum würcklichen und wahren Unterpfande setzen, und was Sie laut Inventarii an Haußgerath, Viehe, und anderen empfangen, nach geendigten Arrende Jahren hinwiederumb also ohne Abgang und Verringerung zu überliefern und abzutreten schuldig seyn. ${ }^{252}$ In einem weiteren Punkt war dieser Arrendevertrag bemerkenswert. Er enthielt keine Bestimmungen über die Holzgerechtigkeiten - ein wichtiger Aspekt in einer Zeit, wo Holz zunehmend teurer und knapper wurde. Aber es bedurfte auch dessen Erwähnung nicht, weil dies den Schweizern schon im Ansiedlungsvertrag vom 16. September 1685 zugesichert war und

250 BLHA, Rep. 2 Kurmärkische Kriegs- und Domänenkammer Nr. D 15409, fol. 28.

251 In der Entrichtung dieser mäßigen, aber beständigen Pension sah im Jahre 1801 das Amt Bornstedt den Beweis, dass es sich dabei nicht um einen Zeitpacht Contract, sondern um einen Contractus perpetuae Coloniae gehandelt habe [BLHA, Rep. 2 Kurmärkische Kriegs- und Domänenkammer Nr. D 15409, fol. 147.]. 
an diesem Vertrag keine Veränderung vorgenommen, sondern solcher nur durch die Beylegung des Vorwercks Golm vermehrt wurde. ${ }^{253}$

In Verbindung mit dem Arrende Contract wurde ein sehr detailliertes Inventarverzeichnis vom Meyerhauß [Wohnhaus], 2 geschoß hoch, von 15 Gebindt mit Ziegel gedeckt Gebäude, vom Hof und von drei unterschiedlich alten und großen (17, 9 bzw. 4 Gebinde), Rohr gedeckten Ställen und der Scheune (21 Gebinde) angefertigt, das von Prediger Wyttenbach und dem Schulzen Hans Bilang unterschrieben wurde. ${ }^{254}$ Wie daraus hervorgeht, war der bauliche Zustand des Vorwerkes, besonders des Wohnhauses, wohl nicht der allerbeste. Die Rede ist an mehreren Stellen von zerbrochenen Fenstern und vielen Dingen, so alt und nichtes wert. Aber man erhält dadurch ein sehr anschauliches Bild von den damaligen Arbeitsbedingungen und Lebensumständen in einem kleinen Vorwerk. Für die Kolonisten stellte das Vorwerk aber keinen Zugewinn an Wohnraum dar, ${ }^{255}$ und dies erklärt, was bisher in der Literatur völlig unbeachtet geblieben und für sich genommen unverständlich ist, dass die Schweizer Kolonisten vom Golmer Bruch sich 1695 an Kurfürst Friedrich III. mit einer Bittschrift wandten, zu verstatten, daß 7 familien von Ihnen wegen des Großen Waßers Ihre wohnungen [Häuser] nach dem Golm transportiren dürften ${ }^{25}$. Daraufhin befahl der Kurfürst Hofjägermeister von Pannewitz, Amtsrat Merian ${ }^{257}$ und Oberbaudirektor Nehring ${ }^{258}$, die Angelegenheit vor Ort zu untersuchen, den entstandenen Schaden in Augenschein zu nehmen und darüber zu berichten (s. Anhang 10). Das bedeutet, dass bis 1695 - abgesehen von vertraglichen Änderungen bzgl. des Vorwerks Neu Töplitz und Nattwerder - die Bewirtschaftung des Vorwerks Golm vom Golmer Bruch aus erfolgt ist.

Das Nachvollziehen der Abläufe in Golm selbst stößt auf Schwierigkeiten. Dies betrifft zunächst einmal die Ausgangssituation, aber auch die erfolgte Umstrukturierung ab 1695. Was zu dieser Zeit noch von den beiden von Kurfürst Friedrich Wilhelm im Jahre 1660 an der Straße nach Bornim gekauften, nebeneinander gelegenen Rittergütern und dem gegenüber gelegenen sogenannten Thümen'schen Gut vorhanden war, ließ sich nicht klären. ${ }^{259}$ Wann noch vorhandene Gebäude abgerissen wurden, ist ebenfalls nicht klar. E. v. Brandt ${ }^{260}$ Mitar-

253 daselbst: fol. 147.

254 daselbst: fol. 28R-30, nicht datiert.

255 Nach dem Gebäudeinventar im Jahre 1689 zu urteilen, war das Meyerhaus ein Mittelganghaus mit je einer Stube auf beiden Seiten plus einer Kammer und der Küche; über eine Treppe gelangte man zum Kornboden [BLHA, Rep. 2 Kurmärkische Kriegs- und Domänenkammer Nr. D 15409, fol. 28R/29.].

256 GStA PK, I. HA, Rep. 21 Nr. 123 (Paket 7998), Schreiben vom 2. Mai 1695. Hier handelt es sich um die Verfügung Kurfürst Friedrich III. auf die Bittschrift der Schweizer Kolonisten; die Supplik liegt nicht mehr in den Akten.

257 Carl Gustav Merian, Amtskammerrat von 1678 - 1704 und Geheimer Kammerrat von 1698-1700 (Bahl, Peter: Der Hof des Großen Kurfürsten, Köln - Weimar - Wien (2000) S. 414.).

258 Johann Arnold Nering/Nehring (+1695) war Architekt und Ingenieur, s. Erika Schachinger: Die Dorotheenstadt 1673-1708, Eine Berliner Vorstadt, Köln, Weimar und Wien (2001), S. 79.

259 Bestehorn, Friedrich: Deutsche Urgeschichte der Insel Potsdam, Potsdam [1936], S. 51/52.

260 Eusebius v. Brandt (1642-1706) war zunächst ausschließlich bei der Kurmärkischen Amtskammer tätig, ab 1703 Präsident des Tribunal- und Oberappellationsgerichts (Peter Bahl: Der Hof des Großen Kurfürsten, Köln - Weimar - Wien (2001), S. 236 u. 440. 
beiter der Kurmärkischen Amtskammer befahl dem damaligen Prediger der Gemeinde Golmer Bruch, Albrecht Wyttenbach, am 8. Mai 1698 die niderreisung des auf dem Golmischen Vorwerck stehenden Meyer haußes inne zu halten. ${ }^{261}$ Dass dieser Neuanfang in Golm letztendlich doch erfolgt ist, geht aus vielen späteren Protokollen hervor. Als Beleg hierfür seien beispielsweise folgende zwei angeführt: Die Vorwercks Gebäude [...] existiren nicht mehr, sondern ein jeder von ihnen hat die erforderliche Gebäude zu seiner Wirthschaft, als Haus- Scheune und Ställe, $[\ldots]$ außgebauet, solchergestalt sind nun 6 Wohnhäuser, eben so viel Scheune und Ställe auf den Vorwerk Golm vorhanden, ... ${ }^{262}$ An anderer Stelle heißt es: Die Materialien des alten Meyer Hauses sind aber zu Bauten bey dem Vorwercks Geltow verwendet worden. ${ }^{263}$ Diese Situation war bis zum Ende des Zweiten Weltkrieges noch gut nachzuvollziehen. Aber durch eine beim Angriff auf Berlin am 26. Februar 1945 abgeworfene Luftmine (Groehler, 1995) wurde die Schweizer Hofe in der heutigen Geiselbergstraße in Golm weitgehend unkenntlich gemacht und später überbaut.

Der Arrendevertrag vom 10. Juni 1689 musste im Jahre 1692 aufgehoben und durch einen neuen Kontrakt ersetzt werden. Der zwingende Anlass hierzu waren die abgelaufenen Freijahre für die im Golmer Bruch erhaltenen Acker- und Wiesenländereien. ${ }^{264}$ Deshalb richteten die Schweizer Kolonisten aus dem Golmer Bruch eine Bittschrift an Kurfürsten Friedrich III. ${ }^{265}$ Darin lobten sie den gnädigsten Kurfürsten, dass sie unter dessen Schutz die Freijahre in ruhe und friden genoßen hätten. Nun wollten sie aber die gewohnlichen onera nach der qualitet des Landeß Jährlich wie billich [...] entrichten. Damit dieser Kontrakt für sie möglichst günstig ausfallen sollte, schilderten sie zunächst ihre Situation im Golmer Bruch: Weyl aber das ohrt so beschaffen, daß das Waßer alle Jahre gemeinigklich biß auf Johanny in Unßern Wysen liget vnd durch der Sonnen hitze dermaßen erwehrmet wird, daß das Fuetor ${ }^{266}$, so daselbsten wachset, so schlecht vnd gering, daß darbey Vnßer Vieh nicht nur wenig Milch gibet, sondern auch das vbrige Graß vnß Niemand mehr abkauffen will: Auch vnsere Hühtung, so anfangs vns gegeben, wegen großen vnd Vilen Morasts, alß auß welchem wir Täglich Vnßer Vieh mit Seil Vnd Sparren ${ }^{267}$ heraußziehen müeßten, dan sie darin biß an den Halß gefallen, Ja etliches gar stecken geblieben vnd crepiert sint,...

Der Kurfürst befahl daraufhin am 10. Juni 1692, die Bittsteller zu vernehmen, alles wohl zu erwägen und zu berichten. ${ }^{268}$ Das Gutachten des zuständigen Amtes Bornstedt fiel auffallend detailliert aus ${ }^{269}$ und scheint an Hand eines Fragebogens erstellt worden zu sein. Zunächst wurden die den einzelnen Schweizer Kolonisten seit 1685 erwiesenen Wohltaten an Getrei-

261 GStA PK, I. HA, Rep. 21 Nr. 123 (Paket 7998) - Schreiben vom 8. Mai 1698 (nicht paginiert), s. Anhang 12.

262 BLHA, Rep. 2 Kurmärkische Kriegs- und Domänenkammer Nr. D 15409, fol. 102/102R.

263 daselbst: S. 147R.

264 gemäß $\$ 6$ des Arrendevertrages vom 16. September 1685.

265 BLHA, Rep. 2 Kurmärkische Kriegs- und Domänenkammer Nr. D 15409, fol. 8-9 [undatiert], s. Anhang 11.

266 Futter (Gras bzw. Heu). Am Johannestag [24.6.] wird der Taufe Johannes des Täufers gedacht.

267 Karren.

268 BLHA, Rep. 2 Kurmärkische Kriegs- und Domänenkammer Nr. D 15409, fol. 3/3R.

269 daselbst: fol. 10-18. 
de, Vieh und Land aufgeführt. Dazu zählten auch die in Tabelle 1 aufgelisteten Baukosten von 14.328 thlr 20 gr und 9 d, die unter Kurfürst Friedrich Wilhelm auf den Golmer Bruch seit 1678 bis 1687 verwandt worden waren. Aufgestellt wurde auch eine aktuelle Namensliste der Kolonisten, so itzo im bruch wohnen. Sie unterschied sich von der im Kirchenbuch von Nattwerder von 1685, weil sich inzwischen zwei Familien im Vorwerk Neu Töplitz angesiedelt hatten und Todesfälle aufgetreten waren. Die Vernehmung der Kolonisten am 21. Juni 1692 im Amt bestätigte die schwierigen Bedingungen, unter denen sie im Golmer Bruch leben mussten: Und gestehen Sie zwar, Das bey guten trocknen jahren ein ieder 25 bis 30 Fuhder heu gewinnen konte, Müsten aber dobey anführen, das die graben und dämme nicht sufficient waren, das waßer aus dem bruch abzuführen und zurückzuhalten; selbige waren gleichsam auf einen schwimmenden grundt gar Zu schmahl angeleget, also das die Erde, so Zur erhöhung dorauff geführet wurde, gleichsam Versünke und, das außen wasser sehr leicht wider durch drünge, wie denn in den 3 leztern jahren geschehen. ${ }^{270}$ Die Beamten, die im Ergebnis wenigstens eine Erhöhung der zu prästierenden Gelder erreichen wollten, protokollierten, die Kolonisten seien incapable eine recocnition oder grund Zinß an gelder abzustatten, weilen sie weder aus der Viehzucht noch acker bauw geldt [er]lößen könten. Deswegen hätten sie einen andern modum ergriffen, und wegen lieferung einer gewißen quantität Heües verhandelt, dass [...] zu der angelegten Stutterey bey Potstam wohl nötig sein würde. Dies hätten die Kolonisten versprochen zu machen, iedoch dass bei gar nassen Jahren [...] ihnen dann billig massige remission [...] widerfahren möge. ${ }^{271}$ Kurfürst Friedrich III. entschied am 11. August 1692 in Anbetracht der Situation, in der sich die Schweitzerische familien noch immer befänden und umb diesen Leüten desto beßer auffzuhelfen, sie die bemelten Landerey noch auf zwei Jahre, mit eben denen Immunitäten und freiheiten, wie Sie selbige bishero beßeßen, nutzen und genießen sollen. ${ }^{272}$

In den späteren Vorwerkskontrakten wurde lediglich die Pachtsumme auf Grund berechneter Veranschlagungen im Zusammenhang mit der Erstellung der Generalpachtanschläge ${ }^{273}$ immer mehr erhöht (s. Tab. 7). ${ }^{274}$

Wie problematisch das für die Schweizer Kolonisten war, lässt sich aus den wiederholten vergeblichen Beschwerden gegen Pachterhöhungen vermuten. Die in den Jahren 1750/1795 numerisch erniedrigten Pachtsummen täuschen (s. Tab. 7), denn durch die Ansiedlung von Hopfengärtnern am Kuhforter Damm im Jahre $1775^{275}$ ist ihnen zu deren Gunsten 120 Morgen gutes Hütungsland entzogen worden. Ähnlich stellte sich für die Schweizer Kolonisten in Golm die Situation schon einmal 1748 dar, als für die Ansetzung von ca. 200 Bauernfamilien

daselbst: fol. 19/19R

73 Beispielsweise wurde das Vorwerk Golm im Generalpachtanschlag des Amtes Potsdam von 1732-1738 mit 535 rt veranschlagt [BLHA, Rep. 2 Kurmärkische Kriegs- und Domänenkammer Nr. D 15254, fol.67 ff.]. Die Differenz von Veranschlagung und Pachtsumme war das Einkommen der Pächter. Im Beispiel $535 \mathrm{rt}-465 \mathrm{rt}$ $=70$ rt. Diese Summe entfiel auf die 6 Schweizer Familien zu gleichen Teilen.

274

275 daselbst: fol. 148 .

BLHA, Rep. 2 Kurmärkische Kriegs- und Domänenkammer Nr. D 15689, fol. 17/17R. 
Tab. 7: Die steigenden Pachtsummen - ein Problem für die Kolonisten ${ }^{276}$

\begin{tabular}{lccc}
\hline \multirow{2}{*}{ im Jahre } & \multicolumn{3}{c}{ Pachtsumme } \\
\cline { 2 - 4 } & Rthl. & gr & d \\
\hline 1689 & $222^{277}$ & 8 & 2 \\
\hline $1713 / 1722$ & $432^{278}$ & 12 & 11 \\
\hline $1732 / 1738$ & 465 & 13 & 11 \\
\hline $1738 / 1744$ & 465 & 13 & 11 \\
\hline $1744 / 1750$ & 535 & 10 & 11 \\
\hline $1750 / 1795$ & 465 & 13 & 11 \\
\hline $1798 / 1801$ & 465 & 13 &
\end{tabular}

aus dem Fürstentum Pfalz-Zweibrücken händeringend Kolonistenstellen gesucht wurden und das Generaldirektorium am 17. Juli 1748 der Kurmärkischen Kriegs- und Domänenkammer zu examiniren befahl, wie viele Colonisten Familien in dem Gollmer Bruch angesetzt werden können. ${ }^{279}$ Da deren Ansiedlung mit einem geschätzten Kostenaufwand von 1195 thal., aber nur mit einer Erhöhung der Pachteinnahmen von 16 thal. verbunden gewesen wäre, wurde damals davon abgesehen.

Außerdem wurde den Schweizern zunehmend die für sie ökonomisch so wichtige Holzgerechtigkeit ${ }^{280}$ verweigert. Sie beschwerten sich deshalb zunächst bei der Kurmärkischen Kammer, blieben aber ungehört. Darauf wandten sie sich am 17. Februar 1798 wegen des ihnen vom Amte Bornim vorenthaltenen Holzes immediat an Friedrich Wilhelm III. und bezogen sich dabei auf $\$ 10$ ihres Vertrages vom 23. April 1716. In die von ihnen gezahlte Pachtsumme gehöre dieses Recht. Auch die Holzassignation in der 3 Meilen entlegenen Potsdamschen Heide sei um so unbilliger, da sie [...] nur schlechtes Vieh haben, u. dieses bei solch strapaziösen Anfuhren [...] noch mehr ruinirt [werden] könnte. ${ }^{281}$ Die Kurmärkische Kammer wurde daraufhin vom König gerügt. Diese ihrerseits instruierte das Amt Potsdam, dass die Beschwerden der Schweizer zum Teil zuträfen. Aber weil der Vertrag, auf den die Schweizer ihr Recht gründen wollen, längst abgelaufen sei, seien ihnen ihre Holzanforderungen zum Teil abgewiesen worden. Nach Ablauf des Vertrages sei zwar die Pacht erhöht, aber kein neuer Vertrag errichtet worden. ${ }^{282}$ Sie besäßen also das Vorwerck nur Zeitpacht weise. Demzufolge werde es lediglich von der Königlichen Kammer abhängen, ihnen die Pacht zu kündigen, u. einen neuen Pachtanschlag aufzunehmen und zu bestimmen, unter welchen Bedingungen ihnen das Vorwerck ferner in Pacht

276 nach dem Bericht des Amts Potsdam v. 23.02.1799. [BLHA, Rep. 2 Kurmärkische Kriegs- und Domänenkammer Nr. D 15409, fol. 110-117R.].

277 davon nur 89 Rthl. gezahlt.

278 Die Grundlage hierfür war ein veranschlagtes Ertragsquantum.

279 GStA PK, II. HA Generaldirektion, Abt. 14 Materien Tit 211 Lit G Nr. 4, fol. 4.

280 Berechtigung auf kauffreies Brenn-, Reparatur- und Bauholz; sie selbst besaßen nicht die geringste Holzung auf ihrer Feldmark [BLHA, Rep. 2 Kurmärkische Kriegs- und Domänenkammer Nr. D 15409, fol. 202.].

281 BLHA, Rep. 2 Kurmärkische Kriegs- und Domänenkammer Nr. D 15689, fol. 85 ff.

282 Er wurde stillschweigend prolongirt. 
überlaßen bleiben oder in Erbpacht gegeben werden soll. [...] Das Amt hat dies den Supplicanten vorzuhalten. Bei ihrer Vernehmung am 20. Mai 1798 gaben die Schweizer u. a. den Wunsch zu Protokoll, dass mit ihnen ein neuer Vertrag abgeschlossen werde, indem dasjenige darin zugesichert wird, was in ihrem bisherigen Contract gestanden habe, damit künftig Beschwerden entfielen. Allein die Schweizer versichern, daß wenn ein neuer Anschlag vom Vorwerck Golm gemacht werden sollte, das veranschlagte Ertragsquantum weitaus geringer ausfallen werde, so wir jetzt geben. Den vorerwähnten Hopfengärtnern seien die hohen Hütungen gegeben worden. Die Niederung sei ihnen geblieben, wordurch ihr Vieh nur schlechtes Gras frisst und alle Jahre ein jeder von ihnen 2 bis 3 Stück Rindvieh verliert. ${ }^{283}$

Unglücklicherweise fielen die geschilderten Vorgänge in eine Zeit einer „Energiekrise“. Holz wurde im großen Stil für die damals üblichen Fachwerkbauten und zugleich als Brennmaterial gebraucht. Die Wälder in der Umgebung der Residenzstadt Potsdam waren über ihre kräfte angestrengt worden, und weitere Anweisungen über Holzdeputate mussten eingeschränkt werden. Es verwundert also nicht, dass das Generaldirektorium am 21. August 1798 der Kurmärkischen Kriegs- und Domänenkammer aufgab, dass den Schweizern kein Holz mehr geliefert werden könne, es sei denn, sie wollten die gewöhnliche Erbpacht-Bedingung eingehen, wozu man nicht abgeneigt sey. ${ }^{284}$ Zur erblichen Annahme ihrer Güter bei Bezahlung des Bauholzes waren sie bereits mehrfach aufgefordert worden. Aber auch diesmal lehnten es die Schweizer ab, denn ihre Pacht sey gar zu hoch gestrengt und sie könnten bey der zu übernehmenden Erblichkeit $u$ bezahlung des Bau Holzes die bisherige Pacht loco canonis nicht übernehmen. ${ }^{285}$ Zweifel bestanden weiterhin bezüglich ihres Rechtsstatus. Unbestritten hatten die sechs Schweizer Familien inzwischen seit ca. 90 Jahren als ein perpetuierliches Etablissement bestanden. Waren sie - auch ohne Vertrag - also wirklich mit Zeitpächtern gleichzusetzen? Das Generaldirektorium entschied am 3. Juli 1799, dass es dem Staats Interesse nicht conveniren [passen] würde, diesen seit 86 Jahren völlig abgebauten bekannten guten Wirthen die Pacht zu kündigen, sie zu exmittiren, und ihrem Schicksal zu überlassen. Da die Schweizer ihre Höfe nicht in Erbpacht nehmen wollten, sollte mit ihnen gleichlaufend mit den Generalpachtverträgen ab Trinitatis 1801 ein Pachtkontrakt über das Vorwerk Golm abgeschlossen werden. ${ }^{286}$ Der Streit um die Holzgerechtigkeit ging indessen weiter. Auf das Angebot des Königlichen Forstdepartments, ihnen bis zum Abschluss des neuen Pachtvertrages das benötigte Brenn- und Nutzholz Forsttaxmäßig $[\mathrm{zu}]$ bezahlen, gingen die Pächter nicht ein, weil sie nicht wißen, wo sie das Holz [...] für solchen Preis $[\ldots]$ ankaufen sollen. ${ }^{287}$ Durch Verfügung der Regierung vom 22. Februar 1800 erhielten sie schließlich ihr Deputatholz für die Jahre 1799-1801. ${ }^{288}$ Aber die Kurmärkische Kammer

283 Bei der ständigen Haltung auf feuchten/sumpfigen Flächen dürfte es sich sehr wahrscheinlich um Fasciolose (Leberegelbefall) mit tödlichem Ausgang gehandelt haben.

284 BLHA, Rep. 2 Kurmärkische Kriegs- und Domänenkammer Nr. D 15409, fol. 100.

285 daselbst: fol. 118.

286 daselbst: fol. 118.

287 daselbst: fol. 124/124R; das königliche Dekret hierzu unter fol. 125/125R.

288 daselbst: fol. 129 und 175. Dabei handelte es sich um 2 kiehnene Sägeblöcke, 40 Klafter Kiehnen- und 8 Klafter Stubbenholz, sowie 2 Fuder Birken (aus dem raupenfräßigen Bestande im Potsdamer Forst) und 2 Stück Eichenholz (Bornimer Forst). 
sollte gleichzeitig das Pachtende für 1801 ankündigen, damit die Schweizer von selbst um eine Pachtverlängerung baten.

Stattdessen ersuchten aber die sechs Schweizer Pächter des Königlichen Vorwerks Golm am 27. Dezember 1800 um Gemeinheits-Aufhebung ${ }^{289}$ [Separation]. ${ }^{290}$ Die Gemeinde Golm hauptsächlich aus Kossäten bestehend - dominiere die bisherige Nutzung der Feldmark in einer Sorglosigkeit, die eine Verbesserung der Zustände nicht zu Stande kommen lasse. Die Hopfengärtner hätten es ihnen vorgemacht, was man mit eigenständiger Wirtschaft erreichen könne Aber nicht allein ihre Umstände würden dadurch verbeßert, sondern auch daß Allerhöchste Königl. interesse vermehret, denn alsdann könnten die erhöhten Getreidepreise und dergleichen angewandt werden. Der Oberamtmann Hart bestätigte mit seinem Bericht und anliegendem Vernehmungsprotokoll vom 14. März 1801, wie vorteilhaft eine Separation für alle in Golm sei. Freylich wird es noch viele Schwierigkeiten setzen, ehe die Gemeine in der Separation einwilligen mögte. ${ }^{291}$ Der Geheime Kriegs- und Domänenrat Meinhart formulierte daraufhin in 11 Punkten die Bedingungen, unter denen er die weitere Verpachtung des Vorwerks Golm an die sechs Schweizer Pächter ab 1801 für möglich hielt, ${ }^{292}$ wobei sie sich drei Aspekte zur Schonung der Wälder gefallen lassen müssten, dass nämlich

- ihre gegenwärtige zu ihrer Wirtschaft gehörenden Gebäude aufgenommen und beschrieben werden und sie nur für diese Gebäude künftig freies Holz erhalten,

- ihnen das Deputatholz zur Hälfte in natura, [... die andere Hälfte gegen Forst Taxe incl. Stamm geld in Gelde angewiesen und

- ihnen nur die Hälfte des künftigen Deputatholzes aus dem Bornimer oder Potsdamer Forst verabfolgt wird.

Das Generaldirektorium stellt am 26. August 1801 gegenüber der Kurmärkische Kammer klar, dass nach rechtlichen Grundsätzen ohne Zweifel die bestehende Pacht der Schweizer Pächter gekündigt werden könne. Es bedürfe daher auch keiner fernere Unterhandlung mit diesen Pächtern, sondern es lasse sich jede Bedingung vorschreiben, wenn man nur überzeugt wäre, daß sie dabey bestehen können. Unter dieser Prämisse sollte die Kammer die Schweizer Pächter unabänderlich vor die Wahl stellen, es bey einer neuen sechsjährigen Zeitpacht - bei Verzicht auf alles Brenn- und Nutzholz und eigener Gebäudeinstandhaltung mit 1/3teiliger Bezahlung des Bau- und Reparaturholzes - bewenden zu laßen oder unter gleichen Bedingungen um die Erbpachtschaft anzusuchen, jedoch mit dem Zusatze, dass die Höhe der Erbpacht an den jeweils bestehenden Roggenpreis angepasst werde. ${ }^{293}$ Die Schweizer Pächter wurden hierzu am 22. Oktober 1801 vernommen und konnten sich nur nach dem Maßstab des mit dem

289 BLHA, Rep. 2 Kurmärkische Kriegs- und Domänenkammer Nr. D 15409, fol. 135/136R.

290 Bei der Separation in der Landwirtschaft findet eine Neuregulierung des Grundbesitzes i. S. von Flurbereinigung statt. Dabei werden die einzelnen Grundbesitzanteile und die Gemeinheit zusammengelegt und auf die Interessenten aufgeteilt. In Verbindung damit werden die verschiedenen Naturalzehnte abgelöst.

291 BLHA, Rep. 2 Kurmärkische Kriegs- und Domänenkammer Nr. D 15409, fol. 143-145.

292 daselbst: fol. 146-152; das Konzept hierzu fol. 166-171.

293 daselbst: fol. 176/176R. und fol. 183/184R. 
Geheimen Kriegs- und Domänenrat Meinhart angefertigten Protokolls vom 21. Januar 1801 zur Erbpacht erklären und um deren weitere Regulierung bitten. ${ }^{294}$ Meinhard berichtete hierüber dem Kurmärkischen Forstdepartment, daß mit diesen Familien nichts auszurichten ist, und machte gleichzeitig an Hand einer Überschlagsrechnung deutlich, dass er jede Verschlechterung ihrer Lage für gefährlich hielt. ${ }^{295}$ Das zeigte insofern Wirkung, als dass das Generaldirektorium am 28. Februar und 21. Juli 1802 der weiteren Verpachtung an die Schweizer von Trinitatis 1801/1807 zustimmte, aber die Bedingungen für Holzlieferungen im Wesentlichen unverändert blieben und erneut mit der möglichen Kündigung gedroht wurde. ${ }^{296}$

Damit gaben sich die Schweizer nicht zufrieden. In einer zehnseitigen Supplik vom 5. Juni $1802^{297}$ an Friedrich Wilhelm III. schilderten sie ausführlich, unter welchen Umständen die Schweizer Kolonisten in den Golmer Bruch gekommen waren. Höchst diplomatisch rekapitulierten sie die letzten 113 Jahre, in denen sie zu allen Zeiten ihre Praestanda redlich erfüllet, [...] sich als gehorsame Unterthanen stets bezeuget, [...] Krieg und Unglück ertragen, ihre Söhne zur Verteidigung des Vaterlandes, ohne Nutzung der sonstigen Colonisten Befreyung, als Soldaten hingestellet, und uns nie irgend einer Patriotischen Beyhülfe zum allgemeinen Landes besten entzogen [hätten]. Sie hielten es für unbillig, wenn man itzt Rechtsgründe aufführen will, die uns und unsere Familien von 50 bis 60 Seelen aus dem Contract setzen. Sie flehten um ein gerechtes und bildiges [billiges] Einsehen in Bezug auf ihre Holzversorgung. Sie müssten insistiren, um endlich nach so ungeheurer Zeit auf einen festen Fuß zu kommen... [Sie hätten] mehrmals um die Erbpacht nachgesucht, zugleich aber auch um die Separation und deren baldige Einleitung mit der übrigen Gemeinde zu Golm gebeten. Auch dies beeindruckte den König und die Kammer nicht.

Die übliche Erlangung der Erbpächterschaft war an Voraussetzungen geknüpft, welche die Golmer Schweizer aufgrund ihrer wirtschaftlichen Situation nicht in der Lage waren zu erfüllen, ${ }^{298}$ und sie versuchten deswegen, ihr Ziel aufgrund ihrer langjährigen Ansiedlung zu erreichen. Ihre sprichwörtliche Zähigkeit ist zu bewundern, mit der sie darum und gleichzeitig gegen eine weitere Pachterhöhung kämpften. Sie erreichten, dass ihre Pacht für die Jahre 1801/07 unverändert bei 465 rthl 13 Sgr 11 d blieb (s. Tab. 7) ${ }^{299}$, dass sie das ihnen in den vergangenen Jahren vorenthaltene Deputatholz teilweise zugestanden bekamen ${ }^{300}$ und dass sie ihre Holzgerechtigkeiten bis zur Separation behielten. ${ }^{301}$

daselbst: fol. 187/187R; das in Bezug genommene Protokoll ist laut fol. 234. zum Kurmärkischen und Forstdepartment des Generaldirektoriums übersandt worden und konnte nicht aufgefunden werden.

295 daselbst: fol. 188-189R.

296 daselbst: fol. 192/192R und 196/196R.

297 daselbst: fol. 197/202R.

298 Die Bewilligung eines Gesuchs um eine erbliche Pacht war seitens des Generaldirektoriums an den Verzicht auf bisher freies (kostenloses) Deputatbrenn- und Nutzholz des Ersuchenden geknüpft. Hinzu kam die Entrichtung eines nach dem Betrage des Kanons zu bestimmenden Laudemiums bei jeder Besitzänderung, die nicht auf Erbschaft beruhte, sowie die proportionale Erhöhung der Erbpacht bei Anhebungen der Kammertaxe für Getreide. [BLHA, Rep. 2 Kurmärkische Kriegs- und Domänenkammer Nr. D 15409 fol. 208R/209.]. BLHA, Rep. 2 Kurmärkische Kriegs- und Domänenkammer Nr. D 15409, fol. 232 (\$ 4).

300 daselbst: fol. 262 und 270.

301 BLHA, Rep. 2A Regierung Potsdam III F Nr. 1721 (nicht paginiert). 
Die Separation kam in Golm im Jahre 1818 in Gang, nachdem die dortigen Schweizer Kolonisten am 13. September 1817 beim Domänenamt um Entflechtung der auf der Golmschen Feldmark gelegenen Grundstücke ortsansässiger sowie fremder Wiesenbesitzer und Aufhebung der gemeinschaftlichen Hütungsberechtigungen angetragen hatten. Der daraufhin verfolgte Golmsche Spezial Separations-, Hütungs- und Ackernutzungs-Ablösungs-Recess kam schließlich 1837 zustande und wurde am 16. Oktober 1839 durch das Kammergericht Potsdam vollzogen. Um dabei allen zu berücksichtigenden Gesichtspunkten gerecht zu werden, war es ein äußerst aufwendiges Vorhaben. Neben den Vorwerksbesitzern (6), Bauern (2), Kossäten (11) und weideberechtigten Büdnern (5) von Golm waren auch Institutionen (Großes Militärwaisenhaus Potsdam, Königlicher Forstfiskus, Bornimer Pfarre und von Golm Kirche, Schulamt und Schulzenamt) sowie die Bauern und Kossäten von Eiche (8) und die weideberechtigten Erbpächter zu Nattwerder (4) - also insgesamt 42 Interessenten - zu berücksichtigen und ggf. zu entschädigen. Dabei ging es nur um die Neuaufteilung von 3414 Morgen und 6 Quadratruten Acker, Wiesen, Grundhütung und Holzung. Auf die Schweizer Kolonisten entfielen davon 1227 Morgen und 174 Quadratruten. Für die Nutzbarmachung dieser neuen Situation bedurfte es einer erweiterten dörflichen Infrastruktur. Dazu gehörten beispielsweis Grenzmarkierungen, Schaffung von Zugangswegen und Viehtriften, Gewährung von Überfahrtsrechten, Anlage von Gemeinschaftsanlagen (Sand- und Lehmgrube), Rohrnutzung, Fischereiberechtigungen. Auch dies regelte der Rezess. ${ }^{302}$ Anhand der vielen Beteiligten bei dieser Separation wird deutlich, welchen Zwängen sie bis dahin unterworfen gewesen waren und welchen Fortschritt die Separation für den einzelnen Betroffenen brachte.

\section{Die Ansiedlung der Schweizer Kolonisten in (Neu-)Töplitz}

Das Jahr 1691 markierte einen weiteren Wendepunkt für das Schicksal der im Golmer Bruch 1685 angesiedelten Schweizer Kolonisten insofern, als ihnen das zum Amt Lehnin gehörende Vorwerk Töplitz übergeben wurde. Bevor darauf im Einzelnen eingegangen wird, soll zunächst die wenig bekannte Geschichte des ehemals vom Kloster Lehnin besessenen Vorwerks Töplitz skizziert werden.

Dem Kloster Lehnin gehörten bis zu seiner Säkularisierung 1542 die Stadt Werder, 39 Dörfer rund um den Schwielowsee und weitere 54 Seen.303 Darunter fiel auch Töplitz, wobei das Kloster unter Abt Dietrich im Jahre 1318 zunächst die Insel Töplitz mit allen Rechten [Hohe und niedere Gerichtsbarkeit], Grund und Boden von Markgraf Woldemar ${ }^{304}$ und erst im Jahre 1321 das gleichnamige Dorf von Herzog Rudolf von Sachsen ${ }^{305}$ gekauft hatte. Der „Hof zu Töplitz“ [später Vorwerk genannt] wurde in dieser Zeit und - für Zisterzienserklöster typisch - außerhalb einer bestehenden Ortschaft, und zwar zwischen Göttin, Leest und

302 BLHA, Rep. 7 Amt Potsdam Nr. 1072, 1072/1, 1072/2 und Rep. 5E Amtsgericht Potsdam Nr. 136 fol. $155-$ 208.

303 Riedel: CDB A X S. 378-398 Nr. 275.

304 daselbst: CDB A X S. 234, Nr. 111; Warnatsch, Stephan: Geschichte des Klosters Lehnin 1180-1542, Bd. 2, Regestenverzeichnis, Berlin (2000), Regeste II.219.

305 daselbst: CDB A X S. 236, Nr. 114; Warnatsch (2000): Regeste II.223. 
Töplitz, angelegt. Kurfürst Joachim II. löste 1542 nach dem Tod des von ihm sehr geschätzten Abts Valentin das Kloster Lehnin auf; die noch verbliebenen Mönche erhielten bis zu ihrem Tode eine Bleibe auf dem Vorwerk Töplitz zugesichert. Das Kloster wurde zum Amt Lehnin umgewandelt und als Verweser (Amtmann) Michael Happen - ein Adeliger aus dieser Gegend - eingesetzt. ${ }^{306}$ Die Grangie Töplitz war seitdem Amtsvorwerk. 1691 gehörten zum Amt Lehnin insgesamt fünf Vorwerke: Damsdorf, Kaltenhausen, Töplitz, Tornow und Wachow. Aus den nur tabellarisch überlieferten Jahreswirtschaftsbilanzen der Jahre 1602 und 1662 (anitzo) dieser Vorwerke erhält man einen guten Einblick über ihre Bewirtschaftung. ${ }^{307}$ Die Schafzucht stand eindeutig im Vordergrund (s. Tab. 8). Angebaut wurde Weizen, Roggen, Gerste, Hafer, Erbsen und Buchweizen. Soweit vorhanden, spielten daneben Weinberge, Mühlen und Garnzüge [Fischerei] ${ }^{308}$ eine Rolle. Außerdem wird hervorgehoben: Im Ambte ist sonsten keine Pferdezucht als beym Vorwercke Töplitz vndt seindt wie bey der Viehe Rechnung Zu ersehen gewehsen. Es können auch bey Diesem Vorwercke selten mehr alß zu bestellungk des Ackerbauws von nöthen gehalten werden, in dehm daß Hew zu erhaltungk der Schäfferey und Rindtviehes mehrenteils gebrauchet werden. Es können noch zwar einige Wiesen gemachet und gerohdet werden, wenn die gnädigste Herrschaft einige mittel dazu verordnen wollte. In Folge des Dreißigjährigen Krieges war 1662 die Anzahl der Bevölkerung (von 14 Amtsdörfern) im Vergleich zum Jahre 1602 noch um $25 \%$ dezimiert. Für das von Heerstraßen abgelegene Töplitz traf das nicht zu. ${ }^{309}$ Nach den Veranschlagungen von 1610-1620 und der Notiz vom 22. Oktober 1621 handelte es sich um ein leistungsfähiges Vorwerk: Töpelisscher werder, ist ein Vorwerck Zum Ambte Lehnin, traget Järlich 1130 thr 11 g 5 d, in selben Jahr haben sollen anlehns-

Tab. 8: Der Viehbesatz des Amtsvorwerks Töplitz im 17. Jahrhundert

\begin{tabular}{lcc}
\hline & $\mathbf{1 6 0 2}$ & $\mathbf{1 6 6 2}$ \\
\hline Rinder & 72 & 50 \\
\hline davon Kühe & 22 & 22 \\
\hline Schafe & 585 & 499 \\
\hline Schweine & 22 & 47 \\
\hline Pferde und Fohlen & 27 & 20 \\
\hline
\end{tabular}

weise darauff genommen 18805 thr Zu den Zerungs geld, daß man Zu bevorstehenden Landtage, $v$. emmpffahung der reichs lehn dan als benötiget gewesen. ${ }^{310}$

Die näheren Umstände, die zur Übergabe des Vorwerks Töplitz an die Schweizer Kolonisten geführt haben, ließen sich nicht ermitteln. Sicherlich bestand ihrerseits hieran Interesse.

308 daselbst: fol. 6R.

309 daselbst: fol. 8R.

310 GStA PK, I. HA, Rep. 2 Nr. 87/2 (Paket 7931, nicht paginiert, Mappe Töplitzesche Werder Göttin Leihest Amt Lehnin) 
Aber dies erklärt nicht die für brandenburgisch-preußische Verhältnisse ganz ungewöhnliche Vorgehensweise, dass das Vorwerk ihnen ohne einen vorhergehenden Vertragsabschluss incl. Der Taxierung der Hofwehr übergeben wurde. Den Akten zufolge wurde am 26. Juni 1691 der Amtskammerrat Neuhaus beauftragt, das Vorwerk Töplitz mit allem Zubehör an die in den Golmer Bruch eingewanderten Schweizer Kolonisten Emanuel Dortschi, Krispin Garmatter und Isaac Muerhofer [...] ad interim und bis auf administration zu übergeben, ${ }^{311}$ damit diese trotz später Erntezeit noch rechtzeitig die Wintersaat ausbringen könnten. Offensichtlich stand es mit dem am 18. Januar 1682 mit allen Früchten ohne die Burg und alte Kirche, samt den Kornhause voll Korn bis auff den grund abgebrannten Vorwerk ${ }^{312}$ generell nicht zum Besten. Überdies waren der Amtskammer Unrichtigkeiten in dessen Bewirtschaftung bekannt geworden, die sich auch bei der im Herbst des gleichen Jahres noch vorgenommenen Zählung und Taxierung des Viehbestandes bestätigten. Für die überstürzte Übergabe spricht insofern vielmehr die Situation des Amtmanns Johann Samuel Clar (der ältere), der in dieser Zeit bei der Amtskammer einen Schuldenstand von ca. 4000 Rthl. hatte. ${ }^{313}$ Unter diesen Umständen sollten höchstwahrscheinlich weitere Einnahmeverluste vermieden werden.

Über den Wiederaufbau des 1682 abgebrannten Vorwerks waren keine Informationen auffindbar. Die Gebäudebeschreibungen (insbesondere die des Schafstalles) lassen aber einen schlimmen Zustand erahnen. Lediglich der Name des Hoffmeyers [Verwalter des Vorwerks], Andreas Schultze († 4. Juli 1664), aus den Jahren davor ist überliefert. Seine familiären Verhältnisse - soweit aus dem ältesten Kirchenbuch von Töplitz ersichtlich ${ }^{314}$ - sind für die damalige Zeit typisch. Er heiratete am 18. Mai 1656 Maria Strites (†13. Februar 1662), mit der er fünf Kinder hatte: Anna Catharina (*22. September 1656), Maria Magdalena $\left({ }^{*} 22\right.$. Januar $1658,+19$. Mai 1659), Andreas $\left({ }^{*} 17\right.$. März 1659), Nicolaus $\left({ }^{*} 26\right.$. April 1660) und Christian (*22. Dezember 1661).

Bei der später vorgenommenen Zählung und Taxierung des Viehbestandes konnte kein Einvernehmen mit der Kurfürstlichen Kammer erzielt werden; sie wurde deswegen am 11. September 1691 wiederholt und vom Töplitzer Pfarrer, Johann Grünenthal, dem Töplitzer Schulzen Joachim Mehls und dem Schweizer Kolonisten Isaac Mührhoffer unterschrieben. Dabei stellte sich heraus, dass an die 66 Schafe fehlten, die der vorherige Arrendator [Pächter], der Amtmann Johann Samuel Clar, zu ersetzen hatte. Noch schlimmer war der Mangel an Pferden und Rindvieh; die Tiere waren zum größten Teil an Michelsdorfer Bauern abgegeben worden. Der vorhandene Viehbestand wurde auf 322 Taler taxiert. Clar beschwerte sich am gleichen Tag darüber, dass bey abnahm des Vorwercks Töplitz Ihme von dem Schultzen von

311 BLHA, Rep. 2 Kurmärkische Kriegs- und Domänenkammer Nr. D 11279, fol. 5/5R.

312 KA Alt Töplitz: Kirchenbuch Alt Töplitz (1652-1804), fol. 24.

313 Als Grund für diese wirtschaftliche Situation führt Sello seinen über seine Verhältnisse hinausgehenden Lebensstil an. Seine Tochter hatte einen Adligen, Herrn v. Krahn, sein Sohn eine Hamburgerin geheiratet. Bei der Einrichtung der beiden Wirtschaften und den Hochzeitsfeierlichkeiten waren grosse Dispense [hier „Ausgaben"] gemacht worden [Sello, Georg: Lehnin, Berlin (1881), S. 207].

314 KA Alt Töplitz: Kirchenbuch Alt Töplitz (1652-1804). 
Töplitz Joachim Mehlis und dem Pauern von Leest Peter Guttschmidt das Vieh und die Weide zu gering abgeschätzet wurden, da si doch nicht geschworne Leuthe seyn.

Auf Befehl des Kurfürsten Friedrich III. wurde am 22. Oktober 1691 mit den oben genannten drei Schweizer Kolonisten im Beisein des Schweizer Hauptmanns Hans Jacob am Biel von Gertzensee und der beiden reformierten Prediger Albrecht Wyttenbach vom Golmer Bruch und Johann Christoph Gerlach ${ }^{315}$ von Lehnin der zweifach ausgefertigte Arrende- und Pensionskontrakt besiegelt. ${ }^{316}$ Im Einzelnen wurde darin in 13 Paragraphen Folgendes geregelt:

- Die Schweizer und ihre Familien sollen, solange sie Sr. Chf. Dhl. Als getreue und gehorsahme Unterthanen sich verhalten, die Pacht zahlen, das Vorwerck sambt der Schäfferey pensionsweise innehaben, besitzen, gebrauchen und genißen (\$ 1),

- die Erhaltung und Instandsetzung aller ihnen übergebener Gebäude mit allen davon nagelfesten immobilien und andern hausgeräthen laut einem hinten angehefteten Inventario (\$2),

- die Bezahlung des übernommenen Viehbestandes innerhalb 3 Jahren mit bahrem Gelde (\$3),

- der Neubau der baufälligen Schäferei auf ihre Kosten, zu dem der Kurfürst freies Bauholz und Mauersteine bewilligt und die Untertanen der benachbarten Amtsgemeinde Spanndienste leisten sollen (\$ 4),

- die Rohrpacht, wie [sie] zuvorn zu diesem Vorwercks gebäuden und deren conservation von den Untertanen aus Göttin und Phöben geliefert worden (\$ 5),

- das freie Bauholz für zusätzliche Wohnungen wegen Vermehrung ihrer Familien (\$ 6),

- die Dienstleistungen, die durch die Schulzen, Bauern und Kossäten aus Göttin, Leest und Töplitz weiterhin zu erbringen sind ( $\$ 7$ und 8),

- die Nutzung des Waldes zur Mästung von Schweinen, wie der vorige Arendator gehabt (\$ 9 und 10),

- der Beschaffung der 66 fehlenden Schafe, ${ }^{317}$ die Abschaffung des Schäfers und dessen Ersatz durch einen eigenen Schäferknecht (\$ 11),

- die Stroh- und Mistbereitstellung für den neu angelegten Weinberg $(\$ 12)$ und

- die jährliche Zahlung an Zinsen und Pacht (\$13).

315 Johann Christoph Gerlach (1697-1733) war reformierter Schweizer Prediger von 1691-1692 in Lehnin; in: Fischer, Otto (bearb.): Evangelisches Pfarrerbuch ..., Berlin (1941), Bd. II/1, S. 244.

316 BLHA, Rep. 2 Kurmärkische Kriegs- und Domänenkammer Nr. D 11279, fol. 21-24; Der Arrendevertrag der in Leest angesiedelten Schweizer aus dem selben Jahr ist ähnlich konzipiert [BLHA, Rep. 7 Amt Lehnin Nr. 38.].

317 BLHA, Rep. 7 Amt Lehnin Nr. 30/1, fol. 1. 
Den drei Schweizer Kolonisten ging damit ihr bisheriger Rechtsstatus als Erbpächter verloren; sie waren bis 1696 nur Pächter und gezwungen, sich bzgl. Bestehender Nutzungsrechte (Hütungsrechte, Flurgrenzen usw.) mit den einheimischen Bauern und Kossäten aus Göttin, Leest und Töplitz zu arrangieren. In dieser Beziehung waren Spannungen und Streitigkeiten vorprogrammiert, da der Kontrakt keine Angabe über die Größe des Vorwerks insgesamt enthielt bzw. unklar war, welche Äcker, Hütungen und Wiesen, soweit sie nicht als Allmende genutzt wurden, ihnen gehörten. Der übernommene Viehbestand war enorm groß. Ohne auf Details (Alter und Geschlecht) eingehen zu wollen, handelte es sich um insgesamt 74 Pferde, 322 Rinder, 52 Schweine, 434 Schafe und 31 Gänse. ${ }^{318}$ Die Zusage für künftige Bauhilfen geschah im damals üblichen Rahmen. Die Rohrpacht und die Waldmästung von Schweinen wurde - wie bisher beim Vorwerk geregelt - tradiert. Dagegen wurden die bislang von den Amtsuntertanen auf dem Vorwerk zu leistenden Dienste völlig neu geregelt. Bis auf vier Tage im Jahr ${ }^{319}$ waren sie von nun an davon befreit; dafür hatten sie aber ein Äquivalent in Form von Dienstgeldern an das Amt Lehnin zu zahlen. An Zinsen und Pacht hatten die drei Schweizer dem Amt Lehnin jährlich 127 Taler und 12 Groschen sowie 10 Wispel Roggen, 9 Wispel Gerste und 2 Wispel Hafer zu zahlen. Undt da Sr. Churfrstl: Durchl: daßelbige Getreydich Zu dero Hoff Stadt naher Cölln an der Spree verlangten, so sollen Sie schuldig seyn, das selbe dahin zu lieffern. Im Übrigen wurde keine Geltungsdauer für diesen Arrende- und Pensions-Kontrakt festgelegt. Sollte es ein Interimsvertrag sein?

Bemerkenswert ist ferner die weitreichende Einbeziehung des Predigers Wyttenbach in dieser Sache, wobei er sicherlich vermittelnd auftrat und darüber hinaus eine Mitverantwortung für das Gelingen der Umsiedlung übernahm: Weylen aber ohne Caution zur Versicherung eines Verlustes dieses Vorwerck nicht übergeben werden kann, Als offeriere [anbiete] Ich Albrecht Wyttenbach ihr prediger solches auf mich zu nehmen. ${ }^{320}$

Zum Problem wurde den Schweizer Kolonisten der ihnen zunächst zugestandene, neu angelegte Weinberg. Er wurde ihnen wieder abgenommen, weil sie ihm nicht die gehörige Aufmerksamkeit gewidmet hätten. Die Hofkammer teilte ihnen am 10. Mai 1693 dazu mit, dass sich dem weiteren Ausbau des Weinberges der tüchtige Weinmeister Jochimb Thielen annehmen solle und dafür eine Bezahlung für die geleisteten Dienste erhalte. Sie blieben aber verpflichtet, weiterhin dorthin kostenlos den Mist und das Stroh zu liefern. ${ }^{321} \mathrm{Ihr}$ schon geringes Potential zur Düngung der eigenen Äcker wurde ihnen dadurch enorm eingeschränkt. Die Folgen verstehen sich von selbst.

Bislang völlig übersehen wurde in der Literatur eine Auseinandersetzung im gleichen Jahr zwischen dem Amtmann Johann Samuel Clar (dem Jüngeren) und den Töplitzer Kolonisten wegen überfälliger Rückzahlungen für das im Jahr 1691 erhaltene Saatgetreide. Obwohl die Geldforderungen gemäß Ansiedlungsvertrag an sich berechtigt waren, war der Amtmann anscheinend

318 BLHA, Rep. 2 Kurmärkische Kriegs- und Domänenkammer Nr. D 11279, fol. 25/25R.

319 Ein tag pflügen, ein tag heü machen, als Ein tag in den Rogten [und] Ein tag in der gersten.

320 BLHA, Rep. 2 Kurmärkische Kriegs- und Domänenkammer Nr. D 11279, fol. 31.

321 daselbst: fol. 27. 
unschlüssig, ob höheren Orts die Durchsetzung im Fall der Schweizer als nicht opportun angesehen werden würde. Er wandte sich deswegen im Juni 1693 mit einem unterthänigem Memoríale an die Hofkammer ${ }^{322}$ und bekam daraufhin prompt den Befehl, diejenige Schweitzer, welche das Vorwerck Töplitz tendiret [betrifft] und mit ihren versprochenen pensions Gelder im rest bleiben und in güte nicht zahlen wollen, durch die würckliche execution und Bezahlung anzuhalten. ${ }^{323}$ Hierauf ergriff Prediger Wyttenbach vehement Partei für die Kolonisten und beschwerte sich beim Amtmann über dessen ungeduldiges Vorgehen: Ich hätte niemahlen gedacht, daß derselbe die Leute in Töplitz so rigurose würde exequiren laßen, ehe und bevor sie auf das wenigste einmahl von dem $\mathrm{Hr}$. Ambtman weren gemahnet worden. Wan Gott so scharpff mit vns procediren thäte, würde gewüßlich der Herr (Amtmann) vnd Ich in seinem strengen Gericht weit zu kurz kommen, und weren schon lengsten in der Hölle.... Er erinnert an ein Versprechen von Herrn Barthus (?), einmahlen in den ersten zwey Jahren etwaß nach zu laßen, damit die Leute möchten auff einen Guten Fuß gebracht werden ... Die Hofkammer erfuhr durch den Amtmann davon. Wyttenbach wurde daraufhin vom Hofkammerpräsidenten Dodo v. Knyphausen ${ }^{324}$ bezichtigt, dass er den Amtmann mit sehr anzüglichen und einen Prediger unanständigen Worten angegriffen habe, und befohlen, künftig sich der Schweizer Sache zu enthalten. Vielmehr solle er denen Schweitzern zu Töplitz zur schuldigen Zahlung zureden, oder der bereits wieder sie verordneten Execution zu gewärtigen. ${ }^{325}$ Zeitgleich musste der Amtmann über die Umstände der nicht erfolgten Rückzahlungen berichten, damit darüber ferner beschieden werden könne. ${ }^{326} \mathrm{Aber}$ es blieb offenbar bei der Höhe der vertragsgemäßen Rückzahlungen, und die noch ungefestigte wirtschaftliche Situation der Töplitzer Schweizer Kolonisten hielt in den folgenden Jahren, in denen sie auch noch wegen einer Klage eine Abfindung für den entlassenen Schäfer zu leisten hatten, ${ }^{327}$ weiter an.

Am 25. Juni 1696 kam es zu einem neuen förmlichen contract, ${ }^{328}$ der auf unterthänigstes Suchen [Nachsuchen] von Emanuel Durtschy, Hanß Garmater, David Garmater, Peter Maurhober ${ }^{329}$, Ulrich Maurhober und Christian Durtschy ${ }^{330}$ zustande kam und zu ihren und ihrer erben beständiges Aufnehmen und Nutze erblich unter bestimmten Konditionen und Bedingungen abge-

324 Dodo v. Knyphausen (1641-1698) wurde 1683 I. Geheimrat Kurfürst Friedrich Wilhelms, für den er in Emden die kurfürstliche „Afrikanische Handelskompagnie“ einrichtete. 1687 zum Präsidenten der neugegründeten Hofkammer ernannt, reformierte er durch Einführung eines Pachtsystems die Domänenverwaltung und initiierte die Aufstellung eines „Generaletats" (1689/90), der erstmals eine relativ genaue Darstellung der kurfürstlichen Finanzen erlaubte, sowie die Einführung einer Generalkasse. 1697 mußte er im Zusammenhang mit dem Sturz Eberhard von Danckelmanns sein Amt aufgeben [Deutsche Biographie Enzyklopädie (DBE), 2. Auflage, hg. von Rudolf Vierhaus, Bd. V, S. 758.].

325 BLHA, Rep. 7 Amt Lehnin Nr. 30/1, fol. 7/7R, s. Anhang 8.

326 daselbst: fol. 8/8R

327 daselbst: fol. 13.

328 BLHA, Rep 5E AG Potsdam Nr. 485 fol 2-7 [Original]; BLHA, Rep. 2 Kurmärkische Kriegs- und Domänenkammer Nr. D 11279, fol. 45-49 [Abschrift].

329 Murhoffer

330 Hier wird zum ersten Male ein Generationswechsel ersichtlich; denn bis auf Emanuel Durtschy handelt es sich hierbei um die Söhne der eingewanderten Schweizer Kolonisten. 
schlossen wurde. Dieser Vertrag wurde unüblicherweise in einem Fließtext abgefasst. Das Vertragsverhältnis basiert auf einer Solidarhaftung aller sechs Familien (allesambt, alß einer und alle für einen) gegenüber dem Kurfürsten mit ihrem gesamten Vermögen im Land und in der Schweiz. Für das gesamte Vorwerk, bestehend aus Äckern, Wiesen, Holzungen, Wohnungen, Stallungen, Scheunen, Hütungen, Triften und Weiden haben die Schweizer Kolonisten jährlich, beginnend von Trinitatis 1695 biß dahin 1696 331 , eine Pachtsumme von 344 Taler und 12 Groschen in einer summa baar in dem Ambte Lehnin zu zahlen. Diese Verpflichtung galt grundsätzlich uneingeschränkt, allerdings eingeschränkt bei allgemein durchgehender Landschade, als Hagelschlag und Krieges Verderbung, ... wo mit ihnen, wie mit andern verfahren werde. Zusätzlich hatten sie für das übergebene Inventar, bestehend aus Viehbestand, Wagen, Pflugund Hausgeräten, nach Abzug der sonst gewöhnlichen Hofwehr [Ausstattung], eine Restsumme von 346 Talern 3 Groschen und 6 Pfennigen aufzubringen, die sie ab Trinitatis 1697 in sechs Jahresraten abzahlen sollten. Auf jede Familie kam damit ein Betrag von 57 Talern 16 Groschen und 6 Pfennige. Für ihre Rechte und Gerechtigkeiten standen sie unter dem Schutz der Beamten zu Lehnin, worin auch die (Wald)mastung ihrer Schweine und die Rohrungwie bisher - mit eingeschlossen war. Auf die bislang vom Amt Lehnin auf dem Vorwerk in der Erntezeit angewiesenen Dienste aus dem Dorffe Töplitz, Leest und Phöeben verzichteten die Schweizer Kolonisten. Lediglich im Frühjahr blieben die sechs Kossäten aus Göttin verpflichtet, bei der Mistausbringung Dienste zu leisten. Dafür war denselben - wie bisher - Land für den Eigenbedarf zum Flachsanbau zu überlassen. Für die nicht mehr zu leistenden Dienste hatten die Kossäten Dienstgelder an das Amt Lehnin zu zahlen. Die Schweizer Kolonisten wurden verpflichtet, die ihnen übergebenen Gebäude jederzeit in baulichen würden zu erhalten, die noch ermangelnden [Gebäude] auf ihre eigene Kosten zu bauen. Den Zustand und die Erträge der Äcker, Wiesen und Gärten sollen sie verbessern. Das ihnen übergebene Vieh, imgleichen alles Haußgeräth, Acker- und Pflugzeug im taxierten Wert von 854 Talern 15 Groschen stand ihnen voll und ganz zur Verfügung; dafür wurde ihnen nach Abzug der gewöhnlichen Hoffwehr 346 Taler 3 Groschen in Rechnung gestellt. Damit sollten sie jedesmahl [...] auf Trinitatis, und zwar auff Trinitatis 1697 den Anfang machen, 57 tal. 16 ggr. Erlegen, biß Zu Volliger tilgung dieser Schuldt. Dieser Kontrakt wurde zweifach ausgefertigt. Prediger Wyttenbach bestätigte durch Unterschrift und Petschaft den von den sechs oben genannten Schweizer Kolonisten unterzeichneten Vertrag.

Trotz der Anstellung eines Weinmeisters hat der vorerwähnte Weinberg weniger eingebracht, als sein Ausbau gekostet hat. Nach Einschätzung der Experten würde sich dies auch in $\mathrm{Zu}$ kunft wegen des schlechten Bodens nicht anders gestalten. Die Töplitzer Schweizer Kolonisten nahmen dies zum Anlass, dem Lehniner Amtmann Martin Rost ein Angebot für den Kauf des Weinberges mit 70 Rthl zuzüglich jährlich 10 Rthl für den dazugehörigen Kossätenhof zu unterbreiten. Dieser meldete dieses pflichtgemäß an den Kurfürsten befürwortend weiter, ${ }^{332}$ und Friedrich III. stimmte dem Kauf am 2. Oktober 1699 zu. ${ }^{333}$ Aber die Schweizer wollten

331 also auch rückwirkend.

332 BLHA, Rep. 2 Kurmärkische Kriegs- und Domänenkammer Nr. D 11279, fol. 67/67R.

333 daselbst: fol. 69. 
den Kossätenhof für einen eigenen Hirten nutzen. Damit beabsichtigten sie vielleicht auch, alte überkommene Strukturen aufzubrechen, die sie für ihre eigene weitere wirtschaftliche Entwicklung hinderlich ansahen. Sämtliche Untertanen von Göttin wandten sich deshalb am 13. April 1700 an das Schweizer Oberdirektorium und berichteten aus dringender Noth, dass die Schweizer Kolonisten aus der Allmende separieren [aussteigen] wollten. Sie behaupteten dreist, dass sie auß alten briffen uber $400 \mathrm{Jahr}$ beweisen können, dass der Hirte, der das Vieh vom Vorwerk und von ihnen gehütet habe, immer in ihrem Dorfe gelebt hat. Der eigentliche Hintergrund aber war, dass sich die Kossätenfischer aus Göttin keinen eigenen Hirten leisten konnten. Diesem ersten überlieferten Streit zwischen den Töplitzer Schweizer Kolonisten und einem ihrer Nachbardörfer folgten noch zahlreiche über Hütungsrechte, Grenzen und Berechtigungen zum Holzeinschlag. Diese Streitobjekte wurden letztendlich erst durch die Separation im 19. Jahrhundert geklärt. Im beschriebenen Fall entschied die Hofkammer, es bey der alten observance zu belassen. ${ }^{334}$

Auch die Töplitzer Schweizer sahen sich mit der Erhöhung der jährlich von ihnen verlangten Pachtgelder konfrontiert. ${ }^{335} 1729$ wurde ihnen zugemutet, statt wie bisher 344 Taler 420 Taler (pro Familie 70 Taler) zu zahlen. Als sie schließlich dieser Forderung zustimmten, hatten sie dies ausdrücklich an fünf Bedingungen geknüpft, nämlich dass

- sie in gewissem Umfange Brenn-, Bau- und Nutzholz zu Verfügung gestellt bekämen,

- jede Familie ein Schwein zur Mastung in die Königliche Heide eintreiben dürfe,

- ihre [Vorwerks] grentzen überall regulirt würden, ${ }^{336}$

- bei Mißwachs oder Viehsterben, Seine Königliche Majestaet aus Hohen Gnaden und nach vorheriger Besichtigung und Taxirung ihnen eine Remission [Abgabennachlass] eingeräumt würde und

- mit ihnen ein neuer erblicher Kontrakt abgeschlossen würde.

Auf ihr Gesuch im Jahre 1751 wurde ihnen beschieden, dass es keines neuen Kontraktes bedürfe. Als ihnen 1772 erneut die Pachtsumme erhöht werden sollte, argumentierten sie mit folgender Feststellung: Ihnen seien zwar die ursprünglichen Pachtsummen ihrer Vorfahren erhöht worden, aber von den Puncten, die sub conditione sine qua non 1729 bewilligt waren, sei keiner in Erfüllung gegangen. Damit verhinderten sie aktuell die Durchsetzung einer Pachterhöhung.

Vergleichsweise hat es durch die Ämter jährliche Bereisungen ihrer Amtsdörfer gegeben, die auf der Grundlage der Verordnung vom 18. Juni 1767 und vorgegebener Fragebögen durchgeführt wurden. Vom Amt Lehnin waren sie für die Jahre 1772, 1773, 1774, 1775, 1776, 1777 und 1786 erhalten geblieben. ${ }^{337}$ Den Neu Töplitzer Schweizer Kolonisten wurde in diesen

336 Auf diese Forderung wurde dem Landmesser Spaldeholtz aufgetragen, die Töplitzer Feldmark aufzumessen und die Äcker und Wiesen, die zum Vorwerk gehörten, zu bestimmen und nach ihrer Bodenqualität zu bewerten [GStA PK, XI. HA, Karte B 591 und Karte E 830]. 
Protokollen durchweg bescheinigt: Die hiesige Erb-Pächter halten ihre Gebäude gröstentheils in guten Stande, und befindet sich sonsten übrigens alles wie Alt-Taeplitz. Mit Übrigens waren der Zustand der Wohnhäuser (Schwellen, Giebel, Dächer und Schornsteine), die Einhaltung des Backofenreglements, die vorhandenen Feuerlöschgeräte, der Stand der Aussaat, das Vorhandensein von Viehkrankheiten (räudige Schafe), Kleeanbau, Vorräte, Nachtwächter, Mäuseschwänze und dergl. gemeint. Eine verbesserte Melioration wäre nötig, aber die erforderlichen Kosten überstiegen die Kräfte der Unterthanen dergestalt, dass so lange sie selbige ex propriis [persönlich] bestreiten sollen, an die angeführte Verbeßerungen nicht zu gedenken. ${ }^{338}$

Aus dem Jahr 1770 stammt die „Geburtsurkunde“ von Alt und Neu Töplitz. Der Kammerpräsident E.v. Brandt hielt es aus fiskalischen Gründen für notwendig, zwischen dem Dorf und dem Vorwerk Töplitz zu unterscheiden, und teilte dies dem Amtmann Ferrari im Schreiben vom 11. Dezember 1770 mit: Nachdem das gewesene Vorwerck der Töplitzer Horst ${ }^{339}$ genant, nun mehro Zum dorff angeleget und mit schweitzern wirklich besezet worden: Alß findet man nötig, dass hinführo, Zum unterschied des dorffes Töplitz und besagten Vorwercks, sowohl in der geld, alß Korn und Küche Rechnung die Rubrique Alt und Neu Töplitz geführet, welches ihr also einzurichten habt. ${ }^{340}$ Hiermit wurde der Besonderheit der Neu Töplitzer Gemeinde Rechnung getragen, dass sie kirchenorganisatorisch zur reformierten Schweizer Gemeinde im Golmer Bruch und damit zur Superintendentur Potsdam, verwaltungsrechtlich aber nicht zum Domänenamt Potsdam, sondern zum Domänenamt Lehnin gehörte. Diese Diskrepanz kirchenrechtlicher und staatlicher Zuständigkeiten besteht bis heute.

Exemplarisch für die Spannungen, die zwischen den Neu Töplitzer Schweizer Erbpächtern und den Nachbargemeinden Göttin, Leest und Alt Töplitz bestanden, soll hier folgender Nutzungs- und Hütungsstreit ${ }^{341}$ angeführt werden; er wurde bislang in der Literatur nur unzulänglich gewürdigt. ${ }^{342} \mathrm{Er}$ war nicht der einzige, in den die Schweizer involviert waren, und begann im Laufe des Jahres 1797. Die (Immediat)Supplik, mit der die Göttiner (Fischer) Kossäten Friedrich Döring, Joachim Bier und Andreas Döring die Neu Töplitzer Erbpächter beim König wegen strittiger Hütungsreviere denunzierten, war nicht auffindbar. Nach der Aktenlage war das Justizamt Lehnin spätestens seit September 1797 mit der Angelegenheit befasst und hatte von der Kurmärkischen Kriegs- und Domänenkammer den Befehl erhalten, Informationen pro fisco einzureichen; den Hoffiskal Uhden hatte König Friedrich Wilhelm II. mit der Wahrnehmung der Rechte des Fiskus betraut. ${ }^{343}$ Der Streit betraf die Nutzung eines Reviers in der Nähe von Göttin zwischen der Havel, dem Kaltenhausenschen Acker und den breiten Wiesen bis nach Alt Töplitz, das die Kossäten (Kläger) als ihr Eigentum beanspruch-

338 daselbst: fol. 5 .

339 s. Anm. 116.

340 BLHA, Rep. 2 Kurmärkische Kriegs- und Domänenkammer Nr. D 11279, fol. 75.

341 Vergleichbare Vorfälle sind von Storbeck (BLHA, Rep. 7 Amt Alt Ruppin Nr. 533, fol. 8R/23R) und Königsstätt bekannt [BLHA, Rep 7 Amt Alt Ruppin Nr. 516, nicht paginiert].

342 Vette, Markus: Töplitzer Geschichte, Bausteine für die Chronik der brandenburgischen Gemeinde Töplitz, Norderstedt (2002), S. 48 und 51.

343 BLHA, Rep. 2 Kurmärkische Kriegs- und Domänenkammer Nr. D. 11312 (nur teilweise paginiert). fol. 2. 
ten, auf dem aber in den letzten Jahren die Erbpächter Gras gemäht und die von ihnen angepflanzten Elsen und dergleichen teilweise abgehauen hatten. Sie verlangten dafür Entschädigung. ${ }^{344}$ Die Schweizer Erbpächter (Angeklagte) beantragten daraufhin, sämmtliche alten Acten, Charten und Vermessung Register einsehen zu dürfen, die aus der Ansiedelungszeit ihrer Vorfahren existierten, aus denen sich näher ergeben würde, wem das Eigenthum des qu: Revieres zustände. ${ }^{345}$ Die Ermittlung der Karten erwies sich schwieriger als gedacht und verzögerte die Verhandlungen der Angelegenheit ungemein. Höchst diplomatisch beantragten die Schweizer Pächter mehrfach im Laufe der Verhandlungen für sich als Erbpächter die Assistenz und Vertretung des Fiskus (Assistentiam Fisci) ${ }^{346}$; darin lag die Brisanz dieses Streits, zumal Untertanen im Zweifelsfall nicht Eigentümer von Land sein konnten. Da aus den Akten und durch mehrfache Ortsbesichtigungen der Streit nicht geschlichtet werden konnte, wurde die Angelegenheit vor Gericht gebracht.

Die gerichtliche Entscheidung vom 16. Oktober $1800^{347}$ führte umfänglich und lesenswert aus, dass sich im vorliegenden Fall sowohl durch die beigebrachten Dokumente als auch durch die Zeugenaussagen die Eigentumsfrage nicht beweisen lasse. Aber alle Zeugen stimmten darin überein, dass die Kläger schon von 1733 an auf dem fraglichen Reviere Elsen gepflanzt und gehauen, gesträußelt, ${ }^{348}$ bei hohem Wasser darauf gefischt und Bruchwehre aufgestellt hatten. Dadurch, dass das Havelwasser gesunken sei, habe sich Gras an den Rändern und einzelnen Flecken angesetzt und konnte gemäht werden. Deswegen bestätigte das Gericht in seinem Urteil das seit fast 70 Jahren bestehende Nutzungsrecht der Kläger, das durch die Beklagten nicht behindert oder geschmälert werden dürfe. Dadurch bleibe aber das Amt Lehnin in eingeschränkter Form Eigentümer, und in so eingeschränkter Art könnten daher die Beklagten das fragliche Revier auch weiter nutzen. Mit dieser Entscheidung konnten sich die Erbpächter offensichtlich nicht abfinden. Das angerufene Appellationsgericht bestätigte am 28. April 1801 das Urteil der ersten Instanz ${ }^{349}$, so dass schließlich König Friedrich Wilhelm

345 daselbst: fol. 6; bei den später zur Entscheidung des Rechtsstreits herangezogenen Akten handelte es sich im Wesentlichen um den Arrende Contract vom 22.10.1691, dessen Bestätigung am 25.06.1696 sowie die Karten von Töplitz von Spaldeholtz (1729) und C. L. Nettke (1754).

346 daselbst: fol. 17.

347 daselbst: fol. 43-53, hier als abschriftliche Anlage vorliegend; Die Verhandlungen fanden vermutlich vor der Krieges- und Domänenkammer-Justizdeputation statt, deren Akten nach Aussage des BLHA (Fr. Bühring) in der Vergangenheit kassiert worden sind. Im Schreiben des Hoffiskal Jannasch v. 17.9.1798 [BLHA, Rep. 2 Kurmärkische Kriegs- und Domänenkammer Nr. D. 11312, fol. 29.] ist die Rede von einem dort schwebenden Prozess in Sachen der Kossäten zu Göttin wider die Erbpächter zu Neu Töplitz. Näheres zur Krieges- und Domänenkammer-Justizdeputation bei F.W.A. Bratring: Statistische-Topographische Beschreibung der gesamten Mark Brandenburg, Veröffentlichungen der Historischen Kommission zu Berlin, Bd. 22, Neudrucke Bd. 2, Berlin (1968), S. 206.

348 in feuchten Gebieten wachsendes, nicht zum Füttern geeignetes Gras, das im Herbst abgeschnitten und den Winter über dem Vieh untergestreut wird [Jacob und Wilhelm Grimm: Deutsches Wörterbuch, Leipzig (1971), Bd. 19, Sp. 2512.].

349 BLHA, Rep. 2 Kurmärkische Kriegs- und Domänenkammer Nr. D. 11312, fol. 56-58. 
III. als letzte Entscheidungsgewalt entschied und beide Urteile am 8. Mai 1802 für Recht erklärte. ${ }^{350}$

Als bis 1802 keine allseits befriedigende Lösung für die Mitaufhütungsberechtigung gefunden war, wandten sich die Schweizer am 8. Juni 1802 mit ihren Vorstellungen an Friedrich Wilhelm III., dass sie dem Staate weit nützlicher werden könnten, wenn [...] jedem [...] sein Privativum zu seiner alleinigen Disposition u Melioration überlaßen würde $e^{351}$, und setzten damit auf der Insel Töplitz die Separation in Gang. König Friedrich Wilhelm III. ließ daraufhin durch die Kriegs- und Domänenkammer Gutachten anfertigen. Nach erneuter Localrecherche des Justizamtes Lehnin bestätigen die Justizräte Körner und Augustin in ihrem Gutachten vom 20. September 1806, dass die Aufhebung der Gemeinheit unter beiden Orten für beide von dem größten Vortheil ist. Denn die ganze jetzt zerstreute Feldmark der Göttiner könnte dicht neben dem Dorfe Göttin angewiesen werden. Das gleiche gelte für die Neu Töplitzer. Vor allem aber befänden sich zwischen beiden Orten mehrere hundert Morgen Brücher, die zum Vorwerk Täplitz gehörig, in denen die Göttiner aber die Mithütung haben. Diese seien wegen der vielen Streitigkeiten und der unruhigen Göttiner [...] bis jetzt gar nicht genutzt und so unzulänglich geworden, daß selbst kein Stück Vieh ohne Lebensgefahr es betreten darf. Ohne Zweifel ließen sich daraus bei zweckmäßiger Entwässerung [...] Wiesen erster Klasse machen. Der Justizrat Jahn habe bereits vor wenigen Tagen den Versuch gemacht, die Separation im Weg der Güte zu bewerkstelligen. [...] Allein die Göttiner [...] haben sich auf das hartnäckigste jeder Separation widersetzt. ${ }^{352} \mathrm{Im}$ Ortsterminprotokoll vom 24. September 1806 wurden die Göttiner als Provokanten bezeichnet, die sich auf nichts einlaßen wollten, und nichts achteten und endlich wie tolle Menschen davon gingen. Die von den Neu Töplitzer Erbpächtern bereits gebilligten Separationspläne des Justizrates Jahn vom 18. September 1806, an deren Zustandekommen sich auch der Königliche Hofgärtner David Garmatter aus Paretz beteiligt hatte, kamen damit nicht zustande. Darunter wurde vermerkt: Die K[önigliche] Cammer hat [...] den Bericht [...] erhalten, muß ihn aber unter den jetzigen Umständen anweisen, diese Sache zu einer günstigern Zeit in Anregung zu bringen. Dadurch kam die Separation in Neu Töplitz erst 1841 zum Abschluss. ${ }^{353}$ Eine Auflistung aller der Separation zugrundeliegenden Einzelrezesse findet sich unter den Akten der Superintendentur Lehnin. ${ }^{354}$

Vor diesem Hintergrund soll noch auf zwei Vorgänge hingewiesen werden. Bis Ende des 17./ Anfang des 18. Jahrhunderts war die Agrarverfassung in Europa weitgehend auf die Dreifelderwirtschaft zugeschnitten. Diese starre Ordnung wirkte sich hemmend auf eine Weiterentwicklung aus, da sie die Landnutzung nur innerhalb des von ihr gesteckten Rahmens zuließ. Dieser bestand darin, dass der zur Verfügung stehende Acker in drei Stücke aufgeteilt war, worauf eine jährliche Rotation von Winterung (Roggen), Sommerung (überwiegend Gerste,

350 daselbst: fol. 61 .

351 daselbst: fol. 64/65.

352 daselbst: am Ende nicht mehr paginiert!

353 KA PM: Rep. 50.37/15, 50.37/16, 50.37/17, 50.37/18, 50.37/19, 50.37/21, 50.37/22, 50.37/24 und $50.37 / 25$.

354 DStA Brandenburg: L-E 12 (nicht paginiert). 
ansonsten Hülsenfrüchte und gelegentlich Buchweizen) und Brache zu Gunsten eines Getreideanbaus stattfand. Demgegenüber wurde für die Viehzucht, die im ökonomischen Sinne nur als ein notwendiges Übel (Düngerlieferant) galt, die Futtergrundlage stark vernachlässigt, und damit fehlte das agrarische Entwicklungspotential. Die Brachfelder wurden wegen Mangel an Dünger nicht besät und einem natürlichen Vegetationsaufwuchs überlassen, der neben der Allmende sowie den Stoppelfeldern als Viehweide, aber auch zur Heugewinnung genutzt wurde. Bei dieser Brachebewirtschaftung bestand - vor allem bei leichten Böden die Gefahr einer Bodenerosion und Sandverwehung. ${ }^{355}$ Mit diesem Problem haben sich die Töplitzer offenbar auch auseinandersetzen müssen, wie aus einem aktenkundigen Streit im Jahre 1711 hervorgeht. ${ }^{356}$ Die Töplitzer Schweizer hatten Klage geführt, dass die Alt Töplitzer ihr Brachfeld mit Roggen und Erbsen besät hatten, so dass gegenwärtig ihr Viehe [Schafe] Futter entbehren undt noth leiden müße. Der Amtmann Limmer besichtigte daraufhin im Beisein der Kontrahenten die fraglichen Brachfelder und konnte die Situation nur bestätigen sowie die Alt Töplitzer zur Rede stellen. Die antworteten trotziglich, Sie müßen zwar gestehen, daß Sie niemahlen dieses Feldt, da es hätte brach liegen sollen, Mit Korn Besäet, sie hätten es aber thun müßen, angesehen das itzige Winterfeld durch die Viele Versandung von Jahren zu Jahren geringer würde. ${ }^{357}$ Dieses Vorgehen der Alt Töplitzer wird als Besömmerung der Brache bezeichnet und ist ein schönes pragmatisches Beispiel für das allmähliche Aufweichen der Dreifelderwirtschaft. Zurzeit von Friedrich II., der die Einführung des Kleeanbaus als Voraussetzung für eine ganzjährige Stallfütterung propagierte, fand sich ein weiteres Beispiel für den Wandel der landwirtschaftlichen Wirtschaftsform auf der Insel Töplitz. Pfarrer Wigand aus Alt Töplitz wandte sich am 3. September $1785^{358}$ mit einem Gesuch direkt an den König, ihm von der hiesigen Gemeinde nur ein Morgen [...] von der gemeinschaftlichen Hütung abzugeben, den er sich für seine 5 Kühe und 2 Pferde zum Klee-Bau aptiren [einrichten, herrichten] wolle. Die Gemeinde hätte davon sogar einen Gewinn. Das Ökonomie- und Justizamt Lehnin wurde daraufhin beauftragt, den Prediger mit der Gemeinde dieserhalb zu einigen und zu berichten. Der Ausgang der Sache konnte nicht ermittelt werden.

Die Separation zog sich auf der Insel Töplitz von 1828 bis zur Unterzeichnung des Vertrages am 22. Juni 1841 hin $^{359}$ und erfolgte in mehreren Schritten. Zunächst wurde die Feldmark von Säge und Bethge 1828 vermessen. Daraus wurden 1829 die Grundstücksklassen und die sich daraus ergebenden Ausgleichssätze berechnet. Die Begleichung der durch den Rezess

355 Krzymowski, Richard: Geschichte der Deutschen Landwirtschaft, Stuttgart (1951) 2. Auflage; S. 42-44; Goltz, Theodor Freiherr von der: Geschichte der deutschen Landwirtschaft, 2. Neudruck der Ausgabe Stuttgart von 1902, Aalen (1984), S. 247 und 258 und Müller, Hans-Heinrich: Märkische Landwirtschaft vor der Agrarreform von 1807, Entwicklungstendenzen des Ackerbaus in der zweiten Hälfte des 18. Jahrhunderts, in: Veröffentlichungen des Bezirksheimatmuseum Potsdam, Heft 13, S. 4.

356 BLHA, Rep. 2 Kriegs- und Domänenkammer Nr. D 11279, fol. 86-92R.

357 Es folgen harrsche Beschimpfungen der Neu Töplitzer Schweizer.

358 BLHA, Rep. 2 Kurmärkische Kriegs- und Domänenkammer Nr. D 11307, fol. 1-2R.

359 KA Alt Töplitz: Alt-Töplitzer Special-Separations- und Ablösungsrezess (1828-1833); KA At Töplitz: Verwandlung von Fleischzehnt in Geldzehnt für die Pfarre 1847 (nicht paginiert) 
entstandenen Kosten war sogar erst 1876 abgeschlossen. Im Zuge der Separation wurde 1847 die Naturalzehntabgaben für die Pfarre Alt Töplitz in Geldzehnt umgewandelt.

Die Separation war offensichtlich auch für die Schweizer Erbpächter in Neu Töplitz eine Befreiung von Zwängen, die ihnen Möglichkeiten für einen enormen wirtschaftlichen Aufschwung eröffnete. Davon zeugen heute noch die von ihnen hinterlassenen, zwischen 1880 und 1890 gebauten $^{360}$ und für brandenburgische Verhältnisse überdurchschnittlich großen Höfe. Als Teil der Reichsbauernschaft und des Reichsnährstands sind sie, wie alle Landwirte im Dritten Reich, hofiert worden; dagegen wurden sie in der frühen DDR als ungeliebte Großbauern mit erhöhten Abgaben wirtschaftlich unter Druck gesetzt und zogen es deshalb vor, in den „Westen " zu gehen. Der letzte Nachkomme der Schweizer Erbkolonisten, Paul Bertz (* 1932), der in Neu Töplitz gelebt hat, ist 2013 verstorben. Damit ist ein historischer Prozess vor Ort zu Ende gegangen. Er konnte dem Autor noch einiges über das alte Neu Töplitz erzählen. ${ }^{361}$

\section{Die Ansiedlung der Schweizer Kolonisten auf dem Natte Werder}

Einige Fragen der Ansiedlung d[er Schweizer Kolonisten im Golmer Bruch werden wohl für immer im Dunkeln bleiben. Die Berichte von Bauernkönig als aussagekräftige Informationsquellen versiegen nach dessen Rückreise in die Schweiz, von wo er sich am 27. Januar 1686 beim Kurfürsten noch einmal in aller untertheinigkeit [...] vor die überaus großen gnaden, so ich als ein geringer und unwürdiger in großer maß von Ew. Dhlt. Gnedigst genossen, bedankte. ${ }^{362}$ Das stringent vom ersten Prediger Elisaeus Malacrida geführte Kirchenbuch Vol. I (s. Kap. VI.2.1.) stellt hierfür keinen Ersatz dar. Das Jahrhunderthochwasser, dass die Schweizer 1689 erlebten, ist erst aus späteren Dokumenten überliefert. (s. Kap. V.1.) Lediglich über den zunächst in Vergessenheit geratenen Bau bzw. die Einweihung der Friedensreichkirche 1690 geben zeitgenössische Dokumente Auskunft. (s. Kap. VI.1.) Wann aber ist die Besiedlung des Natte Werder (Nattwerder) erfolgt? Dazu fehlen jegliche Informationen. Man kann allerdings die Zeit der Errichtung der dortigen vier Höfe durch folgende Überlegungen eingrenzen. 1. Sie muss vor dem Bau der Kirche in Nattwerder geschehen sein. Denn ursprünglich sollte nach der von Kurfürst Friedrich Wilhelm bei einer Ortsbesichtigung des Golmer Bruchs im November 1683 spontan geäußerten Idee die Kirche auf dieser Diluvialsandinsel errichtet werden (s. Kap. IV.3.). Dieser Platz war aber inzwischen mit den Nattwerderaner Höfen verbaut worden, so dass sie auf halber Höhe gebaut wurde. Darüber hinaus gibt es 2. Im Zusammenhang mit den Ansiedlungen von Schweizer Kolonisten in Leest im Jahre

360 Buchinger, Marie-Luise und Marcus Cante: Denkmale in Brandenburg, Worms am Rhein (2009), S. 526.

361 Bleyl, Dietmar Walther Richard: Töplitz, Potsdam (2013), Abb. 59, 67 und 68.

362 GStA PK, I. HA, Rep. 11 Geheimer Rat (Akten) Nr. 10308 (nicht paginiert); der Rest der Akte betrifft das zu dieser Zeit sehr angespannte Verhältnis zwischen den Schweizer Kantonen mit Savoyen und Frankreich sowie das Zustandekommen eines Evangelischen Bündnisses als Garant des Evangelischen Glaubens. Wegen ihrer politischen Brisanz wurde sie zum Teil verschlüsselt geführt. 
$1691^{363}$, auf dem Vorwerk Schulzendorf im gleichen $\mathrm{Jahr}^{364}$, in Vielitz ${ }^{365}$ und Klosterheide ${ }^{366}$ die Anweisung zum Bau von Gebäud[en] nach dem model, wie [sie] im Potsdamer bruch vor die Schweizer erbaut worden. Letzteres könnte aus Kostengründen geschehen sein und/oder weil sich diese Gebäude bewährt hatten. Für die Nattwerderaner Höfe bedeutet dies, dass sie sehr wahrscheinlich unmittelbar nach der Jahrhunderthochwasserflut 1689 errichtet wurden. Allerdings reichte der Platz nur für vier Höfe.

Da es bis 1867 keine Hinweise über einen späteren Neubau von Höfen in Nattwerder gibt, dürfte es sich dabei um die Höfe handeln, deren Grundrisse Abbildung 6 zeigt, die anscheinend auch in Neu Töplitz errichtet worden sind. Denn das Haus der Familie Garmatter in Neu Töplitz weist einen identischen Grundriss auf (s. Abb. 5). Dagegen sind die Grundrisse, die Wallstabe (1939) nach mündlichen Überlieferungen versucht hat zu rekonstruieren, in jedem Fall falsch. ${ }^{367}$ Nach den Grundrissen ist auch keine Ähnlichkeit mit Schweizer Bauernhäusern aus dieser Zeit zu erkennen. ${ }^{368}$ Die Anfertigung der Grundrisse in Abbildung 6 ist im Zusammenhang mit der Separation im Jahre 1830 geschehen, als die Schweizer auf keinen Fall bereit waren, auf ihre Holzgerechtigkeit zu verzichten ${ }^{369}$ (s. Kap. V.3.). Es waren vier parallel angelegte Höfe, die einheitlich aus einem kombinierten Stall-Wohn-Haus $(67 \times 34 \mathrm{Fu})$ und einer Scheune bestanden. Beides waren zweistöckige Fachwerkbauten (12 Fuß hoch, mit 2 Fächern verriegelt) mit verbretterten Giebeln. Das Haus konnte man nur vom Hof betreten. Über den Scheunen Fluhr [Mittelgang], an dem auf der linken Seite die Pferde und auf der rechten Seite die Rinder aufgestallt waren, gelangte man in den Wohnbereich der Familie; dies dürfte eine Einsparung von Feuerungsmaterial zur Folge gehabt haben. In dem in sich geschlossenen Wohnbereich waren um die Küche ein Flur, zwei Stuben und drei Kammern angeordnet, wobei die dritte Kammer in den Stallbereich hereinragte. Zwischen der dritten Kammer und der Aufstallung der Pferde befand sich eine Knechtkammer, die sowohl vom Mittelgang als auch vom Pferdestall betreten werden konnte. Zum Vorratsboden führte eine hölzerne Außentreppe. Die Scheunen waren ebenfalls Fachwerkbauten (zwölf Fuß hoch, mit zwei Fächern verriegelt) mit etwa gleich großen Grundrissen; sie unterschieden sich aber in ihrer Aufteilung. In ihnen wurden die Schweine und das Federvieh gehalten; daneben boten sie die Möglichkeit, Wagen unterzustellen (Remise) sowie Kaff, Holz und andere Dinge zu lagern.

Da bis 1716 mit den vier Nattwerderaner Schweizer Kolonisten keine neuen Verträge abgeschlossen wurden, ist davon auszugehen, dass bis dahin für sie trotz Umzugs aus dem Bruch auf den Natte Werder der Arrendevertrag vom 16. September 1685 (s. Kap. IV.6.) im Unterschied

Autor im Mai 2018 in Bern mitgeteilt. Bei Schweizer Bauernhäusern beständen in der Regel sowohl an der
Stirnseite als auch bei Vorhandensein von Quergängen an den Längsseiten eines kombinierten Stall-WohnGebäudes Ausgänge.

369

BLHA, Rep. 7 Amt Lehnin Nr. 38, fol. 1-4.

BLHA, Rep. 2 Kurmärkische Kriegs- und Domänenkammer Nr. D. 12237, fol. 36R.

BLHA, Rep. 7 Amt Lindow Nr. 72, fol. 57R/59.

BLHA, Rep. 7 Amt Lindow Nr. 100, fol. 8R/11R.

Wallstabe, B.: Nattwerder; in: Walter Iwan, Das Golmer Luch, ..., Stuttgart (1939), Heft 18, S. 34.

Diese Einschätzung hat der Spezialist für Schweizer Bauernhäuser, Herr Heinrich Christoph Affolter, dem

BLHA, Rep. 2A Regierung Potsdam III D Nr. 15007, fol. 54. 
zu den Golmer und Töplitzer Schweizern in vollem Umfang gültig blieb; aber auch sie mussten gemäß $\$ 9$ des bisherigen Vertrages bei König Friedrich Wilhelm I. um dessen Verlängerung nachsuchen. Die Supplik hierfür ließ sich nicht auffinden, aber nach dem Bestätigungsschreiben der Königlichen Amtskammer vom 23. Juni 1716 kam am 26. April 1716 ein neuer Vertrag mit Hans Stuck, Melchior Suttor, Jacob Gerig und Hans Winzeried ${ }^{370}$ und dem Amtmann J. C. Schönberg zustande. Im Einzelnen wurde darin in sieben Paragraphen Folgendes geregelt:

- Den vier Schweizer Familien wird der Nadtwerder mit denen Gebäuden, Gärten, Weinberge, Wiesen, sambt Trifft und Hütunge inhalts vorangelegter Außmeßung, zu bewohnen und solche pertinentz Stücke nach Ihren Besten Wißen und Willen ferner zu Nutzen verstattet (\$1),

- Müßen Sie die Gebäude, welche Ihnen von der gnädigsten Herschafft erbauet worden, jeder Zeidt in guten Dach und Fach halten, und dahin sehen, daß nichts in Verderb, oder Abnehmen Komme (\$2),

- Müßen Sie und die Ihrigen, mit dem Feuer so behuthsam umbgehen, damit kein Schade an denen Gebäuden geschehe, wiedrigen falß Sie solchen zu erstatten und alles wieder in dem Stande, wie Sie die Gebäude itzo empfangen, zu lieffern schuldig seyn sollen, wie Sie den auch auf die Dämme gute Aufsicht haben müssen (\$3),

- Zu reparation derer Gebäude und Gehegen, imgleichen das Benöhtigte Brenholtz, wirdt denen 4 Schweitzern ferner also, wie Sie es bißhero von denen Königl. Forstbedienten Bekommen, gefolget, jedoch daß Sie ohne dero Anweisung sich nicht daran vergreiffen sollen (\$ 4),

- Vor vorbeschriebener Nutzung dieser Gerechtigkeit zahlen die 4 Arendatores Jährlich ingesambt 47 Thlr. 23 Groschen 9 d einjeder aber 12 Thlr: welche Quartaliter von Trinitatis 1715 an ohnweigerlich dem Königl. Ambte abgetragen werden müßen, dahin gegen dieselbe von Contribution, Schoß, Einquartirung und anderen oneribus befreyet seyn sollen (\$ 5),

- So lange nun diese arende von diesen 4 arendatoren dem Königl. Ambte richtig abgeführet wirdt und Sie sich als getreue Unterthanen Jeder Zeidt verhalten, sollen Sie und ihre Nachkommen Jedes mahl bey diesen Contract geschützet werden (\$ 6) und,

- Approbation [Genehmigung] des Vertrages durch die Königl. Preuß. Hochpreißl: Amts Cammer und Besiegelung (\$ 7$)$.

Der Vertrag von 1716 unterschied sich damit in wesentlichen Punkten vom Arrendevertrag von 1685 (s. Kap. IV.6.); einige Regelungen stimmten auffälligerweise mit Formulierungen in den Folgeverträgen der in Golm (s. Kap. V.2.) bzw. Neu Töplitz (s. Kap. V.3.) angesiedelten Schweizer überein. Bei Überschwemmungen war kein Schadensausgleich mehr vorgesehen. Hochwasser war eben eine nicht beherrschbare Naturkatastrophe. Die Gebäude, Gärten, Wiesen und Pertinenzen [Zubehör] standen ihnen zur sorgfältigen Nutzung zur Verfügung $(\$ 1)$. Sie waren für sie errichtet worden, und deren jederzeitige gute Unterhaltung wurde ihnen ausdrücklich zur Pflicht gemacht (\$2). Dazu gehörte nunmehr auch der explizit angeführte sorgsame Umgang mit Feuer, wobei die Schweizer für entstandene Schäden vollständig auf-

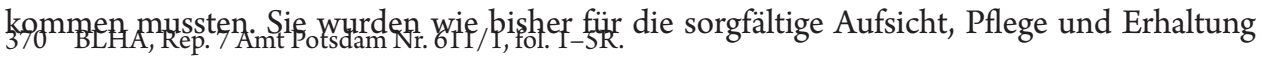


der Dämme im Golmer Bruch verantwortlich gemacht (\$ 3). Das Reparatur- und Brennholz wurde ihnen auch weiterhin aus den Königlichen Forsten zugesagt ( $\$ 4)$. Dafür hatten sie von Trinitatis 1715 an jährlich zusammen 47 Thl. 23 Sgr. 9 d (jede Familie 12 Thl.) zu zahlen. Im Unterschied zu den Golmer und Neu Töplitzer Schweizern wurden sie wie bisher von zusätzlichen Abgaben und sogar von der Einquartierung von Militärs befreit $(\$ 5)$. Gleich den Neu Töplitzer Schweizern wurde ihnen zugesichert, solange sie den vorgenannten Pachtzahlungen nachkämen und sie sich als getreue Unterthanen Jeder Zeidt verhalten, sollen Sie und ihre Nachkommen Jedes mahl bey diesen Contract geschützet werden (\$ 6). Aus Letzterem ergibt sich nicht eindeutig ihr weiterer Rechtsstatus. Sie werden als Arrendatoren - also Pächter - in $\$ 5$ bezeichnet. Bei den Verträgen mit Erbpächtern steht gewöhnlich die Formulierung „erb- und eigenthümlich". Welche Weinberge in $\$ 1$ gemeint sind, ließ sich nicht klären. Allerdings tauchen Weinberge in der summarischen Zusammenstellung der Pertinentien von 1737 und 1743, die die 4. Schweitzer in Nattwerder oder die so genannte 4. Neue Häuser nutzen, auf (s. Tab. 9). ${ }^{371}$

\section{Tab. 9: Die Nutzflächen der Schweizer Kolonisten in Nattwerder}

\begin{tabular}{|c|c|c|c|c|c|}
\hline & \multicolumn{2}{|c|}{ de Anno 1737} & \multicolumn{2}{|c|}{ de Anno 1743} \\
\hline & & Morg. & Quadratruten & Morg. & Quadratruten \\
\hline \multicolumn{2}{|c|}{ An Garten und Weinberge } & 17 & 73 & 17 & 73 \\
\hline & [mittelmäßigen & 76 & 176 & 76 & 176 \\
\hline \multirow[t]{2}{*}{ An Wiesen } & $\begin{array}{l}\text { [schlechten } \\
{[}\end{array}$ & 64 & 29 & 64 & 29 \\
\hline & [Sa an Wiesen & 141 & 25 & 141 & 25 \\
\hline an Röhrung & & 4 & 25 & 4 & 25 \\
\hline rivative Hüt & & 263 & 74 & 263 & 74 \\
\hline
\end{tabular}

Wenn auch die Lage der Weinberge (Westhang des Natte Werders?) nicht klar ist, so gibt diese Aufstellung einen Beleg dafür, dass die Schweizer Kolonisten in Nattwerder bis in die Mitte des 18. Jahrhunderts Weinbau getrieben haben. Dagegen verfügten sie zu dieser Zeit über keinen Acker; später wurde dies durch Zukauf, z. B. in Grube und Leest, ausgeglichen.

Der Bau des Predigerhauses in Nattwerder erfolgte erst unter König Friedrich II. und wird in der Literatur dem Betreiben des Predigers Carl Ludwig Treiber (1738-1766) zugeschrieben. Dabei wurde bislang übersehen, dass es schon vorher Bemühungen in dieser Beziehung gegeben hatte, nicht zuletzt weil der Prediger gemäß Artikel 8 des Ansiedlungsvertrages von 1685 (s. Anhang 4) nur, so lange die Pfarr Wohnung in dem Bruche nicht fertig [ist], eine freye Wohnung in Potsdam zugesichert bekam. Diese übergangsweise Unterbringung des Predigers in Potsdam wurde für die Gemeinde auf Dauer eine schwere Belastung und zugleich eine Kostenfrage, denn er musste zu jeder Amtshandlung in den Bruch geholt und nach Potsdam zurückgebracht werden. Bislang war nicht bekannt, dass sich 1708 Prediger und Gemeine der 
Schweitzer im Gollmisch [en] Bruch an Friedrich I. mit einem Bittgesuch wandten, ob nicht das Vorwerk Grube, für das der Arendator ... nicht praestiren [zahlen] kann, uns umb einen billigen preiß allergnädigst wollten übergeben, und dann zugleich daselbst ein Predigerhaus bauen lassen. Dazu konnten sie gute Gründe anführen: Solchergestallt würde denne der prediger mitten unter der Gemeine, an einem bequemen orthe nahe bey der Kirche, wohnen, und würde die gantze Gemeine dardurch in einen wirklich beßeren Zustandt gesetzet werden. ${ }^{372}$ Obwohl sich in der gleichen Akte $^{373}$ ein befürwortender interner Vermerk [Pro informatione] fand, war ihr Antrag nicht erfolgreich. ${ }^{374}$ Aber ihr Ansuchen ging interessanterweise noch weiter. Sie boten an, im Vorwerk Ehrliche Und fleisige, auch Bemittelte Leuthe [...] aus dem Filial N. Töplitz establiren [zu] wollen und (höchst diplomatisch) die Reform. Religion in dem Potsdammischen Bruch darauf zu gründe $[\mathrm{n}]$. Geschickt verband die Reformierte Gemeinde den im Golmer Bruch zugesagten Pfarrhausbau mit dem privaten Interesse ihrer Mitglieder, um für ihre Kinder eigene Existenzen aufzubauen. Ihre Supplik wurde abgelehnt (s. Kap. II.1).

Als schließlich Prediger Treiber am 24. September 1753 die Genehmigung zum Bau des Predigerhauses erwirkte, versuchten die Nattwerderaner Kolonisten ironischerweise entgegen den vorher geschilderten Bemühungen im Jahre 1708, ihn mit den vielfältigsten Argumenten zu verhindern. Zwar hätte man den prediger bei sich und bräuchte ihn sonntags nicht mehr holen, was übers Jahr einen Fuhrlohn von 30 Rthl. Kostete, den man sparen könne. Der Prediger sei aber so wunderlich, und sie könnten ihm keinen Platz abtreten, [... ] ihn und den Nachfolgern dürfte es gereuen, sich in Nattwerder anzusiedeln. Nicht grundlos wollte bislang niemand von allen bisherigen Predigern draußen in der Einöde [...] leben. Die Nachfolger würden mit Sicherheit klagen, als sie dort fast von allem verlassen, in einer bangen Einsamkeit niemanden zum Umgang und überall nichts Erquickliches dort habe, sondern alles mit gedoppelten Kosten aus der Stadt holen lassen, hiermit die Pfarre wirklich deterioriert [verschlechtert] würde. ${ }^{375}$ Der Grund allen Klagens war: Sie mussten das vor Hochwasser sichere, bislang von ihnen zu Gärten genutzte Pfarrland auf dem Natte Werder als Bauland wieder zur Verfügung stellen, was sich bis heute dahingehend auswirkt, dass das Grundstück des ehemaligen Pfarrhauses aus 10 Teilstücken - einem Flickenteppich - besteht.

Durch den Vertrag von 1716 waren auch den vier Nattwerderaner Schweizer Kolonisten der Erbpächterstatus verloren gegangen. Um diesen alten Rechtsstatus zurückzuerlangen, erschienen die damaligen Contrahenten, Namens Christian Gericke, Peter Dortsche, Simon Suter und Hans Hodeler am 21. Dezember 1764 beim Amt Potsdam und erklärten nach hinlänglicher Überlegung und Bedenkzeit, dass sie

1. ihre inhabende Güter erb und eigenthümlich annehmen wollten, wenn ihnen selbige nebst allen zuBehör, so viel Sr. Majestät davon gehöret,

372 GStA PK, I. HA, Rep. 9 Nr. D 9 Fasc. 4, fol. 34/34R.

373 daselbst: fol. 36/36R.

374 daselbst: fol. 36/36R.

375 GStA PK, X. HA, Rep. 2B, Abt. II, Nr. 690, fol. 14R, KA Alt Töplitz: Pfarrhausbauten im Golmerbruch 1749-1823 (nicht paginiert) sowie Bleyl, Dietmar Walther Richard (Hg.): Nattwerder, Potsdam (2010), S. 48-52. 
geschenket und ohne Erhöhung der jetzigen Abgaben nebst alles dabei jetze

befindlichen freiheiten und Gerechtigkeiten als ihr Eigenthum eingeben werden,

2. praestanda nach wie vor an das Königl. Amt entrichten und

3. da ein jeder unter ihnen deshalb ein vor Sr. Majestät confirmirte

Erbverschreibung erwartet, solche bei der Königl. Kurmärkschen $p$ Kam-

mer Kanzlei auslösen, wenn es auf jeden höchstens Fünf Thaler

ein für allemal kosten sollte.

4. Sie wollten das ganz freie Holz ohne Stammgeld sich bis Trinitatis 1767 nach ihren bisherigen Zeit-Pacht-Kontrakt reservieren lassen, danach darauf bis auf das Bau- und Reparaturholz verzichten sowie

5. ihre Güter bei der allgemeinen Kurmärkischen Feuersozietätskasse eintragen lassen und die Gebühren dafür zahlen. ${ }^{376}$

Umso mehr ist man erstaunt, wie dem Schreiben des Justizamtes vom 15. Mai 1811 an die Regierung zu entnehmen ist, dass nach dessen Aktenlage diese Anträge am 28. August 1766 genehmigt und die entsprechenden Erbpachtverträge unter dem 28. Februar 1767 entworfen wurden, aber die am 28. April 1769 verfügte Vollziehung bisher nicht erfolgt war und deshalb anfragte, ob es die noch immer ausstehende Ausfertigung besorgen solle. ${ }^{377}$ Von der Regierung erhielt das Justizamt die Antwort, dass für den Fall, dass die gegenwärtigen Besitzer noch die von 1769 seien, die Ausfertigung der Pachtverträge ohne weiteres geschehen könne, jedoch der Versuch zu machen sey, die Verabreichung des Bau- und Reparaturholzes gegen eine 1/3theilige Bezahlung zu vereinbaren. ${ }^{378}$ Hierüber konnte kein Einvernehmen erzielt werden, da die Schweizer auf ihr freies Bau- und Reparaturholz beharrten. Hinzu kamen verwaltungsinterne Unstimmigkeiten. Erst am 3. Juli 1828 verlangte die Regierung von den damaligen Besitzern Dokumente, auf welchem Wege sie in den Besitz ihres Etablissements [Höfe] gelangt seien. ${ }^{379}$ Den lückenlosen Nachweis für die Besitzübertragungen von 1685 an beizubringen, waren die Schweizer außer Stande; an Stelle dessen legten sie von Pfarrer Gruss beglaubigte und gesiegelte Extrakte aus den Kirchenbüchern vor, in der Meinung, dass solche zu dem verlangten Nachweise zureichend seien. ${ }^{380}$ Erst nachdem sich die Schweizer Kolonisten in dieser Weise legitimiert hatten und die Dokumente geprüft worden waren, wurde erneut am 20. November 1829 ein Erbpachtkontrakt mit sieben Paragraphen entworfen ${ }^{381}$; dabei wurde in $\$ 3$ die drittheilige Bezahlung des Bau- und Reparaturholzes festgeschrieben, wobei als Maaßstab des Bedarfs der im Jahre 1803 von dem Bau Inspektor Quednow aufgenommene [Gebäude]plan zu Grunde

378 daselbst: fol. 12.

379 daselbst: fol. 31/31R (Randvermerk).

380 daselbst: fol. $37-42$.

381 daselbst: fol. $60-62 \mathrm{R}$. 
gelegt wurde (s. Abb. 6). Ansonsten regelte der Kontrakt die Überlassung der Pertinenzien (54 Morgen Wiesen und 102 Morgen Hütung), sonstiger Gerechtigkeiten und deren Nutzung durch die Erbpächter Carl Friedrich Gericke, Christian Friedrich Dortschy, Emanuel Mauerhof und der Witwe Anne Dorothea Suter, geb. Gütchen ( $\$ 1$ ), die unveränderte Zahlung eines nicht erhöhungsfähigen Kanons von jährlich 12 Talern $(\$ 2)$, die Instandhaltung der Gebäude $(\$ 4)$, die Eintragung der Erbpachtsgrundstücke in das Hypothekenbuch ( $\$ 5)$, Übernahme der Kosten des Vertrages ( $\$ 6)$ und den Vollzug des Vertrages $(\$ 7)$. Für die Schweizer stellte der Kontrakt ein respektables Ergebnis dar. Aber die Erbpachtverträge wurden erst 12 Jahre später im Jahre 1841 endgültig genehmigt; ${ }^{382}$ Dabei spielten vornehmlich wirtschaftliche Schwierigkeiten eine Rolle. Im Schreiben der Erbpächter et Cons. Vom 16. Oktober 1831 an die Regierung begründeten sie ihre Zahlungsrückstände mit den seit einigen Jahren stattgehabten Überschwemmungen ihrer Grundstücke und jährlichen Verlusten von 215 Rthl. ${ }^{383}$ Insgesamt hat damit die Wiedererlangung ihres Erbpächterstatus 77 Jahre in Anspruch genommen.

Die Separation hat in Nattwerder in den 1850/52 stattgefunden und verlief komplikationslos, da die Pertinenzien nur auf die vier Schweizer Familien aufzuteilen waren. ${ }^{384}$ Für die Kirche und den Friedhof wurde ein eigener Grundbucheintrag vorgesehen.

Ihre abgelegene und isolierte Lage hat die Schweizer Kolonisten von Nattwerder weitgehend vor Streitigkeiten mit den umliegenden Dörfern bewahrt. Überliefert ist nur der Nutzungsstreit der Wiesen (Rohrung) längs der Wublitz und dem Damm nach Nattwerder zwischen dem Vorwerk Grube und Nattwerder. Den Schweizern wurde vorgeworfen, dass sie ihre Grundstücke gegen die Königl. Grubowsche Vorwercks Rohrung immer weiter extendiren. Nach dem am 6. Februar 1803 hierzu vernommenen Tagelöhner Lemcke aus Grube seien es mittlerweile 10 Ruthen. ${ }^{385}$ Anhand der 1715 von Grundt ${ }^{386}$ (s. Abb. 4) und 1777 von Erhardt ${ }^{387}$ angefertigten Karten ließ sich der Streit nicht klären, zumal beide nicht übereinstimmten und die Grenzmarkierung nicht mehr eindeutig war. Der Landbaumeister Käferstein wurde beauftragt, die Sache zu klären, und verlangte dafür 29 Tlr., in die sich die Schweizer und das Rentamt zur Hälfte teilen sollten. Aber dagegen wehrten sich die Schweizer vehement. Schulze Mauerhoff schrieb am 21. Juni sowie erneut am 14. September 1804 an König Friedrich Wilhelm III.: ... uns ist mit dem Vorwerk Grubow wegen der Wiese keine Streitigkeit bekannt, $[\ldots]$ auch haben wir den Land Baumeister Kaeferstein nicht verlanget, $[. .$.$] auch ist von Acten$ her nie eine Grenze gewesen. Wir bitten daher, uns die Kosten nicht zur Lasten zu legen, ... ${ }^{388} \mathrm{Das}$ Justizamt Potsdam musste daraufhin der Kurmärkischen Kriegs- und Domainenkammer be-

daselbst: fol. 129-130.

daselbst: fol. 77-78R. Unter den Verlusten wird der Kartoffelanbau erwähnt.

daselbst, BLHA, Rep. 105 GB K I Potsdam Nr. 826 (Kl AG Potsdam HB Golm Bd. 1 Bl. 1-40) und BLHA, Rep. 7 Amt Potsdam Nr. 1895.

BLHA, Rep. 7 Amt Potsdam Nr. 1039, fol. 1.

GStA PK, XI. HA, Karte E 707 (Nattwerder Krs. Osthavelland).

GStA PK, XI. HA, Karte A 733 (Golmerbruch).

BLHA, Rep. 2 Kurmärkische Kriegs- und Domänenkammer Nr. D 15497 (nicht paginiert). 
richten. Diese entschied daraufhin, dass die Schweizer Kolonisten den Streitgegenstand verursacht und die dadurch verursachten Unkosten zur Hälfte zu zahlen hätten.

Schließlich soll auf einen bislang nicht gewürdigten und Nattwerder betreffenden Armenpflegefall in den Jahren 1856 bis 1862 eingegangen werden, weil dabei die Statusfrage von Nattwerder zutage tritt, die im 19. Jahrhundert in Preußen die Voraussetzung für die gemeindliche Zuständigkeit für die Armenpflege war. Der Fall ist im Übrigen detailliert über ca. 250 Folien dokumentiert. ${ }^{389}$ Konkret ging es um den Arbeitsmann Carl Bertz (ein Anverwandter des Erbpächters Bertz in Nattwerder), der am 10. Juli 1856 in Alt-Geltow mit seiner zweiten Frau Friederike, geb. Wille und seinen zwei Kindern ${ }^{390}$ aus erster Ehe wegen Mietrückständen gerichtlich ausgewiesen und obdachlos wurde. Das von ihm aufgesuchte Rentamt Potsdam schickte ihn in seinen Herkunftsort Nattwerder zurück, wo nur eine provisorische Unterbringung im Stall möglich war, und hatte ihn verpflichtet, im Umkreise von zwei Meilen sich um eine Wohnung zu bemühen bzw. Negativatteste vorzulegen. Seine Bemühungen blieben ohne Erfolg. Zeitweise konnte die Familie in Potsdam beim Gärtner Pietsch in der Meierei vor dem Brandenburger Tor untergebracht werden. Die Familie wurde später getrennt; die Frau kam beim Viehhändler in Potsdam unter, die Kinder wurden ins Erziehungs- und Pflegeheim nach Straußberg eingewiesen. Der Landrat von Nauen, Wilkens, der sich von Anfang an in diesen Fall einbrachte, bat die Regierung mit Schreiben vom 3. Mai 1858 zu prüfen, ob die Kolonie Nattwerder als Gemeinde im rechtlichen Sinne angesehen werden könne, da sie weder vor Emanation [Erlass] des Allgemeinen Landrechts als solche bestand, noch später gesetzlich constituirt worden ist und daß mithin dieselbe noch zum Gutsbezirke des Domainen Fiscus gehöre, [...] also auch diesem nach $\$ 56$ des Armengesetzes vom 31. ${ }^{\text {ten }}$ December $1842^{391}$ die Kosten zur Last fallen müßte. ${ }^{392} \mathrm{Im}$ Antwortschreiben vom 7. Juni 1858 gab die Regierung dem Landrat Recht. Die Übernahme der Unkosten wurde dem Rentamt bzw. der Regierungshauptkasse angewiesen. Damit hatte sich die Problematik nicht erledigt. Der Kreistag verhandelte am 26. November 1859 über diesen speziellen Fall und entschied, dass zur Zeit die beabsichtigte Vereinigung [von Nattwerder] mit der Gemeinde Grube auf sich beruhen mag. ${ }^{393}$ Die Obdachlosigkeit spielte in der zweiten Hälfte des 19. Jahrhunderts zunehmend eine Rolle, der mit einer neuen Armengesetzgebung begegnet wurde. In Verbindung damit wurden staatliche Stellen angewiesen, Listen betreffs Incommunalisierung [Eingemeindung] gemeindefremder Grundstücke anzufertigen. Im Schreiben des Landrats von Nauen vom 27. April 1871 wird auch Nattwerder mit folgender Situationsbeschreibung aufgeführt:

390 Friedrich Ferdinand wurde am 01.01.1847 und Heinrich Gustav am 10.10.1852 geboren [KA Alt Töplitz: Kirchenbuch Nattwerder (1847-1949)].

391 Gesetz-Sammlung für die Königlichen Preußischen Staaten 1843, S. 8-14, bes. S. 9.

392 BLHA, Rep. 2A Regierung Potsdam III D Nr. 14958 (nicht paginiert).

393 daselbst: Der Kreistagsbeschluss findet sich als Anhang zum Schreiben des Rentamtes an die Regierung vom 8.02.1859. 
Die 4 Kolonisten-Grundstücke aus Nattwerder, sowie dies ihnen

gehörige früher als Hirtenhaus benutzte sogenannte Ein-

haus sind ursprünglich Terrain der Königlichen Forst bei

Potsdam, wovon diese Parzelle abgezweigt ist, ohne

einem andern Communalverband bisher zugelegt

zu sein. In einem Falle hat Nattwerder die Armen-

last inzwischen schon allein getragen. Allenfalls

könnte, wozu die isolierte Lage drängt, Nattwerder

zusammen mit Einhaus eine Gemeinde bilden

und dies würde voraussichtlich den Kolonisten zu Nattwer-

der erwünscht sein. ${ }^{394}$

Am 3. Juni 1867 brannten die Höfe der Schweizer Kolonisten in Nattwerder ab. ${ }^{395}$ Ein Blitz hatte in den Stall des Kolonisten Schilling eingeschlagen. Das Feuer hatte nach und nach auf alle übrigen Gebäude übergegriffen. An diesen schwärzesten Tag von Nattwerder erinnert in mehreren Wohnungen des Ortes der Zimmermannsspruch von Karl Gartemann anlässlich des Richtfestes der neuen Höfe (s. Anhang 20). Schon zum Erntedankfest 1867 konnten alle Kolonisten in ihre nunmehr massiv gebauten Wohnhäuser mit Schieferdächern einziehen, die noch heute das Ortsbild bestimmen. Der Gemeindekirchenrat von Nattwerder beschloss, dies Ereigniß auch kirchlich [...] am 17. November [...] zu feiern. ${ }^{396}$ Den Akten des Feuer-Societäts-Katasters von Nattwerder war zu entnehmen, dass die Versicherungswerte der neuerrichteten Häuser um das 3,4- und der neuen Höfe insgesamt um das 4,3fache im Vergleich zu den Vorgängerbauten gestiegen waren: ${ }^{397}$

\begin{tabular}{lcc} 
Kolonist & altes Gehöft (Rthr.) & neues Gehöft (RthI.) \\
\hdashline Ernst Wilhelm & 1781 & 7934 \\
Friedrich Mauerhoff & 1616 & 6500 \\
Friedrich Schilling & 1888 & 7934 \\
Karl Gehring & 1800 & 8133
\end{tabular}

Dadurch entstanden neben den noch abzuzahlenden Hypotheken im Zusammenhang mit den Erbverschreibungen enorme finanzielle Belastungen für die Kolonisten. ${ }^{398}$

394 BLHA, Rep. 2A Regierung Potsdam I SW Nr. 22 (nicht paginiert).

395 BLHA, Rep. 41 Amtsbezirk Bornstedt/Bornim Nr. 30, fol. 46.

396 KA Alt Töplitz: Protocoll Buch für den Gemeinde Kirchenrat zu Alt Töplitz und Nattwerder seit 1861 (nicht paginiert), Sitzung am 17. Oktober 1867.

397 BLHA, Rep. 41 Amtsbezirk Bornstedt-Bornim Nr. 30, fol. 51 und 53R.

398 BLHA, Rep. 5D Kreisgericht Potsdam Nr. 104. 


\section{Die Regulierung des Golmer Bruchs}

Unter Bruch versteht man soviel wie eine nasse Region, in der Regel ein Niedermoor. Derartige Landstriche gab es in Brandenburg reichlich, besonders entlang der Flüsse. Sie wurden mehrheitlich in den vergangenen Jahrhunderten entwässert und entgegen unserem heutigen ökologischen Verständnis für eine wirtschaftliche Nutzung urbar gemacht. Die Ansiedlung der Schweizer Kolonisten im Golmer Bruch war ein solcher Versuch und führte zunächst zu einem Desaster, weil die wasserbaulichen Voraussetzungen dafür nicht ausreichten. Wie in Kap. III.2. dargestellt, hatte Kurfürst Friedrich Wilhelm in den Jahren 1678 ff. von holländischen Deichgräbern eine Infrastruktur schaffen lassen, die aus kernlosen Deichen rundherum, Abzugsgräben und einer Windmühle als Schöpfwerk ${ }^{399}$ bestand. Letztere bezeichnete die Abordnung der Schweizer 1684 als doch nur so obenhin gemacht. Sie versprachen sich von ihr offensichtlich nichts und bedungen sich vorsorglich in ihrem Arrendevertrag in Artikel 1 aus, dass der Kurfürst für Schäden durch Überschwemmungen aufkam.

Das spezifische Problem beim Golmer Bruch wurde bereits im Kapitel III.1. beschrieben. Dadurch, dass der ehemalige Gletschersee an dieser Stelle keine Verbindung zur Havel besitzt und zum großen Teil unter dem durchschnittlichen Höhenniveau der Havel bzw. der Wublitz liegt, läuft er im Überschwemmungsfall voll, und das Wasser verbleibt dort, es sei denn, es verdampft allmählich auf natürliche Art und Weise (Sonne und Wind) oder durch künstliches „Ausschöpfen“. Die Möglichkeiten für letzteres waren sehr begrenzt. Insofern waren die Schweizer Kolonisten und die Einheimischen dem Wohl und Wehe der Natur sprichwörtlich ausgesetzt, worauf ein Flurname des Volksmunds Hoffnungsberg hinweist. ${ }^{400}$ Dazu fand sich in der Flurkartensammlung die Anmerkung, blickte er bei Hochwasser noch hervor, so war Hoffnung auf gute Ernte. ${ }^{401}$

Interessant war deswegen in Erfahrung zu bringen, dass im 18. Jahrhundert zurzeit Friedrichs II. Oberjäger Schenck mit Kockers und Schleusen in den an der Wublitz und Havel befindlichen Dämmen mit der Absicht „experimentiert“ hatte, das binnen Waßer aus dem Golmsche bruche dadurch abzulaßen. ${ }^{402}$ Kockers sind - ähnlich wie Schleusen - Dammdurchbrüche, die allerdings schmaler und nicht schließbar sind. Die Kockers seien, weil sie den gehoften effect nicht verschaffet, [...] noch bei Lebzeiten des bemeldeten Ober Jäger Schenck ohne reparatur den Verderb überlaßen worden. Nach dem physikalischen Prinzip der kommunizierenden Röhren konnte das Wasser aus dem Golmer Bruch höchstens bis auf das Havel-/Wublitzniveau abfließen; der Bruch ist aber größtenteils tiefer gelegen.

399 Die im Atlas der Herrschaft Potsdam von Suchodoletz eingezeichnete Poldermühle existierte 1713 nicht mehr.

400 GStA PK, X. HA, Rep. 16 Nr. 1012 fol. 1R.

401 Er liegt von Grube aus in Richtung Marquardt, wo heute das Pumphaus steht.

402 BLHA: Rep. 2 Kurmärkisches Kriegs- und Domänenamt Nr. D 15689, fol. 6/6R. (Bericht vom 14. September 1774). Vermutlich hatte man eingesehen, dass die regelmäßige Überschwemmung des Golmer Bruchs nicht zu verhindern war, und wollte deshalb den Abfluss beschleunigen, um dessen Nutzung zu verbessern. 
Dem Königlichen Ministerium für landwirtschaftliche Angelegenheiten wurde am 21. September 1850 ein Allgemeiner Plan zur Verwallung und künstlichen Entwässerung der Wiesen im Havelthale von Oranienburg bis zur Elbe von der Regierung Potsdam vorgelegt, der aus Kostengründen nicht zu realisieren war. Aber in dem wurde es als unbedingt notwendig erachtet, ein Beispiel hinzustellen, woraus die [...] Grundbesitzer in die Augen springend entnehmen können, auf welche Weise den Nachtheilen, welche das Havelwasser für die Grundstücke bisher gehabt hat, abzuhelfen ist. Da der Golmer Bruch nur circa 3000 Morgen groß ist, wurde es als besonders geeignet für ein solches Entwässerungsbeispiel zur Nacheiferung von weiteren Interessenten gehalten. ${ }^{403}$ Damit beginnt die moderne Geschichte des Golmer Bruchs. Als Erstes wurde die Bildung eines Verbandes zu seiner Entwässerung und Kultivierung angestrebt. Von den hierbei zu beteiligenden Gemeinden wurde dessen Zweckmäßigkeit nicht in Frage gestellt, aber jede Beitragsleistung abgelehnt, und so kam er nicht zustande. Erst dadurch, dass das Interesse an einem solchen Plan bei Friedrich Wilhelm IV. ${ }^{404}$ geweckt werden konnte, wurde am 30. April 1855 nach nordwestdeutschem und holländischem Muster der „Deichverband des Golmer Bruches“ gegründet. ${ }^{405}$ Aber die Situation im Golmer Bruch nahm nach Vollendung der genossenschaftlichen Anlagen im Jahre 1857 (mit Dampf getriebenes Schöpfwerk, Schneidemühle usw.) nicht den erwarteten und wünschenswerten Fortgang. ${ }^{406}$ Ein großer Teil der Deichgenossen verharrte nach wie vor bei seiner ablehnenden Haltung gegenüber dem Unternehmen. Es wurden sogar Anträge zur Auflösung des Deichverbandes gestellt. Diese wurden alle vom zuständigen Ministerium des Innern abgelehnt, da der Verband seine Schulden noch nicht abgetragen hatte. Die Arbeit des Schöpfwerkes musste zeitlich beschränkt und schließlich eingestellt werden.

Erst durch die Fortschritte in der Elektro- und Maschinentechnik wurden 1929 nacheinander drei Dampfschöpfmaschinen in Wildpark-West, Grube/Nattwerder und Grube/Schlänitzsee gebaut $^{407}$, die endlich in der Lage waren, den Hochwasserschutz im Golmer Bruch effektiv zu gewährleisten und die Wasserstände in den Abzugsgräben zu regulieren. Seit 1980 ist das alte Schöpfwerk Grube/Nattwerder (seit 2015 technisches Denkmal) außer Betrieb und von einem noch leistungsstärkeren Pfahlschöpfwerk mit Unterwasserpumpen abgelöst. Seit 1991 betreut der neugegründete Wasser- und Bodenverband Nauen auch den ca. 670 ha großen Golmer Bruch bezüglich Entwässerung.

403 BLHA, Rep. 2A Regierung Potsdam I LW Nr. 1980, fol. 2-5.

404 Friedrich Wilhelm IV. war daran gelegen, die Schwankungen des Grundwassers im Park Sanssouci zu beheben; deswegen wurde der bis dahin bestehende Hauptwassergraben zugeschüttet, und seitdem wird der Park allein durch den Schafgraben entwässert. [Kaschube, Adolf: Der Große Abzugsgraben westlich des Neuen Palais und seine Bedeutung, Ortszeitung der Gemeinde Golm, Februar 2010, S. 6/7.].

405 Gesetz-Sammlung für die Königlichen Preußischen Staaten 1855, S. 246-251.

406 BLHA, Rep. 27 C Kulturbauamt Potsdam Nr. 286, S. 4 ff., Rep. 2A Regierung Potsdam I LW Nr. 1992, fol. 92-96.

407 Kaschube, Adolf: Das Schöpfwerk Wildpark West (Gallin) ist 80 Jahre (I), Das Golmer Luch (bruch) und seine Entwässerungsanlagen (II) und Wassereinzugsgebiet des Schöpfwerkes Grube-Schlänitzsee (III), Ortszeitung Golm November 2009, Juni 2010 und Dezember 2010. 



\section{Reformierte Schweizer Gemeinde im (Golmer) Bruch bei Potsdam}

Ohne Zweifel hat die Aufnahme von Einwanderern mit reformiertem Glaubensbekenntnis die zentrale Bedeutung in der hohenzollernschen Kirchenpolitik gespielt (s. Kap. II.2.), wobei die Ansiedlung im ländlichen Raum größere Schwierigkeiten als im städtischen Bereich bereitete. Die 1685 angesiedelte Reformierte Schweizer Gemeinde im (Golmer) Bruch bei Potsdam nimmt unter den ländlichen Gemeinden die Vorreiterrolle ein und ist - im Gegensatz zu den späteren Ansiedlungen - bis heute noch existent. Auf dem Kirchenbuch Vol. I (1685-1801) wird sie mit Schweitzer-Gemeinde im Bruch bei Potstamb bezeichnet. Das alte Siegel der Gemeinde (s. Abb. 7) war mit Kirchensiegel: Schweizer Bruch beschriftet und enthielt an Stelle eines konfessionellen Symbols - in Anspielung auf die Schiffsreise von Bern/Aarau in den Golmer Bruch - ein Segelschiff.

In der Reformierten Schweizer Gemeinde ist bis auf eine Ausnahme (Presbyterial-Protokolle seit dem 30. November 1766) (08 $^{40}$ das vollständige Archiv überliefert und stand uneingeschränkt für diese Arbeit zur Einsicht zu Verfügung. Das ist besonders hervorzuheben, da auf der Ebene der Dörfer die Pfarrarchive in den meisten Fällen die einzigen erhaltenen Registraturen aus dem 17./18. Jahrhundert sind. Sie stellen in gewissem Maße das letzte Glied in der Kette der preußischen Verwaltung bis 1918 dar. Von den Archiven der Schulzenämter als parallele Lokalbehörde - haben dagegen bestenfalls trümmerhafte Restbestände die Zeiten überstanden. ${ }^{409}$ Eine Zusammenstellung über die vorhandenen Bestände des Pfarrarchivs in Form eines Repertoriums existiert bislang nicht. Die auf Aufforderung des Superintendenten Gielen, Lehnin, von Pfarrer Kietzig am 24. Dezember 1924 verfertigte handschriftliche Aktenauflistung wurde offensichtlich unvollständig und willkürlich zusammengestellt. ${ }^{410}$ Der Ordnungszustand des Archivs erschwerte eine Benutzung zu wissenschaftlichen Zwecken. Eine deswegen vom Autor vorgenommene Bestandsaufnahme im Jahre 2011 hat neben den Lager-, Kirchen- und Rechnungsbüchern 30 Einzelakten in Folioformat ergeben, was einem Gesamtbestand von fast 1,5 Lfm Umfang entspricht. Als bedeutendste Stücke eines

408 Heese, Henning: Aus der Geschichte der evangelisch-reformierten Kirchengemeinde Nattwerder, in: Henning Heese (Hg.): 300 Jahre Schweizer Kolonie im Golmischen Bruch bei Potsdam 1685-1985, St. Augustin (1985), S. 49-67, bes. S. 62, Anm. 18. Die Protokolle sind danach im 2. Weltkrieg durch Brand vernichtet worden (s. Kap. V.2). Nach Kenntnis des Autors hat Friedrich Backschat (Nattwerder - Ein Beitrag zur Geschichte der reformierten Schweizergemeinde im Golmer Bruch und der am 16. November 1690 eingeweihten „Friedrichs-Kirche“, in: Potsdamer Tageszeitung Nr. 272 vom 18. November 1911) als Einziger daraus zitiert: In den Presbyterial-Protokollen lesen wir häufig von Reparaturen [am Pfarrhaus]: so 1767, 1780, 1786. Im Jahr 1801 muss eine Hauptreparatur stattgefunden haben, denn der Prediger wohnte wieder in Potsdam, weshalb man in der Presbyterial-Versammlung am 14. Juli desselben Jahres beschloss, ihm alle 14 Tage von Potsdam zum Gottesdienst abzuholen.

409 Czubatynski, Uwe: 700 Jahre Quitzöbel. Beiträge zur Ortsgeschichte auf der Grundlage des Pfarrarchivs, Nordhausen (2010), S. 40.

410 DStA Brandenburg: BEN 232/176 (nicht paginiert). 
solchen Pfarrarchivs werden die Kirchen-, Lager- und Rechnungsbücher sowie die Protokolle des Presbyterial-/Gemeindekirchenrates angesehen. Letztere enthalten in der Regel nur Ergebnisprotokolle. In den Lagerbüchern sind alle Vermögenswerte der jeweiligen Gemeinde (Grundstücke, das bewegliche und unbewegliche Eigentum, veränderliche und unveränderliche Einkünfte, Schenkungen ${ }^{411}$ sowie Inventarlisten) und deren zeitliche Änderungen enthalten. In den Rechnungsbüchern erhält man einen detaillierten Einblick über die jährlichen Einnahmen (Klingelbeutel, Beckengeld bei Kasualien ${ }^{412}$ und Zinsen für Darlehen; s. Kapitel VII.3.) und Ausgaben (Wein und Brot für Kommunion ${ }^{413}$, namentlich aufgeführte Almosen an Gemeindeglieder). Wie die Beispiele zeigen, finden sich in den genannten Büchern interessante Informationen, die eigentlich nicht in diese Bücher gehören, die es aber zu erschließen gilt. Darüber hinaus liegt der spezifische Wert von Pfarrarchiven in der Erschließung lokaler Besonderheiten aus den Spezialakten, die im Laufe der Zeit ihren schriftlichen Niederschlag gefunden haben.

\section{Friedensreichkirche und Kirchhof}

In Artikel 8 des Arrendevertrages vom 16. September 1685 (s. Kap. IV.6.) waren die kirchlichen Privilegien der Schweizer Kolonisten im Golmer Bruch aufgeführt. Hierin ist nicht die Rede von einer eigenen Kirche, obwohl Kurfürst Friedrich Wilhelm bereits diese Zusage im Schreiben vom 2. September 1684 an die Stadt Bern gemacht hatte. Ursprünglich sollte sie, wan nun die leüthe alle Beherberget, [...] alsobalt an der Kirch angefangen werden Zu Bauen, und Zwar damit sie schleünig aufgerichtet, erst nur von Holtz oder Bretter aufgesetzt, und hernach um daß Holtz daß Maurwerk gesetzt, und daß Holtz wieder weg genommen werden. Dazu ist es entgegen der Darstellung von Heese (1985) und anderen nicht gekommen ${ }^{414}$; das Vorhaben scheint sogar zeitweise wieder in Vergessenheit geraten zu sein, denn in einem Schreiben des Oberjägermeisters von Lüderitz vom 27. April 1688 an den Kurfürsten wird daran erinnert (s. Anhang 5). ${ }^{415}$ Mit dem Bau der Kirche könnte danach frühestens begonnen worden ${ }^{416}$ und

411 Im Lagerbuch Nattwerder finden sich u. a. detaillierte Angaben zur Verwendung des „Schneider’schen Baufonds" - eine Stiftung von 200 Rthl. von Anna Schneider, der Haushälterin von Prediger Treiber aus dem Jahre 1765. Näheres s. Dietmar Walther Richard Bleyl, Töplitz, Potsdam (2013), S. 157/158.

412 kirchliche Amtshandlungen (Gottesdienst, Taufe, Konfirmation, Trauung und Beerdigung).

413 Im Rechnungsbuch der Evangelisch-Reformierten Schweitzer Gemeine im Golmer-Bruch ist im Jahre 1742 NB vermerkt: Es haben bey Lebens Zeit des Hochseel: Königs Majest: [Friedrich Wilhelm I.] sonsten alle hiesige und auch meine Kirche, die Wohlthat des freyen-Communio-Weins genoßen, welches von deßen Absterben an cessiret [entfallen]. Dies ist ein beredtes Beispiel für die Haltung Friedrichs II. zu Religionen.

414 StA Bern: A.V. 19. Teutschland-Buch Preussen-Brandenburg fol. 128; Heese, Heening: Aus der Geschichte der evangelisch-reformierten Kirchengemeinde Nattwerder, in: Henning Heese: 300 Jahre Schweizer Kolonie am Golmische Bruch bei Potsdam 1685-1985, Sankt Augustin 1985, S. 53.

415 GStA PK, I. HA, Rep. 47 Lit P 3 (Paket 15853), fol. 688. Dieses Schreiben ist kurioserweise von v. Lüderitz unterschrieben und an ihn gerichtet.

416 StA Bern: A.V. 19 Teutschland-Buch Preussen-Brandenburg fol. 231: ... daß die eyn wichung unßerer Kirche, alß Zue welchen gebeüw Ihr Cuhrfl. Durchl alles gält avanciert, vnd keinen kosten gesparet, ihr Vortgang bald, sonderlich nachdemme Ihr Curfl. Durchl Durch Gottes gnad vnd güte früsch vnd gesund in ihrer residenz widerumb ankommen, haben werde... 
im Herbst 1690 wird sie vollendet gewesen sein. Denn im Bittgesuch der Schweizerischen Gemeinde im Golmer Bruch (s. Anhang 6) ${ }^{417}$ ist von der erbauten Kirche die Rede, aber durch die Abreise des Kurfürsten nach Cleve sei kein schrifftlicher Befälch über deren Einweihung erfolget. Da aber bey dieser annahenden Wynters zeyt nicht so bequeme fält, in einem ängen gemach den Gottes dienst zu halten, wird darum gehorsamst und unterthänigst gebeten. Die Kirche wurde schließlich am 16. November 1690 auf Befehl des Kurfürsten Friedrich III. durch den Hofprediger Anton Brunsenius eingeweiht (s. Anhang 7) ${ }^{418}$ und erhielt mutmaßlich von Kurfürst Friedrich Wilhelm zunächst den Namen „Friedensreichkirche“, 419 der sich über das 17. Jahrhundert hinaus nicht tradiert hat. Ihr Architekt ist unbekannt.

Die reformierte Kirche Nattwerder ${ }^{420}$ am südöstlichen Abhang des Natte Werder ist heute noch fast vollständig im ursprünglichen Zustand erhalten und seit dem Jahr 2000 der Kern des Flächendenkmals Nattwerder; es ist ein schlichter, massiver Saalbau von drei Fensterachsen Länge und dreiseitigem Ostschluss. Den Westgiebel überragt ein ca. $25 \mathrm{~m}$ hoher Turm mit ziegelgedecktem Pyramidendach und einer Wetterfahne, die fälschlicherweise die Jahreszahl 1685 trägt. Der schlichte, verputzte Sakralbau schließt den dreigeschossigen Turm mit quadratischem Grundriss ins Kirchenschiff ein. Die schmalen Korbbogenfenster schließen mit einer schlusssteinartigen Bekrönung ab. Der Haupteingang ist im Westen, ein weiterer Eingang im Norden (üblicherweise der Brauteingang) angeordnet.

Der Kirchenraum ist gegliedert durch die leicht erhöhte dreiseitige Apsis (s. Abb. 8) und das Kirchenschiff, in das von Westen her der Turmunterbau hereinragt. Zum Kirchenraum korbbogig geöffnet, enthält er eine bauzeitliche Empore (kurfürstliche Patronatsloge) ${ }^{421}$, die sich auf beiden Seiten fortsetzt. Das Innere der Kirche atmet bis auf den heutigen Tag calvinistische Strenge, die durch die schmalen, bis zum Fußboden weiter ausgeführten Fenstereinlassungen unterstrichen wird. Die räumliche und geistliche Mitte bleibt in der Apsis dem schlichten Abendmahlstisch vorbehalten, auf dem erst seit 1854 ein vergoldetes Kruzifix und zwei, ebenfalls vergoldete Altarleuchter stehen, die ein anonymes Gemeindeglied gespendet hat. ${ }^{422}$ Die schlichte achteckige Holzkanzel aus der Bauzeit, die mit einem Knorpelgirlande versehen ist, aber sonst keinerlei weitere Ausschmückung aufweist, steht an der vorderen Südseitenwand. Darüber kann man noch die Verankerung des ehemals vorhandenen Schalldeckels sehen. $\mathrm{Ob}$ sie da von Anfang an gestanden hat, wird bestritten ${ }^{423}$, ungeachtet der Tatsache, dass seit Erbauung der Kirche in der Mitte der Apsis - wo normalerweise eine Kanzel steht - bis heute unterhalb des Fensters ein Spind in die Wand eingelassen ist und von da ab der südliche Teil der

417 GStA PK, I. HA, Rep. 21 Nr. 123 (Paket 7997), fol. 196 (undatiert).

418 daselbst: fol. 195.

419 BLHA: Rep. 2, Kurmärkische Kriegs- und Domänenkammer Nr. D.15409, fol. 9.

420 In der reformierten Theologie nimmt die Bibel, verstanden als göttliche Offenbarung, die zentrale Stelle ein. Dies schlägt sich nieder in der Schlichtheit der Kirchenräume und des Gottesdienstes, der auf die Verkündigung des Evangeliums zentriert ist und möglichst wenige außerbiblische Elemente enthalten soll.

421 Die patronatliche Teilnahme an einem Gottesdienst ist aktenkundig nicht belegt.

422 KA Alt Töplitz: Lagerbuch der Kirchengemeinde Nattwerder (1863 angelegt), S. 37.

423 Kitschke, Andreas: Die Kirchen der Potsdamer Kulturlandschaft, Berlin (2017), S. 44-46, bes. S. 44. 
Apsis vom dreireihigen Presbyterialgestühl eingenommen wird. Unter diesem Spind begrub am 9. September 1707 der Prediger Sigismund Lupichius sein Töchterlein, Anna Louysa. ${ }^{424}$ Insoweit ist es schlecht vorstellbar, dass in der Apsis ursprünglich der Kanzelkorb gestanden hat, wie dies in der reformierten Kirche in Storbeck bis heute der Fall ist. Da für die Aufstellung einer von König Friedrich Wilhelm II. erbetenen Orgel im Jahre $1797^{425}$ auf der Westseite der Kirche kein Aufstellungsort vorhanden war, wurde kurzer Hand in der Apsis bis über den Abendmahltisch ${ }^{426}$ auf zwei wuchtigen hölzernen Balusterstützen eine selten zu findende Ostempore mit vorschwingender Brüstung errichtet, die ein wenig über den Treppenaufgang zur Kanzel reicht. Dafür musste angeblich die Holzkanzel auf die Südseite unmittelbar vor die Empore weichen. Welche Meinung stimmt, ist nicht mehr feststellbar. Im Nachhinein stellte sich die Orgel von Johann Friedrich Starke aus Treuenbrietzen nach dem Gutachten des Orgelbauers Johann Carl Hinneberg vom 21. Oktober 1811 als Pfuschwerk heraus. ${ }^{427} \mathrm{Er}$ ließ sich darin zu folgendem, niederschmetterndem Urteil hinreißen: Ein Pfuscher hat die alte Orgel zusammengestümpert. Sie war schon am Tage der Einweihung der Reparatur benöthigt. Man könne kein elenderes Werk sehen! An Stelle dieser Orgel steht heute - dank der Aktivität des Vereins Schweizer Kolonistendorf Nattwerder - eine Orgel mit 7 Manual- und 1 Pedalregister der Fa. Schuke, Potsdam, aus dem Jahre 1996. ${ }^{428}$ Wie einst drehen sich Sonne und Mond bei Zimbelklang am originalen, spätbarocken Orgelprospekt. Der klangästhetischen Vorstellung des Barocks entsprechend ist sie mit einer Francesco Antonio Valotti-Stimmung ausgestattet.

Von dem sonstigen Inventar der Kirche Nattwerder sind insbesondere die fünf Totenkronenbretter aus den Jahren 1815, 1820, 1821, 1838 und $1847^{429}$ unter der südlichen Westempore und drei Glocken zu erwähnen. Der Totenkronenbrauch war bei beiden christlichen Konfessionen vor allem in Brandenburg vom 17. Bis in das 19. Jahrhundert weit verbreitet. Mit Totenkronen - meist aus künstlichen Blumen und bestickten Bändern - wurden als Ersatz für die zu Lebzeiten entbehrte Brautkrone unvermählt verstorbene Frauen und Männer geehrt. ${ }^{430}$ Leider ist nicht nur eine Reihe dieser Totenbretter abhandengekommen; es fehlen den noch vorhandenen auch das entscheidende Attribut, nämlich die auf der Konsole aufbewahrte Totenkrone. Ihre Inschriften sind zeitgemäß, wie beispielsweise:

425 Die aus 16 großen Familien bestehende zur Kirche zu Nattwerder hiesigen Amts gewidmete Gemeine wünscht zu mehrerer Erweckung in ihrer Kirche eine Orgel und diese um so mehr, da der Küster Wernicke Alters halber mit dem Vorsingen theils nicht mehr fortkommen kann ... [BLHA, Rep. 2A Regierung Potsdam II Osthavelland Nr. 1412, fol. 3.; KA Alt Töplitz: Orgel Nattwerder 1894-1912 (nicht paginiert).].

426 Seit der Unierung steht darauf ein Kruzifix und zwei Leuchter.

427 daselbst: fol. 14.

428 Bleyl, Dietmar Walther Richard (Hg.): Nattwerder, Potsdam (2010), S. 28-31.

4291931 wurden im Zuge einer Bestandsaufnahme der Kirche Nattwerder 13 gestapelte Totenkronenbretter gefunden, die renoviert und farbig wiederhergestellt werden sollten [DStA Brandenburg: L-E AT 1-419 (nicht paginiert), Schr. des Provinzialkonservators von Brandenburg vom 11. November 1931.].

430 Müller, Sylvia: Denkmäler des Totenkronenbrauchs in der Mark Brandenburg, in: Brandenburgische Denkmalpflege 11 (2002) S. 52-65; dies.: Denkmäler der Liebe - Zeugnisse des Totenkronenbrauchs in der Mark Brandenburg, Berlin, 2007, S. 7-15; Tödtman, Hans: Ausdruck des Schmerzes - Die Totenkronenbretter der Dorfkirche Nattwerder, Alte Kirchen (Mai 2017), S. 9. 


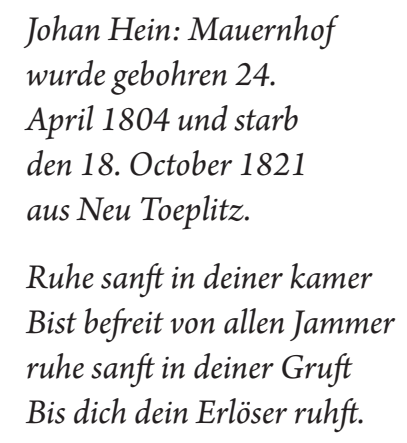

An der nördlichen Seite der Westempore hängt eine hölzerne Gedenktafel ${ }^{431}$, die eine Steinplatte imitiert. Sie erinnert daran, dass im Befreiungskrieg 1813-1815 vier Söhne der Schweizer Kolonisten Friedrich Wilhelm Gerich aus Nattwerder $\left({ }^{*} 10\right.$. September 1791), Christian Friedrich Gerich aus Nattwerder $\left({ }^{*}\right.$ 3. August 1788), Heinrich Schweingruber aus Golm $\left({ }^{*} 23\right.$. Juli $1782)$ und Bendikt Zech aus Golm $\left({ }^{*}\right.$ 7. Juni $\left.1793^{432}\right)$ für die Befreiung vom französischen Joch gefallen sind. (s. hierzu auch Kap. VII.2.). Ein ursprünglich angehängter Orden des Gefallenen Christian Friedrich Gerich ist bedauerlicherweise einem Sammler zum Opfer gefallen. Das Besondere an dieser Gedenktafel ist, dass sie zeitnahe und nicht, wie viele dieser Gedenktafeln, erst 1865 auf Befehl des Königs zum 50. Jahrestages der Befreiung entstanden ist. Außerdem weist sie eine Retusche im Namen Schweingruber auf. Unter dem Eisernen Kreuzes (Emblem) inmitten von zwei Siegerkränzen und den Namen der Gefallenen findet sich folgender Spruch:

Sie zogen hier mit Gott zum Streite.

Für König und für Vaterland,

Der Tod nahm sie von unser Seite,

und führte sie ins beßre Land,

Im Himmel fanden sie ihr Glück,

Doch bleibt ihr Nam, bei uns zurück.

Die drei Glocken stammen aus den Jahren 1677, 1701 und 1964. Älter als die Kirche selbst ist eine eiserne Glocke, gemäß Inschrift „AN 1677“. Sie ist eine der ältesten ihrer Art in Deutschland und wurde aus bisher ungeklärten Gründen 1964 durch eine im gleichen Jahre von der Fa. Schilling \& Lattermann, Apolda, gegossene Stahlglocke ersetzt. Seitdem ist sie im Mittelgeschoss des Kirchturms abgestellt (s. Abb.9); zur Klärung ihrer Herkunft gibt es noch Forschungsbedarf. ${ }^{433}$ Die Bronzeglocke von 1701 war ursprünglich für die längst verschwun-

431 Auf älteren Abbildungen ist sie noch - wie vom König vorgeschrieben - mittig an der Orgelemporenbrüstung angebracht.

432 im Kirchenbuch mit Bendix eingetragen; zu Errichtung von Gedenktafeln für die Gefallenen von 18131815 s. BLHA, Rep. 2A Regierung Potsdam II Generalia Nr. 1837.

433 Es könnte sich dabei um die im gleichen Jahr für Werder gegossene Glocke handeln (Schmidt, Rudolf: Märkische Glockengiesser im 17. und 18. Jahrhundert, in: Jahrbuch der Brandenburgischen Kirchengeschichte, Berlin, 15 (1917), S. 119.), über deren Verbleib und Schicksal in den eher spärlichen Kirchenakten von Werder im DStA Brandenburg nichts in Erfahrung zu bringen war. Diese Hypothese ist wegen der örtlichen 
dene Kapelle in Neu Töplitz gegossen worden. Zur Geschichte dieser Glocke wird auf die Veröffentlichung des Autors verwiesen. ${ }^{434}$ Ihre Inschrift lautet:

GOSS MICH JOHANN JACOB SCHULTZ IN BERLIN ANNO 1701
[kreisförmig angeordnet]
DER SCHWEIZER COLONIE IN NEU TOPLITZ
IST DIESE GLOCKE VON DENEN LOBLICHEN
REFORM. CANTONS FREYGEBIG UBERSANDTEN
COLLEKTEN GELDERN GESCHENKET WORDEN.

Die Kirche Nattwerder verkörpert nach Meinung des Brandenburgischen Landesamtes für Denkmalpflege und Archäologischen Landesmuseums, Wünsdorf, mit ihrer soliden Bauweise, den schlichten Formen und der wenigen Bauzier den „Musterbau“ einer Dorfkirche am Ende des 17. Jahrhunderts; etliche Kirchenbauten in der Umgebung wie z. B. Nudow (1733/34), Phöben (1758) oder Ruhlsdorf (1707) greifen auf diese Form zurück.

Um die Friedensreichkirche herum wurde in herkömmlicher Weise ein Kirchhof angelegt und auf die einzelnen Kolonistenfamilien aufgeteilt. Die ursprüngliche Aufgliederung des Kirchhofs lässt sich bis heute anhand der Grabmale der Familie Kiener im östlichen, der Familien Bertz, Schilling und Dortschy im südlichen und der Familien Gerich und Mauerhoff im westlichen Teil des Friedhofes nachvollziehen. Auf dem nördlichen Teil des Friedhofes sind vor allem die 1945/46 nach Nattwerder gekommenen Umsiedler aus Schlesien und dem Wartheland beigesetzt. Das barocke Sandsteingrabmal der Familie Gerich gegenüber dem Turmeingang der Kirche dürfte vermutlich das älteste erhaltene Grabmal sein. ${ }^{435}$ Ansonsten wäre das kreuzförmige Grabmal von Friedrich Kiener/Regina Kiener, geb. Heese aus dem Jahre 1853 das älteste. Es wurde auf der einen Seite mit den Personenangaben und auf der anderen Seite mit dem Hinweis beschriftet: Sie feierten das seltene Fest der goldenen Hochzeit am 17. Februar 1851. Des Weiteren haben sich 44 historische Grabmale - dank der Aktivität des Vereins Schweizer Kolonistendorf Nattwerder - bis heute erhalten und sind in den Jahren 2000/2001 restauriert worden. Wegen der Vielzahl der bis heute erhaltenen Grabsteine aus dem 19. Jahrhundert (darunter auch auffallend viele Kindergräber) hat der Friedhof Nattwerder historische Bedeutung und ist mit diesem Charakter erhaltenswert. Auf wenigen Grabmalen befinden sich noch die angebrachten Applikationen aus Zinkguss, typischerweise die Darstellung zweier, ineinandergreifender Hände. Die Deutung dieser Symbolik steht noch aus: Es könnte sich dabei um einen Begrüßungs- oder Verabschiedungsgestus handeln. Auch die Inschriften der Grabmale sind insofern bemerkenswert, als sie unverhohlen den Stolz der Kolonistennachkömmlinge auf ihren gesellschaftlichen Stand und vor allem ihre schweizeri-

Nähe und vielfachen Beziehungen zwischen Nattwerder und Werder naheliegend. Günter Schaefer und Heino Strobel (2017) mutmaßen, dass die Glocke aus dem ehemaligen von 1644 bis 1666 errichteten Hochofen in Zehdenick stammt (Glocken aus Eisenwerkstoffen, Teil 1., in: GIESSEREI-PRAXIS 4/2017, S. 155-161, bes. S. 156. Das Gußjahr 1677 spricht dagegen.

434 Bleyl, Dietmar Walther Richard: Die rätselhafte Neu Töplitzer Glocke, in: Mitteilungsblatt der Landesgeschichtlichen Vereinigung für die Mark Brandenburg e. V., 117 (2016), S. 74-80.

435 Die Beschriftung ist nicht mehr lesbar. 
sche Herkunft reflektieren. Mit den Betitelungen Schweizer Gutsbesitzerin (Christine Sophie Kiener, geb. Dortschy, gest. 1877), Schweizer-Erbpächter (Friedrich Ferdinand Schilling, gest. 1883) und Schweizer-Erbzins-Kolonist (Friedrich Mauerhof, gest. 1925) wollten die Schweizer Familien noch im 19./20. Jahrhundert die lebendige Verbundenheit mit ihrer Geschichte demonstrieren. Diese Einstellung, etwas Besonderes zu sein, kam auch bei der Schaffung des Neu Töplitzer Friedhofs zum Tragen. Als sich bei der Beerdigung von Carl Friedrich Schilling im Jahre 1901 herausstellte, dass die Grenzen der einzelnen Familienbegräbnisstätten auf dem Friedhof in Nattwerder unklar sind ${ }^{436}$ - es war beim Herstellen des Grabes zu einer Berührung mit den Särgen der Familie Bertz gekommen -, entschlossen sich die vermögenden Gutsbesitzer in Neu Töplitz, die zur Kirchengemeinde Nattwerder gehörten, einen eigenen Friedhof für sich, ihre Angehörigen und ihre Arbeiter anzulegen. Der Antrag hierfür wurde vom Konsistorium 1903 schließlich genehmigt.

An dieser Stelle soll wenigstens auf eine seit ca. 300 Jahren nicht mehr existierende und deshalb völlig in Vergessenheit geratene Kapelle in Neu Töplitz eingegangen werden. Das Erstaunliche ist daran, dass man in verschiedenen Archivquellen auf Hinweise über eine Kirche in Neu Töplitz stößt, die in der Literatur bislang aber nicht Beachtung fanden. ${ }^{437}$ Vor allem aber stellt die bereits oben erwähnte Neu Töplitzer Glocke selbst einen handgreiflichen Beweis für deren Existenz dar. Statt gezielte Recherchen anzustellen ${ }^{438}$, wurden Behauptungen über die Herkunft und Geschichte dieser Glocke angestellt. Wenn Mehlhardt ${ }^{439}$, Wentscher ${ }^{440}$ und andere hierzu schrieben, diese Glocke hätten die Schweizer mitgebracht bzw. sei ihnen zeitnahe nachgesandt worden, dann zeigt das, dass sie offensichtlich die Widmungsinschrift der Glocke (s. oben - Goss mich Johann Iacob Schultz in Berlin Anno 1701) nicht kannten. Vette ${ }^{411}$ behauptete, dass die Glocke zunächst in der Kirche Nattwerder aufgehängt war und nach der Errichtung des neuen Schulhauses im Jahre 1844 nach Neu Töplitz kam. Die Recherchen des Autors klärten den tatsächlichen Sachverhalt auf. Durch eine Beschwerde bei Kurfürst Friedrich III. im Jahre 1697 über die gottesdienstlichen Verhältnisse in Linow und anderen reformierten Ge-

436 KA Alt Töplitz: Protokollbuch des Gemeindekirchenrates Nattwerder (1900-1909), Sitzung der kirchlichen Körperschaften Nattwerder am 29. April 1901, S. 206.

437 Als Beispiele sollen hier nur folgende Quellenhinweise erwähnt werden: 1) Den 18. Jan [1682] ist das Vorwerck Töplitz mit allen Früchten ohne die Burg und alte Kirche, samt dem Kornhause voll Korn bis auf den Grund abgebrannt, in: KA Alt Töplitz: Kirchenbuch Alt Töplitz 1652-1804, Bl. 24; 2) In dem Plan von der gantzen Gegend bey Potsdam aus dem Jahre 1773 ist in Neu Töplitz ein Kirchensymbol eingezeichnet (BLHA, Allgemeine Kartensammlung Nr. 376 A) und 3) Bei den Inventarlisten des Vorwerks Töplitz aus dem Jahre 1693 findet sich der Eintrag: Alt Schloß so vor die Kellerthure an der Alten Kirche abgebrochen (BLHA, Rep. 2 Kurmärkische Kriegs- und Domänenkammer Nr. D 11279, fol. 36.). Weitere Hinweise s. Bleyl, Dietmar Walther Richard: Die rätselhafte Neu Töplitzer Glocke, in: Mitteilungsblatt der Landesgeschichtlichen Vereinigung für die Mark Brandenburg 117 (2016), S. 74-80.

438 daselbst.

439 Mehlhardt, Dieter: Vierhäuser oder Nattwerder, Auf den Spuren der Schweizer Siedler im Golmer Bruch, in: Brandenburgische Neueste Nachrichten 27 (1977) Nr. 256 vom 29./30. Oktober 1977.

440 Wentscher, Erich: Die Schweizer Kolonien in der Mark Brandenburg, in: Archiv für Sippenforschung und alle verwandte Gebiete 7, S. 238-244, 291-294, 388-391 und 429-432.

441 Vette, Markus: Töplitzer Wege, Arbeits-, Lebens- und Verkehrswege, Kirchen- und Schulgeschichte der Gemeinde Töplitz, Norderstedt (2003), S. 106 und 126. 
meinden im Ruppiner Raum, erreichte Prediger Hercules Delliker ${ }^{442}$, dass der Kurfürst seinem Vorschlag, mit Kollektengeldern aus der Schweiz ein reformiertes „Kirchenbauprogramm“ zu finanzieren, zustimmte. In diesem Zusammenhang wurde dann auch die alte Kapelle in Neu Töplitz wieder in Stand gesetzt, und sie erhielt eine Glocke, deren Widmungsinschrift mit den für die Kirchen in Linow, Lüdersdorf, Schulzendorf, Storbeck und Michelsdorf gegossenen Glocken (bis auf die Ortsbezeichnung und Jahreszahl) identisch ist. ${ }^{443}$ Wie lange die Kirche in Neu Töplitz genutzt worden ist, lässt sich nur in etwa an Hand des Nattwerderaner Kirchenbuches abschätzen (s. Kap. VII.). Gewiss ist die spätere Nutzung der Glocke als Schulglocke. Aktenkundig ist ihr Umhängen von der alten auf die neue Schule in Neu Töplitz, die der Fiskus verhindern wollte. Denn dem Schulzen Wilhelm Dortschy wurde befohlen, sich am 20. Juni 1844, 9.00 Uhr auf dem Königlichen Rent- und Polizeiamt Potsdam wegen der zu Veräußerung bestimmten Glocke einzufinden. ${ }^{44}$ Zusätzlich wurde er angewiesen, in der Zwischenzeit, bis auf weitere Bestimmung sich aller Disposition über die g[edachte] Glocke zu enthalten. Durch den begütigenden Vorschlag des Bauinspektors Ziller blieb der Gemeinde die Glocke schließlich doch erhalten; er schlug vor, über dem Eingangsbereich der neuen Schule einen zusätzlichen Quergiebel zur Aufhängung der Glocke vorzusehen. Diese Situation ist den älteren Einwohnern von Neu Töplitz bis zur endgültigen Auflösung der Neu Töplitzer Schule (1964) noch gut in Erinnerung. Die Evangelische Kirchengemeinde Alt Töplitz betrachtete sich als Nachfolger der reformierten Gemeinde Golmer Bruch und damit als Eigentümer der Glocke und überführte sie Ende 1963 nach Nattwerder, wo sie am 4. April 1964, 15.00 Uhr im Gottesdienst eingeweiht wurde und bis heute im Turm der Kirche hängt. Sie konnte hier aufgrund ihrer Intonation, in h', nicht in ein Glockengeläut eingebunden werden. Aber sie ist seit April 2010 wieder als Halb- und Stundenschlag mit ihrem hellen Klang zu hören. Das entspricht annähernd ihrer ursprünglichen Widmung. ${ }^{445}$

\section{Das Wirken der reformierten Prediger für ihre Gemeinde}

Bezüglich der kirchlichen Organisation der reformierten Gemeinde im Golmer Bruch bei Potsdam wurden im Ansiedlungsvertrag aus dem Jahre 1685 in Artikel 8 lediglich vage Vereinbarungen getroffen (s. Kap. IV.6.). Den Predigern wurde ein iärliches Salario [Gehalt] von 200 Talern und im Bruche etwas Land zum Garten, nebst etwas Wiesewachs zu erhaltung etlicher Kühe, auch Acker zugesichert. Sie waren dadurch nicht auf Einnahmen von Stolgebühren angewiesen und damit gegenüber den lutherischen Predigern privilegiert. Daneben genossen sie, wie alle Geistlichen Potsdams, die Akzisefreiheit. Sie wurde ihnen von den Steuerbeamten immer wieder streitig gemacht. Bis 1734 blieb sie ihnen erhalten; von da an wurden

442 seit 1690 Schweizer Prediger in Linow.

443 http:/ns.gis-bldam-brandenburg.de/hida4web/view?docld (eingesehen am 08.04.2016).

444 BLHA, Rep. 7 Amt Potsdam Nr. 1742 (nicht paginiert): Schreiben vom 13. Juni 1844.

445 KA Alt Töplitz: Protokollbuch des Gemeindekirchenrates Alt Töplitz vom 7. Januar 1865, S. 304 sowie KA Alt Töplitz: Chronik Töplitz (nicht paginiert). 
sämtlichen Predigern in Potsdam das Steuerprivileg wegen Missbrauchs genommen. ${ }^{46}$ Die Schweizer Prediger genossen ferner Freiholz; auch dieses Privileg wurde ihnen 1738 entzogen. Aber in ihrer Amtsausübung waren sie ... so lange in dem Bruche die Pfarr Wohnung nicht fertig [ist] ... gehandikapt. Denn für alle Kasualien [Amtshandlungen] mussten sie mit den verkehrstechnischen Möglichkeiten der Zeit die $15 \mathrm{~km}$ von Potsdam aus in den Bruch fahren bzw. abgeholt werden.

Neben diesen örtlichen Rahmenbedingungen hat der Autor versucht etwas über die Amtsausübung der Prediger der Schweitzer-Gemeinde im Bruch bei Potstamb herauszufinden. Was charakterisierte und unterschied sie gegenüber den lutherischen Predigern? Hierzu ließen sich keine persönlichen Zeugnisse auffinden; das damalige Verständnis für diese Fragestellungen ging in Ansätzen aus dem amtlichen Schriftverkehr hervor. Dazu zählen die jeweiligen Präsentationsschreiben, in denen Schultheiß und Rat der Stadt Bern dem Kurfürsten/König von Brandenburg/Preußen Kandidaten für die Besetzung der Pfarrstelle im Golmer Bruch empfehlen. Im Falle des ersten Predigers im Golmer Bruch, Elisaeus Malacrida (1685-1687), geschah dies folgendermaßen: eine Persohn die nit allein Von Unseren Academien treffenliche Attestationen Vorzuweisen, sonderen die gantze Zeit seines alhiesigen aufenthalts sich Ehrlich und wohl Verhalten hat, auch seiner Erudition [Bildung, Gelehrsamkeit] und lebwesens sonders gerümet wird, haben Wir denselben ohngeacht, Er, in ansehen anderwertig Ihme Vorstehender fortun anfänglichet, was repugnanz Verspühren [Widerstreben, Widerwillen] laßen Zu einem Prediger dieser Leüten Verordnet. ${ }^{447}$ Es wundert nicht, dass er keine zwei Jahre als Gemeindeprediger in Brandenburg blieb; er hatte ganz andere berufliche Neigungen (s. Kap. VI.2.1.). Zum damaligen Amtsverständnis lässt sich weiterhin das Zeugnis für Prediger Sigismund Lupichius (1705-1717) heranziehen, dass ihm sein Vorgesetzter, Prof. Sterky, anlässlich seiner angestrebten Rückkehr in die Schweiz 1710 ausstellte (s. Anhang 13). ${ }^{48}$ Er nimmt darin Bezug auf die von ihm in Neu Töplitz vorgenommene Kirchenvisitation, in deren Ergebnis er dessen Gemeinde [...] in einem sehr guten stand gefunden. Abgesehen von der Schulaufsicht, die damals den Predigern als lokale Schulinspektoren oblagen, sind bei den genannten und wahrgenommenen Aufgabenbereichen grundsätzlich keine Unterschiede zur heutigen Amtsausübung erkennbar. Gemäß $₫ 3$ der Evangelisch-Reformierten Inspektions-Verordnung vom 24. Oktober 1713 bzw. deren konfirmierten Fassung vom 5. Januar 1737 waren sie bei Kirchenvisitationen zu beachten. ${ }^{449}$

Über das religiöse Gemeindeleben der Schweitzer-Gemeinde im Bruch bei Potstamb ließ sich nicht viel in Erfahrung bringen. Welche Meinung vertraten ihre reformierten Prediger (s. Anlage 14) in Bezug auf die strittigen Glaubensfragen vor allem im Verständnis des Abendmahls

446 Die spezielle Situation der Prediger im Golmer Bruch, vor allem solange sie in Potsdam wohnten, ist im Kirchenarchiv Alt Töplitz in der Akte Golmer Bruch - 5 Vorgänge (Accisebonifikation 1735-1768) dokumentiert (nicht paginiert).

447 StA Bern: A.V. 19 Teutschland-Buch Preussen Brandenburg, fol. 95-96.

448 GStA PK: I. HA, Rep. 9 Nr. D. 9 Fasc. 4 fol. 114/114R.

449 GStA PK: I. HA, Rep. 243 Nr. 879, fol. $220 \mathrm{ff}$. 
und der Prädestinationslehre? ${ }^{450}$ Nachweislich wurde zum Abendmahl nach reformierter Tradition Brot und Wein gereicht. Das seit dem Jahr 1735 erhaltene Rechnungsbuch ${ }^{451}$ gibt hierüber penibel Auskunft: Vor Communion-Brodt jedesmahl á 1. gl. Da das Abendmahl auf Weihnachten, Ostern, Pfingsten, Johannis und Michaelis gefeiert wurde, fielen hierfür also insgesamt fünf Groschen als Ausgaben an. Als bedauerlich wird im Rechnungsbuch hervorgehoben, dass die Gemeinde bis 1742 die Wohlthat des freyen-Communio-Weins genoss. ${ }^{452}$ Das Brotbrechen beim Abendmahl ist die einzige reformierte Tradition gewesen, die sich bis in die Amtszeit von Pfarrer Viebeg (1989-2016) erhalten hat. Diese bemerkenswerte Tatsache wurde auch im Protokoll des GKR Nattwerder vom 13. August $1949^{453}$ ausdrücklich festgehalten: Eine reformierte Tradition besteht eigentlich nur noch beim hl. Abendmahl (zum Teil halten des Kelches in der Hand des Kommunikanten).

Die Suche nach exegetischen Hinterlassenschaften der reformierten Prediger verlief erfolglos. Insgesamt 15 Leichenreden einschließlich der Angabe der ausgelegten Bibelstelle sind allein im Kirchen-Buch der Schweitzer-Gemeinde im Bruch bei Potsdamb Vol. I (1685-1801) vermerkt; diese Gepflogenheit kam erst 1739 auf und fand sich nur bei Familie von Wykersloot, Erbpächtern und Schulmeistern - also bei den sozial gehobenen Dorfschichten. Bedauerlicherweise ließen sich davon aber keine in schriftlicher bzw. gedruckter Form auffinden. Erst aus dem 19. Jahrhundert liegen schriftlich fixierte Predigten vor, die in Verbindung mit Kirchen- und Schulvisitationen zustande gekommen sind (s. Kap. VI.3.). Bei dieser Gelegenheit wurde immer ein Gottesdienst gefeiert, und die dabei gehaltene Predigt musste schriftlich niedergelegt werden, damit der Superintendent sie dem Konsistorium zur Prüfung vorlegen konnte. Zu dieser Zeit waren aber schon einheimische Pfarrer im Amt.

Die geistliche Betreuung einer Gemeinde (Seelsorge) erfolgt durch Personen, nicht durch Institutionen. Insofern wäre es verfehlt, hier nicht wenigstens auch auf einige Prediger näher einzugehen. Dabei fallen vor allem die ersten drei ins Auge: Elisaeus Malacrida (1685-1687), Albrecht Wyttenbach (1687-1705) und Sigismund Lupichius (1705-1717); ihr Wirken soll deshalb eingehender in Kap. VI.2.1.-3. dargelegt werden. An anderen Stellen dieser Arbeit finden sich Hinweise zu den Predigern bzw. Pfarrern Karl Ludwig Treiber (s. Kap. VII.4.), Johann Christoph David Hübenthal (s. Kap. VII.5.), Johann Friedrich Kessler (Anm. 563 und 567, s. Kap. VI.4.1.), Walter Martens (s. Kap. VI.4.2. und VI.4.3.) und Dr. Friedrich Wienecke (s. Kap. VI.4.3.). Alle Prediger bzw. Pfarrer des Golmer Bruchs bzw. von Nattwerder sind mit Angabe ihrer Amtszeiten im Anhang II aufgelistet. Von Pfarrer Johann Friedrich Kessler (1832-1852) soll ergänzend erwähnt werden, dass seine Gemeindearbeit von der Kirchen-

450 s. Anm. 83 und 84.

451 KA Alt Töplitz: Rechnungsbuch der Evangelisch-Reformierten Schweitzer Gemeine im Golmer bey Potsdam de Anno 1735-1848, (nicht paginiert).

452 s. Anm. 413.

453 s. Anhang 22. 
leitung sehr geschätzt wurde. Deshalb erhielt er anlässlich seines 50-jährigen Dienstjubiläums und seiner Emeritierung [Pensionierung] 1852 den Roten Adlerorden IV. Klasse. ${ }^{454}$

Da die Prediger im Bruch bei Potsdam einer Migrantengemeinde vorstanden, fungierten sie zumindest anfänglich neben ihrer seelsorgerlichen Tätigkeit vor Ort als Verbindungsglieder zwischen der alten und neuen Heimat. ${ }^{455}$ In dieser Beziehung hielten sie vor allem Kontakt zum Magistrat in Bern, vermittelten aber auch zwischen der Regierung, dem Kirchlichen Oberdirektorium, den Amtmännern und den Schweizer Kolonisten. Auch diesbezüglich sind vor allem die ersten drei Prediger im Golmer Bruch Elisaeus Malacrida, Albrecht Wyttenbach und Sigismund Lupichius interessant. Wegen deren Fürsprache bei der Obrigkeit dürften die einheimischen Bauern die Schweizer Kolonisten beneidet haben. Für die bäuerlichen Einwanderer war dies eine ganz wichtige Unterstützung, denn es mangelte den Schweizer Kolonisten der ersten Generationen sicherlich am nötigen diplomatischen Auftreten und entsprechender Eloquenz, zumal ihnen jegliche Urbanität und persönliche Nähe zum Hofe fehlten. Dagegen werden die Schweizer später mehrfach ausdrücklich als streitbar bezeichnet, die keine gerichtliche Auseinandersetzung scheuten.

Bei der Wahrnehmung dieser Aufgaben bestand allerdings für die Prediger offensichtlich die Schwierigkeit, einerseits den Vorstellungen von Schultheiß/Bürgermeister und Rath der Stadt Bern zu entsprechen und andererseits ab 1713 dem Kirchendirektorium (bzw. den späteren Nachfolgeeinrichtungen) und dem Kurfürsten/König als Summus episcopus zu unterstehen. Man kann zunächst von einer quasi „Doppelunterstellung“ sprechen. Die Berner Stadtväter sahen nämlich die ausgewanderten Schweizer Kolonisten (s. Kap. IV.2.) und die ins Ausland entsandten Prediger weiterhin als ihre Untertanen an. Das beauftragte Mitglied des Rates der Stadt Bern versicherte bei der Verabschiedung in der Nydeggkirche den nach Brandenburg ausreisewilligen Kolonisten: sie können auf die treue Oberaufsicht der Bernischen Regierung zählen. Gehe es ihnen gut, so sollten sie die alte Heimat nicht vergessen; blieben jedoch ihre Hoffnungen unerfüllt, so werde man sie jederzeit mit offenen Armen wieder aufnahmen. ${ }^{456}$ Insoweit waren die Prediger dem Kanton Bern unterstellt, haben in die alte Heimat von ihren Schwierigkeiten vor Ort umfänglich berichtet und sogar um Anweisungen für ihr Handeln gebeten. Dies kommt auch deutlich in den verwendeten Begrifflichkeiten zum Ausdruck. Der Magistrat Bern bezeichnete seine ehemaligen Untertanen als Schweitzer bzw. deren Ansiedlungen als Schweitzer-Coloneyen. Andererseits verwendeten die Prediger in ihren Briefen an den Rath der Stadt Bern die Anrede: Hochgeachte, Gnädige Herren und Oberen etc. ${ }^{457}$

454 DStA Brandenburg: BEN 230/336 (nicht paginiert), Schr. d. Kgl. Consistorium der Provinz Brandenburg v. 06.04.1852. Weitere Informationen zu den Predigern der Schweitzer-Gemeinde im Bruch bei Potstamb finden sich bei Bleyl, Dietmar Walther Richard: Nattwerder, Potsdam (2010), S. 65-68.

455 Zwar gab es offenbar auch private Kontakte, aber die hielten sich in Grenzen. Der Schriftverkehr hierüber dürfte in den wenigsten Fällen in staatliche Archive gelangt sein. Exemplarisch kann er durch den notariell beglaubigten Vertrag über den Tausch von Grundbesitz zwischen Emanuel Dortschy, Erbkolonist in Neu Töplitz, und Mathys Nastzgar, Statthalter von Üttemdorff/Schweiz, vom 12.03.1729 belegt werden [KA PM: Rep. 50.37/9.].

456 Tobler, Gustav: Die Reise der Berner Kolonisten ..., Bern, 19 (1889), S. 44-47, s. Anhang 1.

457 StA Bern: A. V. 19 Teutschland-Buch Preussen Brandenburg, fol. 173-174. 


\section{Reformierte Schweizer Gemeinde im (Golmer) Bruch bei Potsdam}

Das weitgehende Einvernehmen zwischen dem Kanton Bern und Kurbrandenburg über den Sonderstatus der Schweizer Kolonisten erfährt mit dem Regierungsantritt von König Friedrich Wilhelm I. (1713-1740) eine schwere Erschütterung. In diesem Zusammenhang muss zunächst auf die Errichtung des Directorium(s) zum Schweitzer Etablissement 1695 hingewiesen werden. ${ }^{458}$ Dieser Sonderstatus der reformierten Schweizergemeinden widersprach grundsätzlich dem absolutistischen Verständnis König Friedrich Wilhelms I. von einer zentralisierten Verwaltung. ${ }^{459}$ Der Bildung des Generalfinanzdirektoriums als allumfängliche Behörde fiel auch das zum Schweitzer Etablissement verordnete Ober-Directorium zum Opfer und damit wurde die Verwaltung der Schweizer Kolonistendörfer wieder auf die zuständigen Domanialämter übertragen, mithin wieder in die allgemeine Staatsverwaltung eingegliedert und verlor ihren Sonderstatus.

Den abrupten Kurswechsel bekamen die Schweizer Kolonisten im Golmer Bruch als erste von den Schweizer Kolonistendörfern in Brandenburg zu spüren ${ }^{460}$, weil sie einen bitter lutherischen Amtman, v. Görne, hatten. Unter König Friedrich I. (1688-1713) hatten sie bereits verschiedentlich Attaques seitens des lutherischen Amtsmannes erlebt ${ }^{461}$; aber diese hatten sie außgestanden, zumal der König sich auf das Supplik ihres Predigers Lupichius letztendlich mit dem Ausspruch hinter sie gestellt hatte: die Schweitzer möchten in Gottes nahmen in Ihrem bisherigen stande verbleiben. Daraufhin war die Kolonie biß zu des hochseeligen Königs Tod unturbiret [ungestört] geblieben. Der Amtmann, der gegen die Schweizer Kolonisten eingestellt war, hatte sich durch die Verwaltungsreformen unter König Friedrich Wilhelm I. ermuntert gesehen, die Schweizer Kolonisten in den Dörfflein Gollm, Galin und Nathwerder nun erst recht mit drastisch erhöhten Pachtgeldern existentiell zu bedrängen. Dazu zitierte er die 14

458 Die Gründung dieser Behörde erfolgte 1695 unter Kurfürst Friedrich III. Sie stand unter der Leitung von E.v. Brandt, Graf und Burggraf Alexander v. Dohna und Konsistorial- und Amtskammerrat Heinrich von Portz. Der Kurfürst wagte damit einen verwaltungspolitischen Schritt, infolge dessen die beiden Ämter Lehnin und Lindow sowie die vier mit Schweizer Kolonisten besetzten Vorwerke von Altruppin aus der allgemeinen Domanialverwaltung herausgelöst und dieser außerordentlichen Behörde ausschließlich unterstellt wurden. Er schützte damit die Schweizer Kolonisten vor den mehr oder weniger deutlich geäußerten Vorbehalten seitens der Hofkammer, der Amtleute, der landständischen Ritterschaft und der einheimischen Bevölkerung. Der Linower Prediger Delliker kann diese Situation in seinem Schreiben an den Magistrat Zürich nicht genugstem preysen, krafft welcher, Wir nechst dem König unter Niemand stehen ... [StA Bern: A. V. 19 TeutschlandBuch Preussen Brandenburg, fol. 367-369, bes. fol. 367]. Die Neu Töplitzer Schweizer Kolonisten genossen ebenfalls diesen Status, gehörten aber weiter kirchenorganisatorisch zur Reformierten Gemeinde im Golmer Bruch.

459 Baumgart, Peter: Friedrich Wilhelm I., in Frank-Lothar Kroll (Hg.), Preußens Herrscher. Von den ersten Hohenzollern bis Wilhelm II., München (2000), S. 134-159.

460 Die nachfolgenden Zitierungen sind alle dem Schreiben des Predigers, Sigismund Lupichius, an den Schultheiß und den Rat der Stadt Bern vom 14.04.1713 (einschließlich 2 Anlagen) entnommen [StA Bern: A. V. 19 Teutschland-Buch Preussen Brandenburg, fol. 395-405].

461 Dieser hatte in einer weitläuffigen Schrift die 14 Schweizer Familien im Golmer Bruch, ihre Wirtschaft und die Erfüllung ihrer Verpflichtungen gemäß Arrendekontrakt aus dem Jahre 1685 untersucht und „herausgefunden“, dass die Gemeinde eine Schuldenlast von 34,505 Thalern auf sich genommen hatte, worunter auch die Reisekosten und andere Ausgaben, zu denen der Kurfürst Friedrich Wilhelm sich niemals verpflichtet hat, inbegriffen waren [StA Bern: A. V. 19 Teutschland-Buch Preussen Brandenburg, fol. 395.]. 
Schweizer Familienväter auf das Amt und beschimpfte sie geharnischt: Ihr faule Schweitzer habt den Bruch so laßen eingehen, daß er fast unnutzbahr geworden ist, und habt um bald 30 Jahr frey geseßen, ohne der gnädigsten Herrschafft waß zu geben. Sollten sie sich nicht bis zum 11. Juni 1713 dazu bereiterklären für das Vorwerk Golm 500 Taler und für das Vorwerk Gallin 150 Taler jährlich zu zahlen, würden die beiden Vorwerke gemäß königlicher Weisung an den meistbiethenden Verpachtet werden, möget Ihr wieder gehen, wo ihr hergekommen seit, hier /: Mit dem Finger auf des Amtsmanns Tisch weisend:/ soll eüch der abscheidt geschrieben werden. Prediger Lupichius verteidigte daraufhin seine Gemeinde in ganz ungewöhnlich mutiger Art und Weise (s. Kap. VI.2.3.

Auch die Beziehungen zwischen Kurbrandenburg und dem Kanton Bern bekamen dabei einen Dämpfer. Dass sie nicht gänzlich eingestellt wurden, hing nicht zuletzt mit dem Interesse der evangelischen Kantone zusammen, den calvinistischen Glauben in Europa zu verbreiten und zu stärken. Der Verzicht von Kurfürst Friedrich Wilhelm auf das Kirchenregiment (s. Kap. IV.6.) hatte dafür eine günstige Gelegenheit geboten, den es weiter zu nutzen galt. Insoweit waren die seit 1651 (s. Anm. 463) wiederholt stattfindenden Kollektensammlungen in den evangelischen Schweizer Kantonen und Städten ${ }^{462}$ für bestehende ${ }^{463}$ und aufzubauende reformierte Gemeinden nie ganz uneigennützig; die Brandenburgischen Pfarren waren offensichtlich sogar attraktiv, was folgende Zahlen von ihren „Pfarrpfründen“ zeigen: ${ }^{464}$

\begin{tabular}{lcl} 
Lindauw & 200 thlr. (Zürich) & 300 thlr. (Bern) \\
Lütersdorff & 360 thlr. " & 300 thlr. " \\
Lünauw & 260 thlr. " & 300 thlr. " \\
Neüw Rupin & 320 thlr. " & 300 thlr. " \\
Neüw Statt Eberswalden & 230 thlr. " & 230 thlr. " \\
Lehnin & 250 thlr. " & \\
Neu Döplitz & 60 thlr. & \\
\hdashline & Sa. 1680 thlr. & 1430 thlr.
\end{tabular}

Über diese Pfarrpfründe fand schließlich eine unerquickliche Auseinandersetzung zwischen den Ständen Bern und Zürich statt, ${ }^{465}$ wobei man sich nicht einigen konnte über eine proportionirte Eintheilung dieser Pfarreyen nach Anzahl beidseithig sich drunden befindender geweßten Unterthanen oder aber eine terminirte Alternation. Der Hintergrund dieser Streitigkeiten waren die Unterschiede bei den genannten Gemeinden in Bezug auf Annehmlichkeit, Wohlhaben-

462 Appenzell, Basel, Bern, Biel, Glarus, Mühlhausen, Schaffhausen und Zürich.

463 Für die im Dreißigjährigen Krieg zerstörte reformierte Kirche in Magdeburg fand bereits 1651 eine Kollektensammlung in den evangelischen Schweizer Kantonen statt [StA Bern: A. V. 19 Teutschland-Buch Preussen Brandenburg fol. 795-796.]

464 Zur Ermittlung dieser Zahlen korrespondierten beide Magistrate getrennt mit den ehemaligen Schweizer Predigern - Bern mit Albrecht Wyttenbach (nun Pfarrer in Wohlen), Ludwig Benteli (nun Pfarrer in Huttwil) (StA Bern: A. V. 19 Teutschland-Buch Preussen Brandenburg, fol. 657 ff., 665 ff., 669 ff., 672 ff. und 705) und stellten dabei fest, daß nicht mehr alß 6 Brandenburgische pfrüende existieren Vnd Neüw Döplitz nur eine annexe Von Pot $\beta$ dam sey.

465 StA Bern: A. V. 19 Teutschland-Buch Preussen Brandenburg, fol. 701-703, 709-711, 719-722 u.a. 
heit und Einkommen. Dies nahm schließlich König Friedrich Wilhelm I. 1735 zum Anlass, die Pfarrstellen mit einheimischen Pfarrern zu besetzen. Mit dem Ende der Institution der Schweizer Prediger rissen auch für die Kolonisten die Kontakte zur alten Heimat ab.

Anders als die lutherischen Geistlichen, die Hofprediger und die französisch-reformierten Pfarrer bildeten die brandenburgischen Schweizer Prediger keine für protestantische Territorien typischen Pfarrerdynastien aus. ${ }^{466}$ Die von der Stadt Bern berufenen Pfarrer kehrten ohnehin nach nur wenigen Jahren in die Heimat zurück, blieben somit ihren schweizerischen Verwandtschafts- und sonstigen Beziehungssystemen verbunden und begründeten damit ihre Supplikate an den Kurfürsten/König wegen Revokation. ${ }^{467}$ Eine Ausnahme bildete Johann Henrich Ruetschi, der vom Schultheiß und Rat der Stadt Bern als reformierter Prediger für Lehnin in Vorschlag gebracht wurde, ${ }^{468}$ dort auch von 1722 bis 1724 wirkte, von da aber auf mehrfache Bitten der Gemeinde Zerbst dorthin als 3. Prediger auf Lebenszeit berufen wurde. ${ }^{469}$ Die vom Züricher Magistrat präsentierten Schweizer Prediger versahen zwar in der Regel ihren Dienst im Ausland auf Lebenszeit, aber sie spielten zahlenmäßig in der brandenburgischen Geistlichkeit überhaupt keine Rolle.

\subsection{Elisaeus Malacrida}

Der Erste Prediger dieser Gemeinde ware Elisaeus Malacrida (s. Abb. 8), kahme mit derselbigen an d. 18. Junii 1685. ${ }^{470} \mathrm{Ihm}$ ist die Anlegung des Kirchenbuches (Vol. I) gleich nach Ankunft der Schweizer Kolonisten im Golmer Bruch zu verdanken. Schultheiß und Rat der Stadt Bern hatten ihn dem Kurfürsten Friedrich Wilhelm bereits im April 1685 präsentiert. Die darin zur Person gemachten Ausführungen legen die Annahme nahe, ${ }^{471}$ dass er sich auf dieser Stelle fehl am Platz fühlt, und so nimmt es nicht wunder, dass er die erste beste Gelegenheit nutzt und sich 1687 an der Hohen Schule in Bern um die freigewordene Professur für Griechische Sprache und Ethik bewirbt (s. Abb. 10). ${ }^{472}$

Beim Kurfürst findet dieses Ansinnen zugleich Bedauern und Verständnis, und er ersuchte den Berner Magistrat, unß ein anderes tüchtiges Subjectum an seine Stelle zu vorgedachtem Predigt-Ampte in Vorschlag [zu] bringen. ${ }^{473}$ Der Bürgermeister von Bern präsentierte daraufhin im Februar 1687 den ehrwürdigen und gelehrten, unseren Burger Albrecht Weitenbach, den Academicum, der [sich] diese Zeit in Marpurg [Universität Marburg] befinden soll ... und bat,

466 Fischer, Otto, Märkische Pfarrergeschlechter, in: Jahrbuch für Brandenburgische Kirchengeschichte, 21 (1926), S. 22-58 und 25 (1930), S. 122-138.

467 Abberufung, z. B. Prediger Lupichius [GStA PK, I. HA, Rep. 9 Nr. D. 9 Fasc. 4, fol. 113.].

468 StA Bern: A.V. Teutschland-Buch Preussen Brandenburg: fol. 531/532.

469 daselbst: fol. $567 \mathrm{ff}$. und $583 \mathrm{ff}$.

470 AT Alt Töplitz: Kirchen-Buch der Schweitzer-Gemeinde im Bruch bei Potstamb, Vol. I (1685-1801, nicht paginiert), im Vorspann von ihm selbst vermerkt.

471 s. Kap. VI.2.

472 StA Bern: A.V. Teutschland-Buch Preussen Brandenburg. fol. 173-174.

473 daselbst: fol. 179-180, bes. fol. 180; GStA PK, I. HA, Rep. 50 Nr. 6 (nicht paginiert), Schr. des Kurfürst Friedrich Wilhelms an den Berner Schultheiß vom 01.12.1686 und 24.03.1687. 
dass dessen Anstellung mit gleichen Gnaden, als gegen seinen Praedecessor [Vorgänger] geschehen sollte. ${ }^{474}$ Dies bestätigte der Kurfürst am 24. März 1687. ${ }^{475}$ Obwohl die Dienstzeiten der späteren Prediger deutlich länger als zwei Jahre betrug, zeigt sich hierbei ein typisches Charakteristikum der Berner Schweizer Prediger. Sie versahen nur vorübergehend ein brandenburgisches Pfarramt, um nach wenigen Jahren in der Heimat ein attraktiveres geistliches Amt anzutreten.

\subsection{Albrecht Wyttenbach}

Die Auswahl Albrecht Wyttenbachs zum Prediger im Golmer Bruch (1687-1705) war mit Sicherheit ein Glücksfall für die Gemeinde, denn durch ihn hat sie in der schwierigsten Zeit ihres Bestehens tatkräftige Hilfe erfahren. Offensichtlich hat er die Arrendeverträge über die Vorwerke Golm (s. Kap. V.2.) und (Neu)Töplitz (s. Kap. V.3.) mit ausgehandelt; sie sind beide von ihm unterschrieben. Im letzteren Fall übernahm er sogar die Kaution als Garant dafür, dass die Schweizer Kolonisten die eingegangenen Verpflichtungen einhalten würden. Von ihm existieren drei Berichte vom Dezember 1687, April 1692 und Juni 1693 an Schultheiß und Rat der Stadt Bern, die nicht nur des Inhaltes wegen, sondern vor allem wegen ihrer sprachlichen Abfassung lesenswert sind. ${ }^{476}$ Im ersten schildert er optimistisch, welche Entwicklung mitlerzeit die Ansiedlung der 17 Schweizerischen Familien allhier bey Potsdam gemacht hat, und sie hoffen ... Geliebts Gott, daß die eyn wichung [Einweihung] unßerer Kirche, alß Zue welchen gebeüw [Bau] Ihr Cuhrfl. Durchl. alles gält avanciert vnd keinen kosten gesparet, ihr Vortgang bald ... haben werde. ${ }^{477}$ Im zweiten bedankt er sich u. a. bei seinen Gnädigen Herren und Oberen für die Vbersendung der Vilen Vnd Nuzlichen Büecheren [...] als große Unverdiente $G a b{ }^{478}$ ohne nähere Angabe hierzu zu machen. Im dritten führt er Klage über die inzwischen nachgekommenen Schweizer; gemeint sind die Kolonisten, die 1690/91 im Ruppiner Land angesiedelt wurden. ${ }^{479}$

Wyttenbach wurde am 9. April 1691 das jus visitandi über die andern Schweitzer prediger übertragen ${ }^{480}$, und er erhielt in dieser Funktion bereits am 2. Mai 1691 von Kurfürst Friedrich III. den Befehl, sich nach Lindow und Ruppin zu begeben, um dort dem Hauptmann v. Gertzeneinige Exemplare des Neuen Testaments in der Übersetzung Luthers, Letzteres geschah, damit nicht der Eindruck entstünde, als wenn beide Konfessionen gar in allem discrepierten [Kuby, Alfred Hans: Auswanderung von Bern nach Brandenburg 1691. Ein Tagebuch aus dem Berner Ratsmanual, in: Genealogie, Heft 11/1989, S. 730-732.].

479 daselbst: fol. 255-257.

480 GStA PK, I. HA, Rep. 47 Tit 15 (Paket 15707), fol. 281; die Supplik von Johannes Schmiman an den Kurfürsten Friedrich III. vom 03.02.1693 nimmt Bezug auf die Inspektionstätigkeit Wyttenbachs [GStA PK, I. HA, Rep. 2 No. 47 (nicht paginiert)]. Nach der Rückkehr von Wyttenbach in die Schweiz wird diese Funktion Prof. Sterky übertragen [BLHA, Rep. 7 mt Lindow Nr. 181 (nicht paginiert), Schr. v. 24.05.1707]. 
see $z u$ assistiren und der Gemeinde, biß sie Vollkommen eingerichtet [ist], alß Prediger vor[zu] stehen. Dem aus Bern stammenden adligen Hauptmann Johann Jacob am Biel v. Gertzensee hatte man dort die Aufgabe als Lokator übertragen. Dass er ihr offensichtlich nicht gewachsen war, verdeutlicht ein Schriftstück, dass von einem Schweizer Studenten Johan Henrich Amianus verfasst wurde: Weil ein so groser anzahl Schweitzer $Z u$ Lindou Vnd Ruppin anlangen, welche ich allein Vnd ohne hilf ohnmoglich einrichten kann [...] thue ich submisse diser $\beta$ [...] Vorschlagen, Nemlich, daß dem her Wittenbach in dem Schweitzer bruch anbefohlen werde, mich durch diesen somer bis $\mathrm{Zu}$ Volkomner einrichtung der angekomnen Leute zu secundiren ... ${ }^{481}$ In der Zwischenzeit sollte der vorgenannte Student seine Amtsgeschäfte wahrnehmen. Da der Name Ammian im Kirchenbuch nicht vorkommt, wird dies wohl nicht geschehen sein. Aber sehr wahrscheinlich wird die zeitweise Anwesenheit Wyttenbachs im Ruppiner Raum die Anbahnung von vielerlei Beziehungen zwischen den Schweizer Kolonistendörfern bewirkt und sehr erleichtert haben. Das betraf offensichtlich nicht nur den persönlichen Bereich (Erstbesiedlung der dortigen wüsten Stellen mit Kolonistensöhnen aus dem Golmer Bruch, ${ }^{482}$ Einheiratung, Paten), sondern erstaunlicherweise auch in Bezug auf gemachte Ansiedlungserfahrungen. So fand sich im Zusammenhang mit der Neubesiedlung des Vorwerks Schulzendorf im Jahre 1691 eine Liste von zu realisierenden Maßnahmen, in der unter Pkt. 5 steht: Vor Die Ubrige fünff Familien sind fünff newe Wohnung Vnter einen Dach, Stuben Cammer, Ställung Vnd Scheune Zu Bawen nach der model, wie im Podstamschen Bruch Vor die Schweitzer angebawet worden ... Die veranschlagten Kosten wurden mit $5 \times 100$ Talern angegeben. ${ }^{483}$ Wyttenbach wurde 1693 neben anderen Persönlichkeiten hinzugezogen, um die von den Schweizer Kolonisten in den Ämtern Lehnin, Lindau und Ruppin Kurfürst Friedrich III. vorgebrachten gravamina [Beschwerden] zu klären. ${ }^{484}$ Das ihnen in ihren Ansiedlungskontrakten versprochene Vieh war ihnen noch nicht völlig geliefert worden. Durch die Bemühungen, gemeinsam mit dem Linower Prediger Herkules Delliker für das in Kapitel VI.1. erwähnte „Kirchenbauprogramm“ der reformierten Gemeinden Linow, Lüdersdorf, Schulzendorf, Storbeck, Michelsdorf und Neu Töplitz Kollektengelder in der Schweiz zu sammeln, ${ }^{485}$ und wegen der Teilnahme bei den Einweihungen dieser Kirchen wird er praktisch seine ganze Amtszeit mit diesen Ruppiner Schweizer Gemeinden in Kontakt geblieben sein. ${ }^{486}$ Das zeigte sich auch in einem anderen Zusammenhang. Als v. Portz (s. Anm. 458) von der Amtskammer wegen seiner Amtsführung des Direktoriums zum Schweizer Etablissement 1703 verdächtigt wurde und daraufhin seinen Abschied einreichte, waren es ausgerechnet die drei Schweizer Prediger Wyttenbach, Delliker und Ziegler, die ihm höchstes Lob für sein großes Engagement

481 GStA PK, I. HA, Rep. 243 Evangelisch-reformiertes Kirchendirektorium Nr. 423, fol. 1-3.

482 Allein unter den in Storbeck 1691 nachgesetzten 12 Schweizern finden sich 3 Kolonistensöhne aus dem Golmer Bruch: Peter Schweingruber, Hannß Bylang und Ulrich Suter [Stirnemann, Heinz: Woselbst sie wohl aufgenommen, Frankfurt a.M. (o.J.)].

483 BLHA, Rep. 2 Kurmärkische Kriegs- und Domänenkammer Nr. D 12237, fol. 36R.

484 BLHA, Rep. 7 Amt Lindow Nr. 73, fol. 89-91R (Schreiben vom 03.05.1693).

485 StA Bern: A.V. 19 Teutschland-Buch Preußen Brandenburg fol. 1009 ff. und 1017 ff.; GStA PK, I. HA, Rep. 243 Nr. 423 fol. $41 \mathrm{ff}$.

486 GStA PK, I. HA, Rep. 243 Nr. 105. 
spendeten, ${ }^{487}$ worauf v. Portz die Leitung des Schweizer Etablissements weiterhin bis zu seiner Auflösung behielt.

Im Jahre 1700 bekam Prediger Wyttenbach (und seine Nachfolger im Amt) von Friedrich III. das Schulzengericht Göttin geschenkt. ${ }^{488}$ Der Anstoß hierzu war ein undatiertes Supplik Wyttenbachs an den Kurfürsten, ${ }^{489}$ in dem er auf die durch Gottes Gnade anfangs von 14 auf 24 Hauß Wirthe inzwischen vermehrte Gemeinde hinwies, wobei davon der halbige Theil im Pottstamische, der andere halbige Theil aber im Lehninschen Amte etabliert sei, wodurch ihm auch mehr Mühe und Arbeit zugewachsen sei. Der Kurfürst ging nach Klärung der Situation auf die Bitte ein ${ }^{490}$ und beschenkte Wyttenbach mit dem seit vielen Jahren her wüste gelegene kleine Schulzengericht in Göttin zur Besoldungserhöhung. Denn die Gemeinde sei an unterschiedenen Ohrten zertheilet [...], und er müsse bey selbigen nothwenig ab-und zufahren, auch $\mathrm{Zu}$ dem, Pferde und Wagen halten ... Zur Belehnung musste er sich auf die Königliche und Churfürstliche Brandenburgische Lehens Canzley nach Berlin begeben und darum allerunterthänigst anhalten. Er legte dort den Lehns- und Untertänigkeitseid ab, wurde daraufhin mit dem Schulzengericht zu Göttin wirklich belehnt und erhielt die Lehnurkunde ausgestellt:

Ern. Albrecht Wittenbach, Pre-

diger bey der Schweizerischen Gemeinde $\mathrm{Zu}$

Pottstam, hat in dem ihm berahmbten

Termino Persönlich sich gestellet, und umb die Beleihung allerunterthänigst angehalten. So ist er mit dem Schulzengerichte in Göttin inhalts Rescripti vom 11. ${ }^{\text {te }}$ May 1701 würckl. belehnet worden; Actum Cöllen an der Spree den 5. ${ }^{\text {ten }}$ Jul. Ao. $1701 .^{491}$

Viel hat das Lehnschulzengut Göttin nicht eingebracht. Es war zu abgelegen, warf wenig ab und führte regelmäßig zu Auseinandersetzungen mit den dortigen Fischerkossäten, insbesondere Christian Albrecht, der es, weil es längere Zeit wüst gelegen, inzwischen für sich in Anspruch genommen hatte. Es wurde ab 1705 verpachtet, und aus späterer Zeit sind mehrere

487 GStA PK, I. HA, Rep. 9 Nr. 9 Fasc. 2, fol. 9/9R.

488 Decret Friedrich III./I. vom 20.01.1700; Original in: KA Alt Töplitz: Belehnung des Nattwerderschen Pfarrers mit dem Lehnschulzengericht in Göttin 1700 (nicht paginiert) und Konzept in: GStA PK, X. HA, Rep. 2B Regierung Potsdam Abt. II Generalia Nr. 691, fol. 82. Zur Vorgeschichte dieses Schulzengutes s. BLHA, Rep. 78 Kurmärkische Lehnskanzlei III Orte Nr. T 16.

489 vermutlich im Jahre 1699; KA Alt Töplitz: Belehnung des Nattwerderschen Pfarrers mit dem Lehnschulzengericht in Göttin 1700 (nicht paginiert) bzw. GStA PK, X. HA, Rep. 2B Reg. Potsdam Abt. II Generalia, fol. 96.

490 GStA PK, I. HA, Rep. 21 Nr. 87-1 (Paket 7930, nicht paginiert), Schreiben vom 24.07.1699 bzw. GStA PK, X. HA, Rep. 2B Reg. Potsdam Abt. II Generalia Nr. 691, fol. 96R.

491 KA Alt Töplitz: Belehnung des Nattwerderschen Pfarrers mit dem Schulzengericht in Göttin 1700 (nicht paginiert, Schreiben vom 05.07.1701). 


\section{Reformierte Schweizer Gemeinde im (Golmer) Bruch bei Potsdam}

Gerichtsverfahren bekannt. ${ }^{492}$ Daneben gab es für den Prediger Wyttenbach mit der Gemeinde weitere Reibereien. Die Neu Töplitzer wollten ihrem Prediger unter gar keinen Umständen den Fleischzehnten geben. Er musste sich diesen über das Kammergericht erstreiten. ${ }^{493}$ Viel gravierender war die „schwärmerische-pietistische Bewegung“ in Neu Töplitz, die von dem Schuhmachergesellen Andreas Berg aus Werder sonntäglich unter die Schweizer Kolonisten getragen wurde. ${ }^{494}$ Näheres hierüber s. Kapitel V.2.3.

Als Albrecht Wyttenbach 1704 altershalber seine Demission [Rücktritt] über den Schultheiß und Rat der Stadt Bern bei Friedrich I. einreichte, bescheinigte dieser ihm, dass er während seines vieljährigen aufenthalts allhier [...] sich jedesmahl dergestalt Bezeiget, daß nicht allein Wir an seinen guten gaaben und gottseligen Geistlichen wandel ein gnädigstes Vergnügen getragen, sondern [dass] auch die Ihm anvertraute gemeinde dadurch mercklich erbauet worden. ${ }^{495}$ Die große Wertschätzung, die er offensichtlich in Kurbrandenburg genoss, kam noch mehr zum Ausdruck, als ihm 1706 (bereits Pfarrer von Wohlen in der Schweiz) das Angebot für die Pfarrstelle by der Gemeine in dem Amts Stättlin Lehnin samt der inspection auff [alle] übrige schweitzerische Evangel. Reformierten Colonien und Gemeinden in Dero Landen gemacht wurde. ${ }^{496}$ Diesen Ruf glaubte er nicht ablehnen zu können, und auch die Berner Regierung war geneigt, ihn aufs Neue zeitweilig aus dem bernischen Kirchendienst zu entlassen. Aber seine Pfarrkinder baten so flehentlich um Christi und um ihrer Seelen Erbauwung willen, diesen ihren herzwerthen Seelenhirten nicht von ihnen zu nehmen, ... ${ }^{497}$ So blieb er Pfarrer von Wohlen und starb als Dekan des Kapitels Düren 1738, nachdem er wegen seiner Sachkenntnis mehrfach in Sachen der brandenburgischen Kolonisten vom Berner Konvent um seine Ansicht und seinen Rat befragt worden war. ${ }^{498}$

\subsection{Sigismund Lupichius}

Schultheiß und Rat der Stadt Bern präsentierten am 26. Dezember 1704 Sigismund Lupichius als Nachfolger von Albrecht Wyttenbach ... als einen Accademicum, der dieser Zeit in Holland zu Leyden [sich] befinden soll, [...] es werde derselbe in Lehr und Lebwesen und aller erforderlichen Bescheidenheit sich also Betragen, daß Er Königl May: daran ein gnädigstes gefallen schöpfen und die Ihme anvertrauwende gemeind erbauwet werden möge ... ${ }^{499}$ Seine Berufung nahm Lupichius in der charakteristischen Ausdrucksweise seiner Zeit am 6. Januar 1705 von Leyden aus an. ${ }^{500}$

492 BLHA, Rep. 2 Kurmärkische Kriegs- und Domänenkammer Nr. B 1213.

493 BLHA, Rep. 2 Kurmärkische Kriegs- und Domänenkammer Nr. D 11279, fol. 80 ff.

494 GStA PK, I. HA, Rep. 9 Nr. D9, Fasc. 3.

495 GStA PK, I. HA, Geheimer Rat (Akten), Rep. 11 Nr. 10274, fol. 27; StA Bern: A. V. 19 Teutschland-Buch Preußen Brandenburg, fol. 287.

496 StA Bern: A. V. 19 Teutschland-Buch Preußen Brandenburg, fol. $315 \mathrm{ff}$.

497 daselbst: fol. $319 \mathrm{ff}$.

498 Fetscherin, Wilhelm: Die bernischen Colonien in Brandenburg ..., 17 (1868), S. 107-142, bes. S. 138.

499 StA Bern: A.V. 19 Teutschland-Buch Preußen Brandenburg, fol. 303-305, bes. fol. 304.

500 daselbst: fol. 307: Weilen es jesu Christo dem Erzhirten gefallen wollen, Mich Vnwürdigen, Jungen Hirtenknaben außzusenden, seine schaafe zu weiden vnd Mich allßo Durch Ewer Gnädigen Herren Vnd Oberen als seinen Statthaltern 
Seit 1704 gab es unter den Schweizer Kolonistendörfern, u. a. in Neu Töplitz, Anhänger einer „schwärmerischen-pietistischen Sekte“, mit der sich Lupichius auseinandersetzen musste. Eine erste königliche Ermahnung, dagegen vorzugehen, datiert vom 6. August $1704 .{ }^{501} \mathrm{Als}$ der König erneut 1706 mit allergrößesten mißfallen von diesen Vorfällen in den Ämtern Lehnin und Lindow erfuhr, erging sogleich Ernster befehl, an das Zum Schweytzer Etablissement verordnetes Ober Directorium, ohne eintzigen Zeit verluest, alle mittel anzuwenden, daß dißem unweßen mit aller vigeur [Energie] Einhalt geboten werde. Die Anführer sollten sofort aus dem Lande verwiesen werden. ${ }^{502} \mathrm{Die}$ „schwärmerische-pietistische Bewegung “ bestand aus Separatisten, die sich von der Gemeinde und dem öffentlichen Gottesdienst fernhielten wie auch vom öffentlichen Gebrauch des Abendmahls abwandten und stattdessen unter sich und auch mit Fremden heimlich in ihren Privathäusern Conventike ${ }^{503}$ abhielten. Sie galten deshalb als Aufwiegler gegen die bestehende (staatliche) Kirchenordnung. Der führende Kopf war in Neu Töplitz Christian Dursy. ${ }^{504}$ Dem Amtsrat berichtete Lupichius am 19. November 1705 über die verdrießliche Situation in der Gemeinde. Er habe Christian Turtschy auf sein Verhalten angesprochen, worauf dieser ihn zum größen ärgernuß der meisten anwesenden auf offener ga$\beta e n$ ungezügelt wie einen Schweinehirten tractiert habe. ${ }^{505}$ Der König wurde von diesen Vorgängen informiert ${ }^{506}$ und befahl daraufhin dem Schweizer Kirchendirektorium, ungeachtet bereits bestehender Anordnungen dem Schuster aus dem Städtlein Werder [Andreas Berg]... zu untersagen ... forthin das dorffe Neü-Töplitz zu betreten und keiner weiteren Zusammenkunfft derer Schweitzer-Colonisten Bey [zu] wohnen [...] Er würde Beym Kopp genommen und anhero Zur Haußvoigtey gebracht. ${ }^{507}$ Darüber hinaus befahl Friedrich I. dem Hoff-Fiscal Wagner, die Angelegenheit vor Ort zu untersuchen, von der sache eigentlichen Bewandtnuß erkundigung einzuziehen, [...] den benanten Dursy darüber zu vernehmen, mithin ihm aufzuerlegen, daß Er Bey Vermeydung höchstempfindlicher Straffe dergleichen Gottlose reden zu führen, sich ferner nicht gelüsten laße. ${ }^{508}$ Der Angelegenheit wurde so viel Bedeutung zugemessen, dass sogar eine Kommission gebildet wurde, die (ohnmaßgebliche) Vorschläge zu thun hatte, wie solchem übel, damit es nicht weiter einreiße, entgegen zugehen (!) sei. ${ }^{509}$ Trotz dieser aufwendigen Maßnahmen muss die Angelegenheit noch weiter geschwelt haben. Denn im Kirchenbuch Golmer Bruch

Mittel Zu einem Seelsorger der Gemeinde Zu Potzdam in Brandenburg zu verordnen, als bin ich gesinnet [geneigt], dieser vocation willigst zu gehorchen, Vnd Vnter demüthiger anflehung Göttlicher gnad nach möglichkeit zu trachten, solcher gemeind mit lehr Vnd leben Vorzustehen, wie es einem getreüwen Evangelischen Prediger zusteht etc.

501 StA Bern: A.V. 19 Teutschland-Buch Preußen Brandenburg, fol. 331; s. auch Mylius: CCM I. Th., I. Abth. No. LX. Verordnung, daß nicht wieder Pietisten, Separatisten, Labadisten gepredigt werden.

502 GStA PK, I. HA, Rep. 243 Evang. reformiertes Kirchendirektorium, Nr. 423, fol. 155 ff. und fol. 159; s. auch StA Bern: A. V. 19 Teutschland-Buch Preußen Brandenburg fol. 331 ff., 351 ff., 367 ff. und 371 ff.

503 geheime Zusammenkünfte.

504 Christen [Christian], Sohn des Schweizer Kolonisten Emanuel Dortschy, wurde am 7.11.1669 in Thierachern getauft (Chronik der Familie Emanuel Dortschy, Frankfurt a. M. (2007), S. 78 (im Besitz des Autors) und starb am 20.01.1759.

505 GStA PK, I. HA, Rep. 243 Evangelisches reformiertes Kirchendirektorium Nr. 423, fol. 141-142.

506 daselbst: fol. 143-144.

507 daselbst: fol. 145.

508 GStA PK, I. HA, Rep. 9 Nr. D. 9 Fasc. 3, fol. 74.

509 daselbst: fol. 90. 
(Vol. I) fanden sich in den Jahren 1759, 1769, 1776, 1780 und 1785 fünf Sterbeeintragen, davon 2 Militärs, von Separatisten:

Christian Durtschy Sen: ist d. 20 ten

Jan: [1759] in N.T. gestorben u: d: 22 ten auf

verlangen in $d$. stille bey $d$. Kirche begraben

worden. alt 93 Jahre (NB). Dieser alte Sepa-

ratist war ein Prediger-feind u. Lästerer,

d. mit dem abgesetzten Prediger Huntziger

fast die gantze Gemeine verführen

helffen, und als ein beständiger Ver-

ächter des prediger-Amts, auch heiligen

Abendmahls in die unglückseel. Ewigkeit

eingegangen. Sein böser Saame ist noch un-

ter d. Gemeine. ${ }^{510}$

Wie bereits im Kapitel V.2. ausgeführt ${ }^{511}$, entstand nach dem Regierungsantritt König Friedrich Wilhelms I. im Jahre 1713 für die Schweizer Kolonisten im Golmer Bruch eine kritische Situation. Die Pachtzinsen sollten extrem erhöht werden, und die Gemeinde sah ihr Fortbestehen existentiell bedroht. In dieser äußerst schwierigen Situation stand Sigismund Lupichius der Gemeinde nicht nur als Seelsorger, sondern vor allem durch seine Fürsprache bei, obwohl er sich seit 1710 um seine Demission bemühte. Er hatte als einfacher Prediger den Mut, dem Amtskammerpräsidenten v. Görne, der die Schweizer Kolonisten beschuldigt hatte, sie hätten seit ihrer Ankunft den Golmer Bruch vernachlässigt und ruiniert, zu widersprechen und suchte gleichzeitig bei reformierten Würdenträger um Unterstützung (s. Anhang 14). Dem Rat der Stadt von Bern berichtete Lupichius am 28. Juni 1713 verzweifelt in einem siebenseitigen Brief über die beängstigende Situation seiner Gemeinde (s. Anhang 15). Er habe sich um Hilfe an verschiedene, den Schweizer Kolonisten wohl gesonnene Persönlichkeiten (Amtskammermeister Franke, Kammerpräsident v. Sturm, Staatsminister Kameke ${ }^{512}$, Graf und Burggraf v. Dohna, seinen Rechtsberater Doktor Sterky ${ }^{513}$ und andere gute freünde alles Reformierte) gewandt. Aber selbst der den Schweizer Kolonisten besonders zugetane v. Dohna habe es abgelehnt, dem König ein Memorandum zu übergeben. Auch habe er noch einmal beim Amtmann vorgesprochen; der ihn aber wie einen Hunden Jungen traktierte und ihn bedrohte, bey dem Könige zu verklagen. Und so sah er sich verpflichtet, seine Oberen über

510 KA Alt Töplitz: Kirchen-Buch der Schweitzer-Gemeinde im Bruche bei Potstamb, Vol. I (1685-1801, nicht paginiert), Liste der Gestorbenen, Eintrag vom 31.12.1769.

511 s. Anm.: 460-461.

512 Kameke, Ernst Boguslav von (1674-1726), seit 1711 Hofkammerpräsident. Ihm unterstand die Verwaltung der Domänen, der Schatulle, des Forstwesens und der großen Regalien. Unter Friedrich Wilhelm I. verlor er dessen Vertrauen. (Deutsche Biographie Enzyklopädie (DBE), 2. Auflage, hg. von Rudolf Vierhaus, Bd. V, S. 570).

513 Vermutlich handelt es sich um D. Sterky, Jeremias (1656-1718), „Theologe, ab 1685 Prof. d. Theol. in Lausanne und ab 1703-1718 1. Pfarrer an der Parochialkirche in Berlin“, in: Evangelisches Pfarrerbuch ..., Otto Fischer (bearb.) Berlin (1941), Zweiter Teil, S. 855. 
den entstandenen gefährlichen und fast Zur extremitaet gekommenen Zustand seiner Gemeinde ausführlich zu informieren, und bat sie, ein Interzessionsschreiben an den König von Preußen ohne Erwähnung seiner Person zu schreiben, was, weil periculum in mora ${ }^{514}$ sei, fordersamst und ohne Verzug [...] geschehen möge. Gleichzeitig bat Prediger Lupichius in seinem Schreiben um Befehle, wie er sich bey hiernächst befürchteter dimission [Vertreibung] der Colonie [...] aufzuführen habe; auch ob, und auf was weise diese Leüthe wieder nach dem Vaterland geführet werden möchten ... Offensichtlich hatten die Schweizer Kolonisten im Golmer Bruch nicht auf ihr Mann- und Landrecht verzichtet. ${ }^{515}$ Der Berner Magistrat reagierte darauf prompt und sandte am 24. Juli 1713 ein Interzessionsschreiben an König Friedrich Wilhelm I. (s. Anhang 17), ${ }^{516}$ worin er, bezugnehmend auf die Privilegien der Schweizer Kolonisten in ihrem Ansiedlungsvertrag von 1685, energisch Partei für die Kolonisten ergriff und - höchst diplomatisch - das glorwürdigste Angedenken an den Vater und Großvater Friedrich Wilhelms I. und die beidseitigen Bemühungen um die gemeinsame Reliogion beschwor. Nach 1713 ließ sich kein Schriftverkehr zwischen Kurbrandenburg und dem Kanton Bern weder im Staatsarchiv noch im Geheimen Staatsarchiv Berlin auffinden; das bedeutete, dass die Schweizer Kolonisten hinfort keine Unterstützung von Bern erhielten und auf sich selbst gestellt waren.

Die Antwort des Berner Magistrats an den Prediger Lupichius - auch vom 24. Juli 1713 - ist bislang unbekannt gewesen (s. Anhang 16) ${ }^{517}$ Er wurde darin aufgefordert, die Kolonisten zu ermuntern, $[\ldots]$ sich der sparsamkeit $[\mathrm{zu}]$ befleißen, und durch unvertrostene arbeith Ihre subsistentz [Existenz] Zu bestreiten sich angelegen sein [zu] laßen, sich darbey wohl hüten sollind, Von Ihren Häusern und Höffen drunden sich weg zu begeben, als wordurch sie in äußerstes Elend und Verderben gerathen, und alles Heimaths priviert- [beraubt] und Verlürstig wurden.... Sie sollten sich keine Hoffnung machen, nach so langer Zeith und abwesenheit mit Vermehrten Famillen von denen Gemeinden allhier wider aufgenommen $\mathrm{Zu}$ werden.... Diese kategorische Ablehnung einer möglichen Rückkehr in die alte Heimat dürfte für Lupichius eine schwere Enttäuschung gewesen sein, zumal die Überlegung zur Rückkehr in die alte Heimat unter den Kolonisten schon aufgekommen war. Schultheiß und Rat der Stadt Bern waren sich aber offensichtlich der Härte ihres Vorgehens - vor allem gegenüber den Ärmsten der Gemeinde - bewusst; denn Lupichius bekam ein Waxelbriefflein [Wechsel, Gutschein] von Hundert Thaleren [...] für arme übel mögende alte Persohnen ${ }^{518}$, wie auch Vatter- und Mutterlosen Kinderen übermacht. Von diesem Geld sollte er denenselben in diserem letsten fohl [Fall], [...] nach und nach, und auf eine solche weis, als wann es von dir selbst bescheche [geschieht], Handreichungen [Almosen] verteilen, aber verschweigen, daß es von Uns her[ge]kommen ist. Die alte Heimat hatte mit diesem Antwortschreiben die Schweizer Kolonisten im Golmer Bruch abgeschrieben, was sie

514 (lat.) Gefahr (ist) im Verzuge.

515 Rösli, Joseph: Wanderungen der Berner, in: Der Schweizer Familienforscher Bd. 7 (1940), Heft 4-6, S. $43-$ 57, bes. S. 47 .

516 StA Bern: A.V. 19 Teutschland-Buch Preussen Brandenburg, fol. 407-413, bes. fol. 409-410.

517 daselbst: fol. 414-416.

518 Dabei handelt es sich u. a. um den 85-jährigen Hanß Läderach aus Worb, der 1685 ins Golmer Bruch eingewandert war. 
aber keineswegs erfahren sollten. ${ }^{519} \mathrm{Im}$ Übrigen erhielt Sigismund Lupichius für sein Engagement eine scharfe Rüge vom Kirchendirektorium wegen Nichtzuständigkeit in der Sache.

Die Demission von Prediger Lupichius, um die er sich seit 1710 bemühte und weswegen er sich für eine möglichst gute Stelle in der Heimat von seinem Vorgesetzten, Professor Sterky, ein Zeugnis ausstellen ließ (s. Anhang 13), kam nicht zustande. Stattdessen - und dies dürfte als ein weiterer Beleg seiner ungewöhnlichen Befähigungen gewertet werden - wurde er im Januar 1717 zum reformierten Hofprediger der Erbprinzessin von Württemberg ernannt. Ob er je wieder in die Heimat zurückkehrte, ließ sich nicht ermitteln.

\section{Zur Familie von Wykersloot}

Im Rechnungsbuch der reformierten Schweizer Gemeinde Golmer Bruch vermerkte 1745 der Prediger Treiber NB den Herrn v. Wykersloot als Erb-Herrn auf Marquardt und zugleich [als] ein Glied von meiner Gemeine. ${ }^{520}$ Dass sogar eine adelige Familie sich der reformierten „Landgemeinde" Golmer Bruch zugehörig fühlte, ist bislang unbekannt gewesen. Die Familie stammte vom Niederrhein. Johann Arnold v. Wyckersloot $(+10.12 .1724)$ trat unter König Friedrich Wilhelm I. in preußische Dienste und war Hof- und Kommerzienrat. 1713 erwarb er das Rittergut Marquardt für 22.000 Rthl. ${ }^{521}$ und wurde nach Erhalt des Mutungsschreibens im Jahre 1719 Erbherr zu Marquardt. Für die lutherische Gemeinde Marquardt bedeutete dies, dass sie zwar evangelisch-lutherisch blieb, aber unter reformiertem Patronat stand. Das Verhältnis zwischen Patron und Gemeinde scheint trotzdem gut gewesen zu sein, denn im Jahre 1733 wurde unter dem noch unmündigen Arnold Andreas v. Wyckersloot $(+15.12 .1741)$ an Stelle der alten baufälligen Holzkirche aus dem Jahre 1664 eine neue massive Kirche erbaut. Das gute Einvernehmen kommt auch dadurch zum Ausdruck, dass sich Brautpaare während des Kirchenbaues im Gutshaus trauen lassen konnten. ${ }^{522}$

Welche Folgen hatte die Patronatssituation für die Familie v. Wyckersloot selbst? Fontane ${ }^{523}$ hat vermutlich 1869/70 Marquardt besucht und berichtete darüber: Die Familie v. Wyckersloot war eine calvinistische Familie, und das Interessanteste aus ihrer Besitzzeit bleibt wohl, daß, obschon sie die Kirche aus eigenen Mitteln erbaut hatten, ihnen, so lange Friedrich Wilhelm I. regierte, nicht gestattet wurde, das heilige Abendmahl in dieser ihrer Kirche aus der Hand eines reformierten Geistlichen zu empfangen. Die Wykersloot mußten sich, an ihrem eigenen Gotteshaus

519 Ganz anders interpretiert Fetscherin (Die bernischen Colonien in Brandenburg, 17 (1868), S. 133) diese Zusammenhänge: „So fand sich die Regierung auch nach 30 Jahren immer noch verpflichtet, für die Ihrigen im Ausland zu rathen und zu sorgen und Klugheit mit liebreicher Handreichung zu verbinden.“

520 KA Alt Töplitz: Kirchen-Rechnung der Evangelisch-Reformierten Schweitzer Gemeine im Golmer bey Potsdam de Anno 1735-1848, Rechnungsjahr 1745 (nicht paginiert).

521 BLHA, Rep. 23A Kurmärkische Stände, Ritterschaftliche Hypothekendirektion Nr. 364 fol. $3-6$ und Rep. 78 II Familien Nr. W 131 und 132.

522 Wolfgang Grittner: Zur Geschichte der Marquardter Kirche, Marquardt (2013) S. 6.; ders. Marquardt - Illustrierte Zeittafel zur Ortsgeschichte 1313-2016, Marquardt (2017) S. 13.

523 Fontane, Theodor: Wanderungen durch die Mark Brandenburg, Dritter Teil - Havelland, Berlin 1977, S. 299-300 und $600 \mathrm{ff}$. 
vorbei, nach Nattwerder begeben, einer benachbarten Schweizerkolonie, wo das Abendmahl nach calvinistischen Ritus erteilt wurde. Diese anekdotische Schilderung entspricht bei weitem nicht den Tatsachen. Denn im Kirchenbuch Golmerbruch (Vol. I) wurde ausdrücklich vermerkt, dass der am 14. Februar 1738 geborene Johann Arnold und die am 14. Dezember 1738 geborene Ernestine Catharina in Marquardt getauft wurden. Üblicherweise fanden in Adelskreisen Haustaufen statt, und der jeweilige Prediger wurde ins Schloss bestellt. Bei den zwei weiteren 1740 und 1742 geborenen Kindern fand sich kein solcher Hinweis, aber warum sollte von den Gepflogenheiten abgewichen worden sein?

Im Kirchenbuch Golmerbruch (Vol. I) ließen sich insgesamt 12 Eintragungen über die Familie v. Wykersloot finden. ${ }^{524}$ Bemerkenswert war vor allem der Eintrag aus dem Jahre 1737 in der Liste der Getrauten:

den 3 te Augusti sind nach vorherge-
gangenen 3 mahligen Proclama-
tion, und zwar erhaltener Dispen-
sation unter der Unterschrifft Seiner
Königl: Hoheit des Kron-Printzen, ${ }^{525}$
vom 11 ten April. a.c. sich als Geschwi-
ster Kinder heirathen zu können
eingesegnet worden zu Marquard
Herr Arnold Andres von Wyckers-
loot, Erbherr auf Marquard
Mademoiselle Angelique le Jeun,
Seel. Herrn le Jeun, gewesenen
Hoff-Rath zu Berlin Eheleibl.
Jungfer Tochter.

Die Mutter des Bräutigams war eine geborene le Jeun. Braut und Bräutigam waren also Cousin und Cousine bzw. Geschwister kinder und dies bedurfte einer Genehmigung, die in diesem Fall durch den Kronprinzen erteilt wurde. In der Regel wurde eine solche Heirat angestrebt, um den Besitz der jeweiligen Familien nicht aufteilen zu müssen. Der Ehe entstammten ein Sohn und zwei Töchter, die im Kindesalter verstorben sind.

Über das Verhältnis der Familie v. Wyckersloot zur Schweizer Kolonistengemeinde Golmerbruch gibt es nur wenige aktenkundige Belege. Sowohl Johann Arnold (2x) als auch Sohn Arnold Andreas v. Wykersloot (1x) tauchen im Kirchenbuch Golmerbruch als Paten auf. Bei ersterem betraf es den Hrn. Arendator [zu Marquardt] Joh. Peter Jürgens ${ }^{226}$ und Dieterich Lange-

524 Die Schreibweise des Namens ist gelegentlich auch Wickersloth oder Wikersloot.

525 In diesem Fall ist unklar, in welcher Funktion der Kronprinz den Dispens unterschrieben hat - in Vertretung des Königs oder als zuständiger Regimentskommandeur.

526 KA Alt Töplitz: Kirchen-Buch der Schweitzer Gemeinde im Bruch bei Potstamb, Vol. I. (1685-1801, nicht paginiert), Liste der Getauften, Eintrag vom 12.04.1712. 


\section{Reformierte Schweizer Gemeinde im (Golmer) Bruch bei Potsdam}

laer Königl. Amtmann in Bornim. ${ }^{527}$ In diesen zwei Fällen handelte es sich um niedere Beamte, zu denen persönliche Beziehungen bestanden haben könnten. Dagegen übernahm der Sohn Arnold Andreas das Patenamt für die Tochter des Erbpächters Emanuel Durtschi von Vierhäuser. ${ }^{528}$

Darüber hinaus mutmaßte der Prediger Franz Rudolf Becker in den „Historischen Nachrichten von der Reformirten Schweizer Gemeinde zu Nattwerder, Golm und N. Taplitz im Golmerbruch bey Potsdam“, dass das Zinnernen Taufbecken und Gießkanne durch die Familie v. Wyckersloot gestiftet worden sei (s. Abb. 11). ${ }^{529}$ Das Taufbecken existiert heute noch, und ebenfalls ist im Vorspann des Kirchenbuches (Vol. I, Deckelinnenseite) ein solches als Bestandteil des Kircheninventariums aufgeführt; aber leider findet sich darauf keine Datierung für eine genaue Zuordnung.

Ein weiterer, eher ungewöhnlicher Hinweis betrifft ein Darlehen aus dem Jahre 1745:

(NB) Das Kirchen Geld ist zu 4 procento an den Herrn von

Wyckersloot, Erb-Herrn auf Marquard und zugleich ein

Glied von meiner Gemeine, gegen einen Wechsel ausgethan

worden, und da die damahlige Summa sich nur auf $91 \mathrm{Thl}$.

$11 \mathrm{gr} .9$ derstreckte, ist das hundert von meinem eigene geld

mit 8 Rthl: 12 gr: 3 d. doch ohne Theilnehmung der Zinßen, aber

mit Hofnung aufbaldigen Restitution von den künffigen Einnahmen complet gemachet worden. $^{530}$

Die Abtragung des Darlehns erfolgte bis zum Jahre 1767. Ob sich hier bereits die spätere finanzielle Notsituation der Familie v. Wykersloot andeutete, sei dahingestellt. Das Gut musste 1781 an den Hofrat Bernt Friedrich v. Münchow verkauft werden.

\section{Kirchenvisitationen}

Die Kirchenvisitation, das grundlegende Instrument kirchenleitender Tätigkeit, diente dazu, kirchliches Leben und die Vermögensverwaltung in den einzelnen Kirchengemeinden in geordnete Bahnen zu bringen. Unter der energischen Hand Friedrich Wilhelms I. wurde dieses im 16./17. Jahrhundert gängige Instrument 1715 reaktiviert. ${ }^{531}$ Etwa gleichzeitig wurden im Zusammenhang mit der Gründung des reformierten Kirchendirektoriums (s. Kap. II.2.) vier reformierte Inspektionen in der Kurmark gebildet und die dem Inspektor unterstehenden Kirchengemeinden festgelegt. Der Schweitzer Bruch gehörte seitdem neben Spandau, Ziesar,

529 KA Alt Töplitz: Alte Akten von der Golmerbruchkirche 1713-1799; Punkt 5 des Antwortschreibens auf die Verfügung v. 31. März 1780 (Konzept); GStA PK: I. HA, Rep. 243. Nr. 306, fol. 11 (Original).

530 KA Alt Töplitz: Kirchenrechnung der Evangelisch-Reformirten Schweitzer Gemeine im Golmer-Bruch bey Potsdam de Anno 1735-1848 (Rechnungsjahr 1745).

531 GStA PK: X. HA, Rep. 40 Nr. 1784, fol. 17 ff. 
Brandenburg und Lehnin zur Potsdamer Inspektion, die von H. Hendrich geleitet wurde. ${ }^{532}$ Gleichzeitig entstand der Entwurf einer Inspektions- und Visitations-Ordnung, die am 25. Januar 1737 in überarbeiteter Fassung veröffentlicht wurde. ${ }^{533}$ Aus dieser Zeit fanden sich keine Akten über Visitationen der Golmer Bruch Gemeinde. Im Laufe des 19. Jahrhunderts wurden neue rechtliche Grundlagen geschaffen. Im Zuge der Stärkung synodaler Elemente erlebte nun auch die Visitation eine neue Blütezeit. Rechtsgrundlagen boten die Visitationsordnung für die Provinz Brandenburg vom 18. August $1864^{534}$ sowie die Visitationsordnung vom 14. Juni $1910^{535}$. Nach beiden Ordnungen war der Superintendent verpflichtet, alle drei Jahre sämtliche Gemeinden seines Aufsichtsbereiches zu visitieren, wobei sich vor 1918 die Visitation zugleich auch auf die örtlichen schulischen Verhältnisse erstreckte. ${ }^{536}$

Die Berichte dieser Visitationen über die Golmer Bruch Gemeinde fanden sich verstreut in den Akten des DStA Brandenburg, des BLHA, des GStA PK und des Töplitzer Kirchenarchivs. Die Überlieferung setzte 1825 ein, als die reformierte Gemeinde im Golmer Bruch interimistisch von Alt Töplitz versorgt wurde (s. Kap. VI.4.1.), und endet 1954 mit einer Generalvisitation.

Überliefert sind die eingehenden und für das kirchliche Leben außerordentlich aufschlussreichen Berichte der Kirchen- und Schulvisitationen für die Jahre 1825, 1828, 1831, 1837, $1843,1846,1849,1855,1858,1861,1888,1894,1901,1918,1929$ und $1954 .{ }^{537}$ In der Regel war der Superintendent die zuständige Instanz, der diese Visitationen vornahm und dafür auch eine gesonderte Entschädigung seitens der visitierten Gemeinde erhielt. Die Generalvisitationen wurden seitens der Landeskirche ausgeführt, 1954 von Generalsuperintendent D. Braun. In den Berichten sind die Namen der amtierenden Küster sowie Kirchenvorsteher [Presbyter] aufgeführt (s. Kap. IV.6., Art. 8 des Arrendevertrages von 1685).

Wie eine solche Visitation verlief, soll exemplarisch an der Kirchen- und Schulvisitation im Jahre 1825 im Sprengel Alt Töplitz gezeigt werden. Sie fand am 28. August 1825 statt. Der Superintendent Martus berichtete dem Konsistorium zunächst von der ungewöhnlichen Situation einer Matergemeinde (Alt Töplitz) und zwei Filialgemeinden (Nattwerder und Phöben jenseits der Havel). Die Visitation begann mit einem zahlreich besuchten Gottesdienst. Die Schulkinder hätten zwar nur einstimmig, aber ziemlich rein gesungen. Der Prediger Keßler habe über das Sonntagsevangelium mit Verstand, Würde und Herzlichkeit gepredigt, und die Versammlung habe ihm mit Stille und Aufmerksamkeit zugehört. Hierauf fand die Katechisation

532 GStA PK: I. HA, Rep. 243 Evangelisch-reformiertes Kirchendirektorium Nr. 879, fol. 2R; s. auch Anm. 44.

533 daselbst: fol. 220-222; s. auch Heinrich, Gerd von (Hg.): Tausend Jahre Kirche in Berlin-Brandenburg, Berlin 1999, S. 310 mit Nachweis der dazugehörigen Instruktion bei Christian Otto Mylius, CCM Bd. I (1737), Sp. 513-524.

534 Amtliche Mittheilungen des Königlichen Consistoriums der Provinz Brandenburg 1864, S. 31-43.

535 Handbuch der Amtlichen Mitteilungen Berlin 1917, S. 66-74.

536 nach $\$ 10$ der Inspektions- und Visitations-Ordnung von 1737 sollte das alle Jahre gewiß einmal zwischen Ostern und Pfingsten geschehen.

537 BLHA, Rep. 2 Regierung Potsdam II Z Nr. 117, 124 und 443, DStA Brandenburg BEN 232-209, 236-365 und 237-355, GStA PK I. HA, Rep. 47 Tit. 16 Paket 15710 und die jeweiligen Protokollbücher des GKR. 
der Kinder statt, denen er eine gute Bekandschaft mit der Bibel bescheinigte. Keßler verbinde mit einer treuen gewissenhaften Amtsführung [... einen untadelhaften Lebenswandel, Freundlichkeit, Gutmütigkeit und Dienstfertigkeit. Danach folgte die Schulvisitation, bei der festgestellt wurde, dass Schule vorschriftmäßig gehalten werde und der Schulbesuch [...] fein sei. Der bauliche Zustand von Kirche, Schule (zugleich Küsterhaus), Pfarr- und Witwenhaus im Vergleich zur letzten Visitation wurde protokollarisch festgehalten. Es folgte die Prüfung der Kirchenfinanzen, der Schulkasse, der Kirchenbuchführung sowie der Kirchen- und Schulbibliothek. Zum Abschluss fand ein Gespräch mit dem GKR statt. Resümee: Ueber den religiösen Sinn und die Theilnahme an den öffentlichen Gottesdiensten [... ] hätte der Prediger keine Klage zu führen.

\section{Die Reformierte Schweizer Gemeinde als Filialgemeinde der unierten Gemeinde Alt Töplitz}

Bis auf wenige Ausnahmen wurden in der ersten Hälfte des 19. Jahrhunderts unter Friedrich Wilhelm III. alle evangelischen Gemeinden zur unierten Kirche (Preußische Union) gegen enorme Widerstände sowohl von lutherischer als auch reformierter Seite vereinigt. Bei der Schweizer Gemeinde im Bruch bei Potsdam geschah dies in zwei Schritten; sie wurde zunächst Filialgemeinde der Mater-Gemeinde Alt Töplitz (1832) und schließlich mit dieser zusammengelegt (1949). Die wichtigsten Ereignisse auf diesem Wege werden nachfolgend dargestellt.

Nachdem 1613 Kurfürst Johann Sigismund (1608-1619) vom lutherischen zum reformierten Glauben übergetreten war, tat sich ein Dualismus zwischen den beiden protestantischen Konfessionen in Kurbrandenburg auf, wobei trotz großer Bemühungen der Hohenzollern, die reformierte Konfession im Lande zu fördern, diese in der Minderheitssituation verblieb. Keine der dafür ergriffenen Maßnahmen änderte etwas daran, dass die lutherische Kirche die eigentliche Landeskirche blieb. Zur Veranschaulichung dieser Situation: Die Gesamtzahl der deutsch-reformierten Pfarrstellen betrug im Jahre 1680 26, im Jahre 1713 89, im Jahre 1740 84, im Jahre 180081 und im Jahre 1828 77.538 Die Einbürgerung reformierter Glaubensgenossen konnte lediglich bewirken, dass sich früher als in anderen deutschen Territorien eine konfessionelle Toleranz durchsetzte und sich im Laufe der Zeit zum Kennzeichen brandenburgisch-preußischer Kirchenpolitik entwickelte. ${ }^{539}$ Vor diesem Hintergrund haben die Unionsversuche zwischen der lutherischen und der reformierten Kirche in BrandenburgPreußen eine lange Tradition. ${ }^{540}$

538 Gabriel, Paul: Die reformierten Gemeinden der evangelischen Kirche in Berlin-Brandenburg (masch.schriftlich, o.J.), zit. nach: Winter, Friedrich: Die evangelische Kirche in Berlin-Brandenburg - eine unierte Kirche, in: Jahrbuch für Berlin-Brandenburgische Kirchengeschichte, 68 (2005), S. 118-128, bes. 123.

539 Ribbe, Wolfgang: Brandenburg auf dem Wege zum polykonfessionellen Staatswesen (1620 bis 1688), in: Gerd Heinrich (Hg.), Tausend Jahre Kirche in Berlin-Brandenburg, Berlin (1999), S. 267-292.

540 Eine Übersicht hierzu findet sich bei Walter Delius: Berliner kirchliche Unionsversuche im 17. und 18. Jahrhundert, in: Jahrbuch für Berlin-brandenburgische Kirchengeschichte, 45 (1970), S. 7-21. 
Gefördert durch den Pietismus und die Rezeption rationalistischer Aufklärung und Neologie, ${ }^{541}$ konnte sich der Unionsgedanke nach der Entlassung Johann Christoph Woellners als Chef des Geistlichen Departments im Jahre 1798 unter Friedrich Wilhelm III. (17701840) endgültig Bahn brechen. Dabei hatten nicht nur seine Person, sondern auch staatliche Reformen eine Rolle gespielt. Bereits das Allgemeine Landrecht von 1794 enthielt in Teil II Titel $11 \$ 39$ eine Bestimmung zur Abhaltung von Abendmahlsgemeinschaften zwischen den beiden protestantischen Konfessionen. ${ }^{542}$ Im Zuge der Stein-Hardenbergschen Reformen wurden die schon lange Zeit als ineffizient kritisierten drei Konsistorien - das lutherische Ober-Konsistorium, das deutsch-reformierte Kirchen-Directorium und das französisch-reformierte Ober-Konsistorium - aufgelöst und deren Aufgaben 1817 an die neu geschaffenen obersten Regierungsbehörden (Ministerium für geistliche, Unterrichts- und Medizinalsachen) übertragen. ${ }^{543}$ Letztendlich war für die Realisierung des Gedankens einer Union aller evangelischen Konfessionen ein bevorstehender historischer Anlass entscheidend, und die Idee hierfür kam in fast allen protestantischen Staaten gleichzeitig auf, das Reformationsfest 1817 mit der Herstellung der Union zu verknüpfen. ${ }^{544}$ Als Friedrich Wilhelm III. davon erfuhr, war er von dieser Vorstellung begeistert, denn - so der Monarch - würdiger könne das Säkularfest nicht gefeiert werden, als durch diese Vereinigung. ${ }^{545}$

Für die schließlich entstandene Verwaltungsunion ${ }^{546}$ waren zwei Vorgänge maßgebend. Die beiden ehemaligen Mitglieder der Geistlichen Kommission, Oberkonsistorialrat Karl Heinrich Sack und Propst Gottfried August Ludwig Hanstein, erhielten von Friedrich Wilhelm III. den Auftrag, Vorschläge über die Vereinigung beider Konfessionen der evangelischen Kirche auszuarbeiten. Dazu hielten diese nur die Generalsynode für befugt. Daher erging am 18. September 1817 eine Anordnung des Innenministeriums ${ }^{547}$ an das Konsistorium, eine Versammlung sämtlicher hiesiger Geistlichen [Berliner], sowohl der lutherischen als auch der deutschreformierten Konfession auf den 1 . Oktober einzuberufen, auf der über die Organisation der

541 Eine Übersicht hierzu findet sich bei Horst Möller: Toleranz als „zärtliche Mutter“. Kirchen und Konfessionen im Zeitalter der Aufklärung und der religiösen Indifferenz (1740 bis 1797), in: Heinrich, Gerd (Hg.): Tausend Jahre Kirche in Berlin-Brandenburg, Berlin (1999), S. 325-362; Insgesamt gab es in der Provinz Brandenburg ca. 1100 Gemeinden, s. Loock, Hans-Dietrich: Vom „Kirchenwesen“ zur Landeskirche, in: Heinrich, Gerd (Hg.). Tausendjahre Kirche in Berlin-Brandenburg, Berlin (1999), S. 363-424, bes. S. 403.

542 Hattenhauer, Hans und Bernert, Günther (Hg.): Allgemeines Landrecht für die preußischen Staaten von 1794, Berlin (1996), Dritte erweiterte Ausgabe, Teil II Titel $11 \S 39$ : Protestantische Kirchengesellschaften des Augsburger Glaubensbekenntnisses sollen ihren Mitgliedern wechselseitig die Teilnahme auch an ihren eigenthümlichen Religionshandlungen nicht versagen, wenn dieselben keine Kirchenanstalt ihrer eigenen Religionspartey, deren sie sich bedienen können, in der Nähe haben.

543 Loock, Hans-Dietrich: Vom „Kirchenwesen“ zur Landeskirche,..., Berlin (1999), S. 363-424, bes. S. 373 ff., $387 \mathrm{ff}$.

544 Für Preußen spielte dabei zusätzlich eine Rolle, dass die Stadt Wittenberg seit 1815 (Wiener Kongreß) zu Preußen gehörte.

545 Foerster, Erich: Die Entstehung der preußischen Landeskirche, Tübingen (1905), Bd. I, S. 270.

546 Loock, Hans-Dietrich: Vom „Kirchenwesen“ zur Landeskirche, ..., Berlin (1999), S. 363-424, bes. 391 ff.

547 derrselbe: S. 387; Die Verordnung wegen verbesserter Einrichtung der Provinzialbehörden vom 30. April 1815 bestimmte in $\$ 15$ die Wiedereinrichtung von einem Konsistorium in jeder Provinz. 


\section{Reformierte Schweizer Gemeinde im (Golmer) Bruch bei Potsdam}

[künftigen] Synode und über Bedingungen ihrer Gründung beratschlagt werden sollte. ${ }^{548}$ Auf der Versammlung wurde aber gleich der Vereinigung der bestehenden Synoden zugestimmt, diese konstituiert und Schleiermacher zu ihrem Vorsitzenden gewählt. Im Anschluss daran trug Propst Hanstein seine Vorstellung von einem „Unionsritus “549 vor, die im Kern vorsah, dass beim Abendmahl nicht Hostien, sondern - nach reformierter Praxis - ungesäuertes Brot gebrochen und bei der Konsekration [Weihe von Bort und Wein zu Beginn des Abendmahles] die Einsetzungsworte gesprochen werden sollten. Dieser Vorschlag wurde mehrheitlich angenommen und des Weiteren beschlossen, das Reformationsfest 1817 mit einer gemeinsamen Abendmahlsfeier aller Geistlichen Berlins zu begehen. ${ }^{550}$ Unabhängig davon erhielt der Hofprediger und Konsistorialrat Eylert von Friedrich Wilhelm III. den Auftrag, die Confessio fidei S.K.M. unseres Königs in dem Wunsch aufzusetzen, die beiden protestantischen, die reformierte und lutherische, Kirchen zu einer evangelisch-christlichen Kirche zu vereinen ${ }^{551}$; sie wurde später als „Preußische Unionsurkunde“ bezeichnet. Am 6. Oktober 1817 erschien die Confessio fidei des Königs in Form einer Kabinettsorder. ${ }^{52}$

Es schien so, dass damit die lang ersehnte Union erreicht wäre. Aber bisher hatte man sich nur auf das gemeinsame Abendmahl konzentriert. Übersehen wurden die darüber hinaus bei den evangelischen Konfessionen bestehenden sonstigen Divergenzen, ${ }^{53}$ die u. a. im unterschiedlichen Taufverständnis, im „quod non“ bei der Sakralsprache einschließlich der gesamten kul-

548 Allgemeine Synoden sind in allen Superintendenturen der Provinz Brandenburg abgehalten worden. Die Synode in Neustadt Brandenburg fand am 24. September 1817 statt, woran Prediger Schaub (Golmer Bruch) teilnahm, wogegen Prediger Wigand krankheitshalber fehlte [GStA PK, X. HA, Rep. 40 Nr. 1876, fol. $293-$ 302.]. Große Bedenken bestanden gegen die Einrichtung von Presbyterien, deren Mitglieder sich ein Urteil über die Geistlichen anzumaßen berechtigt glauben könnten.

549 Abendmahlsritus.

550 Der lutherische Prediger Hertzberg schilderte den Vorgang: Die Abendmahlssache ward durch die Vorlesung ein [er] Abhandlung zur Sprache gebracht, der man die Gerechtigkeit widerfahren laßen muß, daß sie, so an gelegentlich sie auch die Union empfiehlt, doch auch die großen Schwierigkeiten derselben klar vor Augen stellt. Hätte man uns Zeit gelassen, den Inhalt dieser lehrreichen Abhandlung reiflich zu erwägen, so wäre dagegen nichts $z u$ sagen, So ward aber noch in eben der schon weit vorgerückten Sitzung in aller Geschwindigkeit der Entschluß zu unserer Abendmahlsfeuer gefaßt. [GStA PK, X. HA, Rep. 40 Nr. 1876 (Anlage zum Protokoll der Verhandlung der Vereinigten Berliner Synode vom 3. Dezember 1817, fol. 67.].

551 Look, Hans-Dietrich: Vom „Kirchenwesen“ der Reformation und der Konfessionsunion (1798 bis 1840), in: Heinrich, Gerd (Hg.): Tausend Jahre Kirche in Berlin-Brandenburg, Berlin 1999, S. 384; Der Name „evangelisch-christliche Kirche" wurde bewußt gewählt, da dadurch sich die bisherige Konfession der Gemeinde nicht mehr erkennen ließ („Entkonfessionalisierung“) [Weichert, Friedrich: Die Unionsbestrebungen in Berlin und Brandenburg von 1817 bis 1850, in: Jahrbuch für Berlin-Brandenburgische Kirchengeschichte, 54 (1983) S. 87-137, bes. S. 103.].

552 Foerster, Erich: Die Entstehung der Preußischen Landeskirche, Tübingen (1905), Bd. I, S. 279.

553 Kennzeichnend für die reformierte Konfession ist vor allem der scharfe Gegensatz gegen alle Kreaturvergötterung und gegen alle Lehren und Ordnungen, die Göttliches und Menschliches vermischen. Daher wurden der Gottesdienst und das Leben im strengen Anschluß an die Bibel möglichst schlicht und prunklos gestaltet; Bilder, Altäre, Orgeln, Kerzen, Meßgewänder, alle in der Bibel nicht begründeten Feiertage wurden beseitigt, ebenso die bischöfliche Verfassung, an deren Stelle die Presbyter- und Synodalverfassung trat. [Der Große Brockhaus, Leipzig (1933) Bd. 15. S. 480.]. 
tischen Gestaltung einer Kirche sowie in der Prädestinationslehre ${ }^{554}$ bestanden. Für Friedrich Wilhelm III. waren dies nur noch äußere Meinungsunterschiede. Es käme nur darauf an, wie eine gewisse Übereinstimmung in die äußere kirchliche Form und Verfassung zu bringen, und wie es $z u$ bewirken sei, diese Formen und Gestaltungen so rein evangelisch und biblisch hinzustellen, daß die dogmatischen Differenzpunkte und Ungleichheit nicht nur nicht zur Sprache, sondern auch nicht weiter zur Ansicht kommen vor dem Volke. ${ }^{55}$ Deutlicher kann kaum gesagt werden, dass die Union in dogmatischer Hinsicht eine Verschweigungsunion war und ist. ${ }^{556}$ Hinsichtlich der äußeren kirchlichen Form strebte man an, dass überall Kreuz, Licht und Bibel auf die Altäre gestellt werden sollten, soweit solches allmählich aus den Gemeinden selbst hervorgehe. Damit war in sehr zurückhaltender Form eine Anpassung der reformierten Gemeinden an lutherische Formen verlangt, gleichsam als Ausgleich für den Verzicht der Lutheraner auf die Hostie beim Abendmahl. ${ }^{557}$ Und dies führte zu Widerständen, ja zu Aversionen gegen die Union sowohl in den lutherischen als auch reformierten Gemeinden, was Loock (1999) zunächst als weitgehendes Scheitern der Union bezeichnete, gleiches trifft für die spätere Agendereform zu.

Weichert ${ }^{558}$ hat versucht, die Gründe für die weitverbreitete Ablehnung der Union herauszufinden, und hierfür die mehrfach angeforderten Berichte der Superintendenturen an das Innenministerium nach 1817 ausgewertet. Diese dürften fadenscheinig und zurückhaltend verfasst worden sein, um sich selbst nicht dem Vorwurf einer mangelhaften Aufgeschlossenheit für die Union auszusetzen. Trotz der sicherlich sehr unterschiedlichen Situation in den Gemeinden haben unterschwellig mindestens drei Aspekte eine Rolle gespielt:

- das Konfessionsbewusstsein, dass in den von Kolonisten gegründeten Gemeinden von der Identitätsfrage nicht zu trennen ist,

- die Befürchtung, die bestehenden Rechts- und Besitzverhältnisse (z. B. Stiftungen, Legate, Stipendien) würden sich für die bisherigen Eigentümer negativ auswirken ${ }^{59}$ und

- die Disparität der lutherischen und reformierten Ortsgemeinde. ${ }^{560}$

554 s. Anm. 83 und 84.

555 Protokoll der Vereinigten Berliner Synoden (GStA PK, X. HA, Rep. 40, Nr. 1876, fol. 31R/32.)

556 Hierzu gibt es eine Parallele in der Gegenwart insofern, als in der Grundordnung der Evangelischen Kirche in Berlin-Brandenburg vom 19. November 1994 im Vorspruch unter Ziffer 4 Satz 2 von einer Kirche der lutherischen Reformation die Rede ist. Dabei kommt die Berlin-Brandenburgische Kirche von unterschiedlichen konfessionellen Traditionen her, und insofern ist sie eine konfessionell gegliederte Kirche.

557 Loock, Hans-Dietrich: Vom „Kirchenwesen“ zur Landeskirche, ..., Berlin (1999); S. 363-427, bes. 395; Foerster, Erich: Entstehung der preußischen Landeskirche, Tübingen (1905), Bd. I, S. 327 f.

558 Weichert, Friedrich: Die Unionsbestrebungen in Berlin und Brandenburg von 1817 bis 1850, in: Jahrbuch für Berlin-Brandenburgische Kirchengeschichte, 54 (1983), S. 97-137, bes. S. $106 \mathrm{ff}$.

559 Friedrich Wilhelm III. verfügte deshalb persönlich: Ich verordne deshalb, dass Niemand befugt seyn soll, einer reformierten oder lutherischen Gemeinde, im gleichen einer geistlichen oder weltlichen Kirchen- oder Schulstelle dergleichen Rechte aus einem von dem Beitritt zur Union hergenommenen Grunde vorzuenthalten oder zu entziehen. in: Mengin, Ernst: Das Recht der französisch-reformierten Kirche in Preußen. Urkundliche Denkschrift, Berlin (1929), S. 17.

560 In Oranienburg haben sich am 19. Dezember 18192800 Lutheraner mit etwa 50 Reformierten (bestehend aus vier Teilgemeinden, ohne Schmachtenhagen) zu einer Consensus-Union vereinigt, s. Rehberg, Max: Vor- 
Der Widerstand gegen eine Union ging so weit, dass zumindest einzelne reformierte Gemeinden - Gramzow und zwei weitere Landgemeinden - die Vereinigung mit der ortsansässigen lutherischen Gemeinde ablehnten. ${ }^{561}$ Dieser enorme Widerstand gegen die Union lässt sich auch anhand einer Übersicht über die Kirchenunionen in den Schweizerischen Kirchengemeinden (s. Tab. 10) dingfest machen. Die vollzogenen Vereinigungen waren - mit Ausnahme von Oranienburg (1819) und Lindow (1822) - erst Mitte des 19. Jahrhunderts zustande gekommen. Die reformierte Johanniskirchengemeinde in Brandenburg besteht heute noch.

Tab. 10: Das Aufgehen der bekanntesten ländlichen reformierten Schweizer Kirchengemeinden in die Preußische Union ${ }^{562}$

\begin{tabular}{ccc}
\hline Kirchengemeinde & Gründungsjahr & Kirchenunion/Einpfarrung \\
\hline Lehnin & 1691 & 1836 \\
\hline Lindow & 1690 & 1822 \\
\hline Lüdersdorf & 1694 & 1846 \\
\hline Nattwerder & 563 & 1832 \\
\hline Neuruppin & 1685 & 1841 \\
\hline Neustadt-Eberswalde & 1691 & 1830 \\
\hline Oranienburg $^{564}$ & 1693 & 1819 \\
\hline Storbeck $^{565}$ & nach 1650 & 1841 \\
\hline
\end{tabular}

\subsection{Das Aufgehen der reformierten Gemeinde Golmer Bruch in die Preußische Union}

Wie die Unierung bei der reformierten Gemeinde Golmer Bruch abgelaufen ist, darauf soll nachfolgend eingegangen werden. Boege (1924), Heese (1985) und Asche (2006) geben nur an, wann sie stattgefunden hat. ${ }^{566}$ Der Prediger Johann Friedrich Keßler (1777-

geschichte und Einführung der Union in Oranienburg, in: Jahrbuch für Berlin-Brandenburgische Kirchengeschichte, 43. Jahrgang (1968), S. 44-54, bes. S. 47 und 51.

561 ELAB 14/788, fol. 24.

562 Fischer, Otto: Evangelisches Pfarrerbuch ..., Berlin (1941), Bd. 3, S. 106, 109, 112, 113, 156, 157 und 192.

563 KA Alt Töplitz: Lagerbuch der Kirchengemeinde Nattwerder (1863 angelegt), S. 45 und Nachricht und Acten über die Vereinigung der reformierten Parochie Golmerbruch mit der lutherischen Parochie Alt Töplitz zu einer evangelischen Gemeinde - Aktennotiz (undatiert) von Prediger Keßler (nicht paginiert); DStA Brandenburg: BEN 230/236 (nicht paginiert).

564 Rehberg, Max: Vorgeschichte und Einführung der Union in Oranienburg, in: Jahrbuch der Berlin-Brandenburgischen Kirchengeschichte, 43 (1968), S. 44-54, bes. S. 51.

565 Stirnemann, Heinz: Woselbst sie wohl aufgenommen, Frankfurt a. M. (o.J.), S. 32-33.

566 Boege, Hermann: Die Gründung der Schweizerkolonien, in: Potsdamer Tageszeitung vom 18. Oktober 1924; Heese, Henning: Aus der Geschichte der evangelisch-reformierten Kirchengemeinde Nattwerder, in: Heese, Henning (Hg.): 300 Jahre Schweizer Kolonie am Golmischen Bruch bei Potsdam - 1685-1985, Sankt Augustin (1985), S. 49-65, bes. S. 60 und Asche, Matthias: Neusiedler im verheerten Land, Münster (2006), S. 612. 
$1859)^{567}$ schilderte in einem undatierten Papier die Abläufe der Vereinigung der lutherischen Gemeinde Alt Töplitz und der reformierten Gemeinde Golmer Bruch zu einer unierten Gemeinde und wie letztere zur Filialkirche wurde (s. Anhang 19). Anlass hierfür waren nicht, wie in Oranienburg, die gegenseitigen Beschwerden der beiden Ortspfarrer an das Konsistorium, die durch Vereinigung der beiden dortigen Gemeinden einer Lösung zugeführt wurden. Im hiesigen Fall sah die Königliche Regierung nach dem Tode des Predigers Wigand (1752-1821) von Alt Töplitz eine gute Gelegenheit, im Sinne der gewünschten Union einzugreifen und auf die in der Vergangenheit mehrfach geäußerten Beschwerden der Alt Töplitzer Filialgemeinde Phöben - von der Matergemeinde durch die Havel getrennt einzugehen, indem sie Phöben mit der Kirchengemeinde Schmergow und zum Ausgleich, ganz im Sinne der Union, die reformierte Kirchengemeinde Golmer Bruch mit der lutherischen von Alt Töplitz zu vereinigen suchte. Mit welcher Zähigkeit sich die Schweizer Kolonisten wehren würden, ihre Eigenständigkeit und das Privileg, als kleine Gemeinde einen eigenen Pfarrer zu haben (s. Tab. 10) nicht zu verlieren, hatte man nicht gerechnet, und so dauerte es zehn Jahre, bis schließlich 1832 auf Königlichen Befehl die reformierte Pfarre Golmer Bruch mit der lutherischen Pfarre Alt Töplitz vereinigt wurde. Wie sich das weitere Gemeindeleben gestalten sollte, wurde in einem Bericht über den Erfolg der Vereinigung beider Gemeinden vom 16. November 1832 zusammengefasst. ${ }^{568}$ Als problematisch wurde vor allem die Disparität angesehen (s. Tab. 11).

Aber zunächst blieb die Pfarrstelle Alt Töplitz vakant. Ein Jahr lang verwaltete Prediger Keßler sie interimistisch vom Golmer Bruch aus. Daraus resultierten verschiedene Probleme, die das Ministerium für geistliche, Unterrichts- und Medizinalangelegenheiten in seinem Bericht an die Regierung Potsdam vom 21. August 1823 unter Beilage einer örtlichen/geographischen Lageskizze beschrieb: Die Pfarre Alt Töplitz beziehe ihr Haupteinkommen aus der Landwirtschaft, was vom Golmer Bruch aus zu bewerkstelligen sei, die Pfarrgebäude verfielen, wenn sie unbewohnt blieben, das Pfarrholz würde ohne Aufsicht durch Diebstahl verwüstet, und in Alt Töplitz sei - im Gegensatz zum Golmer Bruch - eine gesunde Wohnung und gut im Stande [vorhanden], weswegen der Prediger Keßler aus ganz pragmatischen Gründen um Genehmigung bitte, nach Alt Töplitz umziehen zu dürfen. ${ }^{569}$ Hinzu kam die nicht leichte und pünktliche Wahrnehmung der Curirung ${ }^{570}$ in den Teilgemeinden. Zu Michaeli 1823 zog er, nachdem ihm die reformirten Eingepfarrten zu Golmerbruch [...] kein Recht, der Verlegung der Pfarrwohnung nach Alt Töplitz zu wiedersprechen; und die Vereinigung beider Pfarren erscheine in Bezug aus Seelsorge und Gottesdienst nicht bedenklich. ${ }^{51}$ Aber der heftige Widerstand blieb offensichtlich nicht ganz

567 auch Kessler geschrieben, er war von 1812-1823 Pfarrer in der reformierten Gemeinde Golmer Bruch, von 1823 bis 1832 interimistisch Pfarrer der unierten Parochie Töplitz und ab 1832 bis 1852 Pfarrer daselbst.

568 DStA Brandenburg: BEN 230-336 Kirchen- und Pfarrsachen der Parochie Alt-Töplitz (nicht paginiert) Original; GStA PK, X. HA, Rep. 40, Nr. 1426 fol. 12 ff. (Abschrift).

569 GStA PK, X. HA, Rep. 40, Nr. 1425, fol. 2-5.

570 Seelsorge.

571 DStA Brandenburg: BEN 230-336 (nicht paginiert), Schreiben der Königl. Preußischen Regierung Erste Abtheilung an den Vicesuperintendenten vom 5. September 1823. 
VI. Reformierte Schweizer Gemeinde im (Golmer) Bruch bei Potsdam

Tab. 11: Gemeindeglieder* zur Zeit der Vereinigung der reformierten Parochie Nattwerder mit der lutherischen Gemeinde Alt Töplitz (1835):572

\begin{tabular}{lcc}
\hline \multicolumn{1}{c}{ Ortschaft } & Erwachsene & nicht Konfirmierte \\
\hline Nattwerder & 19 & 12 \\
\hline Golm & 38 & 21 \\
\hline Neu Töplitz & 23 & 12 \\
\hline Alt Töplitz & 6 & 5 \\
\hline Eichholz & 3 & 2 \\
\hline Einhaus & 4 & -- \\
\hline Summe aller Seelen & $\mathbf{9 3}$ & $\mathbf{5 2}$ \\
\hline in Alt Töplitz & 204 & 159 \\
\hline
\end{tabular}

* Leest, Paretz und Marquardt sind hierin nicht mehr aufgeführt. (Deutsche Biographie Enzyklopädie (DBE), 2. Auflage, hg. von Rudolf Vierhaus, Bd. I, S. 126.).

wirkungslos. ${ }^{573}$ Denn auf Königlichen Befehl erhielt am 1. November 1824 Nattwerder wieder einen eigenen Prediger, Ernst Ferdinand Beck (von 1824 bis 1826), ihm folgte bald Johann Gottlieb Gruss (von 1826 bis 1832) ) $^{574}$. Prediger Keßler wurde gleichzeitig zum evangelischen Pfarrer von Alt Töplitz und Phöben ernannt. Gruss klagte aber so sehr über die Wohnverhältnisse, dass ihm gestattet wurde, auf Kosten des Staates in Potsdam zu wohnen. Um einen notwendigen Neubau eines Pfarrhauses in Nattwerder zu sparen, wendete sich die Regierung am 30. Dezember 1831 an König Friedrich Wilhelm III. Dieser entschied in seinem Schreiben an die Staatsminister Freiherr v. Altenstein ${ }^{575}$ und Maaßen ${ }^{576}$ vom 8. Januar 1832:

„Statt der beabsichtigt gewesenen

Erbauung eines neuen Pfarrhauses

in Golmerbruch will ich auf den von

Ihnen, dem Staats Minister Freiherr

572 KA Alt Töplitz: Alte Acten der Kirche Golmerbruch 1804-1839 (nicht paginiert), Bericht an die Kgl. Regierung vom 26. Oktober 1835.

573 Bemerkenswert ist, dass in der interimistischen Zeit in den Jahren 1823/24 innerhalb der reformierten Gemeinde aus ganz pragmatischen Gründen verschiedene Ansichten über den künftigen Kirchenbesuch aufkommen. Dem Bericht des Superintendenten Deregé an die Regierung Potsdam über seine am 14. Dezember 1823 in Nattwerder durchgeführte Kirchen- und Schulvisitation war zu entnehmen, dass solange ihr Prediger auch in Alt Töplitz Gottesdienst halte, Gemeinde-Glieder aus Neu Töplitz [...] ganz natürlich lieber in die [Alt] Töplitzer Kirche gingen [...] und hätten bereits [...] auf Plätze in der Alt Töplitzer Kirche angetragen [GStA PK: X. HA, Rep. 2B Regierung Potsdan Abt. II Nr. 682, Schr. v. 11.03.1824 (nicht paginiert)].

574 auch Gruß geschrieben.

575 Frh. von Stein zum Altenstein, Karl Sigmund Franz (1770-1840) war Minister für geistliche, Unterrichtsund Medizinalangelegenheiten von 1817 bis 1840 (Deutsche Biographie Enzyklopädie (DBE), 2. Auflage, hg. von Rudolf Vierhaus, Bd. I, S. 126.).

576 Maaßen, Karl Georg (1769-1834) war von 1830 bis 1834 Finanzminister (Deutsche Biographie Enzyklopädie (DBE), 2. Auflage, hg. von Rudolf Vierhaus, Bd. VI, S. 650.). 
von Altenstein vom 30ten v. M. erstatteten weitern Bericht die Vereinigung dieser kleinen reformirten mit der lutherischen Parochie in Alt Töplitz zu einer evangelische Gemeine genehmigen, und in Verfolg Meiner Ordre vom 12 ten September 1830 dem Prediger Gruss die bisherige Entschädigung von 263 rt 29 Sgr vom $1^{\text {te }}$ July vorigen bis $1^{\text {te }}$ July dieses Jahres aus Meinem Dispositionsfonds bewilligen, bis dahin mu $\beta$ aber die bemerkte Vereinigung zur Zufriedenheit der Gemeinden zu Stande gebracht sein, ... "577

Was daraus folgte - würde man meinen -, wäre mehr oder weniger eine Formsache gewesen. Aber nein, es gab noch ein Nachspiel. Die angemahnte Zufriedenheit der betroffenen Gemeinden ließ sich nur in einem Punkt nachweisen. Die vorgenannten Staatsminister bestätigten im Schreiben vom 3. November 1834 der Regierung ihre Anträge, wonach diese u. a. ermächtigt wurde, den bisherigen reformierten Einsassen in Nattwerder das dortige alte Pfarrhaus nebst Zubehör [...] zum vollen Eigenthum unentgeltlich zu überlassen. ${ }^{578}$ Erst darauf haben die vier Nattwerderaner Kolonisten Carl Gerich, Christian Dortschy, Ernst Wilhelm und Emanuel Mauerhoff im Ergebnis der Verhandlungen am 10. Januar 1835 der Auflösung der Pfarre am Ort zugestimmt und verpflichteten sich, 1. ihre den Religionsunterricht bedürfenden Kinder von jetzt ab zu dem jedesmaligen Pfarrer nach Alt-Toeplitz zu senden und nicht zu verlangen, daß derselbe deshalb nach Nattwerder kommen solle. 2. wurde ihnen die Verpflichtung auferlegt, die beiden Pferde des Predigers bei seines jedesmaligen Ueberkunft unter $[\mathrm{zu}]$ bringen. ${ }^{579}$ Was fortan den Abendmahlsritus in der zu einer evangelischen Gemeinde vereinigten Parochie Alt Töplitz und Golmer Bruch betraf, so musste der in Kap. VI.4. erwähnte Superintendent Martus der Regierung gewissenhaft berichten: Das Brot brechen beim heiligen Abendmahl geschiehet in beiden Gemeinden nur mit dem Unterschied, daß in Golmerbruch der Prediger des gewöhnlichen bisher immer gebrauchten Brodtes, in Alt Töplitz aber er Oblaten, die auch gebrochen werden, sich bedient. ${ }^{580}$ Am Beispiel der Einführung des Neuen Berliner Gesangbuches 1837 anstelle des Portsschen Gesangbuches zeigte sich, wie traditionell die Golmer Bruch Gemeindeglieder nach wie vor dachten und wie empfindlich sie auf Neuerungen reagierten. Die Eingabe des Kossäten Bier aus Göttin beim Ministerium bewegte über Jahre das Konsistorium und das

577 DStA Brandenburg: BEN 230-336 (nicht paginiert), Schreiben Friedrich Wilhelms III. an die Staatsminister Freiherr von Altenstein und Maaßen vom 8. Januar 1832.

578 KA Alt Töplitz: Vereinigung von Golmerbruch und Alttöplitz (nicht paginiert).

579 dieselbe.

580 GStA PK: X, HA, Rep. 40 Nr. 1425, fol. 12-15 (Original); DStA Brandenburg: BEN 230-336 (nicht paginiert) Abschrift hiervon. 
zuständige Kultusministerium. Schließlich gab sogar das Konsistorium nach und schrieb am 4. Dezember 1855 an den Superintendenten Neustadt-Brandenburg, es werde das alte Gesangbuch für genügend zur kirchlichen Erbauung halten. ${ }^{581}$

Zum Verständnis, warum diese Vereinigung mit einem derartigen Wirrwarr abgelaufen ist, dürfte eine siebenseitige Beschreibung der dreihundertjährigen Jubelfeier der Augsburger Confession am 25. Juni 1830 in der Kirche Nattwerder von Prediger Gruss erhellend sein. ${ }^{582}$ Schon die Abhaltung einer derartigen Feier in einer Landgemeinde verwundert an sich. Sie sollte nach dem Wunsche des Landesherrn und auf Anordnung der hohen Behörde auf würdige Weise begangen werden, obwohl es einer derartigen Aufforderung in der Gemeinde nicht bedurft hätte. Die Aufzeichnung über das Fest sei geschehen, weil das Presbyterium es zur Pflicht gegen die Nachkommen rechnet, ihnen darüber möglichst vollständige Nachricht zu überliefern. Welche Töne! Es folgten detaillierte Darlegungen (I.) über die Vorbereitung zur Feier dieses Festes und (II.) über Art und Weise, wie dieses Jubelfest in der Kirche zu Golmerbruch gefeiert worden ist. Es ist offensichtlich, dass diese Jubelfeier von Prediger Gruss dazu genutzt wurde, die Unierung in seiner reformierten Gemeinde voranzutreiben, denn er warb regelrecht dafür:

Und damit die Union, die durch eine gemeinschaftliche Agende schon hin-

länglich eingeleitet und sanktioniert sey, überall wirklich ins Leben trete, so hatte an diesem Feste bei der Feier des hiesig. Abendmahls

der ursprüngliche Ritus des brotbechens, sey es nun der (dazu geeigneten) Oblata, oder des brodtes, - eingeführt u. beobachtet worden. - Durch dahin bezügliche u. belehrende Vorstellungen solle den Gemeinden von den Geistlichen auch überdies das Wünschenswerthe u. Nothwendige der Vertauschung der wenig bezeichnenden benennung "reformirt" und "lutherisch" mit "evangelisch"

empfohlen werden, damit die Confessions unterschied sich nicht mehr auf diese zufällige Benennung stütze. --

Diese Zitierung eines behördlichen Textes in der Beschreibung des Jubiläums weist nach den oben gemachten Ausführungen auf einen tiefen Riss in der Gemeinde hin. Anscheinend hatten die später berufenen, einheimischen Prediger kein Verständnis für die noch tief tradierte "Verortung des reformierten Glaubens“ in der Schweizer Gemeinde Golmer Bruch. Als Geistlicher einer Staatskirche fühlte sich Prediger Gruss der Obrigkeit verpflichtet, verhielt sich ihr gegenüber devot und brachte dies mit der Festbeschreibung überschwänglich zum Ausdruck. 


\subsection{Umpfarrungen und Umwidmungen Anfang des 20. Jahrhunderts}

Bis in die Gegenwart ist immer wieder das kleine Örtchen Nattwerder mit seinen 25 - 30 Einwohnern und der verhältnismäßig großen Kirche mit ca. 200 Sitzplätzen thematisiert worden. Das anscheinende Missverhältnis hat sich in Bezug auf die Erhaltung der Kirche quasi seit 1690 als permanentes Problem erwiesen, vor allem weil die reformierten Schweizer Kolonisten einerseits keine Kirchensteuern zahlen mussten und andererseits die patronatliche Verpflichtung zur Erhaltung üblicherweise nur in unbedingt notwendigen Fällen und im sparsamsten Umfang und nur in Bezug auf Holz, Steine und Kalk gewährt wurde. Diesbezüglich war Nattwerder kein Einzelfall.

Als Pfarrer Kohlmann aus Derwitz die Vakanzverwaltung vom Pfarrsprengel Alt Töplitz wegen eines Disziplinarverfahrens gegen den amtierenden Pfarrer Hans Meyer (s. Anhang II) übernehmen musste, kursierten verschiedene Gerüchte in der Parochie Alt Töplitz über deren Zukunft, die er postwendend an den Superintendenten Müller Brandenburg im Schreiben vom 13. Dezember 1905 weitergab:

............. Von den Kirchgebäuden
von Nattwerder wurde gesagt, es würde wohl
ein Mal ein Heuschuppen werden.
Die Golmer Besitzer scheinen den übrigen
Golmern zugesagt werden zu wollen und
Nattwerder scheint auch zu glauben,
später eine Änderung der parochialen Verhältnisse
bekommen zu sollen, Neu-Toeplitz wird sich
aber zu Alt-Toeplitz halten..........

Diese Diskussionen haben in der Region anscheinend wirklich stattgefunden, erhielten aber erst dadurch gewichtige Bedeutung, als vier Nachkommen der Schweizer Kolonisten von Golm, Witwe Marthe Schweingruber, Rudolf Schweingruber, Wilhelm Kiener und Wilhelmine Zech, das Konsistorium am 15. Juni 1928 um die Eingemeindung in die Kirchengemeinde Golm baten. Sie begründeten dies damit, dass sie lediglich aufgrund ihrer reformierten Vorfahren bis zum heutigen Tage [...], obgleich sie in Golm wohnen, rechtlich zur Kirchengemeinde Nattwerder und damit zur Parochie Alt Töplitz gehören. Diese äußere Zugehörigkeit zu Nattwerder ist aber widersinnig geworden, da im Laufe der Zeit die konfessionelle Sonderstellung ganz verschwunden ist. Reformierte Gottesdienste werden schon seit langem nicht mehr in Nattwerder gehalten. Der Antrag enthielt auch gleich die Befürwortung des Kirchenältesten Wilhelm Bertz, Gemeindevertreters W. Ambrosius und Pfarrers Walter Schenk aus Golm. ${ }^{584}$ Das Konsistori-

584 DStA Brandenburg: L-E AT 1-420 (nicht paginiert). Die Antragsteller verschwiegen, dass unmittelbar vor ihren Gehöften 1886 die für damalige Verhältnisse prächtige Kaiser-Friedrich-Kirche erbaut worden war [Kitschke, Andreas: Die Kirchen der Potsdamer Kulturlandschaft, Berlin (2017), S. 217-224, bes. S. 217.], die zu einem sonntäglichen Besuch verlockte, womit man sich zusätzlich noch den etwa $10 \mathrm{~km}$ langen Fußweg nach Nattwerder ersparte. 
um musste sich nun notgedrungen erneut mit der Zugehörigkeitsfrage zur Gemeinde Golmer Bruch beschäftigen ${ }^{585}$ und forderte über die neugeschaffene Superintendentur Lehnin Pfarrer Otto Kietzig (s. Anhang II) auf, einen Lösungsvorschlag zu unterbreiten, aber auch einen Beschluss der Kirchlichen Körperschaften von Nattwerder und Alt Töplitz herbeizuführen. In seiner vorläufigen Antwort an Superintendent Gielen vom 4. August 1928 bezog dieser zu der damaligen schwierigen Situation in seiner Parochie Alt Töplitz ungeschminkt Stellung:

Solange die Kirchengemeinde Nattwerder besteht, werden die beiden übrig bleibenden Teile $e^{586}$ nicht die Steuerkraft der Golmer entbehren wollen. Diese können aus dem bisherigen Verband entlassen werden und müssen doch vielleicht in der gewohnten Weise an den bisherigen kirchlichen Unterhaltungspflichten Nattwerder gegenüber festgehalten werden. Bei Neuordnung der Gemeinde bliebe vielleicht schließlich der kleine Ort Nattwerder mit seiner am Ort befindlichen Kirche übrig. Die Unterhaltung dieser Kirche den Ortsinsassen allein zuzumuten ist unmöglich.

Keine andere Gemeinde wird die Kirche in Nattwerder als ein schweres Belastungsobjekt mit übernehmen wollen. Das Beste ist völlige Auflösung der Kirchengemein[de], Was soll dann mit der Kirche werden? Verwendung für einen anderen Zweck? Aber welchen? (abgeschiedene Lage)

Abreißen ist das beste - aber wer wird sich dazu entschließen, zumal diese Kirche fürs Landschaftsbild von nicht zu unterschätzender Bedeutung ist.

Schwierigkeiten über Schwierigkeiten. Jedenfalls ist der Antrag vollauf berechtigt und ein Ausdruck gesunden Menschenverstandes.

585 Die Frage ist erstmalig im Zusammenhang mit der Errichtung des Friedhofs in Neu Töplitz erörtert worden [Bleyl, Dietmar Walther Richard: Töplitz, Potsdam (2013), S. 131-132.]. Damals hatte das Kgl. Konsistorium der Provinz Brandenburg entschieden, dass zu der kirchlichen Kolonistengemeinde Nattwerder nur diejenigen evangelischen Personen gehören, welche von den alten Schweizer Kolonistenfamilien selbst abstammen und zugleich in Nattwerder, Golm und Neu Töplitz ihren Wohnsitz haben. [KA Alt Töplitz: Kirchhof Neu Töplitz (nicht paginiert), Schreiben vom 11. Oktober 1902]. gemeint sind Nattwerder und Neu Töplitz. 
Wie verfahren die Situation damals war, lässt sich aus den weiteren sehr klar abgefassten Berichten des Pfarrers Kietzig an den Superintendenten entnehmen. ${ }^{57}$ Für die Gottesdienste in Nattwerder sei er praktisch allein zuständig. Seit dem Weltkrieg gebe es keinen Küster mehr, so dass er die Glocken läuten, die Lieder ansagen oder anstecken, die Lieder und liturgischen Gesänge anstimmen und durchhalten, den Kirchenschlüssel holen und den Gottesdienstraum aufschließen, die Abendmahlsgeräte holen müsse usw. [...] Im Jahr würden 10 Gottesdienste gehalten. Die Änderung der Parochialverhältnisse der Kirchengemeinde Nattwerder sei nach den Verhandlungen mit den vereinigten kirchlichen Körperschaften und dem Pfarrer in Bornim ${ }^{58}$ insoweit möglich, als eine gewisse Bereitschaft bestehe, die Evangelischen von Nattwerder als gleichberechtigte und gleichverpflichtete Glieder in Grube bzw. die von Neu Töplitz in Alt-Töplitz aufzunehmen. Aber wenn es dadurch zu Auflösung der Gemeinde Nattwerder käme, würde die Kirchengemeinde Alttöplitz niemals verzichten auf die Verpflichtungen des Fiskus, die er hinsichtlich der Pfarrbesoldung des Alttöplitzer Pfarrers, wie hinsichtlich der Mitunterhaltung des Pfarrhauses Alttöplitz für die Kirchengemeinde Nattwerder vertragsmäßig bei der Einpfarrung von Nattwerder nach Töplitz 1835 übernommen hat. Und was wäre mit der Kirche Nattwerder? Die Regierung habe ihm dazu eröffnet: Die Kirche [...] stehe rechtlich im Eigentum der Kirchengemeinde Nattwerder. Der Staat als solcher [...] habe keine Pflicht und kein Verlangen [...], einen [...] lästig gewordenen Besitz zu übernehmen. Man habe ihn in dieser Beziehung an den Landrat in Nauen, an den Landesdirektor der Provinz Brandenburg, den Landeskonservator und selbst die Stadt Berlin, die unter Umständen alte Baudenkmäler zu Museen, Versammlungs- und Herbergsstätten übernehmen, verwiesen. ${ }^{589}$ Auf weitere Details muss hier verzichtet werden.

Durch den Tod von Pfarrer Kietzig am 14. Juni 1929 wurde die Angelegenheit wegen zeitweiser Vakanz der Pfarrstelle zunächst nicht weiterverfolgt. Sein Nachfolger Pfarrer Walter Martens (s. Anhang II) musste dann sogar noch mehrfach aufgefordert werden, darüber mit den Betroffenen Gespräche zu führen. Schließlich kam der Superintendent Gielen (Lehnin) selbst zu folgender Ansicht:

Ich habe den Eindruck, dass die Einwohner von Nattwerder zäh an dem Weiterbestehen der Kirchengemeinde festhalten. Ich fürchte, dass die nach meiner Ansicht und auch nach Ansicht der Vertretung der Kirchengemeinde Alttöplitz und Neutöplitz notwendige Auflösung der Kirchengemeinde auf lebhaften Widerstand der Gemeinde Nattwerder stossen wird. Ich habe bisher gezögert, weitere Schritte zu

587 DStA Brandenburg: L-E AT 1-420 (nicht paginiert), Berichte vom 8. September, 14. September, 8. Oktober und 12. Oktober 1928 an den Superintendenten.

588 zu dieser Zeit zuständig für Golm und Grube.

$589 \mathrm{Zu}$ dieser Zeit war bereits das ehemalige Pfarrhaus an die Stadt Berlin als Jugendherberge verpachtet. (DStA Brandenburg: L-E AT 1-420 (nicht paginiert), Bericht vom 6. Oktober 1928.). 


\section{Reformierte Schweizer Gemeinde im (Golmer) Bruch bei Potsdam}

tun, deshalb, weil, wie es dem Konsi-

storium bekannt ist, die Gemeinde nach

langjährigen Streitigkeiten der Beru-

higung bedarf. ${ }^{590}$

Superintendent Gielen bat aus diesem Grunde auch die Antragsteller, ihren Antrag auf Umpfarrung zurückzunehmen. Die Witwe Schweingruber ließ sich aber nicht überzeugen. Insoweit blieb die Situation so, wie sie war. Nur einen positiven Effekt hatte die Angelegenheit zeitweise stieg die Anzahl der Gottesdienstbesucher.

Im Zusammenhang mit der von Pfarrer Martens geplanten Renovierung der Kirche Nattwerder für das bevorstehende 250-jährige Jubiläum der Ansiedlung Schweizer Kolonisten im Golmer Bruch im Jahre 1935 nahm der Provinzialkonservator der Provinz Brandenburg, Prof. Blunk, zur Frage der Kirchenumwidmung nach einer Besichtigung vor Ort Stellung:

Wie mir bei der Besichtigung angedeutet wurde, besteht die Gefahr einer Auflösung der Kirchengemeinde Nattwerder, der ausschliesslich Schweizer Kolonisten angehörten, und ihre Zuteilung zu anderen Nachbargemeinden. Ich muss daher betonen, dass es vom Standpunkt der Denkmalpflege nicht zu billigen wäre, wenn das Gotteshaus, das vornehmlich in seiner Innengestaltung besonders eigenartig und charaktervoll ist, ausser Gebrauch käme (und dadurch der laufenden Pflege entbehren würde), oder wenn es anderen als gottesdienstlichen Zwecken - sofern diese seiner Würde nicht entsprechen - zugeführt werden müsste. ${ }^{591}$

Damit war die Vorstellung der Umnutzung der Kirche Nattwerder zu einer Jugendherberge vom Tisch, die in Verbindung mit der vorher erwähnten Verpachtung des ehemaligen Pfarrhauses an die Stadt Berlin als Jugendherberge möglicherweise zustande gekommen wäre. ${ }^{592}$ Welch ein Glück!

\subsection{Die endgültige Auflösung im Jahre 1949}

Nachdem für Nattwerder der Zweite Weltkrieg glimpflich zu Ende gegangen war, taten sich neue Probleme für die Gemeinde auf. Das Dorf hatte unfreiwilligen Zuzug von Flüchtlingen aus dem Osten bekommen, wie die Grabmäler auf dem Friedhof in Nattwerder noch heute zeigen. ${ }^{593}$ Mehrere einheimische Familien verließen aus Angst vor Verfolgung oder wegen Nichterfüllung des Abgabesolls die sowjetisch besetzte Zone.

591 daselbst: Schreiben des Provinzialkonservators an die Preußische Regierung Potsdam, Abt. f. Kirchen- und Schulwesen vom 23. Oktober 1931.

592 daselbst: Schreiben des Pfarrers Kietzig an den Superintendenten in Lehnin vom 6. Oktober 1928.

593 Heinrich Pflaum aus Friedenwalde/Wartheland (13.06.1888-7.11.1953). 
Das kirchliche Gemeindeleben war zum Erliegen gekommen. Dabei spielte die Amtsausübung von Pfarrer Martens (von 1930 bis $1949 \mathrm{im} \mathrm{Amt)} \mathrm{im} \mathrm{Dritten} \mathrm{Reich} \mathrm{eine} \mathrm{wesentliche}$ Rolle. ${ }^{594}$ Nach dem Zusammenbruch 1945 hatte die Evangelische Kirche in Deutschland eine Notverordnung erlassen, in der vor allem die Überprüfung der kirchlichen Angestellten/ Beamten und die Frage des Verbleibens im Amt geregelt war. ${ }^{595}$ Dem Kreissynodalvorstand oblag es, die eingereichten Unterlagen zu sichten und ein Votum über Befürwortung bzw. Ablehnung des Verbleibens im Amt abzugeben. Im Fall Martens gab dieser am 11. Dezember 1947 folgende Stellungnahme ab: Gegen Pfarrer Martens schwebt wegen mangelhafter Amtsführung ein Disziplinarverfahren. Die geistlichen Mitglieder des Kreissynodalverbandes, die seinen politischen Werdegang kennen, haben sich für eine Ablehnung ausgesprochen. Trotzdem hatte das Votum für Pfarrer Martens keine Konsequenzen im Sinne der Amtsenthebung. Er blieb bis 1949 im Amt. Ob sein Fall für die Nachkriegsüberprüfung der Pfarrer als typisch anzusehen ist, sei dahingestellt; es fehlt bis heute immer noch eine repräsentative Studie darüber. ${ }^{596}$

Die Nachfolge von Pfarrer Martens im Jahre 1949 hat Pfarrer Dr. Friedrich Wienecke selbst arrangiert..$^{597}$ Seine politische Karriere begann 1920 bei den Deutsch-Nationalen, er schloss sich 1928 der Bewegung Deutscher Christen an und ließ sich 1929 bei den Kommunalwahlen in Soldin als Spitzenkandidat der NSDAP aufstellen. 1933 wurde er zum Oberkonsistorialrat im Evangelischen Oberkirchenrat (EOK) berufen und war seitdem für Schulfragen (insbesondere den Religionsunterricht an Schulen) zuständig. Noch kurz vor Kriegsende - im März 1945 - wurde er zur Dienststelle der EOK in Stollberg versetzt und übernahm gleichzeitig die Kriegsvertretung in der Pfarrstelle Steinbrücken-Hain (Kirchenprovinz Sachsen). Von da aus strebte er mit allen Mitteln und unter Ausnutzung seiner alten Beziehungen an, wieder in der Nähe Berlins ein Pfarramt übertragen zu bekommen. Im Ergebnis seiner Bemühungen wurde ihm im Gegenzug zur Versetzung von Pfarrer Martens in die Kirchenprovinz Sachsen-Anhalt ab 1. Juli 1949 zunächst kommissarisch - und ab 1950 hauptamtlich - die Verwaltung des Pfarrsprengels Alt Töplitz übertragen.

Eine der ersten Aufgaben, der sich Dr. Wienecke, aufgefordert durch das Schreiben des Konsistoriums vom 27. April 1949, stellen musste, war die Statusfrage der ehemaligen Schweizer Kolonistengemeinde Golmer Bruch. Er berief den Gemeindekirchenrat (GKR) der Filialgemeinde Nattwerder am 13. August 1949 ein, der seit Ausbruch des Zweiten Weltkriegs nicht mehr getagt hatte und noch immer, wie eh und je, aus vier Erbpächtern, Alfred Bertz,

594 ausführlich hierzu: Bleyl, Dietmar Walther Richard: Töplitz, Potsdam (2013), S. 45 ff.

595 Amtl. Mittl. aus der Ev. Kirche der ApU 1945: 9. Verordnung zur Beschränkung und Sichtung des Personalbestandes der kirchlichen Verwaltung (Abbauverordnung) vom 6. November 1945. Die Überprüfung der Pfarrer usw. kam allerdings erst aufgrund eines Telegramms der Evangelischen Kirchenleitung an alle Superintendenten vom 28. Oktober 1947 zustande. Der Hintergrund hierfür war der [SMAD]Befehl 201 gemäß Direktiven 24 und 38. [DStA: L-E 52-42 (Entnazifizierung 1947-1948, nicht paginiert.] Danach hatten die Betroffenen einen Lebenslauf vorzulegen und einen Fragebogen (Mitgliedschaften u. dgl.) zu beantworten.

596 Schuppan, Erich (Hg.): Zur Geschichte des Kirchenkampfes, Bd. I und II, Berlin (1998), zu Martens Bd. I. S. 41,42 u. 46.

597 ausführlich hierzu: Biographisch-Bibliographisches Kirchenlexikon, Bd. XIII (1998), Spalten 1090-1104 und Bleyl, Dietmar Walther Richard: Töplitz, Potsdam (2013), S. 53 ff. 
Ewald Dortschy, Fritz Garmatter (alle Neu Töplitz) und Wilhelm Mauerhof (Nattwerder), bestand. Im Protokoll wurde zunächst die Beziehung der beiden Gemeinden Alt Töplitz und Nattwerder charakterisiert. Der GKR erhebt nicht den Anspruch selbständige Ki-gemd. Zu sein, sondern betrachtet sich als einen organischen Bestandteil der Ki-gmd. Alttöplitz. ${ }^{598}$ Seit der von König Friedrich Wilhelm III. 1832 verordneten Zusammenlegung mit der Matergemeinde Alt Töplitz hätten sich beide Gemeinden mehr und mehr einander angepasst. Die reformierte Tradition bestehe eigentlich nur noch beim Abendmahl. Im Religionsunterricht werde der lutherische Katechismus verwandt. Im Übrigen sei die Kirchengemeinde Golmer Bruch bis auf gewisse nach Golm und Neu Töplitz reichende Familientraditionen praktisch zu einer Lokalgemeinde geworden, die aus etwa 60 Seelen (einschließlich der Flüchtlinge) neben den etwa 40 Auswärtigen bestehe. Traditionsgemäß seien sie von der Kirchensteuer befreit, doch würden sie, da die staatlichen Privilegien zurzeit ruhten, dafür freiwillige Abgaben entrichten. Der Gemeindekirchenrat beschloss, die Übertragung snr. Geschäfte auf den GKR Alttöplitz u. Umwandlg. sr. Funktion in die eines durch seine Mitglieder zu bildenden „Gemeindebeirats Nattwerder". In dsr. Eigenschaft aber gedenkt er d. Traditionen der Kirche Nattwerder nachdrücklich $z u$ fördern. Damit hörte die traditionsreiche Kirchengemeinde „Golmer Bruch“ offiziell auf zu existieren.

Nur Einzelpersonen wie z. B. Fritz Kiener aus Golm (1925-2009) und Otto Bertz aus Neu Töplitz (1902-1982) haben bis zu ihrem Lebensende ihre innere Verbundenheit zur ehemaligen reformierten Kirchengemeinde Nattwerder gelebt und haben alle vier Wochen die Gottesdienste in Nattwerder besucht. Bis zur Amtszeit von Pfarrer Viebeg (1989-2016) wurde in Nattwerder beim Abendmahl Brot nach reformiertem Ritus gebrochen.

\section{Jubiläen als Spiegel der Zeit}

Im 16./17. Jahrhundert hat es sich eingebürgert, dass zur Wiederkehr eines historischen, kirchlichen, wirtschaftlichen, kulturellen oder sogar privaten Anlasses Jubiläen begangen wurden. Seitdem avancierten diese Feiern zu einem festen Modell der europäischen Erinnerungskultur ${ }^{599}$, wobei sie darüber hinaus auch immer ein beredtes Spiegelbild des Zeitgeistes abgaben und deswegen bei den Historikern auf großes Interesse gestoßen sind. Die Jubiläen der reformierten Schweizer Gemeinde im Golmer Bruch stellen hierfür ein gutes Beispiel für eine Gemeinde auf dem platten Lande dar, sie sind aber nicht vergleichbar mit denen einer städtischen Gemeinde. ${ }^{600}$

598 KA Alt Töplitz: Verhandlungsbuch des GKR Alttöplitz/Nattwerder (1928-1976), S. 194/195, s. Anhang 22.

599 Kaufmann, Thomas: Erlöste und Verdammte, Eine Geschichte der Reformation, München (2016), S. 373 ff.

600 Moeseritz, Richard Gottlieb Heinrich: Festschrift zum 275-jährigen Jubiläum der evangelisch-reformierten Hofgemeinde in Halberstadt, Halberstadt (1939) S. 4 ff., bes. S. 10. Diese Gemeinde zählt zu den reformierten Gemeinden, die Kurfürst Friedrich Wilhelm per Decret (30. September 1664) selbst als Hofgemeinde gründen konnte und deren Prediger bis 1932 als „Hofprediger“ betitelt wurden. Die Halberstädter Hofgemeinde beging selbstbewusst erstmalig 1764 und später weitere Jubiläen. 
Nach Boege, Dreifuss und Heese ${ }^{601}$ fand anlässlich des zweihundertjährigen Bestehens der reformierten Schweizer Gemeinde im Bruch bei Potsdam am 18. Juni 1885 ein Dankgottesdienst in der Kirche Nattwerder statt. Auch hätten sich bis zum Beginn des Zweiten Weltkrieges jeden Sommer zahlreiche Nachkommen der Schweizer zu einer Feier getroffen, an der man dankbar des Großen Kurfürsten und der eingewanderten Vorfahren aus den Kantonen Bern und Zürich gedacht hätte. Die Quellen hierfür wurden nicht benannt. Im Kirchenarchiv ließen sich dazu keine Hinweise finden.

Unter der Regie von Pfarrer Martens ${ }^{602}$, der von 1930 bis 1949 Pfarrer in Alt Töplitz und Nattwerder war, sich zu den Deutschen Christen bekannte und Mitglied der NSDAP war, ${ }^{603}$ wurde mit großem Aufwand die 250-Jahrfeier am 23. Juni 1935 begangen. Gleich am Beginn seiner Amtszeit bemühte er sich beim Evangelischen Konsistorium in Berlin um Gelder für die Instandsetzung der Kirche Nattwerder, damit die erneuerte Kirche im Zusammenhang mit den Jubiläumsfeierlichkeiten aus Anlass des 250-jährigen Bestehens der Schweizer Kolonistengemeinde Nattwerder im Jahre 1935 eingeweiht werden kann. ${ }^{604}$ Auch über dieses Jubiläum lieBen sich im Kirchenarchiv keine Hinweise finden. Aber es fand unter reger Beteiligung der Öffentlichkeit statt, zumal es als „Sippenfest“ angekündigt wurde und damit sehr zeitgemäß arrangiert war. Nicht nur die Lokalzeitungen ${ }^{605}$ berichteten darüber, selbst der Völkische Beobachter vom 25. Juni 1935 widmete diesem Ereignis einen anonymen Artikel unter dem Titel: 250 Jahre Gemeinde Nattwerder - Eine Gründung des Großen Kurfürsten, in dem es auszugsweise heißt: Zu einem echten deutschen Sippenfest gestaltete sich das 250-jährige Jubiläum der Kirchengemeinde Nattwerder am Sonntag. In das kleine, nur wenige Bauerngehöfte umfassende Dörfchen wanderten in den ersten Nachmittagsstunden zahlreiche "Sippenangehörige“, teilweise von weither kommend ein, um hier der Vorfahren und ihrer harten Arbeit bei der Errichtung und dem Emporblühen dieser ehemaligen Kolonistengemeinde des Großen Kurfürsten dankbar ehrend

601 Boege, Hermann: Die Gründung der Schweizer Kolonie Golm, in: Potsdamer Tageszeitung Nr. 246 vom 18. Oktober 1924; Dreifuss, Emil: Willkommene Berner Emigranten, in: Der Bund (1985) Nr. 167 (20.07.), 172 (27.07.) und 179 (03.08.); Heese, Henning: Schweizer Kolonisten im Golmer Bruch bei Potsdam, Der Landkreis Potsdam, Heimatgeschichtliche und heimatkundliche Beiträge, Heft 1 (1992); S. 54-63, bes. 63.

602 DStA Brandenburg: L-E 2-422 (nicht paginiert).

603 DStA Brandenburg: L-E AT 319-316 (nicht paginiert), Schreiben von Pfarrer Martens an den Lehniner Superintendenten Gielen vom 8. Juli 1933: Es liegt mir am Herzen, Ihnen davon Mitteilung zu machen, daß ich mich der Glaubensbewegung „Deutsche Christen“ angeschlossen habe. Diese Entscheidung habe ich getroffen, nachdem ich mich gründlich geprüft habe und die Überzeugung gewonnen, daß ich so am besten unserer Kirche dienen kann. Da liegt der einzige Beweggrund für meinen Entschlu $\beta$ und ich bitte Sie, davon überzeugt zu sein, daß ich in aller Treue zu ihnen, sehr verehrter Herr Superintendent, und zu unserem Brüderkreis stehe; mehr zu Pfarrer Martens s. Bleyl, Dietmar Walther Richard: Töplitz, Potsdam (2013), S. 45-53.

604 DStA Brandenburg: L-E AT 1-419 (nicht paginiert): Schreiben Pfarrers Martens an das Evangelische Konsistorium vom 14. November 1932.

605 Potsdamer Tageszeitung, Jg. 86/Nr. 138 vom 17. Juni 1935: 250 Jahre Schweizer Kolonie Nattwerder, Golm und Neu-Töplitz; dgl.: Jg. 86/Nr. 144 vom 24. Juni 1935: Das Jubelfest der Schweizerkolonisten, Die Feier in Nattwerder; Berliner Lokal-Anzeiger (Morgenausgabe, 1. Beiblatt) Nr. 151 vom 25. Juni 1935: Märkische Festtage auf Schweizer Erbhöfen. 
$z u$ gedenken ${ }^{606} \mathrm{Im}$ Einzelnen wurde ausführlich über das geschmückte Dorf, den feierlichen Einzug der Gäste in die Kirche und die Predigt von Pfarrer Martens über Der Herr unser Gott sei mit uns wie er gewesen ist mit unseren Vätern, er verlasse uns nicht und ziehe seine Hand nicht von uns ab (1. Könige 8,57) berichtet. Bei der anschließenden großen Kaffeetafel auf der Dorfstraße begrüßte der Bürgermeister Mauerhoff alle Gäste. Es folgte ein Vortrag von Konrektor i. R.R. Görges (Berlin-Steglitz) über die Entstehung sowie Entwicklung der Kolonistengemeinde Nattwerder. Beim Abendbrot wurden die einzelnen Sippen vorgestellt: die Zechs Garmatters - Dortschy - Mauerhofs - Wilhelms; der Sippenälteste gab den Sippenbericht. An den Führer und Reichskanzler Adolf Hitler und den Reichsernährungsminister Darré wurden vom Ortsbauernführer Bertz Huldigungstelegramme gesandt und ihrer in Liebe durch einen kräftigen Heilruf gedacht (s. Anhang 21) ${ }^{607}$ Der Artikel im Völkischen Beobachter endete mit der perspektivischen Ansage: Aus dem Dank für die Vergangenheit wachse nun für die Nachkommen die heilige Verpflichtung, ihr Leben an die heiligen Gesetze und Pflichten zu binden, wie es die Vorfahren der Schweizer Kolonisten getan hätten. An diesem 250-jährigen Jubeltage müsse Gelöbnis für die Nachkommen sein, an dem Glauben der Väter treu festzuhalten.

Für die inzwischen sehr geschrumpfte Gemeinde Nattwerder war es eine besondere Herausforderung, das 300-jährige Jubiläum der Besiedlung des Golmer Bruchs mit Schweizer Kolonisten im Jahre $1985 \mathrm{zu}$ begehen. Es sollte eine rein kirchliche Veranstaltung sein und gelang nicht zuletzt durch die vielfältige Unterstützung seitens der westdeutschen Verwandtschaft. Unter der Regie von Pfarrer Lorenz wurde schon im Jahre 1983 damit begonnen, die noch immer von Kriegsschäden gezeichnete Kirche Nattwerder zu sanieren. Dazu mussten die benötigten Materialien aus den verschiedensten Quellen mühsam zusammengetragen werden, da der Staat derartige Dorfkirchensanierungen - wenn überhaupt - nur minimal unterstützte. Es wurde Siegfried Gerlach mit seiner „Wochenendbrigade“ gewonnen, die über mehrere Monate mit einem Gerüst des städtischen Bauhofs Potsdam am Freitagnachmittag erschien und am Sonntagnachmittag wieder abzog. In der Zwischenzeit musste an Putz- und Malerarbeiten so viel als möglich geschafft werden. Aber es gelang, wenn auch nach heutigen Maßstäben nicht alle Arbeiten denkmalgerecht ausgeführt worden sind. Im fernen Sankt AugustinHangelar war von Henning Heese die bis heute viel zitierte Festschrift 300 Jahre Schweizer Kolonie am Golmischen Bruche erstellt und mitgebracht worden. ${ }^{608} \mathrm{Zu}$ der 300-Jahrfeier am 23./24. Juni 1985 erschienen rund 300 Menschen aus nah und fern, darunter überraschenderweise auch - und noch dazu ohne Visum - Frau Dauwalder, die Pastorin der reformierten Kirche in Krauchthal (Schweiz), sowie Vertreter der Patengemeinde Wesel. Als Vertreterin der nicht mehr hier lebenden Schweizer Familien hatte Frau Duncker als Gastgeschenk vier historische Trachtenpuppen (Bauer mit einem Säbel, Bäuerin, Hirte mit Peitsche und Magd

606 Völkischer Beobachter Nr. 176 Ausgabe B vom 25.06.1935: 250 Jahre Gemeinde Nattwerder - Eine Gründung des Großen Kurfürsten.

607 Potsdamer Tageszeitung Jg. 86 Nr. 144 vom 24. Juni 1935. Original im KA Alt Töplitz: Akte Allgemeine Verwaltung.

608 s. Anm. 31. 
mit Kochgeschirr) aus der Ansiedlungszeit mitgebracht, die noch heute in der Kirche Nattwerder zu sehen sind.

Eröffnet wurde die Jubiläumsfeier mit einem Festgottesdienst, bei dem Propst Dr. Friedrich Winter (Ost-Berlin) die Predigt hielt; dem folgten ein Kaffeetrinken, ein Vortrag von Henning Heese über die Geschichte der Einwanderung und am Abend noch ein Vortrag von Dr. Winter über 300-Jahre Potsdamer Toleranzedikt - seine geschichtliche Wirkung und seine Bedeutung bis in die Gegenwart. Zur Überraschung der Gäste traten die Nattwerderaner am Nachmittag als Trachtengruppe auf. Aus dem Fundus des Hans-Otto-Theaters hatten sie sich bäuerliche Kostüme aus der Besiedlungszeit beschafft und waren mit entsprechenden Gerätschaften ausgestattet. Es war ein farbenfrohes Bild, was große Heiterkeit auslöste. Zusätzlich hatten die Nattwerderaner bäuerliche Utensilien ausgestellt, die sie von ihren Dachböden und aus ihren Kellern ans Tageslicht geholt hatten. Manches hatte Museumswert. Der zweite Festtag war Gesprächen zwischen den ortsansässigen und angereisten Schweizer Familien, der Pflanzung von drei Esskastanien als Zeichen der Hoffnung und einem abschließenden Festkonzert, das vom Consortium musicum Potsdam gestaltet wurde, vorbehalten. ${ }^{609}$

Die bislang letzte Jubiläumsfeier fand 2010 anlässlich der 325 Jahre Besiedlung des Golmer Bruchs statt. Das Fest wurde nunmehr vom Verein Schweizerkolonistendorf Nattwerder e. V. (SKDN e. V.) ${ }^{610}$ im Einvernehmen mit der Evangelischen Kirchengemeinde Alt Töplitz ausgerichtet und dafür eine Festschrift ${ }^{611}$ erstellt. Bei der Ausgestaltung des dreitägigen Festes standen konfessionelle, historische ${ }^{612}$ und musikalische Aspekte im Vordergrund.

609 Heese, Henning: Dreihundertjähriges geschichtliches Erbe der Schweizer evangelischen Kirchengemeinde am Golmer Bruch bei Potsdam, [KA Alt Töplitz: 300 Jahre Nattwerder - 23. Juni 1985] Festgottesdienst, Fotos-Zeitungsberichte; von der Presseberichterstattung soll hier nur auf die Berner Zeitung vom 23. Juli 1985 hingewiesen werden: DDR-Feier erinnert an die Auswanderung von Berner Familien - Vor 300 Jahren zogen 101 Erwachsene und Kinder auf dem Wasserweg nach Potsdam.

610 Er wurde 1991 mit der Zielstellung gegründet, das kulturelle Erbe der Schweizer Kolonisten im Golmer Bruch zu bewahren und bekannt zu machen.

611 s. Anm. 35.

612 Schmelz, Ulrich: Die Schweizer-Kolonie Nattwerder als Prototyp von Zuwandererkolonien in Brandenburg. Vortrag beim 325. Jubiläum von Nattwerder (18. Juni 2010), im Besitz des Autors]. 



\section{Demographische, sozial- und kirchengeschichtliche Studien über die Reformierte Schweizer Gemeinde im Bruch bei Potsdam}

Die Einführung der sog. Kirchenbücher in der nachreformatorischen Zeit ist nach Strangmeier und Huckenbeck $(1983)^{613}$ wohl in erster Linie in dem Bedürfnis zu sehen, sich von anderen Konfessionen abzugrenzen und den Zusammenhalt der eigenen Glaubensgemeinschaft zu stärken. Die ersten nachreformatorischen Kirchenbücher tauchen zunächst an verschiedenen Orten in Baden aufgrund der Eigeninitiative der jeweiligen Gemeinden bzw. ihrer Prediger auf. Schon bald aber erließen die protestantischen Landesfürsten in ihrer Eigenschaft als „summus episcopus “614 für ihre Territorien Kirchenordnungen. Für ganz Brandenburg ist der Erlass der Kirchenordnung im Zusammenhang mit der Visitations- und Konsistorialordnung von $1573^{615}$ erfolgt, in der es heißt:

Aus sonderlichen bedencken, und vielen er-

heblichen Ursachen, legen wir allen vnd jegli-

chen Pfarrern auff, dass sie ein sonderlich Regi-

ster halten, vnd darinne alle vnd jede Namen

der Personen, so sie vnd ihre Caplene, oder sonst

jemandts von ihrendt wegen, in ihren Kirchen

Thrawen vnd Teüffen, Registrirn, Deßgleichen

die Namen der Todten, so zu ihren zeiten ver-

storben, mit fleisse verzeichnen. Auch solche

Register in den Kasten, darinne sie der Kirchen

Meß: vnd ander Buecher legen, wol ver-

wahren. Mit verwarnung, do sie solchs vorlassen

wuerden, dass ein jeder Pfarrer vnserm Consi-

storio, wegen solchs seines vnfleisses, zehen Tha-

ler straffe zu erlegen solle schuldig sein.

Wie in dieser Zeit üblich, geschah eine solche Aufgabenübertragung an die Prediger bzw. Kapläne in einer pauschalen, nicht näher bestimmten Art und Weise. Die Ausführung wurde dem Beauftragten überlassen. Bemerkenswert ist auch, dass die Umsetzung dieser Aufgaben sich sehr herauszögerte, denn 1649 sind nach Meyerding de Ahna (1935) erst 308 Kirchen-

613 Strangmeier, Heinrich und Ernst Huckenbeck (Hg.): Das älteste Kirchenbuch der reformierten Gemeinde Hilden (1649-1694), Hilden (1983), S. 20.

614 In der Evangelischen Kirche übte der Landesherr das oberste Kirchenregiment bis 1918 aus.

615 Mylius Corpus Constitionum Marchicarum I. Th., Abth. von geistl. Sachen No. VXII Columne 310. Die katholischen Kirchenbücher beruhen auf den Regelungen des Trienter Konzils, 1563 (Tauf- und Ehebuch) und dem Rituale Romanum von Papst Paul V., 1614 (Sterberegister), in: Lexikon der Theologie und Kirche, Freiburg (2006), Bd. 6, Spalte 1476. 
bücher in der Provinz Brandenburg von geschätzten 2000 Gemeinden nachweisbar. ${ }^{616} \mathrm{Ab}$ $1761^{617}$ sind wiederholt Vorschriften zur Führung von Kirchenbüchern erlassen worden, die die inhaltliche Erweiterung (Kommunikanten, Todesursachen, uneheliche Kinder, Konduitenlisten) und Schemata zur ihrer Führung vorgegeben haben.

Da die Zugehörigkeit zu einer Konfession im 16. bis 19. Jahrhundert eine Selbstverständlichkeit war, wurde in den Kirchenbüchern bis auf die Saisonkräfte (Mägde, Knechte, Hirten, u. a.) die gesamte Bevölkerung erfasst. Ihr diesbezüglicher Wert wurde bald von der Obrigkeit erkannt, so dass sie mit der Zeit neben den innerkirchlichen Funktionen bis zur Einführung der Zivilstandsregister ${ }^{618}$ den Charakter von öffentlich-rechtlichen beweiskräftigen Dokumenten gewannen und in steigendem Maße für staatliche Zwecke, etwa bei Allgemeinen Verwaltungsaufgaben, der Steuererhebung, Rekrutierung und Statistik herangezogen wurden. Diese Funktion verloren sie endgültig im Deutschen Reich durch das Gesetz vom 6. Februar $1875^{619}$, mit dem die Standesämter geschaffen wurden und die Führung der Personenstandsregister ganz auf diese öffentliche Einrichtung überging.

Demzufolge stellen Kirchenbücher eine unersetzbare Primärquelle für sozial-, bevölkerungsund kirchengeschichtliche Forschungen dar, und dieser Wert an sich ist augenscheinlich noch immer nicht erkannt worden. ${ }^{620}$ In Verbindung damit gewinnt die pauschale Vorgabe über die Führung der Kirchenbücher gemäß der Visitations- und Konsistorial-Ordnung von $1573^{621}$ ihre besondere Bedeutung. Denn je nach der Persönlichkeit des Predigers gehen die in den Kirchenbüchern unter Umständen enthaltenen Informationen weit über die zu tätigenden Eintragungen hinaus. Sie enthalten viele personenunabhängige Informationen aus dem Leben der jeweiligen Gemeinde, über tragische oder erfreuliche Ereignisse der Nachbargemeinden bzw. sogar aus der Region. Hier unterscheiden sich die einzelnen Kirchenbücher ganz wesentlich von einander. Allerdings werden auch die Kirchenbücher als Quelle nur dann etwas aussagen, wenn man sie daraufhin liest, lohnende Fragen an sie stellt und geeignete Methoden für die Erschließung anwendet. ${ }^{622}$

Glücklicherweise sind alle Kirchenbücher der reformierten Schweizer Gemeinde im Golmer Bruch (Vol. I 1685 bis 1801, Vol. II bis 1846 und Vol. III 1847 bis 1949) erhalten und bis auf Vakanzzeiten gut geführt. Damit bieten sie ideale Voraussetzungen für die Anfertigung demographischer Untersuchungen dieser Kolonistengemeinde. Einschränkungen bestehen ledig-

616 Meyerding de Ahna, Kurt: Die Kirchenbücher der evangelischen Kirchen in der Provinz Brandenburg, in: Archiv für Sippenforschung und alle verwandte Gebiete 10 (1935), S. 97-144.

617 BLHA, Rep. 2A Regierung Potsdam II Generalia Nr. 359, fol. 2 ff., Nr. 360, Nr. 361, Nr. 362, Nr. 363 und 364.

618 BLHA, Rep. 2A Regierung Potsdam II Generalia Nr. 355 (nicht paginiert).

619 Reichs-Gesetzblatt 1875 (Berlin), S. 23-40.

620 s. Anm. 37.

621 s. Anm. 615.

622 Schüler, H.: Die Bedeutung der Kirchenbücher für die Heimatforschung, in: Landeskundliche Vierteljahresblätter der landeskundlichen Arbeitsgemeinschaft der Bezirke Koblenz und Trier, 1970, Heft 3, S. $93-$ 100; ders.: Der Wert der Kirchenbücher für evangelische Kirchengeschichte des Rheinlandes, Bd. 16, 1977, S. 213-299. 
lich dahingehend, dass nicht alle vier Listen (Hochzeiten (ab 1686), Taufen (ab 1685), Konfirmationen (von Auf Weynacht 1726) und Todesfälle (ab 1705) von Anfang an angelegt sind. Das gleiche trifft für die Angaben der Todesursachen zu, die zunächst ab 1728 sporadisch und erst ab 1786 immer angegeben sind. Sowohl das Kirchenbuch Vol. I als auch Vol. II beginnen mit einem Vorspann, der Informationen enthält über das Kircheninventar (undatiert), Kurzbiographien der Prediger der Schweizer Gemeinde im Golmer Bruch, das mitgebrachte Kapital der drei Kolonisten Crispinus Garmatter, Emanuel Durtschi und Isaac Muhrhoffer und eine Liste der 17 Kolonistenfamilien (incl. Knechte, Mägde, Adoptivkinder), die 1685 per Schiff oder auf dem Landwege in den Golmer Bruch übergesiedelt sind.

\section{Zur Methodik der Auswertung der Kirchenbücher von Nattwerder}

Durch die in der Vergangenheit häufige Nutzung der Kirchenbücher zu genealogischen Zwecken hat ihr Erhaltungszustand speziell des Vol. I (1685-1801) schon sehr gelitten. ${ }^{623}$ Das Papier ist dadurch an der Heftung bereits teilweise eingerissen, an den Rändern ausgefranst, brüchig, zum Teil fleckig und abgegriffen. Auch die Schrift ist mehr oder weniger stark vergilbt und zum Teil (vor allem an den bis an den Innen- und Außenrand beschriebenen Stellen) schlecht lesbar. Das ständige bzw. wiederholte Durchsuchen sowie das mühsame Entziffern bei einer Recherche hätten diesen Erhaltungszustand gewiss noch erheblich verschlechtert, zumal eine durchgehende Paginierung fehlt. Deswegen wurde zunächst mit Ausnahme der nicht so interessant erscheinenden Kommunikantenlisten eine vollständige Abschrift der Kirchenbücher Vol. I und II angefertigt. Gleichzeitig wurde damit die Möglichkeit für eine digitale Recherchierung geschaffen, wobei die Ende des 17./Anfang des 18. Jahrhunderts typische "flüchtige" und dadurch unterschiedliche Schreibweise von einzelnen Wörtern und insbesondere Namen diesbezüglich Grenzen setzten. Man schrieb, wie man sprach. ${ }^{624}$

Für die demographische Auswertung der Kirchenbücher erfolgte als erstes eine rein quantitative Erfassung der vitalstatistischen Daten, wobei von 1685 bis 1835 insgesamt 327 Eheschließungen, 1039 Geborene und 650 Gestorbene erfasst wurden. ${ }^{625}$ Eine Vorgehensweise in Anlehnung an Johann Peter Süßmilch ${ }^{626}$, dem eigentlichen Begründer der Bevölkerungsstatistik, kam nicht in Frage. Dabei werden die Geburten-, die Sterblichkeits- und Heiratsraten zur jeweiligen Bevölkerungszahl in Beziehung (pro 1000 Einwohner) gesetzt. ${ }^{627}$ Zwei

623 Durch Bleistifteintragungen, z. B. von Geburts- und Sterbedaten ist dies gut belegbar. Nach dem äußeren Erscheinungsbild ist es in der im Schweizer Jura üblichen Rödelform (Schmalfolio) gestaltet, wobei die Eintragungen der Taufen, Konfirmationen und Gestorbenen von vorn gegen die Mitte, die Hochzeiten dagegen von hinten gegen die Mitte aufgelistet sind.

624 z. B.: Tädenweyler, Tädeweyler, Tädweiler, Tädweyler, Tätweiler, Tättweiler, Thätweiler, Dedweiler, Dedweiller, Daedweiler, Dädweiler, Taeidweiler, Dätweiler, Daetweiler (in dieser Reihenfolge gefunden).

625 Das ist im Vergleich zu den vitalstatistischen Erhebungen von Neuruppin von 1700 bis 1830 eine sehr kleine Grundgesamtheit (Meier, Brigitte: Neuruppin - 1700 bis 1830, Berlin (1993), S. 88.). Der kleinstädtischen Bevölkerungsdichte geschuldet, konnte sie ihren Untersuchungen in einem nahezu identischen Untersuchungszeitraum 21189 Tauf-, 5024 Heirats- und 18759 Sterbeeintragungen zugrunde legen.

626 s. Anm. 39 und 40.

627 Imhof, Arthur: Einführung in die Historische Demographie, München (1977), S. 8 ff. 
Voraussetzungen müssen dabei erfüllt sein: Es muss sich um eine gewachsene Bevölkerung handeln, die lokal begrenzt (Ortsgemeinde) angesiedelt ist. Zur reformierten Gemeinde Golmer Bruch fühlten sich aber viele Familien zugehörig, die in den umliegenden und auch weiter entfernt liegenden Dörfern in wüste Kolonistenstellen an- bzw. umgesiedelt worden waren. Stattdessen wurde eine möglichst vollständige Kirchenbuchverkartung vorgenommen, indem zunächst die Eintragungen in den beiden Hochzeitregistern durchnummeriert und den Einzeleinträgen die jeweiligen Geburten/Taufen sowie Sterbeeintragungen zugeordnet wurden. Personen, deren Geburts- und Sterbedatum (z.B. Dienstleute) nicht zu ermitteln waren, fielen dabei heraus. Das so aufbereitete Material ließ sich im Blick auf verschiedene sozialökonomische, demographische und konfessionelle Einzelaspekte von und anhand von Excel-Tabellen weiter auswerten. Dazu zählt insbesondere:

- Heiratsalter bei der Erst- und Zweitehe (s. Kap. VII.4.1. und VII.4.3.) ${ }^{628}$,

- Kinderzahl pro Ehe (s. Kap. VII.4.5.),

- Zeitabstände zwischen einer Verwitwung und Wiederverheiratung (s. Kap. VII.4.3.),

- Säuglings- und Kindersterblichkeit sowie die altersspezifische Sterblichkeit (s. Kap. VII.5.1. und VII.5.2.),

- konfessionelle Mischehen (s. Kap. VIII.2.) und

- Auswahl der Paten als Spiegelbild der familiären Beziehungen (s. Kap. VII.2.3.).

Bei der Auswertung der Kirchenbücher stößt man auf Grenzen. Die Nachkommen der sprichwörtlich kinderreichen Schweizer Kolonistenfamilien konnten nicht alle vor Ort bleiben. Es stellte sich die Frage, ob sich Anhaltspunkte über das Verhältnis der Einheimischen und den angesiedelten Kolonisten finden lassen. In dieser Beziehung sollte insbesondere das Heiratsverhalten untersucht werden, dem im Übrigen darüber hinaus auch eine zentrale Bedeutung bei demographischen Entwicklungen zukommt. Es wurde erwartet, dass die reformierten Schweizer Kolonisten als konfessionelle Minorität sich zunächst gegenüber den Lutheranern abgrenzten und strikt nur unter sich heirateten. Die Frage war, wann würde es zu einer allmählichen Öffnung dieses endogamen Heiratsverhaltens kommen. Allerdings ließ sich dies nur für die im Ort lebenden Kolonisten untersuchen. Die Regel war, dass der älteste Sohn den Hof des Vaters übernahm, vorausgesetzt, er war dazu in der Lage, und das beurteilte und bestätigte die Behörde. Seine Geschwister mussten sich u. U. beim eigenen Bruder verdingen, einheiraten („Heiratsmobilität“) oder in die Nähe („kleinräumige Wanderung") oder in die Ferne (später sehr häufig nach Ostpreußen) abwandern. Wie weit diese Migrationsmobilität ins Umland reichte, wird anhand des Einheiratens in umgekehrter Richtung abgeschätzt. ten wurde aufgerundet. 


\section{Die Liste der Geborenen}

Den größten Umfang in den Kirchenbüchern nehmen die Taufeintragungen ein; in den Kirchenbüchern von 1685-1801 und 1802-1835 sind es 771 bzw. 268 (insgesamt 1039). Darunter sind 14 Zweylinge (Zwillinge), die als Doppeleintragungen gezählt wurden und 16 Totgeburten. ${ }^{629}$ Drillinge und Monster (Missbildungen) sind nicht vorgekommen.

Anfänglich handelt es sich um Taufeintragungen, die in einer Standardformulierung abgefasst sind, die den Tag der Taufe, den Namen des Vaters, das Geschlecht des Täuflings, den/die Name/n des Kindes und anwesende Zeugen beinhaltet. Die Mutter des Täuflings findet keine Erwähnung. Die weiblichen Zeugen werden über ihre Männer (bzw. ihre Väter) definiert. Beides charakterisiert die Stellung der Frau im 17. Jahrhundert:

Den 6. Hornung ${ }^{630} 1687$ ließe Bendicht

Kiener wieder ein Kind tauffen.

Der Nahme ist Esther,

gezeugen $H$ Emanuel Bucher ${ }^{631}$ vnd

Ich $^{632}$ wie auch Eva Gaarmatter

deß Crispinus Haußfrauw

Ab 1688, d.h. erst unter Prediger Albrecht Wittenbach (1687-1705), enthalten die Eintragungen das Geburts- und Taufdatum des/der Neugeborenen und den vollständigen Namen der Mutter einschließlich ihres Geburtsnamens. Darüber hinaus unterscheiden sich die frühen Eintragungen zu späteren erheblich in der Anzahl der geladenen Zeugen. Gestattet waren maximal fünf Gevattern (Paten); für jeden weiteren mehr sollte 1 Rthl. Strafe gezahlt werden. ${ }^{633}$ Damit sollte den Auswüchsen des Feierns auf dem Lande Einhalt geboten werden. Nur ausnahmsweise wurde davon Abstand genommen:

Nota:

weilen Meistr: Torgler, der Glaser aus

dem Werder, ein armer Mann, ist mit

7 lebendigen Kindern, darzu auch

629 Diese Zahl fällt für das 17./18 Jahrhundert sehr niedrig aus; deswegen ist darauf hinzuweisen, dass es einen fließenden Übergang von Totgeburten zu lebensschwachen Neugeborenen gibt, die unter der Geburt, in den ersten Stunden oder Tagen sterben, wovon ein Teil heute sicherlich als „Frühchen“ bezeichnet werden würde, damals aber keine Überlebenschancen hatten. Jeweils eine Geburtseintragung im Kirchenbuch Vol. I (23.03.1771) und Vol. II (31.12.1830) tragen dieser Auffassung Rechnung: Am einunddreißigsten December 1830 wurde die Ehefrau [...] (zu früh) von einer Tochter entbunden, welche bald nach der Geburt die Nothtaufe erhielt. [...] Das Kind ist 2 Stunden nach der Geburt u Taufe gestorben.

630 s. Anm. 761.

631 s. Kap. IV.5.

632 Prediger Elisäus Malacrida (1685-1687); Überhaupt ist es ungewöhnlich, dass die reformierten Prediger als Pate (erstmalig am 2. Mai 1686) auftreten. Dies scheint eine schweizerische Gepflogenheit gewesen zu sein.

633 Edikt vom 24. November 1690 speziell an die reformierten Kirchen auf dem Lande; Mylius C. C. M., I. Theil, II. Abth. I Cap. No. LII Columne 109-110. 
Schweitzer, so sind ihm aus Mitleyden, die Gevattern von der Gemeine, die er mündl. gebethen, accordiret worden. ${ }^{634}$

Sind es anfänglich nie mehr als drei Paten gewesen, so stieg ihre Anzahl ab 1706 bei den wohlhabenden Familien bis auf dreizehn. Dies ist sicherlich ein Zeichen dafür, dass es ihnen wirtschaftlich besser ging und sie es sich leisten konnten, größere Feste zu feiern, vorausgesetzt, die zuständigen Behörden drangen nicht darauf, die diesbezüglich bestehenden Vorschriften einzuhalten. In den Jahren 1730 bis 1760 und insbesondere während des Siebenjährigen Krieges finden sich dann wieder nur ausnahmsweise mehr als fünf Paten. Danach scheint ein wahrer Wetteifer im Ausstatten von Taufen stattgefunden zu haben. $\mathrm{Zu}$ der von Peter Schweingruber am 29. September $1798^{635}$ wurden 19 Paten eingeladen. Die jeweiligen zeitigen Amtsträger dürften dabei auch eine Vorbildrolle gespielt haben, denn traditionell wurde hier immer im größeren Stile gefeiert. Nach den Befreiungskriegend, d.h. nach 1815, sind diese Vorgänge ebenfalls wieder nachzuweisen. Die umfänglichste Taufe im Golmer Bruch scheint die Taufe von Friedrich Wilhelm Kaiser gewesen zu sein; sie wurde in Golm am 19. Juni 1822 mit 25 geladenen Paten gefeiert. ${ }^{636}$ Den unteren ländlichen Schichten Knechte, Büdnern und Kossäten waren diese ausgiebigen Festlichkeiten nicht beschieden; sie mussten sich mit drei bis fünf Paten begnügen, und häufig - mangels anderer Paten - sprang der Schulze oder Prediger ein (s. Kap. VIII.2.3.).

\subsection{Die unehelichen Kinder}

Schneider $(1906)^{637}$, Wentscher $(1930)^{638}$ und Asche (2006) ${ }^{639}$ hoben bezüglich sittlichmoralischer Fragen die bemerkenswerten Kirchenzuchterfolge der deutsch-reformierten Schweizer Gemeinden hervor, wobei ihnen als Beleg dafür die einzige Taufe eines unehelichen Kindes im deutsch-reformierten Kirchenbuch Lindow diente, und der Prediger Dellicker mit offensichtlicher Genugtuung hinzufügte, der Verführer sei natürlich ein Lutheraner gewesen. Ganz so puritanisch scheint es in der reformierten Schweizer Gemeinde im Golmer Bruch nicht zugegangen zu sein. In den beiden hier in Rede stehenden Kirchenbüchern sind von 1685-1835 insgesamt 29 uneheliche Kinder (2,8\%) eingetragen. Ihre Verteilung im Untersuchungszeitraum - aufgeteilt in Cluster von 10 Jahren - erscheint unauffällig. s. Abb. 12).

634 KA Alt Töplitz: Kirchen-Buch der Schweitzer Gemeinde im Bruch bei Potstamb, Vol. I (1685-1801, nicht paginiert), Liste der Getauften, Eintrag vom 04.06.1756.

635 daselbst: Eintrag vom 29.09.1798.

636 KA Alt Töplitz: Kirchen-Buch Schweizer Gemeinde im Golmer Bruch Amt Potsdam, Vol. II (nicht paginiert), Liste der Getauften, Eintrag vom 19.06.1822.

637 Schneider, Hermann: Die Schweizer Kolonie in der Mark. Beilage zum Programm des Königlichen Wilhems-Gymnasium, Berlin (1906), S. 15.

638 Wentscher, Erich: Die Schweizer Kolonien in der Mark Brandenburg, in: Archiv für Sippenforschung und alle verwandte Gebiete 7 (1930), S. 388-391, bes. 388.

639 Asche, Matthias: Neusiedler im verheerten Land, Münster (2006), Anm. 2130. 
Bei der jeweiligen Eintragung wurde in verschiedener Form die uneheliche Zeugung hervorgehoben und damit eine lebenslange gesellschaftliche Missachtung zum Ausdruck gebracht ${ }^{640}$ und zwar am ausgeprägtesten dann, wenn die Mutter den unteren Ständen angehörte. In diesen Fällen galt sie als Hure und das Kind ein Hurenkind, was ggf. auch noch im Sterbeeintrag vermerkt wurde:

Am vierzehnten $/ 14^{\text {ten }} /$ December [1834], Abends 6 Uhr starb

in Alt-Toeplitz die uneheliche Tochter der jetzt ver-

ehelichten Luise Behrend geb. Hodler

Caroline Friederike Charlotte

an einer unbestimmten Krankheit, alt 9 Jahr 11 Mon-

nat 1 Tag, und wurde am 16ten ej. auf dem

Kirchhofe zu Nattwerder begraben. ${ }^{641}$

Die Mütter der unehelichen Kinder waren vor allem Mägde, zweit- oder drittgeborene Töchter und Witwen ${ }^{642}$. Vor allem für die Mägde, von denen etwa 2/3 der unehelichen Kinder stammten, sahen in einem mündlich von einem Bauernsohn gegebenen Eheversprechen die Chance eines sozialen Aufstiegs. Die Väter der unehelichen Kinder, nach denen die Mütter hochnotpeinlich befragt und im Fall einer Auskunftsverweigerung zum Inspektor ${ }^{643}$ beordert wurden, waren Knechte, Militärs, Witwer und Ehemänner ${ }^{644}$ :

d. 6ten April [1752] sind nach einer 3

mahliger Proclamation in Golm

copuliret worden, der Wittwer

Nic: Zoch Haußmann daselbst

mit

Louyse Webe seel: Hanß webe

eines Leinwebers in Damsdorff

eheleibl: Tochter mit welcher Er

schon 1743 einen unehelichen Sohn gezeuget, $u$.

die Er nach seiner Frauen Tod nun

endlich geheurathet hat.

640 Ganz im Gegensatz zu den Vätern, die um gewüßer ursachen willen in Einzelfällen sogar nachträglich anonymisiert wurden (KA Alt Töplitz: Kirchen-Buch der Schweitzer Gemeinde im Bruch bei Potstamb Vol. I. (1685-1802, nicht paginiert), Taufeintrag vom 01.09.1709.

641 KA Alt Töplitz: Kirchen-Buch der Schweizer Gemeinde im Golmer Bruch, Amt Potsdam, Vol. II. (18021846, nicht paginiert), Liste der Gestorbenen, Eintrag vom 14.12.1834.

642 Zum Rollenergänzungszwang der Witwer/n, wie es Mitterauer (1979) bezeichnet, s. Kapitel VII.4.3.

643 Superintendent

644 KA Alt Töplitz: Kirchen-Buch der Schweizer Gemeinde im Golmer Bruch, Amt Potsdam Vol. II (1802-1846, nicht paginiert), Sterbeeintrag vom 14.12.1834. 
Die angeführten Kirchenbucheinträge ${ }^{645}$ sprechen für sich selbst und führen das gesellschaftliche Leben in der Reformierten Gemeinde Golmer Bruch vor.

\subsection{Die Namen der getauften Kinder}

Die Neugeborenen erhielten bei der Taufe ihre/n Vornamen. Wie auch heute erfreuten sich dabei einige ganz besonderer Beliebtheit. Mit einer Ausnahme, Friedrich ${ }^{646}$, stammten sie von biblischen Personen oder Heiligengestalten ab. Weit an der Spitze liegen die Namen Christian und Maria sowie Anna, die schon im Mittelalter hohe Verehrung genossen. (s. Tab.12, rechte Kolumne).

Die Vornamen der Väter bzw. Mütter wurden in der Regel dem/der Erstgeborenen tradiert, was die Klärung verwandtschaftlicher Beziehungen gelegentlich erheblich erschwert. Zusätzlich ist häufig die Praxis anzutreffen, dass nacheinander geborene Geschwister den gleichen Vornamen haben. Dem Sterberegister ist dann in aller Regel die Erklärung dafür zu entnehmen. Der/die ältere Bruder/Schwester ist zwischenzeitlich gestorben, und der Vorname wird noch einmal innerhalb der Familie zur Kompensation eines erlittenen Verlustes tradiert. Für den Betroffenen mag das nicht ganz unproblematisch gewesen sein:

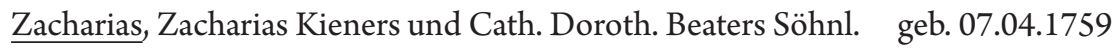

gest. 05.05.1759

Zacharias, Zacharias Kieners und Cath. Doroth. Beaters Söhnl. geb. 09.06.1760

Daneben trifft man bei den einzelnen Schweizer Kolonistenfamilien auf ein unterschiedliches Traditionsbewusstsein. Der typische schweizerische Vorname Crispinus fand sich als Taufname im Kirchenbuch nur bei der Familie Garmatter. Darüber hinaus ist es vermutlich kein Zufall, dass in der Amtszeit von Prediger Albrecht Wyttenbach (1687-1705) vier von sieben Knaben den Vornamen Albrecht erhalten haben.

Wenn anfänglich an der mitgebrachten Tradition festgehalten wurde, den Kindern nur einen Vornamen zu geben, ändert sich das mit der Zeit. Etwa ab 1720 kommen zwei Vornamen und etwa ab 1790 drei Vornamen (Eduard Ludwig Friedrich bzw. Anna Elisabeth Wilhelmine) in Mode. Diese Entwicklung erfährt noch eine Steigerung dadurch, dass der bekannte Königliche Hofgärtner zu Paretz, David Garmatter, 1798 seine Tochter auf die Namen Caroline Valentine Luise Henriette ${ }^{647}$ und der Küster und Schullehrer, Georg Friedrich Zech, 1832

645 Die Fälle mit vorehelichem Verkehr sind ebenfalls sehr drastisch abgefasst (KA Alt Töplitz: Kirchen-Buch der Schweitzer-Gemeinde im Bruch bei Potstamb Vol. I, (1685-1801, nicht paginiert), Liste der Getauften, Eintrag vom 13.09.1772: Nota: Sie ward von mir copulirt, da sie bereits von ihrem Bräutigam in andre Umstände gesezt worden, und es mit ihr schon über die Hälfte gekommen war! Tantam!).

646 Der erste Täufling wurde nach dem Landesherrn Friedrich Wilhelm genannt. Dieser ordnete an, daß in dieser Familie stets der erste Sohn seinen Namen Friedrich Wilhelm erhalten solle, was bis auf den heutigen Tag in der Familie Kiener geschehen ist.

647 KA Alt Töplitz: Kirchen-Buch der Schweitzer Gemeinde im Bruch bei Potstamb, Vol. I (1685-1801, nicht paginiert), Liste der Getauften, Eintrag vom 14.05.1798. 
seinen Sohn Karl August Friedrich Wilhelm ${ }^{648}$ taufen ließen. Seine vier Vornamen spiegeln die inzwischen weitgehende Assimilierung der Schweizer Kolonisten wider (s. Tab. 12):

Tab. 12: Bevorzugte Vornamen der Getauften (1802-1835)

\begin{tabular}{ll}
\hline Knaben & Mädchen \\
\hline Friedrich $(31 \mathrm{x})$ & Caroline $(35 \mathrm{x})$ \\
\hline Johann $(29 \mathrm{x})$ & Henriette $(15 \mathrm{x})$ \\
\hline Carl $(27 \mathrm{x})$ & Wilhelmine $(14 \mathrm{x})$ \\
\hline Christian $(11 \mathrm{x})$ & Luise $/$ Louise $(12 \mathrm{x})$ \\
\hline August $(8 \mathrm{x})$ & Friederike $(10 \mathrm{x})$ \\
\hline Heinrich $(4 \mathrm{x})$ & Sophie $(7 \mathrm{x})$ \\
\hline Franz $(3 \mathrm{x})$ & Charlotte $(6 \mathrm{x})$ \\
\hline
\end{tabular}

Nicht immer finden sich die vollständigen Vornamen bei den Verstorbenen wieder. Im Alltagsleben dürften sie sehr wahrscheinlich keine große Rolle gespielt haben und insofern in Vergessenheit geraten sein. ${ }^{650}$

\subsection{Die Paten}

Die Frage der Anzahl der zulässigen Paten wurde bereits unter Kapitel VIII.2.2. erörtert. Die gebetenen Paten spiegeln die gesellschaftliche Stellung der Tauffamilie. Als Ausnahme hiervon ist die Taufe des ersten Täuflings zehn Tage nach der Ankunft der Schweizer Kolonisten im Golmer Bruch anzusehen. Kurfürst Friedrich Wilhelm und seine Gemahlin nahmen dies zum Anlass, um persönlich die Schweizer Kolonisten in Brandenburg zu begrüßen, und bezeugten mit ihrer Anwesenheit die Taufe von Friedrich Wilhelm Kiener. ${ }^{651}$ Ob dies in Hofkreisen als nachahmenswertes Beispiel angesehen worden ist, lässt sich nicht belegen. Geht man jedoch die Patenlisten durch, stößt man auf unerwartete Einträge. Als Beispiele seien hier nur die Kammerjunker Simeon Bondely (Schweizer) und Daniel Seiler, etliche Hofbedienstete (u. a. der Königliche Thierarzt Schröder) und Militärs (u. a. Unteroffiziere, Quartiermeister) genannt.

Bei den gebetenen Paten unterschieden sich die verschiedenen sozialen Schichten drastisch. Man feierte unter sich und stärkte in der eigenen sozialen Schicht den Zusammenhalt. Das war besonders unter den Erbpächtern ausgeprägt. (s. Kap. VII.2.) Zur Situation in den sonsti-

648 KA Alt Töplitz: Kirchen-Buch der Schweizer Gemeinde im Golmer Bruch, Amt Potsdam, Vol. II (18021846), Liste der Getauften, Eintrag vom 18.11.1832.

649 Aufgelistet ist der erste Vorname, vermutlich der Rufname.

650 z. B. Johannes Turtschi, geb. am 28.02.1706 findet sich sowohl in der Heirats- (29.10.1726) als auch in der Verstorbenenliste (04.12.1753) unter Hanß Durtschy. Als Pate taucht er als Turtschi/Durtschy auf.

651 KA Alt Töplitz: Kirchen-Buch der Schweitzer Gemeinde im Bruch bei Potstamb, Vol. I (nicht paginiert, 1685-1801), Liste der Getauften, Eintrag vom 28.06.1685. 
gen sozialen Schichten sollen nachfolgend zwei extreme Beispiele angeführt werden. Handelte es sich um eine Taufe in der untersten sozialen Schicht (Hirten, Gesinde, Tagelöhner) oder um die Taufe unehelicher Kinder, so fanden sich mitunter gerade mal drei Personen bereit, als Pate zu fungieren; ggf. musste der Schulze oder Schulmeister einspringen:

Den 27. Juli [1704] wurde dem Kuhe hirten im

Schweizerb. Ein Söhnlein getauffet

und Christian genennet worden.

Gezeugen synt Hanß Stucki, Jacob Gerichten, der Schulz, und des

Melchior Suters Haußfr. Maria Baßler. ${ }^{652}$

Das extreme Gegenteil dazu stellen die Taufen bei den Predigern dar wie etwa der Taufeintrag vom Sohn des Predigers Franz Rudolph Becker (1770-1785) zeigt. Schon allein die gefühlvolle Abfassung unterscheidet sie vom vorangegangenen Beispiel und erst recht die gebetenen Paten:

Den 17 ten Novbr: [17]83 ist meine

liebe Frau (geb. Wernicken)

von einem jungen Sohn entbunden

worden, welchen ich den 25 ten $h$ [ujus] $m$ [ensis] [dieses Monats]

im hiesigen Pfarrhause getauft und

genannt habe:

Johann Friedrich Ernst

Pathen waren

1) Sr. Excellenz von Doernberg

Etats und Justiz Minister etc etc Berlin.

2) Herr Kaufmann Fischer, senior, in Potsdam.

3) Herr Phasaan-Jäger Teichmann bei Potsdam.

4) Herr Secretair Draing in Bornstedt. ${ }^{653}$

5) Mademoiselle Freitag, des

Herrn Schwagers Carl Benda Braut. ${ }^{654}$

Wie die beiden Beispiele auch zeigen, geschah die Auflistung der Paten nach zwei Kriterien. Die Männer werden vor den Frauen aufgelistet, die Reihenfolge innerhalb der Geschlechter bestimmte sich nach der gesellschaftlichen Stellung der Person. Die Unverheirateten kamen

652 daselbst: Liste der Getauften, Eintrag vom 26.07.1704.

653 daselbst: Liste der Getauften, Eintrag vom 17.11.1783.

654 Am 21. Juli 1771 heiratete Prediger F. R. Becker Charlotte Henriette Sophie Benda, die 3. Tochter des Hofmusikers, Franz Benda, aus 1. Ehe. (KA Alt Töplitz: Kirchen-Buch der Schweitzer Gemeinde im Bruch bei Potstamb, Vol. I (nicht paginiert), Heiratseintrag vom 28.07.1771. Wolfgang Ferdinand von Dörnberg (1724-1793) war preußischer Finanzminister. 
jeweils ans Ende. Zusätzlich wurden die Frauen in der Regel über ihre Ehemänner bzw. Väter definiert. $^{655}$

Für die Arbeit von Bedeutung ist, dass die Zugehörigkeit eines Paten/einer Patin, der/die nicht der reformierten Konfession angehörte, durch einen Zusatz gekennzeichnet wurde. Abgesehen von dem katholischen Unteroffizier Paul Haase vom Retzowschen Bataillon (C.R., Cathol. Relig. $)^{656}$ waren es ausschließlich Lutherische Paten (L. R., Luth. Religion, usw.). Erstmalig findet sich ein solcher Vermerk bei der Taufe von Anna Elisabeth Kiener am 27. Dezember 1729; sie lassen sich bis 1770 nachweisen, wobei der Anteil dieser Paten z. T. $80 \%$ an einer Taufgesellschaft ausmachte. ${ }^{657}$ Das Verschwinden dieser Vermerke ging zeitlich mit dem Amtsantritt von Prediger Franz Rudolph Becker (s. Anhang II und Anm. 706) einher und wurde von ihm möglicherweise nicht für nötig erachtet. Dem Autor erscheint es eher unwahrscheinlich, dass es danach keine lutherischen Paten mehr gab.

Die Paten brachten zur Taufe Geschenke in Form eines Patenbriefes mit, in dem neben frommen Sprüchen und Glückwünschen für das Wohl des Kindes Patentaler oder Taufdukaten enthalten waren ${ }^{658}$, was für die ärmeren Schichten das Wichtigste war.

\section{Die Liste der Kommunikanten}

Die Liste der Kommunikanten wurde erst vom 5. Prediger der Schweizer Kolonistengemeinde, Joseph Grimm (1725-1729), angelegt: Auf Weynachten 1726 hab ich, nach 3/4 jähriger underweysung Zum H Abendmahl hinzugelassen. ${ }^{659}$ Die einzelnen Eintragungen - für Jungen und Mädchen getrennt - beinhalten den Namen der Kommunikanten (Konfirmanden), ihre soziale Herkunft (des Schulmeist. von Golm, ein Dienstknecht, Schneider, Magd usw.) und ihr Alter (zwischen 15 und 17 Jahren). In der Regel fanden die Konfirmationen an den Feiertagen Ostern, Johannis (24. Juni), Michaelis (29. September) oder Weihnachten nach Endigung des Gottesdienstes statt. Danach galten die Konfirmierten als Erwachsene und mussten sich verdingen oder blieben weiter auf dem väterlichen Hof als Knecht.

655 Die lutherischen Kirchenbücher im benachbarten Töplitz sind diesbezüglich nicht so stringent aufgestellt (KA Alt Töplitz: Kirchenbuch Alt Töplitz 1652-1804.

656 KA Alt Töplitz: Kirchen-Buch der Schweitzer Gemeinde im Bruch bei Potstamb, Vol. I (nicht paginiert, 1685-1801), Liste der Getauften, Eintrag vom 08.04.1749, 16.08.1750, 05.11.1750 und 26.08.1754.

657 daselbst: Liste der Getauften, Eintrag vom 27.12.1730.

658 Zglinicki, Friedrich von: Die Geburt. Eine Kulturgeschichte in Bildern. Braunschweig (1983), S. 353 passim, S. 356.

659 KA Alt Töplitz: Kirchen-Buch der Schweitzer-Gemeinde im Bruch bei Potstamb, Vol. I (nicht paginiert), Liste der Kommunikanten, Eintrag auf Weihnachten 1726. 


\title{
4. Die Liste der Getrauten
}

Die Liste der Getrauten beginnt im Jahre 1686 und ist überschrieben: Verzeichnus der Hochzeiten, Welche allhier im Schweitzerbruch zwüschen den Schweitzern gehalten worden. Offensichtlich ging der erste Prediger der reformierten Schweizer Kolonistengemeinde, Elisaeus Malacrida (1685-1687), davon aus, dass die Kirchengemeinde als solches eigenständig über längere Zeit in dem ansonsten lutherischen Brandenburg bestehen bleiben werde. Die Eintragungen (insgesamt 327) zu den Copulationen ${ }^{660}$ beschränken sich zunächst auf die Angabe des Datums, die Namen des Bräutigams und der Braut ${ }^{661}$ sowie den Hinweis darauf, ob einer von beiden verwitwet ist oder aus einem anderen Ort kommt. Der Prediger war verpflichtet, die Hochzeit vorher zu proklamieren [anzukündigen], um jedermann die Möglichkeit des Einspruchs gegen die Verheiratung zu geben; dies geschah nachweislich an beiden Herkunftsorten der Brautleute und war erstmals 1688 bei der Hochzeit von Ludwig und Barbara Brönniman der Fall. ${ }^{62}$ Ab 1726 wurde der Auflage des Reformierten Konsistoriums nachgekommen und der Zusatz eines stattgefundenen Aufgebotes hinzugefügt: ${ }^{663}$

\author{
d. 22 April [1726], als am Oster Montag sind \\ nach der Predigt Bey 4 Häusern \\ nach 3mahliger Auffbiethung, od. \\ proclamation, vor der Christl. Ge- \\ meinde copuliert worden: \\ Christian Zäch der Vieh Hirt in \\ Golm und \\ Anna Regina Ursula Rümli von Zürich. ${ }^{664}$
}

Der Prediger durfte außerdem eine Trauung nur vornehmen, wenn die Eltern eingewilligt hatten, ${ }^{665}$ bei minderjährigen Eheleuten der Obervormundschaftliche Konsens des Justizamtes Potsdam erfolgt, ${ }^{666}$ bei einer zu nahen Verwandtschaft (Blutschande) Dispensation

660 So wurden die Eheschließungen noch bis ins 19. Jahrhundert genannt. Gemeint war damit die Einsegnung in den heiligen Stand der Ehe.

661 Der Bräutigam wird immer zuerst aufgeführt.

662 KA Alt Töplitz: Kirchen-Buch der Schweitzer-Gemeinde im Bruch bei Potsdam, Vol. I (1685-1801, nicht paginiert), Liste der Getrauten, Eintrag vom 28.12.1688; Ihre vorehelich gezeugte Tochter Elßbeth wurde am 12.11.1688 getauft (s. Taufliste). Weiteres konnte über die Familie Brönniman nicht in Erfahrung gebracht werden. Der NB-Zusatz beim Hochzeitseintrag gibt eine Erklärung dazu: Diße beyden sind nicht aus unßerer Gemeinde.

663 auch als Aufboth [Aufgebot] bezeichnet, wobei gelegentlich auch die Sonntage angegeben sind, an denen es erfolgt ist.

664 KA Alt Töplitz. Kirchen-Buch der Schweitzer-Gemeinde im Bruch bei Potsdam Vol. I, (1685-1801, nicht paginiert), Liste der Getrauten, Eintrag vom 22.04.1726; dabei handelt es sich um den 4. Sohn des 1685 ins Golmer Bruch eingewanderten Schweizer Kolonisten Niclaus Zäch.

665 daselbst: Liste der Getrauten, Eintrag vom 12.11.1688.

666 daselbst: Liste der Getrauten, Eintrag vom 13.12.1829, 28.03.1830 und 03.10.1830. 
erteilt $^{667}$ und bei den Militärs vom Regimentskommandeur der Trauerlaubnisschein unterschrieben war. ${ }^{668}$

Unter den Gestorbenen fanden sich drei Ledige (zwei Junggesellen im Alter von 69 [1804] bzw. 48 Jahren [1808] und eine Jungfrau im Alter 55 Jahren [1765], die bei Pfarrer Treiber (s. Anhang II) 25 Jahre lang Haushälterin gewesen war). Die Ledigenquote war praktisch gleich Null. Die Ehe stellte damit eine generell angestrebte Lebensform dar und wurde den beiden Alternativen einer verlängerten Abhängigkeit als Dienstbote oder einer nachgeordneten Stellung als Mitbewohner in einem Haushalt unbedingt vorgezogen.

\subsection{Das Erstheiratsalter}

Das gesetzliche Mindestalter beim Eingehen der ersten Ehe war für den Mann mit 18 und für die Frau mit vollendetem 14. Lebensjahr festgesetzt. ${ }^{669}$ Die Berechnung des durchschnittlichen Erstheiratsalters der Brautleute aus den beiden in Rede stehenden Kirchenbüchern hat ergeben, dass die Vorgaben bis auf wenige Ausnahmen bei den Frauen und Männern eingehalten wurden. ${ }^{670}$ Bemerkenswert ist dabei die größere Streuung bei den Frauen ${ }^{671}$ :

29,9 Jahre $(16,9-38,8)$ bei den Männern

25,1 Jahre $(15,3-43,5)$ bei den Frauen.

Diese großen Unterschiede sind Folge der damaligen gesellschaftlichen Zwänge. Im 17./18. Jahrhundert waren nicht Liebe und Zuneigung die entscheidenden Voraussetzungen für eine Heirat, sondern die wirtschaftlichen Verhältnisse der Brautleute. Nur wenn die Berufstätigkeit des Mannes oder die Mitgift der Frau die Ernährung der Familie zukünftig sicherte, konnte in der Regel mit Zustimmung der Eltern die Ehe geschlossen werden. Bereits 1761 verwies Johann Peter Süßmilch auf diese ökonomische Abhängigkeit des Heiraten Könnens: „Und da es klar ist, daß der Entschluß zum Heyrathen von dem leichten Unterhalt

667 daselbst: Liste der Getrauten, Eintrag vom 30.03.1769. Erlaubt war eine Heirat erst ab viertem Verwandtschaftsgrad gleicher und ungleicher Linie (s. ALR Zweiter Theil, Erster Titel: Von der Ehe, 8.

668 daselbst: Liste der Getauften, Eintrag vom 03.11.1737.

669 ALR Zweiter Theil, Erster Titel: Von der Ehe, \$ 37.

670 Andere Verhältnisse scheinen in Lindow vorgelegen zu haben. Denn das Kurfürstlich Brandenburgische zum Schweizer Etablissement verordnete Oberdirectorium hatte wahrgenommen, daß sich die Kinder unter der Schweitzer Colonie sehr jung Verheyrathen, und daher inutil [unfähig] geachtet werden, daß sie weder ihren Eltern, noch ihnen selbsten in der Haußhaltung indem sie den Ackerbau nach hiesiger Landes Art noch nicht recht begriffen, mit Nutzen vorstehen können; Als werdet ihr hierdurch befehliget, der Schweitzer Colonie anzudeuten, daß sich ihre Kinder, ohne des Churfürstl: Ober-Directorii Vorwißen und consens nicht verheyrathen, sondern, daß sie sich vorhero allemahl beym Amte angeben sollen; Auf welchen Fall dan ihr von den Contrahenten $Z u$ vernehmen, was bemittelt, auch ob sie den Ackerbau verstehen, und wie alt die Contrahenten seyn; ... [BLHA, Rep. 7 Amt Lindow Nr. 181, nicht paginiert, Schr. v. 10.10.1700 an den Amtmann von Lindow].

671 Vergleichbare Erstheiratsalter ermittelte Zinke (1996) für Steglitz mit 27 Jahren für den Mann und bei 23 Jahren für die Frau (Zinke, Regine: Steglitz bei Berlin, Edition Hentrich (1996)). Vergleicht man diese Daten mit den heutigen Verhältnissen, dann bestehen diese Unterschiede nach dem Bundesinstitut für Bevölkerungsforschung immer noch. Heute spielt die längere Ausbildung die entscheidende Rolle beim Erstverheiratungsalter. 
einer Familie abhängt, so erfordert es die Klugheit, alle möglichen Mittel aufzuwenden, damit derselbe eher erleichtert als schwerer gemacht werde." ${ }^{\text {"672 }}$ Doch die Verhältnisse auf dem Lande schränkten den Kreis der Heiratskandidaten merklich ein: „In den ständischen Gesellschaften der Frühen Neuzeit war die Ehe, ein Privileg (und) keineswegs ein Rechtstitel. ${ }^{\text {“673 Im }}$ Fall der Schweizer Erbpächter kam der erbrechtliche Aspekt hinzu. So wird beispielsweise, nachdem der Schweitzer Pächter Durtschy aus Nathwerder Alters und Schwachheits halber seinem Guthe fernerweit vorzustehen nicht mehr im Stande ist, und daher beym hiesigen Königl. Amt geziemende Ansuchung gethan ${ }^{674}$, seinem ältesten Sohn Christian am 10. November 1774 der Erbhof übertragen. Erst 2,5 Jahre später heiratete er die Jungfrau Maria Carolina Garmatter. ${ }^{675}$

Ob es im 17./18. Jahrhundert schon den Begriff „Wonnemonat Mai“ gab, sei dahingestellt. Trotzdem erschien interessant zu hinterfragen, ob und, wenn ja, zu welcher Jahreszeit bevorzugt in der reformierten Gemeinde im Golmer Bruch geheiratet wurde. Die diesbezügliche Auswertung der Hochzeitstermine ergab im Oktober eine deutliche Zunahme und im November ein Maximum, dagegen im März und Juli ein Minimum. Das ist bemerkenswert, denn zu dem gleichen Ergebnis kommt Zinke (1996) bei der Auswertung des Steglitzer Kirchenbuches von 1606 bis $1810 .{ }^{676}$ Dafür gibt es zwei Gründe: Das ganze Dorfleben war durch die Feldarbeit bestimmt - im Oktober war die Ernte und die Wintersaat bestellt. Die Dienstleute durften erst nach Beendigung des Dienstjahres heiraten. Die Verbote, die seit dem Mittelalter für das Heiraten während der Advents- und Fastenzeit vor Ostern galten, wurden dagegen im 17./18. Jahrhundert offensichtlich nicht mehr streng beachtet.

\subsection{Doppelhochzeiten}

Nur am 9. Januar 1694, 8. Oktober 1725, 20. Oktober 1726 und 3. Juni 1756 wurden laut Kirchenbuch Vol. I (1685-1801) drei Brautleute gleichzeitig getraut. Ist das aus pragmatischen Gründen, zufällig oder arrangiert geschehen? Beim genaueren Hinschauen sieht man, es handelt sich um arrangierte „Doppelhochzeiten“, bei dem ein „Eintausch“ der in die Höfe einheiratenden Bräute bzw. Bräutigame zwischen zwei Bauernfamilien vorgenommen wurde und gleichzeitig eine Braut aus einer dieser Bauernfamilien in eine dritte Familie einheiratete. Bei dem in Abb. 13 gezeigten Beispiel vom 3. Juni 1756 heiratete der älteste Sohn des Emanuel Maurhoffer, Christian, die älteste Tochter von Johann Durtschy, Magdalena Elisabeth, und der älteste Sohn von Johann Durtschy, Johann Heinrich, die dritte und jüngste Tochter von Emanuel Maurhoffer, Anna Christina (Doppelhochzeit, Typ I). Gleichzeitig heiratete Johann Dedweiller, Brauer in Bornstedt und Sohn eines Bauern aus Schulzendorf, die dritte Tochter von Johann Durtschy, Elisabeth:

672 Süßmilch, Johann Peter: Die göttliche Ordnung des menschlichen Geschlechts aus der Geburt, dem Tode und der Fortpflanzung desselben, Theil 1, Berlin (1775), S. 152.

673 Ehmer, J.: Heiratsverhalten, Sozialstruktur, ökonomischer Wandel, Göttingen (1991), S. 46.

674 BLHA, Rep. 7 Amt Potsdam Nr. 1942, fol. $481 \mathrm{ff}$.

675 KA Alt Töplitz: Kirchen-Buch der Schweitzer-Gemeinde im Bruch bei Potstamb, Vol. I (1685-1801, nicht paginiert), Liste der Getrauten, Eintrag vom 07.02.1777.

676

Zinke, Regine: Steglitz bei Berlin, Leipzig (1996), S. 222. 
Diese „Doppelhochzeiten“ sind keineswegs zufällig zustande gekommen, sondern durch die beteiligten Familien arrangiert worden und zum „Besten“ ihrer Höfe geschehen. Die Partnerwahl war für die bäuerliche Ökonomie von allergrößter Bedeutung, weil die Braut nicht nur unerlässliche Arbeitskraft, sondern auch Mitgift und damit Kapital für die Absicherung und den Erhalt des Hofes einbrachte oder nicht. Die Mitgift richtete sich nach dem Vermögen (Taxwert des Hofes und des sonstigen Vermögens) der Brauteltern, und ein Kapitalabfluss durch Mitgift konnte u. U. die Früchte einer langjährigen fleißigen Landwirtschaft der Herkunftsfamilie zunichte machen. Dagegen kam es bei einer Doppelhochzeit dazu nicht, weil zeitgleich ein Kapitalab- und -zufluss stattfand; es war mehr oder weniger ein Nullsummenspiel, wie dies Iida (1998) bereits anhand der brandenburgischen Dörfer Manker und Wustrau beschrieben hat. ${ }^{677}$

\subsection{Wiederverheiratungen und Scheidungen}

Starb ein Ehepartner, so wurde in der Regel wieder geheiratet. Denn sowohl für den hinterbliebenen Mann als auch für die Frau war es im 17./18. Jahrhundert in der Regel unumgänglich eine erneute Ehe einzugehen. Mitterauer (1981) spricht treffend vom Rollenergänzungszwang. ${ }^{678}$ Der Witwer brauchte die Frau für die Wirtschaft, den Haushalt und die Kinder. Die Witwe musste sich durch eine erneute Heirat die Altersversorgung sichern, da sie selten in der Lage war, ihren eigenen Lebensunterhalt zu bestreiten. Gesetzlich wurde dabei ein Unterschied zwischen den Witwern und Witwen gemacht. ${ }^{679}$ Wegen einer möglicherweise bestehenden Schwangerschaft war die Wiederverheiratung den Witwen erst nach neun Monaten erlaubt, wogegen den Witwern dies bereits nach einer Pietätsfrist von drei Monaten gestattet war.

Die Auswertung ergab, dass es sich bei jedem 5. Hochzeitseintrag (von insgesamt 327 Eintragungen 61) um eine Wiederverheiratung handelte. Davon sind insgesamt 49 Fälle (19 Witwer/30 Witwen) auswertbar. ${ }^{600}$ Nicht in jedem Fall sind die Hochzeitseintragungen in Bezug auf die Herkunft der Brautleute vollständig. Ersichtlich wird dies aus der Formulierung nicht aus unserer Gemeinde. Bei den Witwern erfolgte die durchschnittlich Wiederverheiratung 7,2 $(2-5)$ Monate nach dem Tod ihrer ersten Ehefrau; bei den Witwen war dies aus dem besagten Grunde erst nach 12,2 (5 - 27) Monaten der Fall. Bei den neuen Ehepartnerinnen der Männer handelte es sich überwiegend um Jungfrauen. Aus der Sicht der Demographie gesehen, deutet dies auf einen Frauenüberschuss hin. Süßmilch (1757) zieht gegen diese un-

677 Iida, Takashi: Hof, Vermögen, Familie 1700-1820, Jb. f. d. Brandenburgische Geschichte Bd. 49 (1998), S. 143-182, bes. S. 170; ders.: Ruppiner Bauernleben 1648-1806, in: Studien zur brandenburgischen und vergleichenden Landesgeschichte, Bd. 3., S. 163.

678 Mitterauer, Michael: Grundtypen europäischer Wirtschaftsgeschichte, Bd. I, Berlin (1981), S. 506.

679 Im Edict vom 26. Juli 1747 heißt es: daß von nun an Denen Wittwern erlaubet seyn solle, nach Ablauff eines Viertel Jahres von dem Tage des Absterbens ihrer Frauen an zurechnen, sich wiederum zu verheyrathen; In Ansehung Derer Wittwen aber, es bey der Verfassung, daß selbige vor Verlauff Drey Viertel Jahre nicht wieder heyrathen können bleiben (KA Alt Töplitz: Gedruckte alte allgemeine kirchliche Verfügungen für Golmerbruch seit 1730 (nicht paginiert).

680 Die Erstverheiratung ließ sich nicht in jedem Fall ermitteln. 
gleichen Paare wegen der zu erwartenden verminderten Fruchtbarkeit stark zu Felde. ${ }^{681}$ In zwei Fällen verheiratete sich ein Witwer mit einer Witwe. ${ }^{682}$

Nur ein Fall einer zweiten Wiederverheiratung (3. Ehe) kam in den in Rede stehenden Kirchenbüchern vor. Bärbel Läd(e)rach ${ }^{683}$ - noch in der Schweiz geboren - heiratete am 20. Juni 1687 Hanß Wintzeriedt, am 9. Januar 1694 Jacob Thädwyler und am 29. März 1707 Georg Gut aus der Stadt Zossingen in der Schweiz. Ein einziger Scheidungsfall (Maria Dorothea Hodler, geschiedene Rüdiger) war in den Kirchenbüchern auffindbar ${ }^{684}$, was zu dieser Zeit außerordentlich selten genehmigt wurde. $\mathrm{Zu}$ den näheren Umständen, die dazu geführt haben, war nichts zu erfahren.

\subsection{Woher kamen die Ehepartner?}

Aus verschiedenen Quellen haben bereits Wentscher (1930), Schramm (1936) und auch Stirnemann $(1991)^{685}$ Hinweise zum Heiratsverhalten der Schweizer Kolonisten im Golmer Bruch zusammengetragen, nicht jedoch dafür die in Rede stehenden Kirchenbücher ausgewertet. In diesen sind nicht in jedem Fall die Hochzeitseintragungen in Bezug auf die Herkunft der Brautleute vollständig. Ersichtlich wird dies auch aus der Formulierung nicht aus unserer Gemeinde und dem gelegentlichen Zusatz Dienstleute. Soweit lokalisierte Herkunftsangaben über die Brautleute in den Hochzeitseintragungen zu finden sind, handelt es sich bei den 155 Hochzeiten (von insgesamt 327) im Wesentlichen um Ortschaften in der näheren Umgebung, in denen einzelne Schweizer Kolonistenfamilien angesiedelt worden waren (s. Abb. 14). Auffällig viele stammten aus dem Ruppiner Raum, aber in Einzelfällen auch aus weiter entfernt liegenden Orten, wie z.B. Königsberg (Ostpreußen) ${ }^{686}$.

Insgesamt 49 Orte konnten ermittelt werden, aus denen die Eheleute stammten bzw. wohin eingeheiratet wurde. Darunter befinden sich quasi alle Orte, wo Schweizer Kolonisten angesiedelt wurden: Bochow, Damsdorf, Glambeck, Gransee, Hohenbruch, Klosterheide, Lehnin, Lindow, Linow, Lüdersdorf, Michelsdorf, Neuruppin, Neustadt-Eberswalde, Salzbrunn,

681 Süßmilch, Johann Peter: Die göttliche Ordnung des menschlichen Geschlechts aus der Geburt, dem Tode und der Fortpflanzung desselben, Theil 1, Berlin (1775), S. 181/182.

682 KA Alt Töplitz: Kirchen-Buch der Schweitzer-Gemeinde im Bruch bei Potstamb, Vol. I (1685-1801, nicht paginiert), Liste der Getrauten, Eintrag vom 27.09.1744.

683 Dabei handelt es sich um die Tochter Babi des 1685 in den Golmer Bruch eingewanderten Schweizer Kolonisten Hanß Lederich.

684 KA Alt Töplitz: Kirchen-Buch der Schweitzer-Gemeinde im Bruch bei Potsdam, Vol. I (1685-1801, nicht paginiert), Liste der Getrauten, Eintrag vom 30.11.1787.

685 Wentscher, Erich: Die Schweizer Kolonien in der Mark Brandenburg in: Archiv für Sippenforschung und alle verwandte Gebiete 7 (1930), S. 238-244, bes. S. 241.; Schramm, Karl: Die Schweizer Siedlungen, in: Archiv für Bevölkerungswissenschaft Bd. 6 (1936), S. 237-244, bes. S. 242. und Stirnemann, Heinz: Woselbst sie wohl aufgenommen, Frankfurt a. M. (o.J.), S. 27.

686 KA Alt Töplitz: Kirchen-Buch der Schweizer Gemeinde im Golmer Bruch, Vol. I. bzw. II (1685-1801 bzw. 1802-1846, nicht paginiert), Liste der Getrauten, Eintrag vom 11.11.1786 bzw. 6.04.1834. 
Schulzendorf, Storbeck und Vielitz. ${ }^{67}$ Bemerkenswert sind die Eintragungen in den Jahren 1690 bis 1699, da es sich hier zum großen Teil um Trauungen von Kindern der in den Golmer Bruch eingewanderten Schweizer Kolonisten (Vlrich Suter, Hans Bilang, Ulrich Küentzi, Hieronimus Schweingruber, Christian Durtschi, Peter Schweingrueber, Sammuel Suter, Peter Murhoffer, Hanß Schneider usw. ${ }^{688}$ handelt, die inzwischen im heiratsfähigen Alter waren, sich deshalb selbständig gemacht und im Neuruppiner Raum oder Michelsdorf angesiedelt hatten. Sie legten aber offensichtlich großen Wert darauf, von einem reformierten Prediger und in einer reformierten Kirche getraut zu werden und kamen deshalb nach Nattwerder:

den 26. May 1690 ist Vlrich Suter

vnd Verena Willem öffentlich

copuliert Vnd eingesägnet worden

in stand der H. Ehe.

Diße wohnen auch Zu Schönen

Eichen auf einem Curf[urstlichen] Gut im

Ambt Zoßen. Izo zu Storbek

bey der Schweizerischen Coloney im Ambte

Ruppin. ${ }^{69}$

Insofern bestanden die Kontakte zu anderen deutsch-reformierten Gemeinden von Anfang an. Und damit kann weder die von Asche (2006) konstatierte Phase der Endogamie bei den Schweizer Kolonisten bestätigt werden ${ }^{690}$ noch seine Behauptung, dass die Kolonisten im Schweizerbruch bei Potsdam und in der Umgebung von Michelsdorf und Alt Töplitz [offensichtlich eine Doppelung] eine Sonderexistenz mit eigenen Heiratskreisen geführt hätten. ${ }^{691}$ Verständlich ist dagegen, dass die Kontakte zu den Schweizer Kolonisten, die aus dem Kanton Zürich stammten, anscheinend weniger eng waren. ${ }^{692}$

Potsdam als Residenz- und Garnisonsstadt wirkte für die „überschüssigen“ Kinder der Schweizer Kolonisten als Heiratsmarkt wie ein Magnet. Wentscher $(1930)^{693}$ hat detailliert die Potsdamer Kirchenbücher für seine genealogischen Forschungen untersucht und fand dabei heraus, dass bei der Familie Mauerhof besonders auffallend die Neigung bestand, „in das Potsdamer Bürgertum einzudringen“. So wurden in der reformierten Heiliggeistgemeinde zu Potsdam (seit 1726) getraut: „Der Bürger und Kürschnermeister Ludwig Mauerhofer [am]

687 Das belegen die Eintragungen in der Liste der Getrauten im Kirchen-Buch der Schweitzer-Gemeinde im Bruch bei Potstamb (1685-1801) in den Jahren 1690-1696.

688 Hier ist die Schreibweise im Kirchenbuch wiedergegeben, die nicht identisch ist mit der in der Liste der Schiffsreisenden (s. Kap. IV.5.). Zum Kirchenbauprogramm im Ruppiner Raum s. Kapitel VI.1.)

689 KA Alt Töplitz: Kirchen-Buch der Schweitzer-Gemeinde im Bruch bei Potstamb Vol. I. (1685-1801, nicht paginiert), Liste der Getrauten, Eintrag vom 26.05.1690.

690 Asche, Matthias: Neusiedler im verheerten Land, Münster (2006), S. 562.

691 daselbst: S. 575.

692 So findet sich daselbst nur ein Heiratseintrag mit einer Braut aus Neustadt-Eberswalde (Margaretha Louyse Kupper) und einem Bräutigam aus Neu Töplitz (Christian Fischer) vom 02.04.1744.

693 Wentscher, Erich: Die Schweizer Kolonien in der Mark Brandenburg, in: Archiv für Sippenforschung und verwandte Gebiete, 7 (1930), S. 238-244, bes. S. 242. 
31.8.1735 mit der Potsdamer Drechslerstochter Anna Dorothea Wagner, der Bürger, Uhrmacher und Schlosser Samuel Maurhofer (Sohn d. Pächters und Einwohners zu Neu-Töplitz Peter M.[auerhoff]) [am] 24.6.1738 mit der Mühlenmeisterstochter Anna Maria Haken aus Brandenburg, und der Bürger und Uhrmacher Emanuel Mauerhoff [am] 15.7.1751 mit der Goldsticherstochter Anna Christina Morisson aus der Potsdamer französischen Kolonie.“

\subsection{Anzahl der Kinder pro Familie und Geburtenregelung}

Die Kirchenbücher führen alle Geborenen einschließlich Totgeburten auf und bieten durch deren Zuordnung zu den jeweiligen Hochzeitseintragungen die Möglichkeit, die Geburtenzahl pro Familie ${ }^{694}$ direkt zu berechnen. Allerdings muss dabei bedacht werden, dass nicht alle Getrauten lebenslang vor Ort blieben. Für die eingewanderten Schweizer Kolonisten ist dies unter Berücksichtigung der Einwanderliste (s. Kap. IV.5.) geschehen. Demgegenüber besteht bei Dienstleuten die spezielle Situation, dass sie zumeist nur eine Saison vor Ort sind. Des Weiteren stellen die Kinder bei den wiedervermählten Witwern und Witwen ein Problem dar. Sind sie aus der 1., 2. und ggf. weiteren Ehen als eine Familie zu zählen? In der graphischen Zusammenstellung werden diese Kinder zusammengefasst und zugehörig zu einer Familie betrachtet. Aus den genannten Gründen ist eine errechnete durchschnittliche Zahl von Kindern pro Familie in der Tendenz als zu klein anzusehen und zu bewerten. Das Hauptaugenmerk sollte daher auf die Herkunft der Familien mit den meisten Kindern und auf mögliche Unterschiede der Kinderzahlen bei den verschiedenen sozialen Schichten in der dörflichen Bevölkerung gerichtet sein (s. Abb. 15).

Die durchschnittliche Anzahl der geborenen Kinder bei den 131 auswertbaren Familien liegt bei 4,5 Kindern. Das erscheint wenig und ist im Wesentlichen dadurch bedingt, dass rund ein Fünftel Ein-Kind-Familien sind. Die Grafik zeigt aber auch eine große Streubreite (maximal 14 Kinder in einer Ehe), und gleichzeitig deutet sich durch Maxima ein schichtspezifisches Muster des generativen Verhaltens an. Die dörfliche Oberschicht, also die Schweizer Erbpächter aus den Orten Golm, Nattwerder und Neu Töplitz, konnten sich 5 bis 14 Kinder leisten. Auf diese Art und Weise demonstrierte man auch seinen Reichtum. Zu den kinderreichen Familien zählte auch der Prediger Franz Rudolph Becker (Amtszeit von 1770-1785) mit 9 Kindern. ${ }^{695}$ Bei den Familien mit 2 - 4 Kindern (dörfliche Mittelschicht) handelt es sich vornehmlich um Handwerker (Bierbrauer, Glaser, Müller, Radmacher, Schmied, Schneider, Weinmeister). Unter die Ein-Kind-Familien (dörfliche Unterschicht) fallen vor allem Dienstleute, Kossäten und Hausmänner.

Aber die Anzahl der geborenen Kinder ist nicht allein in Betracht zu ziehen. Daneben, vielleicht sogar entscheidender, ist die Zahl der gleichzeitig im Haushalt lebenden Kinder. Das war bei den Dienstleuten neben ihrer materiellen Situation auch aus räumlichen Gründen

694 Die historische Demographie verwendet hierfür den Begriff „eheliche Fertilität“.

695 Prediger Franz Rudolph Becker heiratet am 21.07.1771, Charlotte Henriette Sophie Benda, die Tochter des Kgl. Kammermusikers Benda, und am 10.11.1778 Amalia Elisabeth Wernicke, die Tochter seines Küsters. Aus den Ehen gingen 4 bzw. 5 Kinder hervor. 
von Bedeutung. Insofern ist es interessant, dies am Beispiel einer der beiden Ehen mit 14 Kindern zu überprüfen. Christian Turtschi (1699-1775) war Erbpächter in Neu Töplitz in 3. Generation. Von seinen Kindern sind folgende Daten aus dem Kirchenbuch bekannt:

Tab. 13: Die Anzahl der Kinder im Haushalt am Beispiel der Familie Turtschi

\begin{tabular}{|c|c|c|c|c|}
\hline \multicolumn{5}{|c|}{ Christian Turtschi $\infty 19.11 .1722$ Barbara Schneider } \\
\hline Kinder: & Christian & *30.11.1723, & +21.09 .1724 & \\
\hline & Maria Magdalena & ${ }^{*} 12.05 .1725$ & & $\infty 22.11 .1742$ \\
\hline & Johanna Elisabeth & *26.10.1726 & +07.12 .1726 & \\
\hline & David & * 26.10 .1727 & +24.05 .1729 & \\
\hline & Christian & * 12.06 .1729 & & $\infty 20.04 .1752$ \\
\hline & Elisabeth & *28.01.1731 & +13.04 .1733 & \\
\hline & Anna & *03.03.1733 & +31.07 .1736 & \\
\hline & Maria Elisabeth & ${ }^{*} 12.01 .1735$ & & \\
\hline & Emanuel & *02.01.1737 & +03.03 .1739 & \\
\hline & Christina & *25.12.1738 & & $\infty 17.06 .1756$ \\
\hline & Emanuel & * 10.07 .1740 & & \\
\hline & Maria Elisabetha & * 19.03 .1742 & & $\infty 30.11 .1758$ \\
\hline & Anna Maria & *27.04.1744 & & \\
\hline & David & ${ }^{*} 07.08 .1746$ & & $\infty 15.11 .1774$ \\
\hline
\end{tabular}

Damit lebten im Haushalt der Familie Turtschi bis 1735 nur drei Kinder, und erst von da ab stieg die Kinderzahl kontinuierlich auf sieben im Hause lebende Kinder. Die Tochter Elisabeth ist der Pockenepidemie im Jahre 1733 zum Opfer gefallen; bei den Eintragungen der anderen gestorbenen Kinder ist keine Todesursache angegeben. Auch wenn die Kindersterblichkeit in diesem Beispiel schon sehr hoch ist, ist sie in der Golmer Bruchgemeinde im Durchschnitt - vermutlich auf Grund von hygienischen Problemen und mangelnder Kinderfürsorge - noch höher gewesen.

Ein bemerkenswertes Phänomen stellte die Geburtenfolge dar. Wie in Abb. 10 exemplarisch gezeigt, betrug der Abstand der Geburten zwischen 12 und 18 Monaten; dieser zeitliche Abstand ließ sich in der Regel von der ersten bis zur letzten Geburt feststellen.

Den kinderreichen Familien steht der hohe Anteil der Familien mit geringer Kinderzahl (Ein-

Kind-Familien) gegenüber. Hier stellt sich die Frage, ob die ländliche Familie ihre Nachkommenschaft bewusst geplant bzw. zu bestimmten Zeiten enthaltsam gelebt hat. Haben die Männer und Frauen gewusst, dass man den Geschlechtsverkehr abbrechen kann, um die Zeugung zu vermeiden, oder verstanden sie gar schon mit Vorformen von Kondomen umzugehen? Trieben die Frauen ab, um als Arbeitskraft nicht auszufallen? Es sind nur sehr wenige Überlieferungen zur Beantwortung dieser Fragen bekannt. Es ist aber sehr wahrscheinlich, dass die 
Frauen im ländlichen Bereich des 17. bzw. 18. Jh. Mittel mit abtreibender Wirkung kannten und zur Geburtenregelung anwandten. Schon Hippokrates hat hierzu Hinweise gegeben. In der deutschen Volksmedizin war der Gebrauch von Wacholder, Wermut oder Eisenkraut weit verbreitet. ${ }^{696}$ Bei der Anwendung dieser Arzneien zur Abtreibung kam es nur auf die Höhe der Dosierung an: Dosis sola venenum facit (Paracelsis, 1493-1541). Erstaunlich ist allerdings, dass sich ausgerechnet Notizen zur Abtreibung auf den letzten Seiten des Steglitzer Abgabenbuches finden. ${ }^{697}$ Hier dürfte die Not vieler Familien das Motiv hierfür gewesen sein.

\subsection{Die Militärs}

Der Ausbau Potsdams zur Garnisonsstadt blieb nicht ohne Auswirkungen auf die unmittelbare Umgebung. Unter den Getrauteneintragungen fand sich erstmals 1699 als Bräutigam ein Soldat, Vllrich Brunner, aus dem Kanton Zürich: ${ }^{698}$

den 26 Junij 1699 wurden Hans Vllrich

Brunner Vnd Catharina Fosterin

in stand der Hei. Ehe eingesegnet.

NB diese beyde waren aus dem Canton

Zürich, der Mann ein Soldat, das

Eybe eine Hure. ${ }^{699}$

Diesem Eintrag folgen dann ab 1737 die beträchtliche Anzahl von insgesamt 13 Eintragungen von Dragonern, Füsilieren, Grenadieren und Husaren, die in die Familien von den Nachkommen der 1685 im Golmer Bruch angesiedelten Schweizer Kolonisten einheirateten und im Bayreuthischen, im Bülowschen oder von Phulschen Regiment bzw. im Bataillon der Königlichen Leibgarde zu Fuß dienten und gleichzeitig als Knechte bezeichnet werden. Nach erhaltenem Dimissoriale ${ }^{700}$ traf dies im Jahre 1824 bzw. 1825 auch bei einem Unteroffizier und einem Quartiermeister (beide vom Königl. Garde-Landwehr-Kavallerieregiment) zu.

Hier versteckt sich ein Dilemma des preußischen Agrarstaates. Einerseits sollte Anfang des 18. Jahrhunderts der Ausbau der Armee vorangetrieben werden, andererseits konnten nicht beliebig viele Menschen vom Lande abgezogen werden, da er sich dadurch seiner wesentlichen ökonomischen Stütze beraubte. Deshalb setzte Friedrich Wilhelm I. die jährliche Übungszeit von 3 Monaten auf 2 Monate $[\mathrm{n}]$ herab. ${ }^{701}$ Damit standen die Armeeangehörigen in Wörterbuch, Bd. 27, Sp. 56 (Wacholder), Bd. 29. Sp. 428 f. (Wermut).

697 Zinke, Regine: Steglitz bei Berlin, Leipzig (1996), S. 103.

698 Seit Ende des 17. Jahrhunderts betrieb Brandenburg Söldnerwerbung in den Schweizer Kantonen; in: Guggert, Rudolf: Preußische Werbung in der Eidgenossenschaft, Berlin (1997), S. 15.

699 KA Alt Töplitz: Kirchen-Buch der Schweitzer-Gemeinde im Bruch bei Potstamb Vol. I. (1685-1801, nicht paginiert), Liste der Getrauten, Eintrag vom 16.06.1699.

700 Entlassschein.

701 Büsch, Otto: Militärsystem und Sozialleben im alten Preußen 1713-1807. Die Anfänge der sozialen Militarisierung der preußisch-deutschen Gesellschaft, erw. Ausgabe Frankfurt a. M. (1981), S. 30. 
der Saison als Arbeitskräfte (Knechte) zur Verfügung. Zugleich erwies sich das für die Kompaniechefs als vorteilhaft, weil sie für diese Zeit den Sold einsparen konnten.

\section{Die Liste der Verstorbenen}

Dem jahrzehntelangen Wirken von Johann Peter Süßmilch (1717-1767) ${ }^{702}$ ist es sicherlich zu verdanken, dass die Prediger nach der Ordre und Instruktion über die bessere Kirchenbuchführung vom 16. November $1764^{703}$ ein Verzeichnis (Schema C) der Verstorbenen nach 19 vorgegebenen Haupt-Krankheiten anzufertigen hatten. Über die Schwierigkeiten der Umsetzung einer solchen Forderung lässt die Vorschrift keine Zweifel, zumal die Prediger damit schlichtweg überfordert waren und sie nur lustlos wahrnahmen. ${ }^{704}$ Erfahrungsgemäß braucht die Durchsetzung einer Vorschrift ihre Zeit, und so finden sich erst ab 1766 vom 9. Prediger der Reformierten Schweizer Kolonistengemeinde, Johann Christoph David Hübenthal, bei einzelnen Personen und ab 1772 komplett Angaben über die Todesursachen der Verstorbenen. Davor ist dies nur ausnahmsweise der Fall und betrifft dann im Wesentlichen dramatische Ereignisse (Totgeburten, Ertrunkene) und bestimmte regierende ${ }^{705}$ Kinderkrankheiten. In den Tabellen 9 und 10 sind die Ergebnisse für Kinder bzw. Erwachsene (über 14 Jahre) zusammengefasst.

Bei der Ermittlung der „Todesursache“ war man im 17./18. Jahrhundert - mit Ausnahme der Herztöne und des Pulsfühlens - ausschließlich auf das Betrachten des Körpers des Erkrankten und des Krankheitsverlaufes angewiesen. ${ }^{706}$ So wird im Kirchenbuch als eine der häufigsten Todesursachen angegeben - hitzige $(s)^{707}$ Fieber/Krankheit. Das entspricht nach heutigen Vorstellungen einem Krankheitssymptom, das bei verhältnismäßig vielen Krankheiten als Begleiterscheinung vorkommt und ist folglich nicht pathognomonisch. Das Gleiche trifft auch für die „Todesursachen“ Konvulsionen/Krämpfe, Auszehrung und Seitenstechen zu. In anderen Fällen wird nur die Dauer der Krankheit angegeben: [Er] starb an einer langwierigen und schmerzhaften Krankheit (die an die 4. Jahr ihn auf den Kranckenbette gehalten). ${ }^{708}$ Aus diesen Angaben können deshalb für eine Auswertung aus medizinhistorischer Sicht nur bedingt belastbare Rückschlüsse gezogen werden. Deshalb sind auch einige der in den Tabellen 14 und 15 aufgeführten Fälle mit Vorbehalt interpretiert und mit Fragezeichen versehen worden. Die im Kirchenbuch gefundenen „Krankheitsbegriffe“, für die keine Krankheitsbezeichnung im

702 s. Anm. 39 und 40.

703 GStA PK, Rep. 243 Evangelisches reformiertes Kirchendirektorium Nr. 440, fol. 135 ff., No. 80 Ordre und Instruction, wie die prediger die Kirchen-Bücher zu halten haben. De Dato Berlin, den 16. Nov. 1764.

704 Nur in einem Fall liegt der angegebenen Todesursache („Nervenlähmung“) ein Attest des Arztes Müller zu Potsdam zugrunde (KA Alt Töplitz: Kirchen-Buch der Schweitzer Gemeinde im Bruch bei Potstamb (Vol. II, nicht paginiert), Liste der Verstorbenen, Eintrag 07.11.1729.

705 gravierende.

706 Schlegelmilch, Sabine: Ärztliche Praxis und sozialer Raum im 17. Jahrhundert, Wien, Köln und Weimar (2018), S. $169 \mathrm{ff}$.

707 heftige.

708 KA Alt Töplitz: Kirchen-Buch der Schweitzer Gemeinde im Bruch bei Potstamb, Vol. I. (1685-1801, nicht paginiert), Liste der Verstorbenen, Eintrag vom 03.02.1719. 
heutigen Sinne ermittelt werden konnten, sind nicht in die Tabellen aufgenommen worden, zumal es sich um Einzelfälle handelte.

Die Liste der Verstorbenen beginnt erst 1705. Der einzelne Sterbeeintrag beinhaltet zunächst in Form einer Standardformulierung nur das Sterbedatum und den Namen des Vaters des/ der Verstorbenen und dessen Wohnsitz. Wie bereits bei den Taufen ausgeführt, wurden die verstorbenen Frauen größtenteils über ihre Männer bzw. Väter definiert, wogegen die soziale Stellung der Männer in der Regel präzis benannt wurde:

den 26. febr: [1716] ist Ulrich Zächs, des Leine-

weber frau, gestorben. ${ }^{709}$

In gleicher Weise wurde bei verstorbenen Kindern verfahren. Die Mutter fand keine Erwähnung. Ausnahmen hiervon waren von Anfang an die Sterbeeinträge der Angehörigen der zeitigen Prediger. Hier erhält gelegentlich auch die Betroffenheit Raum:

den 18. Sept [1711] ist meine Töchterlein

Maria Sophia seelig im

Herrn entschlafen, Ihres

alters 4. Jahr, wenige Tage. ${ }^{710}$

Mit der Zeit werden die Eintragungen immer mehr erweitert. Hinzu kommt das Alter, wann und auf welchem Friedhof (im bruch, aufm Galin, in Gollm, in Bochow, in Paretz, in Potsdam usw.) die verstorbene Person begraben wurde. Davon ist nur ein einziges Mal eine Ausnahme gemacht worden. Prediger Sigismund Lupichius (1705-1717, s. auch Kap. VI.1.) nahm sich die Freiheit und beerdigte seine einjährige Tochter Anna Louysa im bruche in der Kirche forne im Chor unter dem kleinen spint. ${ }^{711}$ Gelegentlich finden sich Bemerkungen zur Person: gestorben, Lebens-satt nach einer langen Krankheit ${ }^{712}$ oder Er war ein Muster in der Gemeine; ein sehr frommer, rechtschaffner Mann, der besonders im ehelichen Leben, allen ein Muster sein konnte. ${ }^{713}$ Erst etwa ab 1736 werden bei Kindern die Eltern (Vater und Mutter) genannt. Bei Erwachsenen geschieht dies manchmal ebenfalls, wahrscheinlich zur Unterscheidung der vielen gleichnamigen Personen. Gelegentlich finden sich Angaben zur Hofstellennummer, über den Ablauf eines Begräbnisses und die Bibelstelle, über welche die Leichenpredigt gehalten worden war. ${ }^{714}$ Die Todesursachen sollen nachfolgend nach zwei Altersklassen (Säugling/Kinder und Erwachsene ab 14 Jahre) abgehandelt werden. In den Tabellen 14 und 15 werden die im Kirchenbuch angegebenen Krankheiten - so weit möglich - den heutigen Bezeichnungen gegenübergestellt. 


\subsection{Die Todesursachen der Kinder und Jugendlichen}

Bei den Todesursachen bei Kindern im Alter von 6 Monate bis 7 Jahren fallen besonders die Infektionskrankheiten ins Auge und hier in erster Linie die epidemisch wiederholt aufgetretenen Pocken (1772, 1790, 1794, 1795, 1797, 1804, 1815 und 1819) im Alter von sechs Monaten bis sieben Jahren. ${ }^{715}$ Süßmilch ${ }^{716}$ bezeichnet diese Krankheit als den größten Feind der Kinder. Zwar war in Europa bereits seit den 1720er Jahren die asiatische Methode der Bekämpfung dieser Krankheit bekannt - nämlich die künstliche Einpfropfung von Menschenpocken in die Haut als Schutzmaßnahme -, aber man misstraute dieser Methode, da immer wieder Krankheitsdurchbrüche vorkamen. Selbst Süßmilch, der sich sehr nachdrücklich für sie einsetzte, wagte nicht, sie in dem von ihm verwalteten Waisenhaus in Berlin durchführen zu lassen. ${ }^{717}$ Erst im Jahre 1769 wurde in der Charité mit den ersten Pockenimpfungen begonnen. ${ }^{718}$ Den ländlichen Gemeinden kam dieser Fortschritt erst viel später zugute. Die Impfpflicht wurde in Preußen 1815 eingeführt. Zuständig war für die Pockenimpfung in den Golmer Bruchdörfer ab 1847 der Wundarzt Tschiegner. ${ }^{719}$

Bei der am zweithäufigsten angegebenen Todesursache innerer Jammer (32 Fälle) handelt es sich wahrscheinlich um nicht näher spezifizierte Bauchkrämpfe im Magen-Darm-Trakt, wie sie häufig bei Säuglingen vorkommen. Gelingt es nicht, die Krämpfe zu lösen, kann als Folge einer Darmverschlingung eine Verstopfung auftreten, die tödlich endet.

Ebenso gefährlich waren für die Kinder die Krämpfe (Epilepsie), von Süßmilch auch unter der Bezeichnung Convulsionen zusammengefasst. Sie schienen ihm sogar das nachtheiligste Übel $z u$ seyn für die Kinder. ${ }^{720}$ Sie traten am häufigsten im Zusammenhang mit dem Durchbruch der ersten Zähne auf. Dies ist in Tabelle 14 mit an den Zähnen gemeint. Diese Krämpfe traten vor allem im Alter von 8 bis 12 Monaten auf, und man kann dabei einen Zusammenhang mit der Umstellung der Ernährung auf festere Nahrung vermuten (s. Anm. 720). Den Schaden, den Zahnerkrankungen und Konvulsionen anrichten, vergleicht Süßmilch an anderer Stelle mit der Pest: Die Pest höret wieder auf, diese dauren aber beständig fort. ${ }^{721}$ Heute stellen die ersten Zähne keine Probleme mehr dar. Wenn die sogenannten Zahnkrämpfe bei Säuglingen auftreten, werden sie mit fiebersenkenden Mitteln und ggf. örtlich schmerzstillend behandelt. Als weitere häufige Todesursachen tritt Steckfluß/Stickfluß auf. Darunter versteht man eine Anhäufung von (eitrigem) Schleim in der Lunge. Derartige Lungenentzündungen findet man auch heute noch bei Kindern.

715 Bei der Kirchenvisitation von Alt, Neu Töplitz und Nattwerder erwähnt Superintendent Kollberg (Brandenburg/Neustadt) eine Pockenepidemie im Vorjahr (1871) in den genannten Gemeinden [BLHA, Rep. 2A Regierung Potsdam II Z Nr. 117, fol. 63R.].

716 Süßmilch, Johann Peter: Die göttliche Ordnung, Berlin (1741), S. 284.

717 Brockhaus, Bd. 13, S. $73 \mathrm{ff}$.

718 Schultz, Helga: Berlin 1650-1800 - Sozialgeschichte einer Residenz, Berlin (1987), S. 272.

719 BLHA, Rep. 7 Amt Potsdam Nr. 204 (nicht paginiert).

720 Süßmilch, Johann Peter: Die göttliche Ordnung des menschlichen Geschlechts aus der Geburt, dem Tode und der Fortpflanzung desselben, Theil 1, Berlin (1775), S. 279. 
Tab. 14: Todesursachen bei Kinder und Jugendlichen laut Kirchenbuch

\begin{tabular}{ll}
\hline Bezeichnung im Original & heutige Bezeichnung \\
\hline Pocken, regierende $(39 \mathrm{x})$ & Pocken \\
\hline Jammer, innerer $(32 \mathrm{x})$ & Krämpfe, Krampfanfallsleiden, Epilepsie ${ }^{722}$ \\
\hline an die Zähnen $(16 \mathrm{x})$ & Krämpfe infolge Infektionen beim Zahnen ${ }^{723}$ \\
\hline Stickhusten (z. T. mit Fieber) $(10 \mathrm{x})$ & Keuchhusten \\
\hline Rütteln/Ritteln $(10 \mathrm{x})$ & Röteln \\
\hline Scharlach/roter Friesel ${ }^{724}(10 \mathrm{x})$ & Scharlach \\
\hline Masern $(8 \mathrm{x})$ & Masern \\
\hline Ruhr/Blutsturz $(8 \mathrm{x})$, & Ruhr \\
\hline Konvulsionen/Krämpfe $(8 \mathrm{x})$ & Krämpfe \\
\hline Giechter/Gichter $(4 \mathrm{x})$ & Epilepsie (Krämpfe beim Säugling nach Krankheiten allgemein $)^{725}$ \\
\hline Steck-/Stickfluß $(3 \mathrm{x})$ & Herz-Kreislauf-Versagen (?) \\
\hline Schwindsucht $(4 \mathrm{x})$ & in diesem Alter Abmagerung/Auszehrung \\
\hline Schlagfluß $(1 \mathrm{x})$ & Schlaganfall (?) \\
\hline Auszehrung $(3 \mathrm{x})$ & Abmagerung \\
\hline Entzündung im Mund $(1 \mathrm{x})$ & Pilzinfektion (?) \\
\hline Kopf-Jammer $(1 \mathrm{x})$ & Meningitis, Encephalitis \\
\hline Verschleimung $(1 \mathrm{x})$ & Bronchitis, Pneumonie (?) \\
\hline Lungenschwächung u. Herzklopfen $(1 \mathrm{x})$ & angeborner Herzfehler (?) \\
\hline aus Schwäche unter bzw. unmittelbar & perinatale Sterblichkeit \\
\hline nach der Geburt gestorben $(6 \mathrm{x})$ & \\
\hline Totgeburten $(18 \mathrm{x})$ & \\
\hline & \\
\hline
\end{tabular}

Die auch gegenwärtig noch typischen Kinderkrankheiten (Röteln, Scharlach, Masern) verliefen im 17./18. Jahrhundert häufig tödlich, desgleichen die Ruhr, von der dann allerdings Kinder und Erwachsene gleichermaßen betroffen waren. Auf die Einzelfälle soll hier nicht näher eingegangen werden.

Dass die Kinderkrankheiten oft tödlich endeten, schrieb Süßmilch der Nachlässigkeit der Eltern zu. ${ }^{727}$ Diese hielten sich an schädliche und hitzige Hausmittel, packten die Kinder zu warm ein und gaben Alandwein zum Austreiben der Krankheit zu trinken. Dieser Kräuterwein wurde schon jahrhundertelang als Heilmittel angewandt. Ob dies auch für die Schweizer zutraf, sei dahingestellt.

722 Hermann Metzke: Lexikon der historischen Krankheitsbezeichnungen, Neustadt an der Aisch (2005), S. 76.

723 daselbst: S. 49; galt im 18. Jh. noch als eigenständige Krankheit.

724 daselbst: S. 62.

725 daselbst: S. 67.

726 daselbst: S. 108.

727 daselbst: S. 523. 


\subsection{Die Todesursachen der Erwachsenen}

Die insgesamt 189 auswertbaren Todesursachen bei den Erwachsenen unterscheiden sich natürlich wesentlich von denen der Kinder. (s. Tab. 15) Im Vordergrund stehen die typischen Alterserscheinungen. Dabei ist nicht zu erkennen, wie die Unterscheidung von Altersschwäche/Entkräftung und Auszehrung am äußeren Erscheinungsbild getroffen wurde. ${ }^{728,729}$ Entkräftung bezeichnet vor allem Krankheiten, bei denen ein allmählicher Kräfteverfall einsetzt.

Tab. 15: Todesursachen der Erwachsenen laut Kirchenbuch

\begin{tabular}{ll}
\hline historische Bezeichnung & moderne Bezeichnung \\
\hline Altersschwäche/Entkräftung $(37 \mathrm{x})$ & Altersmarasmus \\
\hline Auszehrung/Abzehrung $(31 \mathrm{x})$ & Abmagerung (ernährungsbedingt $(?))$ \\
\hline Schwindsucht $(23 \mathrm{x})$ & Lungentuberkulose $(?)$ \\
\hline hitziges Fieber/Krankheit $(20 \mathrm{x})$ & $\begin{array}{l}\text { hohes Fieber im Zusammenhang mit einer } \\
\text { Grundkrankheit }\end{array}$ \\
\hline Schlagfluß $(13 \mathrm{x})$ & Schlaganfall \\
\hline Wochen-/Kindbeth $(9 \mathrm{x})$ & Kindbettfieber \\
\hline Ruhr/Blutgang $(9 \mathrm{x})$ & Ruhr \\
\hline (Bauch-)Wassersucht $(5 \mathrm{x})$ & Aszites \\
\hline Gallenfieber, hitziges $(5 \mathrm{x})$ & Gallensteine mit Gallenrückstau (?) \\
\hline Brust-/Lungenentzündung $(4 \mathrm{x})$ & Lungenentzündung \\
\hline Lungensucht $(2 \mathrm{x})$ & Lungentuberkulose (?) \\
\hline Brustwassersucht $(3 \mathrm{x})$ & Rippenfellentzündung \\
\hline Scharlach $(3 \mathrm{x})$ & Scharlach \\
\hline Blattern $(1 \mathrm{x})$ & Pocken \\
\hline Brand, innerl. u. Schwäche $(1 \mathrm{x})$ & Gangrän (?) \\
\hline Engbrüstigkeit $(1 \mathrm{x})$ & Behinderung der Atmung infolge Anomalien \\
\hline Brustkrankheit $(1 \mathrm{x})$ & der Wirbelsäule, des Brustkastens usw. \\
\hline Seitenstechen $(1 \mathrm{x})$ & $(?)$ \\
\hline Magenübelkeit $(1 \mathrm{x})$ & Appendizitis (?) \\
\hline Verstopfung $(1 \mathrm{x})$ & Magenulkus (?) \\
\hline Alterspsychose $(1 \mathrm{x})$ & Verstopfung \\
\hline Erfroren $(1 \mathrm{x})$ & Nachts umhergeirrt und dabei erfroren \\
\hline Frieseln, rote $(1 \mathrm{x})$ & auf dem Heimweg verirrt u. erfroren \\
\hline gelbe Sucht $(1 \mathrm{x})$ & Scharlach \\
\hline & Hepatitis \\
\hline
\end{tabular}

728 Bei der Eintragung vom 06.04.1827 steht sogar Auszehrung und Entkräftung.

729 Meier, Brigitte: Neuruppin - 1700 bis 1830, Berlin (1993), S. 115 interpretiert den Begriff Auszehrung mit vielleicht eine Umschreibung des langsamen Verhungerns. 


\begin{tabular}{ll}
\hline historische Bezeichnung & moderne Bezeichnung \\
\hline Schaden an den Füßen $(3 \mathrm{x})$ & $\begin{array}{l}\text { schwere Durchblutungsstörungen aufgrund } \\
\text { allgemeiner Arteriosklerose }\end{array}$ \\
\hline Gicht $(1 \mathrm{x})$ & Gicht \\
\hline Nervenlähmung $(1 \mathrm{x})^{730}$ & $(?)$ \\
\hline Ertrunken/Ersoffen $(5 \mathrm{x})$ & \\
\hline Unfall ${ }^{731} / \operatorname{Sturz}(3 \mathrm{x})$ & \\
\hline
\end{tabular}

Auch die Abgrenzung zur Schwindsucht ${ }^{732}$ war offensichtlich problematisch, denn bei 3 Fällen steht Auszehrung oder Schwindsucht. Schlagfluß [Schlaganfall] gehört zu den typischen Alterserkrankungen.

Die neun Todesfälle aufgrund von Kindbettfieber bei 1039 Geburten $(0,85 \%)$ sind als niedrig für das 17./18. Jahrhundert anzusehen. ${ }^{733}$ Interessant sind die 4 Ruhrfälle, weil hier in zwei Familien je ein Erwachsener und ein Kind betroffen waren und diese im Abstand von zwei bzw. zwölf Tagen starben.

Eine besondere Stellung bei den gestorbenen Erwachsenen nehmen die ausrangierten ${ }^{734}$ Soldaten und Unteroffiziere ein. Sie sind teils im Lazarett Glienicke oder zu Hause bei Verwandten verstorben. Ihre Sterbeeinträge fallen erheblich umfänglicher als die der Zivilisten aus. Besonders lesenswert ist folgender:

den 25 ten Maij [1725] ist gestorben und den 27 ten

bey 4 Häuser begraben worden Ein

Grenadier aus dem Königl. Leib-

Regiment in Potdam, nach demme

Er ein halbes Jahr bey seinem

Schwieger Vatter in Gollm krank

gewesen, Namens Johan Kähr

Von Lampersweilen aus d. Schweitz aus

Dem Kanton Bern, hat sich während

seiner Krankheit biß in Tod sehr

erbaulich erwiesen; und ware sonder-

lich merckwürdig, daß Sr. Königl.

Majest. ihme in seiner Krankheit

einmahl besucht, u. seinetwegen ex press

nach Gollm gefahren.

730 s. Anm. 704.

731 Hufschlag eines Pferdes.

732 Üblicherweise ist damit Tuberkulose gemeint.

733 Nach Meier sind in Neuruppin 3,8 \% der Gebärenden an Kindbettfieber verstorben; in: Meier, Brigitte: Neuruppin - 1700 bis 1830, Berlin (1993), S. 124.

734 aus dem Dienst entlassene. 


\subsection{Die Lebenserwartung}

Da die Liste der Verstorbenen erst 1705 beginnt, fehlen Altersangaben über nahezu zwei Generationen - der eingewanderten Schweizer Kolonisten und deren mitgebrachten Kinder. Von den im Kapitel IV.5. aufgeführten Schweizer Kolonisten fehlen bis auf Catharina Küentzi († 26.02.1710), Samuel Suter († 12.03.1710), Jacob Gering frauw († 17.03.1712), Hanß Lädrach (†13.08.1714), Alte Muter Garmatterin (†17.03.1715), Isaac Murhoffer hinterlaßne Witwe Elisabeth $(+18.07 .1717)$, Niclaus Schweingruber, deß Vatters frauw († 09.09.1722), der alte [Nicolaus] Schweingruber $(+25.11 .1722)$ und Hanß Schnyder (bey 90 Jahre, †20.02.1725), Barbara Wenger $\left({ }^{*} 1646-+18.01 .1731\right)$ und Crispinus Garmatter ( ${ }^{*}$ Martio 1674 - †05.10.1734) alle weiteren Lebensdaten. Darüber hinaus ließ sich bei weiteren 83 Verstorbenen kein Lebensalter errechnen, da ihr Sterbeeintrag weder ein Geburtsdatum noch ersatzweise eine Altersangabe enthielt. Bei den Letzteren handelte es sich um Bedienstete, Eingeheiratete und dergleichen. Damit konnten insgesamt nur 513 Fälle hinsichtlich ihrer Lebenserwartung ausgewertet werden. Aber auch bei den angegebenen Altersangaben sind Zweifel aufgrund ihrer Formulierungen angebracht: - alt ins 18. Jahr, ungefehr [...], - so 84 Jahre alt, - war meist 10 Monate, - ging ins 77ste Jahr, - hat sein Leben auf [...] Jahr gebracht oder gestorben so im hohen selbst unbewußten Alter -, und stehen einer möglichst exakten Auswertung der Lebensdaten entgegen. Deswegen sind zur Auswertung der Lebenserwartung Alterscluster über 5 Jahre gebildet worden. Zur Erfassung der Perinatalsterblichkeit ${ }^{735}$ wurde ein zusätzliches Cluster gebildet (s. Abb. 16).

Die Analyse der Verstorbenen nach ihrem Alter ergibt hinsichtlich der perinatalen Sterblichkeit eine erschreckende Bilanz. Knapp ein Drittel der Todesfälle ereignete sich innerhalb des ersten Lebensjahres. Bei den insgesamt 146 Personen handelt es sich um 81 Knaben (55,5\%) und 65 Mädchen (44,5\%). Die Ursachen hierfür sind heute klar. Wenn man von unerwünschten Kindern und auch von einer nicht ausreichenden Ernährung absieht, so sind die Kinder im 17. und 18. Jahrhunderts in eine Welt voller Gefahren und vor allem in Unwissenheit hineingeboren worden. Hinzu kam, dass das Hebammenwesen in Preußen und insbesondere auf dem Lande so gut wie unbekannt war. ${ }^{736}$ War die Geburt für Mutter und Kind gut überstanden, stellte das erste Jahr für alle Neugeborenen - wie wir heute wissen - wegen der Anpassung an die äußere Umwelt eine gewaltige Herausforderung dar, vor allem wenn die passive Autoimmunisierung über die Muttermilch aus Unkenntnis verhindert und die Säuglinge falsch ernährt wurden. Hierzu nur zwei Beispiele eines Zeitgenossen: Süßmilch schreibt 1741, die Mütter ließen sich das sogenannte colostrum oder saltzige Wasser, so vor der Milch in

735 Unter Perinatalsterblichkeit versteht man alle bis zum vollendeten ersten Lebensjahr Verstorbenen (einschließlich Totgeburten).

736 Das erste Hebammenbuch erschien in Preußen 1689 von Justine Siegesmund: Ein höchst nötiger Unterricht von schweren und unrecht stehenden Geburten, zit. nach Barbara Beuys: Der große Kurfürst, Hamburg (1979), S. 263-264. Die Existenz einer Wehmutter ist 1811 für die nahe dem Golmer Bruch gelegenen Dörfer mit einer Kirchenbucheintragung belegt: Am 15. März ... starb zu Eichow ... Anna Dorothea Zaechin, geborne Hodler hinterlaßne Wittwe ... und zugleich Wehmutter für 5 Dörfer Bornim, Bornstädt pp. 
den Brüsten ist, aus Irrthum aussaugen. ${ }^{737}$ Der gleiche beschreibt weiter die üble Gewohnheit, dass alle Speisen der Kinder gekauet und erst in den Mund genommen und mit dem Speichel vermischet werden, zumahl wenn es von alten Frauen geschieht, die oft einem todten Gerippe nicht unähnlich, die ungesund und übel riechende Zähne und Othem haben. ${ }^{738}$ Nach überstandenem erstem Lebensjahr nimmt die Sterblichkeit der Kinder sichtlich ab, wobei das Zahlenverhältnis sich umdreht. Von insgesamt 110 Verstorbenen entfallen 38 auf die Knaben (34,5\%) und 72 die Mädchen (65,4\%). Das deutet auf eine Veränderung der Todesursachen hin.

Bei den übrigen Altersgruppen gibt es bei der Häufigkeit der Sterbefälle zwischen den Männern und Frauen in zwei Lebensabschnitten Unterschiede. Während des geburtsfähigen Alters der Frauen (etwa 25-40 Jahre) ist eine Verdoppelung der Sterberate im Vergleich zu Männern zu beobachten. Insbesondere die Geburt eines Kindes stellte im 17./18. Jh. ein erhöhtes Risiko für die Frauen dar. In neun Fällen ist dies explizit als Todesursache (Wochenbett/Kindbeth) angezeigt. Kritisch bei den Männern war offensichtliche das Alter von 60-70 Jahren, denn hier zeigt sich eine deutlich höhere Sterblichkeit als bei den Frauen. Dass die Frauen gerade auf dem Lande weniger und nicht so schwer gearbeitet haben, dürfte wohl nicht stimmen; der Hinweis auf das übermäßige Trinken der Männer könnte schon eher zutreffen.

Die errechnete durchschnittliche Lebenserwartung ohne Berücksichtigung der Einwanderergeneration und einem Teil ihrer Kinder ${ }^{739}$ beträgt bei Männern 27,1 und bei Frauen 22,6 Jahre. ${ }^{740}$ Dies sind im Vergleich zu heutigen Verhältnissen sehr niedrige Zahlen, was aber nicht besagt, dass alle Menschen sehr jung gestorben sind. Wie das Säulendiagramm zeigt, konnten die Menschen, die erst einmal das Erwachsenenalter erreicht hatten, durchaus die Aussicht auf ein recht langes Leben haben.

\section{Zur Entwicklung der Schweizer Kolonistengemeinde}

Für das 17./18. Jahrhundert erweist es sich als schwierig, Aussagen über die Entwicklung der Bevölkerungsverhältnisse zu machen. Bestenfalls stehen Informationen über die Zahl der Häuser, der Hofstellen [Haushaltungen], aber nicht der Menschen zur Verfügung. Aus der Anzahl der Häuser lässt sich unter Annahme einer Durchschnittszahl von Personen, die einem Haushalt angehörten, eine Hochrechnung in Bezug auf die Einwohner vornehmen. In der Literatur besteht aber Uneinigkeit über die Durchschnittsgröße einer Haushaltung.

737 Süßmilch, Johann Peter. Die göttliche Ordnung in den Veränderungen des menschlichen Geschlechts aus der Geburt, Tod, und Fortpflanzung desselben erwiesen, Berlin (1977) [Fotoreprint der Aufl. Berlin 1741], S. 284-286.

738 daselbst: S. 282 .

739 s. Abb. 16.

740 In der Literatur stehen dazu Vergleichszahlen zur Verfügung [Meier, Brigitte: Neuruppin - 1700-1830, Berlin (1993), S. 124.]. So beträgt die durchschnittliche Lebenserwartung der Neuruppiner 21,6 Jahre. In Oppenheim lag sie bei 28,1 Jahren [Thomas Kohl: Familie und soziale Schichtung. Zur historischen Demographie Triers 1730-1860, Stuttgart (1985), S. 148.]. 
Für die Schweizer Kolonistengemeinde Golmer Bruch kommt diese Methode aber auch aus anderen Gründen nicht in Betracht. Im Arrendevertrag von 1685 war zwar jeder Familie ein eigenes Haus zugesichert worden, aber dazu ist es nicht gekommen. Denn auf Grund der Jahrhundertflut 1689 ist die Urbarmachung des Golmer Bruchs, wie ursprünglich vorgesehen, aufgegeben worden. Die stattdessen erfolgte Unterbringung einiger Familien auf den Vorwerken Golm und Neu Töplitz ist nicht mit der Besetzung einer Hofstelle im üblichen Sinne vergleichbar.

Aus diesen Gründen ist der Versuch gemacht worden, die Entwicklung der kleinen ländlichen Gemeinde an Hand der in den beiden Kirchenbüchern registrierten Taufen, Konfirmationen, Hochzeiten und Beerdigungen von 1685-1835 darzustellen. Der Untersuchungszeitraum wurde dafür in Cluster von fünf Jahren unterteilt (s. Abb. 17).

Am auffälligsten an der Graphik der Geburten ist ein absolutes Maximum in der Zeit von 1704-1712. Sie verdoppeln sich in dieser Zeit im Verhältnis zum jährlichen Gesamtdurchschnitt von 36 Geburten pro Jahr, sinken danach abrupt auf ein „Normalmaß“ ab und erreichen ein zweites Maximum in der Zeit nach den Befreiungskriegen. Die Sterberate (erst ab 1710 registriert) steigt in den Anfangsjahren mit der Zunahme des durchschnittlichen Lebensalters der Gemeinde an und schwankt dann innerhalb eines Korridors von 20 bis 30 Sterbefällen pro Jahr. Auffällig ist ein Maximum von 1815-1820 - möglicherweise infolge der Verschlechterung der Versorgungslage durch die ständigen Einquartierungen in den Jahren davor. Nach Ende der Befreiungskriege findet sich ebenfalls bei den Hochzeiten ein Maximum. Ob es sich bei den Bräutigamen vorwiegend um heimkehrende Soldaten handelte, bleibt ungeklärt, weil das Kirchenbuch (Vol. II) nur den Zivilstand angibt. Bis dahin zeigen die Hochzeiten über den ganzen Untersuchungszeitraum große Schwankungen, was der kleinen Grundgesamtheit zugeschrieben und nicht bestimmten Ereignissen (Krieg, Anstieg der Getreidepreise) zugeordnet werden kann. Insofern lässt sich lediglich in der Anfangszeit des Bestehens der Gemeinde ein Wachstum nachweisen, was als ein Sich-Etablieren in der neuen Heimat gewertet werden kann. Hinzu kommt allerdings die zeitweilige Funktion der Gemeinde als geistiges Zentrum der ländlichen Reformierten, die ab dem vollendeten „Kirchenbauprogramm“ im Neuruppiner Raum nicht mehr bestand. Die Reproduktion - ausgedrückt durch das Verhältnis von Geborenen zu Gestorbenen ist dadurch am Anfang überproportional $(4,3)$, sinkt darauf auf den absoluten Tiefstand (ca. 1,0) und steigt von da an kontinuierlich an (mindestens 1,5) und in der Zeit von 1715 bis 1835 zeitweise noch etwas darüber.

Die Gemeinde hat im Laufe der Zeit Verstärkung aus der alten Heimat erhalten. Ausgediente, vormals in der Schweiz angeworbene Soldaten, haben die Potsdamer Kolonie mehrfach verstärkt. Sie genossen ihren Lebensabend bei ihren Landsleuten zumeist in Neu-Töplitz und wurden auf dem Kirchhof in Nattwerder begraben. Weitere Beispiele für den langandauernden Nachschub aus der Schweiz waren zu Zeiten Friedrichs II. Leineweber (Buchmann, Häselyy, Fischer, Lütweiler, Leidweiber u. a.) und der Bandmacher Gansli. Sie alle suchten die Nähe zur Reformierten Gemeinde Golmer Bruch. Und darüber hinaus hat es einzelne direkte Zuzüge aus der Schweiz gegeben. Aktenkundig nachgewiesen sind die spektakulären Fälle der 
Witwe des Schuhmachers Friedrich Zweiffel, Ursula Britt, die 1737 mit sechs Kindern aus dem Glarnerland nach Neu Töplitz ${ }^{741}$ sowie Barbara Tobler, die 1745 mit ihrer Schwester aus der Schweiz zu ihren märkischen Verwandten, kam.

Demographisch scheint aber die Annahme zutreffend zu sein, die Golmer Bruch Gemeinde als eine Gemeinde ohne Wachstum („stationäre Bevölkerung“) ${ }^{742}$ einzustufen. Denn dadurch, dass die Hofstellenzahl im Untersuchungszeitraum in Golm, Neu-Töplitz und Nattwerder unverändert blieb, war nur nach Freiwerden einer Hofstelle die Anwartschaft auf eine solche - in der Regel durch den ältesten Sohn - gegeben und zeitnah mit einer Eheschließung verbunden. In Nattwerder ist dies bis heute nachzuvollziehen, da der Ort nach wie vor im Wesentlichen nur aus den vier Schweizer Höfen besteht und er früher sogar aus diesem Grunde „Vierhäuser“ genannt wurde.

741 KA Alt Töplitz: Kirchen-Buch der Schweitzer-Gemeinde im Bruch bei Potstamb, Vol. I (1685-1801, nicht paginiert), im Vorspann vermerkt.

742 Gehrmann, Rolf: Heiratsverhalten als historisches Problem, Historical Social Research Vol.28 (2003) S. $8-28$, bes. S. 25 . 


\section{Als Fremde im fremden Land}

Zwischen Einwanderern/Kolonisten und Einheimischen bestehen zunächst Unterschiede in Sprache, Kultur, Essgewohnheiten, Wertvorstellungen usw. Diese Ausgangssituation ist unvermeidlich und verändert sich im Laufe der Zeit, wobei es an beiden Seiten liegt, wohin sich das Verhältnis entwickelt (offene Konfrontation und bewusste Abgrenzung, über friedliche Koexistenz bis hin zur Duldung und Toleranz, Assimilation, Integration oder Akkulturation der Kolonisten in der neuen Heimat). Die Erfahrungen haben gezeigt, dass die Ankommenden trotz Bemühungen, aufeinander zuzugehen, auf lange Zeit (wenn nicht über mehrere Generationen) „Fremde im fremden Land“ bzw. aus Sicht der Einheimischen im besten Fall „vertraute Fremde“ bleiben.

In der Vergangenheit sind gern Vergleiche zwischen den verschiedensten Einwanderungen nach Brandenburg angestellt worden. Aber da ist Vorsicht geboten, denn die Bedingungen, unter denen sie stattfanden, waren jedes Mal andere: Waren es Einwanderer aus dem „deutschsprachigen Raum“, kamen sie als Flüchtlinge, waren es Tagelöhner, Bauern, Handwerker, Geistliche oder Offiziere, was brachten sie mit, wie groß war ihr Anteil an der regionalen Gesamtbevölkerung in der neuen Heimat (Diaspora) usw.? Entsprechend unterschiedlich laufen diese Prozesse ab. Nur in Schlesien hat es nach 1830 eine Politik der angeordneten Assimilierung gegeben. ${ }^{743}$

\section{Sprachliche Assimilation}

Die Einbeziehung von Sprachwissenschaftlern in die historische Forschung scheint eine Ausnahme zu sein. Selbst bei großen interdisziplinären Projekten wie der Germania Slavica wird eingangs bedauert, dass auf die wünschenswerte Mitarbeit von Sprachwissenschaftlern nicht zurückgegriffen werden konnte. ${ }^{744}$ Dabei sind Landschafts-, Orts- und Flurnamen eine Fundgrube für diese Disziplin. Ein slawisches Reliktwort ist beispielsweise die im Havelland verbreitete Bezeichnung Luch (abgeleitet von lug) für eine feuchte Niederung, für sumpfiges Wiesenland. Für die Einwanderungen in der frühen Neuzeit liegen zusätzlich Schriftzeugnisse vor, die einer Textanalyse aus sprachwissenschaftlicher Sicht unterzogen werden könnten. In der Literatur wurde hierzu nur ein einziges Beispiel, und noch dazu in einer dafür nicht prädestinierten Fachzeitschrift gefunden, das die Ansiedlung von Schweizern 1738 in Preußen betraf. Dabei handelt es sich außerdem noch um eine Zitierung von Tobler (1896) ${ }^{745}$ Durch Textvergleiche meinte Tobler feststellen zu können, dass die Verdeutschung oder Borussifizierung der Namen schon erhebliche Fortschritte gemacht hatte: „Aus Heer ist Herr geworden, aus Mathis Mathe, Niggli zu Nickel, Häberli zu Heberlein, Bösch zu Busch.“

743 Clark, Christopher, Preußen - Aufstieg und Niedergang 1600-1947, München ('62007), S. 473.

744 Ribbe, Wolfgang (Hg.): Das Havelland im Mittelalter - Untersuchungen zur Strukturgeschichte einer ostelbischen Landschaft in slawischer und deutscher Zeit, Berlin (1987), Vorwort.

745 Tobler, Gustav: Schweizer Kolonisten in Ostpreußen, Anzeiger für Schweizer Geschichte (1896); No. 6, S. 409; zit nach: Hauser, Albert: Schweizer Bauern als Kolonisten in Preußen und Litauen, in: Zeitschrift für Agrargeschichte und Agrarsoziologie, 13 (1965), S. 212-219, bes. S. 218. 
Die neueren Arbeiten von Heese (1985) und Asche (2006) über die Besiedlung des Golmer Bruchs führen zu dieser Frage lediglich an, dass die hier angesiedelten Schweizer Kolonisten einen reformierten Prediger aus ihrer Berner Heimat zugestanden bekamen (s. Kap. IV.6.), da die Kolonistengemeinde nach Meinung des Kurfürsten nicht in der Lage gewesen sei, den einheimischen märkischen Dialekt zu verstehen. ${ }^{746}$ Im Widerspruch dazu geht Letzterer aber von einer „Kultsprache Hochdeutsch“ bei kirchlichen Amtshandlungen aus, und folgert daraus, „dass sich in den Schweizerdörfern wohl eine rasche sprachliche Assimilation vollzogen hat. Nachweisen lässt sich dieses allerdings anhand der Akten nicht. ${ }^{\text {“777 }}$ Dem muss insoweit widersprochen werden, als sich die Eindeutschung insbesondere der Familiennamen in den Kirchenbüchern genau nachvollziehen lässt, wobei allerdings zu beachten ist, dass „geschrieben wurde, wie gesprochen wurde“. Und darüber hinaus ist weiteres Schriftgut aus dieser Zeit überkommen, das die Möglichkeit zu vertiefenden sprachwissenschaftlichen Studien bietet. Aber auch aus Schweizer Sicht wurden die Unterschiede in der Sprache gesehen und ihnen entsprechende Aufmerksamkeit geschenkt. Bauernkönig berichtete am 29. September 1685 Schultheiß und Rat der Stadt Bern über den guten Stand des Ansiedlungsvertrages. Aber wan daß eint und andere nit nach unserem Stylo eingerichtet, habe er Bedenken angemeldet und darauf geachtet, dass nicht an etlichen orten solche Terminj gesetzt waren, die theils auf Zweierlei art und weise haben können ausgeleget und verstanden werden, theils dan solche wort gebraucht worden, Die Bei uns nit üblich. ${ }^{748}$ Einigkeit besteht darüber, dass der deutschsprachige schweizerische Dialekt der hochdeutschen Sprache keine Impulse gegeben hat, die sich - wie der französische Spracheinfluss - durch Worte wie z. B. Muckefuck (Mocca faux), die Boulette (Fleischkügelchen) und Schislaweng (ainsi cela vint) bis heute erhalten haben. Der Begriff „Meier“ (Melker), im 19./20. Jahrhundert synonym mit „Schweizer“ gebraucht, geht auf in Dienst gestellte Schweizer Melkerknechte zurück.

Noch niemals ist die sprachliche Situation der Schweizer Einwanderer betrachtet worden. Welchen Dialekt sprachen sie? Bekanntermaßen kamen sie aus unterschiedlichen Gegenden (s. Abb. 3). Die Auswanderer aus dem Aargau und diejenigen aus der Umgebung von Bern dürften Hochalemannisch gesprochen haben. Diejenigen Einwanderer, die aus der Umgebung von Thun eingewandert waren, gehörten dagegen der höchstalemannischen Sprachgruppe an. ${ }^{74}$ Bei Letzterer unterscheidet man noch zwischen dem Schweer- und dem Schwäär-Sprachgebiet. Da die insgesamt 117 Personen im Golmer Bruch unter sich auf engem Raum zusammenwohnten, werden sie sich zur Verständigung untereinander und mit ihrem Prediger, Elisaeus Malacrida, zunächst ihrer Heimatdialekte bedient und gegenüber der einheimischen Bevölkerung weitgehend ein Eigendasein geführt haben. Im Gegensatz zu den einheimischen Bauern konnten aber alle Schweizer Kolonisten lesen und schreiben ${ }^{750}$; wenn ihre eigenhändigen Unterschriften der Kolonisten unter den Kontrakten auch mit ungeübter Hand erfolgten, so wirft

747 Asche, Matthias: Neusiedler im verheerten Land, Münster (2006), Anm. 822, S. 626.

748 StA Bern: A. V. 19 Teutschland-Buch Preussen Brandenburg, fol. 139-142, bes. fol. 139.

749 Chronik der Familie Emanuel Dortschy, Frankfurt a. M. (2007), S. 14 (im Besitz des Autors).

750 Sämtliche Verträge mit den Schweizer Kolonisten wurden von ihnen eigenhändig unterzeichnet! 
dies doch ein gutes Licht auf die damaligen Schulverhältnisse in der Schweiz. Umso größer war die Enttäuschung, dass ihre schriftlichen Hinterlassenschaften in den Archiven äußerst spärlich sind, um fundiert und vertieft die sprachlichen Diskrepanzen darzustellen.

Aus der frühen Ansiedlungszeit fand sich lediglich ein einziges Dokument, die Ansuchung um Verlängerung ihres Ansiedlungsvertrages bei Kurfürst Friedrich III. aus dem Jahre 1695 (s. Anhang 11). ${ }^{751}$ Unterschrieben ist es mit Die Schweizerische Gemeine im Schweizerbruch. $\mathrm{Da}$ es die alltäglichen Sorgen eingangs beschreibt, vermittelt es eine gewisse Vorstellung von ihrer Umgangssprache. Dortschy ${ }^{752}$ meint darüber hinaus, dass es von unterschiedlichen Personen verfasst worden sei. Der erste Teil könne von einem Einwanderer sein, welcher der „Schweer-Sprachgruppe“ angehörte, der letzte Teil dagegen einem Zuwanderer aus der „Schwäär-Sprachgruppe“ zugeordnet werden. So heißt es im ersten Teil: daß waßer [...] in Unsern Wysen [...] durch die Sonnen Hitze erwehrmet wird und Unßer Vieh [...] crepirt sind; im zweiten Teil heißt es dagegen dann den Zähnden theil oder sehr schlächt und den Allerhöchsten Gott zu bätten. ${ }^{753}$ Das erscheint dem Autor sehr gewagt. Wegen des Mangels weiterer Dokumente der Schweizer Kolonisten im Golmer Bruch aus dieser Zeit erschien es opportun, auf eine anonyme Bittschrift aus dem Jahre 1694 aus Vielitz hinzuweisen, die Schneider (1906) und Dreifuss (1985) - leider ohne Angabe der Quelle - zitieren (s. Anhang 9). Ersterer bemerkte dazu, dass die Sprache dieses Schriftstückes die neuhochdeutsche Schriftsprache sei, ohne dies näher zu erklären. Aber sie enthalte zumindest einige Anklänge an die Schweizer Mundart. „Das Nit und die Endungen auf i wiesen deutlich darauf hin.“

Hilft das Kirchenbuch Golmer Bruch (Vol. I, 1685-1801) in Bezug auf die Sprachassimilierung weiter? Nur bedingt, da es größtenteils - seinem Zweck entsprechend - Standardformulierungen enthält (s. Kap. VII.2.-6.). Aber diese enthalten einen Familienbezug, und so lässt sich eine Sprachassimilierung anhand der Familiennamen belegen. Hierfür sollen nachfolgend vier Beispiele angeführt werden:

1) Muhrhofer $\rightarrow$ Murhoffer/Murhofer (seit 1695) $\rightarrow$ Maurhoffer/Maurhofer (seit 1725) $\rightarrow$ Mauerhoffer (seit 1747) $\rightarrow$ Mauerhof $(1920)^{754}$

2) Durtschi/Turtschi $\rightarrow$ Durtschy/Turtschy (seit 1724) $\rightarrow$ Dortschy (seit 1748) ${ }^{755}$

3) Gering $\rightarrow$ Gericken (seit 1700) $\rightarrow$ Gerig (seit 1712)

4) Schwin(e)gruber Schweingruber (wechselt immer wieder)

751 BLHA: Rep. 2 Kurmärkische Kriegs- und Domänenkammer Nr. D 15409, fol. 8-9.

752 s. Anm. 749.

753 H. Wagener: Die Schweizer-Colonie bei Alt Töplitz, Mitt. d. Vereins f.d. Geschichte Potsdams, Neue Folge 1ster Theil Vortrag Nr. 227, Potsdam 1875, S. 211-227, bes. S. 221-222. Im Übrigen fällt in diesem Zitat eine eigentümliche Lautverschiebung auf. Anstelle des im Deutschen in vielen Wörtern enthaltenen hellen Vokals „e“ wird im Schweizerdeutsch der wesentlich dunklere Vokal „ä“ bzw. „ae“ verwendet; im Zitat ist es bei „schlächt (schlecht), bätten (beten), Zähnden (Zehnten) und zuiflächen (zu erflehen)“ der Fall. Dieser Unterschied besteht bis heute.

754 Die Änderung des Familiennamens ist auf Antrag von Friedrich Mauerhof beim Amtsgericht Potsdam geschehen; Beschluss vom 1. Juli 1920 (im Besitz des Autors).

755 Diese Familie ist z. T. nach Ostpreußen ausgewandert und von dort ins Burgenland übersiedelt (österreichisch-ungarische Linie) und schreibt sich bis heute Dorcsi. 
Auffällig waren dabei die Lautverschiebungen vor allem von „u“ $\mathrm{zu}$ „au“, aber auch von „i“ zu „ei“, Vorgänge, die wie das bekannte Beispiel „hus“ zu „Haus“ zeigt, in Mitteldeutschland vom Mittelhochdeutschen ins Hochdeutsche bereits im 16. Jahrhundert häufig stattgefunden haben. Darüber hinaus änderte sich die Schreibweise der Namen: Kiner ${ }^{756}$ wurde zu Kiener, Schnyder zu Schneider und Zäch zu Zech. Die anderen, heute noch vorkommenden Familiennamen der Schweizer Kolonisten (Garmatter, Hodler, Suter) sind nicht ins Hochdeutsche umgeformt worden. ${ }^{757}$

Was die Vornamen anbelangt, hat es auch hier eine auffällige Veränderung gegeben, nämlich den Übergang zu landesüblichen Namen. Dabei ist zu beachten, dass im statistischen Sinne die Vornamen der Einwanderer als zufällig anzusehen sind, aber die in Brandenburg Geborenen aus einer Grundgesamtheit von 590 Geburten erhoben worden sind. Bei der Gegenüberstellung ergab sich folgendes Bild (s. Tab. 16):

Tab. 16: Vornamenspektrum bei den eingewanderten und in Brandenburg bis 1835 geborenen Schweizer Kolonisten

\begin{tabular}{|c|c|c|c|}
\hline \multicolumn{2}{|c|}{ Jungen } & \multicolumn{2}{|c|}{ Mädchen } \\
\hline Einwanderer & in Bdbg. geboren & Einwanderer & in Bdbg. geboren \\
\hline Hans/Hanß (17x) & Christian (55x) & Barbel/Berbel (11x) & Maria (31x) \\
\hline Nic(o)laus (10x) & Emanuel (26x) & Maria/Marie (9x) & Anna Elisab. (30x) \\
\hline Christen (6x) & Johann Heinrich (22x) & Anna (7x) & Anna (26x) \\
\hline (E)manuel (4x) & Johannes $(20 \mathrm{x})$ & Elisabeth $(7 \mathrm{x})$ & Maria Elisab. (26x) \\
\hline Samuel (4x) & Peter/Petrus (19x) & Catharina $(4 \mathrm{x})$ & Anna Maria (22x) \\
\hline Peter (4x) & Heinrich $(18 \mathrm{x})$ & Magdalene (3x) & Barbara (18x) \\
\hline Issac $(3 \mathrm{x})$ & David (18x) & Verena $(3 \mathrm{x})$ & Elisabeth (18x) \\
\hline $\operatorname{Jacob}(3 \mathrm{x})$ & Friedrich $(17 \mathrm{x})$ & Eva $(2 \mathrm{x})$ & Anna Doroth. (14x) \\
\hline Ully/Ulli (3x) & Johann Friedrich $(13 \mathrm{x})$ & & Maria Charl. (8x) \\
\hline \multicolumn{4}{|l|}{ Caspar (2x) } \\
\hline \multicolumn{4}{|l|}{ Crispinus $(2 \mathrm{x})$} \\
\hline Beat $(2 x)$ & & & \\
\hline
\end{tabular}

Mit wenigen Ausnahmen (Friedrich, Hans) leiteten sich die Vornamen von biblischen Personen oder Heiligengestalten ab. Bei den Mädchen war dies sogar bei beiden Gruppen ausschließlich der Fall. Maria und Anna, die schon im Mittelalter eine hohe Verehrung genossen, standen dabei weit an der Spitze. Lediglich bei den Jungen gab es Veränderungen im Namensspektrum. Der Name Friedrich kommt bei den Einwanderern nicht vor und ist bei den in Brandenburg Geborenen Kindern als Ausdruck der dem Herrscherhaus gegenüber geübten Loya-

756 vielleicht schon langes „“' bei Kiner gesprochen.

757 Das schließt nicht eine unterschiedliche Schreibweise aus, z. B. Schwinegruber. 
lität zu werten. ${ }^{758}$ Dagegen tauchen einige typische Schweizer Vornamen (Caspar, Crispinus, Beat) bei den in Brandenburg Geborenen nicht auf - sie gingen in der neuen Heimat verloren.

Und schließlich soll auf von Prediger Malacrida verfassten Vorspann im hier behandelten Kirchenbuch (Vol I, Seite I und II), hingewiesen werden. Er beginnt mit Nach demme der Kurfürst ... ${ }^{759}$, zählt die 17 Familien auf, die von ihrem Vatterland aufgebrochen sind und aus dem Familienhaupt, seiner Haußfrauw und den einzeln aufgezählten Kindern bestehen. Die kursiv geschriebenen Wörter sind einfache Beispiele für Formulierungen, den Wortschatz und die Schreibweise im damaligen Schweizer Dialekt. ${ }^{760}$ Aber auch bei den Einzeleinträgen fand sich eine erwähnenswerte Besonderheit - das Wort Hornung (Februar) in den Taufeinträgen vom 6. und 20. Februar 1687. Dieser alte schweizerische Monatsbegriff ist im heutigen Sprachgebrauch nahezu unbekannt. ${ }^{761}$

In Bezug auf sprachliche Assimilation bietet sich ein Vergleich mit den französisch-reformierten Hugenotten in Potsdam auf Grund der Nähe ihrer Ansiedlung an. ${ }^{762}$ Dabei handelt es sich zwar um eine anderssprachige und städtische Migrationsgruppe, die aber fast gleichzeitig eingewandert und über die vieles genauer dokumentiert und bekannt ist. Von Anfang an ist für sie der Sprachwechsel von Bedeutung, weil sie einerseits in Gottesdiensten und Versammlungen den französischen Sprachgebrauch kultivierte, andererseits über die Gemeindeschule möglichst alle Kinder der Kolonie erreichen wollte, um sie sowohl im Französischen als auch im Deutschen zu unterrichten. Auch von landesherrlicher Seite legte man bei den Pfarrstellenbesetzungen wie bei den Bestallungen der Schulmeister großen Wert auf die Zweisprachigkeit der Bewerber. Die Einführung deutschsprachiger Gottesdienste wurde in der französisch-reformierten Gemeinde in Potsdam erstmals 1794 thematisiert, aber noch nicht vollzogen. Erst 1801 kam es dazu auf Initiative der Chefs de famille, die nun das Konsistorium aufforderten, deutsche Gottesdienste einzuführen. Der Verlust des Französischen hat sich spätestens bei der heranwachsenden vierten Generation zu einem Phänomen entwickelt, das so in Potsdam und wahrscheinlich auch in anderen Gemeinden vonstatten gegangen ist. Interessant ist ebenfalls der sprachliche Wandel bei den Réfugiés-Dörfern in der Herrschaft Ruppin. In den separierten Kirchengemeinden (Kagar-Rheinsberg-Braunsberg) nahm der Anteil der französisch-deutschen Eheschließungen seit den 1720er Jahren bereits überproportional zu, ${ }^{763}$ während dies in den dicht mit Réfugiés

758 Der erste Täufling wurde nach dem Landesherrn Friedrich Wilhelm genannt. Dieser ordnete an, dass in dieser Familie stets der 1. Sohn seinen Namen Friedrich Wilhelm erhalten solle, was bis auf den heutigen Tag in der Familie Kiener geschehen ist.

759 Der Ausdruck in demme findet sich nur im damaligen Schweizerdeutsch.

760 Kurfürst Friedrich Wilhelm verwendet es zwar auch in seinem Antwortschreiben vom 1. Dezember 1686 an den Rat der Stadt Bern. Aber dies stellt hier die in einem Antwortschreiben übliche Vorgehensweise dar, die ergangene Bitte/Anlaß am Anfang wörtlich wiederzugeben [GStA PK, I. HA, Rep. 50 Nr. 6 fol. 1/1R.].

761 Nach Auskunft des Leiters des Museums Krauchthal, Herrn Ulrich Zwahlen, ist das Wort Hornung nur noch alten Schweizern bekannt.

762 Kamp, Silke: Die verspätete Kolonie. Hugenotten in Potsdam, in: Quellen und Forschungen zur Brandenburgischen und Preußischen Geschichte, hg. im Auftrage der Preußischen Historischen Kommission, Berlin (2011), Bd. 42, S. 306-308.

763 Es gab zu wenige potentielle Heiratskandidaten. 
besiedelten Gemeinden bis zur Mitte des 18. Jahrhunderts nur unwesentlich geschah. Entsprechend wurde durch die Mischehen die sprachliche Assimilation befördert. ${ }^{764}$

\section{Zum Verhältnis von einheimischen Märkern und den Schweizer Kolonisten im Golmer Bruch}

Bei einem Nebeneinander einer kleinen privilegierten und anderskonfessionellen Minderheit (Kolonisten), die zusätzlich in einer besonderen Beziehung zum kurfürstlichen Landesherrn stand, und einer nichtprivilegierten Mehrheit (alteingesessene Bevölkerung) konnten Spannungen verschiedenster Art nicht ausbleiben. Konkrete Konfliktpunkte auf dem Lande waren die mehrfach in der Literatur beschriebenen Abgaben-, Grundstücks- und Grenzstreitigkeiten oder die gemeinsame Nutzung von Kirchen und Friedhöfen. Für diese „Wahrnehmung als Fremde" dürfte nicht zuletzt ganz entscheidend gewesen sein, dass die Schweizer mit ihren Traditionen in die neue Heimat kamen und sie lange Zeit beibehielten. Bereits durch ihre andersartige Kleidung und Sprache fielen sie in der Öffentlichkeit auf, womit sie stolz als „freie Menschen" im absolutistischen Kurbrandenburg gemäß Artikel 12 ihres Arrendevertrages auftraten (s. Kap. IV.6. und V.1., s. Anhang 4). Auch das Tragen eines Degens war ihnen gestattet. Diese „Fremdwahrnehmung“ hat lange Zeit angehalten und kam nicht erst beim Vorliegen krisenhafter Zustände zu Tage. Es war ein schwelender Prozess, wie zu Recht Lieselott Enders (2001) an Hand des amtlichen Sprachgebrauches nachwies. Hier wurde „noch lange zwischen Bauern als Altsiedlern und Kolonisten unterschieden, auch als sich ihr Rechts- und Sozialstatus längst schon angenähert hatte oder sogar kongruent geworden war. Aber abgesehen davon bestimmte sich das Verhältnis zwischen alten und neuen, d.h. in der Regel ausländischen Siedlern, nach dem Maß der Interessengleichheit bzw. Interessendivergenz. Überwog letztere in den Fällen, wo durch die neue Kolonie ein altes Dorf geschädigt wurde, begehrten die Alt-Bauern auf. [... Solidarität zwischen Alt- und Neusiedlern aber erwuchs wie selbständig aus der gemeinsamen Abwehr gemeinsam erfahrenem Herrschaftszwangs oder zur Durchsetzung gemeinsamer Ziele." ${ }^{\text {"765 }}$

Für die Enders'sche These kann eine bislang unbekannte Verleumdung der Schweizer Kolonisten aus dem Jahre 1728 als konkreter Beleg angeführt werden (s. Anhang 18). ${ }^{766}$ Darin bezichtigt ein Anonymus die sechs Neu Töplitzer Schweizer, dass sie mit 60 Rthl. jährlich viel zu wenig Pacht zahlen müssten, die sie von den Schafen, Vieh, Weinberg garten und Tobacks plantagen ${ }^{767}$ leicht erwirtschaften könnten. Die schönen Acker haben sie umsonst. [...] Daher werden sie aufgeblasen und reyset fast jährlich einer oder zwey nach der schweitz, [...] um dort

764 Asche, Matthias: Neusiedler im verheerten Land, Münster (2006), S. 569.

765 Enders, Lieselott: Neu-Brandenburger in der Zeit der friderizianischen Kolonisation, in: Klaus Neitmann und Jürgen Theil (Hr.), Die Herkunft der Brandenburger. Sozial- und mentalitätsgeschichtliche Beiträge zur Bevölkerung Brandenburgs vom hohen Mittelalter bis zum 20. Jahrhundert, Potsdam (2001), S. 111.

766 BLHA, Rep. 2 Kurmärkische Kriegs- und Domänenkammer Nr. D 11279, fol. 106.

767 Dies ist bislang der einzige Beleg, dass die Schweizer Kolonisten neben ihrer Viehzucht einen Anbau von Spezialkulturen (Tabak) betrieben. Für Reisen in die Schweiz von Schweizer Kolonisten aus dem Golmer Bruch gibt es keine Belege, hingegen von Schweizer Kolonisten aus dem Raum Ruppin (BLHA, Rep. 7 Amt Lindow Nr. 73, fol. 88 . 
[...]. wie jedermann glaubt geldt ab $[\mathrm{zu}]$ legen. Es versteht sich von selbst, dass König Friedrich Wilhelm I., dessen höchste Staatsdoktrin in der Sparsamkeit lag, darauf sofort reagierte und einer hierfür bestellten Kommission befahl, die Sache vor Ort näher zu untersuchen, ob die Schweizer in viel höherer Pacht gesetzet werden könnten. ${ }^{768}$ Über die Arbeit der Kommission fand sich leider kein Ergebnisprotokoll.

In einem Punkt besteht in der Literatur Einigkeit. Die Schweizer Kolonisten waren extrem darauf bedacht zusammenzuhalten. Das ist ein typisches Verhalten von Minderheiten. Dazu kam die Bindung im Glauben, denn sie standen als Reformierte auf dem Lande so ziemlich allein. Diese Zusammengehörigkeit kam in zwei Verhaltensweisen besonders deutlich zum Ausdruck - nämlich im Heiratsverhalten und im Abweichen vom landesüblichen Erbrecht. Ersteres Verhalten wird in der Literatur als das wohl aussagekräftigste Indiz für das Verhältnis zwischen eingewanderten Kolonisten und alteingesessener Bevölkerung angesehen. In dieser Beziehung bewirkte der reformierte Glauben der Kolonisten neben der Sprachbarriere gegenüber den umwohnenden Lutheranern eine zusätzliche Abschottung. Deshalb ist die Heirat von Caspar Zoberist und der Kossätentochter Catharina Hainicke aus Golm am 7. Oktober 1689 als ein Sonderfall anzusehen. Ausdrücklich ist im Kirchenbuch hierzu vermerkt ... eine frömde [...], sie war Luterischer religion, und (erleichtert) hinzugefügt, sind aus dem land gezogen. ${ }^{769} \mathrm{Im}$ Untersuchungszeitraum finden sich ansonsten nur noch sechs weitere Mischehen (zwei Bräutigame und vier Bräute lutherisch), allerdings erst in den Jahren 1748, 1752, 1768, 1769, 1770 und 1776. Diese Aussage wird mit dem Vorbehalt getroffen, dass jede dieser Heiraten im Kirchenbuch mit L. R. oder Luther. $R$. gekennzeichnet wurde. Damit stellen diese Mischehen bei insgesamt 241 Hochzeiten über den Untersuchungszeitraum im Gegensatz zu den Schweizer Gemeinden im Ruppinschen Raum ${ }^{770}$ bis in die zweite Hälfte des 18. Jahrhunderts eine eher unbedeutende Anzahl dar. Davon entfällt die Hälfte auf die Golmer Schweizer Kolonisten. Anscheinend bewirkte dort das dauernde Zusammenleben mit der alten lutherischen Bevölkerung eine schnellere Annäherung der beiden Bevölkerungsanteile. Aufs Ganze gesehen hatte aber der soziale und kulturelle Anpassungsprozess bis dahin offensichtlich noch nicht begonnen.

Zusätzlich ließ sich eine Konvertierung nachweisen:

den 28. Novemb 1698 wurden Martin

Lehemann Vnd Maria Suter in den

stand der Heil. Ehe eingesegnet.

NB. dißer Martin warn ein Lutheraner

$u$ Volgends zu vnser religio willig

getretten. Hat noch keine stelle. ${ }^{71}$

768 BLHA, Rep. 2 Kurmärkische Kriegs- und Domänenkammer Nr. D 11279, fol. 105/105R.

769 KA Alt Töplitz: Kirchen-Buch der Schweitzer Gemeinde im Bruch bei Potstamb, Vol. I. (1685-1801, nicht paginiert), Liste der Getrauten, Eintrag vom 7.10.1689.

770 Asche, Matthias: Neusiedler im verheerten Land, Münster (2006), S. $562 \mathrm{ff}$.

771 KA Alt Töplitz: Kirchen-Buch der Schweitzer Gemeinde im Bruch bei Potstamb, Vol. I. (1685-1801, nicht paginiert,) Liste der Getrauten, Eintrag vom 28.11.1698. 
Berührung mit der römisch-katholischen Konfession ${ }^{772}$ hat es offensichtlich nur in einem Fall gegeben - den des Unteroffiziers Paul Haase vom Retzowschen Bataillon, der mehrfach in den Jahren 1749 und 1750 im Kirchenbuch als Pate aufgeführt ist.

In einem Punkt sind die Schweizer Kolonisten eisern geblieben. Auf den Schweizerhöfen im Golmer Bruch hat bis 1800 kein männlicher Fremder eingeheiratet.

Aus den ältesten [nicht mehr erhaltenen] Grundbüchern des Amtes Potsdam konnte Bohse noch 1878 ermitteln, ${ }^{773}$ dass die Schweizer Kolonisten anfänglich das Schweizer Erbrecht ${ }^{774}$ auf sich anwandten, und belegte dies anhand von zwei Beispielen: 1) 1687 war Bendix Kiener mit Tode abgegangen, seine Wittib Maria Raffskern will eine neue Ehe mit Christian Hodlern ${ }^{775}$ eingehen, da aber drei Kinder vorhanden, so erklären die Brautleute vor der „priesterlichen Copulation" im Beisein des Schweizer Predigers Herrn Albrecht Wyttenbach, des Schulzen Hanß Bielangen und des Schulmeisters Niclauß Hodler, daß sie auf eine Theilung der Hinterlassenschaft verzichten und die Kinder erster und zweiter Ehe als gleichberechtigt ansehen wollen. Das Amt bestätigt diese "Gemeinmachung" der Kinder umso lieber, als die Eltern selbst davon Nutzen hätten. 2) Ein zweiter fast gleicher Fall ereignet sich, als 1688 Batt Sutor stirbt und ebenfalls drei Kinder hinterläßt (Ulrich, Barbara und Salomon). Die Wittwe Anna Thätlewerin verspricht sich mit Hans Stucki $i^{776}$ und erklären beide vor dem Amte, wohin der bereits obgenannte Prediger und zwei Zeugen aus der Gemeine, Jacob Gericke und Crispin Kahrmattern, sie begleiten, daß ebenfalls die Kinder beider Ehen nach dem Tode sich gleichmäßig in ihrem Habe zu theilen hätten, sei es hier vorhanden oder noch in der Schweiz, sei es zugebracht oder erworben. Sie wollen sie alle gleichmäßig halten in Kleidung, Essen und trinken, und auch fleißig zur Schule anhalten. Eine gewisse Bedeutung scheint von Amts wegen für diese Acte dadurch ausgedrückt zu sein, daß sie nicht blos vom Amtsschreiber, sondern auch vom Amtshauptmann unterzeichnet sind. Später ging man zum deutschen Erbrecht über.

Im Übrigen soll wenigstens erwähnt werden, dass sich die Schweizer Kolonisten an der enormen freiwilligen Opferbereitschaft - über alle Stände hinweg - in den Befreiungskriegen 1813/14 tatkräftig beteiligten. Das ist als Ausdruck einer Verwurzelung mit der neuen Heimat zu werten. Dokumentiert sind diese Kollektengelder und anderen freiwilligen Beiträge für Verpflegung und Ausrüstung der Truppen, für invalide Krieger und Hinterbliebene der Vaterlandsverteidiger usw. in den Extra-Blättern zum Amtsblatt 1813-1815. Als Beleg hierfür sollen hier nur aus den akribisch geführten Listen folgende Eintragungen angeführt werden:

772 Im Kirchenbuch mit C. R. vermerkt.

773 Bohse: Notizen aus Obligationen und Kaufbriefen, in: Mitt. d. Vereins f. d. Geschichte Potsdams, Neue Folge II. Theil, 1867, S. 41-68, bes. S. 57.

774 Rennefahrt, H.: Grundzüge der bernischen Rechtsgeschichte, 2. Teil, Bern (1931), S. 218 ff., bes. S. 220.

775 KA Alt Töplitz: Kirchen-Buch der Schweitzer Gemeinde im Bruch bei Potstamb, Vol. I. (1685-1801, nicht paginiert), Liste der Getrauten, Eintrag vom 28.11.1684; die Braut ist mit Maria Nafzer angegeben. daselbst: Liste der Getrauten, Eintrag vom 9.04.1689. 
1) 23. Nov. 1813: Kirche zu Golmerbruch 1 Rthl.; Neu-Töplitz 6 Rthl. 12 gr für Verwundete, gesammelt von Superintendent Cremer Potsdam

2) Dez. 1813: 18 Pfd. Leinen Erbpächter Dortschy für das Potsdamer Lazarett

3) 2. März 1814: 14 Pfd. Kompressen Gemeinde Neu-Töplitz

4) 12. Aug. 1815: Golmerbruch 3 Rthl. 8 Gr. gesammelt durch den Superintendent Cremer Potsdam.

\section{Konfessionelle Spannungen}

Schramm (1939) hat als erster im Storbecker Dorfsippenbuch betont, dass bei den Schweizer Kolonisten ein stetes Bemühen um Zusammengehörigkeit als solches bestand. Dieses zu fördern war immer ihr Ziel. Dazu kam die Bindung im Glauben, denn sie standen als Reformierte ziemlich allein. ${ }^{777}$ In den gemischt besiedelten Landgemeinden Gallin, Golm, Grube und Alt Töplitz war nur wenig über konfessionelle Spannungen bzw. Auseinandersetzungen in Erfahrung zu bringen. Diese Phänomene sind insbesondere typisch für den städtischen Bereich, wo eine lutherische und eine reformierte Gemeinde nebeneinander bestanden und die Prediger ihrer Intoleranz bis zu gegenseitigen Verbalattacken von der Kanzel aus freien Lauf ließen. Aber auch in kleineren Ortschaften, wo beiden Gemeinden die Ortskirche zur Nutzung zugesprochen worden war (Simultankirche), spielten unter Umständen konfessionelle Spannungen eine Rolle. Dafür stellt die Situation in Lehnin ein eklatantes Beispiel dar. ${ }^{778}$ Mit der „Friedensreichkirche“ (s. Kap. VI.1.) stand den Schweizer Kolonisten im Golmer Bruch dagegen eine eigene Kirche zu Verfügung, sie waren in dieser Beziehung privilegiert, und vielleicht blieben sie deshalb vor solchen unliebsamen Auseinandersetzungen bewahrt. ${ }^{779}$

Die in der Literatur häufig angeführten Streitigkeiten, wann und an wen bei Trauungen von Mischehen Stolgebühren ${ }^{780}$ zu zahlen waren [Dimmorialstreitigkeiten], können nach Meinung des Autors nicht wirklich als Beleg für bestehende konfessionelle Spannungen gelten. Ein solcher Fall kam 1804 bei der Golmer Bruchgemeinde zwischen dem lutherischen Prediger Krusemark (Bornim) und dem reformierten Prediger Schmidt (Golmer Bruch, s. Anhang II) vor und ist ausführlich einschließlich Beschwerde beim Superintendenten/Hofprediger Pischon in Potsdam dokumentiert. ${ }^{781}$ Solange die Königlichen Konsistorien dieses Problem nicht eindeutig geregelt hatten, war verständlicherweise die reformierte Trauung ohne Zah-

777 Schramm, Karl: Die Schweizer Siedlungen, in: Archiv für Bevölkerungswissenschaft Bd. 6 (1936), S. 237 244; ders.: Dorfsippenbuch Storbeck, Kreis Ruppin, Kurmark, Goslar (1939), S. 13. Diesen ansonsten nicht von politischem Zeitcouleur freien Abhandlungen ist in der Frage des Konfessionsbewusstseins zuzustimmen.

778 GStA PK, I. HA, Rep. 243 Königl. Kons. d. Prov, Brandenburg, Nr. 307. Auch nach der Errichtung einer Trennmauer im Kirchenraum 1695 gingen die Streitigkeiten zwischen den beiden Gemeinden munter weiter [Sello, G.: Lehnin, Berlin (1881), S. 207.].

779 s. Anm. 77-79.

780 Stolgebühren wurden von den Lutheranern als Teil ihrer Einkünfte bei der Feier von Kasualien wie Taufe, Traunung und Begräbnis erhoben. Bei diesen Amtshandlungen tragen die Geistlichen über dem Talar eine Stola.

781 KA Alt Töplitz, Alte Acten Golmer Bruch 1804-1839 (nicht paginiert). 
lung von Stolgebühren insbesondere für die ärmere Bevölkerung attraktiv und ein Ärgernis für die lutherischen Prediger, die kein Gehalt erhielten und deshalb auf die Einnahme von Stolgebühren angewiesen waren.

In Bezug auf konfessionelle Spannungen sind vor allem die grenzüberschreitenden Fälle interessant. Insofern war ein Taufeintrag im Kirchenbuch Golmer Bruch (Vol. I) im Jahre 1786 eine Überraschung. Der Säugling wurde am 25. Juni in Neu-Töplitz geboren, welcher daselbst d. 1 Jul. (vom [lutherischen] Pred. aus Alt Taeplitz H Wigand) die Noth Taufe empfangen [und war] gleich darauf gestorben. Mehr war dazu dem Kirchenbuch nicht zu entnehmen. Aber dass ihr Sohn überhaupt den Taufsegen erhielt, war den Eltern offensichtlich wesentlich wichtiger als die Konfessionsfrage. Für die gegenseitige Toleranz fand sich noch früher im Schreiben der Kurmärkischen Kriegs- und Domänenkammer vom 17. April 1747 an das Amt Potsdam ein Hinweis. Vermerkt war darin, dass die Reformirte Gemein zu Neu-taeplitz in der Lutherischen Kirche zu Alt-taeplitz ihre eigenen Stühle [Sitzplätze] hätten. ${ }^{782}$ Diese wurden in einer ständischen Gesellschaft standesgemäß vergeben und mussten bezahlt werden. ${ }^{783}$ In der Kirche Alt Töplitz bestand die „Bauernbank“ bis $1945 .{ }^{784}$ Asche $(2006)^{785}$ konnte je einen Fall in Linow und Storbeck nachweisen, wo ein Lutheraner in einen reformierten Hof einheiratete und letztendlich konvertierte. ${ }^{786}$ Er meint deshalb, dass konfessionelle Verbindlichkeiten angesichts von materieller Not keine Rolle spielten. Vielmehr musste ein Aufstiegswilliger bereit sein, den Konfessionswechsel dezidiert zu vollziehen. Diese Einschätzung erscheint dem Autor sehr gewagt; vor allem bestand bei den beschriebenen Fällen nachweislich keine materielle Not.

\section{Beziehungen der reformierten Kolonistengemeinden untereinander}

Hierbei sollte man zwischen einer staatlichen und einer persönlichen Ebene unterscheiden. $\mathrm{Zu}$ ersterem gehören zum Beispiel die Bauvorgaben für neu zu errichtende Gebäude in den erst 1691 mit Schweizer Kolonisten besiedelten Dörfern (s. Kap. V.4.). ${ }^{787}$ Gewiss ist darunter auch die Übertragung des Jus visitandi an Prediger Wyttenbach im Jahre 1691 (s. Kap. VI.2.2.) und die durch Friedrich I. genehmigte Kollektensammlung für ein reformiertes Kirchenbauprogramm im Kanton Bern und Zürich (s. Kap. VI.1.) zu zählen.

Die persönliche Ebene betrifft fast ausschließlich die Wahl des Partners und der Paten. Wenn hierzu Asche $(2006)^{788}$ schreibt, dass die Kolonisten im Schweizerbruch bei Potsdam (und in der Umgebung von Michelsdorf) eine „Sonderexistenz mit eigenen Heiratskreisen ... führten“,

786 Ein vergleichbarer Fall in der Schweizer Gemeinde im Golmer Bruch ist unter Kap. VII.2 beschrieben.

787 s. Anm. 365-368.

788 Asche, Matthias: Neusiedler im verheerten Land, Münster (2006), S. 575. 
kann der Autor dem nur widersprechen. Durch die hohe Kinderzahl bei den Schweizer Kolonisten im Golmer Bruch waren deren Söhne und Töchter quasi gezwungen, zu gegebener Zeit anderwärts eine Existenz für sich zu gründen, wobei persönliche Verbindungen in der Regel involviert waren. Dabei hat sicherlich Prediger Wyttenbach in seiner Inspektorenfunktion eine vermittelnde Rolle gespielt. Die diesbezügliche Auswertung des Kirchenbuches (s. Abb. 14) ergab 49 Orte, wo dies in näherer Umgebung wie in weiterer Entfernung erfolgte. Der Autor war deshalb auch nicht verwundert, bei Stirnemann sogar schon 1691 bzw. 1696 in Glambeck, Storbeck und Klosterheide erwähnte Nachkommen der Schweizer Erstbesiedler aus dem Golmer Bruch zu finden: Hans Suthor, Peter Schweingruber, Hannß Bylang, Ulrich Suter und Crispinus Garmatter. ${ }^{789}$ Zusätzlich konnte der Autor unter den nachbesetzten Kolonisten des Vorwercks Linow im Jahre 1693 einen Sohn eines Erstbesiedlers aus dem Golmer Bruch, Ulrich Zech, auffinden. ${ }^{790}$ Diese Angaben sind selbstverständlich nicht enumerativ zu verstehen. Auch wenn anscheinend die Kontakte zu den Schweizer Kolonisten, die aus dem Kanton Zürich stammten, weniger eng waren, so fand sich trotzdem im Kirchenbuch eine Braut aus NeustadtEberswalde. ${ }^{71}$ Im Übrigen bedauert der Autor sehr, dass die jahrzehntelangen genealogischen Recherchen von Scherler über die Schweizer Kolonisten in Brandenburg nicht mehr existieren; sie waren speziell darauf angelegt, die Vernetzung der reformierten Kolonistengemeinden untereinander aufzudecken. Ihren Umfang kann man heute nur noch aus seinem Artikel Schweizer Kolonisten in Brandenburg - Vorstellung einer Datensammlung aus dem Jahre 2008 erahnen. ${ }^{792}$

789 Stirnemann, Heinz: Woselbst sie wohl aufgenommen, Frankfurt a. M. (o.J.), S. 30, 42 u. 44.

790 BLHA, Rep. 2 Kurmärkische Kriegs- u. Domänenkammer Nr. D 12231 fol. 5 ff.

791 s. Anm. 692.

792 Klaus Scherler war selbst Nachkomme des 1691 aus der Schweiz nach Vielitz eingewanderten Abraham Scherler und hat nicht nur jahrzehntelang Familienforschung als Hobby betrieben, sondern darüber hinaus die umfängliche Vernetzung der einzelnen Schweizer Familien unter Auswertung der Kirchenbücher von 26 brandenburgischen Orten aufzudecken versucht. Sein Nachlass wurde nach Aussage seiner Frau dem Verein HEROLD angeboten, aber von diesem nur die Unterlagen zur Familie Scherler übernommen (Scherler, Klaus: Schweizer Kolonisten in Brandenburg - Vorstellung einer Datensammlung, in: Brandenburgisches genealogisches Jahrbuch 2008, Bd. 2. S. 46-51.). 



\section{Zusammenfassung}

Die Ergebnisse dieser Arbeit über die Reformierte Schweizer Gemeinde im Golmer Bruch stellen auf den ersten Blick nur einen Beitrag zur Geschichtsforschung auf lokaler Ebene dar. Mit der Auswertung des Pfarrarchivs Alt Töplitz ergab sich aber eine zusätzliche Perspektive von unten, die nicht unbedingt mit landläufigen Geschichtsbildern übereinstimmen muss, diese ggf. korrigiert und neue Fragestellungen aufwirft, indem Quellen genutzt werden, die bisher fast ausschließlich nur genealogisch ausgewertet worden sind. Bei der Reformierten Schweizer Gemeinde im Golmer Bruch handelt es sich um die erste ländliche Gemeinde im lutherisch geprägten Kurbrandenburg, die auf der Grundlage eines „Staatsvertrages“ im Jahre 1685 von Kurfürst Friedrich Wilhelm vor den Toren der Residenzstadt Potsdam angesiedelt wurde und deren Mitglieder aus ganz unterschiedlichen Regionen des Kantons Bern nach Brandenburg kamen (s. Abb. 3). Insofern schlägt in diesem Fall die Staatspolitik bis auf die lokale Ebene durch.

IX.1. Die vorliegende Arbeit hat sich die Aufgabe gestellt, das Schicksal der reformierten "Schweizer Gemeinde im Golmer Bruch bei Potsdam“ von 1685 bis zu ihrem Aufgehen in der lutherischen Gemeinde Alt Töplitz 1835 hinsichtlich ihrer Vorgeschichte, ihrer eigenen Geschichte und ihrer Beziehung zu anderen Schweizer Kolonisten zu untersuchen und zu würdigen. Ein solches Vorhaben erschien lohnenswert, da Recherchen hierfür seit 2009 sehr deutlich gezeigt haben, dass dies bisher in nicht ausreichendem Maße geschehen ist und die Einwanderung der Schweizer Kolonisten in den Golmer Bruch zu Recht als Prototyp aller späteren Einwanderungen gelten kann (Schmelz, 2010). ${ }^{793}$ Bereits im 18./19. Jahrhundert war die Ansiedlung von Schweizer Kolonisten in Kurbrandenburg weitgehend in Vergessenheit geraten; sie zählte nicht zur glorreichen brandenburgisch-preußischen Geschichte. In naher Zukunft besteht sogar die Gefahr, dass sie ganz in Vergessenheit geraten könnte. Zwar wurde in den meisten der ehemaligen Schweizer Ansiedlungen im Ruppiner Raum und in Nattwerder des 300- sowie 325-jährigen Jubiläums der Ansiedlung gedacht. Aber vor Ort wohnen so gut wie keine Nachfahren der einstigen Schweizer Kolonisten mehr. Außer den drei Fachwerkkirchen (Linow, Lüdersdorf, Storbeck) ${ }^{794}$ existieren im sonstigen öffentlichen Raum keine sichtbaren Hinweise mehr, die auf ihre einstige Ansiedlung aufmerksam machen. Nur in Nattwerder ist es 2001 gelungen, den fast noch vollständig erhaltenen historischen Dorfkern unter Denkmalschutz (seit 2000 Flächendenkmal, Amtsblatt Potsdam Jg 11, Nr. 12 S. 32) zu stellen. Der Verein Schweizerkolonistendorf Nattwerder e. V. setzt sich seit 1991 für die Erhaltung der noch vorhandenen Bausubstanz ein.

793 Schmelz, Ulrich: Die Schweizer-Kolonie Nattwerder als Prototyp von Zuwandererkolonien in Brandenburg. Vortrag beim 325. Jubiläum von Nattwerder (18. Juni 2010).

794 Die Schweizer Kirchen in Lindow (1874) und Schulzendorf (1901) wurden wegen Baufälligkeit abgerissen (Schmidt, Peter: Schweizer - Schweizer Kirchen, in: Die Mark Brandenburg, Berlin (2009), Heft 75, S. 34-40.). 


\section{Zusammenfassung}

Der Wert von Pfarrarchiven insbesondere für soziale und historische Forschungen scheint bislang weitgehend unterschätzt zu sein (Imhof, 1977); die Nutzung der Kirchenbücher für genealogische Recherchen hat hierbei zu einer gewissen Voreingenommenheit beigetragen. In jüngster Zeit zeichnet sich ein Wandel ab, und die Pfarrarchive erfahren zunehmend die Aufmerksamkeit der Historiker, weil sie einen geschlossenen Archivbestand darstellen, der am Ort selbst entstanden ist, und weil sich der Blick der Geschichtsforschung nicht mehr nur auf die "große“ politische Geschichte richtet. Gefragt sind in zunehmendem Maße solche Quellen, die die Lebenswelt aller Schichten einer Gesellschaft sichtbar machen (Diederich, 1991) ${ }^{795}$ und die Menschen der Vergangenheit als handelnde Personen mit unterschiedlichen Zielen zu verstehen (Schlumbohm, 1998). ${ }^{796}$ Im heutigen Kirchensprengel Alt Töplitz, zu dem seit 1835 die Reformierte Schweizer Gemeinde Golmer Bruch gehört, sind noch die Pfarrarchive aller Filialgemeinden vollständig erhalten. Bisher sind sie höchstens sporadisch genutzt, geschweige denn ausgewertet worden. $\mathrm{Zu}$ den Beständen eines derartigen Archivs gehören Generalia- und Specialia-Akten. Zu ersteren sind u. a. Urkunden, Praestationsablösungsrezesse (Separation), Erbpachtverträge und Verfügungen der Kirchenleitung zu rechnen. Zu letzteren zählen Dokumente über Einkommen, Vermögen und Grundbesitz (Lagerbuch) der Kirchengemeinde, Personalien, Seelsorge, Amtshandlungen (Kirchenbücher), Protokolle des Presbyteriums bzw. Gemeindekirchenrates, Schule, Feuerversicherung, Armenpflege und dergleichen.

Ein Pfarrarchiv allein gibt keine hinreichende Materialbasis her, um alle denkbaren Aspekte der Reformierten Gemeinde im Golmer Bruch bei Potsdam darzustellen. Deshalb erfolgten umfangreiche Recherchen auch in anderen deutschen Archiven (BLHA, GStA PK, DStA Brandenburg, ELAB, AKPS Magdeburg usw.) sowie im Staatsarchiv Bern. Recherchen in Letzterem sind bislang nur in unzulänglichem Umfang betrieben worden. In diesem Archiv ist die gesamte Korrespondenz zwischen Kurbrandenburg und dem Kanton Bern zu dem Thema dieser Arbeit aufbewahrt.

IX.2. Die Arbeit stellt zunächst dar, vor welchem Hintergrund die Repeuplierung in der Mark Brandenburg am Ende des 17. Jahrhunderts stattgefunden hat. Dazu wird insbesondere auf die beiden hierbei dominierenden Aspekte - die wirtschaftliche und konfessionelle Situation im Lande - eingegangen (s. Kap. II.1. und 2.). Kurbrandenburg war geprägt von einem Nebeneinander von einer lutherischen Mehrheits- und einer elitären reformierten Minderheitsreligion, der das hohenzollernsche Kurhaus angehörte. Das durch den Dreißigjährigen Krieg verwüstete Land musste, um weiterhin bestehen bleiben zu können, so schnell wie möglich die Kriegsfolgen bewältigen. Zu diesem Zweck betrieben Kurfürst Friedrich Wilhelm und Friedrich III./Friedrich I. in Konkurrenz zu anderen Fürstentümern eine aktive

795 Diederich, Toni: Gedanken zum Wert der Pfarrarchive und zur Sicherung ihrer historisch relevanten Kernüberlieferung, in: Überlieferung, Sicherung und Nutzung der Pfarrarchive. Redaktion: Hans Ammerich, Speyer 1991, S. 10-26.

796 Jürgen Schlumbohm: Mikrogeschichte - Makrogeschichte, in: Jürgen Schlumbohm (Hg.): Mikrogeschichte Makrogeschichte komplementär oder inkommensurabel? Göttingen (1998), S. 7-32. 
Migrationspolitik, die bereits vor Ende des Kriegs nachweisbar ist. ${ }^{797}$ Dieser bekannte Rahmen wird allerdings durch eine dritte Dimension, die Situation der Schweizerischen Eidgenossenschaft zu dieser Zeit, erweitert. Denn nur wegen der dort seit etwa 1650 zunehmenden sozialen Spannungen und der engen Beziehungen zwischen dem reformierten Kurhaus und den Evangelischen Kantonen (vor allem Bern und Zürich) lässt sich die ungewöhnliche und gewagte Anfrage des Kurfürsten Friedrich Wilhelm an eine entstehende Republik erklären. Das bekannte Schreiben (allerdings nicht von Friedrich Wilhelm, sondern von Friedrich III. unterzeichnet) vom 24. November 1683 an den Schultheiß und Rat der Stadt Bern würdigt die Arbeit als das auslösende Moment, das die Besiedlung des Golmer Bruchs in Gang setzte (s. Kap. IV.2.).

IX.3. Zuvor geht der Autor auf die Situation vor Ort ein und widerlegt die tradierte Meinung, dass Friedrich Wilhelm den Golmer Bruch für die Besiedlung mit Schweizer Kolonisten vorgesehen habe. Hierbei handelt es sich eindeutig um zwei getrennte historische Vorgänge. Mit dem Bau des neuen Potsdamer Stadtschlosses 1662-1668 und dem Ausbau der Stadt zur Nebenresidenz waren Versorgungsprobleme zu bewältigen. Die in der Nähe der neuen Residenz vorkommenden Feuchtgebiete (Uetz, Golmer Bruch, Havelländische Bruch) boten sich für Meliorationsvorhaben und Urbarmachungen als Experimentierfelder geradezu an. Außerdem dürfte Friedrich Wilhelm den Golmer Bruch durch die Nähe zu dem von ihm erbauten Bornimer Schloss und Jagden in dieser Gegend persönlich gekannt haben. Die Topographie und Siedlungsgeschichte der Wublitzrinne wird referiert (s. Kap. III.1.). Wie zahlreiche archäologische Funde beweisen, war die Region seit der Steinzeit besiedelt. Die in ihr liegenden Ortschaften Paaren, Uetz, Marquardt, Leest, Grube und Golm stellen kleine dichte Siedlungsballungen dar, wogegen der Golmer Bruch aus archäologischer Sicht ein weites fundleeres Gebiet ist. ${ }^{798}$ Dies war zurzeit Kurfürst Friedrich Wilhelms gewiss nicht bekannt. Aber die „alten Leute“ wussten von immer wieder vorkommenden Überschwemmungen im Golmer Bruch zu berichten, und insoweit konnte es sich nicht um ein für Siedlungszwecke günstiges Land handeln. Entgegen diesen Warnungen empfahl der damit beauftragte Oberforstmeister Jo(a)chim Georg v. Lüderitz nach einer Ortsbesichtigung im Sommer 1678 dem Kurfürsten, den Golmer Bruch zu einer „Milchbude“ umzuwandeln (s. Kap. III.1.). Der pragmatische Kurfürst sah offenbar eine Chance zur Realisierung seiner Pläne und gab am 19. Juli 1678 seine Zustimmung zu diesem Vorschlag. Wie wichtig ihm die Urbarmachung des Golmer Bruchs gewesen sein muss, kann man vor allem anhand der Geldmittel von insgesamt 14.300 Rthl. (s. Tab. 1) ermessen, die er dafür von 1678 bis 1687 aufbrachte.

Dadurch erhielt der Golmer Bruch bereits 1683 eine Infrastruktur (s. Kap. III.2.), wie dies der Kartenausschnitt vom Blatt VI (Golmischer Bruch) des Atlasses der Herrschaft Potsdam zeigt (s. Abb. 2). Da bis heute Detailauswertungen dieses wichtigen Dokumentes des in preu-

797 Schulze, Johannes: Die Mark Brandenburg, Berlin 2. Aufl. Bd. 5 (1989), S. 59 ff.; Neugebauer, Wolfgang: Brandenburg im absolutistischen Staat, in: Ingo Materna und Wolfgang Ribbe (Hg.), Brandenburgische Geschichte, Berlin (1995), S. 291-394 und Duchhardt, Heinz: Europa am Vorabend der Moderne 1650-1800, Handbuch der Geschichte Europas - Bd. 6, Stuttgart (2003).

Ribbe, Wolfgang (Hg.): Havelland im Mittelalter, Berlin (1987), S. 24. 


\section{Zusammenfassung}

Bischen Diensten stehenden polnischen Kartographen Samuel de Suchodoletz fehlten, geschieht dies in der vorliegenden Arbeit ausführlich. Bei einem Vergleich mit der heutigen topografischen Situation fällt sofort auf, dass sich keine wesentlichen Unterschiede ergeben. Die Grundstruktur ist bis heute unverändert geblieben. Neben den abgebildeten Dämmen, Gräben und dem Weg über Bornim nach Potsdam finden sich überraschende Details, eine Wind Mühle am Längsgraben, eine Milchstelle am Einhaus sowie Espenhörste am Mitteldamm. Damit hält der Autor es für belegt, dass die wesentlichen anthropogenen Eingriffe im Golmer Bruch schon vor der Besiedlung des Golmer Bruchs geschehen sind.

IX.4. Brandenburg begann mit der Werbung von Kolonisten gegen Ende des Dreißigjährigen Krieges (s. Kap. IV.2.) und wiederholte sie periodisch. Durch die persönlichen Beziehungen des Kurfürsten nach Holland geschah dies zunächst in diesem Land, ab 1650 wurden überall im Heiligen Römischen Reich Deutscher Nationen Werbepatente mit erheblichen Privilegien verteilt, um Kolonisten nach Kurbrandenburg zu locken. Sie blieben ohne nennenswerten Erfolg, da schon damals dem Land der Ruf als Streusandbüchse anhaftete. Auch auf verschiedene, wenig bekannte private Initiativen der Vermittlung von Kolonisten geht die Arbeit ein. Insoweit war im Gegensatz zur gängigen Darstellung Kurfürst Friedrich Wilhelm vor der Anfrage beim Kanton Bern im Jahre 1683 bereits mehrfach mit der Frage der Ansiedlung von Schweizern in Kurbrandenburg befasst. Die schriftliche Anfrage beinhaltete eine Überlassung von 10 oder 20 Familien, die der Wirtschafft und Viehzucht wohl erfahren seyn, sollte durch den Grafen v. Dohna als brandenburgischer Ambassador persönlich übergeben und durch zusätzliche eigene Bemühungen befördert werden. Zugleich enthielt das Schreiben Zusagen von attraktiven Privilegien. Die Resonanz war unterschiedlich: Schultheiß und Rat der Stadt reagierten aufgeschlossen und fühlten sich geschmeichelt; die Ämter äußerten Bedenken, wenn nicht sogar Misstrauen. Interessenten für eine Umsiedlung waren nicht ohne weiteres $\mathrm{zu}$ finden. Schultheiß und Rat hielten es deswegen für notwendig, den Ort der vorgesehenen Ansiedlung in augenschein zu nehmen und weitere Dinge zu klären.

In der bisherigen Literatur zur Besiedlung des Golmer Bruchs fand die Erkundungsreise des Stadtsyndikus Bauernkönig und weiterer drei Handwerker im Jahre 1684 zwar Erwähnung, ohne dass darauf aber näher eingegangen wurde. Im Staatsarchiv Bern konnte der Autor eine „diplomatisch“ gehaltene Instruktion der Berner Obrigkeit für Bauernkönig auffinden. Darin wurde ihm aufgetragen, nicht nur auf die Beschaffenheit deß Landes Vndt sonsten alle Umbstand wol Acht zu geben; vor allem waren Schultheiß und Rat der Stadt Bern daran gelegen, dass er sich nicht als ihr Beauftragter, sondern als der der Untertanen ausgab. Damit vermied seine vorgesetzte Stelle im Vorfeld der Verhandlungen, sich in irgendeiner Weise durch verbindliche Äußerungen zu prejudizieren. Diese abwartende Haltung behielten sie bis zum Abschluss des Arrendevertrages bei, den sie - wie der Autor am einzig erhaltenen Original des Vertrages sehen konnte - erst am 5. Oktober 1687 und damit gut zwei Jahre nach Inkrafttreten des Vertrages bestätigten (s. Kap. IV.6.). Die Berichte Bauernkönigs geben sehr realistisch die Situation im Golmer Bruch wieder. Beispielsweise wird die unter Kapitel IV.3. erwähnte Windmühle als doch nur so obenhin gemacht bezeichnet. Auch die ersten bereits errichteten Wohnhäuser wurden vom mitgereisten Zimmermann bemängelt. Vor allem aber wurde die 
bestehende Gefahr einer Überflutung der Wiesen im Golmer Bruch und die Beibehaltung des Rechtsstatus der Schweizer Kolonisten als freie Bürger thematisiert. Der Delegation wurde ein persönlicher Brief des Kurfürsten und ein Vorvertrag auf die Heimreise mitgegeben, der aus Schweizer Sicht eine Reihe von wirtschaftlichen Vorteilen und Garantien für die potentiellen Übersiedler enthielt, so dass die angebotenen Bedingungen für die Ansiedlung zumutbar erschienen. Demzufolge kam es zu einer erneuten Ausschreibung des Vorhabens an die Ämter, mit dem Hinweis, dass für die Auswahl keine liederlichen Leute infrage kämen, denn es ginge um die Ehre der Schweizerischen Nation.

Die nach Brandenburg Ausreisewilligen 101 Personen stammten aus sehr unterschiedlichen Gegenden (s. Abb. 3 und Kap. IV.5.), trafen sich schließlich in Bern (bzw. Aarau) und traten am 30. April 1685 eine spektakuläre Schiffsreise über die Aare, den Rhein, die Zuider- und Nordsee, die Elbe und die Havel bis in die Wublitzmündung an. Zwei Reiseberichte, von Bauernkönig selbst und Gabriel Groß lateinisch geschrieben, enthalten reichlich Anekdoten. Wenig Beachtung und Würdigung erfuhr bislang der Tod der Mitreisenden Magdalena Schnyder, welcher der lutherische Rat der Stadt Hamburg als Reformierte ein ehrliches Begräbnis verweigerte. Am 18. Juni 1685 trafen die Kolonisten im Golmer Bruch ein. Damit enden die meisten Arbeiten zu dieser Thematik

Der mit den Schweizer Kolonisten im Golmer Bruch am 16. September 1685 abgeschlossene Arrendevertrag regelte für sie quasi alle gesellschaftlichen, wirtschaftlichen, kulturellen und erbrechtlichen Belange (s. Kap. IV.6.). Die weitläufige Ausstattung mit Privilegien kam nur zustande, weil es sich hier um ein „Regierungsprojekt“ handelte. Zu Recht sieht Schmelz (2003) diesen Vertrag als den Prototyp aller späteren Arrendeverträge an. Das „Edikt von Potsdam", das fast gleichzeitig am 29. Oktober 1685 in Kraft trat, nahm in Pkt. 9 sogar Bezug auf den Ansiedlungsvertrag der Schweizer Kolonisten im Golmer Bruch. Offensichtlich sollten die wenigen ländlichen Réfugiés den Schweizer Kolonisten im Golmer Bruch gleichgestellt werden. Aber das „Edikt von Potsdam“ wurde für eine unbestimmte Anzahl von Menschen erlassen, während der Arrendevertrag nur für die dort angesiedelten Kolonisten bzw. deren Nachfolger galt. Die besondere Rechtsqualität dieser geschlossenen Privilegiengemeinschaft bestand u. a. in der Garantie der persönlichen Freiheit (Art. 12), der Überlassung von Land (Art. 5 und 6) und der für sie gebauten Höfe (Art. 3) zu Erbpachtbedingungen sowie der Befreiung von allen Abgaben und Lasten für 30 Jahre mit der Option einer Verlängerung (Art. 9). Damit waren sie gegenüber den einheimischen Bauern rechtlich deutlich bessergestellt. Zusätzlich wurde ihnen ein eigener reformierter Prediger aus ihrer Berner Heimat zugestanden, womit der Kurfürst auf sein „Ius praesentandi“ zugunsten des Magistrats von Bern verzichtete. Wie die Tabellen 4 und 5 zeigen, erhielten sie als "Starthilfe“ gemäß Art. 4 Vieh, Instrumenta rustica und Aussaat für die erste Winterbestellung gegen sofortige Bezahlung oder $5 \%$ Verzinsung. Offensichtlich waren sie damit sehr gefordert, denn ihre Rückzahlungen erstreckten sich in Einzelfällen bis in das Jahre 1729. (s. Tab. 6) Wie aus Kapitel V.3. beispielhaft hervorgeht, kamen sie schon bald mit ihren jährlichen Pensionszahlungen in Verzug, so dass sie verständlicherweise auch nicht in der Lage waren, ihre sonstigen Darlehensschulden abzuzahlen. 


\section{Zusammenfassung}

Ihre finanziellen Schwierigkeiten dürften im Wesentlichen an den Folgen der Überschwemmungen des Golmer Bruchs und den damit verbundenen schlechten Heuernten gelegen haben. Wie die erwähnten alten Leute prophezeit hatten, kam es nach einigen trockenen Jahren 1689 trotz aufgeschütteter Dämme zu einem Jahrhunderthochwasser, und alle Anstrengungen, die sie bis dahin in den Golmer Bruch gesteckt hatten - einschließlich ihres Geldes -, waren über Nacht im moder des Golmer Bruchs versunken. Dem Prediger Sigismund Lupichius ist es zu verdanken, dass wir davon aus zwei Briefen aus dem Jahre $1713 \mathrm{im}$ Nachhinein überhaupt Kenntnis haben (s. Anhang 14, Kap. VII.2.3.). Die im 17./18. Jahrhundert nur begrenzt möglichen Wasserschutzmaßnahmen waren nicht in der Lage, derartige Katastrophen zu verhindern. Die Besiedlung des Golmer Bruchs war also eine Fehlentscheidung gewesen. Damit gerieten die Schweizer Kolonisten in eine schwierige wirtschaftliche Situation, worauf König Friedrich Wilhelm I. (1713-1740) und seine ausführenden Behörden keine Rücksicht nehmen wollten.

IX.5. Bei der 1688 verwitweten Kurfürstin Dorothea Sophia, die immer als Protektorin der Schweizer aufgetreten war und die sich 1689 von der Situation im Golmer Bruch selbst ein Bild gemacht hatte, waren die Schweizer vorstellig geworden und hatten sie um pensionsweise Überlassung ihres Leibgedinges, des Vorwerkes Golm, gebeten. Vermutlich auch durch Vermittlung von Eberhard v. Danckelmann kam am 10. Juni 1689 ein Arrendekontrakt (s. Kap. V.2.) mit sechs Schweizer Kolonisten aus dem Golmer Bruch zustande, der eigenhändig von der Kürfürstin einerseits und vom damaligen Prediger Albrecht Wyttenbach, dem Schulzen Hans Bilang sowie dem Schulmeister Niclaus Hodler andererseits unterschrieben wurde. Neben der schwierigen wirtschaftlichen Situation kam nun für die Schweizer Kolonisten eine weitere Belastung durch eine örtliche Trennung hinzu, die mit dem Abschluss eines weiteren Arrendevertrages im Jahre 1691 über das Vorwerk (Neu)Töplitz mit 4 Schweizer Kolonisten dauerhaft Bestand haben sollte. Denn ebenfalls im Jahr 1691 kam für die restlichen Schweizer Kolonisten der Arrendevertrag auf dem Natte Werder zustande.

Die unterschiedliche Entwicklung und vorliegenden Gegebenheiten an den drei Standorten werden anhand der Nachverträge verdeutlicht. Parallelen bestehen in ihrem zähen Festhalten an den Holzberechtigungen und der Wiedererlangung des Erbpächterstatus zu ihrer wirtschaftlichen Sicherheit. Die Neu Töplitzer tendierten zu einer Verselbständigung, was u. a. in der Errichtung eines eigenen Friedhofs daselbst zum Ausdruck kam, aber auch ihrer Abgelegenheit geschuldet war.

Eine wirksame Melioration von überschwemmungsgefährdeten Feuchtgebieten konnte im 17./18. Jahrhundert mit denen bis dahin in Brandenburg angewandten wasserwirtschaftlichen Anlagen nicht gelingen (s. Kap. V.5.). Insoweit war die Ansiedlung der Schweizer Kolonisten im Golmer Bruch im Jahre 1685 eine folgenschwere Fehlentscheidung, wie es sich bereits vier Jahre später bei einer Jahrhunderthochwasserflut herausstellte. Auch der Berner Abordnung, die 1684 das Golmer Bruch vorab besichtigte, war diese große Gefahr aufgefallen und hatte daher sich vorsorglich den Artikel 1 im Arrendevertrag (s. Kap. IV.6.) als Entschädigungsregel im Überschwemmungsfall ausbedungen. Zu dieser Zeit dürfte allerdings noch nicht klar gewesen sein, dass der Golmer Bruch immer dann überschwemmt wird, wenn 
es durch den eiszeitlich bedingten frontalen Zufluss der Wublitz in die Havel es zu einer Aufstauung des Nebenflusses kommt (s. Kap. III.1.).

Wie der Autor herausfand, ist zu Zeiten Friedrichs II. mit Kockers experimentiert worden, um den Schäden durch die Überflutung des Golmer Bruchs besser Herr zu werden. Aber nach dem physikalischen Prinzip der kommunizierenden Röhren konnte dies nicht zum gewünschten Erfolg führen (s. Anm. 402). 1857 wurden deswegen zwei dampfbetriebene Schöpfwerke im Golmer Bruch installiert, ${ }^{799}$ was zu Teilerfolgen führte, sich aber als viel zu energieaufwendig sowie maschinen-technisch anfällig erwies und deswegen wieder aufgegeben wurde. Erst durch die späteren großen Fortschritte in der Elektro- und Maschinentechnik wurden 1929 nacheinander drei Pumpwerke in Wildpark-West, Grube/Nattwerder und Grube/Schlänitzsee gebaut, die endlich in der Lage waren, den Hochwasserschutz im Golmer Bruch verlässlich zu leisten. Das Pumpwerk Grube/Nattwerder wurde 1980 durch ein noch leistungsstärkeres Pfahlschöpfwerk ersetzt und das alte 2015 zum technischen Denkmal erklärt.

IX.6. Nachdem die Arbeit die wirtschaftlichen Aspekte der Schweizer Kolonisten auf ihren drei Standorten bis zur Separation behandelt hat (s. Kap. V.2.-4.), widmet sie sich der reformierten Kirchengemeinde, die auf dem Kirchenbuch Vol. I (1685-1801) als SchweitzerGemeinde im Bruch bei Potstamb bezeichnet wird. Manche Autoren sprechen von einer calvinistischen Gemeinde, was von der Herkunft ihrer Mitglieder wohl zutrifft (s. Abb. 3), aber nicht durch Textauslegungen und dergleichen, wohl aber durch die Abendmahlspraktiken (s. Kap. VI.2.) bis in die Amtszeit von Pfarrer Viebeg (1989-2016) belegt werden konnte.

Die Einweihung der Friedensreichkirche war von der Gemeinde schon lange ersehnt worden. Dies ist der Supplik vom Oktober 1690 an Friedrich III. deutlich zu entnehmen (s. Anhang 6). Der Kurfürst befahl daraufhin am 10. November dem Hofprediger Brunsenius, auf bevorstehenden Sontag (16. November 1690) die Kirche einzuweihen, und den Beamten von Potsdam (u. a. Oberforstmeister v. Pannewitz), dabei anwesend zu sein. Es gleicht einem Wunder, dass diese Kirche heute noch mit originaler Ausstattung existiert. Sie hat schwere Zeiten insbesondere unter der napoleonischen Besetzung und im 2. Weltkrieg überstehen müssen. Mit der Zeit wurde sie für die schrumpfende Gemeinde zu groß, und sie wäre deswegen beinahe in den 20er Jahren des 20. Jahrhunderts abgerissen oder umgenutzt worden (s. Kap. VI.4.2.). Ihre Ausstattung entspricht genau den Anforderungen an eine solche Kirche - allein das gesungene oder gesprochene Wort war von Bedeutung und sollte zur Wirkung gebracht werden. Trotz ihrer Schlichtheit, ja Kargheit ist man von ihr beeindruckt. Ihre bislang nicht gewürdigte Ausstattung und Besonderheiten werden im Kapitel. VI.1. ausführlich dargestellt. ${ }^{800,801}$

Das Zugeständnis Kurfürst Friedrich Wilhelms der reformierten Gemeinde im Golmer Bruch einen eigenen, aus der alten Heimat mitgebrachten Schweizer Prediger zu gewähren, verdeut-

799 BLHA, Rep. 2A Regierung Potsdam Abt. I LW Nr. 1992, fol. 92-96.

800 Bleyl, Dietmar Walther Richard (Hg.): Nattwerder, Potsdam (2010), S. $24 \mathrm{ff}$.

801 ders.: Die rätselhafte Neu Töplitzer Glocke; in: Mitteilungsblatt der Landesgeschichtlichen Vereinigung für die Mark Brandenburg, 117 (2016), S. 74-80. 


\section{Zusammenfassung}

licht die Sonderstellung dieser Gemeinde (s. Kap. VI.); dies war bis 1735 der Fall und dieses Privileg genossen nicht alle Schweizer Kolonistengemeinden in Brandenburg. Ihre Sonderstellung wurde durch die Gründung des Zum Schweitzer Etablissement verordneten Ober-Directoriums 1695 zeitweise noch verstärkt; dieses wurde aber später von Friedrich Wilhelm I. aufgehoben und dem allumfänglichen Generalfinanzdirektorium unterstellt. Dem Autor war es wichtig, das Wirken der ersten drei Schweizer Prediger Elisaeus Malacrida (1685-1687), Albrecht Wyttenbach (1687-1705) und Sigismund Lupichius (1705-1717) darzustellen, weil in ihren Amtszeiten die in Kapitel VI.2.1.-3. geschilderten Ereignisse fielen.

Von Elisaeus Malacridas Wirken in der Gemeinde zeugte nur die Anlage des Kirchenbuchs Vol. I (1685-1801). Seine Bewerbung 1687 um die freigewordene Professur für Griechische Sprache und Ethik in Bern ließ kein besonderes Interesse an Gemeindearbeit erkennen. Dagegen war wohl Prediger Albrecht Wyttenbach ein Glücksfall für die Gemeinde (s. Kap. VI.2.2.). Er musste die Aufteilung der Gemeinde auf drei Standorte als Überlebenschance für die Gemeinde akzeptieren, begleiten und übernahm für das (Neu-) Töplitzer Vorwerk sogar die Kaution als Garant dafür, dass die Schweizer Kolonisten die eingegangenen Verpflichtungen einhalten würden. Wegen seines tatkräftigen Handelns erhielt er 1691 das jus visitandi über die anderen Schweizer Prediger übertragen, dass für die Vernetzung der Schweizer Ansiedlungen untereinander in vielerlei Hinsicht nicht zu unterschätzen war. Die Anbahnung von Heiraten bis zu der gemeinsam mit Herkules Delicker initiierten Kollektensammlung in den evangelischen Kantonen für ein reformiertes „Kirchenbauprogramm“ sind hierfür ein Beleg. In diesem Zusammenhang wurde auch die heute völlig in Vergessenheit geratene Kapelle in Neu Töplitz instand gesetzt und erhielt eine 1701 in Berlin gegossene Bronzeglocke. ${ }^{802}$ Seine übergemeindliche Tätigkeit ist bisher überhaupt nicht bekannt gewesen. Ab 1704 war Sigismund Lupichius dritter Prediger in der Gemeinde Golmer Bruch (s. Kap. VI.2.3.). Er hatte sich einerseits mit der schwärmerisch-pietistischen Sektenbewegung in Neu Töplitz auseinanderzusetzen, andererseits die existentielle Bedrohung der Gemeinde abzuwenden, die durch verdoppelte Pachtzinsforderungen seit dem Regierungsantritt Friedrich Wilhelms I. zustande gekommen war. (s. Tab. 7) Für den Fall, dass sie dazu nicht in der Lage seien, wurde ihnen angedroht, wieder [zu] gehen, wo ihr hergekommen seit. Lupichius brachte als einfacher Prediger den ungewöhnlichen Mut auf, sich als alleiniger Fürsprecher vor seine Gemeinde zu stellen und deren willkürliche Beschimpfung seitens des Amtskammerpräsidenten schriftlich zu widersprechen (s. Anhang 14). Er erhielt für sein Engagement eine scharfe Rüge vom Kirchendirektorium wegen Nichtzuständigkeit in der Sache. Wie bislang nicht bekannt war, wandte er sich in dieser prekären Situation auch an seine Oberen in Bern und bat um Verhaltensregeln für den Fall der Vertreibung (s. Anhang 15). Bern reagierte mit einem diplomatisch gehaltenen Interzessionsschreiben an Friedrich Wilhelm I.; Lupichius selbst erhielt dagegen zur Antwort, dass an eine Wiederaufnahme der Kolonisten nach so langer Zeit und Abwesenheit mit Vermehrten Familien nicht die Rede sein könnte (s. Anhang 16), wovon die

802 Ders.: Die rätselhafte Neu Töplitzer Glocke, in: Mitteilungsblatt der Landesgeschichtlichen Vereinigung für die Mark Brandenburg, 117 (2016), S. 74-80. 
Gemeinde aber nichts erfahren sollte. Schultheiß und Rat der Stadt Bern hatten damit ihre ehemaligen Untertanen abgeschrieben.

Bis auf die Familie v. Wykersloot (Erbherren auf Marquardt von 1719-1781) bestand die Reformierte Schweizer Gemeinde im Golmer Bruch aus bäuerlichen Familien (s. Kap. VII.6.). Durch Einheiratungen kamen später bürgerliche Familien hinzu. Dass eine adelige Familie sich dieser ländlichen Gemeinde zugehörig fühlte, war bisher unbekannt. Die Familie stammte vom Niederrhein. Johann Arnold v. Wyckersloot (†10.12.1724) kam unter Friedrich Wilhelm I. in preußische Dienste und war Hof- und Kommerzienrat. Ihm verdankte die Gemeinde die Stiftung von Abendmahlsgeräten, die heute noch verwendet werden. Trotz seiner Anstellung am Hof geriet die Familie in finanzielle Schwierigkeiten. Vor diesem Hintergrund ist auch die mit Dispens des Kronprinzen zu Stande gekommene Heirat seines Sohnes mit seiner Cousine Angelique le Jeun zu verstehen.

Die Arbeit widmet sich danach den späteren einschneidenden Ereignissen in der Gemeinde. Die Auflösung der Reformierten Schweizer Gemeinde ist schrittweise und insbesondere durch die Vereinigung aller evangelischen Konfessionen (Union) erfolgt. Nach wiederholten Versuchen zwischen der lutherischen und der reformierten Kirche in Brandenburg kam es schließlich unter Friedrich Wilhelm III. im Jahre 1817 zur Bildung der Union aller evangelischen Konfessionen. Dem Monarchen war der Zeitpunkt besonders wichtig, denn würdiger könne das Säkularfest [der Reformation] nicht gefeiert werden, als durch diese Vereinigung. Die dabei ungeklärt gebliebenen dogmatischen Differenzen führten zu erheblichen Widerständen gegen die Union sowohl in den lutherischen als auch den reformierten Gemeinden. Der Autor verdeutlicht dies in Tabelle 10 an Hand der sehr verzögerten Einpfarrung ländlich reformierter Schweizer Kirchengemeinden. Bis auf wenige französisch-reformierte Gemeinden gelang es schließlich, durch Druck von oben (Aussetzung der Stellennachbesetzung u. dgl.) die Union flächendeckend durchzusetzen. Wie die Unierung unter Friedrich Wilhelm III. zustande kam und bei der Reformierten Gemeinde Golmer Bruch mit der lutherischen Gemeinde Alt Töplitz unter den reformierten Predigern Kessler, Beck und Gruss ablief, wird im Einzelnen in Kapitel VI.4.1. geschildert. Auch in diesem Fall wurde die vakante Stelle des lutherischen Predigers in Alt Töplitz als eine gute Gelegenheit genutzt, die Angelegenheit im Sinne der staatlich gewünschten Union zu regeln. Aber es spricht für die Zähigkeit der reformierten Schweizer, dass erst nach 10 Jahren - und letztendlich auf Befehl Friedrich Wilhelms III. - die Vereinigung dieser beiden Gemeinden 1832 zustande kam. Bemerkenswert war dabei aber auch die Rolle von Prediger Gruss, wie sie ein von ihm verfassten Bericht über die dreihundertjährige Jubelfeier der Augsburger Konfession am 25. Juni 1830 in der Kirche Nattwerder offenbart. Darin warb er regelrecht mit der Zitierung behördlicher Texte für die Unierung. Anscheinend hatten die einheimischen Prediger als Geistliche einer Staatskirche kein Verständnis für die noch tief tradierte „Verortung des reformierten Glaubens“ in der Schweizer Gemeinde Golmer Bruch.

Die endgültige Auflösung der Reformierten Gemeinde Golmer Bruch geschah 1949, wobei diese Problematik schon einmal 20 Jahre früher im Zusammenhang mit dem Wunsche einer 
Umgemeindung von vier Nachkommen Schweizer Kolonisten aus Golm in die Kirchgemeinde Golm aufgekommen war (s. Kap. VI.4.2.). In Verbindung damit war die Frage der Zugehörigkeit zur Gemeinde aufgeworfen worden, und das Konsistorium hatte hierzu entschieden, dass dies nur für Personen zutreffe, die von den alten Schweizer Kolonistenfamilien abstammten und zugleich ihren Wohnsitz in Nattwerder, Golm oder Neu Töplitz hätten. Dies traf nur noch für sehr wenige Personen zu, und die Erhaltung der Kirche Nattwerder wurde demzufolge zur Disposition (am besten Abriss) bzw. Umnutzung (als Jugendherberge oder Heuschuppen) gestellt. Dagegen hatte der Provinzialkonservator der Provinz Brandenburg, Prof. Blunck, mit seinem Schreiben vom 23. Oktober 1931 Einspruch erhoben. Während und nach dem Zweiten Weltkrieg war das Gemeindeleben in Nattwerder zum Erliegen gekommen. Dabei spielte Pfarrer Martens eine wesentliche Rolle, dessen Überprüfung nach „Abbauverordnung“ vom 6. November 1945 zu keiner Konsequenz im Sinne einer Amtsenthebung führte. Als schließlich Pfarrer Dr. Wienecke 1949 sein Amt antrat (s. Kap. VI.4.3.), hatte er als eine der ersten Aufgaben die Statusfrage der Schweizer Kolonistengemeinde Golmer Bruch zu klären. Er berief den Gemeindekirchenrat am 13. August ein, und dieser verzichtete darauf, weiterhin eine selbständige Kirchengemeinde (Filialgemeinde), sondern erklärte sich damit einverstanden nur noch Bestandteil der Kirchengemeinde Alt Töplitz zu sein.

Jubiläen sind in besonderer Weise ein Spiegel der Zeit, in der sie stattfinden (s. Kap. VI.6.). Nach Berichten von Boege, Dreifuss und Heese fand erstmalig am 18. Juni 1885 ein Dankgottesdienst anlässlich des zweihundertjährigen Bestehens der Reformierten Schweizer Gemeinde in der Kirche Nattwerder statt. Daraus entwickelte sich in dieser Jahreszeit ein jährliches Treffen von Nachkommen in Nattwerder. 1935, in der Amtszeit von Pfarrer Martens, der sich zu den Deutschen Christen bekannte und Mitglied der NSDAP war, wurde mit großem Aufwand, im Zeitgeist und unter erheblicher Beteiligung der Öffentlichkeit am 23. Juni das 250-jährige Jubiläum als echtes deutsches Sippenfest begangen. Die Sippenältesten der Familien Zech, Garmatter, Dortschy, Mauerhof und Wilhelm trugen Sippenberichte vor. An den Führer und Reichskanzler Adolf Hitler sowie den Reichsernährungsminister Darré wurde vom Ortsbauernführer Bertz sogar ein Huldigungstelegramm gesandt und ihrer in Liebe durch einen kräftigen Heil-Ruf gedacht (s. Anhang 21). Obwohl die Gemeinde inzwischen erheblich geschrumpft und es politisch nicht ganz opportun war, wagte es Pfarrer Lorenz 1985, ein langfristig vorbereitet 300-jähriges Jubiläum der Besiedlung des Golmer Bruchs am 23./24. Juni zu begehen. In diesem Zusammenhang ist die in der Arbeit vielzitierte Festschrift von Henning Heese ${ }^{803}$ entstanden und wurde die von Kriegsschäden noch immer gezeichnete Kirche Nattwerder durch eine „Feierabendbrigade“ innen und außen saniert. Die Resonanz, die das Fest auslöste, war erstaunlich - rund 300 Gästen nahmen daran teil, zumeist Nachkommen der Schweizer Kolonisten, u. a. aus der Bundesrepublik und Frau Pastorin Dauwalder aus der Schweiz. Als Zeichen der Hoffnung wurden am 2. Festtag drei Esskastanien gepflanzt. In vergleichbarer Weise wurde das 325-jährige Jubiläum am 18./20. Juni 2010 begangen.

803 Heese, Henning (Hg.): 300 Jahre Schweizer Kolonie am Golmischen Bruch bei Potsdam 1685-1985, Festschrift zur Erinnerung an die Landung der Schweizer am 18. Juni 1685, Sankt Augustin (1985). 
IX.7. Die historische Demographie verwendet in der Regel als Grundlage für ihre bevölkerungsgeschichtlichen Studien Massendaten aus publizierten vitalstatischen Reihen (z. B. Volkszählungen, öffentliche Statistiken, Stammtafeln, Ortssippen- und Geschlechterbücher) und ist dementsprechend meist makroregional und langzeitlich ausgerichtet. Zur Überprüfung ihrer dabei entwickelten Thesen eignen sich Mikrostudien, wie sie in der Arbeit bei den Schweizer Kolonisten im Golmer Bruch anhand der Auswertung ihrer Kirchenbücher angestellt worden sind, da sie weitere Differenzierung der Makrostudien erlauben.

Bei der ehemaligen Schweitzer-Gemeinde im Bruch bei Potstamb existieren noch alle Kirchenbücher, so dass die Möglichkeit für eine demographische und konfessionelle Auswertung bestand (s. Kap. VIII.). Die quantitative Erfassung der vitalstatistischen Daten von 1685 bis 1835 ergab insgesamt 327 Eheschließungen, 1039 Geburten und 650 Todesfälle. ${ }^{804}$ Im Vergleich zu anderen Studien dieser Art (Zinke, 1996) ${ }^{805}$ handelt es sich also um eine relativ kleine Grundgesamtheit, und bei der Gemeinde lässt sich auch kein Wachstum im üblichen Sinne nachweisen (s. Kap. VIII.7., Abb. 17). Eine Auswertung in Anlehnung an Johann Peter Süßmilch, ${ }^{806}$ dem Begründer der Bevölkerungsstatistik, kam ebenfalls nicht in Frage, weil dazu eine gewachsene Bevölkerung Voraussetzung ist, die zusätzlich lokal begrenzt (Ortsgemeinde) angesiedelt sein muss. Zur Gemeinde fühlten sich aber viele reformierte Familien zugehörig, die entweder aus der unmittelbaren Umgebung oder sogar aus weiterentfernt liegenden Dörfern nach Nattwerder kamen. Bis zum reformierten Kirchenbauprogramm in den Jahren 1700/01 war die Golmer Bruch Gemeinde für die übrigen ländlichen reformierten Gemeinden das geistliche Zentrum in Kurbrandenburg.

Die vitalstatistischen Daten wurden insbesondere bezüglich folgender demographischer (sozial-ökonomischer) und konfessioneller Einzelaspekte ausgewertet:

- Heiratsalter bei der Erst- und Zweitehe (s. Kap. VII.4.1. und VII.4.3.) ${ }^{807}$,

- Kinderzahl pro Ehe (s. Kap. VII.4.5.),

- zeitlicher Abstand zwischen einer Verwitwung und Wiederverheiratung (s. Kap. VII.4.3.),

- Säuglings- und Kindersterblichkeit sowie die altersspezifische Sterblichkeit (s. Kap. VII.5.1. und VII.5.2.),

- konfessionelle Mischehen (s. Kap. VIII.2.) und

- Auswahl der Paten als Spiegelbild der familiären Beziehungen (s. Kap. VII.2.3.).

Den größten Umfang in den Kirchenbüchern nehmen in der Regel die Taufeintragungen ein; dies ist auch bei den Kirchenbüchern der reformierten Schweizer Gemeinde im Golmer Bruch (speziell in Vol. I von 1685-1801) der Fall und kommt durch die Anzahl der im Einzelfall bis zu 19 geladenen, untereinander aufgeführten Paten zustande. Damit demonstrierte

804 Das sind pro Jahr 2,2 Eheschließungen, 6,9 Geburten und 4,3 Todesfälle.

805 Zinke, Regine: Steglitz bei Berlin, Edition Hentrich (1996).

806 Süßmilch, Johann Peter: Die göttliche Ordnung, Berlin (1741); zur Person s. Anm. 39.

807 Bei der Bestimmung des Alters von einer bestimmten Person (z. B. Heiratsalter) wurde gerundet; ab 7 Monaten wurde aufgerundet. 


\section{Zusammenfassung}

die jeweilige Familie in Zeiten, wo dies nicht streng reglementiert war, ihren Wohlstand und ihre gesellschaftliche Stellung. Gleichzeitig festigte sie durch die Auswahl der Paten den Zusammenhalt in der eigenen sozialen Schicht vor Ort, knüpfte auch auf diese Weise Kontakte zum Bürgertum in der Residenzstadt und bei Pfarrern Verbindungen bis in die Hofgesellschaft. Demgegenüber hatten die untersten Dorfschichten (Arbeitsmänner, Büdner) Mühe, die Mindestanzahl an drei Paten als Taufzeugen aufzubieten. Die unehelichen Kinder hatten an der Gesamtzahl der Taufen einen Anteil von 2,8\%. Ihre Häufigkeit erscheint über die Zeit unauffällig (s. Abb. 10).

Die Liste der Kopulationen (Hochzeiten) spiegelt den Unterschied zwischen Gesetz und gelebter Realität wider. Das gesetzliche Mindestalter bei Männern (18 Jahre) und Frauen (14 Jahren) wurde im Durchschnitt bei der Erstheirat mit etwas mehr als 10 Jahren (29,9 Jahren bei den Männern und 25,1 Jahren bei den Frauen) überschritten (s. Kap. VII.4.1.). Hierunter verbergen sich die gesellschaftlichen Zwänge der Brautleute. Nur wenn die Erwerbstätigkeit des Mannes und/oder die Mitgift der Frau die Ernährung der Familie zukünftig sicherte, konnte in der Regel die Ehe geschlossen werden. Bei den Hofbesitzern war dies erst mit der alters- bzw. gesundheitsbedingten Hofübergabe an die nachfolgende Generation der Fall. Hierfür werden Beispiele gegeben (s. Kap. VII.4.1.). Wie für Steglitz durch Zinke $(1996)^{808}$ nachgewiesen, gab es eine jahreszeitliche Schwankung der Hochzeiten. Ein Maximum fand sich im Oktober/November nach Beendigung der Ernte und Wintersaat, ein Minimum dagegen im März/April zur Zeit der Frühjahrsbestellung. Der Nachweis von Doppelhochzeiten bei den Schweizer Kolonisten überraschte (s. Abb. 10). Diese sind grundsätzlich aus wirtschaftlichen Erwägungen und zum „Besten“ beider Familienhöfe (Wegfall der Mitgift) geschehen. Darüber hinaus fanden die Wiederverheiratungen das spezielle Interesse des Autors. Durch die durchschnittliche Lebenserwartung von 27,1 Jahren bei Männern und 22,6 Jahren bei Frauen waren sie unumgänglich (s. Kap. VII.5.3.). Mitterauer spricht in diesem Zusammenhang von einem Rollenergänzungszwang (s. Kap. VII.4.3.) ${ }^{809}$ Insofern verwunderte es nicht, dass es sich bei etwa jedem fünften Hochzeitseintrag um eine Wiederverheiratung handelte. Von den 61 Fällen waren 47 auswertbar in Bezug auf den zeitlichen Abstand zwischen Tod des Ehepartners und einer Wiederverheiratung. Bei den Witwern erfolgte dies nach 3,2 (2-5) und bei den Witwen, bei denen dies wegen einer möglichen Schwangerschaft erst nach neun Monaten geschehen durfte, nach 12,2 (5-27) Monaten. Die neuen Ehepartnerinnen der Männer waren überwiegend Jungfrauen; aus der Sicht der Demographie deutet dies auf einen Frauenüberschuss hin. Auch ein Fall einer 3. Ehe und einer Scheidung fand sich, was im 17./18. Jahrhundert außerordentlich selten genehmigt wurde. Die Ehepartner kamen, wie Abbildung 11 zeigt, von Anfang an aus anderen deutsch-reformierten Gemeinden aus insgesamt 49 verschiedenen Orten. Damit kann weder die von Asche $(2006)^{810}$ konstatierte Phase der Endogamie bei den Schweizer Kolonisten im Golmer Bruch bestätigt werden noch sei-

808 Zinke, Regine: Steglitz bei Berlin - Dorfleben im Spiegel des Kirchenbuches 1605-1810, Leipzig (1996), S. 222.

809 Mitterauer, Michael: Grundtypen europäischer Wirtschaftsgeschichte, Bd. I, Berlin (1981), S. 506.

810 Asche, Matthias: Neusiedler im verheerten Land, Münster (2006) S. 575. 
ne Behauptung, dass sie eine Sonderexistenz mit eigenen Heiratskreisen geführt hätten. Die Nähe zur Residenz- und Garnisonsstadt blieb nicht ohne Auswirkungen. Im Untersuchungszeitraum fanden sich 13 Eintragungen von Dragonern, Füsilieren, Grenadieren und Husaren als Ehemänner (s. Kap. VII.4.6.).

Aus den Kirchenbüchern ließ sich auch die Anzahl der Kinder pro Familie ermitteln (s. Kap. VII.4.5.). Da nicht alle Familien vor Ort blieben, waren diesbezüglich von 327 Hochzeiten nur 131 auswertbar. Hier ergab sich eine klare soziale Differenzierung: Während die Schweizer Pächter 5-12 Kinder und die diversen Handwerker 2-4 Kinder hatten, fallen unter die Ein-Kind-Familien vor allem Dienstleute, Kossäten und Hausmänner. Auch in dieser Beziehung demonstrierte man seinen Reichtum. Was dabei allerdings immer beachtet werden sollte, ist die Zahl der gleichzeitig im Haushalt lebenden Kinder. Der Autor demonstrierte dies am Beispiel der Familie Christian Turtschi und Barbara Schneider ( $\infty$ 19.11.1722), dass trotz ihrer 14 Kinder nur maximal 7 Kinder gleichzeitig im Hause lebten.

Die Angaben in der Liste der Gestorbenen war aufgrund einer Ordre und Instruktion an die Prediger vom 16. November 1764 um die Angabe der Todesursache der Verstorbenen nach einem vorgegebenen Verzeichnis von 19 Haupt-Krankheiten zu ergänzen ${ }^{811}$. Da die Prediger damit schlichtweg überfordert und außerdem daran auch nicht sonderlich interessiert waren, bedurfte es zur Durchsetzung dieser Vorschrift seine Zeit. Erst ab 1772 fanden sich dann im Kirchenbuch Schweitzer-Gemeinde im Bruch bei Potstamb (Vol. I und II) Angaben über die Todesursachen aller Gestorbenen, wobei es sich dabei fast durchweg nicht um Krankheitsbezeichnungen im heutigen Sinne handelt, weil man dazu ausschließlich die äußere Inspektion des Körpers des Gestorbenen und den Krankheitsverlauf heranziehen konnte. Unterteilt in Todesursachen bei Kindern und Jugendlichen (bis 14 Jahre alt) bzw. Erwachsenen wurden die Eintragungen tabellarisch nach Häufigkeit quantitativ erfasst. Unter den Todesursachen bei Ersteren (s. Tab. 14) fanden sich unter insgesamt 201 Todesfällen ca. $10 \%$ Totgeburten. ${ }^{812}$ Pocken nahmen mit $20 \%$ den Hauptteil der Todesursachen bei Kindern und Jugendlichen ein. Die Jahre, in denen diese Todesfälle auftraten, stimmen zeitlich mit den bekannten Pockenepidemien in Brandenburg überein. Nicht überraschend waren die klassischen Kinderinfektionskrankheiten Keuchhusten, Röteln, Scharlach und Masern. Dagegen lagen gehäuft Todesfälle mit vorangehenden krampfartigen Erscheinungen vor, die heute praktisch keine Bedeutung mehr haben. Ob sie alle im Zusammenhang mit Wundinfektionen beim Durchbruch der ersten Zähne standen, sei dahingestellt. Dafür spricht allerdings ihr Auftreten vor allem im Alter von 8 bis 12 Monaten; daneben spielten die häufig auftretenden „Bauchkrämpfe“ bei Säuglingen eine Rolle. Das ist ein typisches Beispiel dafür, dass das die Krankheit prägende klinische Symptom (ohne Abklärung der Genese) als Todesursache angegeben wurde.

Die Todesursachen bei Erwachsenen waren verständlicherweise anderer Natur (s. Tab. 15). Bei den 189 auswertbaren Fällen bestand die Haupttodesursache in Altersschwäche (20\%) und Auszehrung (19\%). Auch die weiteren Hauptkrankheiten waren nicht überraschend: Schwind-

811 GStA PK: Rep. 243 Evang. ref. Kirchendirektorium Nr. 440, fol. 135 ff.

812 Bei Hinzuzählung der perinatal Verstorbenen erhöht sich dieser Anteil auf $12 \%$. 


\section{Zusammenfassung}

sucht, hitziges Fieber (wieder ohne Angabe der Grundkrankheit) und Schlaganfall. 9 Fälle von Wochen- bzw. Kindbettfieber schlugen mit $5 \%$ zu Buche. Ohne Zweifel stellte im 17./18. Jahrhundert die Geburt eines Kindes für die Frauen ein erhöhtes Lebensrisiko dar. Relativ häufig kam das Ertrinken vor, denn zu dieser Zeit konnten die wenigsten Menschen Schwimmen. Bei allen anderen aufgeführten Todesursachen handelt es sich um Einzelfälle. Bei dem Sterbeeintrag des ausrangierten Grenadiers Johan Kähr vom Königlichen Leibregiment wurde ein sonderlich merckwürdig[er] Besuch Friedrich Wilhelms I. an seinem Sterbebett vermerkt.

Die Lebenserwartung der Schweizer Kolonisten im Golmer Bruch ließ sich nur bedingt ermitteln, weil die Geburtsdaten der ersten zwei Generationen im Kirchenbuch von 1685-1801 (Vol. I) fast vollständig fehlen. Dies traf auch für weitere 83 Personen zu. Außerdem waren Altersangaben wie beispielsweise ... ging ins 77ste Jahr ... als zweifelhaft anzusehen. Dadurch waren nur 513 Fälle auswertbar. Deswegen wurden zur Auswertung der Lebenserwartung Alterscluster über 5 Jahre und zur Darstellung der Perinatalsterblichkeit zusätzlich ein Alterscluster von 0 bis 1 Jahr gebildet (s. Kap. VII.5.3., Abb. 16). Die errechnete durchschnittliche Lebenserwartung lag bei Männern mit 27,1 und bei Frauen 22,6 Jahre deutlich niedriger als heute. Dabei wurde in Einzelfällen durchaus ein Alter von 90 Jahren erreicht. Hinsichtlich der Perinatalsterblichkeit ergab sich - gemessen an heutigen Verhältnissen $(<0,1 \%$ ) - ein noch krasseres Bild. Bis zum 1. Lebensjahr verstarben 28,5\% der Kinder. Davon entfielen $55,5 \%$ auf Knaben und 45,5\% auf Mädchen. Das entspricht größenordnungsmäßig Vergleichszahlen aus der Literatur. ${ }^{813}$

IX.8. Die Frage der Toleranz Fremden gegenüber ist bis heute aktuell geblieben. Bei den Unterschieden, die die Arbeit an verschiedenen Stellen zwischen den eingewanderten Schweizer Kolonisten und den einheimischen Bauern deutlich zum Ausdruck bringt (s. Kap. V.1. und VIII.1.), musste der Toleranzfrage besondere Aufmerksamkeit geschenkt werden. Als kleine Einwanderergruppe und von ihrer Profession her war für die Schweizer Kolonisten eine totale Assimilation in der neuen Heimat unvermeidlich. Da bislang diese Vorgänge (Umgangssprache, Erbrecht u. a.) so gut wie nicht beschrieben wurden, kam es dem Autor vor allem darauf an, hierauf in seinen Ausführungen einzugehen. Dass sich die Kanzleisprache in Berlin und Bern/Zürich unterschied, ist leicht und unzweifelhaft an Hand der Anredeformeln, der Schreibweisen vieler Wörter sowie Dialektbesonderheiten (wie z.B. Hornung) nachzuvollziehen.

Die Befürchtung des Kurfürsten Friedrich Wilhelm, dass die Schweizer Kolonisten möglicherweise den märkischen Dialekt nicht verstehen könnten und daher einen eigenen Prediger zugestanden bekamen, ${ }^{814}$ war sicherlich, abgesehen von kirchenpolitischen Aspekten, nicht ganz unberechtigt. Der Beweis dafür lässt sich leider nicht sprachwissenschaftlich durch einen exemplarischen Vergleich der bäuerlichen Umgangssprache erbringen. Zum Glück sind aber einige wenige Schriftstücke von den Schweizer Kolonisten aus der frühen Ansiedlungs-

813 Meier, Brigitte: Neuruppin - 1700-1830, Berlin (1993), bes. S. 124; Zinke, Regine: Steglitz bei Berlin Dorfleben im Spiegel des Kirchenbuches 1605-1810, Leipzig (1996), bes. S. 108-111.

814 Art. 8 des Ansiedlungsvertrages vom 16.09.1685; s. Anhang 4 und Kap. IV.6. 
zeit überkommen. Der Autor hat dafür als Beispiele die Bittgesuche aus den Jahren 1694 und 1695 (s. Anhang 9 und 11) ausgewählt und zitiert. Das letztere kann als unverfälschte bäuerliche Umgangssprache angesehen werden und belegt pars pro toto, dass die Schweizer Kolonisten im Gegensatz zu den Einheimischen schreiben und lesen konnten, wobei die Lesbarkeit auf Grund der ungewöhnlichen Schreib- und Ausdrucksweise Schwierigkeiten bereitete.

Die Sprachassimilierung ließ sich im Kirchenbuch (Vol. I) leicht anhand der sich mit der Zeit ändernden Schreibweise der Familiennamen belegen und zeitlich zuordnen/verfolgen (s. Kap. VIII.1.). Zumeist handelte es sich dabei um Lautverschiebungen, wie dies beim Übergang von der mittelhochdeutschen in die hochdeutsche Sprache, z. B. „hus“ zu „Haus“, ebenfalls geschehen ist. Aus der Grundgesamtheit von 590 Geburten ließ sich ein allmählicher Übergang zu landesüblichen Vornamen verfolgen. Wenn das Vornamenspektrum der Schweizer Kolonisten (Kinder wie Erwachsene) stark an biblische Personen und Heiligengestalten angelehnt war, dann blieb diese Tradition nur bei den Mädchen noch lange unverändert erhalten. Es lag nahe, auf die Sprachassimilation bei den französisch-reformierten Hugenotten einzugehen; soweit sie im städtischen Bereich erfolgte, verlief sie nach eigenen Gegebenheiten und hinterließ bis heute in der deutschen Sprache ihre Spuren.

Bei einem Nebeneinander einer kleinen wirtschaftlich privilegierten und zusätzlich anderskonfessionellen Minderheit (Kolonisten) einerseits und der Mehrheit (alteingesessene Bevölkerung) anderseits konnten neiderfüllte Spannungen verschiedenster Art nicht ausbleiben. Dazu haben zunächst sicherlich die Fremdlinge mit ihrem selbstbewussten Auftreten als „freie Menschen“ im absolutistischen Brandenburg ihren Teil beigetragen. Diese „Fremdwahrnehmung " ${ }^{815}$ hat lange Zeit als schwelender Prozess angehalten und trat regelmäßig beim Vorliegen krisenhafter Zustände zu Tage. Was Enders (2001) von der friderizianischen Kolonisation beschreibt, konnte der Autor u. a. anhand einer bislang unbekannten anonymen Verleumdung der Neu Töplitzer Schweizer Kolonisten belegen (s. Kap. VIII.2. und Anhang 18).

Der den Schweizer Kolonisten nachgesagte extreme Zusammenhalt findet sich praktisch bei allen Minderheiten. Dieses Verhalten ist immer ein Teil der Überlebensstrategie von Minderheiten im fremden Land, und lässt sich bei den im Golmer Bruch angesiedelten Schweizer Kolonisten vornehmlich im Heiratsverhalten und im Abweichen vom landesüblichen Erbrecht nachweisen. Wie die vitalstatistische Auswertung des Kirchenbuchs (Vol. I) der Schweitzer Gemeinde im Golmer Bruch bei Potzdam ergab, fanden im Gegensatz zu den Schweizer Gemeinden im Ruppinschen Raum erst ab 1748 Hochzeiten mit Lutheranern statt (s. Kap. VIII.2.). ${ }^{816}$ Auch bei den erbrechtlichen Fragen blieben sie eisern. Da die ältesten Grund-

815 Zum Begriff der „Fremdwahrnehmung“ siehe Peters, Jan: Das Gesetz und der Gebrauch, in: Klaus Neitmann/Jürgen Theil (Hg.): Die Herkunft der Brandenburger, Sozial-und mentalitätsgeschichtliche Beiträge zur Bevölkerung Brandenburgs vom hohen Mittelalter bis zum. 20 Jahrhundert, 2. Aufl., Potsdam (2003), S. 79-93.

816 Caspar Zoberist, der bereits am 7. Oktober 1689 die lutherische Kossätentochter Catharina Hainicke aus Golm heiratete, dürfte als Ausnahme von der Regel angesehen werden, zumal sie danach aus dem land gezogen sind. 


\section{Zusammenfassung}

bücher verloren gegangen sind, ist bislang in Vergessenheit geraten, dass die Schweizer Kolonisten anfänglich das Schweizer Erbrecht weiter tradierten. Danach wurden die von dem Witwer bzw. der Witwe in die Ehe gebrachten Kinder mit den aus der 2. Ehe stammenden Kindern gleichgestellt. Später ging man allerdings zum deutschen Erbrecht über.

Was der Autor bereits an anderer Stelle thematisiert hat ${ }^{817}$, ist die große Opferbereitschaft der Schweizer Kolonisten während der Befreiungskriege 1813-1815 (s. Kap. VIII.2.). Die hierüber gebrachten Beispiele aus den Extra-Blättern zum Amtsblatt dürfen keineswegs als enumerativ angesehen werden. Sie hatten gleichermaßen wie die Einheimischen unter der französischen Fremdherrschaft gelitten und identifizierten sich anscheinend mit der Situation vor Ort.

Die in der Literatur häufig angeführten konfessionellen Spannungen als Teil der Streitigkeiten zwischen der einheimischen Bevölkerung und den zugewanderten Kolonisten haben bei den Schweizer Kolonisten im Golmer Bruch praktisch keine Bedeutung gehabt. Durch die eigene Friedensreichkirche war ein in anderen Orten häufiges Konfliktpotential nicht gegeben. Die zeitweise ungeklärten Stolgebührenbestimmungen sieht der Autor nicht wirklich als ein Beleg dafür an. Allerdings haben die Schweizer Kolonisten in für sie schwierigen Zeiten ein unterschiedliches Verständnis bei den lutherischen bzw. reformierten Beamten erfahren. Das spiegelt sich wider, indem beispielsweise in der Korrespondenz zwischen Lupichius und seinen Oberen in Bern immer in Verbindung mit der Zitierung eines Beamten dessen Konfession kenntlich gemacht wird. In gewisser Weise war das ein Missbrauch einer staatlichen Funktion (s. Kap. VI.2.3.).

Die Arbeit verfolgte die Absicht insbesondere zwei Aspekte der Ansiedlung der Schweizer Kolonisten im Golmer Bruch zu bearbeiten: ihre wirtschaftliche Entwicklung und konfessionellen Eigenarten bis zu ihrer Gleichstellung (Separation bzw. Aufgehen in der unierten Kirche) mit der einheimischen Bevölkerung. Durch die breit angelegte Recherche dieser beiden Aspekte in zehn Archiven konnten hierzu einerseits eine Reihe von bislang nicht bekannten Fakten und Zusammenhänge aufgefunden und andererseits bisherige Darlegungen in der Literatur richtig gestellt werden. Der Autor hofft, dass diese Arbeit neben den neuen Erkenntnissen Anregungen und Anstöße zu weiteren Diskussionen und Forschungen gibt. 


\section{Abbildungen}

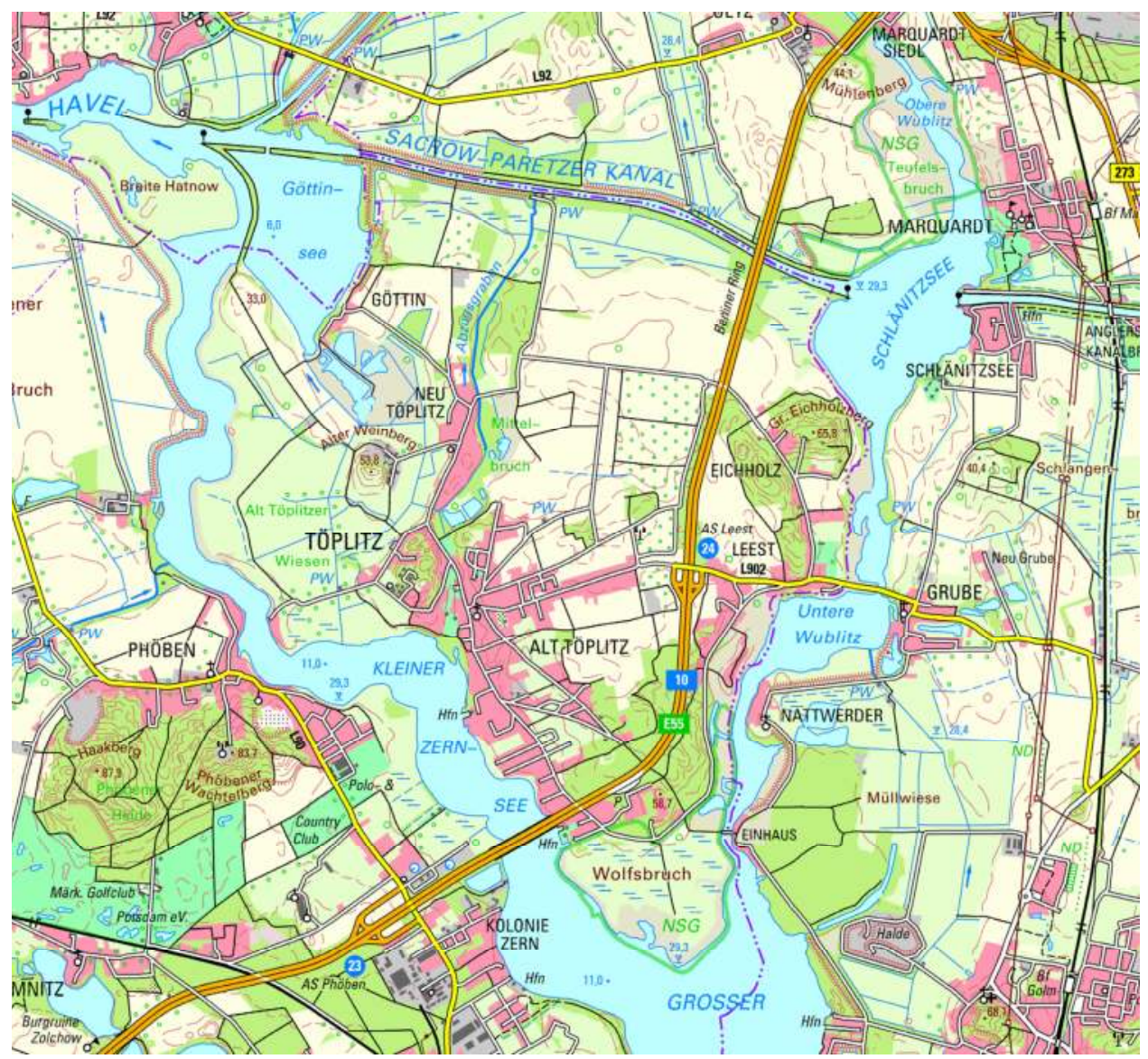

Abb. 1: Kartenausschnitt der Niederungslandschaft jenseits der Wublitz, Quelle LGB Kundenservice. 


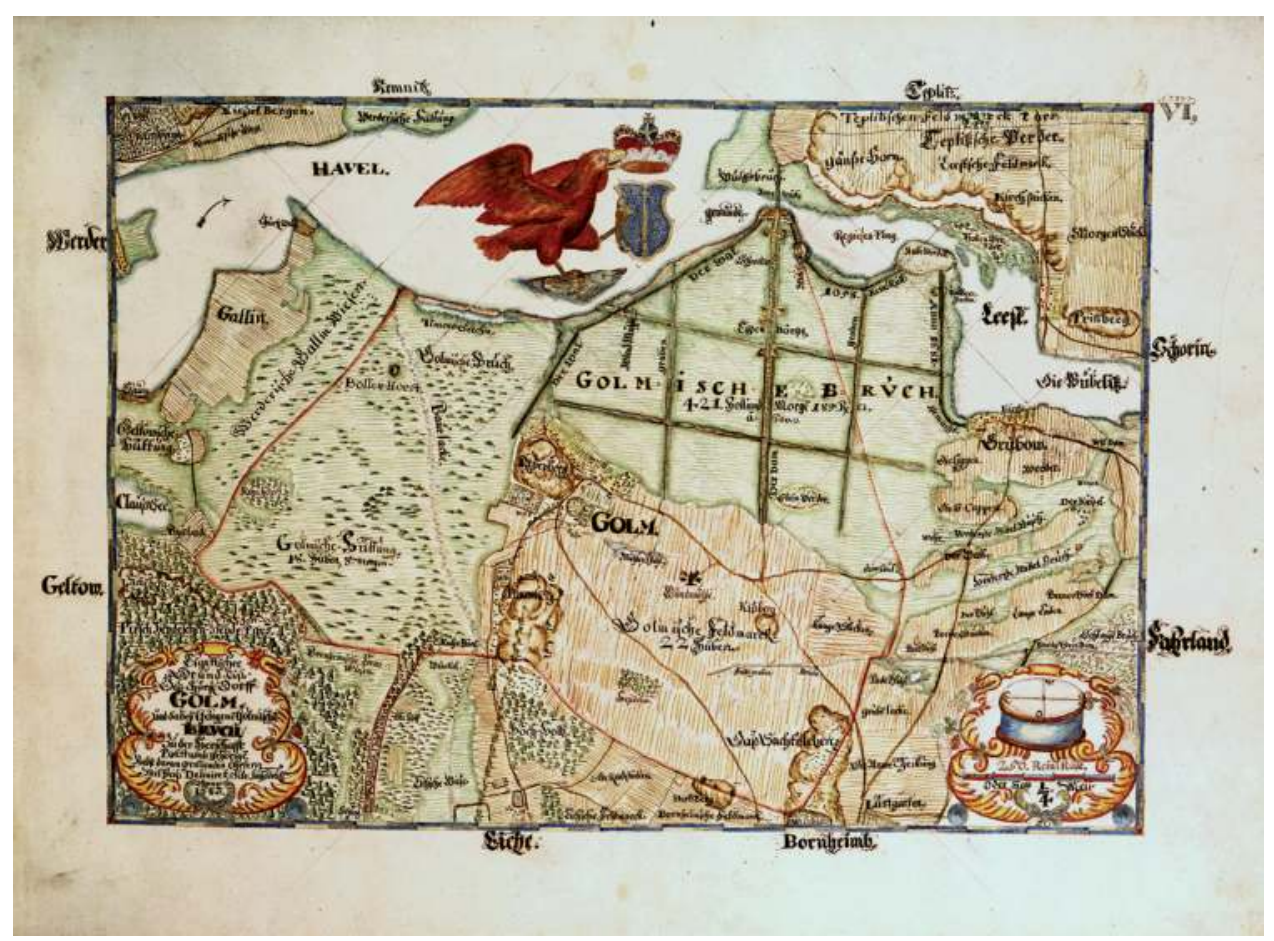

Abb. 2: Atlas der Herrschaft Potsdam von Suchodoletz (1683), Blatt V| ${ }^{818}$; Quelle GStA PK. 


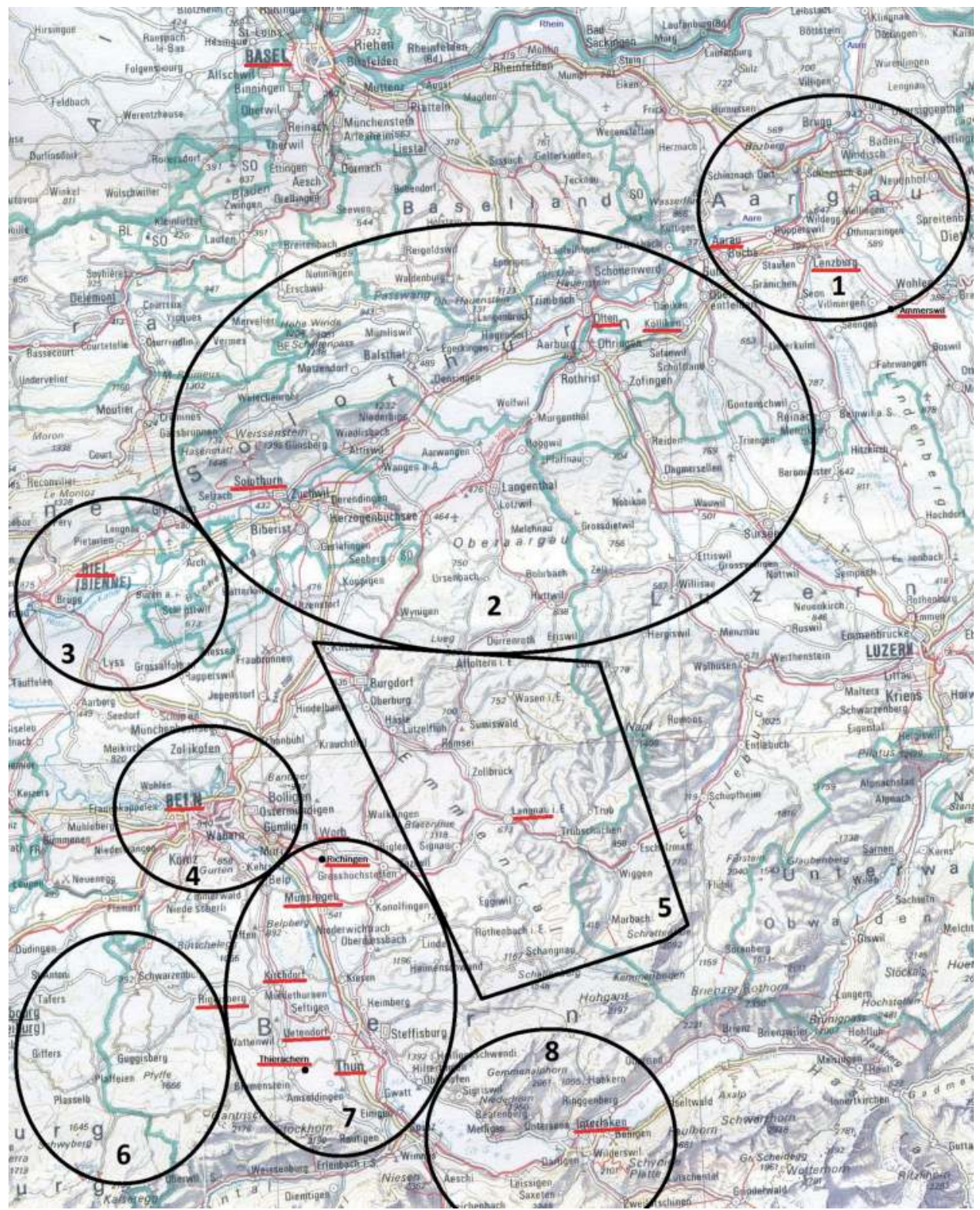

Abb. 3: Herkunftsorte (rot unterstrichen) ${ }^{819}$ und Dialektzugehörigkeit der Schweizer Kolonisten: 1)

Aargauer Dialekt, 2) Solothurner Dialekt, 3) Zweisprachiges Biel (dtsch. + frz.),

4) Stadtberner Dialekt, 5) Emmentaler Berndeutsch, 6) Guggisberner Berndeutsch,

7) Aaretaler Berndeutsch und 8) Oberländer Berndeutsch, Quelle Museum Krauchthal. 


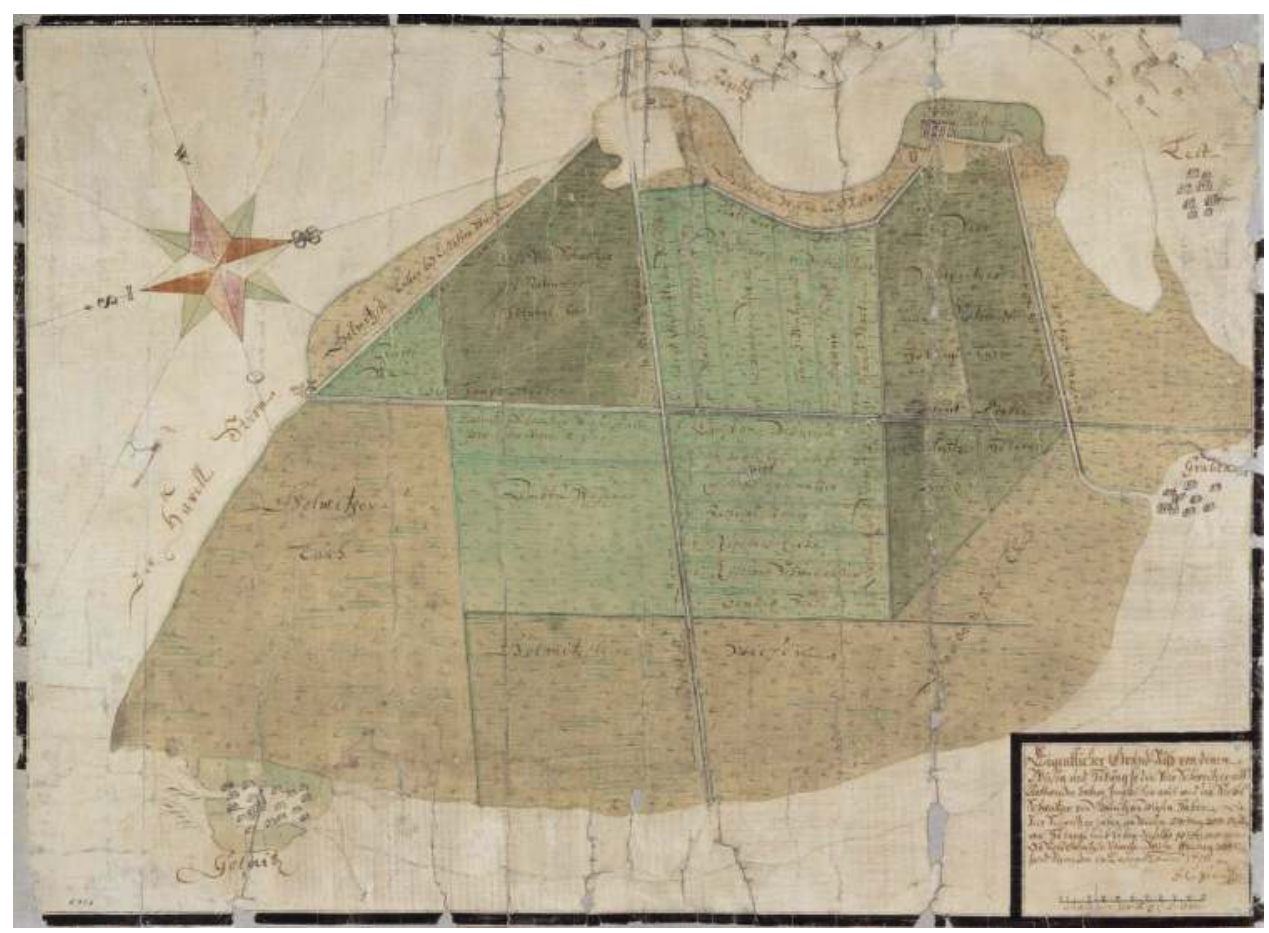

Abb. 4: Spezialkarte des Golmer Bruches von J.C. Grundt aus dem Jahre 1715, wo zum ersten Mal auf einer Karte die vier Höfe der Schweizer Kolonisten in Nattwerder und ihre in Kaveln aufgeteilte Feldmark (hell- und dunkelgrün koloriert) eingezeichnet sind, die praktisch mit den tiefer gelegenen Teilen des Golmer Bruchs identisch ist. ${ }^{820}$, Quelle GStA PK.

820 GStA PK, XI. HA, Plankammer der Regierung zu Potsdam, E 707.

Ihre Beschriftung lautet: Eigentlicher Grund-Riß von denen Wiesen und Hütung so die Vier Schweitzer aus Nathwerder haben Imgleichen auch was die Sechs Schweitzer von Golmitz an Wiesen haben, Die Vier Schweitzer haben an Wiesen 54. Morg. 305. Ruthen an Hütungs Luch haben dieselbe 102 1/2 morgen Die Sechs Golmitzsche Schweitzer an Wiesen 62 Morg. 360 Ruthen seind Vermeßen im Decembr: Te. 1715 von J.C. Grundt, Maßstab 100 Reinl. Ruthen. 


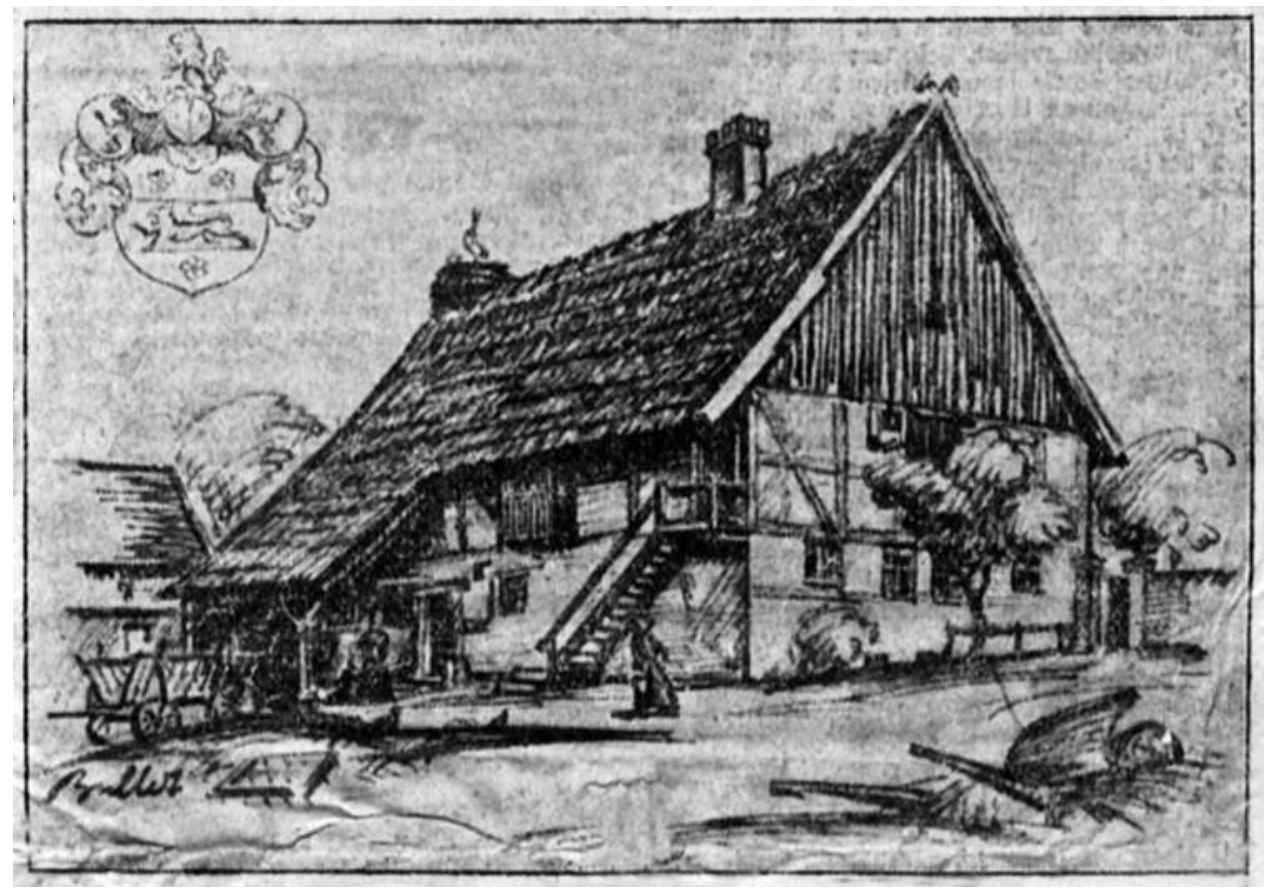

Abb. 5: Schweizer Haus der Familie Garmatter in Neu Töplitz, Graphik von Walter Bullert ${ }^{821}$, Quelle Potsdamer Tageszeitung vom 18. Oktober 1924.

821 abgedruckt in der Potsdamer Tageszeitung vom 18. Oktober 1924 (Nummer 246), dort wie folgt beschriftet: Sonderzeichnung für die P.Z. von Walter Bullert, Schweizerhaus der Familie Garmatter. Aus dem 17. Jahrhundert, jetzt niedergelegt, Links oben das Wappen des Geschlechtes Garmatter. Walter Bullert war ein Potsdamer Maler, Graphiker und Bildhauer (1895-1986).

Interessanterweise scheint der Grundriss dieses Hauses mit den Grundrissen der am 3. Juni 1867 abgebrannten Nattwerderschen Schweizer Gehöfte übereinzustimmen (s. Abb. 6). 


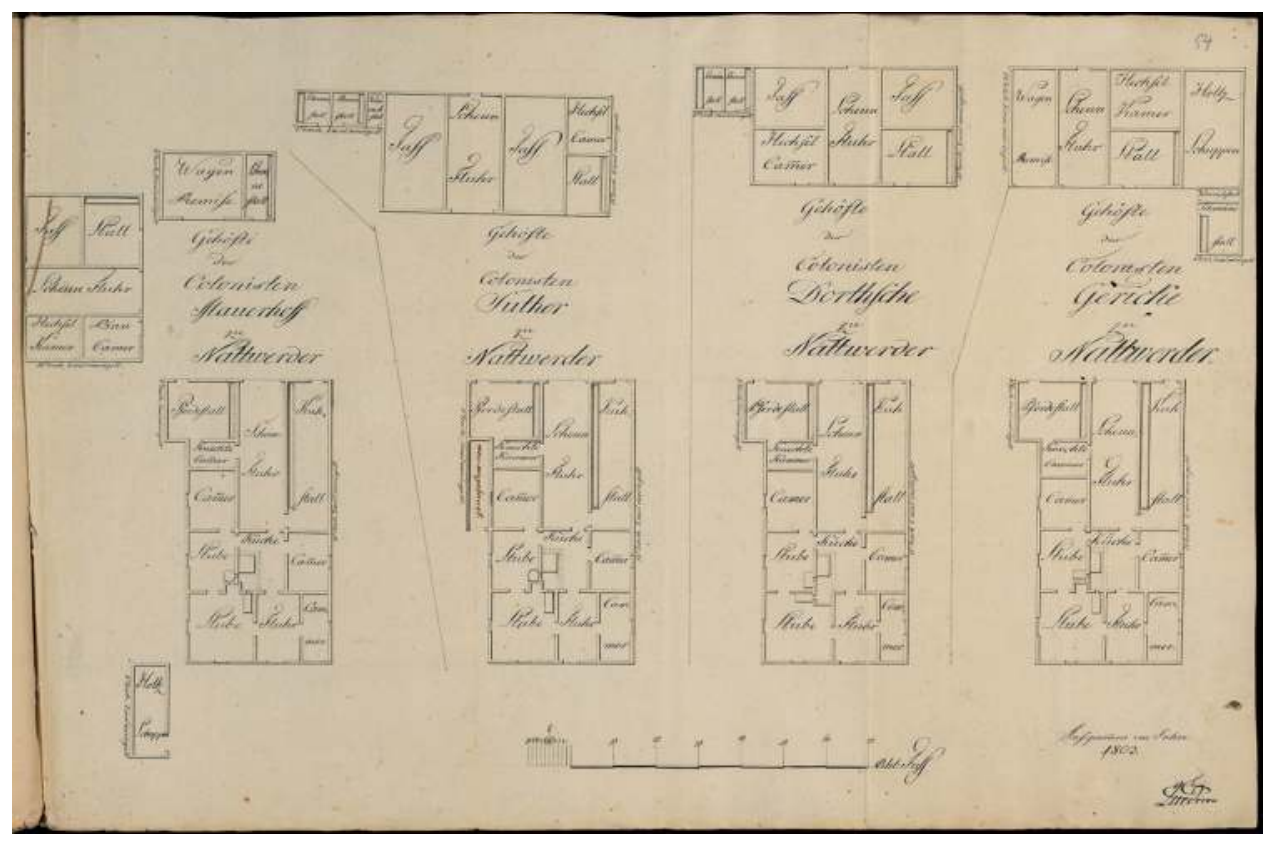

Abb. 6: Grundrisse der vier Höfe der Schweizer in Nattwerder, die im Jahre 1867 auf Grund eines Blitzeinschlages komplett abgebrannt sind; ${ }^{822}$ Quelle BLHA.

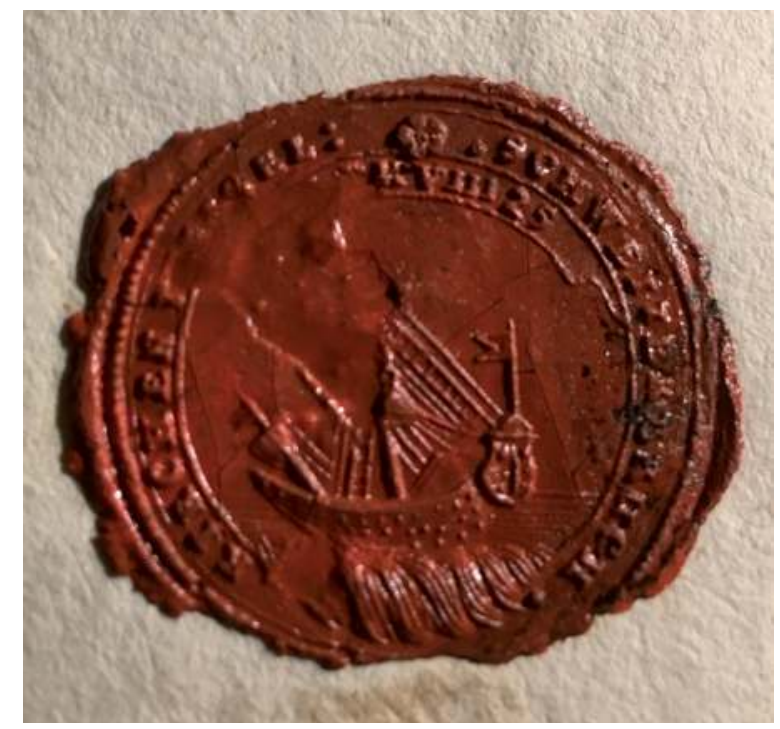

Abb. 7: Das erste Kirchensiegel der Reformierten Schweizer Gemeinde, Quelle, KA Alt Töplitz: Alte Akten 1713-1799.

822 BLHA, Rep. 2A Regierung Potsdam III Nr. 15007, fol. 54. 

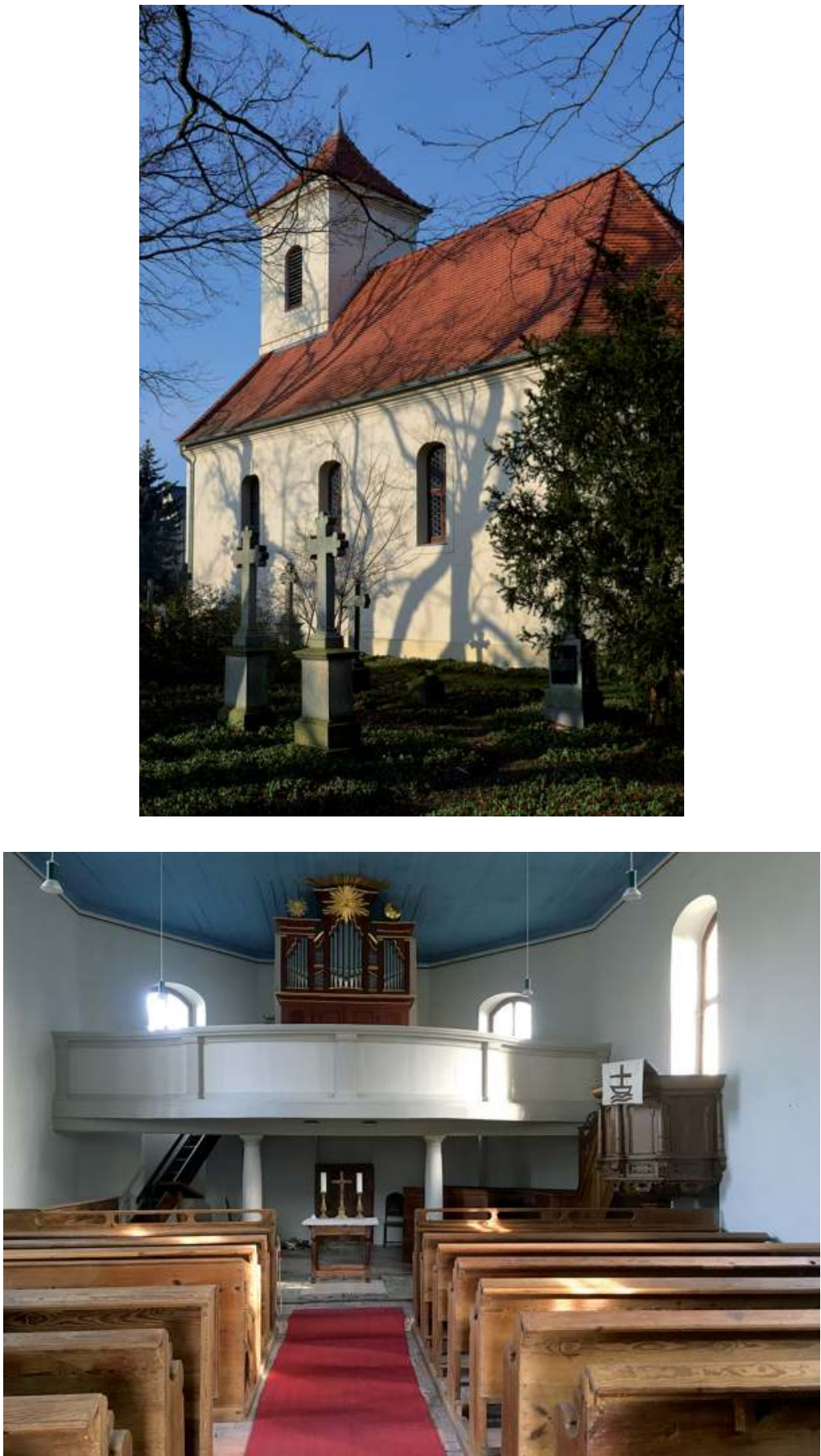

Abb. 8 a und b: Die Kirche Nattwerder mit dem sie umgebenden Kirchhof von 0sten (a) und ihr Kirchenraum nach der Sanierung 2013/2017 (b), Quelle Autor. 


\section{Abbildungen}

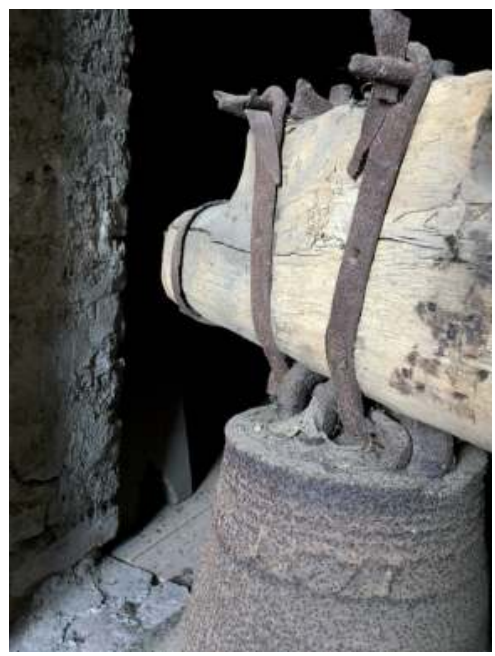

Abb. 9: Eisenglocke von 1677 mit handgeschmiedeten Eisenbänderaufhängung, die zeitgemäß lediglich verkeilt sind, Quelle Autor.

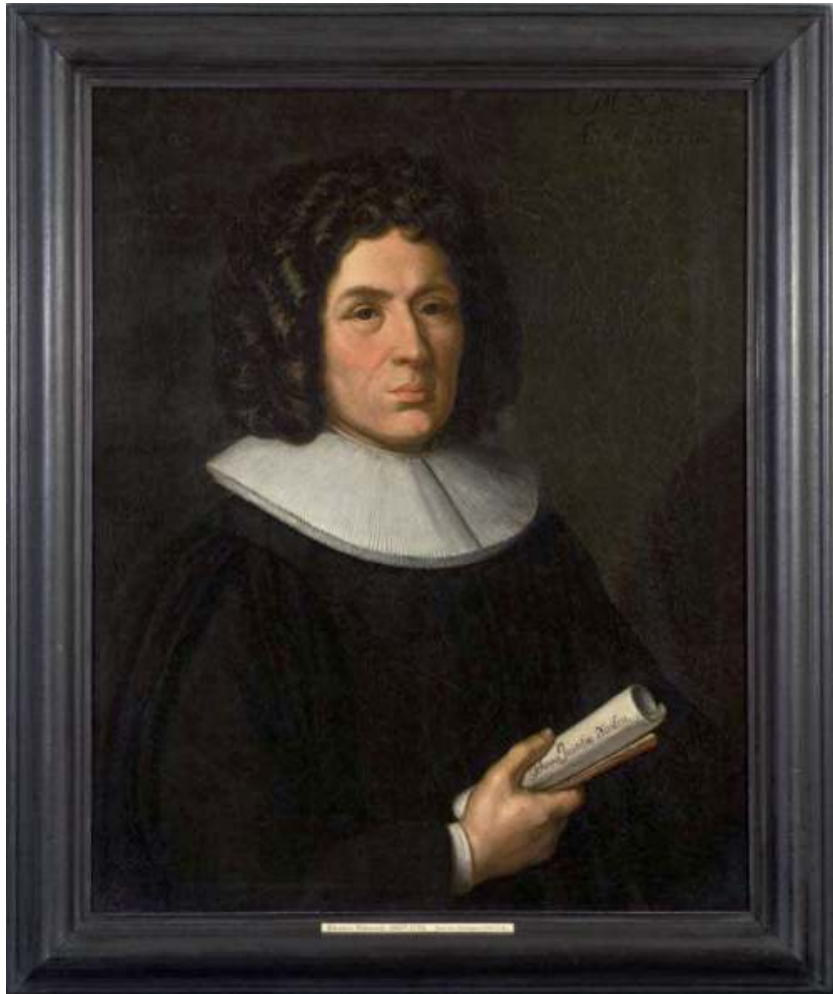

Abb. 10: Elisaeus Malacrida (1657-1719), hier als Professor der Hohen Schule in Bern im Jahre 1713, Quelle Burgerbibliothek, Bern. 


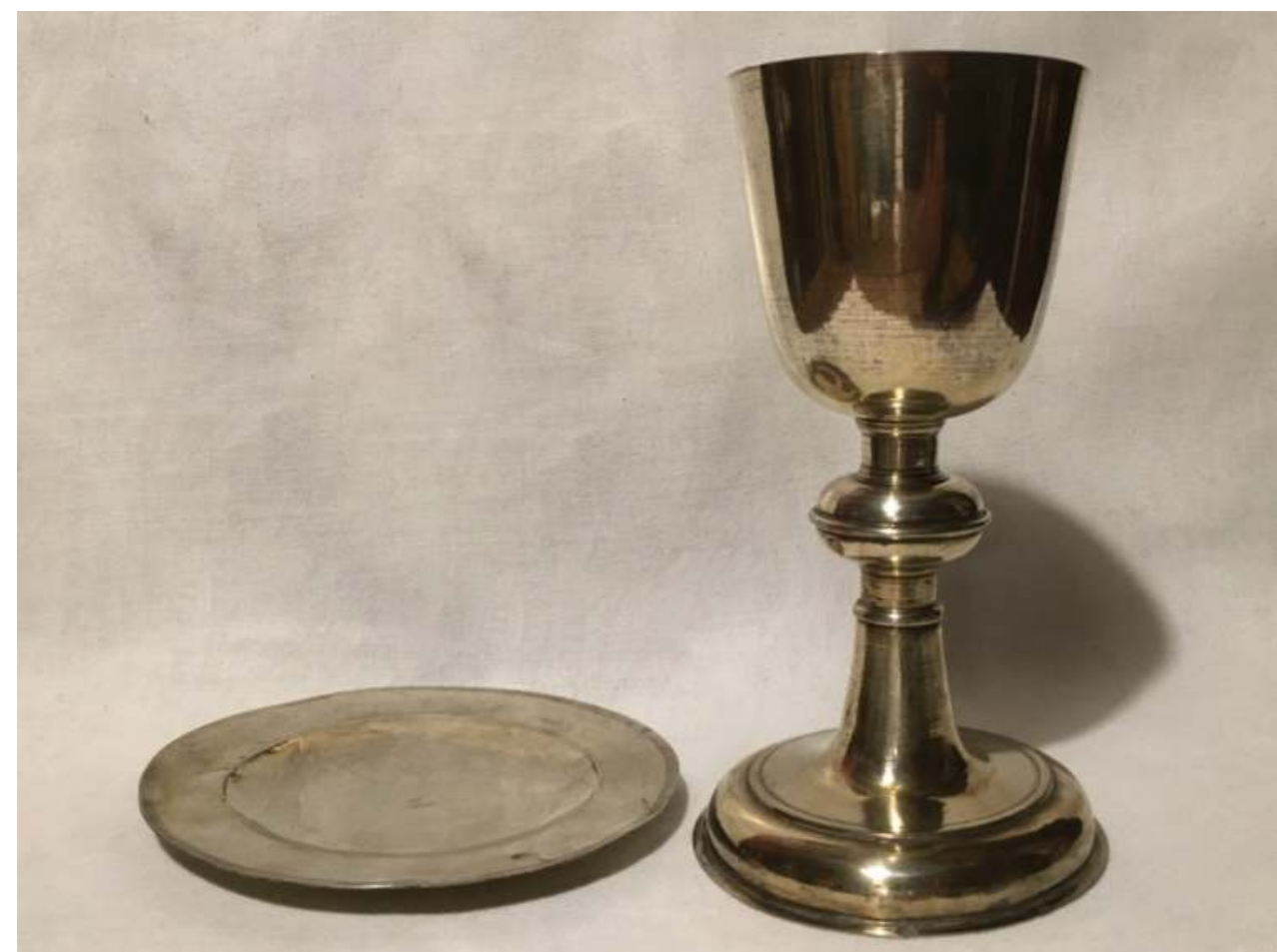

Abb. 11: Oblatenschale und Abendmahlskelch der Reformierten Schweizer Gemeinde Golmer Bruch (nicht datiert), Quelle Autor. 


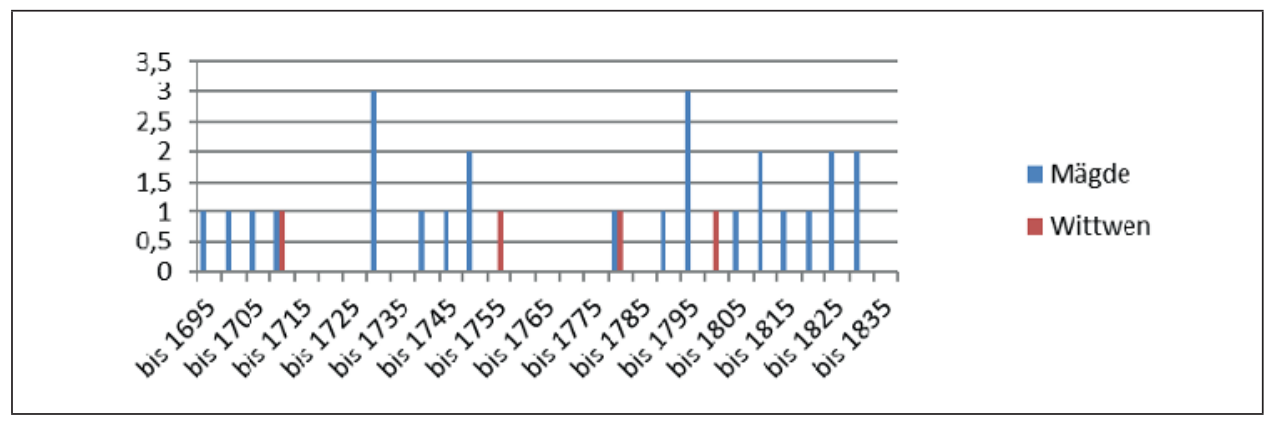

Abb. 12: Verteilung der unehelich geborenen Kinder von 1685-1835.

Eman. Maurhoffer $\infty$ Mar. Magd. Lenz Johann Durtschy $\infty$ Elßbeth Garmatter Jacob Dedweiller

\begin{tabular}{|c|c|c|c|}
\hline Christian & ${ }^{*} 03.02 .1726$ & Johann Heinrich & Johann \\
\hline Joh. Friedr. & $* 26.07 .1727$ & Magd. Elisabeth & * 18.06 .1730 \\
\hline Emanuel & *26.03.1729 & Anna & $* 26.10 .1731$ \\
\hline Maria & * 10.09 .1730 & Elisabeth & *05.05.1734 \\
\hline Reg. Elis. & *21.04.1732 & & \\
\hline Jacob & * 16.12 .1733 & & \\
\hline An. Christina & ${ }^{*} 16.03 .1735$ & & \\
\hline
\end{tabular}

Abb. 13: Doppelhochzeit zwischen Familie Maurhoffer und Durtschy von Neu Töplitz sowie Hochzeit zwischen Familie Durtschy mit Familie Dedweiller von Bornstedt, Quelle: KA Alt Töplitz. 


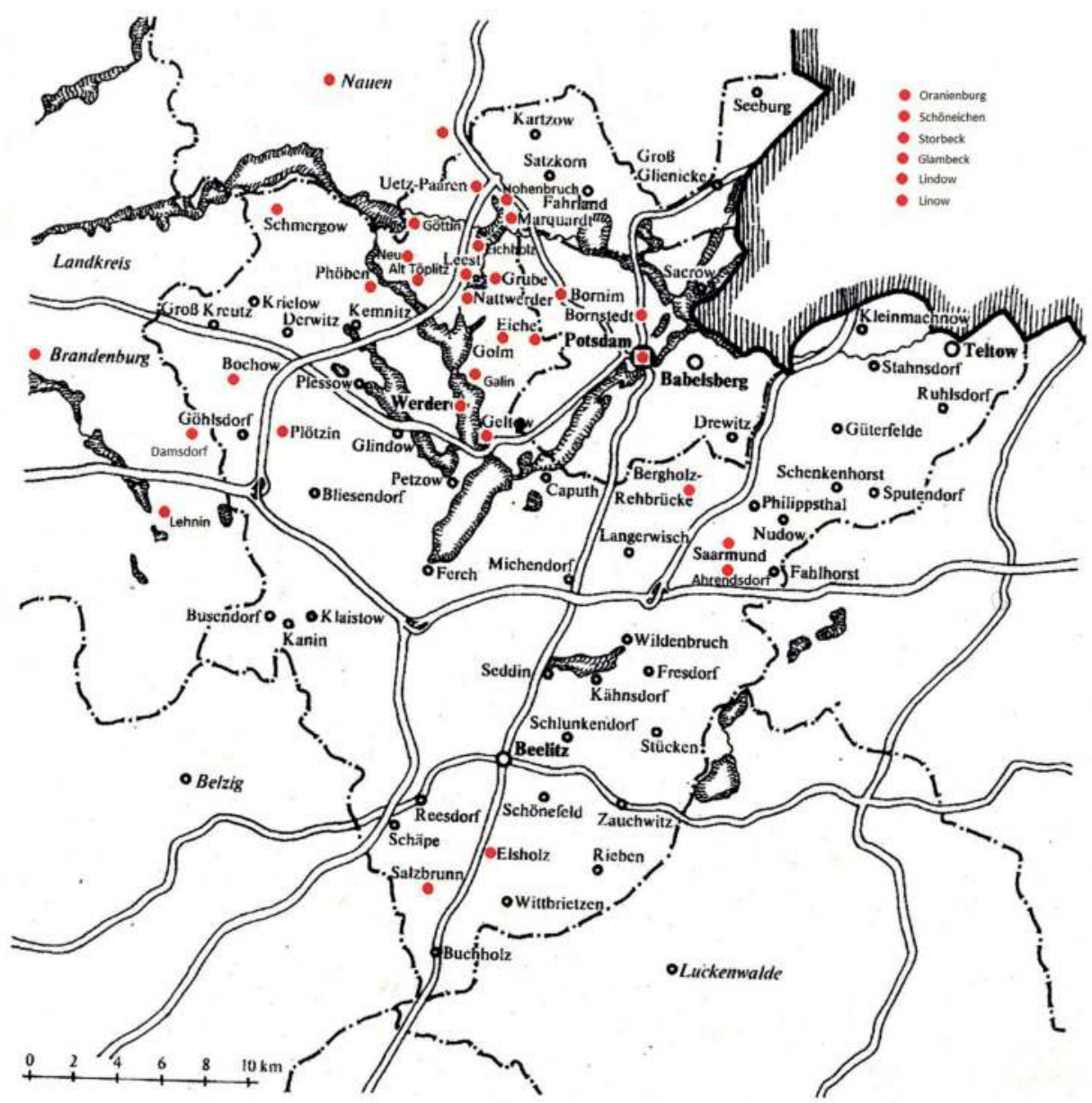

Abb. 14: Herkunft der Brautleute aus der näheren Umgebung mit Schwerpunkt Amt Potsdam und Lehnin (Oranienburg, Schöneiche Storbeck, Glambeck, Lindow und Linow liegen außerhalb des Kartenausschnittes, überarbeitete Quelle: Die Bau- und Kunstwerke, Bezirk Potsdam (1978). 


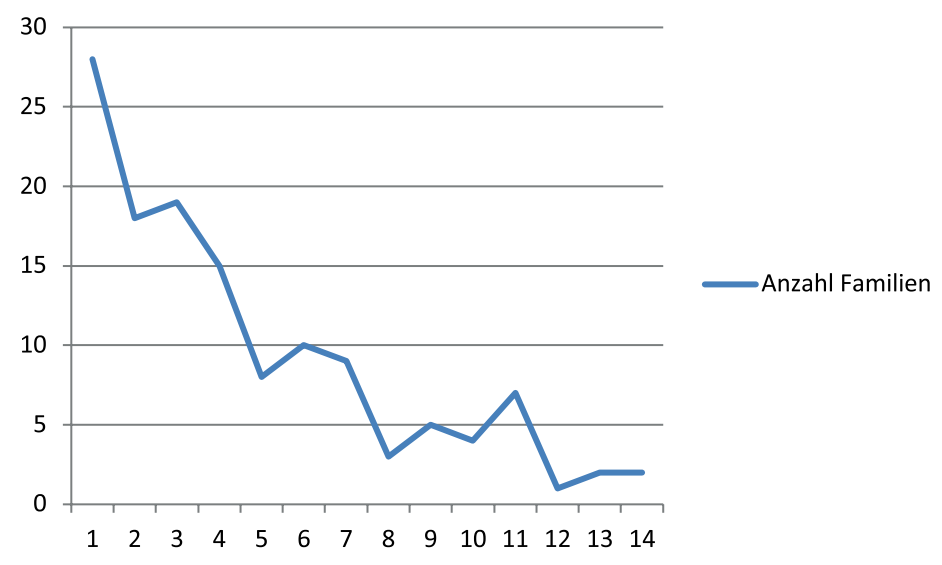

Abb. 15: Die Anzahl der geborenen Kinder pro Familie.

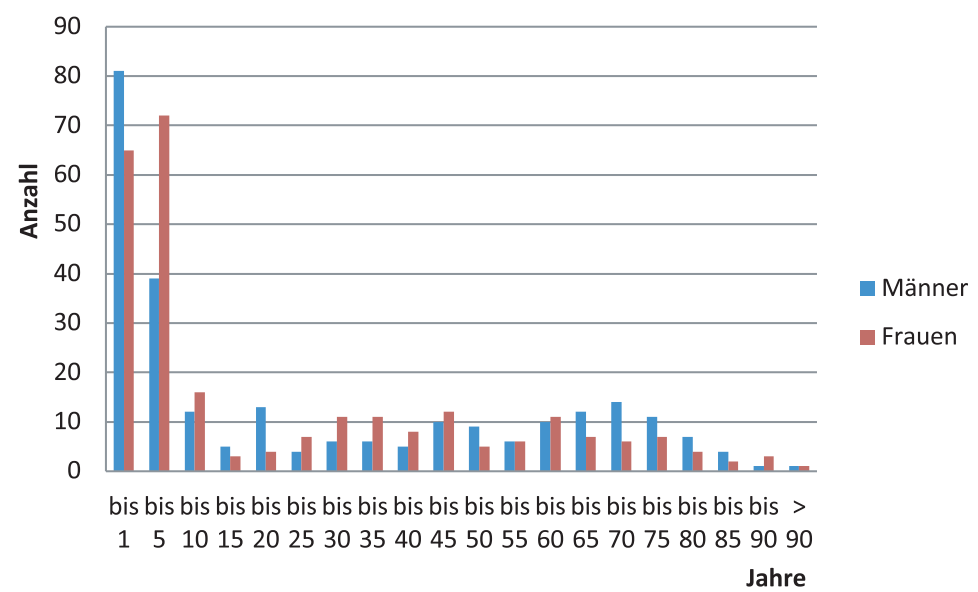

Abb. 16: Lebenserwartung der von 1705 bis 1835 gestorbenen Männer und Frauen in 5-jährigen Altersklassen von 1685-1835. 


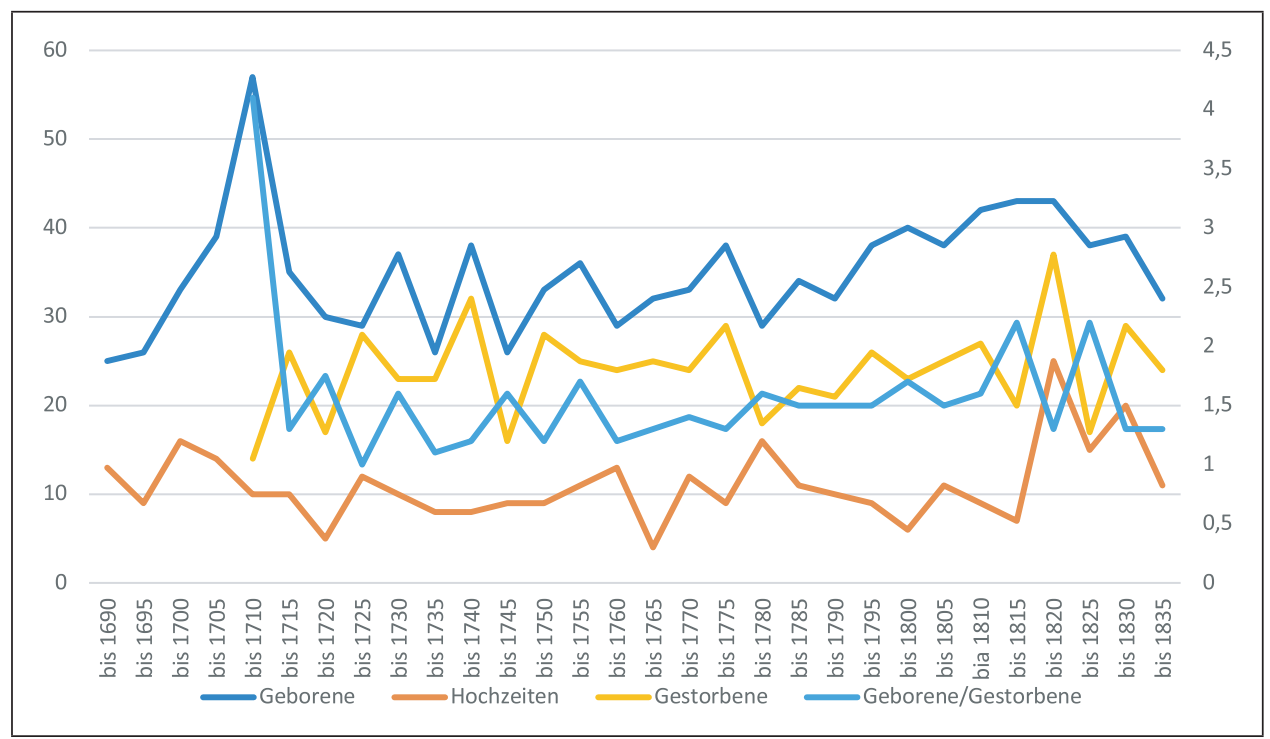

Abb. 17: Entwicklung der Reformierten Gemeinde Golmer Bruch, dargestellt anhand der Anzahl der Geburten, Hochzeiten und Beerdigungen (linke y-Achse) und des Verhältnisses von Geborenen/Gestorbenen (rechte y-Achse) von 1685-1835. 



\section{Abkürzungsverzeichnis}

Abb.

a.c.

Abth./Abt.

AKPS

ALR

amtl.

Anh.

Anm.

Ao/ao.

Apr.

ApU

Art.

Aug.

A. V.

Bd.

Bdbg.

bearb.

bes.

BLHA

BRD

CCM

$\mathrm{CDB}$

Charl.

Churfl. Durch.

d./d

DBE

DC

DDR

dgl.

Diss.

Doroth.

drs.

dsg.

DStA Brandenburg

ej.

ELAB

Elisab.

EOK

etc.

Abbildung

anni currentis (lat., laufenden Jahr)

Abtheilung (Abteilung)

Archiv der Evangelischen Kirche der Kirchenprovinz Sachsen

Allgemeines Landrecht

amtlich/e

Anhang

Anmerkung

Anno (lat., Jahr)

April

Altpreußische Union

Artikel

August

Akten (Korrespondenzen) der Kanzlei Bern

Band

Brandenburg

bearbeitet

besonders

Brandenburgische Landeshauptarchiv

Bundesrepublik Deutschland

Corpus constitutionum marchicarum

Codex Diplomaticus Brandenburgensis

Charlotte

Kurfürstliche Durchlaucht

denar (lat., Pfennig), gelegentlich "der, dieser"

Deutsche Biographische Enzyklopädie

Deutsche Christen

Deutsche Demokratische Republik

dergleichen

Dissertation

Dorothea

derselbe

desgleichen

Domstiftarchiv Brandenburg

ejusdem (lat., desselben [Monats, Jahres])

Evangelisches Landeskirchliches Archiv in Berlin

Elisabeth

Evangelischer Oberkirchenrat

et cetera (lat., und so weiter) 


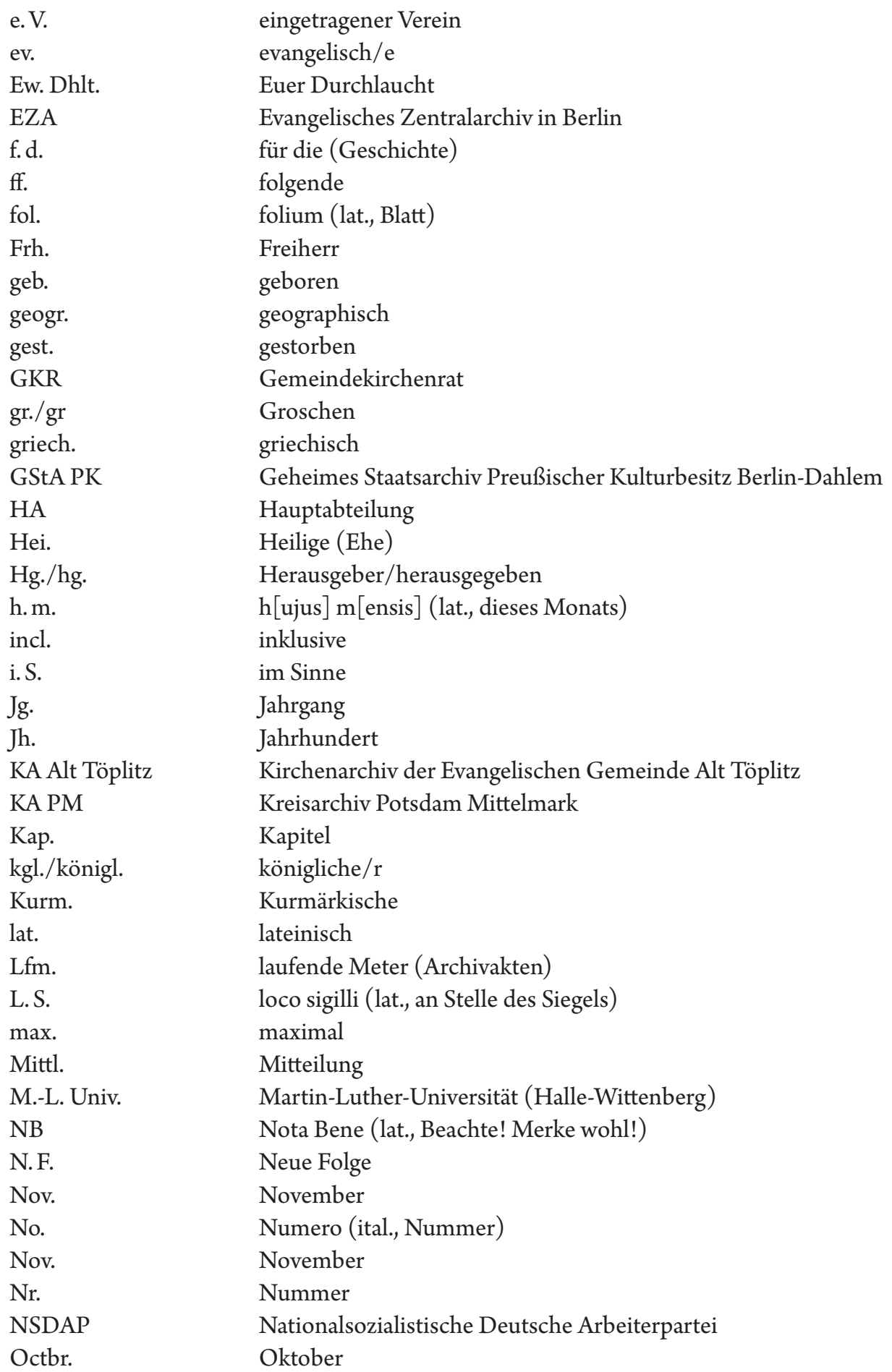




$\begin{array}{ll}\text { o.J. } & \text { ohne Jahresangabe } \\ \text { Reinl. } & \begin{array}{l}\text { Reinländische (Ruthen) } \\ \text { Rep. }\end{array} \\ \text { Rthl./rthl./Rtlr/Rt./ } & \\ \text { rt./thlr./Thl./Tlr. } & \text { Reichstaler } \\ \text { s. } & \text { siehe } \\ \text { S. } & \text { Seite } \\ \text { Sa } & \text { Summe } \\ \text { Sch./Schf. } & \text { Scheffel } \\ \text { Schr. } & \text { Schreiben } \\ \text { Septbr. } & \text { September } \\ \text { Sgr./Sgr } & \text { Silbergroschen } \\ \text { SKDN e. V. } & \text { Verein Schweizer Kolonistendorf Nattwerder e. V. } \\ \text { SMAD } & \text { Sowjetische Militäradministration [in Deutschland] } \\ \text { sog. } & \text { sogenannt/e } \\ \text { Sp. } & \text { Spalte } \\ \text { Sr. } & \text { Seine/Seiner/seiner } \\ \text { StA Bern } & \text { Staatsarchiv Bern } \\ \text { StadtA Potsdam } & \text { Stadtarchiv Potsdam } \\ \text { Tab. } & \text { Tabelle } \\ \text { Th. } & \text { Theil/Teil } \\ \text { v. } & \text { von } \\ \text { vgl. } & \text { vergleiche } \\ \text { Vol. } & \text { Volumen (lat., Band) } \\ \text { Wsp. } & \text { Wispel } \\ \text { zz. } & \text { zurzeit } \\ & \end{array}$





\section{Quellen- und Literaturverzeichnis}

\section{Verzeichnis ungedruckter Quellen}

1) Archiv der Evangelischen Kirche der Kirchenprovinz Sachsen (AKPSA Magdeburg)

Rep. A Spec G Pfarrstellen

Rep. A Spec P Personalakten

2) Brandenburgisches Landeshauptarchiv (BLHA)

Rep. 2 Kurmärkische Kriegs- und Domänenkammer

Rep. 2A Regierung Potsdam

Rep. 5D Kreisgericht Potsdam

Rep. 7 Amt Lehnin

Rep. 7 Amt Potsdam

Rep. 7

Amt Alt Ruppin

Rep. 23A Kurmärkische Stände, Rítterschaftliche Hypothekendirektion

Rep. 27C Kulturbauamt Potsdam

Rep. 41

Amtsbezirk Bornstedt/Bornim

Rep. 78

Kurmärkische Lehnskanzlei

Rep. 105

Grundbücher K I Potsdam

3) Domstiftarchiv Brandenburg (DStA Brandenburg)

BEN Ephorie Brandenburg Nattwerder

L-E Ephorie Lehnin

L-E AT Ephorie Lehnin Nattwerder

4) Evangelisches Landeskirchliches Archiv Berlin (ELAB)

Bestand 7 Personalakten

Bestand 14 Kirchenprovinz Brandenburg (18. Jh. - 1945)

Bestand 15 Kirchengemeinden

Bestand 35 Ev. Konsistorium Bln.-Bbg. (Ost) 1945-1993

5) Evangelisches Zentralarchiv Berlin (EZA)

Bestand $7 \quad$ Unierung 


\section{6) Geheimes Staatsarchiv Preußischer Kulturbesitz (GStA PK)}

Registraturbücher der Kurmark B3, B4

I. HA, Rep. 2 Geheimer Rat, Angelegenheiten der Kirche

I. HA, Rep. 9 Geheimer Rat, Allgemeine Verwaltung

I. HA, Rep. 11 Geheimer Rat, Auswärtige Beziehungen

I. HA, Rep. 21 Geheimer Rat, Brandenburgische Städte, Ämter und Kreise

I. HA, Rep. 47 Geheimer Rat, Geistliche Angelegenheiten

I. HA, Rep.50 Geheimer Rat, Beziehungen zu den Reichsstädten sowie zu anderen Städten außerhalb der Mark

I. HA, Rep. 122 Französisches Koloniedepartment

I. HA, Rep. 131 Archivkabinett

I. HA, Rep. 243 Evangelisches reformiertes Kirchendirektorium

II. HA, Abt. 14 Generaldirektorium, Kurmark

VI. HA Fürstliches Hausarchiv Dohna Schlobitten

X. HA, Rep. 2B Regierung Potsdam

X.HA, Rep. 16 Kleine Erwerbungen

X. HA, Rep. 40 Kurmärkisches Konsistorium bzw. Oberkonsistorium, später Evangelisches Konsistorium der Mark Brandenburg

XI. HA (AKS) Allgemeine Kartensammlung

XI. HA (PKP) Plankammer der Regierung Potsdam

7) Pfarrarchiv der Evangelischen Gemeinde Alt Töplitz (KA Alt Töplitz)

8) Kreisarchiv Potsdam Mittelmark (KA PM)

Rep. 50 (Töplitz)

9) Stadtarchiv Potsdam (StadtA Potsdam)

$1-12 / 46$ (Fischereirecht)

10) Staatsarchiv des Kantons Bern (StA Bern)

A. V. 19 Teutschland-Buch Preussen Brandenburg

\section{Quelleneditionen, Regestenübersicht und Bestandsverzeichnis}

Allgemeine Deutsche Biographie, Leipzig 1877.

Beck, Friedrich (Bearb.): Regesten und Urkunden kurmärkischer Stände (Rep. 23A) des Brandenburgischen Landeshauptarchivs 2006.

Berliner Lokal-Anzeiger (Morgenausgabe, 1. Beiblatt) Nr. 151 vom 25. Juni 1935: Festtage auf Schweizer Erbhöfen. 
Biographisch-Bibliographisches Kirchenlexikon, Nordhausen (1998), Bd. XIII.

Brandenburg-Berlinisches Wörterbuch, Bd. II, Neumünster (1985), Kolumne 489 und Bd. IV, Berlin (2001), Kolumne 501.

Brockhaus Konversationslexikon, Leipzig (1902).

CCM: Christian Otto Mylius (Hg.): Corpus Constitionum Marchicarum, Oder Königl. Preußis. und Churfürstl. Brandenburgische in der Chur- und Marck Brandenburg, auch incorporirten Landen publicirte und ergangene Ordnungen; Edicta, Mandata, Rescripta etc. Von Zeiten Friedrichs I. Churfürsten zu Brandenburg etc. biß dato unter der Regierung Friderich Wilhelms, Königs in Preußen etc. ad annum 1736. inclusivé; Berlin/Halle, I. Th. No. XXXXVI Columne 395 ff. und VI. Th. I. Abth. No. CXIII Columne 1650/1651.

CDB: Adolph Friedrich Johann Riedel (Hg.): Corpus diplomaticus Brandenburgensis.

Sammlung der Urkunden, Chroniken und sonstigen Geschichtsquellen für die Geschichte der Mark Brandenburg und ihrer Regenten, I. Haupttheil, Bd. 10., Berlin (1856)

Der Große Brockhaus, Leipzig 1933, Bd. 15, S. 480.

Deutsche Biographie Enzyklopädie (DBE), 2. Auflage, hg. von Rudolf Vierhaus, München, Bd. I (2005), S. 126 und Bd. VI (2006), S. 650.

Fidicin, Ernst: Die Territorien der Mark Brandenburg oder Geschichte der einzelnen Kreise und Dörfer in derselben als Fortsetzung des Landbuchs Kaiser Karl's IV., Bd. I., Berlin 1860.

Gesetz-Sammlung für die Königlichen Preußischen Staaten, Berlin (1855).

Grimm, Jacob/Grimm, Wilhelm: Deutsches Wörterbuch (Nachdruck), Gütersloh, Bd. 27 (1991), Sp. 56, Bd. 29. Sp. 428 f.

Hattenhauer, Hans/Bernert, Günther (Hg.): Allgemeines Landrecht für die preußischen Staaten von 1794 , Berlin ${ }^{3} 1996$.

Kaschube, Adolf: Das Schöpfwerk Wildpark West (Gallin) ist 80 Jahre (I), Das Golmer Luch (bruch) und seine Entwässerungsanlagen (II) und Wassereinzugsgebiet des Schöpfwerks Grube-Schlänitzsee (III), Ortszeitung Golm November 2009, Juni 2010 und Dezember 2010.

Krollmann, Christian (Hg.): Altpreußische Biographie, Marburg/Lahn. 1974.

Lexikon der Theologie und Kirche, Freiburg (2006), Bd. 6, Spalte 1476.

Meinardus, Otto: Protokolle und Relationen des Brandenburgischen Geheimen Rathes aus der Zeit des Kurfürsten Friedrich Wilhelm, Dritter Bd., Leipzig (1835), Nr. 458, S. 691 und Nr. 469, S. 705.

Namenbuch, Teil 10: Die Gewässernamen Brandenburgs, bearb. v. Reinhard E. Fischer, Weimar 1996. 
Neue Deutsche Biographie, Berlin, Bd. 25 (2013) S. 686.

Potsdamer Tageszeitung: Jg. 86/Nr. 138 vom 17. Juni 1935: 250 Jahre Schweizer Kolonie Nattwerder, Golm und Neu-Töplitz;

Potsdamer Tageszeitung: Jg. 86/Nr. 144 vom 24. Juni 1935: Das Jubelfest der Schweizerkolonisten. Die Feier in Nattwerder.

Ratsmanual: in: Blätter für bernische Geschichte, Kunst und Altertumskunde 13 (1917) Heft 3, S. 303.

Stille Jagd auf stumme Tiere, hg. Ministerium für Landwirtschaft, Umwelt und Raumordnung (2001).

Urkunden und Akten zur Geschichte Kurfürst Friedrich Wilhelm, 9 (1879), S. 473 Anm. 1.

Verhandlungsbuch des Gemeindekirchenrates Alttöplitz/Nattwerder (1928-1976).

Völkischer Beobachter Nr. 176 Ausgabe B vom 25.06.1935: 250 Jahre Gemeinde Nattwerder - Eine Gründung des großen Kurfürsten.

Warnatsch, Stephan: Geschichte des Klosters Lehnin 1180 - 1542, Bd. 2, Regestenverzeichnis, Berlin 2000, in: Studien zur Geschichte, Kunst und Kultur der Zisterzienser, Bd. 12.2.

\section{Literaturverzeichnis}

275 Jahre Stiftung Großes Waisenhaus zu Potsdam, hg. Stiftung Großes Waisenhaus zu Potsdam (1999).

Asche, Mathtias: Neusiedler im verheerten Land - Kriegsfolgenbewältigung, Migrationssteuerung und Konfessionspolitik im Zeichen des Landeswiederaufbaus, Münster 2006.

Bachmann, A.: Les émoires du Burgrave et Comte Frédéric de Dohnan (Hg.: Heinrich Borkowski, Königsberg i. Pr.) 1898.

Bachmann, Adrian: Die preußische Sukzession in Neuchatel. Ein ständisches Verfahren um die Landesherrschaft im Spannungsfeld zwischen Recht und Utilitarismus (1694-1715), Zürich 1993.

Backschat, Friedrich: Nattwerder - Ein Beitrag zur Geschichte der reformierten Schweizergemeinde im Golmer Bruch und der am 16. November 1690 eingeweihten „Friedrichs-Kirche“, in: Potsdamer Tageszeitung Nr. 270, 271 und 272 vom 16., 17. und 18. November 1911.

Badstübner, Sybille: Hugenotten in Berlin, Berlin 1988.

Bahl, Peter: Der Hof des Großen Kurfürsten, Studien zur höheren Amtsträgerschaft Brandenburg-Preußens, Köln - Weimar - Wien 2001. 
Baumgart, Peter: Friedrich Wilhelm I., in Frank-Lothar Kroll (Hg.), Preußens Herrscher. Von den ersten Hohenzollern bis Wilhelm II., München 2000.

Beek-Schweingruber, Heinz van: Kolonisten aus der Schweiz in Preußen, Mühlheim an der Ruhr 1993.

Beheim-Schwarzbach, Max: Hohenzollernsche Colonisation. Ein Beitrag zu der Geschichte des preußischen Staates und der Colonisation im östlichen Deutschland, Leipzig 1874.

Berwein, Lothar: Ansiedlung von Schweizer Kolonisten im Rahmen der Repeuplierung Ostpreußens - Untersuchung einer 1712 ausgewanderten Gruppe aus der Landvogtei Sax, Hamburg 2003.

Bestehorn, Friedrich: Deutsche Urgeschichte der Insel Potsdam, Potsdam 1936.

Beuys, Barbara: Der große Kurfürst, Hamburg 1979.

Bleyl, Dietmar Walther Richard (Hg.): Nattwerder - 325 Jahre Besiedlung des Golmer Bruchs, Potsdam 2010.

Bleyl, Dietmar Walther Richard: Töplitz - 700jährige Geschichte einer märkischen Kirchengemeinde, Potsdam 2013.

Bleyl, Dietmar Walther Richard: Die rätselhafte Neu Töplitzer Glocke, in: Mitteilungsblatt der Landesgeschichtlichen Vereinigung für die Mark Brandenburg, 117 (2016), S. 74-80.

Boege, Hermann: Die Gründung der Schweizerkolonie Golm, Nattwerder und Neu-Töplitz, in: Beilage der Potsdamer Tageszeitung Nr. 246 vom 18.10.1924

Boege, Hermann: Die Wublitz und ihr Tal, in Beilage der Potsdamer Tageszeitung Nr. 54 vom 03.03.1928.

Bohse, Lehrer Notizen aus Obligationen und Kaufbriefen des Amts Potsdam aus den Jahren 1678 bis 1696, in: Mitteilungen des Vereins für die Geschichte Potsdams, Neue Folge II. Theil, 1867, S. 41-68.

Brandenburg-Berlinisches Wörterbuch, Berlin (1985), Bd. II, Kolumne 720.

Bratring, Friedrich Wilhelm August: Statistisch-topographische Beschreibung der gesamten Mark Brandenburg, Berlin 1968.

Breysig, Kurt: Geschichte der brandenburgischen Finanzen in der Zeit von 1640 bis 1697 Darstellung und Akten, I. Bd., Leipzig 1895.

Buchinger, Marie-Luise/Cante, Marcus: Denkmale in Brandenburg - Landkreis PotsdamMittelmark, Teil 1: Nördliche Zauche, Worms am Rhein 2009.

Büsch, Otto: Militärsystem und Sozialleben im alten Preußen 1713-1807. Die Anfänge der sozialen Militarisierung der preußisch-deutschen Gesellschaft, erw. Ausgabe Frankfurt a.M. 1981. 
Clark, Christopher: Preußen - Aufstieg und Niedergang 1600 - 1947, München ${ }^{6} 2007$.

Czech, Vinzenz: Brandenburg und seine kleinen Nachbarn, in: Jürgen Luh/Vinzenz

Czech/Bert Becker: Preussen, Deutschland und Europa 1701-2001, Groningen 2003.

Czubatynski, Uwe: 700 Jahre Quitzöbel. Beiträge zur Ortsgeschichte auf der Grundlage des Pfarrarchivs, Nordhausen 2010.

de Capitani, Francois: Beharren und Umsturz (1648-1815), in: Geschichte der Schweiz- und der Schweizer. Bd. 2. Basel, Frankfurt 1983.

Delius, Walter: Berliner kirchliche Unionsversuche im 17. und 18. Jahrhundert, in: Jahrbuch für Berlin-brandenburgische Kirchengeschichte, 45 (1970), S. 7-21.

Diederich, Toni: Gedanken zum Wert der Pfarrarchive und zur Sicherung ihrer historisch relevanten Kernüberlieferung, in: Überlieferung, Sicherung und Nutzung der Pfarrarchive. Redaktion: Hans Ammerich, Speyer 1991, S. 10-26.

Dortschy, Jochen: Chronik der Familie Emanuel Dortschy, Frankfurt a. M. 2007 (Eigenverlag). Dreifuss, Emil: Willkommene Berner Emigranten - Bauernfamilien aus dem Bernergebiet siedeln im 17. Jahrhundert in deutschen Gebieten, in: Der Bund, „Vor Jahr und Tag“, in: Nr. 167 (20.07.), 173 (27.7.) und 179 (03.08.1985).

Drescher, Horst/Kroll, Renate: Potsdam -Ansichten aus drei Jahrhunderten, Weimar 1981.

Duchhardt, Heinz: Europa am Vorabend der Moderne 1650-1800, Stuttgart 2003.

Ehmer, Josef: Heiratsverhalten, Sozialstruktur, ökonomischer Wandel - England und Mitteleuropa in der Formationsperiode des Kapitalismus, Göttingen 1991.

Enders, Lieselott: Neu-Brandenburger in der Zeit der friderizianischen Kolonisation. Aktionen und Reaktionen der Einheimischen und Zuzügler, untersucht vornehmlich am Beispiel der Prignitz, in: Klaus Neitmann/Jürgen Theil (Hg.), Die Herkunft des Brandenburger. Sozial- und mentalitätsgeschichtliche Beiträge zur Bevölkerung Brandenburgs vom hohen Mittelalter bis zum 20. Jahrhundert, Potsdam 2001, S. 95-111.

Engelcken, Albert Bogislaw von: Der Grosse Kurfürst auch in dem Feldlager Verwalter der Potsdamer Amts-Oekonomie, Mitteilungen des Vereins für die Geschichte Potsdams III Theil (1867), S. 101-107.

Feller, Richard: Die Geschichte Berns, Bd. II, Bern 1953.

Fetscherin, Wilhelm: Die bernischen Colonien in Brandenburg am Ende des 17. Jahrhunderts, in: Berner Taschenbuch, 17 (1868), S. 107-142.

Fischer, Otto: Märkische Pfarrergeschlechter, in: Jahrbuch für Brandenburgische Kirchengeschichte, 21 (1926), S. 22-58 und 25 (1930), S. 122-138. 
Fischer, Ottto (bearb.): Evangelisches Pfarrerbuch für die Mark Brandenburg, Berlin 1941, Bd. 1 und Bd. 3.

Foerster, Erich: Entstehung der preußischen Landeskirche unter der Regierung Friedrich Wilhelms des Dritten, Tübingen 1905, Bd. I, S. 270 und 327 f.

Fontane, Theodor: Wanderungen durch die Mark Brandenburg, Dritter Teil - Havelland, Berlin 1977.

Gabriel, Paul: Die reformierten Gemeinden der evangelischen Kirche in Berlin-Brandenburg (masch.-schriftlich, o.J.), zit. nach: Friedrich Winter: Die evangelische Kirche in Berlin-Brandenburg - eine unierte Kirche, in: Jahrbuch für Berlin-Brandenburgische Kirchengeschichte, 68 (2005), S. 118-128.

Gloger, Heinrich: Friedrich Wilhelm - Kurfürst von Brandenburg, Berlin 1986.

Goltz, Theodor Freiherr von der: Geschichte der Deutschen Landwirtschaft, Stuttgart (1951).

Graf zu Dohna, Lothar: Die Dohnas und ihre Häuser - Profil einer europäischen Adelsfamilie, Bd. I, Göttingen 2013.

Grittner, Wolfgang: Vom Schiffgraben zum Kanal, Zwischen Havelland und Fläming - Heimatkalender für den Landkreis Potsdam-Mittelmark (2002), S. 57-65.

Grittner, Wolfgang: Zur Geschichte der Marquardter Kirche, Marquardt 2013.

Grittner, Wolfgang: Marquardt - Illustrierte Zeittafel zur Ortsgeschichte 1313-2016, Marquardt 2017.

Groehler, Olaf: Der Luftkrieg gegen Brandenburg in den letzten Kriegsmonaten, in: Werner Stamg/Kurt Arlt (Hg.) Brandenburg im Jahr 1945, Potsdam 1995, S. 9-37.

Gugger, Rudolf: Preußische Werbungen in der Eidgenossenschaft. Ein nicht-avouierter Dienstort auf dem schweizerischen Söldnermarkt im 18. Jahrhundert, Diss., Berlin 1997.

Haagen, Bernhard: Burggraf Alexander zu Dohna und die Schweizerkirchen in Litauen Zum zweihundertjährigen Gedächtnis der Entstehung der reformierten Gemeinden zu Judtschen und Gumbinnen 1713-1913, Berlin 1913.

Hanke, Max/Degner, Hermann: Geschichte der amtlichen Kartographie Brandenburg-Preußens bis zum Ausgang der Fridrizianischen Zeit, in: Geogr. Abhandlungen, III. Reihe, Stuttgart ${ }^{3} 1996$.

Heese, Gerhard: Stammfolge des Geschlechtes oder des freien Kurfl.-Kgl. Erbpachter-Geschlechtes Garmatter, im Selbstverlag, Minden 1982.

Heese, Henning (Hg.): 300 Jahre Schweizer Kolonie am Golmischen Bruch, Sankt Augustin 1985. 
Heese, Henning (Hg.): Schweizer Kolonisten am Golmer Bruch bei Potsdam, in: Der Landkreis Potsdam - Heimatgeschichtliche und heimatkundliche Beiträge (1992), Heft 1, S. 5462.

Heese, Gerhard: Heese zu Golm bei Potsdam - Ein Überblick über 13 Generationen, Minden 1995.

Heinrich, Gerd (Hg.): Tausend Jahre Kirche in Berlin-Brandenburg, Berlin (1999).

Hensell, Gottfriede: Das protestantische Moment in der Außenpolitik des Großen Kurfürsten 1672-1688, Diss., Philosoph. Fak. Univ. Hamburg 1927.

Hermann, Joachim/Donat, Peter: Corpus Archäologischer Quellen zur Frühgeschichte auf dem Gebiet der Deutschen Demokratischen Republik (7. bis 12. Jahrhundert), 3. Lieferung, Berlin 1979.

Hintze, Otto: Soziologie und Geschichte - Gesammelte Abhandlungen zur Soziologie, Politik und Theorie der Geschichte, Göttingen 1964, Bd. III.

Historisches Lexikon der Schweiz (Hg. Stiftung Historisches Lexikon der Schweiz), Bd. I, Basel 2016.

Historisches Ortslexikon für Brandenburg, Teil III Havelland, bearb. von Peter P. Rohrland, Weimar 1977.

Historisches Ortslexikon für Brandenburg, Teil V Zauch-Belzig, bearb. von Lieselotte Enders, Weimar 1972.

Hüttl, Ludwich: Friedrich Wilhelm von Brandenburg - Eine politische Biographie, München 1981.

Iida, Takashi: Hof, Vermögen, Familie 1700-1820, Jahrbuch für die Brandenburgische Landesgeschichte, Berlin Bd. 49 (1998), S. 143-182.

Iida, Takashi: Ruppiner Bauernleben 1648-1806, in Studien zur brandenburgischen und vergleichenden Landesgeschichte, Berlin, Bd. 3 (2010), S. 130-180.

Imhof, Arthur: Einführung in die Historische Demographie, München 1977.

Iwan, Walter: Das Golmer Luch, BERLINER GEOGRAPHISCHE ARBEITEN, Stuttgart 1939, Heft 18.

Jänckel, Ronald: Die kartographische und siedlungsgeographische Bedeutung des ältesten Atlas der Mark Brandenburg, Dissertation M.-L. Univ. Halle-Wittenberg 1966.

Kamp, Silke: Die verspätete Kolonie. Hugenotten in Potsdam, in: Quellen und Forschungen zur brandenburgischen-preußischen Geschichte, Berlin 2011, Bd. 42.

Kaufmann, Thomas: Erlöste und Verdammte, Eine Geschichte der Reformation, München 2016. 
Kitschke, Andreas: Die Kirchen der Potsdamer Kulturlandschaft, Berlin 2017.

Klinski-Wetzel, Marianne von: Wildpark-West an der Havel - Die Geschichte der Wiese Gallin, Potsdam 2007.

Kohl, Thomas: Familie und soziale Schichtung. Zur historischen Demographie Trieres 17301860, Stuttgart 1985.

Krzymowski, Richard: Geschichte der Deutschen Landwirtschaft, Stuttgart (1902).

Kuby, Alfred Hans: Die Schiffsreise der schweizerischen Kolonisten (1985), in: Henning Heese (Hg.) 300 Jahre Schweizer Kolonie am Golmischen Bruch, Sankt Augustin 1985, S. 44-48.

Kuby, Alfred Hans: Auswanderung von Bern nach Brandenburg 1691. Ein Tagebuch aus dem Berner Ratsmanual, in: Genealogie, Heft 11/1989, S. 730-732.

Lachenich, Susanne: Hugenotten in Europa und Nordamerika, Migration und Integration in der frühen Neuzeit, Frankfurt am Main (2010).

Lackner, Martin: Die Kirchenpolitik des Großen Kurfürsten, Witten 1973.

Lange, Julius: Das Vorwerk Gallin, Zur Geschichte des Potsdamer Schlächtergewerks, in: Verein für die Geschichte Potsdams NF. 1. Theil (1875), S. 376-401.

Lewin, Louis: Die Fruchtabtreibung durch Gifte und andere Mittel, Berlin 1925.

Loock, Hans-Dietrich: Vom „Kirchenwesen“ zur Landeskirche. Das Zeitalter der Reformen und der Konfessionsunion (1798 bis 1840), in Gerd Heinrich (Hg.): Tausend Jahre Kirche in Berlin-Brandenburg, Berlin 1999, S. 363-427.

Mehlhardt, Dieter: Vierhäuser oder Nattwerder, Auf den Spuren der Schweizer Siedler im Golmer Bruch, in: Brandenburgische Neueste Nachrichten. 27, Nr. 256 vom 29./30. Oktober 1977.

Meier, Brigitte: Neuruppin - 1700 bis 1830 - Sozialgeschichte einer kurmärkischen Handwerker- und Garnisonstadt, Berlin 1993.

Mengin, Ernst: Das Recht der französisch-reformierten Kirche in Preußen. Urkundliche Denkschrift, Berlin 1929.

Metzke, Hermann: Lexikon der historischen Krankheitsbezeichnungen, Neustadt an der Aisch 2005.

Meyerding de Ahna, Kurt: Die Kirchenbücher der evangelischen Kirchen in der Provinz, in: Archiv für Sippenforschung und alle verwandte Gebiete 10 (1935), S. 97-144.

Mitterauer, Michael: Grundtypen europäischer Sozialformen. Haus und Gemeinde in vorindustriellen Gesellschaften, Stuttgart 1979. 
Mitterauer, Michael: Grundtypen europäischer Wirtschaftsgeschichte, Bd. I, Berlin (1981). Moeseritz, Richard Gottlieb Heinrich: Festschrift zum 275jährigen Jubiläum der evangelischreformierten Hofgemeinde in Halberstadt, Halberstadt 1939.

Möller, Horst: Toleranz als „zärtliche Mutter“. Kirchen und Konfessionen im Zeitalter der Aufklärung und der religiösen Indifferenz (1740 bis 1797), in: Gerd Heinrich (Hg.): Tausend Jahre Kirche in Berlin-Brandenburg, Berlin 1999, S. 325-362.

Müller, Hans-Heinrich: Märkische Landwirtschaft vor der Agrarreform von 1807, Entwicklungstendenzen des Ackerbaus in der zweiten Hälfte des 18. Jahrhunderts, in: Veröffentlichungen des Bezirksheimatmuseum Potsdam, Heft 13, S. 4.

Müller, Sylvia: Denkmäler des Totenkronenbrauchs in der Mark Brandenburg, in: Brandenburgische Denkmalpflege 11 (2002), S. 52-65.

Müller, Sylvia: Denkmäler der Liebe - Zeugnisse des Totenkronenbrauchs in der Mark Brandenburg, Diss., Berlin 2007.

Neugebauer, Wolfgang: Brandenburg im absolutistischen Staat - Das 17. und 18. Jahrhundert, in: Ingo Materna/Wolfgagn Ribbe (Hg.) Brandenburgische Geschichte, Berlin 1995, S. 291-394.

Neugebauer, Wolfgang: Zentralprovinz im Absolutismus - Brandenburg im 17. und 18. Jahrhundert, Berlin 2001.

Neugebauer, Wolfgang: Handbuch der preußischen Geschichte, Bd. I, Das 17. und 18. Jahrhundert, Berlin- New York 2007.

Opgenoorth, Ernst: Der Grosse Kurfürst von Brandenburg, Teil I (1620-1660), Göttingen, Frankfurt und Zürich 1971.

Opgenoorth, Ernst: Der Grosse Kurfürst von Brandenburg, Teil II (1660-1688), Göttingen, Frankfurt und Zürich 1978.

Orlich, Leopold von: Geschichte des Preußischen Staates im siebzehnten Jahrhundert mit besonderer Beziehung auf das Leben Friedrich Wilhelm’s des großen Kurfürsten, Berlin 1839.

Peters, Jan: Das Gesetz und der Gebrauch. Zur Fremdwahrnehmung in der Mark an der Wende zum 18. Jahrhundert, in: Klaus Neitmann/Jürgen Theil (Hg.): Die Herkunft der Brandenburger, Sozial-und mentalitätsgeschichtliche Beiträge zur Bevölkerung Brandenburgs vom hohen Mittelalter bis zum. 20 Jahrhundert, Potsdam ${ }^{2} 2003$.

Philippson, Martin: Der Große Kurfürst Friedrich Wilhelm (1903).

Rehberg, Max: Vorgeschichte und Einführung der Union in Oranienburg, in: Jahrbuch für Berlin-Brandenburgische Kirchengeschichte, 43 (1968), S. 44-54.

Rennefahrt, H.: Grundzüge der bernischen Rechtsgeschichte, 2. Teil, Bern (1931). 
Ribbe, Wolfgang (Hg.): Das Havelland im Mittelalter - Untersuchungen zur Strukturgeschichte einer ostelbischen Landschaft in slawischer und deutscher Zeit, Berlin 1987, Vorwort.

Ribbe, Wolfgang: Brandenburg auf dem Wege zum polykonfessionellen Staatswesen, in: Gerd Heinrich (Hg.): Tausend Jahre Kirche in Berlin-Brandenburg, Berlin 1999, S. 267-292.

Rösli, Joseph: Wanderungen der Berner, in: Der Schweizer Familienforscher, 7 1940), Heft 4-6, S. 43-57.

Schachinger, Erika: Die Dorotheenstadt 1673-1708. Eine Berliner Vorstadt, Köln, Weimar und Wien 2001.

Schaefer, Günter/Strobel, Heino: Glocken aus Eisenwerkstoffen, in: GIESSEREI-PRAXIS, 4 (2017), S. 155-161.

Scherler, Klaus: Schweizer Kolonisten in Brandenburg, Vorstellung einer Datensammlung, in: Brandenburgisches Genealogisches Jahrbuch Bd. 2 (2008), S. $43 \mathrm{ff}$.

Schlegelmilch, Sabine: Ärztliche Praxis und sozialer Raum im 17. Jahrhundert, Wien, Köln und Weimar 2018.

Schlumbohm, Jürgen: Mikrogeschichte-Makrogeschichte: Zur Eröffnung einer Debatte, in: Jürgen Schlumbohm (Hg.): Mikrogeschichte Makrogeschichte komplementär oder inkommensurabel? Göttingen 1998, S. 7-32.

Schmelz, Ulrich: Schweizer Kolonisten in der Kurmark Brandenburg im 17./18. Jahrhundert, in: Birgit Kletzin (Hg.) Fremde in Brandenburg Münster - Hamburg - London ${ }^{2} 2003$.

Schmelz, Ulrich: Die Schweizer-Kolonie Nattwerder als Prototyp von Zuwandererkolonien in Brandenburg. Vortrag beim 325. Jubiläum von Nattwerder (gehalten am 18. Juni 2010).

Schmidt, Heinrich Richar: Konfessionalisierung im 16. Jahrhundert, München (1992).

Schmidt, Peter: Schweizer - Schweizer Kirchen, in: Die Mark Brandenburg, Berlin 2009, Heft 75, S. 34-40.

Schmidt, Rudolf: Märkische Glockengiesser im 17. und 18. Jahrhundert, in: Jahrbuch der Brandenburgischen Kirchengeschichte, Berlin 15 (1917), S. 119.

Schneider, Hermann: Die Schweizer Kolonie in der Mark, ein ländliches Kulturbild aus dem Ende des 17. Jahrhunderts. Beilage zum Programm des Königlichen Wilhelms-Gymnasium, Berlin 1906.

Scholz, Eberhard: Bau- und Oberflächengestaltung des Reiherberges bei Golm westlich Potsdams; in: Zeitschrift für den Erdkundeunterricht 9 (1957), Heft 3 S. 129 ff.

Schramm, Karl: Die Schweizer Siedlungen in der Herrschaft Ruppin, in: Archiv für Bevölkerungswissenschaft 6 (1936), S. 237-244. 
Schramm, Karl: Dorfsippenbuch Storbeck, Kreis Ruppin, Kurmark, Goslar 1939.

Schüler, H.: Die Bedeutung der Kirchenbücher für die Heimatforschung, in: Landeskundliche Vierteljahresblätter der landeskundlichen Arbeitsgemeinschaft der Bezirke Koblenz und Trier 1970, Heft 3, S. 93-100.

Schüler: H.: Der Wert der Kirchenbücher für evangelische Kirchengeschichte des Rheinlandes, Bd. 16 (1977), S. 213-299.

Schultz, Helga: Berlin 1650-1800 - Sozialgeschichte einer Residenz, Berlin 1987.

Schulze, Johannes: Die Mark Brandenburg, Bd. 5, Berlin ${ }^{2} 1989$.

Schuppan, Erich (Hg.): Zur Geschichte des Kirchenkampfes, Bd. I, Berlin 1998.

Sello, Georg: Lehnin - Beiträge zur Geschichte von Kloster und Amt, Berlin 1881.

Stirnemann, Heinz: Woselbst sie wohl aufgenommen, - 300 Jahre Schweizer Kolonien in der Mark Brandenburg am Beispiel der Gemeinde Storbeck, Frankfurt/a. M. 1991.

Strangmeier, Heinrich/Huckebeck, Ernst (Hg.): Das älteste Kirchenbuch der reformierten Gemeinde Hilden (1649-1694), Hilden 1983.

Süßmilch, Johann Peter: Die göttliche Ordnung, Berlin 1741.

Süßmilch, Johann Peter: Gedanken von den epidemischen Krankheiten, Berlin 1757.

Thadden, Rudolf von: Die Hinwendung des Kurhauses zum reformierten Bekenntnis, in: Gerd Heinrich (Hg.): Tausend Jahre Kirche in Berlin-Brandenburg, Berlin 1999, S. 255-266.

Tobler, Gustav: Die Reise der Berner Kolonisten nach Brandenburg, in: Alpenrosen - Ein schweizerisches Sonntagsblatt, Bern, 19 (1889), S. 44-47.

Tobler, Gustav: Schweizer Kolonisten in Ostpreußen, Anzeiger für Schweizer Geschichte; No. 6 (1896), S. 409; zit. nach: Hauser, Albert: Schweizer Bauern als Kolonisten in Preußen und Litauen, in: Zeitschrift für Agrargeschichte und Agrarsoziologie, 13 (1965), S. 212-219.

Tödtman, Hans: Ausdruck des Schmerzes - Die Totenkronenbretter der Dorfkirche, Alte Kirchen 2017, S. 9.

Vette, Markus: Töplitzer Wege, Arbeits-, Lebens- und Verkehrswege, Kirchen- und Schulgeschichte der Gemeinde Töplitz, Norderstedt 2003.

Vette, Markus: Die Schweizer Gemeinde Nattwerder als wirtschaftliche, soziale und kulturelle Bereicherung für die Insel Töplitz, Norderstedt 2007.

Wagener, H.: Die Schweizer-Colonie bei Alt-Töplitz, in: Mitteilungen des Vereins für die Geschichte Potsdam 1875 I. Theil, S. 211-227.

Wallstabe, B.: Nattwerder, in: Walter Iwan, Das Golmer Luch, Stuttgart (1939). 
Weichert, Friedrich: Die Unionsbestrebungen in Berlin und Brandenburg von 1817 bis 1850 , Berlin (1983).

Wentscher, Erich: Die Schweizer Kolonien in der Mark Brandenburg, in: Archiv für Sippenforschung und alle verwandte Gebiete 7 (1930), S. 238-244, 291-294, 388-391 und 429432.

Wentscher, Erich: Schweizer in der Mark, in: Kleiner Bund, 1932, Nr. 9.

Wentscher, Erich: Woher stammen die ersten Schweizer Kolonisten in der Mark Brandenburg, in: Archiv für Sippenforschung und alle verwandte Gebiete 12 (1935), S. 60-61.

Wentscher, Erich: Familienbuch der Schweizer, hg. von der Schweizerischen Gesellschaft für Familienforschung und alle verwandte Gebiete 18 (1941), S. 166.

Widerstände und Motive, in: Jahrbuch für Berlin-Brandenburgische Kirchengeschichte, 54 (1983), S. 97-137.

Winter, Friedrich: Die evangelische Kirche in Berlin-Brandenburg - eine unierte Kirche, in: Jahrbuch für Berlin-Brandenburgische Kirchengeschichte, 68 (2005), S. 118-128.

Zglinicki, Friedrich von: Die Geburt. Eine Kulturgeschichte in Bildern, Braunschweig 1983. Zinke, Regine: Steglitz bei Berlin - Dorfleben im Spiegel des Kirchenbuches 1605-1810, Leipzig 1996. 



\section{Anhänge}

\section{Quellenanhänge}

\section{Anhang 1}

Oberförster v. Lüderitz berichtet dem Kurfürsten Friedrich Wilhelm über den abgeschlossenen Kontrakt (Verdingzettel) mit dem Teichgräber Friedrich Witten aus dem Liebenbergschen Bruch hinsichtlich bestimmter, im Golmer Bruch vorzunehmender Meliorationsarbeiten. Amt Saarmund, 1678 August 7.

GStA PK, I. HA, Rep. 21 Nr. 123 (Paket 7997) fol. 145/145R, Ausfertigung.

Verding Zettul mit dem Teichgräber wegen des Gollmschen Bruchs.

Demnach Sr. Churfürstl. Durchl: zu Brandenburgk (etc.),

Unser gnädigster Herr (etc.), gnädigst Befehlen, daß das Golmische Bruch mit einem Graben, alß von der Havell ab biß in der Wubelitz in der länge undt dann von dem Gollmischen Acker an biß auff das Gemünde undt auch in der Wubelitz in die quer durchzogen werden soll, Alß [ist] mit dem Teichgräber Friederich Witten auß dem Liebenbergischen Bruche folgender Vergleich getroffen undt geschloßen worden: Er verfertiget obgedachten Haubtgraben in die länge, von 14 Fueß Breit, undt in solcher tieffe, biß das Wasser darein kombt, undt man künfftig es tieffer machen kan, so woll durch die Berge undt, wo es hoch, alß durch die Niederung und fänget sofort, alß das Bruch nur ausgebrandt sein wirdt, daran zu graben an, undt Continuiret darmit, so lange das wetter und der frost es zulaßen wirdt. die Zwo Quergraben aber von dem Golmischen Acker auff den Steinwerder undt Espenhorst zu biß in die Wubelitz Verfertigt Er also, daß Jeder 7 Fuß Breit undt darzwischen ein Tham geschüttet werde, zu welchem Tham die Fachinen, wo es nötig, Ihme geleget werden sollen undt Er nachmals solchen mit Rasen zu setzen undt die Erde darauff zu werffen hatt.

Für solche arbeith, wenn solche wöchentlich richtig befunden wirdt, ist Ihme Zugesagt undt versprochen worden, Vor den Breiten graben, von jeder Niederländischen Ruhten 15 Fueß lang, Neun gr: an gelde undt von Zwantzigk Ruhten einen scheffell Rogken undt 1 tonne speise Bier zu entrichten. Von denen Zwo quergraben aber bekombt Er die Helffte, nemblich von 1 Ruhte 15 fueß lang 4 1/2 gr: geldt und von 20 Ruhten $1 / 2$ scheffell Rogken und $1 / 2$ tonne speise Bier. Dahingegen hatt Er versprochen, solche arbeith nach Teichgräber arth gut und beständig zu machen, daß es untadelhafft befunden werden soll. Zu mehrerer nachricht undt fester Haltung ist dieses von dem Herrn Oberförster von Lüderitz eigenhändig unterschrieben.

Geschehen im Ambte Sahrmundt den 7. Augusti Anno 1678

J.E.v Lüderitz. 


\section{Anhänge}

\section{Anhang 2}

Kurprinz Friedrich fragt beim Schultheiß und Rat der Stadt Bern wegen Ansiedlung von 10 oder 20 Familien mit Kenntnissen in der Landwirtschaft und Viehzucht in Brandenburg an. Potsdam, 1683 November 24.

StA Bern A. V. 19 Teutschland-Buch Preussen Brandenburg, fol. 5/5R, Ausfertigung.

Von Gottes gnaden Friderich Wilhelm Marggraf zu Brandenburg, des Heyl. Röm: Reichs Ertz Cammerer und Churfürst, in Preußen, zu Magdeburg, Jülich, Cleve, Berge, Stettin, Pommern etc. Hertzog etc.

Unsern gönstigen gruß und geneigten willen zuvor. Edle, Ehrenveste und Wollweise, Liebe besondere. Demnach Uns wißend, daß in dem unter Eurer bothmäßigkeit gelegenen Canton eine große anzahl Von Einwohneren auf dem Lande sich befinde, welche der Wirthschafft und Viehzucht woll erfahren seyn, So haben wir, aus sonderbahrem guten Zu Euch tragenden Vertrauen, hierdurch Vernehmen wollen, ob Ihr Uns den gefallen erweisen und Verstatten woltet, daß ein Zehen oder Zwantzig Dergleichen Familien sich anhero in diese Unsere Churund Marck Brandenburg begeben möchten, woselbst Sie wol aufgenommen, an bequeme Öhrter gesetzet, mit Wonungen und behörigem Besatz Versehen, und gegen eine leidliche und erträgliche Jährliche Pacht wol accomodiret werden sollen. Wir zweiflen nicht, Ihr werdet Uns hierunter geneigt willfahren, und werden Wirs mit aller gefälligen freundschafft und gutem willen zu erkennen nicht unterlaßen, womit Wir Euch sonsten auch woll zugethan Verbleiben.

Gegeben zu Potstam den 24. Novembris

Anno 1683

Friderich Chur Printz

\section{Anhang 3}

Berner Rats-Manual anlässlich der Verabschiedung der nach Brandenburg ausreisewilligen Schweizer Kolonisten. Bern, 1685, April 29 (Mittwoch): Abdruck in der Zeitschrift Blätter für bernische Geschichte, Kunst und Alterskunde, Bd. 13 (1917), Heft 3 S. 303.

Zedul an $\mathrm{m}$ [einen] h[errn] von Muralt. Über den heüt geschehenen anzug $\mathrm{m}$ [einen] $\mathrm{h}$ [errn] Weltsch Seckelmeister Sinners, daß es nun an demme sein wolle, daß nächst künfftigen Freytag [31.04.1685] nach angehörter predig uff der Nidegk die nach Brandenburg parat stehende Colonie sich embargieren und verreisen werde, wan nun Ihr gn. darbey gutfunden, daß von Oberkeits wegen jemandts da seye, der disen leüthen nit nur gleichsam das Vale gebe, sondren noch darzu ihnen alles ernsts zuspreche, daß $\mathrm{m}$ [ein] g[gnädiger] $\mathrm{h}$ [err] als ihre lands oberkeit sich ihrer nit vergessen werden, item daß auch $\mathrm{m}$ [ein] g[nädigen] $\mathrm{h}$ [errn] in alle weg gemeint seyen, wan sie sich wohl, from, ehrlich, eidtgenößisch und gezimmendt verhalten 
werdindt, sie in ihrem steten patrocinio, es seye drunden als auch wan sie widerum hinauff in ihr Vatterlandt kämen, sein sollen. Alß habend Ihr gn. ihne mh. verordnen wollen, mit gesinnen, diesen leüthen disen Ihr gn. intent mit mehrerem anzudeüten und darbey ihnen wol zu repraesentiren, sich einig und zusammenzuhalten, auch ihrem führer allen respect, folg und gehorsame zu leisten, und damit es desto mehr krafft und impression habe, von jedem haus vatter ein glübt an eidts statt abzunehmen, daß sie solches alles erstatten und sich im übrigen drunden also comportiren und verhallten wöllind, daß es zu der schweitzerischen Nation lob und ruhm gereichen thüye.

Zedul an $\mathrm{m}$ [ein] h[errn] Decan. Durch den herren, so künfftigen Freitags uff der Niedegk predigen wirt, seine action uff die wegzüchenden Familien richten zu laßen und zwar also, daß neben anwünschung göttlichen segens und gleits, ihnen zu gesprochen werde, was in ansehen ihres seelen heils und guten vertrauwens halb, beides zu ihrer churfürstlichen Durchlaucht, als $\mathrm{m}$ [einen] g[nädigen] $\mathrm{h}$ [errn], zu erinnern nothwendig sein wirt.

\section{Anhang 4}

Kurfürst Friedrich Wilhelm schließt zur Urbarmachung des Golmer Bruches mit der Republik zu Bern einen Ansiedlungsvertrag für 14 Schweizer Familien aus dem Kanton Bern ab. Cölln an der Spree, 1685 September 16.

StA Bern: A. V. 19 Teutschland-Buch Preussen-Brandenburgfol. 213-225, Ausfertigung.

Zu wißen sey hiemit, Nachdem der Durchlauchtigste Fürst und Herr, Herr Friderich Wilhelm, Marggraff zu Brandenburg, des heiligen Römischen Reichs Ertz Cammerer und Churfürst, in Preußen, zu Magdeburg, Jülich, Cleve, Berge, Stetin, Pommern, der Caßuben und Wenden, auch in Schlesien zu Croßen und Jagerndorff Hertzog, Burggraff zu Nürnberg, Fürst zu Halberstadt, Minden und Camin, Graff zu Hohenzollern, der Marck und Ravenßberg, Herr zu Ravenstein und der Lande Lauenburg und Bütow etc. etc., an die Löbliche Republique zu Bern in der Schweitz vor einiger Zeit gnädigst geschrieben und dieselbe ersuchen laßen, daß einige Familien, so der Viehe Zucht woll erfahren weren, anhero geschicket werden möchten, welche sich alhier in der Chur- und Marck Brandenburg niederlassen und das sogenante Golmische Bruch ohnweit Potstam cultiviren solten, ihnen auch gewiße conditiones, auff was maße dieselbe verlanget würden, und weßen sie sich alhier zu versehen hetten, vorgeschrieben, und übersant worden. Und dann darauf anfänglich ein Gevollmächtigter von bemelter Republique, Albrecht Baurenkönig genant, nebst noch einigen andern Leuten aus der Schweitz sich alhier eingefunden und den Ort in Augenschein genommen, mit dem Deputirten Baurenkönig auch Handlung gepflogen, und die von Seiner Churfürstl. Durchl. gethane oblata und Conditiones ihme schrifftlich außgeantwortet worden, mit welchem er sich wieder zurück nach der Schweitz gemachet, bis endlich im nechst verstrichenen Monat Junio dieses Jahres Vierzehen Schweitzerische Familien unter der vorhin benanten abgeordneten conduite sich alhier eingefunden und den benanten Ort unter dem Amte Potstam bezogen, Der Gevollmächtigte Albrecht Baurenkönig aber noch einige Erinnerungen, 


\section{Anhänge}

welche die Republique bey den offerirten conditionen gethan, gehorsamst uberreichet und umb Außfertigung eines schrifftlichen Contracts unterthänigst angehalten; daß dannenhero höchstgedachte Seine Churfürstliche Durchlauchtigkeit gegen diese Familien sich folgender gestalt gnädigst erkläret, und wie es in einen und andern gehalten werden solle, hiedurch öffentlich verschreiben laßen.

1.

Anfänglich versprechen Seine Churfürstl. Durchl. diesen Familien gnädigst, daß Sie allen Schaden, so durch Überschwemmung des Waßers an den Ländereyen zu befürchten, wieder erstatten und davor garantieren wollen, iedoch daß ein ieder bey dem übergebenen Lande auch allen möglichen Fleiß anwende, damit solches nicht allein verbeßert, sondern auch mit Graben und wie es sonst die Nothdurfft erforderst, conserviret und aller Schade nach muglichkeit verhütet werde.

2.

Gleich wie auch Seine Churfürstl. Durchl. diese Familien frey anhero bringen und alle Reiseund Zehrungs Kosten Zahlen laßen, Also geben sie denenselben hiemit nochmals die Versicherung, daß von ihnen deßfalß hinfuro keine Erstattung gefodert noch iemals einige praetension gemachet werden solle.

3.

Seine Churfürstliche Durchlauchtigkeit wollen mit erbauung der Wohnungen fleißig continuiren laßen, biß eine iede Familie mit einem eigenem Hause versehen. Und sollen diese Wohnungen ihnen erb- und eigenthumlich gelaßen, auch deßhalb keine Erstattung gefodert werden, Gestalt dann sothane Häuser anitzo bereits mehrentheils Zur gäntzlichen perfection gebracht seyn.

4.

Seine Churfürstliche Durchl. wollen denen Familien das benötigte Rind Vieh, auch nach ihrem Verlangen Pferde geben, da dann ein ieder, so viel er bey seinem Hoffe dienlich achtet, an sich nehmen kan, welche nach dem Empfang entweder in billigem Preiß sofort bezahlet, oder so lange es nicht bezahlet, der Zins von dem capital, so viel daßelbe von dem Vieh in billigen wehrt außträget, ad 5 pro Cent iärlich gegeben werden mus; Jedoch, daß das geliefferte Vieh auf deßen Gefahr, so es empfanget, verbleibe und nach Verfließung des Jahres entweder vor voll bezahlet, oder der vorgemelte Zins weiter continuiret werde. Sollte auch ein Gemein Viehsterben sich eräugen, so soll darüber Handlung gepflogen und alles nach Billigkeit eingerichtet werden.

5.

Mit dem Acker und Wiesen Lande, so denen Familien eingethan und zugemeßen wird, soll es also gehalten werden, daß von dem ienigen, so annoch mit Holtz und Stubben bewachßen, Sechs frey Jahre, von dem andern aber, so nur mit Hüllen bewachßen, vier frey Jahre concedi- 
ret werden sollen. Wer aber von dem itzo bereits nutzbahren Grunde etwas empfänget, mus davor nach Beschaffenheit des Landes sofort etwas erleidliches Zinsen, weßhalb mit einem ieden absonderlich gehandelt und Rechnung gehalten, der Zins auch nach Billigkeit eingerichtet werden soll, und soll dieses von kommenden Michaelis hujus anni seinen Anfang nehmen, und der erste Zins auff Michaelis 1686 erleget werden.

6.

Wann auch einer oder der ander itzo oder ins künfftige von dem bereits gereinigten und fruchtbahren Acker und Ländereyen etwas käufflich an sich bringen oder auf das ienige, was ihm Zugemeßen, bezahlen wolte, so soll deßhalb umb einen billigen Preiß mit ihm verhandelt und es im übrigen also eingerichtet werden, daß der ienige, so nichts kauffet, einen gewißen Zehend oder grund Zins nach genoßenen frey iahren iärlich erlegen, der ienige aber, so die helffte des Wehrts zahlet, nur den halben grund Zins nach den frey Jahren entrichten, und der, so gantz bezahlet, über dem gar nichts weiter hievon $\mathrm{Zu}$ praestiren schuldig seyn soll. Der Kauff Schilling von dem, was bezahlet wird, wie auch der iärliche Zins von dem unbezahleten soll als dann, wann ein Land zu seiner völligen Nutzbahrkeit gebracht worden, nach der Natur und Güte des Fundi gesetzet werden.

7.

Seine Churfürstl. Durchl. wollen dero Amte Zu Potstam und neben dem auch dem Schultzen ihres Mittels die Inspection aufftragen, damit ein ieder das seinige fleißig bestellen und die Brücken Graben und Dämme in gutem Stande erhalten, hingegen durch eines oder des andern Nachläßigkeit denen Nachbahren keine Schade veruhrsachet, auch Streitigkeiten unter ihnen bald zur Richtigkeit gebracht werden mögen, Gestalt dem Schultzen, wie derselbe in einem und andern sich zu verhalten, absonderliche instruction gegeben werden soll.

8.

Dem Prediger, so aus der Schweitz mit kommen, wollen Seine Churfürstl. Durchl. aus dero Amt Potstam Zwey Hundert thaler zum iärlichen Salario und also quartaliter Fünffzig thaler zahlen, ihm auch, so lange die Pfarr Wohnung in dem Bruche nicht fertig, eine freye Wohnung in Potstam wie auch überdem im Bruche etwas Land zum Garten, nebst etwas Wiesewachs zu erhaltung etlicher Kühe, auch Acker, iedoch daß er auff seine Kosten nutzbahr mache, auch seines Gefallens an andere vermiete, einräumen laßen, und soll sein Salarium den Anfang von Johannis dieses Jahres nehmen, also daß ihm auff Michaelis das erste quartal gezahlet werde.

Es wird ihm auch vergönnet, etliche Eltisten und ehrbahre Männer zu erwehlen, welche nebst ihm dahin sehen sollen, damit gute Kirchen Ordnung und Disciplin gehalten werde. Auff einen Schulmeister wollen Seine Churfürstl. Durchl. iärlich Zwantzig Thaler auch aus dero Amt Potstam, und also quartaliter Fünff thaler gnädigst reichen laßen. Es werden aber die Familien zu desto beßerer Unterhaltung des Predigers und Schulmeisters hiernegst auch etwas beyzutragen sich nicht entbrechen. 


\section{Anhänge}

9.

Seine Churfürstl. Durchl. wollen diese Familien von allen oneribus, Sie haben Nahmen wie sie wollen, auch so noch ins künfftige erdacht werden möchten, gäntzlich befreyen. Es sollen aber die Familien und ihre Nachkommen schuldig seyn, von dreyssig zu dreyssig Jahren umb continuation dieser Befreyung unterthänigst anzuhalten.

10.

Den Krug, welchen Seine Churfürstl. Durchl. erbauen laßen, mögen die Familien durch iemand ihrer Lands Leute bewohnen laßen, und soll demselben gut Bier und Brantewein aus dem Amte Potstam, als woher Sie solches alles, was Sie von nöten haben, nehmen müßen, geliefferd, iedoch nicht mehr als Zwo tonnen auff einmahl geborget werden. Wegen dieses Kruges und freyen Schancks soll der Besitzer iärlich Sechs thaler Zur recognition erlegen und Zum Anfang Ein frey Jahr genießen.

11.

Was Zur Saat iemand im ersten Jahre benötiget, soll auff sein Ansuchen ihm gegeben werden, dergestalt, daß er bey der Ernte es entweder in natura oder mit Gelde erstatte.

12.

Wann auch iemand von diesen Leuten oder ihren Nachkommen wieder in sein Vater Land zurück gehen wolte, so hat derselbe sich anzugeben, und soll er, wann er entrichtet, was er schuldig seyn möchste, dimittiret, niemand aber von ihnen zu einigen Zeiten der Leibeigenschafft unterwürffig gemachet werden.

13.

Damit zu Anfangs denen ankommenden die Haußhaltung nicht zu schwer falle, So wollen Seine Churfürstl. Durchl. ieder Familie von 9 bis 10 Persohnen Zwölff Scheffel Rogken und einer Familie von 5 Personen halb so viel, wie auch einer ieden Familie eine Tonne Bier und einen Scheffel Saltz in Gnaden schencken, Gestalt Sie solches auch bereits wircklich, und noch ein weit mehrers ohne endt geld erhalten; hetten Sie etwas mehr nötig, soll ihnen solches

gegen Billige Bezahlung auch gelieffert werden.

14.

Zum Ackerbau vor die Haltungen haben Seine Churfürstl. Durchl. einiges Land von dero Stadt Werder, so bereits gantz uhrbahr, erkaufft, wovon Sie diesen Familien die Nothdurfft nach Proportion einräumen laßen wollen, deßen sie sich dann ihres gefallens zu ihrem Nutz und Besten, so gut Sie immer können und wollen, gebrauchen, und davon einen Landublichen Zins nach der qualitaet des Fundi [Boden, Grundstück], so lange Niemand davon etwas käufflich an sich nimmet, (denn wenn solches geschicht, so bleibet es bey dem, wie im 6 . Art: angeführet,) iärlich erlegen sollen. 
15.

Das benötigte Bau und Brenn Holtz soll in der Linewitz gegeben und auf der Leute Ansuchen allemal frey angewiesen werden.

16.

Mit der Angel auf der Havel zu fischen, soll ihnen frey gelaßen werden, wie sie dann auch in den Graben hinter ihren Häusern sich Fische halten und selbige vor sich genießen mögen.

17.

Wann ein Hauß Vater mit Tode abgehet, so soll das Gut den Wittwen und Waysen nicht entzogen, sondern Sie dabey gelaßen und gehandhabet werden, mit eben den Rechten und Genoß, so der Hauß Vater bey Lebezeiten daran gehabt hat.

18.

Über das einige, was etwan von einem und andern testiret oder sonst durch letzten Willen disponiret worden, soll denen Rechten gemäs gehalten werden.

19.

Wann eine Familie gantz außstürbe und weder Erbe noch Testament vorhanden, so wollen Seine Churfürstl. Durchl. die Verlaßenschafft einem andern von der Nation ihres Gefallens, nicht aber einem frömbden, zuwenden.

20.

Wenn auch einer von hiesigen Lands Leuten sich durch heyrath mit denen Schweitzerischen Familien befreunden und ihm die Erbschafft einiger diesen Familien sonst Zugestandenen Güter zufallen solte, So wollen dennoch Seine Churfürstl. Durchl. gnädigst geschehen laßen, daß denen übrigen Familien frey stehen solle, dieselbe Erbportion an sich zu erhandeln und den frömbden, so nicht ihrer nation, außzukauffen, Jedoch daß solches gerichtlich geschehe und der Frömbde gebürlich contentiret werde.

21.

Seine Churfürstl. Durchlauchtigkeit wollen dem Schultzen iärlich einen neuen Rock oder Mantell geben. Zu fester haltung alles deßen, was obstehet, haben offt höchstgedachte Seine Churfürstl. Durchl. diese Verschreibung in triplo außfertigen laßen, alle drey Exemplaria eigenhändig unterschrieben und eines davon in dero Archivo beylegen, das andere der löblichen Republique zu Bern übersenden und das Dritte denen Familien außantworten laßen.

So geschehen und gegeben

zu Cölln an der Spree, den 16. Septembris

Friderich Wilhelm.

Anno 1685 . 


\section{Anhänge}

\section{Anhang 5}

Kurfürst Friedrich Wilhelm befiehlt Oberjägermeister J.E. v Lüderitz, den noch ausstehenden Kirchenbau für die Schweizer im Golmer Bruch in Angriff zu nehmen. Potsdam, 1688 April 27.

GStA PK, I. HA, Rep. 47, Lit P 3 (Paket 15853), fol. 688, Konzept.

Rubrum

27 April 1688.

Den Kirchenbaw vor die im Bruch Friderich Wilhelm Churfürst wohnende Schweitzer werckstellig zu machen.

Unseren gnädigen Gruß zuvor

etc. Ihr erinnert euch

unterthänigst, daß Wir

Zum offteren erwehnet, daß

Wir Vor die im Bruch Woh-

nende Schweitzer noch gerne

eine Kirche bauen lassen

wolten. Weill Wir

nun bey der gnädigsten

intention noch beharren

und solchen Kirchenbaw

Werckstellig machen

zu lassen nunmehr hochnöthig

befinden, Alß befehlen

Wir euch hiemit gnädigst,

solchen Kirchenbaw ie

eh(er) ie besser fortzusetzen

und euch nichts davon

abhalten zu lassen. Was

die bauwmittel betrifft, dieselbe habt Ihr aus den

bahresten Ambts holtz gefällen zu nehmen, und also diesen Unsern

gnädigsten willen gehorsambst zu vol-

bringen. Seyndt etc. Geben

Potstam, den 27. April

An

den Ober Jägermeister

den von Lüderitz

Auff Sein Churf.

G(naden) Specialbefehl
1688

J.E. v Lüderitz 


\section{Anhang 6}

Die Schweizer Gemeinde im Golmer Bruch bittet Kurfürst Friedrich III. um Einweihung ihrer neuerbauten Kirche. Golmer Bruch, 1690 Oktober.

GStA PK, I. HA, Rep. 21 Nr. 123 (Paket 7997), fol. 196/196R, Ausfertigung.

Durchleuchtigster Churfürst

Gnädigster Herr.

Eüwer Churf. Durchl. haben die gnädigste Verordnung gethan, daß vor die Schweitzerische Coloney im Golmischen Bruch eine Kirche ist erbauet worden, haben auch bey deroselben Abreiße nach Cleve dero Hoffprediger Hr. Brunsenio die Commission solche einzuweyhen gnädigst aufgetragen. Weylen aber nach der Zeyt kein schrifftlicher Befälch darüber erfolget, ist diß Christliche Wärck bißhero Vnderlaßen worden. Nachdeme nun die Kirche schon eine Zeyt lang fertig gestanden hat, vnd vns bey dißer annahenden Wynters Zeyt nicht so bequem fält, in einem ängen gemach den Gottes Dienst zuehalten, Alß Bitten wir Vnderthänigst Eüwer Churf. Durchl. wollen gnädigst geruhwen, diße zur Ehren Gottes erbauwte Kirche einweyhen vnd zue Vnßerem Gottsäligen gebrauch widmen zu laßen. Gott wird Eüwer Churf. Durchl. Davuor sägnen vnd gleich wie dem Dauid ein Beständiges Hauß Bauwen. Worumb vnabläßlich Bitten

Eüwer Churf. Durchl.

Vnderthänigsten vnd gehorsambste Vnderthanen, die Schweitzerische Gemeind im Golmischen Bruch 


\section{Anhänge}

\section{Anhang 7}

Kurfürst Friedrich III. befiehlt Hofprediger Brunsenius, sowie dem Oberforstmeister v. Pannewitz und den Beamten zu Potsdam die Kirche im Golmer Bruch am 16. November 1690 einzuweihen und an der Einweihung teilzunehmen. Cölln an der Spree, 1690 November 10. GStA PK, I. HA, Rep. 21, Nr. 123 (Paket 7997), fol. 195, Konzept.

10. Nov. 1690

Einweihung der Schweitze-

rischen Kirche im Golmischen

bruche

Fridrich 3. Churfürst

Unsern gnädigsten Gruß zuvor etc.

Demnach Wir vernehmen, daß die Kirche, so vor die

Schweitzerische Colonie im golmischen bruche erbauet worden, nunmehro gantz fertig sey, daß darinnen geprediget werden könne, als befehlen wir euch hirmit gnädigst, solche Kirche auf bevorstehenden Sontag [16. November 1690] für die Schweitzerische Colonie Zu Ihren gottesdienst ein $\mathrm{Zu}$ weihen. Seind etc. Colln an der Spree 10. Nov. 1690

An

H. Brunsenius

Fridrich 3. Churfurst

Unsern gruß zuvor. Liebe getreue, demnach Wir Unseren Hoffprediger Ern Brunsenius gnädigst befehlen, die Neuerbaute Kirche vor die Schweitzerische Colonie im golmischen bruche auf bevorstehenden Sontag einzuweihen, Als befehlen wir euch hiemit gnädigst, solchem Actui an Unser stat mit beyzuwohnen. Seind etc. Colln den 10. Nov. 1690

An

den Oberforstmeister den Von

Pannewitz u. die beamten

zu Potsdam

$\mathrm{O}$ (tto) $\mathrm{F}$ (reiherr) v. Schwerin 


\section{Anhang 8}

Kurfürst Friedrichs III. befiehlt dem Prediger Wyttenbach wegen seines Schreibens [vom 30. Juni 1693] an den Amtmann von Lehnin, Johann Samuel Clari, die Unterstützung der widersetzlichen Schweizer zu Töplitz zu unterlassen und sie zu den schuldigen Zahlungen zu veranlassen. Cölln, 1693 Juli 18.

BLHA, Rep. 7 Amt Lehnin Nr. 30/1, fol. 7/7R, Konzept.

18. Jul. 1693

den Schweitzer Prediger Zu Pots

tamb wird ernstl. anbefohlen, sich

der Schweitzer Sache Zu enthalten und Sie vielmehr zur Zahlung

$\mathrm{Zu}$ reden, und der Execution $\mathrm{Zu}$

gewärtigen [Registraturvermerk]
Friderich der 3. Churfürst etc.

Unsern etc. Wir ersehen aus

beygehenden des Ambtmans Zu

Lehnin Joh: S: Claren abgestatteten

Bericht, welcher Gestalt Ihr

Ihn nicht allein in Einen an Ihn

abgelaßenen Brieff mit sehr

anzüglichen

und einen Prediger

unanständigen

Worten angegriffen,

sondern auch ohne Noth vor die

Schweitzer aufn Vorwercke

(Zu) Töplitz intercediret und

dieselbe in ihrer wiedersetzlich-

keit gestärcket.

Nun erinnern Wir Unß annoch

gnedigst, daß Wir Euch bereits

vor einiger Zeith anbefohlen haben,

Euch der Schweitzer Sachen gäntz(lich)

zu enthalten, dahero Wir

dergleichen unternehmunge(n)

gantz Mißfällig vernehmen,

und hätten vielmehr geglaubt,

daß Ihr die Töplitzschen Schweitzer

alß welche des ged(achten) Ambtmans

Bericht nach keine Uhrsache zu

Klagen haben sollen, zu ihrer

Schuldigkeit würdet angemahnet

alß davon abgehalt(en) haben,

Indem Sie vi contractus [Kraft des Vertrages]

praestanda zu praestiren

schuldig seyn; 


\title{
IX. Anhänge
}

\author{
$\mathrm{AlB}$ wird Euch hier mit alles \\ ernstes anbefohlen, hin künfftig \\ keine Schweitzer Zur wieder- \\ setzlichkeit aufzuwiegeln, \\ sondern Euch dergleichen gäntzl(ich). \\ zu enthalten, und Vielmehr \\ denen Schweitzern zu Töplitz \\ zur schuldigen Zahlung zuzu- \\ reden, oder der bereits \\ wieder Sie verordneten \\ Execution zu gewärtigen. \\ Und Wir Seind Euch übrigens \\ mit g(naden) gewogen. Geben \\ Cölln d. 18 Jul. 1693
}

An

Dodo v. Knyphausen

den Schweitzer Prediger

Zu Potsdam Albrecht

Wittenbach

\section{Anhang 9}

Bittschrift eines Schweizer Kolonisten aus Vielitz an Kurfürst Friedrich III. aus dem Jahre 1694, zit. nach Schneider, Die Schweizer Kolonie in der Mark, in: Beilage zum Programm des Königlichen Wilhelms-Gymnasium 1906, Berlin. S. 17 bzw. Dreifuss, Willkommene Berner Siedler, in Bund: (1985) Nr. 167 (20.07), 172 (27.07) und 179 (03.08.), Abdruck

Seiner Kur Fürstl. Durchlüchtigkeit Mein hoch gearhten Kumisari Unser gantz Freündliches Biden Und begären an sei Unser hoch Gearhten Kumissari. Unser gantz Fründliches Biden Und begären an sei Unser hoch Gearhten Kumisari wier schweitzer von Fylitz byten das dye hoch gearhten Kumisari das dorf Fylitz Mit schweitzern besetz bleibe. Synd aber dort welche, dye Nit Gute Hauswirden sind, so söllen sei dye hoch gearhten Kumisari Ab schafen Und andre guti Erliche schweitzer hynsetzen aber wyder seiner Churfürstl. Durchl. Unsren Gnädigesten heren Und Einer Gnädigen herschaft welen wier Nit dibstediren [? wahrscheinlich: disputieren] sonder wier biden Under däniglich drum.

wan Es aber Nit Kan sein das die hoch Gearhten Kumisari Uns darrin werden schützen Und schyrmen als bis här Geschehen yst so welen wyer Unser gnädigen oberkeit yhn der schweitz Es zu schreiben das sie Uns wiederum zer gelt schyck, Und wier begären den abscheid von hyer al mit einandren.

wen Uns aber kan geholfen werden hye Rin so welen wier Uns gantz Underdänig Erzeigen Mit der gotes hülf. 


\section{Anhang 10}

Kurfürst Friedrich III. befiehlt Hofjägermeister Pannewitz, Amtsrat Merian und Oberbaudirektor Nehring die Bitte der Schweizer Kolonisten im Golmer Bruch, nach Golm umzuziehen, zu prüfen und darüber zu berichten, Cölln an der Spree, 1695 Mai 02.

GStA PK, I. HA, Rep. 21 Nr. 123 (Paket 7998) - nicht paginiert, Original.

den 2" May 1695

wegen transportirung der

Schweitzer vom Bruche bey

Pottstam nach den Golm
An

H HoffJägermst von Pannewitz,

Ambtsraht Merian und

Oberbau Director Nehring.
Friedrich der III: ${ }^{\text {te }}$ Churfürst etc

Unseren etc. Ihr ersehet aus dem Beyschluß, welchergestalt die sämbtliche in dem

Bruch bey Potstam wohnende Schweitzer unterthänigst gebeten, $\mathrm{Zu}$ verstatten, daß 7 familien von Ihnen wegen des Großen Waßers Ihre wohnungen nach dem Golm transportiren mögen.

Wir committiren und Befehlen euch darauf in gnaden, die sache förderlichst in loco zu untersuchen, den von dem Waßer Ihnen Zugefüegten schaden in augenschein zu nehmen, und unß davon zu fernerer gnädigsten Verordnung unterthänigsten Bericht abzustatten.

Seind etc. Cöllen den 2 May 1695

\section{Anhang 11}

Die Schweizerische Gemeinde im Golmerbruch bittet Kurfürst Friedrich III., bei der anstehenden Verlängerung ihres Vertrages auf Grund der schwierigen Lebensbedingungen im Golmer Bruch ihre Abgabenlast zu vermindern. Golmer Bruch, 1695 Mai.

BLHA, Rep. 2 Kurmärkische Kriegs- und Domänenkammer Nr. D 15409, fol. 8-9, Original.

$$
\begin{gathered}
\text { Durchlauchtigster, Großmächtigster } \\
\text { Herr } \\
\text { Gnädigster Churfürst. etc. }
\end{gathered}
$$

Demnach wir Unsere frey Jahr Vnder Eüwer Churf. Durchl. gewaltigen Schutz In ruhe vnd friden durch Gottes Gnaden genoßen: So ist es nun an demme, daß wir auch die gewohnlichen onera nach der qualitet des Landeß Jährlich wie billich so schuldig entrichten. Weyl aber das 


\title{
IX. Anhänge
}

ohrt so beschaffen, daß das Waßer alle Jahr gemeinigklich biß auf Johanny In Vnßern Wysen liget Vnd durch der Sonne hitze dermaßen erwehrmet wird, daß das fueter, so daselbsten wachset, so schlecht vnd gering, daß darbey Vnßer Vieh nicht nur wenig Milch gibet, sondern auch das Vbrige Graß Vnß Niemand mehr abkauffen will: Auch unsere Hüthung, so anfangs Vns gegeben, wegen großen vnd Vilen Morasts, alß auß welchen wir Täglich Vnßer Vieh mit Seil Vnd Sparren heraußziehen müßten, dan sie darin biß an den Halß gefallen, Ja etlicher gar stecken Blieben Vnd crepiert sint - Vnnutzbahr Gemacht, Vnd dißeren Vbell Vor Zu kommen auß nothdurfft Vnsere Wisen auf dem Galin Zuieiner andern Hütung haben machen müßen, welche aber weyl sie zimblich enge, Wir nicht mehr Vieh an der Zahl alß gewohnlich, das übrige fueter den Winter durch, so wir nicht debitieren müßen, Zui - Verzehren halten Vnd anstellen können, Zue denn auch In Vnßerem Instrument so Von Eüwer Churfl. Durchl. Hocher eigener Hand aller gnädigst corroboriert, einen Articul deß ynhalt stehet: daß nach Verfließung Vnserer frey Jahren wir Einer gnädigsten Herschafft Den Zächenden Theil von dem gewächse oder aber einen gewüßen grund Zinß Jährlich abstatten sollen: Alß gelanget an Eüwer Churf. Durchl. Vnsere demütigste Vnd Underthänigste Bitte, Vnß hierin allergnädigst Zu wilfahren; daß Nambliche entwederst das Zächende theil laut Instruments in natura Von Vnß Jährlich möchte abgenohmmen werden, oder aber, so dieses Eüwer Churf. Durchl. nicht Beliebig sein möchte, $\mathrm{Vn} ß$ anstat deßen einen geringen grund $\mathrm{Zin} ß$, welcher das aequivalent des Zächenden theilß Bringen thäte, allergnädigst aufzulegen, damit also Vnsere onera, weyl das ohrt an Vnd für sich selbst sehr schlächt, nicht Zui hoch Vnd wir Vnd Vnsere Kinder darbey samplichen Subsistieren können, Vnd Hiemit fehrners dardurch Veranlaßen werden. Für Eüwer Churf. Durchl. Zeitliche vnd ewige wolfahrt Leibß Vnd der seelen In vnßern sogenanten Fridenreichs Kirchen eiffrig vnd vnableßlich den Allerhöchsten Gott Zue bätten vnd anzuiflächen: Getröste Vns gnädigst Erhörung

\author{
Eüwer Churfürstliche Durchlaucht \\ gehorsamme, Vnderthä- \\ nigste Vnd getreüwe \\ Vnderthanen
}

Die Schweizerische Gemeine

Im Schweizerbruch

\section{Anhang 12}

Amtskammerrat, E.v. Brandt, befiehlt auf Grund einer Bittschrift des Predigers im Golmer Bruch, dem Amtmann zu Potsdam wegen des Abrisses des Wohnhauses vom Vorwerk Golm zu berichten, und ihn vorläufig einzustellen. Cölln an der Spree, 1698 Mai 08

GStA PK, I. HA, Rep. 21 Nr. 123 (Paket 7998) - nicht paginiert, Konzept. 
Auf Alberti Wyttenbaches, Prediger

Bey der Schweitzer Colonie Zu

Potstam Supplicat

Sr: Churf. Durchl. Zu Brandenb. etc.

Unser gnädigster Herr

Befehlen dero Ambtmann Zu Potstam

hiermit gnädigst und ernstlich, hierauf

$\mathrm{Zu}$ fernerer gnädigster Verordnung

also forth unterthänigsten Bericht ab-

Zustatten, Indeßen aber mit nider-

reisung des auf dem Golmischen Vorwerck ste-

henden Meyer haußes inne zu halten

Sig. Cölln, den 8 May 1698

E v Brandt

\section{Anhang 13}

Prof. Sterky stellt Prediger Sigismund anlässlich dessen angestrebter Rückkehr in die Schweiz ein Zeugnis aus und beschreibt darin ausführlich dessen treue und fleißige Amtsausübung, Berlin, 1710 August 12 .

GStA PK, I. HA, Rep. 9 Nr. D. 9. Fasc. 4, fol. 114/114R, Kopie.

Vorweiser dieses, Herr Sigismund Lupichius, Prediger in dem Schweitzerbruch im Ambt Potstam und in Neu-Töplitz im Amt Lehnin, hat mir unterschriebenen Vorgestellt, wie daß Er von seinem Vater, Herrn Joh. Jacob Lupichius, Ersten Pfarrern Zu Thun, im Bernergebieth, sehr sollicitiret [gedrängt] und Vermahnet werde, wiederumb in sein Vaterland Zu Kehren, Ihme in seinem hohen Alter behülf lich $\mathrm{Zu}$ seyn, Er sich auch seines ohrtes in seinem gewißenVerpflichtet befinde, Ihmer seinen Kindtlichen gehorsam darinnen zu leisten, wann Er die allergnädigste permission [Erlaubnis] von S. K. Mayt erlangen könne; und weilen zu diesem Ende Ihme ein Attestatum seines Verhaltens in seinem Predigambt nöthig seye, ersuche Er mich, als seinen Vorgesetzten, Ihme solches zu ertheilen; Und weilen seinem billigen Begehren ich mich nicht wollen noch sollen wiedersetzen, Als bezeüge ich hiemit, daß bey der Kirchen visitation, die ich in Neu Töplitz gehalten, ich gefunden, daß obermelter Herr Sigism: Lupichius in allen stücken seines ambtes sich sehr treu und fleißg gehalten, sowohl in den Predigten, Kinderlehren, Tauffen und andern öffentlichen Verrichtungen seines Ambtes als auch in Besuchung der Kranken, Betrübten und sterbenden und aufsicht auf die schulen, alßo daß ich seine Gemeinde in ansehen der alten und Jungen in einem sehr guten stand gefunden und Verspühret, daß Er von seiner gantzen Gemeinde geEhret und geliebet seye, 


\title{
IX. Anhänge
}

und in währender Zeit meiner aufsicht auf die Schweitzer Kirchen niemahlen die allergeringste Klage wieder Ihne geführet worden.

$\mathrm{Zu}$ urkundt deßen habe ich diesen gegenwärtigen schein eigenhändig ertheilen und unterschreiben

\author{
wollen; Berlin den 12. Aug: 1710. \\ J. Sterky SS. Theol: Dr. \\ et Prof. Director \\ der Schweitzerischen
}

Kirche.

\section{Anhang 14}

Der Prediger im Golmer Bruch, Sigismund Lupichius, ersucht den Geheimen

Kammermeister Franke [Reformirter] wegen der Beschuldigungen der Schweizer Kolonisten durch Amtskammerpräsident v. Görne [Lutheraner] um Unterstützung, der sie bezichtigt hatte, faule Leute zu sein und seit ihrer Ankunft das Golmer Bruch vernachlässigt und ruiniert zu haben, 1713 April 11. [Auszug]

BLHA, Rep. 2 Kurmärkische Kriegs- u. Domänenkammer Nr. D. 15382, fol. 3-4, Konzept.

Wohlgebohrener, Hochgebiethender Herr

Insondere HochgeEhrtester Herr Cammermeister etc.

Wann mir obliget für meiner Gemeinde sowohl leib- als geistlichen wohlstand, nach dem exempel meiner Antecessoren, zusorgen, so hoffe ich, es werden Ew. Wohlgeb. mir desto weniger Verdenken, wann aus anlaß deßen, was mann itzo mit gedachter Gemeine Vorhat, mich unterstehe, an dieselbe gegenwärtige Zeilen in aller gebührenden unterthänigkeit abzulaßen: Die harte anrede, die der /:Titl:/ Herr Präsident Von Görne Verwichenen sonnabendt in hiesigem Ambte an die anwesende Colonisten gethan, ging mir sehr nahe Zuhertzen: Nemlich, sie wären faule Schweitzer, und hätten den Bruch so laßen eingehen, daß er fast unnutzbahr worden, hätten auch nun bald 30 Jahr frey geseßen, ohne dem Könige etwas Zu geben; darumb solten für Künftighin, Von nächsten Trinit: an $\mathrm{Zu}$ rechnen, Jährl. 500 rt. geben, oder wieder hingehen, wo sie hergekommen; zu hiesigem Ambte solte Ihnen der abscheid und $\mathrm{Pa}$ geschrieben werden; sie wären so liederliche haußhalter, daß Er gehört, die meiste hätten schon itzo Kein Brot mehr im Hause, etc:

Ew. Wohlgeb. werden mir großgünstigst permittiren, hierüber, nach meinen wüßen und gewüßen, Zur defension dieser guten leüthen, die außert mir sonst niemanden haben, der für sie spreche, einige anmerkungen $\mathrm{Zu}$ machen.

I. Was die Beschuldigung betrifft, als wann der Bruch durch der Schweitzer faulheit in ruin gerathen, so glaube ich, daß denenselben hierinnen $\mathrm{Zu}$ Viel gethan werde: Diejenige, die 
dem Hochseel. Churfürst Friedrich Wilhelm die räumung dieses Bruches angegeben, haben Ihm übel gerathen, ihn umb sein gelt gebracht, und die gute Schweitzer darzu unglücklich gemacht. Man mag zur selbigen Zeit, da einige nacheinander folgende extraordinair Truckene Jahre waren, sich eingebildet haben, es würde immer so bleiben, und bezeügen die Schweitzer einhällig, es hätten Anno 1685 bey ihrer ankunfft hiesige allte leüthe die Köpfe über dem gantzen wercke geschüttelt und geprophezeyet, daß es keinen bestand haben würde, sondern bey Wiederkunfft der naßen Jahren und waßergrößen alles wieder ruinirt werden und in allten stande gerathen, wie dann auch, leider! geschehen. Dann der Bruch ist fast durch und durch grundloß, so daß ein schwacher Knabe die längste pique ohne mühe hinunter steken soll; Die Dämme waren nur Von loser Brucherde aufgeworffen und hatten unter sich keinen festen grund, so daß auch dieselbe, wann ein geladener wagen darüber fuhre, Zitterten und sich Zusehens beügeden; Als die waßergrößen und ergießungen Kamen und der dichte an den Bruch liegende Havelstrohm anzulauffen begunnte, wie itzo noch alle frühjahr und herbst $\mathrm{Zu}$ geschehen pfleget, Thaten die Schweitzer zu erhaltung der Dämme und des Bruchs so viel, als ihnen möglich war; Sie führeten Viel hundert füder sand und z.T. mist darauff und wachten Tag und nacht dabey, aber alles Vergeblich, denn die unwiederständliche gewalt des waßers riße die dämme ein, die gräben wurden wieder gefüllet, nebst dem daß das waßer nicht nur Von außen hereinkam, sonderen auch aus dem Bruche selbsten hervorquillete. So ließ auch das Ambt die Mühle, die das waßer auß dem Bruch mahlen solte und deren unterhaltung denen Schweitzeren nicht oblage, wieder eingehen. Als gedachte überschwemmung und gewaltsamme einreißung der dämme erfolgete, kame die Hochseel. Churfürstin Dorothea expresse von Potstam heraus gefahren und sahe selbsten in hoher Persohn alles mit an, konnte sich auch der Thränen nicht enthalten, als Sie die im Bruch erbauete Schweitzersche Häuser sahe im Waßer stehen, dergestallt daß mann anderß nicht als mit Kahnen Von einem hauß Zum anderen kommen konnte: Damahls NB. [Nota Bene] hat weder die hohe Herrschafft noch sonst jemand die Schweitzer wegen faulheit angeklaget oder Ihnen die schuld des ruinirten Bruches beygemeßen, sondern mann hat gar wohl erkennet, daß solches zu verwehren denen wenigen Schweitzern absolut unmöglich gewesen. Darumb hat auch die Höchstged. Gnädigste Churfürstin Dorothea aus sonderbahrer erbärmbd denen Schweitzeren das Vorwerk Gollm, wohin sie auch, umb nicht zu ersauffen, ihre Häusers translociren müßen, in geringem preiß Pachtsweise eingethan, solange als sie sich als gehorsame unterthanenaufführen würden, welches sie biß dato getreulich praestirt Zu haben Vermeinen; Hernach hat auch der Hochseel. König solches allergn. confirmirt. Als sich das gewäßer ein wenig verlauffen und gesetzet, haben die Schweitzer gemeinet, sie wollen es erzwingen den Bruch wieder $\mathrm{zu}$ repariren, haben tag und nacht darinnen gearbeitet, auch nahmhaffte geldsummen, so sie aus der Schweitz kommen laßen, daran gewandt und, sozusagen, in diesen moder versenket, aber alles umbsonst und Vergeblich, und seithero ist mehrgedachter Bruch Von Jahr zu Jahr schlimmer geworden, weilen das viele gewäßer ordinair wiedergekommen, und ist es nichts anders als ein grundloses aufgeschwommenes wesen; dann bald schwimmet hier ein stücke auf, bald setzt sich dort wieder ein stüke nieder. Es mag ein so 


\section{Anhänge}

trukenes Jahr seyn, als es will, so müßen die arme Schweitzer im waßer und moder gehen offt biß an die Knie, wann sie Von denen aufgeschwummenen Hüllen das heu abmehen wollen; Alßo ist freylich der Bruch itzo in schlechtem stande. Daß aber die schuld denen Schweitzeren aufgebürdet wird und sie deßwegen bey der Allergnädigsten Herrschafft als faule leüthe angeschwärtzet und Verhaßt gemachet werden, darüber haben sie große ursache sich wehund demüthig Zu beschwähren: Si anusasse sufficit, quis innocens erit?* Hat doch der Herr Ambtmann Vor einiger Zeit selbsten, nebst einen Teichgräber, den Bruch besehen, ob derselbe $\mathrm{Zu}$ guten wiesen könnte gemachet werden; weil aber seithero nichts tentirt [versuchen] worden, so glaube ich, daß es für unmöglich seye gehalten worden; Kann jemand solches praestiren, so wollen die Schweitzer es Ihm gerne ablehrnen. Ich setze aber doch den fall, die Dämme würden wieder erhöhet und die graben aufgeworffen, welches ohne unsägliche unkosten nicht geschehen könnte, wegen der ungemeinen länge der Dämme und weitläuffzigkeit des Bruches, so würde es aufs längste solange bestand haben, als es Vor diesem gehabt hat. Allso ist es unnütz, was an diesen grundlosen Bruch gewandt wirt, und wann die Schweitzer anfänglich alle umbstände gewußt hätten, wie sie es nachhero, leider! Zu ihrem großen schaden erfahren, so würden sie denselben nimmermehr angenommen haben. Ich enthalte mich ein mehrers $\mathrm{Zu}$ dieser armen leüthen entschuldigung beyzubringen, in Hoffnung, daß das angebrachte genug seye, sie Von der ungütlichen blâme [Rüge, Tadel] der faulheit Zu liberiren

II. .......

Ew. Wohlgeb. Meines hochgeehrtesten Herrn Cammermeisters

Unterth: und gehorsamer diener

Potßtam den 11. April 1713 S. Lupichius. Prediger

der hiesigen Schweitzer Colonie

*Wenn es genügt in Ketten zu liegen, wer wird unschuldig sein?

\section{Anhang 15}

Der Prediger im Golmer Bruch, Sigismund Lupichius, wendet sich an den Rat der Stadt Bern wegen der beängstigten Situation in der Gemeinde und dem Wunsche einiger Gemeindeglieder in die alte Heimat zurückzukehren. Berlin, 1713 Juni 28.

StA Bern: A. V. 19 Teutschland-Buch Preussen Brandenburg, fol. 395/401, Original. 
Hochwohlgebohren, HochEdle etc. etc. etc.

Hochgeachte, Gnädige Herren und Oberen etc.

Dieweilen die hiesige Vielfältige Veränderungen auch leider! meine Gemeine betreffen, und ich mich in meinem Gewißen verpflichtet finde Meinen allerseiths hochgeachten und Gnädigen Herren Von dem jtzigen gefährlichen und fast Zur extremitaet gekommenen Zustand gedachter meiner Gemeine nachricht $\mathrm{Zu}$ geben, so unterstehe mich in aller unterthänigkeit und schuldigster devotion solches hiemit kurtzl. und Substantzlich zu praestiren: Ich würde Villeicht Ew. Gnaden gedult mißbrauchen, wann ich Ihnen weitläufftig Klagen sollte, welcher gestallt meine Gemeinde, die Neunt-halb [8 1/2] Jahr her, so ich ihr Vorgestanden, dann und wann, und sonderlich von dem itzigen bitter - Lutherschen Amtmann einige attaques außgestanden; Wie dann dieser letztere Vor etwas mehr als 3 Jahren eine weitläufftigeschrifft aufgesetzet, mit diesem Titul „Ambts Potstam gründliche untersuchung derer in denen dörfferen Gollm, Galin und Nothwerder befindl. 14 Schweitzerische familien Zustand und Von denenselben führenden wirthschafft, auch ob und wie weit sie dem mit Ihnen getroffenen Contract gemäß gelebet; worinnen Er auf eine, sehr odieuse [gehässig] und passionnirte weise diesen guten leüthen unter Vielen anderen absurden dingen, auch so gar ihre reiß- und Zehrungs-Kosten, so Ao. 1685 der Hochseel. Churfürst Friedrich Wilhelm Ihnen zu Ihrer herbringung aus der Schweitz gut gethan, Item, die auf der Allergnädigsten Herrschafft unkosten gebaute Kirche und Häuser, des Predigers, Schulmeisters, und Schultzen besoldungen, die von dem hochseel. Churfürst Frid. Wilhelm und hochseel. König Friederich genoßene donneurs [Geschenke], und freyheiten etc. Verwißen und aufgerücket, auch deßwegen und unter dem praetext [Vorwand], daß das ihnen übergebene landt viel höher hätte können genutzet werden, Ihnen eine Rechnung Von 34 505. thaler gemachet hat; Alles nur zu dem end, damit Er diese arme Leüthe bey der hohen Herrschafft Verhaßt machen möchte, wie es dann damahls schon würklich so weit gekommen, daß der Colonie, selbst im nahmen des Königs, proponirt worden, entweder künfftighin der AllerGnädigsten Herrschafft anstatt der bißherigen 85. Thl. Vom Vorwerk Gollm, Jährl. 400. abzutragen, oder so fort des abscheidts gewärtig Zuseyn. Nachdem ich aber hierauf erst diese sache mit dem Ambtmann, in Seiner hochgräfflichen Exellentz des Herren General-Feldmarschalls, Grafen Von Wartensleben, als unsers Amtshaubtmanns, presentz debattirt, und meine Gemeine ritterlich defendiret, hernach auch eine Supplique an den König gemacht, so erhielte ich von höchstged. Sr. Königl. Mayst. durch den mund hochgedachter Sr. Hochgräffl. Excell: die allergnädigste antwort, die Schweitzer möchten in Gottes nahmen in Ihrem bisherigen stande verbleiben; wie ich die Acta hievon in händen habe, und heüte oder morgen auf Ew. Gnaden hohen befehl zu produciren so willig als schuldig, bin etc.

Hierauff ist die Colonie biß Zu des Höchstseel. Königs Tode unturbirt [ungestört] verblieben; bald aber auf diesen höchstbetrübten Todesfall fieng der Amtmann wiederumb an bey itzt regierender Königl. Mayt, unter dem praetendo des suchenden Königl. Interesses diese arme Leüthe anzugeben und verhaßt zu machen, dadurch Er es dann so vorbrachte, daß der Herr Ambts Cammer praesident Von Görne ein Lutheraner, den 8. April, und ein paar Tage her- 


\section{Anhänge}

nach der herr Amts Cammer Meister Franke, im nahmen des Königs nacher Potstam gekommen, und der erstere die Schweitzer, so Zu dem Ende ins Amt citirt waren, mit diesen und dergleichen harten worten angeredet; Ihr faule Schweitzer habt den Bruch so laßen eingehen, daß er fast unnutzbahr worden ist, und habt nun bald 30. Jahr frey geseßen, ohne der Gnädigsten Herrschafft waß Zugeben; Ihr soltet künfftighin Jährlich Von dem Vorwerk Gollm 500 und Von dem Galin 150 Thl. geben, und soltet Ihr biß nächsten Trinitatis /: das ist, den 11. Junij: / bedenkzeit haben; wollet Ihr so Viel geben, wohl und gut, „wo nicht, so soll das Vorwerk Gollm und übrige Ländereyen so ihr habt, alsdann an den meistbiethenden Verpachtet werden, und möget Ihr wieder gehen wo ihr hergekommen seit, hier /: mit dem finger auf des Amtmanns Tisch weisend: / soll eüch der abscheidt geschrieben werden, etc. Hierauff schreibe ich an Vorgedachten Herren Cammer Meister Franke /: so ein Reformierter ist: / einen weitläufftigen brief, beklagte mich in aller bescheidenheit über des Herren Von Görne harte anrede, Zeigete die unbilligkeit daß mann die Schweitzer faule leüthe hieße, in dem sie des bruches ruin, wegen denen eindringenden waßeren nicht haben praecaviren [verhüten] können; die unmöglichkeit die geforderte ungeheüre Pacht abzutragen; bathe aufs innständigste umb einige nachlaßung etc., wobey ich aber nichts mehr ausrichtete, als das die denen in Gollm und Nothwerder wohnenden eilf familien gefordete Pacht auf 436 Thl. moderirt worden, welche sie aber eben so wenig, als die 500 geben können; wegen denen Galineren aber blieb mann absolute bey denen 150 Thl. da sie biß dato Jährlich nicht mehr als 9 Thl. abzutragen schuldig gewesen. Die Gemeine offerirte sich durch mich schrifftlich

anstatt der bißherigen 85 Thl. Vom Vorwerk Gollm den Ao. 1689 gemachten anschlag á 222 Thl. und Von Galin 18. abzutragen, solches aber wollte Von dem König nicht angenommen werden: Zwey Von der Gemeine unterstuhenden sich, /: ohne mein Vorwüßen, dann sonsten ich es Ihnen gewehret hätte, wohl wißende, daß es nichts nützen würde: / den König in Potsdam auf der straße anzureden, da sie dann die ungnädige antwort erhielten, daß, wann sie so viel nicht geben wollten, so möchtensie gehen. Eine solche vom König selbstunmittel bahr ertheilte antwort nahme uns den muth Ziemlich, doch faßete ich, im Vertrauen auf Gott, die resolution, mit wenigen Von der Gemeine Vor 14 Tagen nacher Berlin zu reisen, da ich dann, nachdem mich bey hohen Patronen und Verständigen guten Freünden, berathet, eine Supplique, deren Copiam ich Sub Lit: A. mit sende, an Seine Excellentz den Herren Geheimen Staats-Ministry Von Kameke /: so ein Reformirter ist : / übergeben, mit demüthigster bitte, sie dem König Vorzutragen, der aber hernach freymüthig bekennet, Er habe den Vortrag nicht gethan noch Thuen dörffen /: obwohl Er sonsten Vor itzo den Vortrag der Schweitzer sachen hat: / weilen mann Ihm einen Vom König 3 mahl reiterirten [wiederholten] eigenhändigen befehl Vorgewiesen, daß Seine, des Königs, gänzliche resolution seye, die Potstamschen Schweitzer gar nicht mehr daselbsten zu dulden, wan sie den Vorgeschriebenen anschlag nicht bezahlen wollten, und daß wann Er, der Herr Geheime Rath, die sache Vorgetragen, Er Seine Königl. Mayt: nur mehr irritirt hätte, wie Er bey unterschiedlichen anderen gelegenheiten $\mathrm{Zu}$ seiner höchsten betrübnüß erfahren; Auch at er nicht undeütlich Zu Verstehen gegeben, daß es denen übrigen Colonien nicht beßer gehen werde:/: dann daß bey unser Colonie der anfang macht wird, kommt daher, weilen die übrige Colonien Reformirte, wir aber einen bitter 
Lutherschen Amtmann haben: / Also habe ich auf obgedachte Supplique kein unmittelbahre Königl. sondern nur eine Vom GeneralFinantz-Directorio, in Copia sub Lit B. mitkommend schrifftliche antwort erhalten können; und obschon ich gestern expresse wiederumb anhero gereiset, umb die übergebung eines Zweyten Memorials an den König Zu tentiren, so muß ich doch Zu meiner höchsten betrübnuß erfahren, wie daß kein eintziger StaatsMinistre, auch nicht einmahl Seine Hochgräffl. Exell. der Herr Graff und Burggraff Von Dhona, der sonsten unserer Nation sehr gnädig und günstig sich unterstehen, darff daßelbe anzunehmen, und Vorzutragen, umb obangeführten ursachen willen daß nemlich der König dadurch nur mehr irritiert und die sache eher schlimmer als beßer gemachet würde. etc. Dergestallten, daß unsers ohrtes bey dieser sache gar nichts mehr $\mathrm{Zu}$ thun ist, angesehen

ich alles ersinnliche und möglichste gethan, auch wo durch mühe, Verdruß, ungunst und unkosten, so bey dem so vielen reisen habe, /:als der ich nicht nur der Gemeine Prediger sondern auch Advocat seye, mich abschreken laßen, diesem unglük der bevorstehenden destruction meiner Gemeine Vorzubeügen, wie alle Menschen, so davon wißen, und sonderlich der herr Doctor Sterky, mit dem ich in allen dingen fleißig conferirt, und ohne deßen rath ich das geringste nicht gethan, wie, auch der Königl. Geheimte Secretarius Herr Ammon, mir als ein getreüer Compatriot, dieser angelegenheit jederzeit aufrichtige dienste geleistet, und andere gute freünde mehr, werden attestiren müßen etc. Allso habe ich und die gantze betrübte Gemeine bey solchem gefährlichen Zustand nechst Gott keine weitere Zuflucht als Zu Meinen hochgeachten Gnädigen Herren, meinen Theuersten Väteren, die ich aufs demüthigste und auf den knien bitte, Sie möchten doch sich meiner Gemeine Väterlich annehmen, und nach dero gnädigen und hocherleüchteten Gutfinden, in kräfftigen Terminis an den König schreiben, daß Er diese Von Seinem hochseel. Herren Großvater, Churfürst Friederich Wilhelm, glorwürdigsten andenkens, anhero beruffene Colonie allergnädigst conserviren und eine solche Pacht Von Ihnen begehren möchte, die sie abtragen und dabey ihr nothdürfftig brot haben können: Und zwar bitte ich unterthänigst, daß solches fordersamst und ohne Verzug, weil periculum in mora [Gefahr in Verzug] ist, geschehen möge, Jedennoch aber so, daß Von meiner wenigen Persohn nicht die erwehnung geschehe, allermaßen, wann Seiner Königl. Mayt. ich hierunter denunciret, besorglich Dero Ungnade, auch wohl gar die empfindtliche effecten Dero promptitude auff mich Ziehen würde; Zu welchem ende $\mathrm{M}$ (eine) g(nädigen) $\mathrm{h}$ (erren) ohnmaßgeblich in solchen Terminis, als wann Sie solches Von jemand anders in erfahrung gebracht hätten, sich Verlauten Zulaßen, Gnädigst belieben wollen etc., Inmittelst bitte gehorsamst M(eine) g(nädige) h(erren) möchten geruhen, mir Copiam Von Dero schreiben an den König Zu Zusenden als welches Zu meinem ferneren gouverno gereiche [Nachricht, Richtschnur] wird, wie ich dann hiemit auch demüthigst gebäten haben will, Ew. Gnaden möchten mir doch dero hohen befehl ertheilen, wie auf allen fall und bey hiernächst befürchtender dimission der Colonie ich mich aufzuführen habe; auch ob, und auf was weise diese Leüthe wieder nach dem Vaterland geführet werden möchten. gleichwie ihr erster Prediger, der jtzige $\mathrm{H}$. Theologus Malacrida, sie anhero geführet hat: Die gantze Colonie Tröstet sich, es werden Ew. Gnaden sie nicht Verlaßen, als Wisse Ihnen, wie die alte männer erzehlen, bey ihrem abzug auf der Nydek nach einer express hierauff gerichtete Predigt durch Deputirte aus 


\section{Anhänge}

Ihrem hohen Mittel Gnädigst Versprochen, sie wollten sich allezeit väterlich gegen sie verhalten und, wann je /: wie leider itzo geschiehet sie den abscheid bekommen sollten, so wollten Sie sich ihrer kräfftiglich annehmen und weiter für sie sorgen, weil sie auf Dero hohen befehl und genehmhaltung, auch durch pacta mit dem hochseel. Churfst. Fried: Wilhelm anhero geschiket worden. Das lamentiren unter diesen armen Leüthen ist unaussprechlich, so daß ich arbeit genung habe, sie in in diesem Creütz und Trübsahl Zutrösten und aufzurichten. Die 7 in Gollm wohnende familien, weilen sie laut des Königl. Decrets, so der Amtmann uns vorgelesen, sofort sollten dimitirt und Von hauß und hoff Verstoßen werden, erbothen sich Zwar, diese excessive Pacht Zugeben / : obgleich sie Vorher wißen, daß sie es absolute unmöglich werden praestiren können : / nur damit möchten so Viel zeit gewinnen bey Ew. Gnaden diesen rath und Väterliche hülffe Zu suchen; hingegen die 4 familien aufm Nothwerder und 3. auf dem Galin wollten und konnten sich Zu nichts erklähren, so daß sie würklich die bevorstehende Erndte werden im stich laßen müßen; und weil sie all, wie leicht $\mathrm{Zu}$ gedenken, nicht lange ohne brot werden bleiben können, so wirt solcher gestallt die helffte von der Gemeine im Bruch, neml. 7 familien, abgehen; und, welches warhafftig Zu beweinen, weil auf dem Galin ein 85. Jähriger mann, der nicht mehr fort kann, nahmentlich Hanß Lädrach Von Worb, und 3 Vater und Muterlose unerzogene wäysen, Zum spott und spectacul [Schauspiel] Lutheraner /: die ohne dem ihre freüde über diß unglück der Schweitzer Ziemlich merken laßen: / müßen betteln gehen, weilen diejenige, aus deren güteren sie erhalten worden, sollen Verstoßen werden. Als ich ohnlängst dem Amtmann Zwar etwas ernstlich doch ohne schimpfen und schmähen, sondern mit aller bescheidenheit Zugeredt, daß Er nemlich an allem die eintzige schuld seye etc., so hieß Er mich liegen und tractirte mich wie einen Hunden Jungen, mit beygefügter bedrohung, mich bey dem König Zu Verklagen: Da ich nun resolvirt bin für meine Gemeine, nach meiner Pflicht und gewüßen $\mathrm{Zu}$ reden und $\mathrm{Zu}$ streiten, so hoffe, ja, bitte ich demüthigst, Ew. Gnaden werden mich allezeit väterlich schützen etc. Was etwa in diesem schreiben dunkel vorkommen möchte, daß kann der Herr Prediger Witenbach Zu Wohlen gründlich erklähren.

In gedultiger erwartung, daß Ew. Gnaden mich und meine liebe Gemeine in ansehen unsers demüthigsten petiti [Bittgesuch] erhören und sich Väterlich unser annehmen werden, unterlassen wir nicht den Großen Gott eifrigst anzuflehen, daß Er Sie an Dero hohen Persohnen, Gott seeligen Regierung und hochansehenl. familie Gnädigst seegnen wolle! Womit ich in tieffster devotion ersterbe

Hochwohlgebohren, HochEdle etc. etc. etc. Insonders hochgeachte Gnädige Herren und Oberen etc.

Meiner allerseiths Gnädigsten Herren

Unterthnänigst-Treü-gehorsamster Bürger und Knecht

Sigism. Lunpichius

Berlin d 28. Junij 1713. 


\section{Anhang 16}

Schultheiß und Rat der Stadt Bern antworten dem Prediger vom Golmer Bruch, Sigismund Lupichius, auf dessen Schreiben vom 28. Juni 1713 und lehnen trotz der erbärmlichen Situation im Golmer Bruch die Rückkehr der Schweizer Kolonisten in die alte Heimat kategorisch ab, fordern sie auf, für ihre Existenz selbst Sorge zu tragen und fügen zur Unterstützung der Alten, Armen und Waisenkinder einen Scheck von 100 Thaler bei.

StA Bern: A. V. 19 Teutschland-Buch Preussen-Brandenburg, fol. 413-418, Konzept.

An Pfarhrhernn Lupichium

In Potzdamm.

den 24: July 1713

Schulth: und Rath der Statt Bern

Was Wir über dein außführliches an unseren fürgeliebten Mit Raht Herren Weltsch Seckelmeistern [Kämmerer] Steiger underem 28: Juny letsthin auß berlin abgebenes, und Vns vorgetragenes Schreiben, die bedauerliche Beschaffenheit der Schweitzerischen Colonien in Brandenburgischen, sonderheitlichen aber deren $\mathrm{Zu}$ Gollm Nathwerder, und Gallin Betreffend, Zum trost dieser guthen Leüthen an Ihro Königl: Mayst: in Preüßen angelegenlichst gelangen laßen, wirst du auß beygefügter Copia des mehreren $\mathrm{Zu}$ ersehen haben, so Wir die sambt dem Original, umb selbiges seines hochen ohrts überreichen Zulaßen, Zur nachricht begehrter maßen hiemit überschicken, by sothaner bewandnuß der sachen aber dir Zugleich befehlen wollen, diseren guten Leüthen wohl Vorzustellen, daß sy sich die Rechnung gar nicht machen müßen, allezeith auf dem ersten Fuß, wie zu anfangs diser Colonien verbleiben zu können, sonderen daß nach erhaltener in Nutz stellung des Landes, sie, wie der Tractat im 5 articul außweiset, sich werden bequemen, und damit sy bey hauß und hoof bleiben, mit einem billichen grundt Zinß begegen müßen, Zu welchem Ende, und damit sie die gebühr und billichkeit außzurichten im stand sein möchtend, sie sich der sparsamkeit befleißen, und durch unvertrostene arbeith Ihre subsistentz $\mathrm{Zu}$ bestreiten sich angelegen sein laßen, sich darbey wohl hüten sollind, Von Ihren Häusern und Höffen drunden sich weg zubegeben, als wordurch sie in äußerstes Elend und Verderben gerathen, und alles Heimaths priviert [beraubt] und Verlürstig wurden, dann wider allhero $\mathrm{Zu}$ kommen kein hoffnung noch ansehen, so daß sy Ihnen die gedancken nicht machen sollen, nach demme sie mit haab und guth under ein andere Herrschafft sich gesetzet, auch noch mißlich seien, sie nach so langer Zeith und abwesenheit mit Vermehrten Famillen von denen Gemeinden allhier wider aufgenommen Zu werden, Vnderdeßen wanne Ich wider all beßer Verhoffen Vnser Vorschreiben den Verlangten Effect nicht haben, sie über Vermögen beschwährt und beladen bleiben wurden, so daß Einichen under Ihnen absolut unmöglich fiele, und deßthalb, wie betreüwt, also hauß und Hoof verlaßen müßten, habend Wir $\mathrm{Zu}$ bezeügung unsers mitleidens, und $\mathrm{Zu}$ etwelcher [zu irgendeiner] hand reichung für arme übel mögende alte Persohnen, wie auch Vatter- und Mutterlosen Kinderen dir hiermit ein Waxelbriefflein [Wechselbrief] von Hundert Thaleren übermachen wollen, Von welchem gelt du denenselben in diserem letsten fohl, denen aber der allgütige Gott gnädig vorsein wolle, nach und nach und auf eine solche weis, als wann es von dir selbs bescheche, mit Verschweigung, daß es von Uns herkomme, etwelche handrei- 


\section{Anhänge}

chung thun solst; Welches Wir dir über dein schreiben Verdeüten, und dich der Gnädigen obsorg Gottes sambt deiner gemeinde bestens anbefehlen wollen. Datum 24: Julij

1713

[keine Unterschrift]

\section{Anhang 17}

Schultheiß und Rat der Stadt Bern interzessieren beim König Friedrich Wilhelm I. gegen die von Kammerpräsident v. Görne 1713 den Schweizer Kolonisten auferlegten Pachterhöhungen und vielseitigen nichtzutreffenden Beschuldigungen, indem sie sich dabei auf die von Kurfürst Friedrich Wilhelm 1685 den Kolonisten eingeräumten Ansiedlungsprivilegien berufen. Bern, 1713 Juli 24.

StA Bern: A. V. 19 Teutschland-Buch Preussen-Brandenburg, fol. 407 - 413, Konzept.

Allerdurchlüachtigster etc.

Warumb Ew. Königl: Mayst. Wir mit gegenwährtigem respectuosen [erehrbietigem, respektvoll] Schreiben einzukommen die freyheit nemmen, ist der Vns erbärmblich vorgekommene Zustand der in denen Vorwerkeren Gollm, Nothwerder, und Galin Potsdammer ampts sich niedergelaßenen Schweitzerischen Famillen, Wann, Wie Vns der bericht eingelanget, Von Er. Königl. Maystl: General Finantz Directorio der von Ihnen gnädigst gegonten Landereyen diseren Leüthen auferlegte Grundt Zinß frischer dingen umb ein so namhafftes und über Ihr Vermögen verhöcheret [erhöht], oder in Mangel deßen Entrichtung, sie gar derselben Verstoßen oder vertriben werden solten, Worüber nun Wir von gewüßens wegen nit umbhin können, als wir hiemit beschieht, Ewr. Königl. Maystl mit gezimmender Ehrerpietigkeit und respect $\mathrm{Zu}$ gunsten dieser armen Leüthen recommendando einZulegen, und dieselbe demüthig Zubitten, Sie großgünstigest und nach angebohrener Clementz [Gnade, Milde] gnädigest Zubehertzigen geruhwen wolle, daß diesen gute Leüth von Ew. Königl. Maystl in Gott ruhwenden Herren Groß-Vatter sel. Ihro Churfrstl. Drchlt. Fridenrich Willhelm glorwürdigste, angedenkens im $9^{\text {te. }} 1684$ von Vns begehrt, daraufhin derselben, wie auch des Ihnen übergebene Landes halb ein Vergleich errichtet und von Ihro Königl. Maystl. dero Herren Vatter höchstsel: glorwürdigster gedächtnuß allergnädigest Confirmieret worden, welchesten [welches im] $6^{\text {ten }}$, und 10: articul, sowol wegen des Grund Zinses, als auch anderen Jährlichen recognitionen sy [sie] also genißlich Zuhalten allergnädigst Zusagen, daß sie sich Zubeschwehren keine ursach haben werdint, das frisch geforderte aber Ihr Vermögen übersteigen thüye, und so sey unvermögens wegen disers Ihnen allergnädigst gegonten Landes priviert [beraubt] werden sollten, sie als die Ihr Vatterland schon vor so langem Verlaßen, und Das Ihrige allhier wegund hinabgezogen, und dorthin angewendet, in höchste noth, Ja gantz lichen ruin gerathen, und das Elend Zubauwen sich getrungen sehen müßten; In welch kläglichem fohl dann die schöne Reformirte, von Ewr. Königl. Maystl höchst sel: Hrl: Vatteren erbauwet und in höchster Persohn selbs eingeweihete Kirchen und gemeind Zu, Spott und Spectacul anderer Religionen öd und dissipiert [zerstreuen, verschleudern] werden müßte; Ersuchend demnach vors 
allerinnständigste Er. Königl. Mayst nach dero angebohrnen höchsten Clementz und Königl. Großmühtigkeit, dieselben auß betrachtung der von dero glorwürdigsten Herren Großvatter und Vatter sah Vns und Vnseren Stand öffters gnädig erzeigten hochen affection [Zuneigung] und von vns hingegen auch jeder Zeith willfährig geleisteter Diensten, Ja fürnemblichen umb der Ehre Gottes und der zwüschen Ewr. Königl. Mayst und vns gemein habenden wohren [wahren] Reformierten Religion willen, gnadigst geruhwen werde, dero hoche gnad also wolten zulaßen, daß diesen Armen Glaubens Genoßen nicht über vermögen beschwährt, wenigst anderen dero Vnderthanen gleich und genißlich gehalten, und mit einem leidenlichen proportionirten Grund Zinß allergnädigst angesehen, wir auch Ihnen der Errichtete Tractat und Vergleich, wie von Ew. Königl. Maystl: glorwürdigsten Vorfahren beschechen continuiert und Confirmirt werden möchte, damit solche der sonst bevorstehenden ruin entgehen, und under Ihr Königl. Mayst. allergnädigsten Schutz ihre Subsistentz und erleidenliche Nahrung dar von tragen mögen. Ewr. Königl. Mayst. hochen benevolentz [Wohlwollen] laßet Vns keinen Zeifel, dann daß sey disen vnsere $\mathrm{Zu}$ gunsten dieser guten Leüthen in hoher venera- [Verehrung, Ehrfurcht] tion gethane recommendation [Empfehlung] und ansuchen mit geneigtem willen annemmen, und deßen selbige aller gnädigst gewähren, und dero Königl: Huld und gnad fehrners genißen laßen werden; die Wir hinwiderumb solche Vns erweisende hoche gunstgewogenheit gegen Ewr. Königl. Mayst. immerforth $\mathrm{Zu}$ demerieren beflißen sein werden; Zumahlen den allerhöchsten bittend, daß Er Ew. Königl. Mayst. sambt dero gantzem Königl. Hause in selbs erwünschlich, und stehts blühendem Wohl sein auf Immerwährende zeithen erhalten wolle. Datl. 24: July

\section{3.}

An Ihr Königl:

Maystl. in Preüßen

abgangen

\author{
Er. Königl: Maystl: \\ pp: pp. \\ Schultheiß und Rath der \\ Statt Bern.
}

\section{Anhang 18}

Mit einem anonymer Brief vom Oktober 1728 werden die sechs Neu Töplitzer Schweizer Kolonisten bei König Friedrich Wilhelm I. angezeigt, weil diese eine viel zu geringe Pacht zahlen würden. BLHA, Rep. 2 Kurmärkische Kriegs- und Domänenkammer Nr. D 11279, fol. 10, Original.

Ew: Königl. Majestat melde aus allerunterthänigster Pflicht und Treüe, daß die Hörster und der Dom: Rath Dero Revenüen gar nicht Verbeßern, wenn sie mir ein wenig Luges [ Luch] abzwacken, weit mehr aber wenn [er] die Schweytzer, welche als freye Leuthe dort sitzen, beßer anzöge wie seine Pflicht ihm befiehlet. Ein jeder der sechs Bauern gibt jährl. nur 60 rt, die er von dem Schafen, Vieh Weinberg garten und Tobacks plantagen leicht nehmen kan, den schönen Acker haben sie umsonst, daher werden sie aufgeblasen und reyset fast jährl. einer oder Zwey nach der schweitz, die gewiß wie jedermann glaubt dort geldt ablegen. Ein jeder ist 


\section{Anhänge}

persuadirt [überzeugt], wenn sie noch ein mahl so Viel und noch mehrgeben die dennoch übrig aus kommen können. Indem ich mir aber mit dieser entdeckung Viel Feinde Vermuthe, bitte llerunterthanigst mich elenden allergnädigst obgleich ungenandt zu schützen.

[keine Unterschrift]

\section{Anhang 19}

Prediger Keßler beschreibt in einer Aktennotiz wie die Vereinigung der lutherischen Gemeinde Alt Töplitz mit der reformierten Gemeinde Golmerbruch zustande gekommen ist (undatiert, wahrscheinlich 1832).

KA Alt Töplitz: Vereinigung von Golmerbruch mit Alttöplitz - nicht paginiert, Original.

Nachdem der Prediger Herrn Wigand zu Alt-Toeplitz im August 1821 gestorben war, beabsichtigte die K. Regierung die reformirte Parochie Golmerbruch mit der lutherischen Parochie Alt-Toeplitz in der Art zu vereinigen, daß das Filial Phoeben, wegen der Beschwerden und Gefahren die mit der Curirung desselben von Toeplitz aus verbunden sind, von AltToeplitz abgezweigt und mit der Parochie Schmergow vereinigt würde. Interimistisch nahm diese Einrichtung mit dem 1ten Oktober 1822 auch ihren Anfang. Ein Jahr hindurch verwaltete der unterschriebene von Nattwerder aus als Prediger von Golmerbruch die Parochie Alt-Toeplitz mit Ausschluß von Phoeben. Zu Michaeli 1823 zog er nach Alt-Toeplitz und curirte von hier aus nun die Golmerbrucher Gemeine. Indeß kam obiger Plan der K. Regierung nicht zu Stande, da einige Mitglieder der reformierten Gemeine in Golmerbruch - jedoch mit Ausnahme von Neu-Toep litz - namentlich der Schweizerpächter Schweingru ber in Golm der Vereinigung sich durchaus wieder setzten. Jene Gemeine erhielt auf Befehl Sr. Maj estät des Königs am 1ten November 1824 einen eigenen Prediger wieder, worauf der Unterschriebene von der K. Regierung zum evange lischen Pfarrer von A. Toeplitz und Phoeben ernannt und bestätigt wurde. Da aber von dem letzten in Nattwerder wohnenden Prediger Herrn Gruss über die ungesunde Lage des Pfarrhauses anhaltend und dringend viele Klagen geführt wurden und ihm deshalb gestattet wurde, in Potsdam auf Kosten des Staats zu wohnen, so beschloß die K. Regierung, um die Kosten eines neuen auf einen höheren Platz zu erbauenden P(f)arrhauses zu ersparen, abermals auf die Vereinigung der beiden gedachten Pfarren anzutragen, und Sr. Majestät der König genehmigte dieselbe, so daß seit dem ersten Juli 1832 die Parochie Golmerbruch mit der Parochie Alt-Toeplitz zu einer evangelischen Gemeine vereinigt und Phoeben als Filial mit Schmergow verbunden ist. Es wurden nun, da es Sr. Majestät des Königs Wille war, gegen diese so zweckmäßige Einrichtung keine Schwierigkeiten mehr erhoben und man ist von allen seiten mit derselben sehr zufrieden.

Keßler 


\section{Anhang 20}

Zimmermannsspruch anlässlich des Richtfests der nach dem Brand vom 3. Juni 1867 neuaufgebauten vier Höfe in Nattwerder, 1867 Oktober. Druck im Besitz des Autors, Original.

Zur Erinnerung an den 3. Juni 1867.

Wie groß des Allmächt'gen Güte, wie ist sein Rath so wunderbar! Er war ein Schutz der Schweizer Blüthe hier hundertzweiundachtzig Jahr.

Ja, Sechzehnhundertfünfundachtzig zählteman damals in der Christenheit, Als der Kurfürst. Markgraf von Brandenburg wählte hier diesen Ort für Schweizer-Leüt';

Ja Er, der Edle, ließ erbauen: Vier Häuser und die Kirche hier,

Er war ein Mann, der that vertrauen auf Gottes Hülfe für und für.

Drum war ihm Gott in allen Dingen mit seinem Rath und Hülfe nah, Er half ihm jedes Werk vollbringen; so wie auch dieses hier geschah.

Er zog dann aus dem fernen Schweizerland vier Männer her mit Weib und Kind, Sie waren nicht vom hohenn Stande, doch aber fromm und gut gesinnt.

Er that dann je nach seinem Belieben einem jedem schenken Haus und Land, So daß sie Ackerbau betrieben, sich nährten treu mit fleiß'ger Hand.

Sie führten nun ein frommes Leben und dankten Gott zu jeder Zeit

Für Alles, was er ihnen hat gegeben und was ihr frommes Herz erfreut.

Doch jetzt sind nun die lieben Alten schon in der Ewigkeit dahin,

Ihre Nachkommen aber walten noch heute dort mit frommem Sinn.

Sie lebten stets zusammen im väterlichen Haus,

Als daß des Feuers Flammen sie trieben einst hinaus.

Ja, Achtzehnhundertsiebenundsechszig, den dritten Juni um halb acht,

Da ward ein Ungewitter mächtig, so daß der Donner furchtbar kracht,

Und ach, zum Unglück konnte man sehen des Blitzes hellen Feuerstrahl

Auf Schillings Stall herniedergehen! Ach, welch ein Schreck, welche Gefahr!

In wenigen Augenblicken sah man nichts als Feuersflammen

Und als eine Stunde verflossen war, stürtzte Alles schon zusammen.

Die dunkle Nacht kam nun heran! Denkt, Freunde, welche Schmerzen

Erfüllen jetzt hier Frau und Mann und auch der Kinder Herzen.

Ach Gott, es war ein großer Jammer hier auf der ganzen Kolonie;

Sie suchten Zuflucht jetzt, und auf der Kammer, die Gott zur Wohnung noch bestimmt für Sie.

Nun sprachen Sie zusammen mit frommen Christen-Muth:

Obgleich uns auch die Flammen verzehrten Hab und Gut,

So bauen wir doch feste allein auf Gottes Gnad',

Ja er ist stets der Veste, er giebt uns immer Rath;

Er ist's, der uns erschaffen hat, er wird uns auch erhalten,

Er wird ja bei uns früh und spat mit seiner Gnade walten;

Er wird uns auch in dieser Zeit mit seinem Rath beistehen, 


\section{Anhänge}

Und uns zu helfen sein bereit, wenn wir ihn bittend flehen. Mit diesen Worten fingen Sie den neuen Bau wohl an, Und Gott half Jedem spät und früh mit neuer Kraft daran. So ward denn in nur kurzer zeit der neue Bau vollbracht; Ich selbst muß sagen, hab' mit Freud' gearbeitet Tag und Nacht. Und als man feierte dies Jahr das Erndte-Dankfest wieder, Da war nicht mehr Noth und Gefahr hier bei den edlen Brüdern; Sie wohnten ja schon Alle im neu erbauten Haus.

Nach Gottes Wohlgefallen gehen Sie dort ein und aus.

So mög' denn Gott in Gnaden stets schau'n auf Sie herab, Mög' Sie vor allem Schaden behüten bis in's Grab,

Gotte wolle Ihnen seinen Segen im neuen Haus verleihn, Auf allen Ihren Wegen ein Trost und Helfer sein!

Er mög, wenn Sie einst scheiden aus diesem Jammerthal, Sie nehmen zu seinen Freuden im schönen Himmelssaal! -

Gewidmet von Karl Gartemann, Zimmmer- und Tischler-Geselle. 


\section{Anhang 21}

Telegramm an den Führer und Reichskanzler Adolf Hitler anlässlich des 250-jährigen Jubiläums der Besiedlung des Golmer Bruchs. Alt Töplitz, 1935 Juni 18.

KA Alt Töplitz: Akte: Chronik der Insel Töplitz, Original

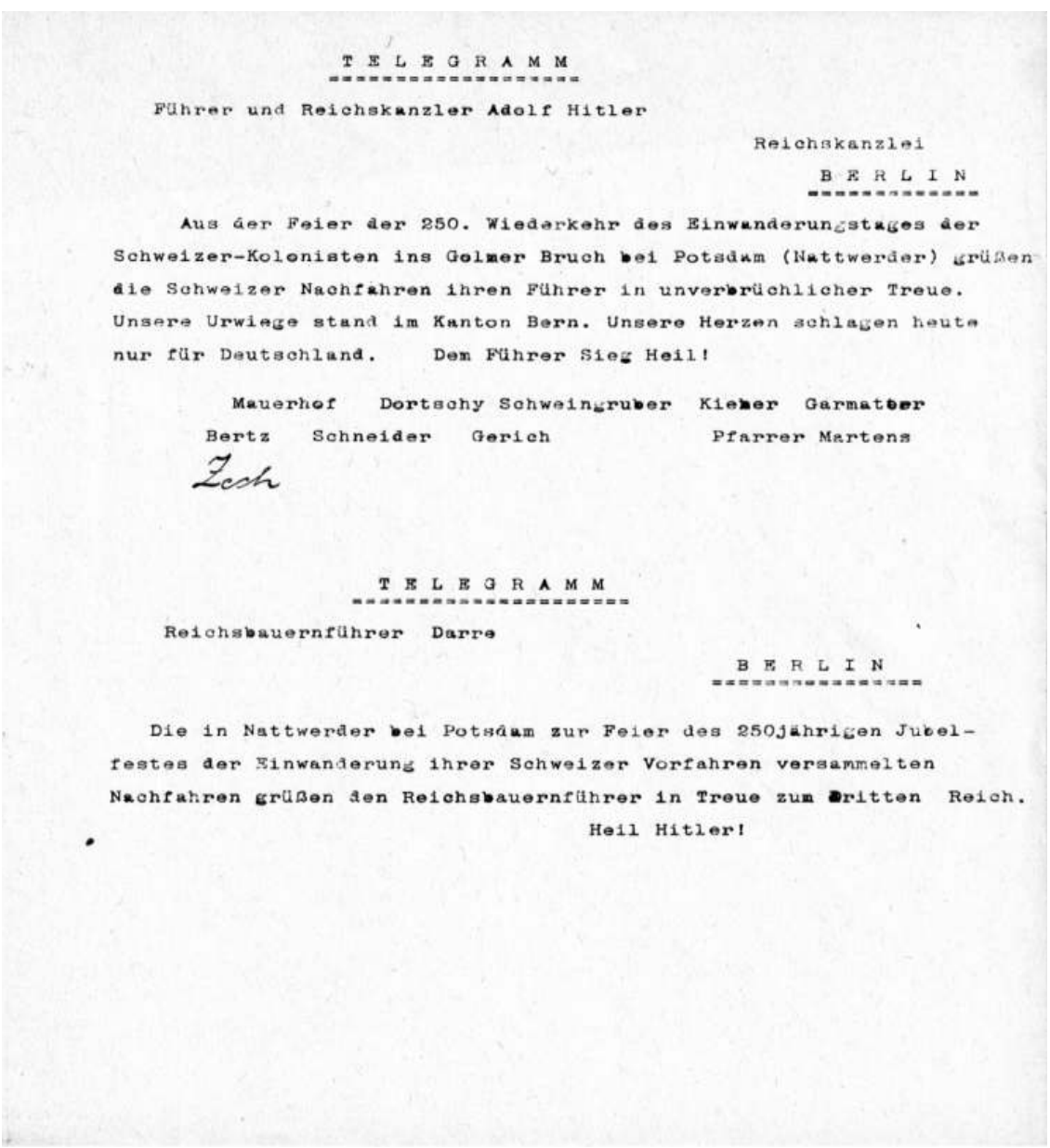




\section{Anhänge}

\section{Anhang 22}

Protokoll des Gemeindekirchenrates Nattwerder wegen Bestimmung des Status der ehemaligen Kolonistengemeinde „Golmerbruch", Neu Töplitz, 1949 August 13,

KA Alt Töplitz Verhandlungsbuch Alttöplitz/Nattwerder, Angefangen mit 16. September 1928, Geschlossen am 24.8.1976, S. 194/195, Original.

Gemeindekirchenrat Nattwerder, verhandelt in Neutöplitz am 13.VIII. 49

Anwesend:

Dr. Wienecke

Ält. Alfred Bertz - Neut.

„Ewald Dortschy“

„Fritz Garmatter

Es fehlt entschuldigt:

Ält. Wilhelm Mauerhof - Nattw.

1) Am 3.VIII hat O.Kons. Rt Dr Wienecke

(ist über Inh. d. Verhandlgn.

in einer Voraussprache

eingehend unterrichtet

u. damit einverstanden).

folgende Stellg.: als neuer kommissar. Pfarrer in Nattwerder seine Antrittspredigt gehalten. Er stellt sich als neuer Vors. des GKRs vor. Seine Amtszeit läuft ab 1.VII.49.

2) Nach Verlesung des Schreibens $I 972$ des Konsistoriums Berlin-Brandenburg vom 27.IV.49 u. nach Mitteilg. weiterer Anliegen der kirchl. Aufsichtsbehörde durch den Vorsitzenden nimmt der GKR dazu

a. Die Ki-gemd. Nattwerder erhebt nicht den Anspruch selbständige K.gemd. zu sein, sd. betrachtet sich als einen organischen Bestandteil der Ki-gemd. Alttöplitz. Der GKR besteht der Form nach, ist jedoch seit Jahren nicht einberufen.

b. Die ehem. Schweizer Kolonistengmd. „Golmerbruch“, die einen deutsch-reformierten Charakter trug, hat sich nach Aufhebg. ihres eigenen Pfarramtes 1832, bzw. nach dessen Verschmelzg. mit dem v. Alttöplitz, bekenntnismäßig mehr u mehr der ev. Ki.gemd. Alttöplitz angepaßt. Eine reformierte Tradition besteht eigentlich nur noch beim hl. Abendmahl (zum Teil halten des Kelches in der Hand des Kommmunikanten). Im Unterricht wird der lutherische Katechismus verwandt. Im übrigen ist die Personalgmd. Golmerbruch bis auf gewisse nach Golm u. Neutöplitz reichende 
Familientraditionen praktisch zur Lokalgemd. Nattwerder geworden, die etwa 60 Seelen (einschl. Flüchtlinge) neben den etwa 40 Auswärtigen umfaßt. Im Laufe der Zeit, namentlich seit 1945 dürfte die überwiegende Mehrheit lutherischen Charakter tragen.

c. Traditionsgemäß besteht Ki.steuerfreiheit, doch werden, da die staatl. Privilegien zur $Z t$. ruhen, dafür freiwillige Abgaben entrichtet.

d. der GKR legt Wert darauf, daß die Ki. gemd. Nattwerder wie bisher durch die ev. Kreissynode Lehnin vertreten wird, wäre aber auch einverstanden, zur ev. Kreissynode Potsdam überzugehen, wenn der GKR Alttöplitz dies beschlieBen sollte, zumal Nattwerder politisch ein Teil der Stadt Potsdam ist. Ein Anschluß an eine reformierte Kreissynode wird nicht $f$. erforderlich gehalten.

e. Um den Zustand der prakt. Untätigkeit infolge sr. Nichteinberufg. ein Ende zu machen, beschließt der GKR: Übertragg. seiner Geschäfte auf d GKR Alttöplitz u. Umwandlg. sr. Funktion in die eines durch seine Mitglieder zu bildenden „Gemeindebeirats Nattwerder". In dsr. Eigenschaft aber gedenkt er d. Anliegen der örtlichen u. personellen Traditionen der Kirche Nattwerder nachdrücklich zu fördern.

$$
\begin{array}{ll}
\mathrm{v}(\text { orgelesen }) & \mathrm{g}(\text { enehmigt }) \quad \mathrm{u}(\text { nterschrieben }) \\
& \text { Dr. Wienecke }
\end{array}
$$




\section{Anhänge}

\section{Anhang 23}

Schultheiß und Rat der Stadt Bern bestätigen den Ansiedlungsvertrag für 14 Schweizer Familien aus dem Kanton Bern im Golmer Bruch, 1687 Oktober 5

StA Bern A. V. 19 Teutschland-Buch Preussen-Brandenburg fol 228, Ausfertigung

\section{Articul}

Welche Ihr Churfrstl. Durchlt

Zu Brandenburg denen

Bernischen Familien so

In dero Landen sich Nider-

gelaßen gnädigst

concediret

Dat: 16. Septembris. 1685

Vndt zu Bern Vor Rähten

Vndt Bürgeren Vor

dank Beliebig angenommen

5. Octobris. 1687 


\section{Liste der Prediger}

a) der selbständigen reformierten Gemeinde Golmer Bruch:

Elisaeus Malacrida (1685-1787)

Albrecht Wyttenbach (1687-1705)

Sigismund Lupichius (1705-1717)

Heinrich Hunziger (1717-1725)

Joseph Grimm (1725-1729)

Johann Jacob Le Comte (1729-1735)

Johann Jacob Wessel (1735-1738)

Karl Ludwig Treiber (1738-1766)

Johann Christoph David Hübenthal (1766-1770)

Franz Rudolf Becker (1770-1785)

Leopold Leberecht Hanckwitz (1785-1793)

Samuel Peter Schaub (1793-1800)

Christian Ludwig Schmidt (1801-1809)

Friedrich Georg Ludwig Athenstädt (1809-1810)

Karl Philipp Ludwig Jacob (1810-1812)

Johann Friedrich Kessler, Keßler (1812-1823)

Ernst Ferdinand Beck (1824-1826)

b) der Filiale der preußisch unierten Gemeinde Alt Töplitz:

Johann Gottlieb Gruss 1826-1832)

Johann Friedrich Kessler (1832-1852)

Eduard Rodatz (1852-1884)

Joachim Friedrich Franz Rodatz (1884-1899)

Hans Meyer (1899-1905)

Otto Kietzig (1908-1929)

Walter Martens (1930-1949)

c) der in Alt Töplitz eingegliederten Gemeinde:

Dr. Friedrich Wienecke (1949-1956)

Bruno Lüscher (1957-1968)

Jürgen Lorenz (1968-1988)

Hans-Jürgen Viebeg (1989-2016)

Almut-Susanne Gaedt (ab 2016) 



\section{Orts- und Personenverzeichnis}

Aarau [Arraw $]$ 37, 177

Abt Valentin (Kloster Lehnin) 64

Affolter, Heinrich Christoph VII, Anm. 368

Albrecht, Christian (Fischerkossät) 103

Altona 39

Ammerswil [Ammerswiel] (Schweiz) 38

am Biel v. Gertzensee, Johann Jacob (Arrendator im Ruppiner Raum) 66, 101, 102

Anklam 21

Apolda 91

Appenzell Anm. 462

Athenstädt, Friedrich Georg Ludwig (Prediger) Anhang II

Augustin (Justizrat) 73

Barthus (Amtmann) 68

Basel Anm. 462

Baßler, Maria 140

Bauernkönig, Albrecht [Baurenkönig,

Bauwnkönig] 34, Anm. 156, 35,

Anm. 162, 36, 39, 40, Anm. 190, 47, 48, 75, $163,176,177$

Beater, Catharina Dorothea 138

Beauvais, Wilhelm Hermann (Prediger in

Lehnin) 16, Anm. 81

Beck, Ernst Ferdinand (Prediger) 118, Anhang II

Becker, Franz Rudolf (Prediger) 110, 140, Anm. 654, 148, Anm. 695, Anhang II

Behrend, Luise 137

Benda, Charlotte Henriette Sophie (3. Tochter Karl Bendas) Anm. 654

Berg, Andreas (Separatist, Schuster in Werder) 104

Berlin 14, 57, 113

Bern incl. Kanton $3,36,37,38,39,88$, Anm. 462, 97, 100, 176, 177

Bertz, Alfred (Ortsbauernführer) Anh. 22

Bertz, Carl (Arbeitsmann) 82

Bertz, Otto (Schweizer Kolonist in Neu Töplitz) 126

Bertz, Paul (letzter Nachkomme d. Neu Töplitzer Kolonisten) 75
Bestehorn, Friedrich (Fischereihistoriker) 46, Anm. 213

Bethge (Vermesser) 74

Bier, Joachim (Fischerkossät in Göttin) 71

Bilan $(\mathrm{g})$ [Bielangen, Belangen], Hans [Hanß]

(Schweizer Einwanderer, 1. Dorfschulze)

38, Anm. 197, 48, 54, 147, 168, 178

Blunck, Erich (Provinzialkonservator) 124, Anm. 591, 182

Bochow 146

Bondeli, Simon (Patriziersohn) 38,

Anm. 179

Bornim [Bornheimb] 13, 24, 59

Bornstedt 13, 51, 57, 144

Brandenburg 36, 112

Brandt, Eusebius v. (Präs. d. Tribunal- u. Oberappellationsgerichts) 56, Anm. 260, Anh. 12

Brachwitz 13

Braun, Walter Max Emil (Generalsuperintendent) 111

Braunsberg 165

Britt, Ursula 160

Brunner, Hans Vlrich (Soldat) 150

Brunsen(ius), Anton (Hofprediger) 179, Anh. 6, Anh. 7

Burchard(i) [Borchardt], Jacob(us) 10, Anm. 112, 31, Anm. 142, 32

Bucher 38

Buchholz 13

Bullert, Walter (Potsdamer Graphiker)

Abb. 5, Anm. 821

Bylang, Hannß 171

Caputh Anm. 48, 13, Anm. 68, 44

Clar(i) der ältere, Johann Samuel (Lehniner Amtmann) 65, Anm. 313, 66, Anh. 8

Clar(i) der jüngere, Johann Samuel (Lehniner Amtmann) 67

Coppet-Prangins (Schweiz) Anm. 138

Damsdorf 16, 64, 146

Dauwalder, Marie (Schweizer Pastorin) 128, 182 
Dedweiller, Jacob Anm. 624, Abb. 13

Dedweiler, Johann 144, Abb. 13

Deichverband d. Golmer Bruchs 85

Delliker, Hercules (Reformierter Prediger in Lindow) 94, 102, 136

Deregé (Superintendent Brandenburg/Neustadt) Anm. 573

Derwitz Anm. 2

Döring,Andreas (Fischerkossätin Göttin) 71

Döring, Friedrich (Fischerkossät in Göttin) 71

Dörnberg, Wolfgang Ferdinand von (Staatsminister) $\quad 140$

Dohna, Friedrich Graf und Burggraf von 30, Anm. 138, 31, 32, 106, 176, Anh. 15

Dortsche, Peter 79

Dortschy, Ernst (Schweizer Erbpächter) 119

Dortschy, Ewald 126, Anh. 22

Dortschy, Wilhelm (Schulze in Neu Töplitz) 94

Draing (Sekretär in Bornstedt) 140

Drewitz 13

Durtschy [Dursy], Christian (Separatist) 68, 105

Durtschy [Durtschi], Emanuel (Schweizer Einwanderer) 65, 68, Anm. 455, 110, 133

Durtschy, Elisabeth 144, Abb. 13

Durtschy, Johann 144, Abb. 13

Durtschy, Johann Heinrich 144, Abb. 13

Ehmer (Regierungsinspektor) 46

Eiche [Eichow] 63, Anm. 736

Eichholz 118

Einhaus 24, 83, 118

Elisabeth Charlotte von der Pfalz 15

Emmental (Schweiz) 33

Eylert, Ruleman Friedrich (Hofprediger u. Konsistorialrat) 114

Famckhufer, Davit Anm. 160

Fa. Schilling \& Lattermann 91

Fischer (Kaufmann) 140

Fontane, Theodor 108, Anm. 523

Forster, Catharina $\quad 150$

Freiherr von Printzen, Marquard Ludwig

(1. Präs. des Kirchendirektoriums)

Anm. 91
Freitag (Karl Bendas Schwägerin) 140

Frh. von Stein zum Altenstein, Karl Siegmund Franz (Staatsminister) 118, 119, Anm. 575

Franke (Geh. Kammermeister) 106, Anh. 14, Anh. 15

Frutingen (Schweiz) 33

Gaedt, Almut-Susanne (Pfarrerin) Anh. II

Gallin [Galin] 8, 51, 53, Anm. 244, Anm. 245, 98

Gansli (Bandmacher) 159

Garmatter [Kahrmatter], Crispin[us, Krispin]

(Schweizer Einwanderer) 38, 65, 133, 157,168

Garmatter, David (Hofgärtner zu Paretz) 73,138

Garmatter, Elßbeth Abb. 13

Garmatter, Fritz 126, Anh. 22

Garmatter, Hanß 68

Gaarmatter, Eva 135

Gartemann, Karl 83, Anh. 20

Geltow 13

Gerich [Gericht, Ge(h)ring, Gericke, Jerig], Carl (Schweizer Erbpächter) 119

Gerich, Christian Friedrich (Gefallener der Befreiungskriege 1813/3) 91

Gerich, Friedrich Wilhelm (Gefallener der Befreiungskriege 1813/3) 91

Gerich, Jacob [Jagkeli] (Schweizer Einwanderer) 38 , Tab. 3-6, 140, 157, 168

Gericke, Christian 79

Gehring, Karl (Erbpächter) 83

Gerhardt, Paul (luth. Theologe) 16

Gerlach, Johann Christoph (reform. Prediger in Lehnin) 66, Anm. 315

Gerlach, Siegfried 128

Gielen (Superintendent, Lehnin) 87, 124

Glambeck 171, Abb. 14

Glarus Anm. 462

Glienicke 13

Görges, R. (Konrektor in Bln.-Steglitz) 128 Görne, Hans Friedrich Christoph v. (Präs. d. Kurmärk. Amtskammer) 52, Anm. 239, 98, Anm. 461, Anh. 14, Anh. 15, Anh. 17 Göttin 63, 70, 71, 103, Anm. 488, Anm. 489 
Gohlitz Anm. 2

Gohlwerder 47, Anm. 218

Golm [Gollm] incl. Vorwerk 8, 13, 19, 20,

23, 48, 51, 54, 55, 58, Anm. 273, 60, 61, 63,

$77,91,98,101,118,121,126,148$

Golmer Bruch 2, 19, 20, 22, Tab. 1, 24, 36, 47, 51, 56, 58, 63, 163, Anm. 767, 175

Grimm, Joseph (Prediger) 141, Anhang II

Groß, Gabriel (Patriziersohn) 38, Anm. 178

Grote, Otto v. (Hauptmann v. Tangermünde)

Anm. 200

Grube 13, 20, 23, Anm. 401, 79, 85, 123

Grünenthal, Johann (Prediger in Töplitz) 65

Grundt, J. C. (Kartograph) Abb. 4, Anm. 820

Gruss, Johann Gottlieb (Pfarrer) 80, 118, 120, 181, Anhang II

Gurzelen [Gurtzelen] (Schweiz 38

Guttschmidt, Peter (Bauer in Leest) 66

Haase, Paul (Unteroffizier im Retzowschen

Bataillon) 141, 168

Hamburg 39, 177

Hanckwitz, Leopold Leberecht (Prediger) Anhang II

Hanstein, Gottfried August Ludwig (Probst an der Bln. Nikolaikirche) $\quad 113,114$

Happen, Michael (1. Amtmann Lehnin) 64

Hart (Oberamtmann) 61

Havelberg 39, 40.

Havelländische Bruch 175

Heidelberg 36

Hendrich, H. 111

Hertzberg (luth. Prediger, Berlin) Anm. 550

Herzog Rudolf von Sachsen 63

Hinneberg, Johann Carl (Orgelbauer) 90

Hitler, Adolf $\quad$ 128, 182

Hodeler [Hodler], Hans 79

Hodler, Christian 168

Hodler, Niclaus [Nickeli] (Schweizer Einwanderer, Schulmeister) $\quad 38,54,168,178$

Hübenthal, Johann Christoph David (Prediger) 96, Anhang II

Hürner (Student) 38

Hunziger [Huntziger], Heinrich (Prediger) Anhang II
$\mathrm{Hu}(\mathrm{e})$ tmacher, Christian [Christen] (Schweizer Einwanderer) 37, 53

Jaberg (Schweiz) 37

Jacob, Karl Philipp Ludwig (Prediger) Anhang II

Jannasch (Hoffiskal) Anm. 347

Jürgens, Johann Peter (Arrendator zu Marquardt) 109

Kähr, Johan (Grenadier d. Kgl. Leibregiments) 156

Kagar 165

Kaiser, Friedrich Wilhelm (Kolonist in Golm) 136

Kaltenhausen 64

Kameke, Ernst Boguslaw von (Hofkammerpräsident) 106, Anm. 512, Anh. 15

Kaschube, Adolf Anm. 407

Kessler [Keßler], Johann Friedrich (Prediger) 96, 111, Anm. 563, 117, Anm. 567, 118, Anh. 19, Anhang II

Ki(e)ner, Bendix [Bendicht] (Schweizer Einwanderer) $\quad 37,136,168$

Kiener, Elisabeth 53

Kiener, Friedrich 92

Kiener, Fritz 126

Kiener, Regine, geb. Heese 92

Kiener, Wilhelm 121

Kiener, Zacharias 138

Kietzig, Otto (Pfarrer) 87, 122, 123,

Anm. 592, Anhang II

Kleve 17

Klosterheide 76

Kloster Lehnin 63

Kölliken [Kolligken] (Schweiz) 38

Knyphausen, Dodo v. (Hofkammerpräsident) Anm. 200, 68, Anm. 324, Anh. 8

König Friedrich II. 74, 78, Anm. 413.

König Friedrich Wilhelm 77, 98, 100, 106, Anm. 512, 107, 178, 180, Anh. 17, Anh. 18

König Friedrich Wilhelm II. 71

König Friedrich Wilhelm III. 62, 73, 112, 114, 115, Anm. 559, 118, Anm. 138, 181

König Friedrich Wilhelm IV. 85, Anm. 404

König Ludwig XIV. Anm. 138, 45

Königsberg (Ostpreußen) 1, 146 


\author{
Körner (Justizrat) 73 \\ Kohlmann (Pfarrer von Derwitz, Vakanzver- \\ walter) 121 \\ Kollberg (Superintendent Brandenburg/Neu- \\ stadt) Anm. 595 \\ Küentzi, Catharina (Schweizer Einwanderin) \\ 157
}

Küentzi,Nickeli(SchweizerEinwanderer) 37

Küentzi, Ulrich 147

Kuhfort 58

Kurfürst Friedrich III./König Friedrich I. 3, Anm. 120, 29, Anm. 145, 33, 40, 45, Anm. 193, 52, 56, 57, 58, 66, 69, 79, 98, Anm. 458, 101, 102, 103, 104, Anm. 525, 163, 170, 174, 179, Anh. 2, Anh. 6, Anh. 7, Anh. 8, Anh. 9, Anh. 10, Anh. 11

Kurfürst Friedrich Wilhelm 1, 2, 3, 11, 12, $14,15,16,17,20,21,23,29,30,31,32$, 34, $35,36,40,44,47,51,52,53,58,75,84,88$, Anm. 413, Anm. 416, 101, 107, Anm. 646, 174, 175, 176, Anh. 4, Anh. 5, Anh. 15

Kurfürst Joachim Friedrich 21

Kurfürst Johann Sigismund 14, 112

Kurfürst Georg Wilhelm 15

Kurfürstin Louise Henriette von Oranien 2

Kurfürstin Dorothea Sophia 52, 54, 178

Kurfürstin Elisabeth-Charlotte Anm. 71

Küstrin 31

Lamy (Gebrüder), Pierre und Hugues 11.

Lädrach [Lederich], Hanß 37, Anm. 518, 157, Anh. 15

Langelaer, Dieterich (Amtmann in Bornim) 109

Langnau [Langenaw] (Schweiz) 37

Laufenburg 39

Le Comte, Johann Jacob (Prediger) Anhang II

Leest $13,20,63,69,71,75$

Lehnin 99, 100, 102, 112, 116

Lenz, Marie Magdalena Abb. 13

Liebenwalde 12

Lindow [Lindou, Lindauw] 99, 101, 102, 116, 136, Anm. 670, Anm. 794, Abb. 14

Linow [Lünauw] 3, 94, 99,102, 146, 171, 173, Abb. 14
Lorenz, Jürgen (Pfarrer) 128, 182, An-

hang II

Lüderitz, Jo(a)chim Georg von (Amtmann von Potsdam/Oberjägermeister) 21, Anm. 104, 35, 40, 48, 88, 175, Anh. 1,

Anh. 5

Lüdersdorf [Lütersdorff] 94, 99, 102, 116, 146,173

Lüscher, Bruno (Pfarrer) Anhang II

Lupichius, Anna Louysa 90

Lupichius, Sigismund (Prediger) 8, 20, Anm. 101, 51, 88, 95, 96, Anm. 460, 104, Anm. 500, 106, 107, 108, 178, 181, Anh. 13, Anh. 14, Anh. 15, Anh. 16, Anhang II

Maaßen, Karl Georg (Finanzminister) 118, Anm. 576

Manker 7

Marburg [Marpurg] 100

Markgraf Woldemar 63

Markgraf Johann von Küstrin 21

Martens, Walter (Pfarrer) 96, 123, 125, 127, Anm. 603, Anm. 604, 128, Anh. 21, Anhang II

Malacrida, Elisaeus (Prediger) 38, 75, 95, 96, 100, Anm. 632, 142, 165, 180, Anh. 10, Anh. 15, Anhang II

Marquardt [Schorin] 20, Anm. 401, 108, 109

Martus, Johann Friedrich (Superintendent) 111

Mauerhober, Peter 68

Mauerhober, Ulrich 68

Mauerhof, Wilhelm 126, Anh. 22

Mauerhoff, Friedrich (Schweizer Erbpächter) 46, 83, Anm. 754

Mauerhoffer, Anna Christina $\quad$ 144, Abb. 13

Mauerhoffer, Emanuel $\quad 119,144$, Abb. 13

Mauernhof, Johann Heinrich 91

Mehl(i)s, Joachim (Schulze in Töplitz) 65, 66

Meinhart (Geh. Kriegs- u. Domänenrat) 61, 62, Anm. 248

Merian, Carl Gustav (Amtskammerrat) 56, Anm. 257, Anh. 10

Meyer, Hans (Pfarrer) 121, Anhang II

Michelsdorf 94, 102, 146, 147 
Mühlhausen Anm. 462

Müller, Peter Anm. 160

Müllroser Kanal 14

Münchow, Bernt Friedrich v. (Hofrat) 110

Münsingen (Schweiz) 37

Muralt, von (Berner Ratsmitglied) Anh. 3

Muhrhoffer [Muerhofer], Isaak [Issac]

(Schweizer Einwanderer Anm. 195, 51, $53,65,133,157$

Muhrhoffer, Peter (Schweizer Einwanderer) 147

Murhoffer, Elisabeth (Schweizer Einwanderin) 157

Nahmitz Anm. 2

Nantes (Frankreich) 17, 45

Nattwerder [Nathwerder, Natte Werder] 24, $46,47,48,49,50,52,56,75,76,77,82$, $83,85,91,98,116,118,121,122,123$, Anm. 589, 148, 173

Nehring, Johann Arnold (Oberbaudirektor) 56, Anm. 258, Anh. 10

Nettke, C. L. (Kartograph) Anm. 345

Netzen Anm. 2

Neuhaus (Amtskammerrat) 65

Neuruppin $101,102,116,146$

Neustadt/Dosse 13, 116, 146

Neustadt Eberswalde [Neüw Statt Eberswalden] 99, Anm. 692

Niebel 13

Nudow 92

Oranienburg Anm.560, 116, Abb. 14

Ostpreußen 4, 27, 28, 42

Paaren 20, 175

Pannewitz, von (Hofjägermeister) 56, 179, Anh. 7, Anh. 10

Peitz 13

Pfalz-Zweibrücken 59

Pfister, Dorothea 53

Pfister, Hans 53

Pflaum, Heinrich (Umsiedler aus d. Wartheland) Anm. 593

Phöben Anm. 2, 69, 92, 117

Pietsch (Gärtner in Potsdam) 82

Potsdam incl. Amt $2,19,21,45,48,49,59$, $78,79,95,165$
Portz, Heinrich v. (Konsistorial- und Amtskammerrat) 102, 103

Raffskern, Maria 168

Ravensberg 17

Rheinsberg 165

Richingen (Schweiz) 37

Riedt (Schweiz) 37

Rodatz, Eduard (Pfarrer) Anhang II

Rodatz, Joachim Friedrich Franz (Pfarrer) Anhang II

Rost, Martin (Amtmann von Lehnin) 69

Rottenberg (Schweiz) 33

Rüeggisberg [Rükisberg] (Schweiz) 38

Rümli, Anna Regina Ursula 142

Ruetschi, Johann Heinrich (ref. Prediger in Lehnin) 100

Ruhlsdorf 92

Ruppin(er Raum) [Neüw Rupin] 42, 44, 99, 146

Ryhiner, Joh. Frid, (Amtmann v. Trachselwald, Schweiz) 33

Saanen (Schweiz) 33

Sack, Karl Heinrich (Mitglied der Geistlichen Kommission) 113

Sacrow-Paretzer-Kanal Anm. 96

Säge (Vermesser) 74

Salzbrunn 146

Savoyen Anm. 362

Schaffhausen Anm. 462

Schaub, Samuel Peter (Prediger) Anhang II

Schenk (Oberjägermeister z.Zt. Friedrich II.) 84

Schenk, Walter (Prediger in Golm) 121

Scherler, Klaus (Genealoge) Anm. 792

Schilling, Friedrich (Erbpächter) 83

Schlänitzsee $\quad 85,179$

Schlalach 13

Schleiermacher, Friedrich Daniel Ernst (Theologe) 114

Schmergow Anm. 2, 117

Schmidt, Christian Ludwig (Prediger) Anhang II

Schnyder [Schneider, Schnider], Hanß

(Schweizer Einwanderer) 38, Anm. 174, 147,157 
Schneider, Anna (Haushälterin v. Prediger

Treiber) Anm. 411

Schneider, Barbara 149

Schnyder, Magdalena (Schweizer Einwanderin) $\quad 39,177$

Schöneiche Abb. 14

Schultheiß/Rat der Stadt Bern 32, 33, 36, $39,41,47,48,97,100,101,104,106,107$, 162, 176, Anh. 2, Anh. 15, Anl. 16, Anl. 17

Schuke, Matthias (Orgelbauer) 90

Schulzendorf $76,94,102,144,147$, Anm. 794

Schultz, Johann Jacob (Berliner GlockengieBer) 92

Schultze, Andreas (Verwalter d. Vorwerks Töplitz) 65

Schweingruber [Schwingruber], Hieronymus (Schweizer Einwanderer) 147

Schweingruber, Heinrich (Gefallener der Befreiungskriege 1813/3) 91

Schweingruber, Marthe 121,124

Schweingruber, Nicolaus [Niclaus] (Schweizer Einwanderer) Anm. 195, 51, 157

Schweingruber, Peter (Schweizer Einwanderer) $37,48,53,171$

Schweingruber, Rudolf 121

Schweizer Gemeinde im Golmer Bruch 3, 5, 51, 53, 78, Anm. 396, 87, Anm. 425, 94, 95, Anm. 446, 100, 110, 111, 117, 120, Anm. 584, Anm. 585, 123, 125, 136, Anh. 6, Anh. 11

Schwerin, Otto v. (Oberpräsident d. Geh. Rates) Anm. 71

Schwielowsee 63

Spaldeholtz, Simon (Kartograph) 70, Anm. 336, Anm. 345

Spandau [Spandow] 40, 49, 111

Sputendorf 13

St. Augustin Hangelar 128

Starke, Johann Friedrich (Orgelbauer) 90

Steinwerder 24

Sterky, Jeremias (Prof. d. Theologie, Superintendent) 106, Anm. 513, Anh. 13

Storbeck 3, Anm. 43, 94, 102, Anm. 482, 116, 147, 171, 173, Abb. 14
Strites, Maria 65

Stucky, Hans [Hanß] (Schweizer Einwanderer) Tab. 3-6, 140, 168

Sturm v. (Kammerpräsident) 106

Suchodoletz, Samuel de (Kartograph) 23, Anm. 111, 24, 47, Anm. 399, Abb. 2

Süßmilch, Johann Peter (Theologe, Oberkonsistorialrat, epidemiologischer Statistiker und Demograph) Anm. 39, Anm. 40, 143, $145,151,153,154,157$

Suter, Melchior (Schweizer Einwanderer)

Tab. 3-6

Suter, Simon 79

Suter, Ulrich [Vlrich] 147, 171

Suthor, Hanß 171

Sutor [Suter, Suthor], B(e)at(t) (Schweizer Einwanderer) 38, 168

Sutor, Sam $(m)$ uel (Schweizer Einwanderer) $38,147,157$

Tangermünde 12

Teichmann (Fasanjäger) 140

Thätweiler [Tädenweyler, Tädweiler, usw.], Anna Anm. 624, 168

Thielen, Jochimb (Weinmeister) 67

Thierachern [Ti(e)rracher] (Schweiz) 38

Thun (Schweiz) 33

Töplitz (Alt) 3, 71, 94, 106, 112, 117, $118,123,126,147$

Töplitz (Neu) [Neüw Döplitz] 8, 56, $58,63,71,75,77,78,99,101,102,104$, $118,123,126,148,160,166,180$

Töplitz (Grangie) 5, 64, 65

Töplitz (Vorwerk) 64, 65, 68, 69, 71, 74

Tornow 64

Trachselwald (Schweiz) 33

Treiber, Karl Ludwig (Prediger) 78, 79, 96, 108, Anhang II

Turtschi, Emanuel (Schweizer Einwanderer) 38

Turtschi, Christian 149

Uckermark 43

Uetendorf (Schweiz) 38

Uetz 20, Anm. 100, 21, 175

Uhde (Hoffiskal) 71 
Valotti, Francesco Antonio (Franziskaner, Komponist u. Musiker) 90

Verein Schweizerkolonistendorf Nattwerder 92, 129, Anm. 610, 173

Viebeg, Hans-Jürgen (Pfarrer) 96, 179, Anhang II

Vielitz 3, 76, 147, 163, Anh. 9

Vierhäuser/ 4. Häuser $\quad$ 142, 156, 160

Wachow 64

Wagner (Hoffiskal) 105

Waldshut 36

Graf von Wartensleben (Amtshauptmann) Anh. 14, Anh. 15

Webe, Louyse 137

Wenger, Barbara (Schweizer Einwanderin) 157

Werben 12

Werder 63

Wessel, Johann Jacob (Prediger ) Anhang II

Wichman von Rochow (Amtmann v. Lehnin) Anm. 3

Wienecke, Dr. Friedrich (Pfarrer) 96, 125, Anh. 22, Anhang II

Wigand (Alt Töplitzer Pfarrer) 74, 117, 170

Wildpark-West Anm. 245, 85, 179

Wilhelm, Ernst (Schweizer Erbpächter) 119

Wilkens (Landrat v. Nauen) 82

Willem, Verena 147

Winkelmann, Maria 53

Winter, Friedrich Dr. (Probst in Ost-Berlin) 129

Wintzeridt, Hans (Schweizer Einwanderer) Tab. 3-6
Wische 12

Wittbrietzen 13

Witten, Friederich (Teichgräber aus Liebenberg) 22, Anh. 1

Wyttenbach, Albrecht [Wittenbach, Weitenbach] (Prediger) 8, 54, Anm. 247, 55, 57, 66, 67, 68, 69, Anm. 464, 101, 102, Anm. 488, 104, 135, 138, 168, 170, 171, 178, 180, Anh. 8, Anh. 12, Anhang II

Wohlen (in der Schweiz) 104

Wustrau 7

Wykersloot, Arnold Andreas v. 109

Wykersloot [Wickersloth, Wikersloot], Johann Arnold v. (Hof- und Kommerzienrat) 109 , Anm. 524, 110, 181

Zäch, Christian (Golmer Viehhirte) 142

Zech Anh. 21

Zech [Zaech], Anna Dorothea (Hebamme

[Wehmutter]) Anm.736

Zech, Bendikt (Gefallener der Befreiungskriege 1813/3) 91

Zech, Friedrich Georg (Küster und Schullehrer in Golm) 138

Zech, Nickeli (Schweizer Einwanderer) 37

Zech [Zäch], Ulrich 152, 171

Zech, Wilhelmine 121

Zehdenick 14

Zerbst 100

Ziegler (reform. Prediger) 102

Ziesar 111

Zobrist, Caspar Anm. 195, 51, 53

Zoch [Zech], Nicolaus 137

Zürich 3, Anm. 462, 100, 175

Zwahlen, Ulrich VII, Anm. 761 


\section{Freier Zugang zur brandenburgischen Landesgeschichte}

Der Jahreswechsel 2020/2021 leitete den Auftakt einer Open-Access-Initiative des Brandenburgischen Landeshauptarchivs und des Berliner Wissenschafts-Verlags ein: Über 70 Titel aus den gemeinsamen Schriftenreihen steht jetzt kostenfrei zum Download zur Verfügung. Die Forschung und die interessierte Öffentlichkeit haben somit Zugriff auf wichtige Grundlagenwerke der brandenburgischen landesgeschichtlichen Forschung - vollständig durchsuchbar als eBooks.

Zu den Highlights der Backlist gehören bspw. die Historischen Ortslexika für Brandenburg, die Niederlausitz und die Altmark, die erstmals vollständig digital verfügbar sind.

Auch alle zukünftigen Publikationen der Schriftenreihen erscheinen ab sofort im „goldenen“ Open Access - das eBook ist also bereits zum Erscheinen der Printausgabe frei downloadbar.

Entdecken Sie die Vielzahl alter wie neuer Titel selbst!
VERÖFFENTLICHUNGEN DES BRANDENBURGISCHEN LANDESHAUPTARCHIVS

๑) blha.bwv-verlag.de

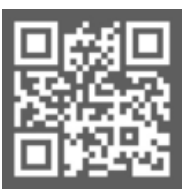

BIBLIOTHEK DER BRANDENBURGISCHEN UND PREUßISCHEN GESCHICHTE

๑) bbpg.bwv-verlag.de

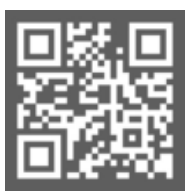

Berliner Wissenschafts-Verlag | Behaimstr. 25 | 10585 Berlin Tel. 0308417 70-0 | Fax 0308417 70-21 


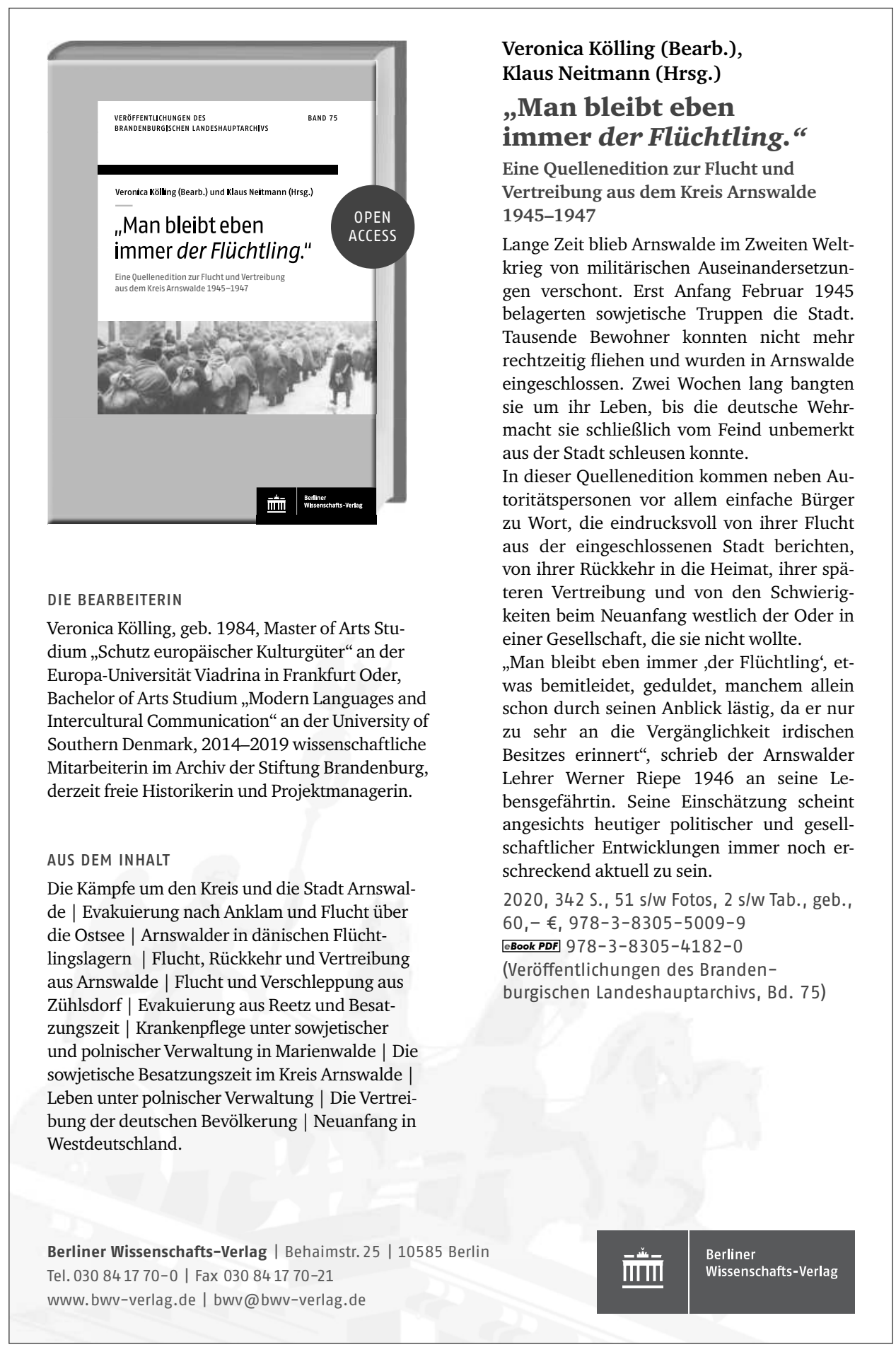




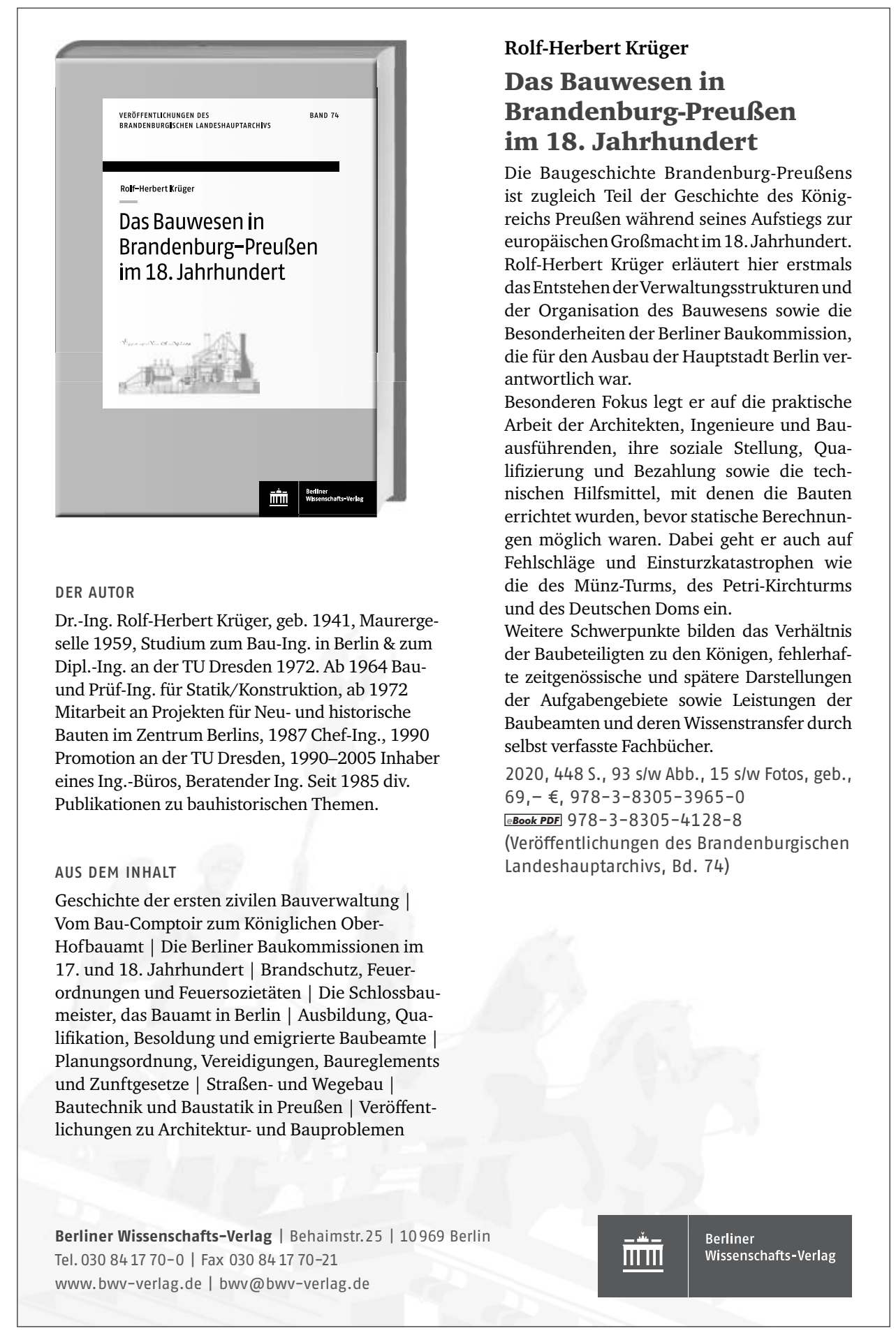




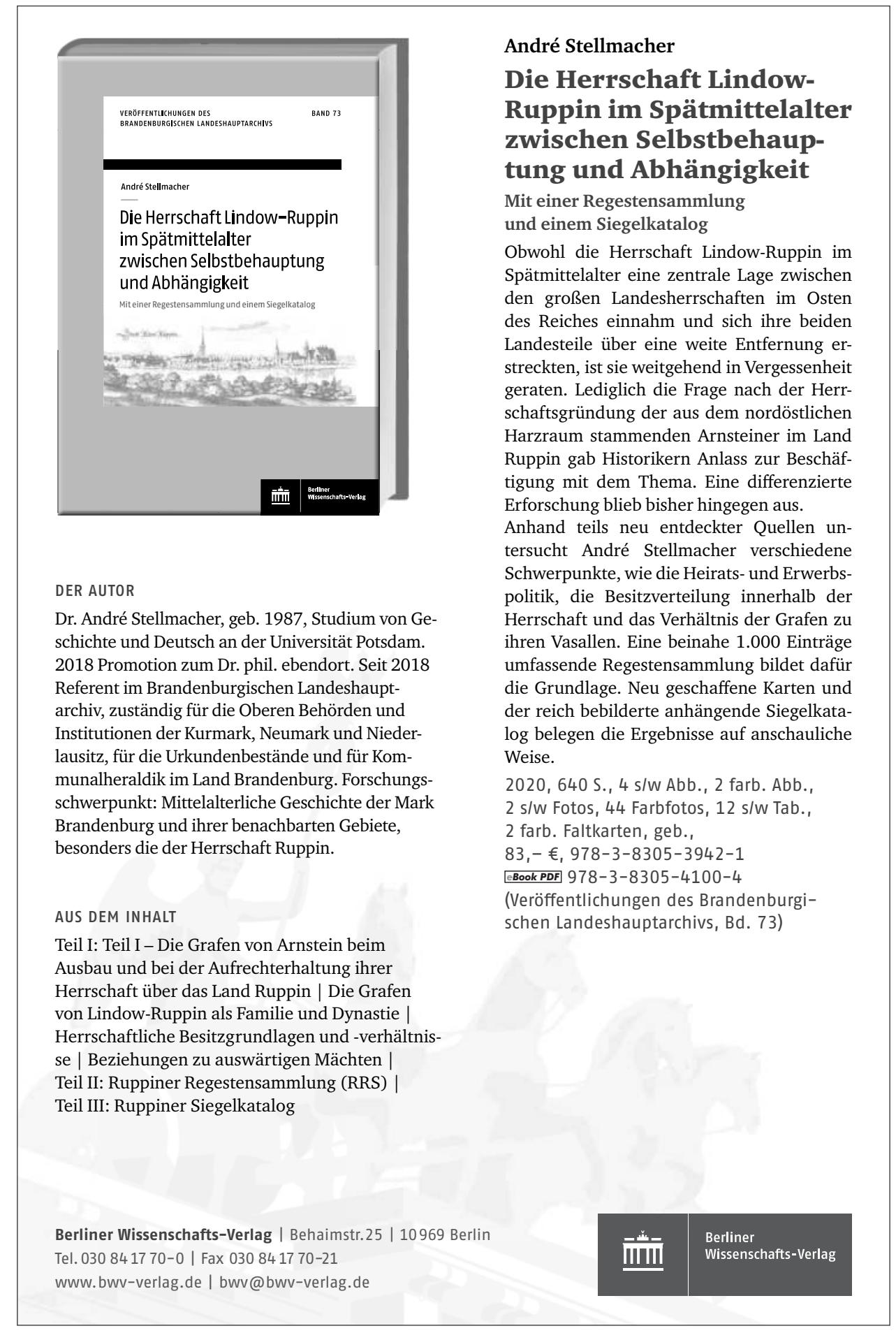


Was wäre Brandenburg ohne seine vielen Einwanderer? Ohne die Hugenotten, ohne die Böhmen - und die Schweizer!? Die Zuwandererung von Schweizer Kolonisten nach Brandenburg hat die Migrationsforschung bisher nur marginal wahrgenommen.

Der "Große Kurfürst" Friedrich Wilhelm hatte sich, nachdem es in der Schweiz Ende des 17. Jahrhunderts zu enormen sozialen Spannungen gekommen war, 1683 an den Bürgermeister und den Rat der Stadt Bern gewandt: Er bat um Überlassung von „Zehen oder Zwantzig Familien“, „welche der Wirthschafft und Viehzucht wohl erfahren seyn". Die Folgenbewältigung des 30-jährigen Krieges, der die Kurmark vielerorts entvölkert hatte, war für inn oberstes Staatsziel. Unter den nachgeborenen Schweizer Söhnen fanden sich viele Einwanderwillige, sodass eine Auswahl unter ihnen nötig wurde, "denn es ginge um die Ehre der Schweizerischen Nation." Auch heute noch kann man den Stolz dieser kleinen Einwanderungsgruppe in Nattwerder erleben.

Dietmar Bleyl untersucht ihr Schicksal sowohl unter dem wirtschaftlichen Aspekt (bis ins 19. Jahrhundert) als auch unter dem konfessionellen Aspekt (bis 1949) und schließt damit eine Lücke in der bisherigen Forschung. 